$$
\begin{aligned}
& \angle B L=P U B=677 \\
& \text { Vol. (6) }
\end{aligned}
$$

5

(C) 8 T i

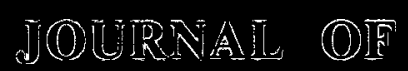

GITNN TI STABORG

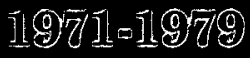

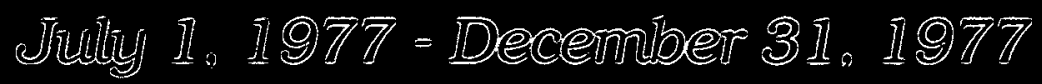

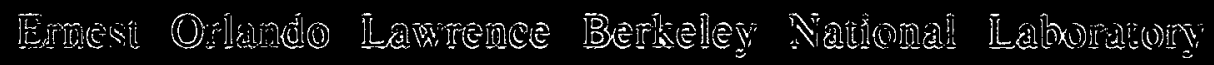
Uimiversity of Calliform 


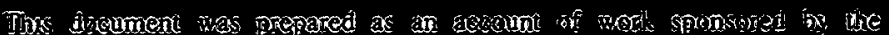

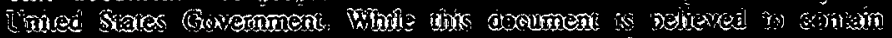

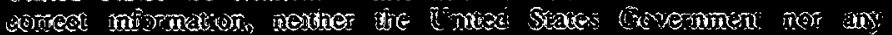

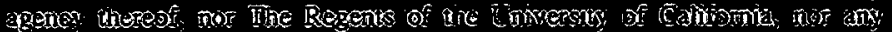

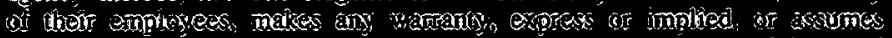

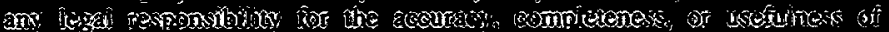

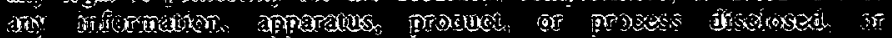

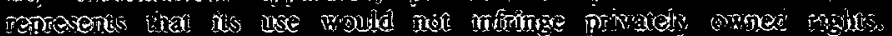
If os

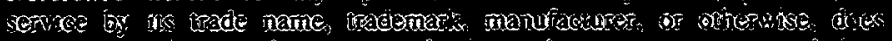

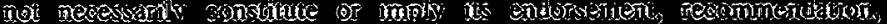

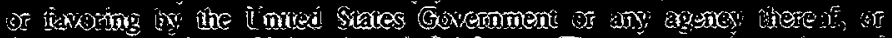

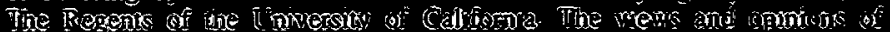

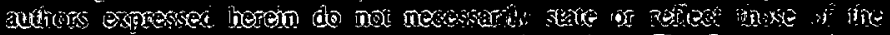

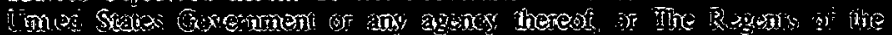

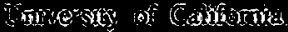

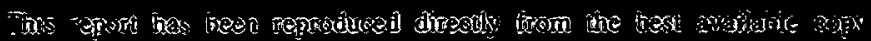

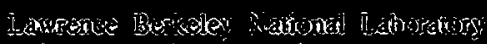

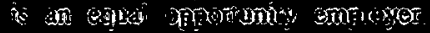




\section{LBL- PUB-677}

\section{Journal \\ of \\ GLENN T. SEABORG}

1971-1979

\section{VOLUME $6 b$}

\section{MASTER}

This work was supported by the U.S. Department of Energy under Contract DE-AC03-76SF00098

DISTFISUTION OF THS DOCUMENT IS UALSMTEO 
$\therefore \quad 3$

$\begin{array}{lll}4 & 0 \\ 4 & 0\end{array}$

87 recyed pape 
Friday, July 1, 1977 - Berkeley

At 8:50 a.m., I placed a call to Hunter spilian of the Senate Public Works Appropriations Subcommittee, regarding the heavy ion uranium beam facility line item and its chances to be reinstated in the budget by the Conference Committee. We reviewed the names and attitudes of the senate conferees and particularly what might be expected by the Chairman, Senator Stennis. Spillan said that James Schlesinger talked with stennis about cutting down the items in the Appropriations Bill to approximate the President's original request; I reminded him that the uranium facility was in the President's budget. Spillan thought there would be value in my contacting Proctor Jones and senator stennis, if possible.

At 9:10 a.m., I called George Rogosa and described my conversation with Spillan. Rogosa identified the line item as "78-12-B, High Intensity Uranium Beam, Iawrence Berkeley Laboratory, California." Six million dollars is authorized. I described the situation regarding the nuclear physics add-on item and Rogosa will talk with Herman Feshbach about approaching senator Brooke. He has talked with weneser and a number of other people.

At 9:45 a.m., a telegram came from Sidney Smith which said that Madame Ceausescu declined our invitation to speak at the CHEMRAWN conference. The formal reply will be sent to me through the Embassy and will raise the possibility of the Romanians sending a representative in her place.

I then called Jesse Hwa to tell him the news about Madame Ceausescu. He consulted with Schneider and Rossiter and no alternate has been clearly identified, but we agreed to approach the following people in this order: (1) Dzhermin Gzishiani, Russian and (2) KIaus Schtantke, Director of Science and Technology for the United Nations, nominated by Rossiter. Three other names were also suggested. We will take this matter up again in the near future.

At 10:55 a.m., Mrs. Mildred Lampey Gamble called me for an appointment. At 2:30 p.m., she came to the office. It turns out that she taught 11 th grade English at Ishpeming High School from 1955-56 and is in Berkeley for the summer participating in the Bay Area Writing Project; she is staying at International House. She grew up in the Finnish community in Ishpeming and now lives in Iongmont, Colorado.

Paul Kienle, from Munich and GSI, dropped in at 11:30 a.m. He told me about experiments at GSI where his group have apparently observed positions (as predicted by walter Greiner) in heavy ion bombardments. I then took Kienle to see Dave Morrissey, Ken Thomas and Trish Baisden and then on to Building 70 to talk to Al Ghiorso. While in Building 70, Kim Williams introduced me to an incoming graduate student, David Goodin, from the University of Oklahoma. Kienle, $A I$, and $I$ had Iunch in the cafeteria and were joined by $D r$. and Mrs. Lester Winsberg.

After lunch, I went by Room 203 to talk to Rollie Otto and Dave Morrissey about our U plus ${ }^{4} \mathrm{Ca}$ paper. 
Friday, July 1, 1977 (con't)

I met with Sherman Fried from 3-4:00 p.m. While visiting his children in the Bay Area, he is also visiting LII and LBI. We discussed my Met Lab C-I history and he recalled a number of incidents for my possible use. He is looking for a postdoc in solution chemistry. Before leaving, he and I went down to say hello to Norman Edelstein.

Fried and I were interrupted by a telephone call from Senator Mark Hatfield who was returning an earlier call I made to him. I described the problem that is developing on support for the high intensity uranium beam facility and explained that its not being budgeted would be a severe blow to heavy ion nuclear physics in the U.S., particularly because it is the only basis for our competition with the Germans and Russians. I also pointed out its use in controlled fusion, in which he has an interest. He plans to get more information and call me back, although it might take a while.

Sheila and I surveyed the room in which my files, paper, reprints, books, etc., are stored to decide what can be disposed of and what can be sent to the UC warehouse for storage. She wiIl go through the materials this weekend to sort it all out.

At 4:30 p.m., I went by 203/70 and talked with Otto, Morrissey, de Saint-Simon and Baisden. Otto will work on a draft of our paper, "Uranium + Xe..." to look for SHE in which we refute the Dubna claims that a 150-day S.F. SHE is formed in this bombardment.

Stig Ramel wrote in response to my request that the Joseys and Wehners be invited to attend the Nobel ceremonies in December. No commitment can be made at this time and the request may have to wait until 1978 or 1979.

I sent Pat Tsuchitani of the Committee on Scholarly Communication with the People's Republic of China, the responses (attached) to her questionnaire about the Chinese Chemistry Group visit from Gabor Somorjai, Mitchel Shen and Robert Budnitz. Letters written today were to: Russell Peterson, quite a strong. letter in response to his request for comments on the New Directions brochure about arms limitation (letter attached); James Heneghan, to thank him for his translation of the Flerov article; Lawrence Mitchell, National Research Council, to tell him that the American Chemical Society International Activities Committee did not have a chance to discuss the idea of setting up a relief program for university laboratories damaged in the Rumanian earthquake; Gordon Bixler (ACS, IAC) suggesting that we put Mitchell's proposal on the IAC agenda for the August ACS meeting; C. H. Wang, oregon State University, a copy of my China Journal, sent at the suggestion of Walter Loveland; and, finally, a letter of recommendation to accompany Stanley Hong's application to UC Dental School.

Before dinner, I took a hike at Iafayette Reservoir. Helen and I had dinner in the kitchen because the playroom TV is out of order. She told me she had the radiator replaced in the Bonneville today at a cost of $\$ 165.00$. Dianne had dinner a little later. 


\section{Evaluation of the Visit of the Chinese Chemistry Group April 28 - May 28, 1977}

Answers to questions:

1. What, particular, interested the members of Subgroup which visited your Institucion? What topics seemed to be of primary importance? Were these topics in basic or applied areas?

The group that I was associated with is the one on Cataiysis. The members of this group were very knowledgeable in the field of industrial catalysis and it is pretty clear that this is an area of importance for China ai this time. Their research effort involves applied research in most cases, but they are vary knowledgeable of the basic science research areas in the fields of surface chemistry and heterogeneous catalysis. They clearly have access to all the modern scientific literature as they were asking me questions on papers that were published only a few months prior to their arrival in Berkeley.

On" the other hand, their research is clearly applied and doesn't appear to be of high quality.

2. What are the applications of the research topics which you and your colleagues discussed with the group?

Much of the research that they were interested in concerned hydrocarbon conversion by metal catalysts as well as by oxide and zeolite surfaces. "It appears that China has a great deal of petroleum at. this time and they are trying to develop their petroleum refining and chemical industries based on the model of the United States. As a result, the catalytic processes involved in petroleum refining and in the chernical industry are of great importance and interest to them.

3. Please evaluate the nature of the exchange on information. Were you able to ascertain from the members of the group the nature of their own reseach or of other research projects in chemistry in China?

It appears that the research laboratories in the field of catalysis are all located in northeastern China. These have a great number of members, however, the level of research is not very high. They are concentrating on applied research projects - mostly copying what appears to be coming from the West. They have a great deal of interest in basic research but very little is being done in this area.

There are several research institutes in various parts of China in the area of chemistry. Those that are of the highest quality appear to be associated with the Academy and these are older research establishments. I have learned that the Academy, although it has not selected new members for the past fifteen years, still is very much in control of the quality chemical education and research in China. It appears that in spite of all the propaganda, high quality students still find it easy to get admitted to various universities. 
In sum, they have a great deal to learn and they definitely want to learn from the industrial technological and scientific experience in this country. They have very little to offer in exchange, but petroleum is abundant and they very much need to develop the petroleum industry in their country.

4. How would you characterize level of sophistication of the members of the group?

These were very intelligent, well educated people。-Although their research projects are not up-to-date, they read avidiy $a 71$ the scientific literature and are very familiar with the new trends and new techniques that have been developing in this country in the fiald of surface chemistry and heterogeneous catalysis. Their English and their level of communication was certainiy sophisticated.

\section{Please make additional comments about the group?}

They appear to be eager to learn and find out about the problems with which we are dealing. They were interested in equipment. They were interested in research problems. And it is clear that many of our catalytic problems are also of interest to them and they seem to be working on them. Metal catalysis is a major probiem in China as well as catalysis by zeolite and oxide surfaces. Their connections with the Russians seem to be nonexistant and they would welcome more exchange and more trijs to the United States, I am sure.

Their university educational facilities and programs are not very high level at this point but $i t$ appears that ilere are changes taking place and they welcome this change to increase the quality of their educational sysiam and research opportunities. 
TO: $\quad$ Professor G. Seaborg

FROM: $\quad$ M. Shen

SUBJECT: Response to CSCPRC Questionnaire

Three chinese polymer chemists visited with Sub-Group B, and met with Professors Hearst, Iichtenthaler, O'Konski, Williams and myself. Our general impressions are as follows:

1. The visitors showed little evidence of their particular interests. However, generally they seemed to be more interested in the applied rather than theoretical topics.

2. Some of the more applied topics were:

a. Polymer processing, such as injection molding;

b. Low temperature elastomers, such as polyphosphazenes;

c. Solvent removal from polymers;

d. Polymer solution thermodynamics at high pressures;

e. Plasma polymerization for such use's as reverse osmosis membranes; and,

f. Polymeric alloys.

3. There was practically no exchange of information. They took copious notes, and sometimes asked some good questions. They were not very communicative about their own work.

4. Since there was very Iittle two-way communication, it is difficult to tell about their level of sophistication. They seemed knowledgeable about some of the topics, as was reflected from their questions.

5. The visit may have been useful to thein as a form of surveying the U:S. chemical research scene. It is doubtful that the amount of information supplied to them at such a rapid pace could be assimilated. In fact, it would be humanly impossible for anyone to understand the sophisticated research activities too far outside of one's own field.

Hopefully now the Chinese will have a better understanding of the scope of scientific research in this country. In the future, the visitors should meet with a team of experts to discuss restricted topics, so that information of some real substance could be exchanged. It would be a waste of time for both sides to continue with the present format.

MS :md 
June 28,1977

MEMORANDUM

TO:

G. T. Seaborg

FROM: R. J. Budnitz, Acting Head

Energy \& Environment Division

SUBJECT: Evaluation of Recent Visit by Chinese Chemistry Group

I am responding to the five questions posed by Pat Tsuchitani in her letter to you of 16 June.

1. Subgroup C seemed most interested in instrumentation, especially advanced electronic instrumentation. They often asked about the commercial availability of various instruments. The research being performed with the advanced instruments and techniques was of lesser interest.

2. A whole range of applications came up, emphasizing geochemical, environmental, and coal-chemistry areas. Questions on geochemical application seemed to arise frequently.

3. We were not very successful in ascertaining the nature of their work from the visiting Chinese chemists, There was not very much effort in that direction; however, most of the discussion was "one way;" with our American groups presenting their own work."

4. The level of sophistication of Subgroup $C$ was higher by far than that of the previous Chinese visitors to LBL (November 1975). These scientists clearly understood almost all that was being presented to them. I would characterize these visitors as at a level of some of our good American universities, with at least one of them perhaps at the level of our finer LBL staff.

5. The group's obvious positive personal feelings towards us was a pleasure. They were courteous, curious, and happy. They communicated reasonably well, on a personal level, about their families and working conditions. This was especially true at the dinner at my house.

I hope that these comments are an adequate response to Pat's questions. If not, please let me know. 
University of California

Berkeley, California 94720

Telephone 415/843-2740

July I, 1977

Dr. Russell W. Peterson, President

New Directions

2021 I Street, N.W.

Washington, D.C. 20036

- Dear Russ:

This is in reply to your request for comments and

criticisms of the brochure entitled "The President of the United States and the Secretary of State could be wasting their time in negotiating any arms limitation agreement with Russia! Why?" ...

I don't agree with such a negative approach whose central theme is to play on people's fears. I realize that it is necessary to get people'.s attention, but I think you may be repelling a number of opinion leaders by this approach.

I have the impression from your letter of June 14, 1977--in which you do not comment on my assessment that New Directions is employing demagoguery--that you may be justifying this approach on the basis that it adds the most numbers to the membership roster.

Cordially yours,

Glenn T. Seaborg

GTS/sms

cc: Norman Cousins Theodore M. Hesburgh

William M. Roth

bcc: Sol Linowitz 
Saturday, July 2, 1977 - Lafayette - Paradise Pines

Helen and I had breakfast at home, then left at 8:30 a.m. for Feather Falls. We drove on Highways 24, 680, 80, 113, 99, etc. to Oroville, then Olive Highway to the Feather Falls parking lot. We started our hike at $12: 30 \mathrm{p.m}$. and went about a mile to Frey Creek where we had our backpack lunch. We then hiked to Feather Falls and found a rather substantial amount of water there. We then tried Iong Point Trail but decided this would not get us back to our starting point, so we turned around and hiked back to Feather Falls and to the parking lot. We arrived there at 6:00 p.m. after hiking a total of about 10 miles.

We then drove, with Helen still at the wheel, to Jeanette and Ray's at 39 Magnolia Drive in Paradise Pines. Jeanette prepared dinner for the four of us and then Helen and $I$ spent the night in their mobile home bedroom while Jeanette and Ray slept in their living room.

Sunday, July 3, 1977 - Paradise Pines

Helen and I had breakfast with Jeanette and Ray. We think they have a very nice, comfortable place in a beautiful area of pine and other trees. Helen and $I$, in our station wagon, and Jeanette and Ray in their camper, drove a couple of miles north on Sky Way to De Sabta, then proceeded on Humbug Road, to Understock Road to the bridge over Big Butte Creek. Here Helen and I left Jeanette and Ray (who returned home) and hiked on Butte Creek Trail some 2 miles to the end of the trail. The last mile or so was quite treacherous. We turned back, hiked a mile or so, then went down the hill to Big Butte Creek where we ate our backpack lunch. We then hiked back to the bridge to our car. We saw a road to Tregoning Mines - Black Prince and Iron King. (There is much reddish dirt around here.) We drove back to De Sabta, then north to Inskip. We dropped in at the Inskip Inn (an old stagecoach stop) for refreshments and to hear the local gossip. We hiked down about a mile on an unimproved road toward the West Branch of the North Fork of the Feather River. We noticed an old abandoned road running parallel (to the south) which we might hike on another occasion. We drove back south on Sky Way to Paradise Pines.

Jeanette and Ray then drove me to the 9-hole Paradise Pines Golf Course, the Paradise Property Owners Association (POA) club house (swimming pool, tennis courts, etc.) and around town while Helen stayed in their home. Jeanette then prepared dinner for the four of us.

Monday, July 4, 1977 - Paradise Pines - Quincy

We all had breakfast, then Helen and I drove down to Highway 70 and headed northeast. At about 2 miles past the summit of Jarbo Pass (the site of Grand View Cafe), we entered Plumas National Forest. About 0.4 miles past this (at a point where power lines cross Highway 70), we saw a dirt road heading up the hill to the left. We parked the station wagon about 0.2 miles down the highway at a convenient opening, walked back and hiked up the road, starting at 9:45 a.m. We hiked a couple of miles, climbing some 1,000-1,500 feet on the old, 
abandoned, somewhat rock-filled road. At the top, we found a better road and walked on it for a short distance. After exploring another old road, we hiked back to our starting point on the road we came up, arriving at 12:30 p.m. We continued northeast on Highway 70 to Belden where we had lunch in the Belden Town Restaurant--actually a kind of tavern and snack bar temporarily carrying on the business of a larger resort restaurant that burned down last year. Belden is the point where the Pacific Crest Trail crosses the North Fork of the Feather River, Highway 70, and the old Western Pacific railroad tracks.

Helen and I walked a bit on the Western Pacific tracks, which is where the train ran on its route through the Feather River canyon in October 1922 when my family and I travelled to Los Angeles, California (via San Francisco) from Ishpeming, Michigan.

Helen and I then hiked south on the Pacific Crest Trail up the mountain, starting at $1: 45 \mathrm{p} . \mathrm{m}$. I hiked to the top of the mountain, a distance of perhaps 4 miles and an altitude gain of perhaps 3,000 feet. I found a marvelous $360^{\circ}$ panoramic view at the top, which was above the timber line. I could see the Pacific Crest Trail continuing on ahead for a good distance. I started back down, meeting Helen at a point about $3 / 4$ of the way to the top. We proceeded on down together, arriving back in Belden at 6:00 p.m.

We then continued east on Highway 70 to Quincy where we checked into Lariat Lodge. We then drove back to Perko's Koffee Kup (closer to the town) where we had dinner. We drove back to Lariat Lodge. Helen called Dianne at home and found things in order. Dianne told her that the Pulley's Fourth of July celebration (a neighborhood barbecue) held in our field had been held today; it was still in progress at $8: 30 \mathrm{p} . \mathrm{m}$. We watched the CBS Fourth of July show "From Yankee Doodle to Ragtime" on the TV.

Tuesday, July 5, 1977 - Quincy - Lafayette

We had breakfast in Mountain House (a mile or two west), then drove back to Belden. Starting at 8:45 a.m., we hiked on the Chip's Creek Trail--this is also the Pacific Crest Trail at this point and the trail head is just north of Highway 70 at Belden: About a halfmile along the trail, just beyond the new bridge over Chip's Creek, the Ben Lomond Trail takes off up Ben Lomond Mountain (altitude about 6,200 ft.). We missed seeing this trails' juncture and continued on the Chip's Creek Pacific Crest Trail (also labeled the California R\&H-Riding and Hiking--Trail). I hiked on ahead as far as the Myrtle Flat Camp, a distance of perhaps 6 miles and an altitude gain of some 1-2,000 feet. The trail followed the Chip's Creek canyon hillside, weaving in and out as it progressed. Much of the trail was rocky and therefore somewhat hard on the feet.

I started back, meeting Helen about a half-mile back at about noon. We soon met Tom Newland and Jim Werner (of San Jose) who had started at the southern end of the Pacific Crest Trail (in Mexico) on April 5 and are on their way to the northern end (in Canada), which they expect to reach in october. They told us the Pacific Crest Trail crosses Highway 80 at soda springs and Highway 50 at Echo summit. 
Helen and I had our backpack Iunch, then, as we continued on, she showed me the long stretch of hot rocks where she encountered a rattlesnake on the way in; both she and the rattlesnake were anxious to avoid each other. This occurred right next to Rattlesnake spring. (when we returned to the trail head, we read a sign which said it is advisable to carry a snake kit.)

As we came nearly back to our starting point, we took an alternate well-marked trail which led us down to Highway 70 at Maple Leaf Tavern and Little Indian Creek Resort. We had to walk about a halfmile along Highway 70 to reach our parked station wagon at Belden. Apparently this is the previous route of Pacific Crest Trail across Highway 70. We arrived at our car at 3:00 p.m. The Pacific Crest Trail is designated by white metallic diamond-shaped markers (about 3 " on the side) attached to trees.

We drove home along Highways $70,99,113,80,680$ and 24 , arriving at a little after 7:00 p.m. Eric was there and was in the process of preparing a spaghetti dinner for us. Eric, Dianne, Helen and I had a pleasant dinner in the kitchen. Dianne told us about the argument some of our neighbors had over fireworks at the party on our field yesterday and after dinner she showed us the progress she has made in cataloging our books in our library.

Wednesday, July 6, 1977 - Berkeley

When I arrived at the office, Sheila showed me all the work she did over the long weekend putting my files in order.

At 8:45 a.m., Joe Katz called to tell me that things for the revision of Chemistry of the Actinide Elements will not be ready for him to come here in July. Also, he is having problems with the transition to his continuing position as an emeritus member of the Laboratory. He wants to meet at Chicago to discuss the status of the book. He seconded John Farmakes's invitation to me to give the dedication address at Argonne on September 27, which I had to decline because I will be in Europe.

Sheila told me that Bob Silva had called here on Tuesday. He expects that the Energy and Environment Division will make him a job offer to start in september.

Norman Hackerman called at 10:35 a.m. as a follow-up to our earlier talk. I explained that I was not getting strong recommendations on Aron Kuppermann. I suggested that he should look further and keep in touch. He asked if I was acquainted with Thomas C. Bruice at the Santa Barbara campus ( I am not).

Ty Jenkins dropped in at 10:30 a.m. She is starting to work in Donner Iaboratory today. She told me that Bill, her dad, may visit us this summer.

At 11:25 a.m., Howard stein called to tell me that he is going off the Dreyfus Third Century Fund Board because it now contains:an inside majority. He wants to put Alice Jones (Senior Vice President, Fiduciary Trust, New York, now retired) on the Board before the July 
18 meeting, and I agreed. Stein told me that the Dreyfus Third Century Fund may drop its sales charge, market themselves and advertise; this will be decided at the July 18 meeting.

Garff Wilson called (11:40 a.m.) to tell me that the People's Republic of China is sending a metrology delegation here on August 3. Their interest is in "lasers and super-conducting technology". I suggested that he contact Dean Ernest Kuh and Geoffrey Chew to help with the program. I agreed to attend a coffee reception in the Chancellor's Conference Room that morning at 9:30 a.m.

I attended the luncheon meeting of actinide chemists in room 191/70. Present were Norman Edelstein, David and Lieselotte Templeton, Jerome Bucher, Alex Avdeef, George Shalimoff, John Conway, Edgar Baker, Gordon Halstead, John Reynolds, Fred Weidl, Bob Fischer and others. Bucher reported on Pat Durbin's work with mice to test the efficacy of gne of Raymond's chelating agents on receiving injected plutonium $\left({ }^{238} \mathrm{Pu}\right)$; the results are inclusive. Halstead reported on the structure of $\mathrm{UCp}_{2} \mathrm{Cl}_{2}$ and related compounds and Baker on Cerium COT compounds.

I went by to see Otto, Morrissey, Thomas, de Saint-Simon and Baisden. I discussed with otto our recoil paper, which I worked on over the weekend. I discussed with de Saint-Simon his progress on treatment of iodine isotope data from uranium plus $4 \mathrm{Ar}_{\mathrm{Ar}}$ and with Baisden her treatment of alpha data from actinide fractions of our uranium plus $86 \mathrm{Kr}$ bombardments.

Sheila set the machinery in motion with the LBL Personnel office to find her replacement.

Ken Thomas dropped by the office in late afternoon to give me his analysis of the $\mathrm{Pu}$ fraction from $U$ plus $86 \mathrm{Kr}$ which shows a near 40-minute beta emitter as well as the new 15-minute beta emitter.

I signed and sent 43 fund raising letters (sample and list attached) for the Swedish Council of America, which Nils Wessell will co-sign. I received a letter (attached) from Tang Ao-ching, head of the Chinese Chemistry Group, thanking us for the arrangements we made for their visit here at Berkeley on May 26-27.

Ty Jenkins came by at 5:15 p.m. and introduced me to her friend, Doug Heller, a physicist with whom she (and Mrs. Heller) rode out to California from washington. Ty just finished her first year in Jefferson Medical College in Philadelphia. She will stay with us until she finds a place to rent a room or apartment.

Ty and I stopped at Lafayette Reservoir on the way home and took a hike. Ty, Dianne, Helen and I had dinner in the kitchen. Ty then went in to Berkeley or Oakland to spend the night with friends.

Thursday, July 7, 1977 - Berkeley

I conferred with Margie Hollander, as usual, about progress on Met Lab section C-I (Vol. II). She told me she has personal problems with Jack, who does not want her to continue on this. 


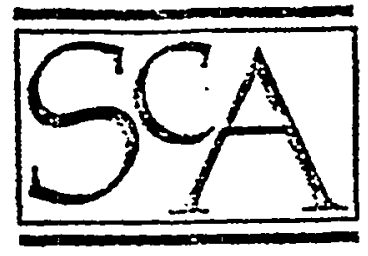

Office of the Executive Dircctor

HEXIKD OE DIRE.CIOXS

Arulssun, Kanl Cinumat Detroit. AII

Biörck-Kitplan, Lena Xerr York, NY

Broden, Edwin $R$. Ithan, $P_{\Delta}$

Carlson. Curtis 2 . Mismeapolis, $31 \mathrm{~N}$

Enluml, E. Stanley Clicesgo, IL

Erickson. Rolanul A. Crecuwich. C'r Tice Presiderit

Hasselquist, Maynard 13. Minneapolis. MIX I.egal Counsel

Jolunson. Custave F. Ifinneapolis, $31 \mathrm{~N}$ Treasurer

Karistrom, Signe Detroit. MII

Lund, Eric Chicago. IL

Luncieen. Joel Chicago, II

Lundin. Oscar A. Detroit. MiI

Olsson. Nils Willia:n Wasinington. D.C. Executive Divecto:

Plicro, Lavisence J. NiItes. $M I I$

Rameil. Gunilla C. Los Angeles, $\mathrm{CA}$

Scaborf. Glenn $T$. Perkeley, CA

IIessill. Nils $Y$. New York. AI President

Wciteriverg. Wiesiey MI. Mfinncapolis, Ma Sccretcry

\section{SWEDISH COUNCIL OF AMERICA}

4970 Sentinel Drive . Sumner, Maryland 20016 - Phone 301-229-6467

Mr: Bengt Gyllenhoff

American-Scandinavian Travel Service

500 Fifth Avenue

New York, New York 10036

Dear.Mr. Gyllenhoff:

Your past support of the Swedisi Council of America is anprecisteă very nuch inaeed. We have indicated our gratitide to you by listing you in our publications as a Patron ( $a$ contributor of $\$ 100$ to \$999 to the Courcil). If you find it possible to increase your contribution to $\$ 1,000$, you will be listed as a Berefactior. The officers and board of the Council jelieve that it has achieved en imprsssive record $i n$ its short Deriod of existence and tiat the future possicilities for the Council. ere even more zromising. To achieye this pronise we will neeg your continued support.

You know of the rery successful spcinorsitp by the Ccincil oi Ailan Kastrug's book "The Sveaish Feritiage in America." A seccrá book under the aegis of the Ccrincil is about to eppear. It is a colieciion or essays by Dresent lesders of business, education, science and gorernment in sweden who pay tribute to the role vlayed in their careers by their experiences as exchange-seudents in tinis country. Yoli know, too, of the design ard distribution of a special meàl conmezorating the American Bicentennial and the contributions nade by Anericane of Swedish background to the jistory of the Unitej States. Earliex the Council was an actire supporter of the concert tour or the Stockhoim Philharmonic.

The principal purpose of the Swedish Council of America is to bring into cooperative relationship all groups and indirijuals, whose objectives are to promote knoviedse and unkerstanding or the Swedish heritage in American lïfe and to strengthen the cultural ties between Amarica and Sweden.

AMERICAN STEDISH IIISTORICAL FOUNDAHOX, PHILAUELFIHA, PENASYLVANIA - THE AMERICAN SWEDISII INSITTUTR,

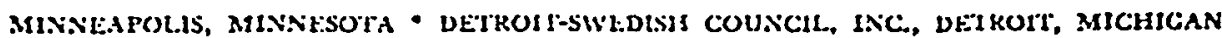
SWEDISH PIONHER HISTORICAL SOCIFIX, CHICAGO, ILLINOIS 
American-Scandinavian Travel Service - 2.

Iisted in the left margin of this letter are the officers end Board members of the Council. All of these individuals are actively intolved in the affairs of the Courcil and attest to the significance of what the Council has done ena plans for the future. They join us in urging you to continue your support at the level of a Beneiactor.

Sincerely yours,

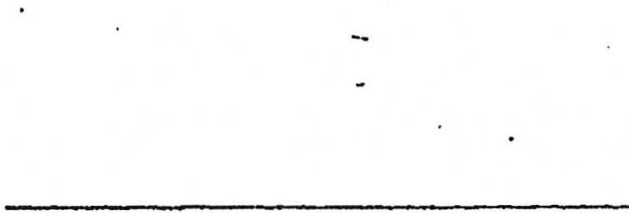

Wils Y. WesselI Presiant

P.S. Please Piegly To:

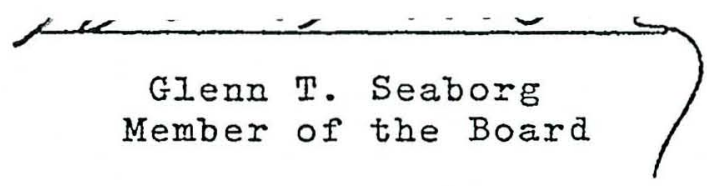

IIIIs Y. H'esseII

Alfred $P$. S Soan Folindatior. 630 Fith Avenue

New York, New York 10020 
300 Swedish Council of America J 43: LAWRENCE BERKELEY LABORATORY

Room: Bldg.: Ext.: .

July 6,1977

Dr. Seaborg signed and sent back to Nil $Y$. Wessell letters for:

Mr. Bengt Gyllenhoff

American-Scandinavian Travel service

Edgar Bergen Foundation'

500 Fifth Avenue

New York, New York 10036

American SF Products, Inc.

\& Gert K.A. Siggelin

P. O. Box 7439

Fort Iauderdale, Florida 33304

MI. Robert H. Bergsten

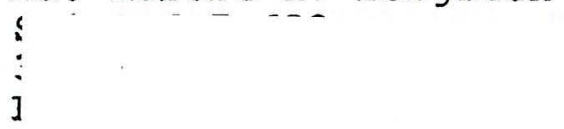

Mr. A. W. Anderberg

Anderberg Manufacturing $\mathrm{Co}$.

Mr. Herbert G. Carlson

3727 Broadway Place

Ios Angeles, California 90007

Mr. Burnett Anderson

USIS, American Embassy

APO, New York 09777

Mr. Bernhard Citron

Mr. Hugo Anderson

Ms. Bernice Danielson

Dr. Ingel I. Anderson

Swedish Consulate

503 West Puget Avenue

Phoenix, Arizona 85021

Mr. Gunnar Back

Dr. S. Edward Backstrand

5011 S.W. Humphrey Boulevard

Portland,

Oregon 97221

Mr. Clifford C. Benson

Swedish Consulate

1020 Joseph Vance Building

Seattle, Washington 98101

Mr. Philip I. Benson
Mr. John Danieison

q "Swedish Consulate.

615 South Flower Street

Los Angeles, California 90017

Mr. Walter G. Danielson

* Swedish Consulate

615 South Flower street

Ios Angeles, California 90017

Mr. Sven A. Eliason

President

Scandiline Industries, Inc.

1217 W. Artesia Boulevard

Compton, California 90220

Mr. Elmer W. Engstrom

Mr. Arne Falk

Falk Construction Co.

2680 Middiefield Road

Redwood City, California 94063 


\section{4 \\ LAWRENCE BERKELEY LABORATORY \\ Room: Bldg.: Ext.: \\ July 6, 1977 page 2}

Dr. Seaborg signed and sent back to Nil Y. Wessell letters for:

Dr. Nils Hasselmo

i

Mr. Nels M. Hokanson

Mr. Cecil A. Johnson

Mr. Charles V. Johnson

Dr. Walter G. Johnson

Mr. Lawrence Linäaren

Ambassador Gunnar Ionaeus

Mr. Sigfrid K. Loneqren

Mrs. Gergrude Sidener Lord

1

I

Mr. Ray Olson

Dr. Karl A. Olsson

Wigh-Gustafson Properties Co.

:9
Mr. Bengt $T$. Helisten

Oriflame Corporation

154 Pico Boulevard

Santa Monica, California 90405

Mr. Glenn D. Peterson

Swedish Consulate

1210 California Street

Denver, Colorado 80204

Mr. Ronald W. Peterson

Mr. Rudolph A. Peterson

Mr. Elmer F. Pierson

]

了

Mr. Elmer E. Rasmuson

Swedish Consulate

National Bank of Alaska

P. O. Box 600

Anchorage, Alaska 99510

.Mr. Harvey Schweers

Mr. Robert C. Sorensen

Mx. Elton Strand

Mr. Evald I. Swanson

4

Mr. Bo Svenson, President Trollebo Productions, Inc. 515 South Barrington Avenue Los Angeles, California 90049 
$\exists$ rons:

中华人民关和国科学技术、协会 THE SCIENTIFIC AND TECHNICAL ASSOCIATION OF THE PEOPLE'S REPUBLIC OF CHINA PEIKING, CHINA

\section{June 24,1977}

Dear Prof. Glenn T. Seaborg:

AlI members of the Chinese Chemistry Group returned to Peking on llay 31, after having concluded their visit to USA. We have been pleased to visit your country at the kind invitation of the US Committee on Scholarly Communication with the People's Republic of China.

During our stay in your country, we visited many faculties, departments and laboratories of higher learning and research institutes. Everywhere we went, we have been accorded wara welcome and kind hospltality. We have not only met old friends who had visited China, but also made mant new ones. Please allow us to send you anö your. colleagues our friendly greetings and thaik you Ior your v warm welcome and kina reception.

The firmly believe that the exchange of visits between Chinese ana fimerican scientists on the basis of Shanghai Communique will surely enhance their friendship and mutual understanding.

With best wishes

Yours 'sincerely

The Chinese Chemistry Group 
Thursday, July 7,1977 (con't)

At 9:45 a.m., Mr. K. N. Johry came to see me. He is head of India's International Scientific Collaboration Council for Scientific and Industrial Research in New Delhi. I showed him a copy of Cyril Ponnamperuma's letter to Edgar Piret of June 3 and described to him our plans for an ACS-Chemical Society of India workshop in the spring of 1978. We discussed my idea for an international chemical society and he was very interested in this. He is extremely hopeful that I might visit India at the time of the workshop but I cautioned him not to be too hopeful.

At 11:00 a.m., Jesse Hwa called to say that he had received a phone call from Glynn Michaels informing him that Maurice strong had withdrawn from our CHEMRAWN Program because of a conflict of dates. Michaels and Tishler suggest asking William Hopper (David's brother) to be the backup (he is also Canadian). I agreed to this and Hwa will call Michaels and Tishler. Jesse also told me that he had heard Handler's group returned from China where responses to their program were not very enthusiastic.

I had Iunch in the cafeteria with otto and Morrissey. We talked about writing a summary of all our conclusions about heavy ion reactions.

Lew Keller called me at 1:15 p.m. They have translated the paper that Goldanskii sent to me in his last letter and find that it criticizes the latest Flerov-Zvara claims (in Dubna preprints P6-10581 and P6-10589) of the discovery of superheavy elements in meteorites. We decided to be very cautious and not reveal our source of information when discussing the Dubna meteorite work with Ter-Akopyan and Druin when they are at Oak Ridge next week and Berkeley the following week. Lew said that we will receive the page proof on our Annual Review article on the "Chemistry of the Transactinide Elements" next week according to schedule.

At 1:30 p.m., I met with Candace Voelker of the IBI Technical Information Department. She gave me the attached letter from Roger Donald of Little, Brown and Company. I showed her samples of my journals and told her that when I finish Volumes II and III of Travels in the New World, we might get together again to discuss my next writing project which she feels Little, Brown and Company will be interested in. She said that Jim Platt, an old friend of mine when he was with Prentice-Hall, and Milton Johnson are very anxious for Iittle, Brown and Company to do something with me.

At 4:00 p.m., I dropped by to see Morrissey, Thomas and Otto. Morrissey is treating the $\mathrm{Au}+$ protons data of Bachmann (at Darmstadt University) to compare it with our $\mathrm{Au}+25-\mathrm{Bev}{ }^{12} \mathrm{C}$ data. I gave Baisden some Dubna reprints on $\mathrm{Bi}$ isomers to read. On the way home, I dropped by the HILAC Building to talk to Leber and Nitschke.

I took a hike at Lafayette Reservoir, after which Helen, Ty and I had dinner in the kitchen (Ty came home a little early via BART). Dianne ate early and then drove to Berkeley to attend a bicycle repair class at Sather Gate. 

LITTLE, BROWN AND COMPANY
PUBLISHERS
34 BEACON STREET
BOSTON, MASSACHUSETTS O2IOG

ROgER DONALD

EOITOR IN CHIEF

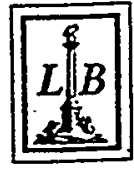

1837

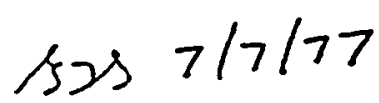

27 June 1977

Ms. Candace Voelker

Publications Coordinator

Technical Information Department

Lawrence Berkeley, Laboratory

University of California

I Cyçlotron Road

Berkeley, CA: 94720 .

Dear Mś: Voelker:

I apologize for the length of time I've held Dr. Seaborg's journals, but as $-I^{2} m$ sure you will understand, they comprise-a great deal of reading naterial and a number of us have had to look at them.

The result of our readings and cogitations are not,..I'm afraid, extremely. helpful. I find it exceedingly difficult to imagine how a . memoir could be drawn from this material; at least one whose purpose would be to inform the general public. Aside from the obvious problems that exist with the technical data -- deciding which sections would be dropped entirely. and which sections would have to be made accessible to the layman -- is a more general, difficult one, that of overall structure. It seems to me that if .Dr. Seaborg wishes to publish a memoir,- he would have to..start with a general outline and structure, using. these materials as:inotes. and background material for himself or an assigned.writer:-

I wonder if it would not be more profitable; and considerably easier, to move from the -idea of a memoir to a more specific subject; such as-the birth of the atomic age -- the Manhattan Project and the first years of the AEC -- in which selections of material and structure of the book would be far less random and more nearly dictated by the subject itself.

I'm sorry I did not get out to San Francisco earlier this month so that we could have discussed this at length, perhaps with Dr. Seaborg. I think that might have been very helpful. Given the impossibility at this time of such a conversation, I think I should sumarize our general attitude:- I don't think the memoir is a possible undertaking for us,: at this stage. I'm not sure I could successfully recruit a writer of 'adequate skills and experience by turning over this material to him/her, stating only that Dr. Seaborg wanted to write a memoir. Our collective-mind-could 
Ms. Candace Voelker

27 June 1977

Page 2.

be changed, however, if Dr. Seaborg presented us with a definite plan for such a memoir, which would facilitate both our and a potential author's vision of the final product. Moving on, if Dr. Seaborg wished to undertake a specific topic, and would draw the boundaries of -it, I think we . could proceed with considerably more ease.

Again my apologies for the amount of time we've taken, and for the somewhat vague reply $I^{\prime} m$ finally providing. Unfortunately, my colleagues and I have been unable to conceptualize the book -- which is what we need to do in order to make decisions -- from the materials we've read.

Sincerely,

cc: Milton H. Johnson, James. B. Plate

$\mathrm{RD}: \mathrm{kc}$

Dictated but not read.

Signed in Roger Donald's absence. 
Friday, July 8, 1977 - Berkeley

Allan Bromley called at 10:40 a.m. to say that he is trying to put pressure on his senators Ribicoff and Weicker to restore the money for the uranium high intensity beam facility. I described my conversation with Mark Hatfield and my thought that I might call senators Stennis and Magnuson. I was unable to identify any particular person in the subcommittee who carried the burden of the opposition. Bromley had just returned from Moscow and described how impressed he is at the activity they are putting in. He mentioned that Flerov has achieved impressive heavy ion beams. Bromley asked me to call him if he can be of further help. We reviewed the full list of conference committee members and he said he might contact Case and schweikert.

I had Iunch in the cafeteria with Baisden, Gottstein and Nishida and we were joined by Lester Winsberg and Nir (who worked with $I$. Perlman). Iz Perlman is in town but I have not seen him yet. Helen is having Iunch with Lee Perlman today.

Around 2:00 p.m., I went by to see otto to discuss our $\mathrm{Kr}$ and $\mathrm{Xe}$ plus U article for Physical Review. Then I went up to the HILAC Building to talk to Cynthia Lee, who is working on the target production apparatus, and Edward Sebesta, who is working on FAKE.

I called Melvin Calvin at 4:00 p.m. to ask for his suggestions for literature that would help me prepare my opening remarks for the Cosmochemistry Conference in November. He suggested my calling Edwin Duckworth at the City College of San Francisco, who organized the Cosmic Evolution Program in San Francisco a few years ago. Calvin will send me reprints of his and Richard Lemmon's review articles.

I then called Edwin Duckworth (at 4:20 p.m.) and spoke with Don warren. I described my need for background material in preparing my introductory remarks for the Cosmochemistry Conference. He will send me several of the transcripts of the papers that were presented there for my review. ( I later canceled this request because I found that I had enough material.) I then arranged with Calvin's administrative assistant, Marilyn Taylor, to send me the papers of Calvin and Lemmon.

I answered Arthur Toy's letter of July 1, 1977 regarding currency conversion prospects with the USSR. I told him we would keep this matter going through the ACS International Activities Committee. I wrote to Paul Lochak in Paris to tell him that I will look forward to having lunch with him in New York on Monday, July 18 th and gave him a brief outline of my New York itinerary. I wrote to Dr. Fritz Weigel at the Institut fur Anorganische Chemie, Munchen, West Germany, to thank him for the recent photograph he sent and to advise him that Hans Hauske's thesis had arrived. I also advised him that he would soon be hearing from Joe Katz about the plutonium chapter (Chapter VII) of the revision of The Chemistry of the Actinide Elements. Sheila sent Dr. Janan Hayes an abstract of my keynote address "Transuranium Elements" to be given at the 19th Annual Asilomar summer Conference of CACT on Sunday, August 21.

Ty came by at 5:15 p.m. and we drove by Eric's place to pick him up and then drove home. Helen, Ty, Eric, Dianne and I had dinner in 
the kitchen. After dinner, Dianne took the Sherman girls (Yehudit and Tamar) to the carnival on Deer Hill Road (near the BART station - on the auxiliary dirt parking lot). Eric and I went there a little later; we met Norman Leavitt and his two boys (friends of Saburo Yashita), Pete Bernard and Al Iindstrom (Eric's friend).

Saturday, July 9, 1977 - Lafayette

Eric and I participated in a EBRPD Field Trip to plan the Briones to Mt. Diablo Trail. About 25 people assembled at Acalanes High School at 8:30 a.m., then proceeded by van (stretched out station wagon) and cars. Present were Jana Olson, Carol Thompson, Hulet Hornbeck, Judy Walsh, Bill Gries (EBRPD), Bruce Lee, Don Good (member, Lafayette-Moraga Trail Committee), Mary Bowerman, Margo Gwinn, Nancy Turner (Pleasant Hill), Bob Headley (Contra Costa Hills Club), Claude Finch (Contra Costa Hills Club), Agnes (Mrs. Claude) Finch (President, Contra Costa Hills Club and Secretary, East Bay Area Trails Council), Mr. and Mrs. Gale H. Reedy (she was born in Sweden) and others.

We started at the top of Martino Drive and traced the trail route along Acalanes Ridge, Mokelumne Aqueduct, Larkey Park, Contra Costa Canal, Heather Farms Park, Ygnacio Canal, private property and Shell Ridge. We ate our pack lunches on Shell Ridge, then drove back to Acalanes High School. Eric and I then drove back home in our station wagon.

Helen, Eric, Ty, Dianne and I had dinner in the kitchen. After dinner, I worked on a draft of my introductory remarks for the November Welch Conference on Cosmochemistry, of which I shall serve as chairman. Eric and TY went out to one of Eric's friend's homes. Eric, as well as Ty, spent the night with us.

Sunday, July 10, 1977 - Lafayette

I drove to st. Mary's College in Moraga for a trail-scouting expedition by the Lafayette-Moraga Trail Committee. At 8:30 a.m., I met Hulet Hornbeck, Chuck Cavanaugh (Chairman of the Committee.), Committee members Don Good, Frank Stephens, Lana Meloyneaux and Ken Briney and EBRPD members Jerry Kent, Bill Gries, Jana Olson and Don Harms. Our purpose was to explore the connection from the lafayetteMoraga Trail to Las Trampas Regional Wilderness. We hiked up to st. Mary's Peak, then along the Old Moraga Ranch Trail (the Utah easement), all on St. Mary's property. This in turn connects with the panhandle of EBMUD property through which connection with the EBMUD Rocky Ridge Trail can be made. Thus, if permission from St. Mary's College can be obtained, we can complete the connection to Las Trampas. We hiked back along a road that led into St. Mary's College. We then reviewed the maps for Phase II (part of the Moraga phase) of the Iafayette-Moraga Trail. I drove home, arrived about noon and had Iunch with Dianne and Eric. Ty was out sailing with Doug Heller and other friends on the Bay.

In the afternoon, I finished my draft introductory remarks for the Welch Conference, wrote a draft preface for Vol. III of Travels in the New World and for my Benchmark book on the transuranium elements. 
Helen and Dianne went canoeing on Lake Chabot in the afternoon, dropping Eric at home on the way. Helen and $I$ had dinner in the playroom. Dianne ate later and Ty stayed in with the Hellers for dinner and spent the night in Berkeley.' After dinner,' I finished my article on Stan Thompson for CHEMTECH. Helen checked with Alice Thompson to get her suggestions.

Monday, July 11, 1977 - Berkeley

Helen drove me to my office in the station wagon so Dianne could have it to drive to her job at the Contra costa Times. The Bonneville is out of commission due to a leak of brake or transmission fluid. replacement.

Sharon Date started to work this morning as Delores Mason's

Art Kerman, here for a couple of weeks, dropped in at 9:30 a.m. I brought him up-to-date on our efforts to save the uranium beam facility, the $\$ 6,000,000$ add-on for nuclear physics, the office of energy research in DOE (Moss Amendment) and the Shieks SHE and actinide program.

At 10:30 a.m., Lew Keller called. He has returned the galley proofs for our Annual Review article, and will send me a copy. I agreed to his sending copies, for their information only to Gunter Herrmann, Robert Silva, W. O. Milligan, Darleane Hoffman and Earl Hyde (but not to Mikheev).

I went by to see de Saint-simon at 11:30 a.m. and discussed with him, Otto and Morrissey some puzzling results of de Saint-Simon's treatment of data on iodine isotope yields from U from Ar bombardments.

I had lunch in the cafeteria with Iz Perlman (the first time I have seen him during his present three-month visit to work with Frank Asaro at IBI). Asaro, Ghiorso, Nitschke, Morrissey and de Saint-simon ate with. us.

I. attended a meeting of Associate Directors in the Director's Conference Room from 1:30-3:40 p.m. Present were Andy Sessler, Earl Hyde, Raymond Wakerling, Will Siri, Walter Hartsough, David Hendrie, Edward Lofgren, James Bassham, David Shirley, Ed Alpen, Luis Alvarez, Robert Birge and George Pappas. On the "Overhead" item, Alpen, Lofgren and Siri voted for an increase from 39.5\% to 40.4\%, which lost because Shirley, Bassham, Birge,.. Hendrie and $I$ voted against and Alvarez abstained. Paul Witherspoon will head a new Division of Earth Sciences beginning october 1, 1977.

After the meeting, I. talked to Earl Hyde about their plan to put the fusion program in the Accelerator Division (which I said is a poor idea), Sheila's impending change and her replacement (replacement at Administrator III level is okay), the Goldanskii correspondence incorporating his views on the latest Dubna SHE discovery in meteorites (in which Goldanskii expresses grave doubts according to Keller, who has had the document translated) and plans for entertainment of Druin and Ter-Akopyan next week (if they come). 
Sheila wrote to Doreen Tuttle, Chemistry Department, and enclosed eight copies of my article The Future of Science, and a list of monographs listed in Scientific Papers (of my curriculum vitae) for the purpose of keeping my bibliography up-to-date in the department.

I also wrote to Dr. Carl O. Helvie, Old Dominion University, Norfolk, Virginia to decline a speaking invitation for spring or Fall 1978. I sent a floor plan for West stands which I plan to use in Volume II of my C-I history to Leonard Dreher to ask him if he could recall the location of Room 5, any additional room section C-I used and whether the group used any rooms other than those on the first floor.

Helen came by at 5:00 p.m. and a little later we were joined by Ty. Doug Heller and Abbott Weatherly (a UCB Engineering student) drove her up the hill. Helen, TY and I drove home where we found that Steve had just arrived. Eric came a little later via BART. Helen, Steve, Eric, Dianne, Ty and I had dinner in the kitchen. Doug joined us for coffee, then $T y$ rode to Berkeley with him to attend a concert and to spend the night at the Weatherly's Watergate apartment in Emeryville. Eric returned to his home later in the evening.

Tuesday, July 12, 1977 - Berkeley

I worked on my Benchmark book on the transuranium elements throughout the day.

At 11:00 a.m., Darleane Hoffman called for the reference on our Annual Review article. I referred her to Lew Keller. She told me that one of the two Dubna papers has appeared in the English Nuclear Physics (Volume A273, P505, November 30, 1976). I described Goldanskii's paper which criticizes the claims of Flerov and zvara and said that I will send her a copy (which was done later that day by Sharon).

At 9:30 a.m., Bob Parry called to go over with me the letter he drafted in response to C\&EN editorial of June 16. I had only a few suggestions to make. Bob said that he found the ACS Board retreat somewhat useful. The only discussion in the international arena was Cairns's report on the question of ICS--apparently, people did not respond vigorously and we will have to move step by step. We agreed that Bixler has done a tremendous job in the short time he has had.

Sheila brought me into a telephone conversation she was having with Louise Taylor who works for Errol Mauchlin in the Berkeley Chancellor's Office. I asked for her evaluation of Pat Quinn and she believes that Pat would be an excellent candidate for Sheila's job.

Just before noon, I went by to see Otto. He is working on our paper describing negative results in search for SHE from U plus ${ }^{136}$ Xe. Morrissey and I had lunch in the cafeteria.

Stan Schneider called at 2:45 p.m. to tell me that he is making good progress on my Uppsala speech "Knowledge and Survival".

I met with Pat Quinn, a candidate for Sheila's replacement, at 3:30 p.m. She is a good prospect. 
At 4:00 p.m., I attended the Bevalac Research Seminar in room 191/70. After two short talks; Bill Myers spoke on "The Fire Streak Model".

Ty came by at 5:15 p.m. and rode home with me. I stopped for a hike at Lafayette Reservoir, but Ty stayed in the car and did not hike. Steve went to the dentist today. Helen, Steve, Dianne, Ty and I had dinner in the kitchen. Later, Helen drove Steve to the san Francisco airport to catch a plane to Washington, D.C. Where he will visit Lynne and Bill for two weeks. He will also see Pete. He left E. Coli (his dog) with us.

Wednesday, July 13, 1977 - Berkeley

Helen drove Ty and me to LBL so we could let Dianne use the station wagon to drive to her work at the Contra Costa Times. She couldn't use steve's Pontiac because he forgot to leave us his keys.

Nitschke called me at 9:15 a.m. to confirm that Druin and Ter-Akopyan will arrive on Tuesday, JuIy 19. Nitschke will pick them up and he and Hulet will take care of their entertainment over the subsequent weekend. During the morning, I talked with Rasmussen and Hyde about this schedule. I confirmed that Druin and Ter-Akopyan will be at IBL for four days. They will visit in the Bay Area on Saturday and Sunday and will fly back to New York on Monday.

At 9:35 a.m., Edgar Piret called to review several pending matters of International Activities Committee business before his departure for Paris. He will discuss Ponamperuma's letter about Miratra with the Science Counselor in the Indian Embassy. He told me that the State Department is enthusiastic about the Yugoslav project and he will talk with Wotiz about this. He will see the President of the French Chemical Society and push the ICS idea with him. I decided to take no action for the time being on his suggestion that I talk during the Chicago meeting with Vlad Haensel, head of the US/USSR Chemical Catalysis Exchange Program.

I spent about an hour in the morning with Margie Hollander going over the Met Lab Section C-I history.

At 10:00 a.m., I interviewed Ann Van Dorn as a candidate for Sheila's replacement. She is pleasant but has a somewhat limited education (high school graduate). She works in the College of Engineering, Materials Science Division, on the campus, so she does have campus experience.

At 11:30 a.m., I called Fred Lothrop to make definite our $20 \mathrm{Ne}$ Bevalac bombardment on JuIy 25-26.

At noon, we held our usual Sheik's lunch meeting. Otto, Nitschke, de Saint-Simon, Nishida, Diana Lee, Cynthia Lee, Baisden, Morrissey, Thomas and Gottstein were present. Otto reported on Bill Myer's Fire Streak Theory and its application to our Bevalac bombardments. De saint-Simon reported on his treatment of our yields of iodine isotopes from $U$ plus $40_{\mathrm{Ar}}$ at various energies. This is turning out very well and should make a good publication. 
Nitschke, Otto, Baisden, Morrissey, Thomas and I met to make plans for the Druin/Ter-Akopian visit next week.

The referees reports on our article "Lowered Fusion Cross Sections in the Quadruply Magic Heavy-Ion system ${ }^{48} \mathrm{Ca}+{ }^{208} \mathrm{~Pb}$ " submitted to Physical Review Letters arrived today. One referee is completely favorable and one suggests some changes which we will make.

At 4:20 p.m., I called Robert Johnson (former Vice Chancellor for Student Affairs at Berkeley) to ask for his evaluation of Patricia quinn. He emphasized her loyalty, industriousness, professionalism, skills, work habits, and decorum. He recommends her without reservations. I then called Pat's present boss, Paul Craig, at the Council on Energy and Resources in University Hall. He does not want to lose her and regards her as outstanding in every conceivable way. He tried to think of something negative without success.

Dianne came in a little before 5:00 p.m. I took her by room $203 / 70$ to meet de Saint-Simon and Nishida and to talk to otto, Morrissey and Thomas. I discussed with otto the referees' comments on our $\mathrm{Pb}$ plus ${ }^{48} \mathrm{Ca}$ paper.

Dianne drove me by Lafayette Reservoir on the way home so I could take a hike. Eric met Ty at Donner Laboratory where she works and took her out to dinner. Ty spent the night with friends and plans to go to San Francisco tomorrow to watch a surgeon operate.

Thursday, July 14, 1977 - Livermore

I drove to Livermore, arriving at the west Gate of LLI at 8:30 a.m., where I was met by Joan Gigliati (Jack Erazer's secretary), who escorted me to the Chemistry Building (No. 222). We went to the Copa Room (No. 1305), where the meeting of the scientific Review Panel of the Chemistry and Materials Science Research Department was held for the purpose of hearing presentations by various staff members preparatory to our task of making recommendations on the FY 1978 proposed program. Panel members present were John I. Margrave (Rice University), Van Derck Frechette (Alfred University), Norman Bruce Hannay (Bell Laboratories), Carroll $k$. Johnson (Oak Ridge National Iaborato$r y)$, Oleg D. Sherby (Stanford University) and $I$. Additional III staff, changing in composition, also attended during the day. Quintin Johnson, an Assistant Director of the Division, was there most of the time.

Jack Frazer, Director of the Division, opened the meeting at 9:00 a.m. with some general remarks and asked us to recommend about a $20 \%$ cut in the program and determine the top 10-20\%, and bottom 10-20\%, of the programs in each division. The first presentation was by the Metals and Ceramics Division, introduced by James Hauber. The next speaker was Richard Landingham on acoustic emission technology. Then, Oscar H. Krikorian spoke on fusion-cast ceramics. Next, Clark Souers (Phillip Clark Souers), of the Chemical Engineering Division was introduced by Bob Hickman and he spoke on bludgeon-derived frozen DT.

Klaus Ernst introduced the program of the General Chemistry Division. This was followed by the presentation by Larry Hrubesh who 
Thursday, July 14, 1977 (con't)

spoke on laser research applied to chemical measurement problems, molecular fluorescence, far infra-red spectroscopy, laser-induced photoelectrochemistry, etc. Roman Bystroff spoke next on multielement analysis systems, including use of microwave and microarc exatatum spectroscopy, at temperatures up to $5000^{\circ} \mathrm{K}$ to measure atomic emission lines. Next, Fred Milanovich spoke on spectroscopic identification of molecular species and their configurations on surfaces of uranium. Finally, Walter Selig spoke on nonaqueous titrimetry in support of organic materials analysis.

We went to Iunch in the conference room adjoining Frazer's office. Jack Frazer, Quintin Johnson, Lee Roberts (who came by to see me about the trail through Crow Canyon some years ago with his mother) and Hugh wilson joined us. I told Margrave about the adverse reports I have received about Aron Kuppermann.

After Iunch, we heard the presentation of the Nuclear Division introduced by Ken Hulet who spoke first on transuranium element research. He discussed progress on physics of fission and their search for superheavy elements. In collaboration with Peter (?) Butler of Berkeley, they found coulomb induced fission doesn't occur. In the study of 262105 they found a total kinetic energy of fission of about $200 \mathrm{MeV}$, in disagreement with the thegry of Schmitt and Mosel. He reported 12 -minute $256 \mathrm{Cf}$ and 90 -minute $259 \mathrm{Md}$. He described the $248 \mathrm{Cm}$ plus $48 \mathrm{Ca}$ experiments. He believes the negative results are due to short half-lives and described apparatus to be used for volatile short-lived isotopes. He also discussed plans to look for the $4.4-\mathrm{MeV}$ alpha particle emitter which has been investigated for the last 50 years. He also described plans to look for extinct $247 \mathrm{~cm}$ via daughter $235_{U}$.

Next, Gordon Struble reported on his nuclear structure research. They have a $15-\mathrm{MeV}$ cyclotron feeding into a $13-\mathrm{MeV}$ van de Graaf produce $27-\mathrm{MeV}$ protons. They have studied $152_{\mathrm{Eu}}$ via $153_{\mathrm{Eu}}(\mathrm{d}, \mathrm{t}){ }^{152} \mathrm{Eu}$. They deduced that ${ }^{152} \mathrm{Eu}$ exists in three isomeric states of three different shapes. He showed a TV movie of the operation of his fast f. p. chemistry apparatus. He also described Dick Hoff's work with actinide isotopes and the Grenoble Reactor. Hoff plans to study $23 \mathrm{Th}_{\mathrm{Th}}(\mathrm{n}, y){ }_{\mathrm{Th}} \mathrm{3}$ and $24 \mathrm{~g}_{\mathrm{Bk}}(\mathrm{n}, y) 25 \mathrm{~B}_{\mathrm{Bk}}$.

Dave Camp then described his work on $\mathrm{x}$-ray fluorescence analysis program rising "exnal" ( $x$-ray spectrum analysis code). Mel Cooper reported on pyrochemical methods for reprocessing spent nuclear fuel using molten metals and molten salts as solvents. Mike Guinan reported on the swelling in americium produced by internal alpha-decay.

Harry Rizzo introduced the program of the organic Materials Division. Ed Catalano spoke on the Single Photon Absorption Reaction Chemistry in the Solid state (SPARCSS) Process. Bill von Holle spoke on reaction in shock waves. Milt Finger then spoke on their Safe High Energy Explosives (SHEE) effort. The last presentation was by Dick Christensen on materials damage prediction. The presentations were concluded a little after 4:00 p.m. The members of our review panel then met in executive session to evaluate the various programs to give 
Van Frechette guidance for writing our report to Jack Frazer tomorrow on the Nuclear Chemistry program. We rated the transuranium program first and the swelling in americium last. We finished at 5:30 p.m. (C\&MS Research Program FY78 Scientific Review Panel Report attached.)

I drove home, picking up Eric, Brian Sawyer and Judy Hoer (their luggage, that is) as they were walking along Glen Road. Eric had met them at the San Francisco airport and accompanied them to Lafayette via BART. Helen, Ty, Eric, Brian, Judy and I had dinner in the dining room. Dianne ate earlier, then drove to Berkeley to attend the bicycle class.

Friday, July 15, 1977 - Berkeley

Ty came in to LBI with me, then walked down to Donner Lab. She has found a room in some friend's home in Oakland and will move in this weekend. We had to stop in orinda on the way to Berkeley to get air in the right rear tire.

Baisden dropped in to tell me the problem she, Leber and Nitschke are having with Mike Lederer, who wants to report their work on " $\mathrm{x}$ " at a Nuclear science seminar on Wednesday. Ghiorso.

At 10:00 a.m., I went to the HILAC building and talked with AI

At noon, I attended the Program Committee bag-Iunch meeting. Present were David Hendrie (chairman), Al Ghiorso, Art Poskanzer, Harry Heckman, Homer Conzett, David Scott, Hermann Grunder, Frank Stephens, Norman Glendenning and Wanda Smith. We discussed the schedule for contributions to the NSD Annual Report, the Lab Space problem, results of the Associate Directors meeting, budget status, etc. I gave a report on my efforts on behalf of the $\$ 6,000,000$ Nuclear

Physics add-on for FY78 and the High Intensity Uranium Beam project problem in the senate Appropriations Subcommittee. Sheila returned in the afternoon. She spent yesterday and today at the U.C. Regents meeting in San Francisco.

At 2:40 p.m., Congressman Norman $Y$. Mineta returned my call.. I told him about my effort to get the $\$ 6 \mathrm{M}$ add-on to the FY78 ERDA budget for nuclear physics via the relevant Senate Authorization Subcommittee. I told. Mineta that I had talked to Olin Teague who agreed to clear it through House Appropriations Committee. When I told him Mike McCormack had suggested I talk with him, he said he would call McCormack and try to find a way to help. He will also talk to McCormack about our high intensity uranium beam project and help get it through the relevant Senate Appropriations Committee.

I received a science Service memorandum to the effect that Robert J. Trotter, formerly Senior Editor and Behavioral Science Editor of Science News, has agreed to become Acting Editor to replace Kendrick Frazier. Dietrick Thomsen will continue as Senior Editor and Physical Science Editor.

At 4:15 p.m., I called Paul Witherspoon to get his appraisal of Ann Van Dorn as Sheila's replacement. He gave a favorable report, 
TO: J. W. Frazer

FROH: V. D. Frechette/J. L. Margrave

SUBJECT: C\&MS Research Program FY'78 Scientific Review Panel

\section{INTRODUCTION}

This is to report the findings of the Scientific Reviev Pane? consisting of:

Dr. Van. D. Frechette, Alfred University

Dr. N. Bruce Hannay, Bell Laboratories

Dr. Carroll K. Johnson, Oak Ridge National Laboratory

Dr. John L. Margrave, Rice University

Dr. Glenn T. Seaborg, Lawrence Berkeley Laboratory.

Dr. Oleg D. Sherby, Stanford University

The Panel would like to convey their unanimous impression that the entire list of proposals showed a high degree of scientific/technological merit and that alt deserve support in providing useful scientific and tesinical information. In response to your instructions, however, we have rated. them with respect to one another. Ratings were assigned numbers (listed in parenthesis) indicating the Panel's opinions as to priority, one being the highest priority, on a scale of one to five.

The presentations were generally excellent and many were outstanding. The improvement over last year's program was noteworthy.

A few general comments might be made concerning organization aspects of the review. Firstly, the fatigue factor in having twenty to thirty presentations in one day is appreciable. Two half day sessions, 
rather than one full day session, might be considered. Secondly, the Perry system titles tend to negate the scientific dignity of the abstracts. Concise scientific titles, without a sales pitch would great7y strengthen the first impression. The abstracts themselves were very well done. Finally, the presentation of slides with classified material to the review panel added little in helping the evaluation of scientific values. The reviewers not accustomed to seeing classified slides were in somewhat of a dilemma about weighing such information in the evaluation.

\section{GENERAL CHEMISTRY DIVISION}

The panel ranked the General Chemistry Division proposals as follows:

(2) Lasers for Chemical Aratysis

(2) Multi-Eiement Analysis

(3) Spectroscopic Analysis of Surface Passivation

(3) Non-f.guscus Titrimetry

Actually, all four proposals have interesting and scientifically important aspects and some sub-areas of the first-rated laser proposal were certainly no more highly regarded than the surface chemistry or the non-aqueous titrimetry.

There was general agreement that the chemical laser program was living up to expectations in terms of fore-front instrumental developments but some concern that instrument building might be getting more attention than basic/applied laser research of significance to the C\&MS Department. We recognize several interactions 
with groups seeking to use laser Raman techniques. Are there still other activities where lasers would be applicable? How about laser melting/quick quenching to get amorphous metal surfaces? Can a $\mathrm{CO}_{2}$-laser provide research-size șamples for fusion casting? For fusion coatings? There is clearly a laser-research aspect to SPARCSS -- unless one is to be restricted to a narrow band of vibrational frequencies.

In terms of Department-wide and perhaps Laboratory-wide usefulness in terms of supporting chemical analysis, we recognize the importance of both multielement analysis and non-aqueous titrimetry. These both are strongly service-oriented projects.

\section{A. Lasers for Chemical Analysis}

The general competence and widely-recognized activities of this section are noted and the participants are to be complimented. Services to a variety of Livermore projects and externa] colfaborations confirm the viewpoint that laser analytical measurement technology is an important research goal.

The proposed new work on laser-induced photoelectrochemistry appears especially exciting and important. The time-resolved laser spectroscopy development appears to have important analytical applications. Other areas are becoming more routine and widely researched across the country. It would appear especially desirable to ascertain that the LLL program on metal 
oxides was not duplicating the work of Zare and others. This system might, in fact; interact usefully with the multielement excitation methods.

There was some concern that both the laser-induced molecular fluorescence and the far infrared laser. studies were neither exciting, forefront science nor of top relevance to LLL needs based on the examples cited. A search for projects to strengthen these activities would be desirable.

\section{B. - Multi-Element Analysis Systems}

The proposal outlined new efforts to develop the microarcmicrowave mulitielement analytical device. The potential wide applicability of such a unit is obvious, and important. Several questions recording the urgent status of the work and the future activities are appropriate:

(1) Have the investigators confirmed the fact that the microwave discharge will significantly improve the excitation of atomic spectra? Will the excitacion of a multiplicity of ions and molecules lead to complex/overlapping/interfering emission lines, bands or continua? Shouldn't there be a strong spectroscopic aspect of the research in progress confirming the nature of emissions from this microwave part of the device? 
(2) In terms of the hot filament/discharge sampling system, there is a temptation to talk about metals as if they are atoms in the discharge. In fact, the species are undoubtedly molecules -- MCL, MOH, MO, etc. The formation and transport of these molecules to the microwave tube is critical for meaningful analyses. How will condensation be avoided? Since oxides/nitrates can't be avoided as samples, wili Ir or some other oxidation resistant cathode wire be desirable?

\section{c. Spectoscopic Analysis of Surface Passivation}

This proposal would make unique surface studies possible at LLL and should provide detailed insight and understanding of metal surface coniaminant. The $\mathrm{U} \div \mathrm{O}_{2}$ and $\mathrm{U}+\mathrm{H}_{2} \mathrm{O}$ interactions are extremeiy important. Both the EEL and Laser Raman studies appear feasible and there should be practical applications of the techniques in studying hydrogen embrittlement, stress-cräcking, halide-sensitized failure of alloys, etc.

D. Non-Aqueous Titrimetry

This is a modest proposal for development in the analytical area through extensions of titrimetric methods to a variety of solvents. There appears to be unique Laboratory needs for such methods -- determinations of PETH, BTF, NQ, etc. A broader range of available solvent systems should significantly enhance the potential of the division to provide important analytical services. 


\section{ORGANIC MATERIALS DIVISION}

All of these continuing programs showed progress amply justifying the investment of resources in them. Safe High Energy Explosives seemed particularly worthy of support (2), partly because so little scientific work is currentiy in progress in this field. Single Photon Absorption Reaction Chemistry was considered equalty meritorious (2). While some questions about the choice of chemical systems for study may be raised; exploitation of this novel principle for separation and synthesis is thought to warrant high scientific priority. Materials Damage Prediction was considered well worthwhile pursuing, especially if the progress to date can be carried successfully into the composites following the initial work with homogenous materiais reported (2.5). The potential for valuable results from Reactions in Shock liaves is impressive, as are the resulits in instrumental development that were reported (3).

4. CHEMICAL ENGINEERING

The proposal of Cryogenic Heavy Hydrogen Technology was not exciting but it was felt to be a good program (3). The exceptional facilities of the Laboratory for work in this system and the scientific importance of it were considered grounds to continue its support.

\section{METALS AND CERAMICS DIVISION}

Metallic Alloy Glasses remains an area of great scientific interest and high technical potential and as such deserves top priority (2) in the Panel's opinion. While noting the success in explosive self- 
welding and cladding and in compaction of powders some questions were raised as to the extent of progress in this work to date. Static Equation of State is believed to have tremendous potential, particularly in vieiv of the Laboratory's existing expertise and interest in dynamic equation of state determinations (2.5). Acoustic Emission was considered well worth support (3), not so much for its novelty as for the prospect of unusually high quality work in the field as the result of simple and highly characterized specimens and excellent $A E$ and ancillary diagnostic tools. Fusion Casting of Ceramics offers littile of scientific interest in the plans presented. Its technological value in the system to be siudied may be considerable but the Panel had reservations about the lack of a clearly planned approach to the project (4).

Basic Study of Toughness was thought highly interesting but probably approaching a p=riod of diminishing returns when termination should be planned before long (4). The structural metallurgy of welds at the atomic level might-provide a fruitful area for future work.

\section{NUCLEAR 'CHEMISTRY DIVISION}

The proposals of this Division were extraordinarily interesting and closely linked with the central capability and mission of the Laboratory. The Transuranium Element Research proposal was assigned highest priority (2) by the Panel in view of the crucial question in fission theory which is to be addressed with the experimental plan. However, the continued search for super heavy elements in terrestrial nionazite 
does not seem particularly fruitful. The long history of reports

$\because \quad$ on the $44^{\circ}$ MeV $\alpha$-particle emitter should be brought to some logical conclusion. Pyrochemical Investigation vas rated nearly as hign (2.5). Equal emphasis (3) was given the proposals Nuclear Structure Research, Neutron Capture Gamma and X-Ray Fluorescence. Somewnat less enthusiasm. was expressed for Swelling in Americium (4), principally reflecting doubt as to the scientific relevance of the question.

jing 
although he is not well acquainted with her. I also talked to Professor H. F. Morrison, her present supervisor, who gave her a pretty good recommendation. Afterward, I went by room 203/70 to work with Morrissey and otto to amend our $\mathrm{Pb}$ plus $48 \mathrm{Ca}$ paper to conform with the referee's suggestions. Mike Lederer's talk on " $x$ " scheduled for Monday's NSD seminar has been canceled, due to suggestions by Baisden, Leber, Nitschke and Ghiorso that such a report on their work would be premature.

I mailed a letter to Knut Bachman, Darmstadt University, regarding his recent article containing the first results from bombardment of $\mathrm{Ag}, \mathrm{Ta}$ and $\mathrm{Au}$ targets with relativistic protons that appeared in Volume 13 nos. 5/6 of Inorganic and Nuclear Chemistry Letters. (His is the first data we have seen for protons plus Au.) I submitted to The People's Almanac a write-up or predictions (attached) for the future as requested by Randi Cushnir, Assistant Editor.

Ty did not come home with me but stayed in Berkeley with friends. When I got home I learned that Judy Hoer was taken to the emergency room of the hospital today because of cramps in the stomach area; she recovered and was at home when I arrived. Helen, Eric, Dianne, Brian, Judy and I had dinner on the patio. Ty came out later to spend the night.

Saturday, July 16, 1977 - Lafayette

Eric and I drove to Acalanes High School to participate in the EBRPD field trip to study the route of the Briones to Las Trampas Regional Trail. Present were Jana Olson (leader), Carol Thompson, Bill Gries (of the EBRPD), Sue and Bob Watson, Don de Fremery, Don and Ruth Ann Good, Howard Cogswell, the Finches, Jim McLaren, Sam Connery (of Sunset magazine), Arland Christophersen, Bob Headley, Ernie Marriner, Dr. Art Emmes and Richard Newey (brother of Bob Newey, author of "East Bay Trails - A Hiker's Guide").

Eric and I rode in a van driven by Ms. Christophersen, along with Dr. Emmes, the Watsons and Gries. Jana Olson drove the EBRPD van (the one Eric and I rode in last Saturday), which was full of people, and a private car completed the caravan. We started by driving to st. Mary's College. We hiked up St. Mary's Peak, then on along the old Moraga Ranch Trail to near the EBMUD panhandle, then back on the dirt road to our starting point. We then drove along St. Mary's Road, made a stop to inspect the Lafayette-Moraga Trail, then drove to the junction of this trail with Fourth Street across Las Trampas Creek from Mt. Diablo Blvd. We inspected the route for the connecting trail in this area, including the 3.5-acre tract owned by John Hallgren. A bridge across Las Trampas Creek (or two bridges across Lafayette Creek and Las Trampas Creek) is needed at this point. We then crossed Las Trampas Creek at the "dam" behind Ernie's Liquor Store, then walked along EBMUD property under Highway 24 to Deer Hill Road.

We drove along Deer Hill Road to Elizabeth Lane, where we stopped. This is the preferred entrance to Lafayette Ridge. We then drove around to Spring Hill Road and up Martino Road to the top to get a view of the proposed trail on Lafayette Ridge. We then drove back to Acalanes High School. Eric and a number of others left us here. 


\section{PREDICTIONS FOR THE FUTUPE \\ Glenn T. Seaborg}

Much propiess will be made in the understanding of life processes--in biochenistry, molecular biology, and related areas concerning the study of proteins, enzynes, nucleic acias and other macromolecules. Chemical and biological investigations at the inolecular and cellular leveis, aidea by enormous?y efficjent computers, will elucidate tine origin of life and lead to the ariificial creation of life. Biochenical genetics will give us a great deal of control over the genetic code and, beneficently applied (which will pose a real challenge), should resilt in a reduction or elimination of genetic defects.

Compuicex-aidea molecular mecicine, imnuochemistry and chemotherapy shouli loaj to the alleviation, treatment, cure or prevention of our major ailments, incluaing "mental" illness, and to a slowing of the aging process. Fna tre will understand tise structure, nechanism and functioniug of ilerve anj brain, leading to control of our menory, through investigations in seurochenistry, neuroanatomy, neuropiysiojogy, statistical biology and experimental psychology. Bio-angineering should make available implantable (micro-coriuter assisted) artificial hoarts, kinineys, eyes (instruments to pernit the bilnd to rsee"), ears (instruments to permit the deaf to "hear"), and other bodily parts and organs.

science and technology, properly supported, will solve 
our energy, food and mineral resource problems, even with our expending horldwide population (hopefully at a amimisher rate). our eniless supply of solar energy will be put to practical use throvgh processes yet to be discovered--direct caralytlc conversion to electricity, splitting of water to prouuce hydrogen Euel, or widespreal biaconversion of vegetation and waste projucts. In auäition to breeding of nen crops, new sources of fooj will cone From biological nitrogen fixation, protein extraction Erom lor-cost grain, legunes and leaves, and the produation of single-cell protein fron all types of wastes and algae. Geologists will finz new sources of ninerals, chemists will increase the efficiency of extraction, and materials scientists will synthesize substitute materials from more abunkant sizplies.

Scientific advances vill incluge in physics, the understanding of findamental particles and nuclear structure, and synthesis of many adaitional chemial elenents; in:space scieeces, the colonization of the noon and mannea travel to frars; in chemistry, the synthesis of millions of new compounds tailored for a wide syoctrun of practical uses; in seismology, the prediction of earthquakes; in corputer scjence, the placement of miniaturizal computers in tize hairis of neanly everyone and perlaps production Gf macilines that "think"; in engincering sciences, the translation of scientific discoveries on $\pi 12$ fronts into a besiluering total of practicai aiplications; and in astronomy and astrophysics, advances far beyond guasars, pulsars and black holes. 
The rest of us, including the Watsons, Finches, de Fremery, Jana olson, Carol Thompson, Gries, Headley, McLaren and I ate our backpack lunches here. I rode with the Watsons into walnut Creek where we looked in vain for the advertised solar home. They then drove me home.

I called Ben Loeb to see if he is interested in coming to LBI to work on writing projects with us. He probably is not. He is earning $\$ 150$ a day as a consultant.

Eric had a barbecue for a number of his friends including $\mathrm{Ty}$, Judy Hoer, Brian Sawyer, Richard Sproul, Bill Sprotte, Scott (Hodgie) Alexander and his friend Corinne Farreli, Al Lindstrom, Tom Mochisuki, Mary Borchers and Dianne. Helen and $I$ joined them in the patio as they were finishing their hamburgers. Eric and his friends, except Hodgie and Corinne, then went to visit his friend Clark Bailey at his girl friend's apartment.

Ty went to her place in Oakland. Richard Sproul spent the night with us and left early sunday morning. I read the proofs on the Keller-Seaborg article "Chemistry of the Transactinide Elements".

Sunday, July 17,1977 - Lafayette - New York

Eric, who spent the night with us, drove Brian and Judy to the railroad station in Oakland to catch an 8:00 a.m. train to Santa Barbara where they will stay about a week. He then came back to our house.

I wrote the introduction for the compilation of Stan Thompson's publications that we are putting together ( 6 copies).

I called Lew Keller at his home in Oak Ridge to pass on some corrections to the page proof of our article "Chemistry of the Transactinide Elements" to be published in Annual Review of Nuclear Science. He said Druin and Ter-Akopyan are giving him some trouble, claiming that I wrote the article on "Criteria for the Discovery of Chemical Elements" which he and others co-authored with me for publication in science.

Helen drove me to San Francisco International Airport where I boarded United flight \#34 which left at 2:30 p.m. and arrived at Newark Airport at New York at 10:45 p.m. I took a taxi to the Chemists' Club and checked into room 741. I found the weather hot and muggy.

Monday, July 18, 1977 - New York - Lafayette

I had breakfast in the dining room of the Chemists' Club.and checked out, then walked up Fifth Avenue to the General Motors Building to attend the meeting of the Board of Directors of the Dreyfus Third Century Fund, held in their conference room on the 35 th floor. I first went to Howard Stein's office where, together with Stein, John McCloy and George Harrar, I met Alice P. (Mrs. Russell K.) Jones, the nominee to be a Director. 
Monday, July 18,1977 (con't)

The meeting began at a:little after 9:30 a.m. Present were Kenneth J. Oberman (President), Michael A. Glass (Secretary), William Berkowitz (Treasurer), Howard Stein (Chairman of the Board), Lawrence M. Greene (Vice President and General Counsel), Monte J. Gordon (Vice President and Director of Research), Russell J. Guglielmino (of Reavis \& McGrath, counsel to the Corporation), John J. McCloy (Director), J. George Harrar (Director) and Elizabeth Hamilton (staff).

With oberman presiding, we elected Mrs. Jones as a Director, then elected Stein as a Director (he had been forced to resign to keep the number of outside Directors in the majority as required by law). Stein then took the chair and conducted the meeting according to the agenda. We approved the new distribution agreement with the Dreyfus Service Corporation. We set the date for the Annual Meeting (and accompanying Board meeting) for september 29. I pointed out that I will not be able to attend. Joseph P. Martino, vice President, came in to describe the consequences of the new distribution agreement.

At 10:45 a.m., John Fitting, Jr., Assistant to the Chairman, described a life insurance purchase plan for shareholders with 50 or more shares. He found Bankers Security Life Insurance Society of Washington to give the best insurance deal. We adjourned at noon.

I walked to nearby Hotel Pierre (Fifth Avenue and 60th Street) to meet Paul Lochak and Roger Godino. We went to lunch in the Pierre Restaurant. They described to me the status of GETEX negotiations with Italy. The uranium exploration project will get started when the agreement is signed on the basis that GETEX (through TEAM or its equivalent) will put up $\$ 400,000$ and Italy $\$ 700,000$; in the second stage, GETEX and Italy will share costs on a 50-50 basis. The parties may sign this agreement at Godino's ski resort in a couple of weeks. They told me about their discussions with Albert Buchalet (a former French general) who will proceed with discussions with Brazil if I will assure him that Milly's method is sound. I agreed to talk to Buchalet in Paris in September. I reminded Lochak to check with SoI Linowitz about U.S. official attitudes toward explorations for uranium in Brazil.

The composition of the governing Board of a contemplated European financial arm of GETEX (which is not the same as TEAM) will be: Paul Lochak, Roger Godino, Norbert Beyrard, Olivier Giscard d'Estaing, Albert Buchalet, Glenn Seaborg; and possibly Rodney Rockefeller (son of Nelson Rockefeller), Raphael w. Hodgson (vice President, Goldman-Sax International, and a long-time friend of Lochak) and George Milly. Lochak and Godino will talk to Rodney Rockefeller and Raphael Hodgson during this present visit to New York. Beyrard wants his funds to go $80 \%$ toward development of known deposits.

We also discussed the financial arrangements for this group to pay me $\$ 20,000$ per year as compensation for my services. The payments will start as soon as a contract for a source of funds is signed (perhaps the agreement with Italy) and will be retroactive to september 1976. 
At 3:00 p.m., I took a taxi to Kennedy International Airport and boarded American flight \#19, which left at 4:40 p.m. and arrived at San Francisco International Airport at 7:00 p.m. The temperature in New York was a little over $100^{\circ} \mathrm{F}$ as I rode to the airport. Helen met me in the Bonneville (just picked up at Shepherd's following their fixing of the gear box) and drove me home.

Tuesday, July 19, 1977 - Berkeley

Helen drove me to my LBL office in our station wagon. She is going to the Doe Library Annex to find 1943-44 news items for my Met Iab Section C-I history and to get our tires fixed at the Berkeley General Tire Company on University Avenue while she is at the library.

Dick Hahn called at 8:45 a.m. from ORNL to report on the visit of Dr. Victor A. Druin and Dr. G. M. Ter-Akopyan and to tell me that they are on their way here. He described the airplane ticket help still needed from Sheila on this, which she will handle, Druin still insists on his observation of $260_{104}$ via ${ }^{249} \mathrm{Bk}+{ }^{15} \mathrm{~N}$.

Lew Keller called me shortly thereafter and, as Hahn had done, described their discussions with Druin and Ter-Akopyan. They discussed our "Criteria for the Discovery of Chemical Elements" paper for $2 \frac{1}{2}$ hours. They are quite disturbed by this paper.

Fred Wall called from Rice University to get my information on Aron Kuppermann.

I then went by rogm $203 / 70$ to discuss further the referee's report on our $\mathrm{Pb}$ plus ${ }^{48} \mathrm{Ca}$ paper with otto. We are revising the paper to meet the objections.

At 9:45 a.m., I interviewed Dorothy Johanson as a possible replacement for Sheila. She is working as a secretary for Giauque Laboratory and David Iyon for the last eleven years; she seems quite competent and is about sixty years old.

At 10:30 a.m., I talked to Marilyn Stern, another candidate for Sheila's job. She worked for Frank Beach from 1959 to 1971 and remembers my efforts on his behalf to find a place for his primate laboratory on campus when I was chancellor. She seems somewhat shy.

At 11:02 a.m., I called Pat Quinn to explain that we are still interviewing people and asked if she is still interested in our job here, which she is.

At 11:40 a.m., I called Bryant Rossiter who had learned from Jesse Hwa that Madame Ceausescu had declined our invitation to speak at the first day of the CHEMRAWN Conference. He will talk to Professor Emanuel at the meeting in Warsaw about the general health of Dzhermin Gzishiani. Rossiter is going to Russia after the Warsaw meeting and will try to make the arrangements there. I encouraged him to line up Gzishiani and told him to use my name freely in this regard. I agreed to his sending to members of the U.S. National Committee to the IUPAC Congress copies of Cairns's report of discussions in the Hague about ICS, my short letter on the subject and the 
Tuesday, July 19,1977 (con't)

material written up in C\&EN. Rossiter feels that the ICS proposal should not be an agenda item at IUPAC although he would not be entireIY against it. He suggests that the U.S. National Committee should get involved only if the possibility arises that IUPAC might be restructured to make the ICS idea more acceptable. I suggested that he could have Gordon Bixler call me about this if necessary.

At noon, I interviewed Ruth Dean for Sheila's job. She has worked since 1976 for Frank Giunta in UCRS. She seems very selfreliant.

I had lunch in the cafeteria with Baisden and Nishida. After lunch I dropped by to see Thomas. He now has resolved a 2.4-hour activity in the Th fraction from $\mathrm{U}$ plus $86 \mathrm{Kr}$. He, as well as Baisden, has received notification of potential jury duty.

At 1:45 p.m., I interviewed Ingeborg Murphy for Sheila's job. She works in the U.C. Patents Office, seems mature and competent and speaks with a German accent.

Jack Josey called at 2:30 p.m. to discuss again with me the Welch Foundation Professorship at Rice University. He asked me to collect. information regarding Tom Bruice, Professor of Chemistry and Biochemistry at the University of California, Santa Barbara. Apparently, his wife might get a position in the Medical Center in Houston. Bruice is a graduate of USC and is 52 years old. Josey said that doubts coming out of my inquiries led them not to pursue further the appointment of Aron Kuppermann. He confirmed that neither Marvel nor Corey was enthusiastic about Kuppermann.

Paul Randolph called at 2:50 p.m. He wants to talk with me about a proposal he is drafting that would permit the construction of nuclear reactors along the coastline. I asked him to send me written material and explained that my schedule is very tight.

Mike Nitschke met Dr. Victor A. Druin and Dr. G. M. Ter-Akopyan at the San Francisco airport and helped them check into the Durant Hotel, then brought them to my LBI office at 3:00 p.m. I spent about an hour with them in general discussions, describing the work of $\mathrm{my}$ radiochemistry group, while they had a cup of tea with me. I then took them by to see Otto, Morrissey, Thomas, de Saint-Simon, Marsh, Ni ishida and Gottstein. They gave me a couple of preprints ( $\mathrm{Pb}$ plus $48 \mathrm{Ca}$ to produce asymmetric fusjon-fission at low energy and mass distribution from $243 \mathrm{Am}$ plus $4 \mathrm{O}_{\mathrm{Ar}}$ ). I then took them up to the HILAC building to see Ghiorso and Nitschke and to meet Baisden and Sebesta. Nitschke and I showed them FAKE and FAMSY.

Nitschke took them back to the Durant Hotel where the two of them had dinner and spent the evening alone. My conversation with them covered three pending items: (1) I asked them to send me a biography, summary of main scientific accomplishments and complete bibliography for Polikanov so that I can nominate him for the APS Bonner Prize. I emphasized that my letter must go out by August 26 . (2) In connection with the article I am writing about Stan Thompson, they gave me the 
full name of Perfilov as Nikolai Alexandrovich Perfilov. (3) When they return to the Soviet Union, they will inquire about the permission forms for my Benchmark book on the transuranium elements that have been sent to Dubna people and not returned. I will give them duplicate copies of the forms to take back to Dubna to see if they can get the signatures.

Professor Hari Sharma called late in the day from the University of Waterloo in Ontario, Canada. He would like to recommend me to his University's administration to give the distinguished lecture series that is named for their first president, sometime in 1978-79 (three lectures). Further, he asks that I visit waterloo for a full week to give three or four lectures in their chemistry department distinguished lecture series. Sharma will be on sabbatical leave next year and has talked with Dick Diamond about possibly coming to LBL for an eight-month visit. Sheila encouraged him to write to me about this and asked him to indicate the kind of program he would like to undertake.

In response to my request, EBRPD sent me an extract of their Board letter acknowledging efforts made by me and others concerning the acquisition of the Wallace property as part of the Robert Sibley Regional Preserve.

I received a letter yesterday from Donald C. Stewart, ANL, acknowledging receipt of my book dealing with the history of section C-I of the Met Lab. He said that the only problem he has with it is that his wife, Dorothy, started to read it and Don cannot get it away from her. Paul Fields and winston Manning have had glimpses and both have asked to be put on the reading list for Don's copy.

I stopped at Lafayette Reservoir and took a hike before dinner. Helen and $I$ had dinner in the playroom and watched part of the AlIStar Baseball Game from Yankee Stadium in New York. The NL won, 7-5.

Wednesday, July 20, 1977 - Berkeley

At 10:00 a.m. I met with Camille oni, a candidate for Sheila's job. She probably does not have the experience required. She aspires to be a creative writer.

Allan Bromley returned my call at 10:40 a.m. We discussed progress on restoring the high intensity uranium beam budget item (78-12-B). He read me a note that had been sent to senators Case, Schweiker, Byrd, Stennis and Sasser. I suggested that it also be sent to Tom Bevel, Chairman of the relevant House Appropriations Committee. I also brought him up-to-date on $\mathrm{my}$ effort to add $\$ 6 \mathrm{M}$ to the nuclear physics budget. He will work through Connecticut Congressman Robert $\mathrm{N}$. Giaimo of the House Committee on Appropriations to enlist his aid. We agreed to keep in touch.

At 11:45 a.m., Gordon Bixler and I discussed numerous matters in the IAC office: (1) draft resolutions for the Board of Directors to publicize the Board action on UNESCO and the Two Chinas policy, which I approved; (2) When I go to Europe I will contact a number of people mentioned in Dermott O'Sullivan's article in C\&EN (Gallais, Baranowski 
Wednesday, July 20, 1977 (con't).

and others); (3) mailing to Rossiter (Cairns's June 27 report, my short letter, draft proposals of Kirschner's subcommittee, C\&EN article) for distribution to U.S. National Committee to IUPAC Congress; (4) Egyptian workshop; (5) Program Review Committee and (6) the June minutes.

At noon, George Rogosa returned my call to compare notes about our efforts to get the line item for the uranium high intensity beam project and the nuclear physics add-on. I described Bromley's activities. It is Rogosa's understanding that sessler will give some relief on the overhead of the power costs in the Bevalac even though this would not have a great net effect.

I had lunch in the cafeteria, lower level, with Druin and TerAkopyan, Ghiorso, Nitschke, Otto, Baisden, Stephens, Poskanzer, Morrissey, Cynthia Lee, Diana Lee, Thomas, de Saint-Simon, Hulet and stephen Wilde. Druin and Ter-Akopyan told me they have been associated with Flerov since the 1950 's, starting at leningrad. Neither has his Ph.D. yet.

After lunch, at 1:55 p.m., I called Earl Hyde to ask if we could pay modest honoraria to Druin and Ter-Akopyan, particularly since they are paying for their own housing. Hyde and I agreed that they should receive $\$ 125.00$ each. Hyde will authorize the standard forms to be completed by Wanda Smith, if this can be, arranged through the LBL/ERDA procesis.

At 2:20 p.m., I called George Pappas for his evaluation of Jan Richardson who is applying for sheila's job. He said that she is smart but needs substantially more experience for a position like this. He did not think that her writing abilities would be adequate for this position.

Iater, at 2:40 p.m., I called John Whinnery to get his appraisal of Ruth Dean, who is also applying for Sheila's job. She had worked with him until 1971 and he thinks very. highly of her.

Jane Kingston dropped in at 3:15 p.m. She would like an expanded job in the fall when she starts school at Hayward state. I said I doubted that this would be a reasonable schedule for her.

At 3:45 p.m., I had tea in my office with Druin, Ter-Akopyan and Nitschke, then we all went to the seminar room in building $70 A$. I presided, first introducing Druin, who gave a general talk on heavy element and SHE research at Dubna (he did not mention 260104), then Ter-Akopyan, who spoke on the search at Dubna for SHE in meteorites and geothermal, water. His evidence for SHE did not appear very convincing.

I drove Druin and Ter-Akopyan to the Durant Hotel and then picked them up a little -later and drove them to the Earl Hydes' house for dinner. Present, besides Earl and Jean and their daughter, Carol, were Dr. and Mrs. Poskanzer, Dr. and Mrs. Hendrie and Nitschke, who drove Druin and Ter-Akopyan back to the Durant Hotel following dinner. 
I wrote to the editors of Physical Review Letters regarding our manuscript LF1112 entitled "Lowered Fusion Cross Sections in the Quadruply Magic Heavy-Ion System ...". I told them we were presently in the process of beginning to write the full paper describing these results and that we were pleased to read the personal concerns that the referees had offered.

A letter (attached) arrived today from Vitalii Goldanskii with two preprints on superheavy elements and his analysis of the data described in these preprints.

Helen and Dianne left for Davis this afternoon to attend a twoday orientation for Dianne.

Thursday, July 21, 1977 - Berkeley - San Francisco

I had breakfast at Sambo's in Lafayette. When I arrived at my LBL office at 8:15 a.m., I received a telephone call from George Rogosa who said the Senate-House Appropriations Conference Committee on the ERDA budget met yesterday but he did not know how the high intensity uranium beam project came out. I called Hunter Spillan and received the bad news that it was not included. He said the Senate was adamant about leaving it out. They said that they could not give ERDA everything they asked for. When I asked if there was anything more that could be done this year, he was not encouraging. I, in turn, called Rogosa back and briefed him on our conversation. George hopes to include it in the FY79 budget. I called Earl Hyde and Hermann Grunder to let them know.

At 9:25 a.m., I talked to Frank Giunta of the U.C. Retirement System for his evaluation of Ruth Dean. Like John Whinnery, he was very laudatory in his appraisal of her and gives her the very highest recommendation. He described the career development program that he has had in mind for her there.

I left the office for the University of California Medical Center in San Francisco at 10:30 a.m. I went to the Millberry Union, Room 238, where I met Al Minvielle and Steve Leonoudakis (Sam Muccio, who arranged my visit, was sick). Minvielle is a friend of Alex Avdeef's since grammar school days.

I had a quick hamburger in the Millberry Union cafeteria and then went to Room 203 of the Health Sciences Building where Minvielle gave me a one-sentence introduction for my talk on the energy problem. About 30-40 people were present. I illustrated my talk with 18 slides, talking from shortly after noon until 1:00 p.m. This was followed by about 15 minutes of questions--mostly critical of nuclear power. I then drove back to my LBL office, arriving at 2:15 p.m.

Upon my return, I went to room 203/70 to see Otto, Morrissey, Thomas and de Saint-Simon to discuss our research writing progress, etc.

I found that Allan Bromley had returned my call. Sheila gave him the message that the Senate-House Conference Committee on Appropriations for the ERDA budget met yesterday and did not include the line 
465

RECD PUL \& 01971 Moscow, 121977 Scar Glens.

Judging from your letter on June, 23-rd You have not obtained two pregrints on superheavy clements and my analysis of the data described' in these preserints.

Therefore I sent you all these materials again.

I made an analysis of data for myself just to satisfy my scientific curiosity and have no mutentron to discuss say conclusions with somebody else but fou or to

Therefore feel yourself free to use them in any way which you find reasonable; e.g. in the general survey of SHE problem of discussing some particular works along this line.

There will be an International leering on Cherry Lois Nuclear Interactions and Synthesis of New Elements - in Dulia; in December, 13 는 16 th. Problems of natural SHE will ald be discussed there. I. issuer whether you on some of your colleagues from Bericely will one here. 
466

What means to the letter of Dr. Lewis I still have not sent any answer and $I$ thine that there is no real need in such answer.

In ring letter sent with the presents to you I have apparently mentioned that $I$ hope to be $s$ the UAA for a couple of weens in November - as an invited speaker on the "Molecular Tunneling" at the Conference in Tunneling in Biological Systems organize w by Briton Chance in Philadelphian (Nov, Bird io 5 -th). As you could see from the pregnant on the Interstellar Polgmerizetrow of Formaldehyde, which Jive mailed to yous on June, 24-th, I am entering now the field of "interstellar molecular tunneling" in chemical reactions. I was surprised to obtain an urgent telegramme from Profs Fifth ale and N. Wickramasinghe withy me (apter come reading of my prom as posset) to England fer discussing astroghinsical problems. Certainly, I can't do that now lat I hope to see them in 1978. Right now I have finished another short note on the "Interstellar Grans as Possible Cold feeds of Life". Enclosed is also a joke which 
467

I am going to sent to the Journal of Irreproducible Results. Sad joke, but true one. Another the thongs which I have apparently written so the missed bitter was the advice to Al Ghiseso to ask e International Boon-starce in New York for the assistance in getting the book on. birds, published in Moscow several years ago. 'It cant' \& frosted here. it was sold out long time ago.

Well that's all for present til and I sent our cordial grcetsugs to Helen and you

Yours, as ever - Yitaler.

P.S. I would appreciate any comments of yours concerning my treatment of $\dot{S H E}$ date. I thine that this treatment can be 3 std as a base for the paper entitled lite: "On the relation between numbers of detected siciliple neutron coincidences and of events of multiple "rentron emission" (title is certainly tentative). It would be of interest to see whether such paper would be accosted af a contributed payer at the abovenentioned Meeting in December. V. 
MPDXI

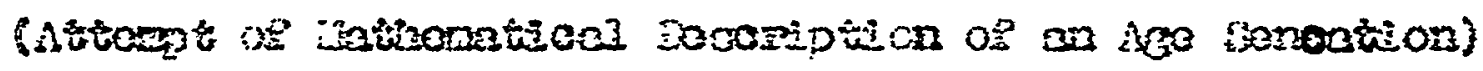

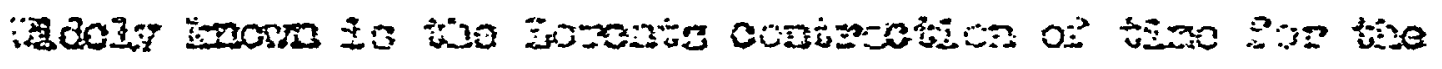

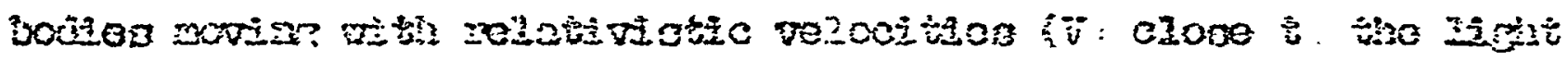

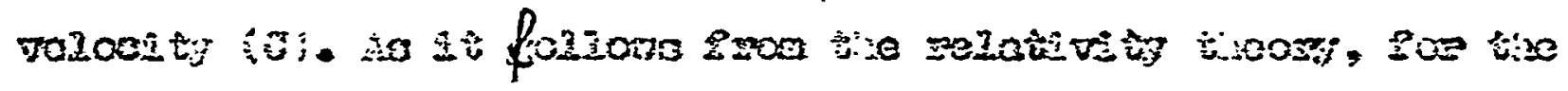

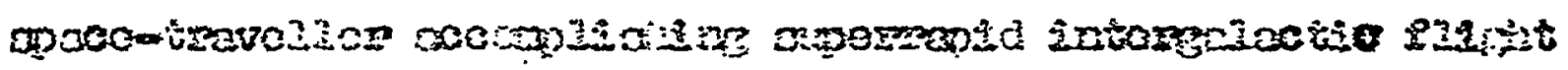

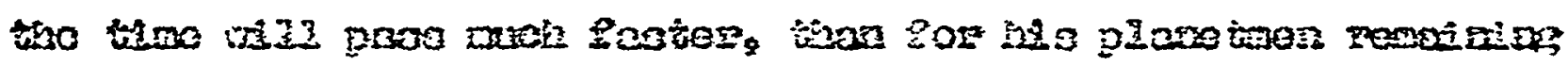
a) 2000 .

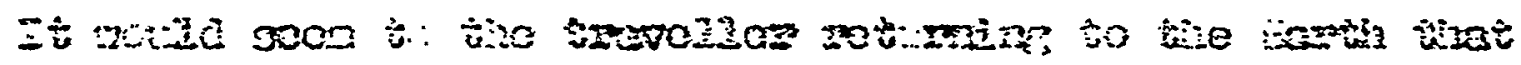

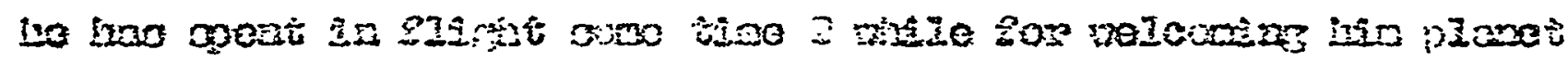

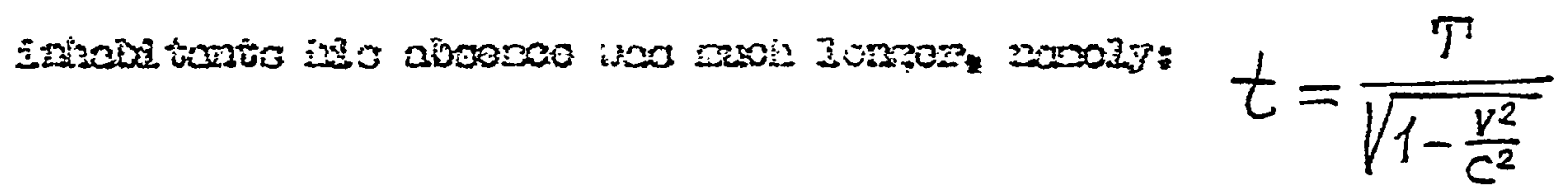

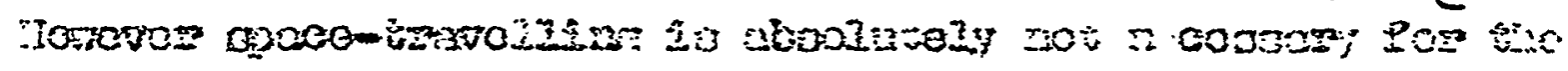

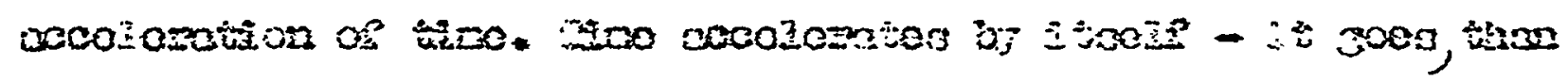

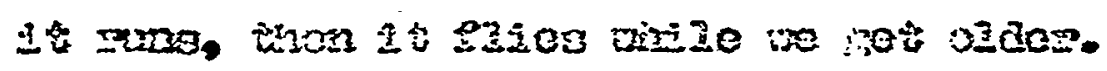

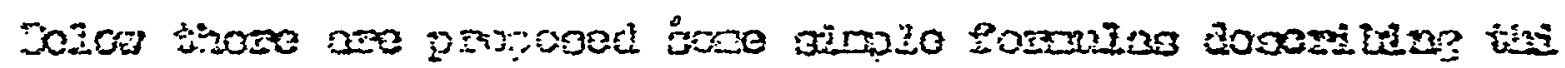
rom

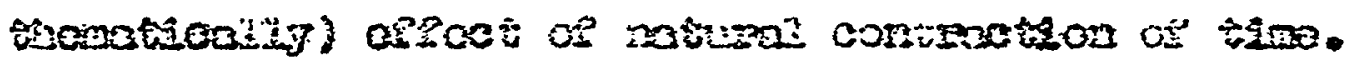

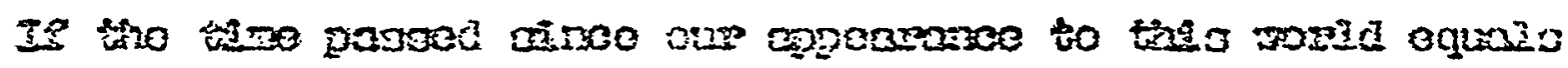

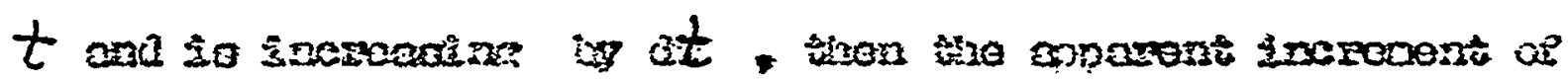

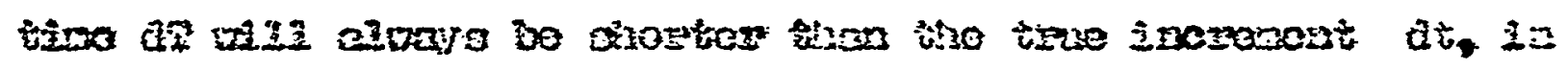

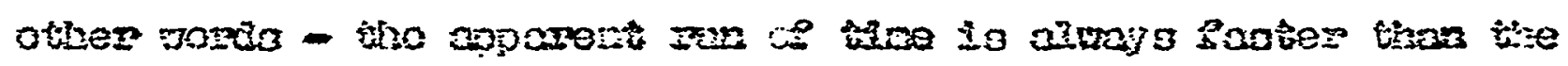

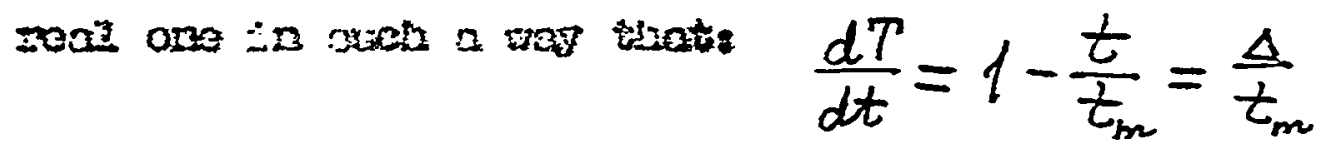

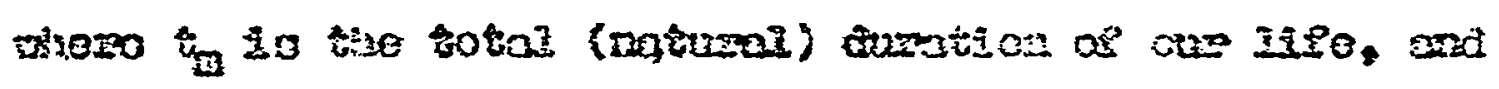
$\Delta=t_{\mathrm{m}}-\mathrm{t}$ io 1 to remaindor.

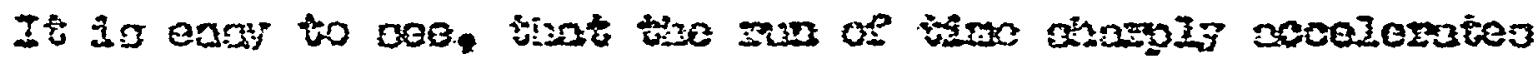

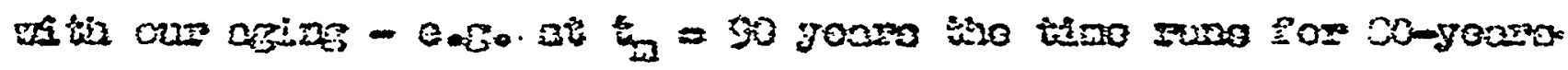




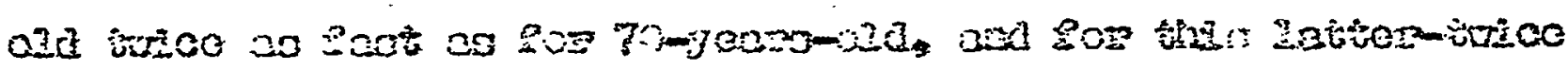

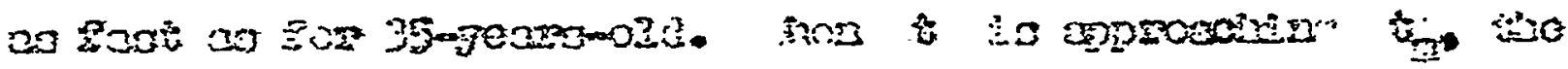

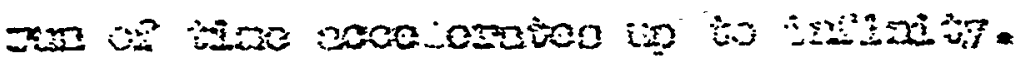

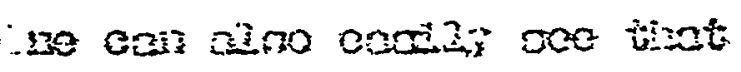

$$
T=t\left(1-\frac{1}{2} \frac{t}{t_{m}}\right)
$$

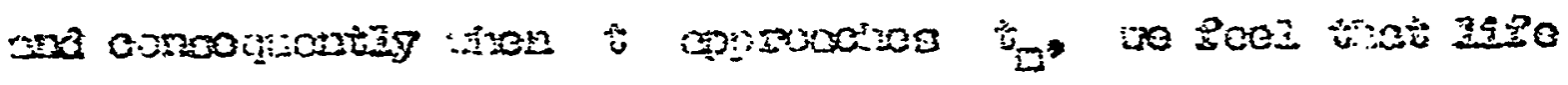

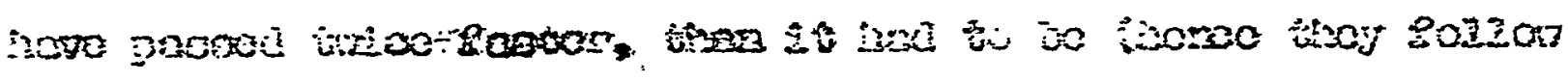

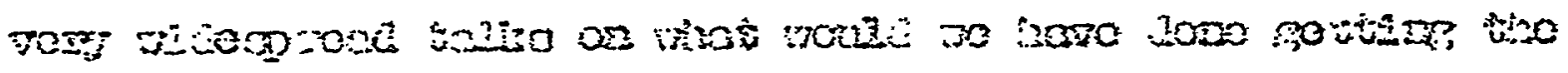

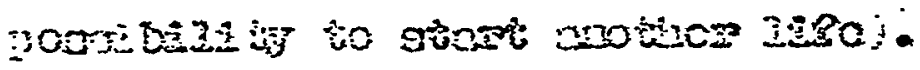

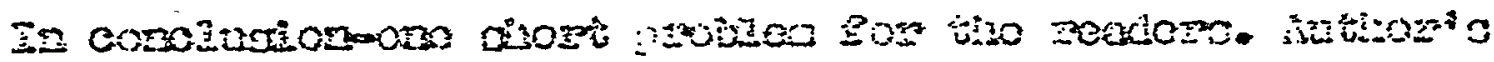

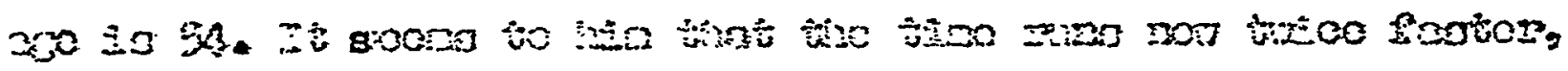

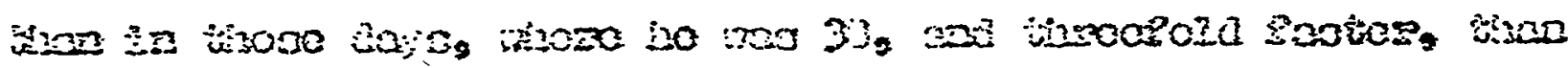

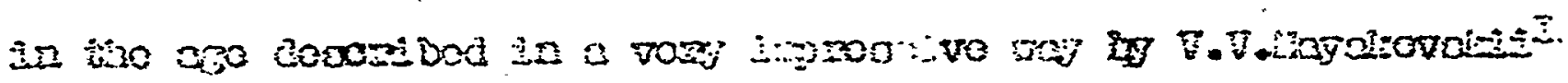

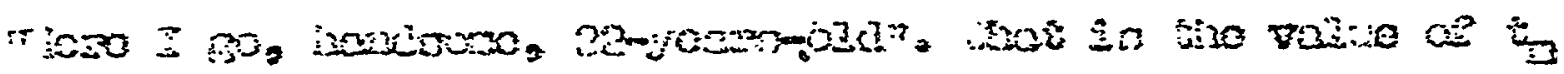

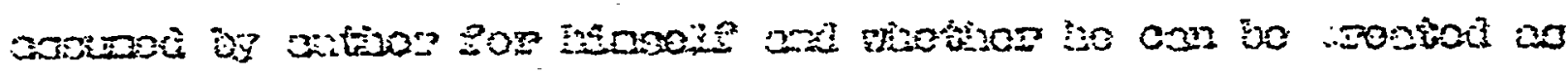

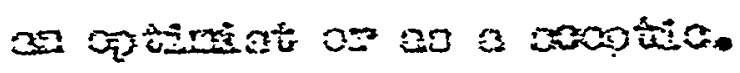

\section{0}

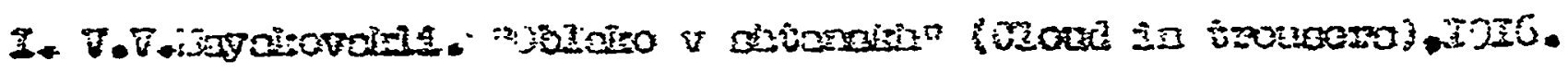

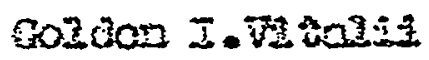

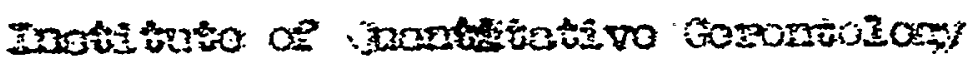

$3080-0$ is ty 
item for the high intensity uranium beam project. Bromley expressed the opinion to Sheila that it was an uphill battle from the beginning because this item was at the long variable list that ERDA had submitted--thus making it appear that it was a low priority item. He thinks we need to do a job of educating congressmen on these matters.

I mailed copies of Volume I of the Met Lab Section C-I history to Paul Fields and Winston Manning, both of whom had expressed to Don Stewart an interest in reading it.

At 4:00 p.m., I went to the cafeteria to attend a champagne reception honoring Melvin Calvin for his selection to receive the 1978 ACS Priestley Medal. I talked to Melvin and Gus, Ken Pitzer, Ed McMillan, Emilio Segrè, Owen Chamberlain, Edward Lofgren, Neil Bartlett (who arrived home from Europe last week), George Pimentel (who is in the last stages of being appointed Deputy Director of the National Science Foundation), John Hearst, Andy Sessler and others. I told Pitzer, MoMillan, Segrè and Calvin about the negative results by Iz Perlman and Frank Asaro on the Drake plate and Jim Hart's reluctance to accept this. Neil Bartlett told me he is trying to convince Professor Oscar Glemser (President of West Germany's Gesellschaft Deutscher Chemiker) of the value of an international chemical society; he will also write to Glemser.

I went by the 88" cyclotron on the way home. Hulet, Wilde, Lougheed and Nitschke were busy on their experiment to confirm their new Md isotope.

I took a hike at Lafayette Reservoir where I encountered Paul Hernandez and the LBL Mechanical Engineering Department picnic. Later I had dinner at Sambo's in Lafayette. I fed Moses and E. Coli, as I did last night. The two dogs were alone all day during the absence of Helen and Dianne, who return from Davis tomorrow.

Friday, July 22, 1977 - Berkeley, Bohemian Grove

At 8:45 a.m., I called Nils Wessell, President of the Swedish Council of America, to ask him to send information about the council to Louis V. Lundborg at the Bank of America in San Francisco.

Wessell will also send Iundborg information about Allen Kastrup's book. Checks are starting to arrive in response to the recent solicitation letters that Nils and I signed.

Mike McCormack returned my call at 10:00 a.m. I confirmed with him that the Conference Committee on the ERDA markups dropped off the high intensity uranium beam project, which is a dreadful blow. Mike shares our disappointment. He expects that the Clinch River Project and such projects as this will be authorized in the supplemental to be handled in the middle of September. McCormack will attempt to help Senator Teague in this, although he commented that Teague's health is deteriorating rapidly and he may not be present at that time. McCormack's interpretation of the cut is that Stennis's committee was trying to save money. McCormack assured me that he will try to get the uranium beam project on the supplemental and I told him I would do what I could to help although I will be in Europe most of September. 
Friday, July 22,1977 (con't)

I went by room $203 / 70$ to see Druin and Ter-Akopyan who were ialking with otto, Morrissey and de Saint-Simon about their work.

When I returned I talked with Pat Quinn and offered her the job as Sheila's replacement, which she accepted. She will start the week of August 8. or earlier.

I then went over with Jane kingston the final production mark-up for Volume II of Travels in the New World. The index still needs to be typed.

John Andelin returned my call at 11:25 a.m. Mike McCormack briefed him on our earlier conversation. Andelin described their disappointment at the deletion of the uranium high intensity beam project and I. asked him to probe behind the scenes as to what happened if he could. Andelin said that they understand President Carter does not want the authorization to come up for final clearance until after the August recess of Congress. They then expect to make a request to the Appropriations Committees for supplementals on one or two conservation programs, the uranium beam facility and the nuclear physics authorization. He suggested that, if I have the opportunity to talk about any other matters with the committee, I might mention the importance of their sympathy toward the supplemental when it comes up. We agreed to further discussions about this matter in early october.

Otto, Morrissey, de Saint-Simon and I went by Moretto's office (he returned from his sabbatical yesterday) to pick up Druin and Ter-Akopyan and we then went to the cafeteria for lunch; we were joined by Nitschke and Hyde. After Iunch, Druin and Ter-Akopyan, with Nitschke, came by my office for a final meeting before they leave. Nitschke will take them to San Francisco, Marin County, etc., tomorrow and the Hulets will entertain them on Sunday. They leave for the East on Monday morning where they will visit with Allan Bromley at Yale.

At 1:50 p.m., I called Andrew Streitwieser for his appraisal of Thomas Bruice. Streitwieser explained that Bruice's field is bio-organic chemistry; he was trained as a physical-organic chemist. He is one of the best people in the department at santa Barbara. Streitwieser pointed out that he recently was elected to the National Academy of Sciences. He further said that he believed it would be difficult to make a comparison if Bruice were at Berkeley.

Cynthia Lee dropped in at 2:30 p.m. to give a report on her progress. One of her friends heard me speak in San Francisco yesterday.

I talked to Jeannette Mahoney about various items for the NSD Newsletter, after which I went by to see otto and Baisden. They are getting ready for their, bombardments on Monday $\left(400-\mathrm{MeV}\right.$ nucleon $2 \mathrm{O}_{\mathrm{Ne}}$ on $\mathrm{U}$ and $8-\mathrm{MeV} /$ nucleon $130 \mathrm{Xe}$ on $\mathrm{U}$ ).

I sent a letter to $\mathrm{w}$. Quentin smith regarding his response to my July 14th letter in which I advised him that I will bring out the concern we had with the progress by German scientists in later volumes 
of the Met Lab C-I history and my intention to re-read David Irving's book. I also thanked him for finding a few errors in the index and asked him if he recalls the name of his office building and room number.

I declined an invitation to address the opening Plenary Session of the International Conference on Structural Mechanics in Reactor Technology, to be held in San Francisco on August 15-19; the letter was sent to Dean Bruno A. Boley at Northwestern University. We mailed my contribution for the special issue of the New York Journal of Commerce to be released at the National Meeting in Chicago to Dorothy Smith of the ACS News Service. A draft of the program for the $25 \mathrm{th}$ Anniversary Symposium commemorating the discovery of Elements 99 and 100 was sent Paul Fields, R. W. Spence, Al Ghiorso and Norman Edelstein requesting their comments. I also sent in a confidential recommendation for Wayne Marsh for graduate school admittance.

I wrote to Vitalii Goldanskii regarding the Welch Foundation Conference on Cosmochemistry and enclosed a program in the event he might like to attend. I also mentioned Druin and Ter-Akopyan's visit and my inability to attend the International Meeting on Heavy Ion Nuclear Interactions and Synthesis of New Elements to be held in Dubna on December 13-16.

At 3:40 p.m., I left for the Bohemian Grove, arriving at 5:40 p.m. I walked, with my bag, up to Wayside Log camp and changed clothes. After spending some time with my campmates, I went down to Sons of Toil camp for their regular Friday reception. I had dinner with Gunnar Johansen, Emanuel Fritz and campmates, then went to the Friday night show at the Grove stage. This included singing by Dennis Day and a Charlie McCarthy act by Edgar Bergen. I retired soon after the show, staying in a room with Norman strouse.

Saturday, July 23, 1977 - Bohemian Grove

I had breakfast at the Dining Circle with Norman Strouse, Tom Neblett and other campmates. After breakfast, I took a hike, starting out alone. I went up Trail 10 to South Ridge Road, on to Mt. Heller and back to High Point where I met Jed Ballard (who met me in my AEC office in 1968 as a Cal-in-the-Capital student) and Henry Wilkins (whose firm does fabricating work for an LLI fusion project). I walked back on the South Ridge Road with them, then down Trail 9 to Druids' Camp. Here I met owsley Hammond. I mentioned Sheila's new position to him and he told me he was impressed and pleased when she introduced herself to him at the Regents' meeting last week.

I walked back to Wayside Log, encountering Wayne Thompson in route, who recalls how I handled a bomb threat that came during a luncheon at Alumni House when I was Chancellor. He said he was impressed by how I "bluffed it out." When I returned to Wayside Log, Senator Howard Baker was there. I told him about the loss of the LBL High Intensity Uranium project, describing the circumstances in detail. He said he will talk to senator Stennis about it on Monday and perhaps ask him to call me. 
I went down to Iakeside to hear the noon band concert. Here I talked to Louis Iundborg and promised to send him information on the Swedish Council of America and Kastrup's book. After the band concert, I attended a reception at Mandalay Camp where I talked to Henry Kissinger, Peter Flanigan and his brother, John, Steve Bechtel, Sr., Charles Black (Shirley Temple's husband), and his brother Jim, Najeeb Halaby, Jack Horton, Howard Allen (Southern California Edison Company), Herman Phleger, George Shultz, Lee DuBridge, Edward Carter and Roger Lewis.

I walked back to Wayside Iog and had Iunch there with my campmates. After Iunch, I gave a twenty-minute talk on our energy problem and the role of nuclear power, with an assessment of President Carter's policy on plutonium.

I went down to hear Jerry Ford's Iakeside talk at 4:30 p.m. He talked on U.S. national and international policy including points of agreement and disagreement with President. Carter; on energy, he advocated more water-cooled reactors and said he disagrees with Carter's policy on breeder reactors. After his talk, I told him I agree with his statements on energy policy.

I talked to Greg Thomas, a member of the 1957 and 1958 Berkeley football teams. He majored in ceramic engineering and I sponsored him for recognition by Chemical and Engineering News. He is now a lawyer as well.

I went, to a reception at Cuckoo's Nest, where I talked to Rudy Peterson and said I would send him information on the Swedish Council of America. I also talked to Glenn Dumke, Art Iinkletter, Frank Murphy and Al Bowker. Dennis Day participated in the entertainment. I talked to him for a while. He sang on the Jack Benny radio program from 1939 to 1954 and had a TV program from 1954 to 1964. Art Iinkletter and I exchanged views on our IPA Vice Presidencies. He also gets inquiries from people who receive IPA literature inviting them to join IPA.

On the way back to Wayside Log I met Fred De Hoffmann. He now runs the Salk Institute. After a short stay at Wayside Log, I had dinner with some campmates--Ed strong, his son-in-law, Ian Mackinlay and his guest Harb Al-Zuhair of Saudi Arabia and others. I then went to the Field Circle to see the show, "Nature's Way." It was a pretty good show; Joe knowland did a good job in his single appearance. I retired soon after returning to Wayside Log.

Sunday, July 24, 1977 - Bohemian Grove - Lafayette

I had breakfast at the Dining Circle with Wayside Iog campmates. Ed strong extended an invitation to be the banquet speaker at the National Council of YMCA's.Pacific Region 1978 Assembly Program on Thursday, April 20th on the energy potential for the next decade. I said that I would consider it and let them know.

After breakfast, I took a hike on Trail 10, Smith Ridge Road to Mt. Heller, back on South Ridge Road to High Point, then back to Wayside Log on South Ridge Road and Trail 10. 
I packed my bag and went to hear the Lakeside talk by Allen Puckett (California Aircraft Industry) on the "Electronics Explosion," then went to the parking lot. I drove home, stopping for a cheeseburger at a little place on Highway 116 east of Sebastopol. I arrived home at 4:20 p.m. and found that Iz and Lee Perlman, John and Marilyn Howe and their son, Jack, were still visiting, following a luncheon prepared for them by Helen. The Perlmans left a little after 5:00 p.m., the Howes a little after 6:00 p.m.

Dianne was off with Eric to pick up Brian Sawyer and Judy Hoer at the San Francisco airport. The three of them had dinner with us and will stay with us until Tuesday.

Monday, July 25, 1977 - Berkeley

Helen picked up Steve at the San Francisco airport at 2:00 a.m. this morning. I had my LBI physical examination from 9:45-10:30 a.m. conducted by Dr. William Donald. It seemed to come out all right.

In mid-morning, I went to the HIIAC Byilding and room $203 / 70$ to talk to Baisden and Thomas. The U plus ${ }^{136}$ Xe bombardment is underway; it's a long bombardment and was interrupted at 10:30 a, m. by a short ( $1 \frac{1}{2}$-hour) one. Morrissey told me the $200-\mathrm{MeV} /$ nucleon ${ }^{20} \mathrm{Ne}$ plus $U$ (and Ta) bombardment is still scheduled to start this afternoon.

I called Dan Koshland for his assessment of Tom Bruice at UCSB who is being considered for a high-level professorship elsewhere. Dan said he is very good (perhaps at the same level as Hearst and Tinoco but not in the absolute top echelon), is very prolific and deserved election to the Academy. He may have a volatile temperament which would make him less suitable for a chairmanship.

Sidney Fox, a UCLA friend, came by for lunch which we ate at the table overlooking the campus outside the cafeteria. I first took him by to meet Baisden, Nishida and Gottstein. He told me that he found 5 or 6 amino acids in moon rocks, in disagreement with the negative findings of Cyril Ponnamperuma.

I went by room 203/70. Thomas told me the yield in the plutonium-fraction, in the short bombardment, is not as large as expected-maybe he lost some of this fraction; he finds large yields in the $\mathrm{Np}$ and Th fractions. Baisden, Nishida and Gottstein are busy with their chemistry on the short bombardment and are preparing for the long bombardment to come tonight.

Morrissey, Otto and I had a long phone conversation with Walter Loveland, just returned from his vacation, to bring him up-to-date on numerous fronts. He will come down from Oregon next week to work on our papers with us.

Richard Frankel called to let me know that KEVEX has moved to a new building and they are back in operation. He invited me to visit them to see the R\&D Department. The first showing of the device should be in october. They are calling the new technique A-XRF. He hoped that I might be able to suggest a more technical name for the device and technique. I asked Dick about Iicensing and he does not 
seem to think that this will be an insurmountable problem and said the device could be announced before the license is obtained. It appears that they are on schedule and next year they should have new products coming out.

Sam Markowitz dropped in at 4:00 p.m. He has just returned from a week's mourning following the death of his father. I' told him about the Druin/Ter-Akopyan visit.

I went by room 203/70 at 4:30 p.m. Baisden had finished her chemistry with the help of Nishida and Gottstein and had placed the chemical fractions from the adsorption-election (with alpha-hydroxyisobutyrate) in the counters. The long $U$ plus ${ }^{136} \mathrm{Xe}$ bombardment will stop at 8:00 p.m. and Thomas and Baisden will do chemistry on it. The concurrent $200 \mathrm{-MeV} /$ nucleon $20 \mathrm{Ne}$ plus uranium (and tantanium) bombardment will stop at midnight, when otto, Morrissey and de Saint-simon will start counting the gamma rays. They will do chemistry on one of the several uranium targets.

Today I received official notification (attached) from Elena Ceausescu that it is impossible for her to participate in the CHEMRAWN Toronto Conference in July 1978. She added that she would be pleased if I could accept another representative of the central Institute of Chemistry in Bucharest to attend the Conference in her place. I replied immediately that we would be happy to accept another representative and asked that she send that designee's name and address to Dr. Schneider in ottawa (letter attached).

'Ty and her brother, Andy, came by at 5:00 p.m. and rode home with me. We stopped at Lafayette Reservoir where Andy and I took a hike. When we arrived home, Eric and steve were busy preparing a meat patty dinner for all of us. Ben orlove soon arrived. Our dinner party, in the dining room, consisted of Ben, Brian, Judy, Ty, Andy, Dianne, Eric, steve and $I$. (Helen was in Berkeley sitting in for Dave at the Berkeley Hill Chapel).

After dinner, steve drove Ty to the BART station (to return home) and Ben to San Francisco, where he will spend the night preparatory to flying to New York tomorrow for a month's vacation with his parents. (He left his car with us.)

Tuesday, July 26, 1977 - Berkeley

Eric, Andy, Brian and Judy took a bus to Yosemite this morning; they will do some hiking until sunday when Helen, Dianne and I will meet them there and we will all drive home together.

I went by room 203/70 at 10:00 a.m. I found that the long $U$ plus $136_{\mathrm{Xe}}$ bombardment ended at 8:00 p.m. as scheduled and that Thomas took out the $\mathrm{Np}$ and $\mathrm{Pu}$ fractions successfully and Baisden et al jsolated the heavy actinide, etc., fractions. The $200-\mathrm{MeV} /$ nucleon $2 \mathrm{Ne}_{\mathrm{N}} \mathrm{plus} \mathrm{U}$ (and Ta) bombardment ended at 8:00 p.m. and 10:00 p.m. as scheduled, with a good beam. The chemistry (according to the Kratz-Iiljenzin SHE scheme) started at 8:00 p.m., went well as one U target, and these fractions and the other targets are being gamma counted starting shortly after 10:00 p.m. 
Acad.Dr.Elena Ceauşescu, Director General

Central Institute for Chemistry

Splaiul Independenţei 202, Bucharest,

Romania

Prof.Dr.GLENN T.SEABURG

Laurence Berkeley Laboratory,

University of California 94720,

USA

Dear Professor Seaborg :

3o June 1977

received with particular interest your kind invitation to serve as a panel speaker in one of the sessions of the World Conference on Future Sources of Organic Raw Materials in Toronto, Canada, next year.

Since I am well aware of the weight attached to a firm commitment in this respect, I looked carefully into my projected, 78 schedule, to realize that next summer I am supposed to have a very busy time. That's why, unfortunately, I have to defer the pleasure to participate at the Conference.

However, given the importance of the event and the appeal of its topic, I must say that I should be very pleased if you could accept another representative of the Central Institute of Chemistry in Bucharest to attend the Conference. If so, please let me know.

Looking forward to your answer, I take the opportunity to wish you full success in coping with your important duties as one of the chief organizers of the Conference.

With best regards,

Yours sincerely, 


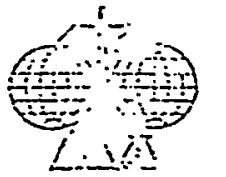

IOORLD FUTURE

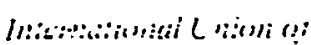

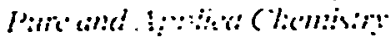

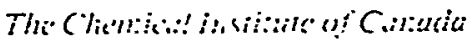

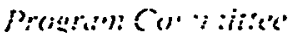

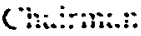

Ma: Tivile:

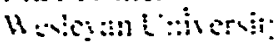

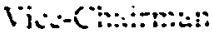

O.C.11. A.:?:B:

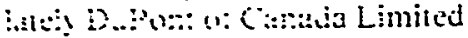

$1: \because \cdots:$

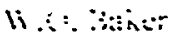

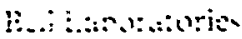

ㄱ. B,: :..: :

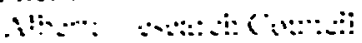

$\because \therefore: \therefore . \therefore$

$\because \because \vdots \ldots \quad \because \ldots, \cdots$

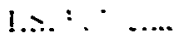

I?. $\therefore \mathrm{i}: \ldots$

li. $\because \cdots$ !

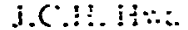

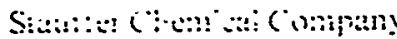

J.F. $11: \div: \because$

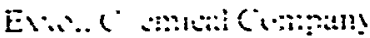

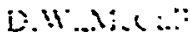

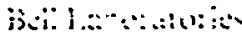

6.7. $1.20 \%:=$

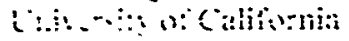

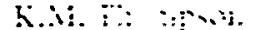

$\mu_{1}: \therefore$ : :

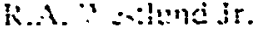

Euvi C:!rnion! Company
CONFERENCE ON

OF ORGANIC

IORONTO, CANADA

ULL: 10-1!-12-13, 197S

Cospromisored by

The American Che'mical Sricicty

Lawrence Berkeley Laboratory

University of California

Berkeley, California 94720 U.S.A.

JuIy 25, 1977

Acad. Dr. Elena Ceausescu

Director General

Central Institute for Chemistry

Splaiul Independentei 202

Bucharest, Romania

Dear Dr. Ceausescu:

We were of course disappointed to learn that your schedule

doès"not permit you to accept our invitation to speak at

the World conference on Future Sources of Organic Raw

Materials next year. However, we understand fully the

circumstances that lead you to this decision.

We would be happy to accept another representative of the

Central Institute of Chemistry in Bucharest to attend the

conference. In order that we can send the needed information, 'would you send your representative's name and address to:

Dr. W. G. Schneider

General Chainman, CHEMRAwN

President, National Research Council

The Chemical Institute of Canada

151 slater street, Suite 906

ottawa, ontario KIP 5H3, Canada

With best regards,

Cordially,

cc: W. G. Schneider

bcc: J. Hwa

B. Rossiter

M. Tishler

Sidney G. Smith
Glenn T. Seaborg 
Tuesday, July 26, 1977 (con't)

Later in the morning, Rodney Banks, back from his vacation, came in. He is having trouble crystallizing his neptunium borohydride so he has not succeeded in getting an x-ray picture.

The morning paper states that the ERDA budget went to President Carter for his signature yesterday; the high intensity uranium project, of course, is not on it.

From 10-11:00 a.m., I went to room 203/70 to talk to Morrissey and Diana Lee (the rest were home resting after the big runs last night); the counting is proceeding satisfactorily. I then went up to the HILAC building and talked to Nitschke (about his conversations with and travels to Sausalito, etc., with Druin and Ter-Akopyan), Sebesta (working on FAKE), Pat Somerville (who returned from his vacation yesterday; he went fishing with his family in Canada) and Cynthia Lee (who is making targets with the electro-spray apparatus).

I had lunch with Mac Laetsch in the cafeteria and, at his urging, agreed to accept the chairmanship of the LHS Advisory Committee.

I read proof on Chapters 32, 33, 34 of Volume III, Travels in the New World and picked pictures for illustrations.

At 2:20 p.m., Saburo Yashita dropped in, just back from the vacation with his family in Tokyo.

In preparation for my European trip in September, I wrote to Reinhard Brandt (Marburg, West Germany), Gunter Herrmann (Mainz, West Germany), Walter Haefner (Zurich, Switzerland) and F. C. Gallais (President, Chemical Society of France). I also wrote to Bogdan Baranowski, member of the Mathematical, Physical, Geological and Geographical Science Section of the Polish Science Academy, to suggest a meeting with him to discuss my concept of an international chemical society during the IUPAC Conference in Warsaw August 16-19.

I received a letter from John W. Tuthill, President of the Salzburg Seminar in American Studies, regarding my commitment to give one lecture plus participation in a smaller seminar for the session on nuclear proliferation to be held in Salzburg from September 3-16, 1978. I responded immediately to the effect that I would plan to spend a couple of days or so at the Salzburg seminar sometime during the period September $13-16,1978$.

Because I will be unable to attend the dinner honoring Nello Pace on October 22, 1977 I sent a letter via Professor Lawson L. Rosenberg (UCB) to be used on that occasion, plus a contribution toward a gift. I received a letter from Ben Loeb with information for our nonproliferation treaty manuscript to which I replied with suggestions on how we might proceed from here.

I dropped by room $203 / 70$ on my way home. De Saint-Simon was holding down the fort. He, Otto and Morrissey are counting the samples around-the-clock. I took a hike at Lafayette Reservoir. Helen and I had dinner alone in the kitchen. Dianne ate later. 
Wednesday, July 27, 1977 - Berkeley

I went by the Medical Building on my way to the office and had accumulated wax washed out of my ears.

At 10:00 a.m., I went by room 203/70, where Thomas was busy plotting his currently accumulating data ( $\mathrm{Pu}$ and $\mathrm{NP}$ fractions) from the $\mathrm{U}$ plus ${ }^{136} \mathrm{Xe}$ bombardments. Otto and I met with Luciano Moretto from 1011:00 a.m. to discuss our recoil range paper.

At 11:00 a.m., I. had an interview session with Kim McDonald of Public Information on my athletic activities--participation in the "Bay to Breakers" race,-hiking--chairman of CUWA, member of Citizen's Task Force of EBRPD, etc.

We had our Sheiks luncheon meeting from 12-1:30 p.m. with Otto, Sebesta (first attendance), Morrissey, Somerville, de Saint-Simon, Yashita, D. Lee, C. Lee, Leber and Nishida. Morrissey reported on our revised $48 \mathrm{Ca}$ plus $\mathrm{Pb}$ paper and his work with Wayne Marsh on the rafjo of forward to backward yields (10) of x-rays from $200-\mathrm{MeV} /$ nucleon $20 \mathrm{Ne}$ on Ta. Baisden reported on the short and long $136 \mathrm{Xe}$ plus $\mathrm{U}$ bombardments, various chemical fractions, etc. Somerville reported on his new plan to look for ${ }^{2}{ }^{4} \mathrm{Pu}$ (daughter of $234 \mathrm{Am}$ ) from $\mathrm{U}(\alpha, 3 \mathrm{n})$, using decay-in-flight S.F. detection apparatus. Sebesta described his progress in getting FAKE in order and Cynthia Lee her work on preparation of targets by the electrospray method.

I worked much of the afternoon proofreading and selecting pictures for Volume III of Travels in the New World.

At 2:20 p.m., I called Jack Josey in Houston to report that Tom Bruice has a generaliy good rating; he was elected this year to the National Academy of Sciences and comes out very well. Josey said he will call Hackerman immediately. Jack told me that the University of Texas Board of Trustees will meet in Houston on Friday before our conference. He would like to arrange a gathering in which they could meet all of us connected with the Welch Foundation. He told me that he is arranging for an airplane to bring me from my lecture at Baylor back to Houston for anything that is scheduled on Friday evening. Jack urged me to bring Helen with me and I said that I would try.

I took a hike at Lafayette Reservoir. Helen fed me an early dinner before she went to Berkeley for a YWCA committee dinner meeting. In the evening, Ray stoughton called to get a story from me for use at a retirement party for Cas Borkowski tomorrow. I told him I was unhappy to have Iz Perlman steal Borkowski to take him to Oak Ridge in September 1943, so soon after we hired him at the Met Lab.

Thursday, July 28, 1977 - Walnut Creek, Berkeley

Helen and I drove to the Contra Costa Times building in walnut Creek to attend the last day session of Dianne's participation in the six-weeks program of CCT-2 (Career Communications Training, Contra Costa Times) at 10:00 a.m. Tom Martens gave us a complete tour, after a greeting by Mardy. Douglas, who is in charge of CCT-2. We met Jack Wining, Head of the Editorial Department, Justin Roberts, Chris 
Westphal (editor of special projects like "Trends" in today's Times), Larry Lowry (TV section), Jo Ann Davidson and Maggie Crum. Tom took Helen, Dianne and me by to see Dean Lesher. We talked about his and our trips to the People's Republic of China. He favors the return of Taiwan to the People's Republic. Helen and I left a little before noon; I dropped Helen off at home and drove to my LBL office.

I had lunch at the table at the lower level outside the cafeteria with Norman Edelstein (just back from his vacation), Alex Avdeef, Rodney Banks, Jerome Bucher and another person. Edelstein agreed to give a short paper on the chemistry of fermium at the 25th Anniversary symposium of the discovery of elements 99 and 100 in January 1978. I also exchanged some remarks with Avdeef about his childhood friend (whom I met at UCSF when I talked there a week ago today).

I worked on selecting pictures for Volume III of Travels in the New World.

At 2:05 p.m., I returned a call to John Reynolds who wanted to know how long he should talk at the welch Conference. I told him he would have a two-hour period so he might make a one-hour presentation and have another hour for discussion.

I received notification from the Journal of Inorganic and Nuclear Chemistry that our paper, "A Search for Superheavy Elements with Half-lives..." has been accepted for publication. I wrote to Gardner W. Stacy to regret an invitation he had extended to attend the ACS Tenth Biennial Education Conference in Chicago on October 20, 1977. I also had to regret an invitation to speak at the San Gabriel valley Alumni Club on Friday, October 14, 1977 extended by Marjorie Chang, California Alumni Association, Los Angeles, California. GEOMET, Inc. sent a resolution concerning the appointment of Carl J. Cope as Assistant Treasurer and Assistant Secretary, effective August 1, 1977. I signed the resolution and returned it to corporate headquarters. Walter Loveland forwarded a copy of a letter he received from Mark Hatfield regarding the ERDA nuclear authorization bill. As a result of Walter's letter to Hatfield, the Senate Energy and Natural Resources Committee adopted language directing ERDA to schedule use of accelerator facilities for maximum availability during the months of June, July and August. In addition, the Committee approved an increase of $\$ 6$ million for operation of the national accelerators. Finally, I wrote to Per Möller and olaf Bloom in Sweden to suggest dates when Eric and I might visit relatives during our visit there in September.

As I was driving home out of the East Gate to Centennial Drive (about 5:45 p.m.) I saw a bicyclist, who had just run into a car, lying on the ground. An ambulance was called; however, the bicyclist was not badly hurt. I took a hike at Lafayette Reservoir. I had dinner with Helen in the kitchen. (Dianne ate later).

Friday, July 29, 1977 - Berkeley - Merced

I spent much of the morning with Jane Kingston selecting pictures for Volume III of Travels in the New World. 
At 10:00 a.m., I received a call from Michael Drosnin, who sometimes writes for New Times magazine and now is writing a book about Howard Hughes. He interviewed me for about twenty minutes on the efforts of Howard Hughes to halt the underground tests in Nevada in the $1960^{\prime}$ s. Sheila prepared a paraphased transcript of the interview.

At 10:40 a.m., Ed Goldfinger called to invite me to speak on "Science and the Creation of an Ideal Society" at a TM assembly in Contra Costa County on september 27, 1977. I told him I would be in Europe and I did not have any suggestions for a speaker from LBI to give to him at that time. He is sending me a ballot to nominate someone for their "creating an ideal society" award.

Michael Glass of Dreyfus Third Century Fund called at 11:25 a.m. to inform me that KMS Industries has begun trading (he mentioned that Narcissa of Beverly Hills, apparently a venture capital group, has signed a contract of intent with them). Glass recommends that Dreyfus value their stock at $40 \%$ of the bid price (which would be about $35 \$$ ) rather than setting a $\$ 1$ value. Oberman and Mrs. Jones think he should hold the stock for a while longer. I thought this sounded reasonable.

I mailed the introductory material for the volume of Stan's reprints that we are putting together to Alice Thompson for any corrections or suggestions that she might have.

I had lunch in the cafeteria with williams (returned a few days ago from her vacation) and Morrissey. Kim's mother is recovering, slowly, from her heart surgery.

After lunch, Harvey dropped in, just returned from his vacation in France. I brought him up-to-date on our budgetary reverses. We will go to work next week to try to get our two items in the FY78 budget supplement.

I left for home a little before 3:00 p.m. Helen, Dianne and I packed a couple of bags, put the other required items in our car and left at 4:30 p.m. in our station wagon for Merced. With Dianne driving, Helen, Moses and I. arrived in Merced at a little before 7:00 p.m. and checked into the sierra Motel, a mile or two south of town. We had dinner at the Mother Lode Restaurant on Highway 140, a couple of miles east. We spent the rest of the evening in our motel room reading.

Saturday, July 30, 1977 - Merced - Yosemite Park

Helen and I had breakfast in the Joaquin Restaurant across the street and brought back a donut and orange juice for Dianne. We left a Iittle before 9:00 a.m. and drove toward Yosemite on Highway 140, arrived at the Yosemite Visitor's Center a little before 1I:00 a.m. We picked up some maps, then drove to Yosemite Lodge. I signed in but our room wasn't available for occupancy. We went to Yosemite village for lunch at a kind of snack bar. Dianne then drove us to Curry Village where Helen and I started a hike. (Dianne then went back to Yosemite Lodge and checked into our room with Moses.) Helen and I hiked to Happy Isle. Starting at noon, we hiked the Mist Trail past 
Vernal Falls to the top of Nevada Falls, a total of 3.4 miles, which we covered in about 2-1/4 hours. It was quite hot. We then hiked on the John Muir Trail back to Happy Isle, again about 3.4 miles. Our time from Happy Isle to the top of Nevada Falls and return was about 4 hours. This represents a climb of about 1,900 feet. We then walked to Curry village (about a half mile), took the shuttle bus to Yosemite Village and walked to Yosemite Iodge (about a half mile). It was about $6: 15 \mathrm{p} . \mathrm{m}$. by the time we found our room and Dianne was quite concerned because she had expected Helen to return much sooner. We then drove up to Glacier Point to watch the sunset with a Park Ranger as host. We had a picnic lunch for our dinner as we sat at a table overlooking Vernal and Nevada Falls, Half Dome and surrounding views. The scene was quite spectacular as the full moon came up in the east. We saw flashlights brandished by people on Half Dome and a campfire (illegal) at the top of Vernal Falls. At 9:00 p.m., the Park Ranger, Larry Huggins, set up a telescope, gave a little talk on astronomy and let us each look at the moon through the telescope. He then focussed on a star for people to see. We started back down at 9:45 p.m. Our station wagon's lights soon began to fail and we lost all our power a mile or so below Chinquapin on Highway 41 and had to park the car alongside the road. After walking, carrying our bags, a half-mile or so, Dianne insisted the distance was too far (it turned out to be 20 miles), so she flagged a passing VW van and got us a ride down to Yosemite Lodge. I called the Ranger Headquarters to report our car's situation and the Yosemite Garage to make arrangements to have it towed down tomorrow. We did not get to bed until nearly midnight.

\section{Sunday, July 31, 1977 - Yosemite Valley - Lafayette}

Helen and I walked to Yosemite Village, went to the garage to report again on our car situation and had a quick breakfast in the Loft. I then rode with the tow truck up to our car and Helen went back to join Dianne in our room. The tow. truck brought our car down, but it was not possible to start to work on it immediately. I called Helen to bring her up-to-date, then packed some food (from our car) in my knapsack, took my canteen and rode on the shuttle bus to Curry Village. I hiked to Happy Isle, then started up the Mist Trail to meet Eric, Andy, Brian and Judy as they would be coming down from Tuolumne Meadows ( 28 miles distant) where they planned to start on Thursday. I met them when I had proceeded about a half-mile up the trail. We hiked back to Happy Isle together, then soon took a shuttle bus to Mirror Lake, where we had Iunch from our backpacks. (We found that Mirror lake is also dry - it is turning into Mirrow Meadow.)

After lunch, Andy, Brian and Judy proceeded to the Visitor's Center (carrying Eric's backpack as well as theirs). Eric and I took a hike along Tenaya Creek Trail, then up Snow Creek Trail toward North Dome. We hiked about 2 miles (gained about 700-800 feet in altitude), then returned to Mirror Lake and rode the shuttle bus to the Visitor's Center, where we joined the rest of our party. We learned from Helen that our station wagon was fixed; the fan belt had broken which had made the alternator inoperative. The total cost, for a new fan belt and labor was $\$ 10.00$. (AAA covered our towing.)

We all started for home, with Dianne driving, at a little before 4:00 p.m. We drove on the Big Oak Flat Road (Highway 120), with a 
side trip to view some large redwood trees, on through Manteca, arriving at our home in Lafayette a little before 8:00 p.m.

Ty Jenkins came by at 10:00 p.m. and joined us as we were finishing a waffle dinner on the patio.. Ty took Andy home with her and will drive him to Oakland airport early tomorrow so he can fly to seattle to join a student group for work on trails in Washington state.

After I went to bed, Cathy Sherman called from Los Angeles to ask Dianne to see if they had left their checkbook at their house. Dianne found an overflowing toilet tank which Helen managed to turn off.

Monday, August 1, 1977 - Berkeley

Pat Quinn started to work today. She will work half-time this week and start: full-time next week.

I started to call possible speakers for our Symposium Commemorating the 25th Anniversary of the Discovery of Elements 99 and 100. At 8:55 a.m., I called John Conway. He will speak on "The Free Ion Spectroscopy of Einsteinium and Comments on Fermium." We decided to ask William Carnall to speak on "Crystal and Solution Spectroscopy of Einsteinium." At 9:20 a.m., I called Richard Hoff. He will speak on "The Production of Einsteinium and Fermium in Nuclear Explosions."

At 9:25 a.m., I called Richard Frankel, President of Kevex, to arrange to go over to Foster City to see the new building. I will go on Thursday, August 4, in the afternoon.

Walter Loveland arrived today for two days of conferences with us to plan our schedule for writing papers. I met with him, otto and Morrissey in room $191 / 70$ at 10:00 a.m.

At 11:35 a.m., Mike McCormack called regarding my letter of JuIY 26, 1977 inviting him to visit the Lawrence Berkeley Laboratory. I will meet his plane on August 14 (he could not come on August 15 or 16 as suggested in my letter).

I had Iunch in the cafeteria with Loveland, Morrissey, de SaintSimon and Victor Viola (who is here for an experiment at the SuperHIIAC). I talked to Viola about his talking to senator Mathias about restoring our line item in the FY78 budget $(\$ 6,000,000)$.

I called Donald Ferguson at 1:35 p.m. He will speak on "The Production of Einsteinium and Fermium" at our symposium.

Raymond Mariella called at 1:40 p.m. from Washington regarding Edgar Piret's payroll status. Robert Cairns wants Piret off after December 31, but Mariella is trying to stay neutral. We will discuss this in Chicago when we meet: Gordon Bixler will replace Piret. The phase-over will begin about october 1 .

At 2:30 p.m., I met in my office with Baisden, Thomas and williams to discuss problems they are having in getting bombardments during day shifts at the 88" cyclotron; Cerny wants them to have their bombardments on the owI shift which is not too satisfactory. 
Baisden stayed on to discuss her data from her last ${ }^{86} \mathrm{Kr}$ plus U bombardment; the yields in the Md fraction seem too small to identify.

At 3:20 p.m., I spoke with Joseph weneser regarding the Bevalac line item cut. I told him that we will try to get this into the September supplemental. We will work on the senate Appropriations Subcommittee on Public Works and the House Committee.

I spoke to Ken Hulet at 4:40 p.m. He will talk on "The Chemical Properties of Einsteinium." No response yet from our paper submitted to Physical Review Letters. He also has had no further communication with Mikheev regarding his coming visit.

At 5:15 p.m., I spoke with Iinda stephenson of public information regarding the table of isotopes I did with John Livingood. She will let me read the draft of the write-up.

My piece for CHEMTECH on stanley G. Thompson went out to them today with 14 photographs and some supplementary notes. They will let me look at the final draft before publication. I wrote to victor Schmidt today in response to his letter regarding the American Council on Education. Sheila mailed an updated biobibliographical sketch on David Shirley to William Dauben at the National Academy of Sciences. Shirley will be included on the informal ballot for election to the Academy. I also wrote to Ingmar Bergstrom in Sweden regarding plans for my trip to Europe in september.

I took a hike at Lafayette Reservoir. Helen and I had dinner in the kitchen. Eric's Washington friend, Scott Luria, and Scott's girlfriend, Janet Hodges, arrived at 7:00 p.m., having driven out from the East. (He has graduated in biology from M.I.T. and is going on to Medical School.) Eric, Brian, Judy, Scott and Janet had a pizza dinner in Lafayette.

I had a talk with Dianne about her forthcoming trip to Washington, where she will try to get our house in order and to help Pete. A fire broke out on Mt. Diablo at about 5 p.m., started by lightning, on Eagle Peak on the north slope. I worked on articles for the Nuclear Science Division annual report.

\section{Tuesday, August 2, 1977 - Berkeley}

The fire on Mt. Diablo burned all night out of control and has consumed about 3,000 acres in the Eagle Peak, Mitchell Canyon, north slope area. Scott Iuria drove Brian Sawyer and Judy Hoer to the airport to start their trip home.

I continued my process of calling potential speakers for the Symposium Commemorating the 25th Anniversary of the Discovery of Elements 99 and 100. At 8:50 a.m., I talked with Joseph Peterson. He will give a paper jointly with Kenneth Hulet on "The Chemical Properties of Einsteinium."

From 10-10:45 a.m., I met with Luciano Moretto. He wanted to discuss problems he is having with Harvey regarding funding for his research, etc. He has been offered the position to be in charge of 
Tuesday, August 2, 1977 (con't)

heavy ion research at GANII in France. I advised him to remain at LBL and said I will do what I can to help him.

At 10:10 a.m., I spoke with William Carnall regarding his talk. He will give a paper on "Crystal and Solution Spectroscopy of Einsteinium." He invited me to a picnic at his home on August 31 , but I will be leaving for the ACS meeting so declined his invitation.

I received a phone call from Earl. Hyde regarding a letter from Mark Oliphant in connection with Australia's selling of uranium. I suggested that he, Sessler, Harvey and I get together to discuss strategy for the Bevalac line item. We also discussed the Druin/TerAkopian visit. I told him I thought Druin's paper had been translated.

Norma Bowles and Jane Otto visited with me at 11:00 a.m. I agreed to sign a preface to her book on Psi Search along with Terry Stanford, William Friday, Vernon Cheadle, Charles E. Young, Joseph B. Platt and others.

I went to room 203/70 to talk with Loveland, Otto and Morrissey about our schedule for writing papers, from 11:15 a.m. to noon. When I-came back to my office Norma and Jane were still there and I composed the following preface:

"The subject of psychic phenomena has long been controversial and confused. In this book, Psi Search, the authors render a useful public service by calling attention to the need to distinguish information which has been scientificalIy demonstrated in the laboratory from the many other kinds of material popularly associated with psychic phenomena."

I met in Sessler's office with Sessler, Hyde and Harvey from 12:15-12:45 p.m. to discuss means of restoring the line item. Sessler is going to Washington tomorrow and will. discuss with ERDA officials (George Rogosa, James Kane, Mel Greer, etc.) the possibility of their funding it because it has been authorized. We will meet again on Monday to discuss strategy in view of results from sessler's visit. We also made plans for Mike Miclormack's LBL visit on August 14. Williams.

I had Iunch in the cafeteria with Loveland, Morrissey, Thomas and

From 2:30-3:30 p.m., I talked in room 203/70 with Loveland, Otto and Morrissey, and with Thomas and Baisden, at the HILAC Building with Somerville, Yashita, Sebesta; Nitschke and Ghiorso.

After working in my office with Kathy putting together all the material for mailing the Benchmark book, I went by room 203/70 at 5:00 p.m. to say goodbye to Loveland. He will drive back home to Corvallis, Oregon tomorrow.

I replied to $A$. C. Shotter in regard to an invitation to me to talk on "Production of Heavy Elements" at a conference on Nuclear 
Structure Physics at Edinburgh on April 5-8, 1978. I declined because of a previous commitment. I also accepted an invitation to attend the Chicago Chemists' Club reception in Chicago on Monday, August 29 from Mr. Paul C. Adlif, President of the club.

I drove down to campus a little before 6:00 p.m. to attend the pre-dinner reception in Stern Hall of the 1977 Berkeley Experience Week. I spoke on "The Energy Problem," downstairs in the lounge. Debbie Pugh acted as hostess and introduced me.

The fire on Mt. Diablo was still raging, in clear view, as I drove into Lafayette. I arrived home at 9:30 p.m.

Wednesday, August 3, 1977 - Berkeley

Mt. Diablo was still burning when I drove to work this morning. A total of some 4,500 acres has burned and the fire has spread to the south side.

I walked down to California Hall at 9:30 a.m., where, with Chancellor Bowker, Garff Wilson and Dean Ernest Kuh, I met the delegation of metrologists (Iist attached) from the People's Republic of China. We then proceeded to the Chancellor's Conference Room where we were met by other faculty and staff members.

Before I returned to my office, I stopped by latimer Hall to check my mailbox. I met Jim Cason there and we discussed my responsibilities for advising the cluster group this fall.

Richard Allen (Vice President and Secretary, GEOMET, Inc.) called at 11:45 a.m. to ask me about the next meeting of the GEOMET Board of Directors. I explained that I could not set a time until my European trip plans developed.

I called Sherman Fried at Argonne and he agreed to reminisce at our January symposium.

I attended the Actinide Chemistry Iunch meeting in room 190/70 from 12:30-1:40 p.m. Attending were Norman Edelstein, Ken Raymond, Andrew Streitwieser, Allan Zalkin, David Rubin, George Shalimoff, Gordon Halstead, Edgar Baker, Fred Weidl, Barbara Fisher, Beatrice Sibley, Rod Banks, Alex Avdeef and Wayne Luke. Raymond reported on his visits to Karlsruhe, Strasbourg and Sao Paulo (to attend a meeting). Streitwieser talked on the electronic structure of uranocene and luke on the molecular structure of substituted uranocenes.

We had a meeting of Edelstein, Streitwieser, Raymond, Zalkin and me after this meeting to discuss planning. Notker Rësch of the University of Munich is coming to work with streitwieser during February 1978. Streitwieser stressed the need for NMR apparatus. The Actinide Chemistry group will come in within their FY77 buaget, but barely.

Jane McWilliams of the Cluster Program Office called at 2:05 p.m. to tell me that I would have a total of 34 students. 


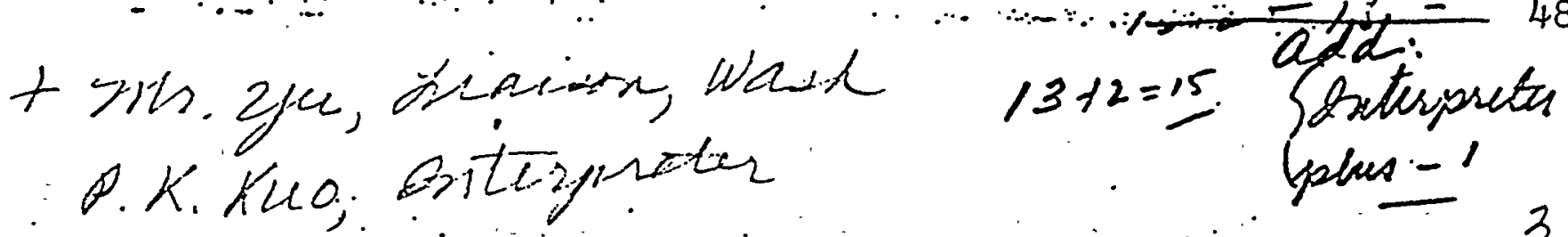

$$
\begin{aligned}
& \text { NAXT IIST: } \\
& \text { OF THE CHIVESE HATROLOEY GROUP } \\
& \text { Arif: } \\
& \text { EDED OF THE GROLP }
\end{aligned}
$$


Wednesday, August 3,1977 (con't)

At 2:15 p.m., I met with Elizabeth Rauscher and her older sister, Hope Mullins (she and her husband run an engineering firm in Corvallis, Oregon). Since I am now responsible for sponsoring her Ph.D. thesis, on alpha particle decay, I asked her to give me an outline of her thesis, a history of her work on this and related subjects and copies of her related papers and reprints. Elizabeth and Hope also. talked about their work on Psi phenomena, in which they are very interested.

I went to room $191 / 70$ to attend the 2:30 p.m. Theoretical Seminar at which Arthur Kerman from MIT spoke on "A Statistical Theory of Heavy Ion Reactions."

At 3:45 p.m., I called Henry Taft of the Western Regional Conference of the YMCA which is to held at the Holiday Inn, Emeryville, in April 1978, in regard to my speech "The Energy Problem."

I called stanley schneider at 4:00 p.m. to compliment him on the writing of my speech for Uppsala ("Knowledge and Survival"). We also discussed his workload for Frank Press.

I received a letter from Howard Brown acknowledging receipt of the copy of Travels in the New World, Volume $I$, that I sent him. Today I sent necessary information for my volume on the transuranium elements to Dr. A. M. Dowden.

Darleane Hoffman returned my call; she accepted my invitation to speak at the 25th Anniversary of Elements 99 and 100 on January 23, 1978.

Alice Thompson called to say that she approves my introduction to Stan's volume of research papers (being assembled) and that she is ready to give a substantial amount to the Stanley G. Thompson Memorial Fund so the undergraduate chemistry scholarship can start.

At 5:00 p.m., I went by to see Otto, Morrissey, Thomas, de SaintSimon and Wiliams. Thomas was busy analyzing his plutonium fractions from his $23{ }^{\mathrm{U}}$ plus 180 bombardment.

On the way home, I went by the 88" cyclotron and talked to Ghiorso (Baisden has been down there all day). They failed to get a $4 \mathrm{Ar}_{\mathrm{r}}$ beam (to investigate " $\mathrm{x}$ ") so they are giving their time over to Somerville for his He bombardment.

I took a hike at Lafayette Reservoir. Mt. Diablo is still afire; a total of 5,000 acres has burned. Helen told me she drove Dianne to San Francisco Airport so she could catch the 12:55 p.m. plane to Washington (Dulles Airport.) Pete will meet her and she will spend several weeks with him trying to help. Helen and I had dinner in the playroom and watched TV news. Eric, Scott Luria and Janet Hodges visited San Francisco and had dinner in Chinatown. I worked on articles for the NSD Annual Report. 
Thursday, August 4, 1977 - Berkeley

I had a session with Pat quinn and Sheila saxby to discuss the progress in transition for Pat to take over sheila's job. It is going very well.

I returned a call to Mike Crisp in Senator Howard Baker's office regarding the loss of the Bevalac High Intensity Uranium Beam project. There is a plan to put it in the senate supplemental Appropriations Bill, and Baker's office will try to get someone (like Hatfield) to introduce it.

I went by room 203/70 to discuss with otto and Morrissey my changes in the drafts of our NSD Annual Report articles. I also discussed with Thomas and williams their articles. I then talked to Baisden and Leber about the disappointment of not getting their bombardment yesterday.

At 11:00 a.m., I met with Yoriteru Inoue. He inquired about the reasons for the opposition to the use of nuclear power in the United states. I gave him a copy of an article from the San Francisco Chronicle discussing nuclear power and we also discussed Proposition 15. On departing, he gave me a fan as a gift.

At 11:50 a.m., I called Gordon Bixler to discuss Wayne White's letter offering his services. Bixler will draft a letter to white for my signature.

I had lunch with Richard Frankel and we discussed Kevex.

At 1:55 p.m., Milo Dowden of Dowden, Hutchinson \& Ross, Inc., returned my call of yesterday regarding the "Benchmark Series: Transuranium Elements." He suggested that we send the manuscripts to him by United Parcel Service and that we insure it. He also remarked that DH\&R got door-to-door service from UPS. The next best method would be to send it parcel post.

I visited room $203 / 70$ and talked to de saint-Simon about his calculations and to Thomas about his new plutonium isotope data.

I called Benjamin Ioeb in reply to his recent letter. We discussed various items concerning my writing projects.

I took a hike at Iafayette Reservoir. Helen told me that Scott and Janet left late this afternoon to drive to Big sur. Eric also returned to his apartment late this afternoon; he had dinner with Ty at her place. Helen and I had dinner in the playroom, watching the news on TV. I worked on NSD Annual Report material. The Mt. Diablo fire was finally contained after burning about 6,000 acres.

Friday, August 5, 1977 - Berkeley

I called John Huizenga at 8:40 a.m. to talk with him about the subject of his speech for the 25th Anniversary of Es and Fm. He will talk on "The Nuclear Properties of Einsteinium and Fermium." We also discussed the loss of the Bevalac line item. 
Friday, August 5, 1977 (con't)

I worked on Baisden's and Somerville's contributions to the NSD Annual Report.

I received a call from David Vieira at 10:10 a.m. requesting me to serve on his thesis committee, which I agreed to do. He will have it ready for me to read in October.

At 11:45 a.m 8 I went by room $204 / 70$ to talk to Baisden about her results from her $86 \mathrm{Kr}$ plus $\mathrm{U}$ bombardment.

I had Iunch at the table outside the lower level of the cafeteria with Edelstein, Bucher, Avdeef, Weidl, Banks, Zalkin and others.

My benchmark book on the transuranium elements was mailed to A. M. Dowden today.

At 12:45 p.m., I returned a call to Myron Kratzer. He invited me to testify at the public hearings in Saskatoon, Saskatchewan on september 9. I declined because of my schedule.

At 1:00 p.m., I rode down to the campus with Sheila, then walked to Lucas Book Company on Bancroft Way and bought a copy of the High Sierra Hiking Guide \#1, Yosemite (Wilderness Press) and walked back up to my LBL office.

Thomas dropped into my office at 3:00 p.m. to go over his data from his ${ }^{86} \mathrm{Kr}$ plus $\mathrm{U}$ bombardment (possibiy 2 new $\mathrm{Pu}$ and 1 new $\mathrm{Th}$ isotopes or isomers).

I spoke with Curtis Bowers at $3: 40$ p.m. regarding identification of five pictures I had made from the framed ones in Ed Dutto's office (410A Latimer Hall).

I called Ray Stoughton at Oak Ridge at 4:00 p.m. regarding some addresses for the Met Lab History.

Pat quinn informed me that I will have 35 students in my cluster group. Since the group is so large there is a possibility that I may get another graduate assistant to help me.

I wrote to Professor Lars-olof Sundelöf in reply to his correspondence to me regarding $\mathrm{my}$ speech and travel plans to Sweden in September. I wrote to Professor Oliver Manuel regarding the Dubna reprints on Flerov et.al.'s work. I told him I doubted that they proved the presence of superheavy elements. I sent a copy of the Stanley G. Thompson article, which was sent today to CHEMTECH, to Alice Thompson, explaining that changes could be made. I wrote to Moses Passer in reply to his request for comments on the ACS statement on additional modes for scientific research specifying my doubts about including "profit institutions."

At 5:00 p.m., I went by Building 70 to see Morrissey, Baisden, Williams and Thomas. 
I took a hike at Lafayette Reservoir. Helen and I had dinner in the playroom, then drove to Berkeley to the Ecology Center (2179 Allston:Way) where Will and Jean Siri were presented a 1977 Sol Feinstine Award ( $\$ 1,000$ and a plaque), by the State University of New York, College of Environmental Science and Forestry, for outstanding volunteer work in the environmental field. Among those present that Helen and I talked to were the Siris, Tom and Lucretia Edwards, Sylvia McLaughlin, Joyce Burr, Mary Lee Jefferds, Helen Burke, Francis Gendlin (editor of the Sierra Club Bulletin and whom I knew when she worked with the Bulletin of Atomic Scientists during 1968-1973), Paula Carroll (Oakland office of the Sierra Club Bulletin) and Parmer (President of the College of Environmental Science and Forestry). (Mike McCloskey was also present). I mentioned to Frances Gendlin Eric's writing interests and she suggested he get in touch with her.

Parmer made the presentation of the Award to the Siris, Helen Burke (as one of the nominators) proposed a toast to them and Will and Jean Siri responded with words of appreciation. (I was also one of the nominators for this award.)

After we left this affair, Helen and I drove to the nearby Bayview Chapel (on Grove Street near Dwight Way) where we visited with Dave and his roommate steve Durkin (a physics graduate student). Dave gave us a tour of the chapel and explained the nature of his duties for which he is paid $\$ 75$ a month and furnished a room. Helen and I then drove home, arriving about 10:00 p.m. For the first time in a long time, beginning last night, we are alone in our house.

Saturday, August 6, 1977 - Lafayette - Los Gatos

In the late morning, I took a hike, clockwise, on the Rim Trail around the Lafayette Reservoir.

In the afternoon, Helen and I drove to Los Gatos to attend the 4:00 p.m. wedding of Robert Kraus, Jr. and Debra Ekstrom in the Faith Lutheran Church. Paster Francis Jeffery officiated and their friend Tom Lamb spoke in a meditative and semi-humorous vain. The matron of honor was Trudy (Mrs. John) Mestemacher (Debra's older sister) and the bridesmaids were Prudy McWaters, Lorrie Ekstrom (Debra's cousin and daughter of Dr. Robert. Ekstrom) and Shelley Stroeher; the best man was Richard Fox (Bob's schoolmate, who will start Berkeley this fall in chemical engineering) and the groomsmen were John Mestemacher, William Kraus (Bob's younger brother, interested in science) and Loren Kohnfelder; the ushers were Paul Poenisch and Robert Fox.

After the wedding, Helen and I met Mr. and Mrs. James Ekstrom (the bride's parents), Mr. and Mrs. Robert Kraus (Bob's parents), Richard Fox, the bridesmaids and groomsmen, Dr. and Mrs. Robert Ekstrom and one of their married daughters, Virginia (from Milwaukee) and Richard (Rick) Ekstrom (son of the Robert Ekstroms--interested in chemistry but presently not in school). The Robert Ekstroms live in Chicago and the four of them (Mr., Mrs., Lorrie, Rick) drove out for the wedding. Dr. Robert Ekstrom, who sang at the wedding (as did the Mestemachers), got his Ph.D. in music at USC (where Rick was from) and is Honorary Director in Chief, American Union of Swedish Singers and 
past President (1952-1964), Swedish Cultural Society of Duluth. The Robert Ekstroms have six children, four daughters and two sons.

Rick rode with Helen and me to the Los Gatos Elk's Lodge to attend the dinner reception. About 130 people were present. Helen and I sat at a table with Bob and Betty Mudd (distant relatives of Seeley Mudd); Bob is an English and (formerly) Latin teacher at the high school that Bob and Debra attended and he taught them English. Rick introduced us to his recently married cousin Steve Petersen (son of a sister of Robert and James Ekstrom), who lives nearby.

Dr. Robert Ekstrom sang several songs during dinner and acted as a sort of master of ceremonies; he introduced me in the course of the evening and also Dr. Gershar, a psychologist (Xerox Corporation). Richard Fox led a toast to the bride and groom. Helen and I left soon after dinner was finished, at a little before 8:00 p.m. and drove home to Lafayette, arriving at 9:00 p.m.

Sunday, August 7, 1977 - Lafayette

Helen and I took a hike in Las Trampas Regional Wilderness Park and on EBMUD land. Starting at the Bollinger Canyon parking lot at 11:00 a.m., we hiked on trails near Rocky Ridge Road up to Upper Trail, on Upper Trail to the top of Rocky Ridge--generally east or south along Rocky Ridge on EBMUD land, on trails below the upper rocks (where we had our back pack Iunch) to Rocky Ridge Trail, up Rocky Ridge Trail to the top, cross country on EBMUD land to the start of Upper Trail, then back down to our starting point on trails near Rocky Ridge Road. We arrived back at Bollinger Canyon parking lot a little after 3:00 p.m. and drove home.

Helen and I had dinner in the playroom, watching IV news. Steve, with E. Coli, arrived at $7: 15 \mathrm{p.m}$. He drove up from San Diego via Sacramento. He has found an apartment in San Diego. Helen served him dinner. Dianne called about 8:30 p.m. She is getting along fine at the Harrison Street house with Pete.

Monday, August 8, 1977 - Berkeley

I sent a letter to Malcolm Pruitt regarding the American Chemical Society's International Activities Committee relations with Egypt's National Research Centre. I would like Etcyl Blair to be invited to participate in the Egyptian Workshop in Cairo. I also wrote a letter to Jens Kratz to inform him of our progress on the paper "Charge and Mass Distributions in the Reaction of $84 \mathrm{Kr}$ and $136 \mathrm{Xe}$ Ions with $238_{\mathrm{U}}$." I sent a copy of Test Ban Resources, 7/63-12/64 to Benjamin Loeb. I also included copies of relevant journal entries and a draft of Chapter I, "Notes On A Nuclear Age - Prologue," January 14, 1971. I mailed out sets of pictures of the May visit of the Chinese Chemistry Group at Berkeley with various assortments to each member of the delegation in China, in addition to the other principal participants-Gabor Somorjai, Mitchel Shen, Bob Budnitz, W. M. Laetsch (for the Lawrence Hall of Science), Norman Phillips, Joe Cerny, Judson King, Yuan Lee, Jesse Hwa and Pat Tsuchitani. 
Monday, August 8, 1977 (con't)

At 9:30 a.m., Margie Bowman called to check with me about the possibility of the CUWA coalition group's meeting with the Administrative Committee before August 23, 1977. I informed her that I would check with John Harnett but, if so, I would not be able to attend because of my trip to Warsaw. I called John Harnett at 10:00 a.m. but he was not in so I spoke with John Larkin, Harnett's assistant. Larkin was unable to give me an answer but promised to speak to the members of the Administrative Committee of the Board of Directors and would let me know the outcome. I then called Tom Bowman at 10:15 a.m. to inform him of my talk with Larkin and said I would let him know about the meeting as soon as I heard from Larkin.

At 10:30 a.m. I attended the scheduling session for the 88" cyclotron in Building 88 . We 3 were scheduled for Williams on the day shift, Thursday, August $18,235 \mathrm{U}$ plus $1_{\mathrm{B}}(69-\mathrm{MeV})$ and $\mathrm{f}_{\mathrm{B}} \mathrm{r}$. Somervilie,

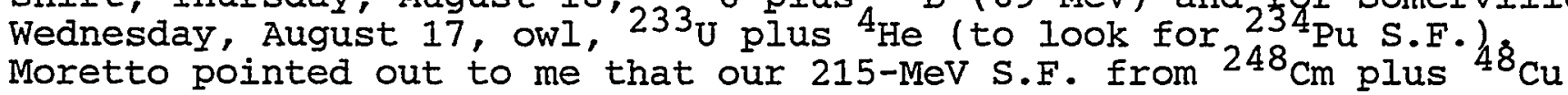
can't be due to actinide impurity because it is so asymmetric.

I returned a call to clifford Smith regarding his receipt of my Met Lab Book.

At 11:15 a.m., Ken Hulet called to inform me that "search for Superheavy Elements in the Bombardment of $24 \mathrm{Cm}^{\mathrm{c}}$ with $48 \mathrm{Ca}$ " has been accepted for the August 15 issue of Physical Review Letters.

I' had Iunch in the cafeteria with Ghiorso, Otto, Morrissey and de Saint-simon. Ghiorso, otto and I discussed plans for another $248 \mathrm{~cm}$ plus $48 \mathrm{Cu}$ bombardment as early as October at energy near the fusion barrier as determined by the vield of iodine isotopes.

Dick Hahn from Oak Ridge called at 1:30 p.m. to say that he had received a note from New York from Victor $A$. Druin and G. M. Ter-Akopyan expressing satisfaction with their visit to Berkeley. I told Hahn that there was no discussion of the 260104 problem during their visit to Berkeley.

Harvey and I met with Sessler and Hyde, in Sessler's office, from 2-3:15 p.m. to discuss means of restoring the Uranium Heavy Ion Capability line item in the FY78 budget. Sessler is afraid to do much because he feels it could antagonize ERDA and DOE people. I was quite critical of Sessler's general lack of support for this project over the last few years. Harvey and I will make some additional congressional contacts and do what we can to get the item restored.

Larkin from EBMUD returned my call of earlier in the day to say that the President of the Board of Directors and other members of the administrative committee did not think the meeting would be possible. I expressed my disappointment and he suggested the CUWA members contact their local directors on a personal basis.

At 5:00 p.m., I went by room 203/70 to talk to williams, who was getting ready for her $235_{U}$ plus $11_{B}$ bombardment at the $88^{\prime \prime}$ cyclotron to look for $242_{\mathrm{Bk}}$ on the swing shift tomorrow. 
I took a hike at Lafayette Reservoir. I had a casserole dinner at home. Helen was attending a western regional meeting of the YWCA in EI Rancho Motel in Millbrae. Steve left for Sacramento today; he left E. Coli with us.

Tuesday, August 9, 1977 - Berkeley

I called Peter Goldschmidt at 9:45 a.m. in Washington to talk with him about getting the uranium high intensity beam project included in the FY78 budget supplement. He was out of town. His assistant Elizabeth Morris said that she would advise Pete of my call and that I should be hearing from him in a day or two.

Andrew Sessler came by my office and we talked from 10-10:40 a.m: about our difference of opinion on how much he has supported the need for a third injector at the superHILAC.

Jacquelyn Philpotts of John Wiley \& Sons, Incorporated called to request a photograph of me to be included with the article "Actinides and Transactinides."

Pat Quinn informed me that H. E. Manville called regarding my plans for my september trip to Europe. She also received a call from Henry Taft regarding my speaking engagement for the Western Regional Conference of the YMCA. He confirmed the date for my speech is Thursday, April 20, 1978.

I went by to see Morrissey and Baisden in the late morning. I then had Iunch in the cafeteria with Nitschke and Morrissey.

I met in my office with Baisden from 1:30-3:15 p.m. to go over her research program in detail. We decided she will start to write a paper on her work on the yields of actinide and translead nuclides in her various heavy ion reactions, including references to all the data of other workers in laboratories around the world.

I attended in 191/70 the Bevalac Research meeting at which Hank Crawford spoke on "Temperature and Statistics in Heavy Ion Reactions." I then went by room $203 / 70$ to talk to otto and Morrissey about our writing program. Williams was at the 88 " cyclotron waiting for her $235 \mathrm{U}$ plus ${ }^{1 I_{\mathrm{B}}}$ bombardment to look for $242 \mathrm{Bk}$ to get started.

My dictation today included a letter of support for Norman Edelstein as a Staff Senior Scientist to David Shirley. I also sent a letter to Robert Sachs to acknowledge receipt of the Fermi souvenir record album. I wrote a letter to Paul Lochak to inform him of my plans for my trip to Europe in September; and a letter to Roderick Spence regarding his offer to hold the 25 th anniversary of the discovery of elements 99 and 100 at Los Alamos. I responded to Lt. Gen. H. C. DonnelIy regarding his request of me to support his candidate for the position of the Director of the Office of Technical Assessment.

I took a hike at Lafayette Reservoir. Helen again attended the YWCA regional meeting in Millbrae and got home about 5:00. p.m. We had dinner in the playroom and watched TV news. She told me Dianne called from Washington a little after 5:00 p.m.; she is getting along fine. 
Wednesday, August 10, 1977 - Berkeley

At 9:30 a.m., I went by room 203/70 to talk to otto and Morrissey about correlations of yields of different kinds of heavy ion reactions for $\mathrm{U}$ target and different projectiles $\left(40 \mathrm{Ar},{ }^{56} 6_{\mathrm{Fe}},{ }^{48} \mathrm{Ca},{ }^{8} 6_{\mathrm{Kr}}\right.$, berkelium fractions from last night's bombardment of $235_{U}$ plus $13 I_{B}$ which are being counted for x-rays.

I walked up to the HILAC Building and talked to sebesta (who is making progress on FAKE), Cynthia Lee (working on the target preparation spraying apparatus and Somerville (who is still measuring S.F. mica tracks from his $233_{\mathrm{U}}$ plus ${ }_{\mathrm{He}}$ bombardment at the 88 " cyclotron). I talked.at length with Ghiorso about our schedule for SuperHILAC bombardments this fall. I returned to my LBL office at 11:00 a.m.

I talked several times to Margie Hollander about the final version of May, June and July, 1943, of the Met Lab Section C-I history, Vol.. II, which is nearly ready to go to press in the LBL Technical Information Division.

I held the regular biweekly luncheon meeting of the Sheiks in my office from 12-1:05 p.m. Present were Ghiorso, Baisden, Somerville, Morrissey, Gottstein, Marsh, de Saint-Simon, Otto, Leber, Diana Lee, Cynthia Lee, Nitschke, Thomas and Nishida. De Saint-Simgn reported on his calculations on the yield of iodine isotopes from $238_{\mathrm{U}}$ plus $40_{\mathrm{Ar}}$ (excitation function), Morrissey on correlations of fusion, deep inelastic and quasi-elastic cross sections for different heavy ions ( $\left.4 \mathrm{Ar}_{\mathrm{Ar}}{ }^{56} \mathrm{Fe}^{8 \sigma_{\mathrm{Kr}}},{ }^{138} \mathrm{Xe}\right)$ incident on uranium, somerville on his search for $240 \mathrm{Pu}$ from $233_{\mathrm{U}}$ plus ${ }^{4} \mathrm{He}$ (Decay-in-Flight method) 40 Otto on (excitation function), Sebesta on his progress 22 putting FAKE in working order; Nishida on yields of $224 \mathrm{AC}$ and ${ }^{226}$ Af from U plus ${ }^{136} \mathrm{xe}$, Baisden on the tentative (?) yields of $256_{\mathrm{ES}}$ and $254 \mathrm{~m}_{\mathrm{ES}}$ from $238_{\mathrm{U}}$ plus 136 Xe, Cynthia Lee on the spray method for preparing heavy ion targets and Diana Lee on problems caused by the change in our computer program at the LBL Computer Center.

At 1:45 p.m., David Ridgway called to see if I would be available to have lunch with Pimentel, Pitzer and him on August 16th or 17th. Pat informed him that I would be in Warsaw. Unfortunately, a time could not be set because of schedule conflicts.

I went to room $209 / 70$ and talked to Williams about her bombardment last night. She found $x$-ray activity in the Bk fraction but hasn't identified the half-life yet.

During the course of the day, the following correspondence was sent out: a statement of support of the Gray Panthers for "an epidemiological study of the various health hazards of air pollution," information to the participants of the symposium Commemorating the 25th Anniversary of the Discovery of Elements 99 and 100, at the Lawrence Berkeley Laboratory, January 23, 1978, a letter to Owen Chamberlain stating my intention to renew the nomination of John 0 . Rasmussen for membership in the National Academy of Sciences (with a copy of the "Intersectional Proposal for Nomination" form for his 
Wednesday, August 10, 1977 (con't)

signature in case he chose to join John Huizenga, Gerhart Friedlander, John wheeler and me as one of the five proposers), letters to Dan Tyler Moore and Mike Du Russel regarding Du Russel's inguiry as to how he was chosen for membership in the International Platform Association and a letter of regret to the American Committee for the Weizmann Institute of Science because prior commitments will not permit me to attend the Annual Weizmann Dinner to be held in New York, on October 16,1977 .

I received a letter from George $H$. Esser, National Academy of Public Administration, thanking me for my nomination of Emilio 0 . Daddario; Daddario's name was not selected for placement on this year's ballot. His file will be kept on file for reference to next year's nominating committee.

From 3-4:00 p.m., a farewell reception, planned by Kathy and Trish, was held for sheila in the Conference Room of Building $70 \mathrm{~A}$. Helen drove in to LBL in order to attend. A total of about 70 people were present, including olivia Austria, Bonnie Acuna, Maxine Adams, Elliott Amon, Daniel Andes, Dick Bailey, Patricia Baisden, Robert Budnitz, Marty Casazza, Joseph Cerny, David Clark, Homer Conzett, Sharon Date, Norman Edelstein, Eileen Eiland, Anne Fleming, Albert Ghiorso, Norman Glendenning, Billie Hagar, Bernard Harvey, David Hendrie, Margie Hollander, Earl Hyde, George Kagawa, Jane Kingston, Ted Kirksey, Ruth-Mary Larimer, Michael Lederer, Cynthia Lee, Diana Lee, Bud Larsh, Richard Lemmon, Crystal Ilewellyn, Ron Lowder, Jeannette Mahoney, Frances Mann, Sam Markowitz, Ed McMillan, Louise Millard, William Myers, David Morrissey, Bonner Nishida, Michael Nitschke, Rollie Otto, George Pappas, Arthur Poskanzer, Elinor Potter, Peggy Pracht, Pat Quinn, Beatrice Ramsay, John Rasmussen, David Richards, Andrew Sessler, David Shirley, Douglas Smith, Wanda Smith, Linda Stephenson, Ken Thomas, Dorothy Tuley, Kathy Van Der Haeghen, Carroll Weiss, Kim Williams, Peggy Yamada and Saburo Yashita.

GTS and Sheila Saxby: August 8, 1997.

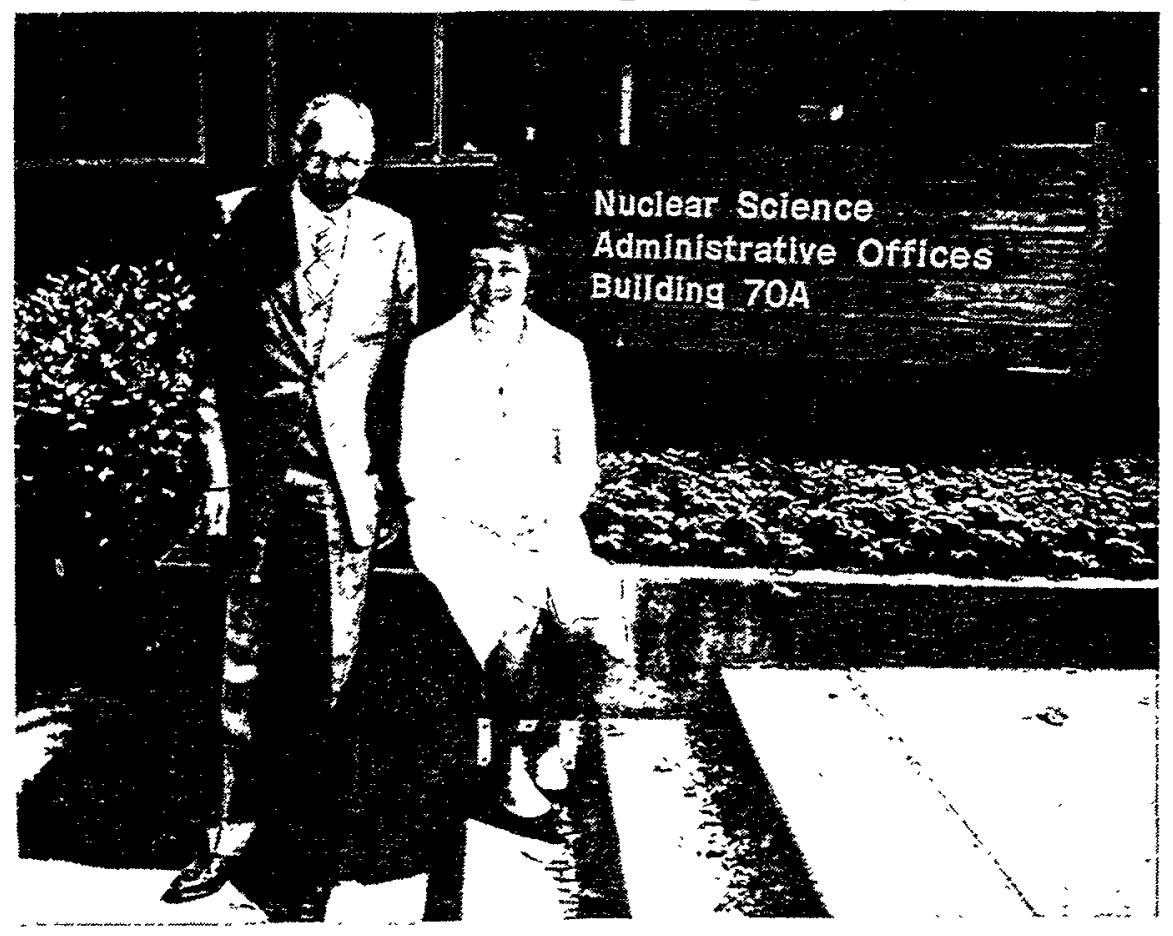




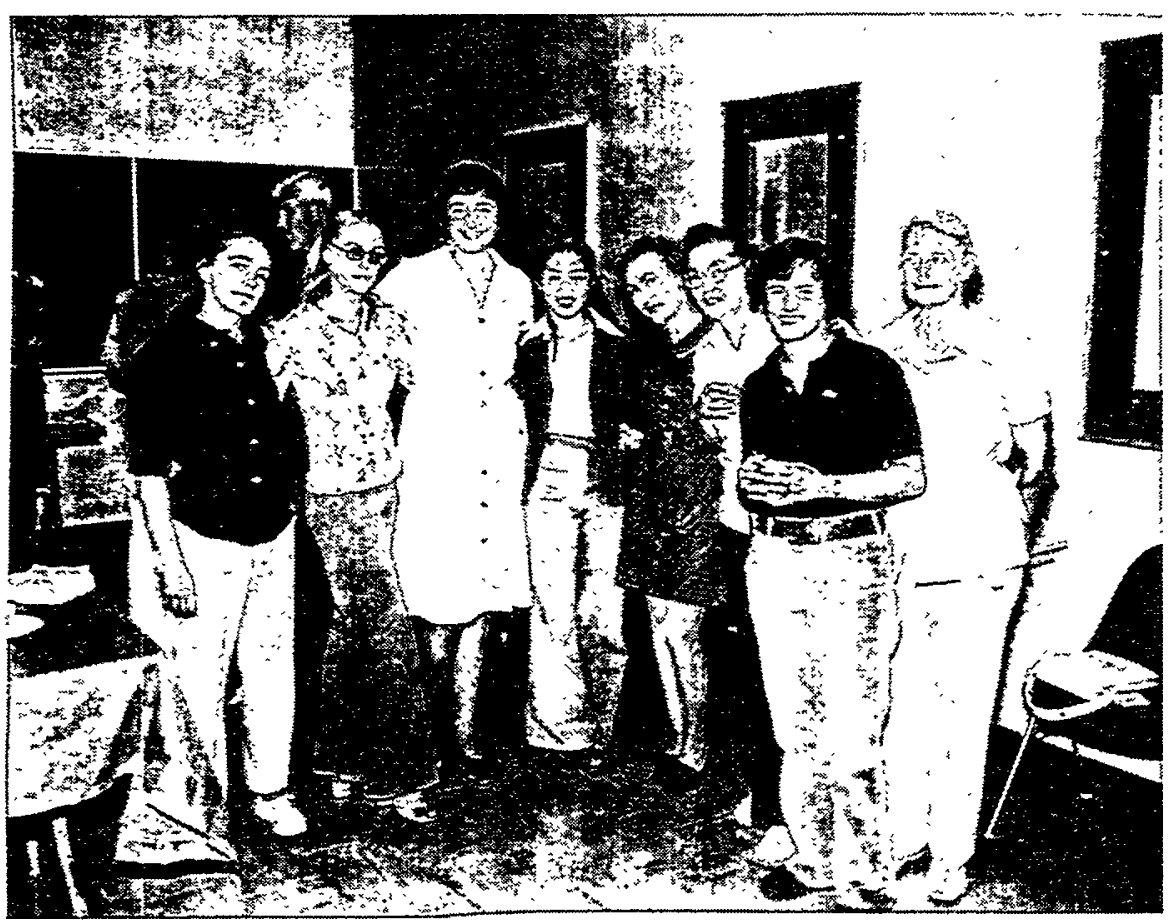

Ruth-Mary Larimer, Crystal LleweIlyn, Sheila Saxby, Cynthia Lee, Dorothy Tuley, Carroll Weiss, Kim Williams and Helen Seaborg: 8/10/77.

Albert Ghiorso, Sheila Saxby, Elliott Amon, Raymond Wakerling and Ted Kirksey: 8/10/77.

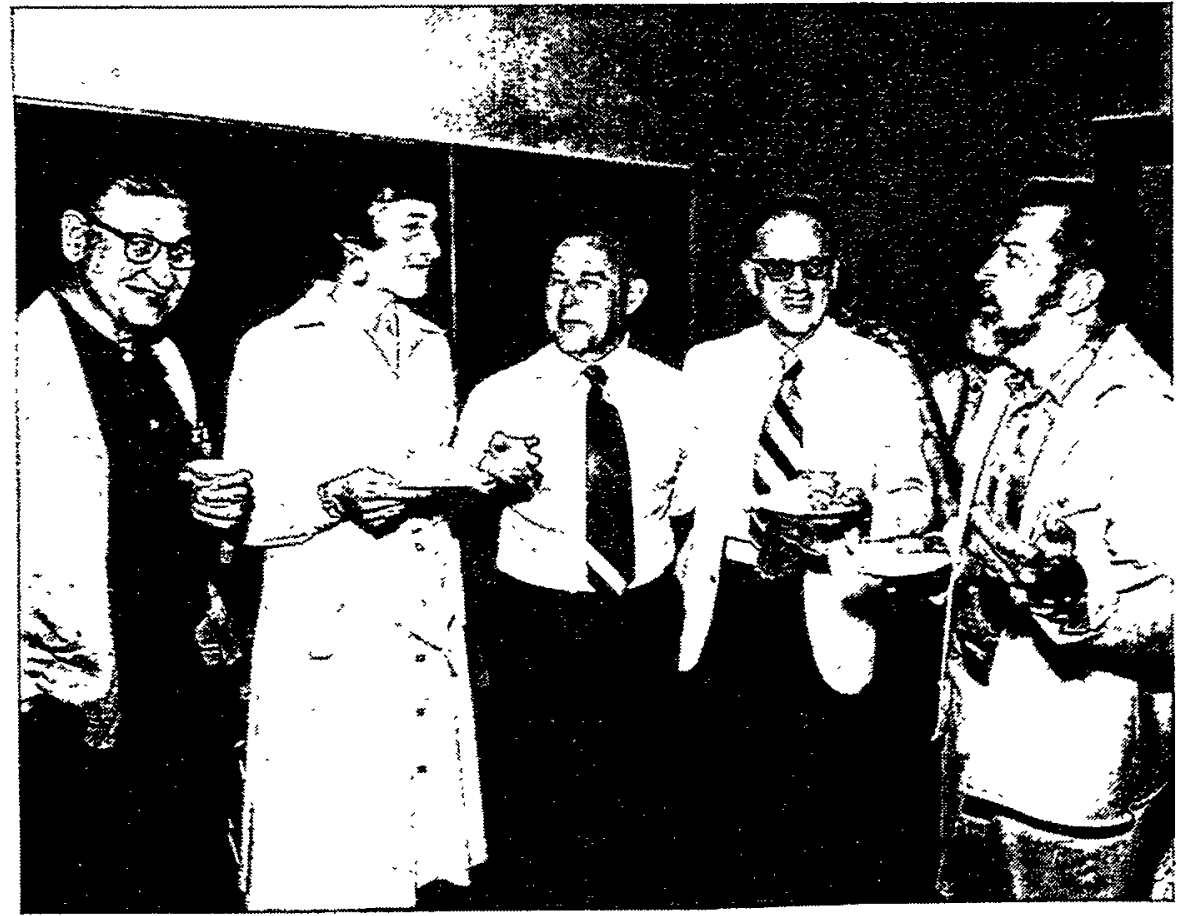




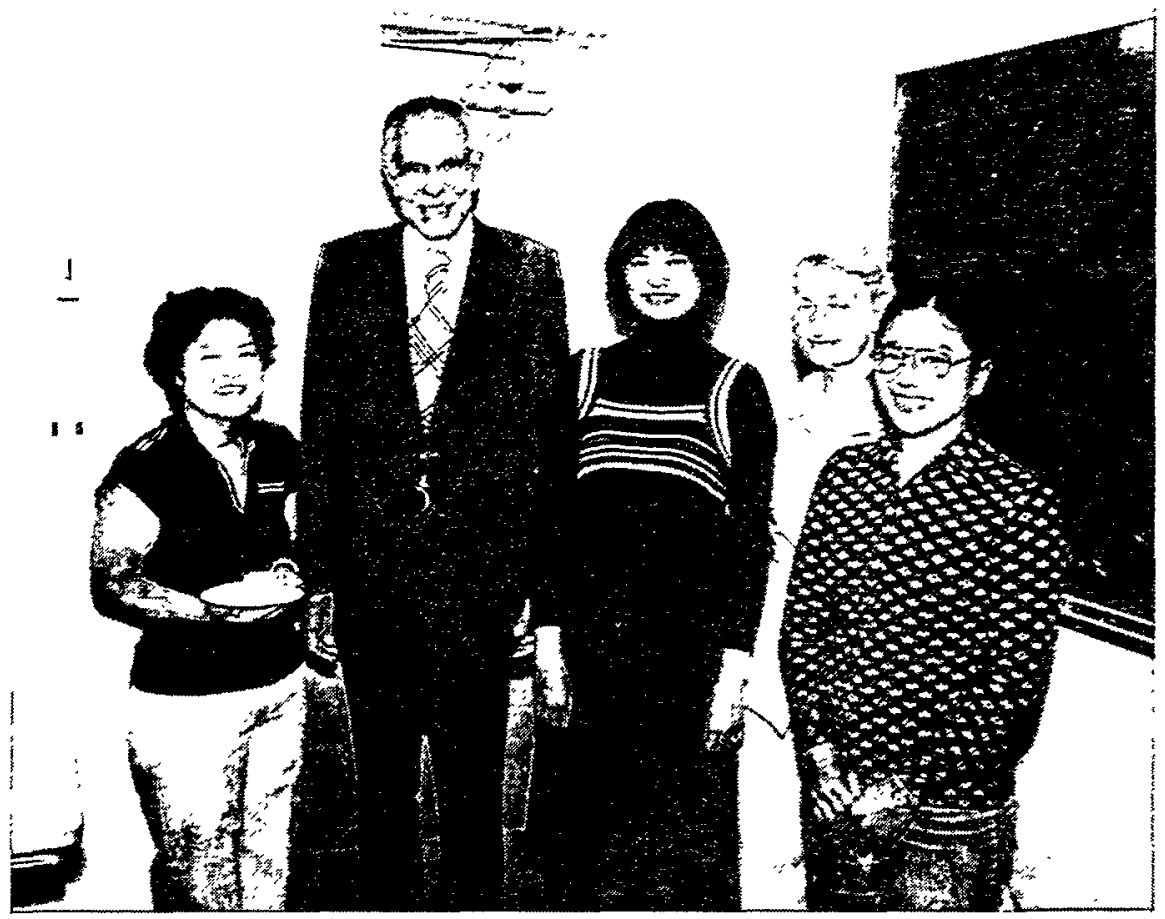

Sharon Date, GTS, Kathy Van Der Haeghen, Helen Seaborg and Bonner Nishida: August 10, 1977.

Sam Markowitz, GTS and John Rasmussen: 8/10/77.

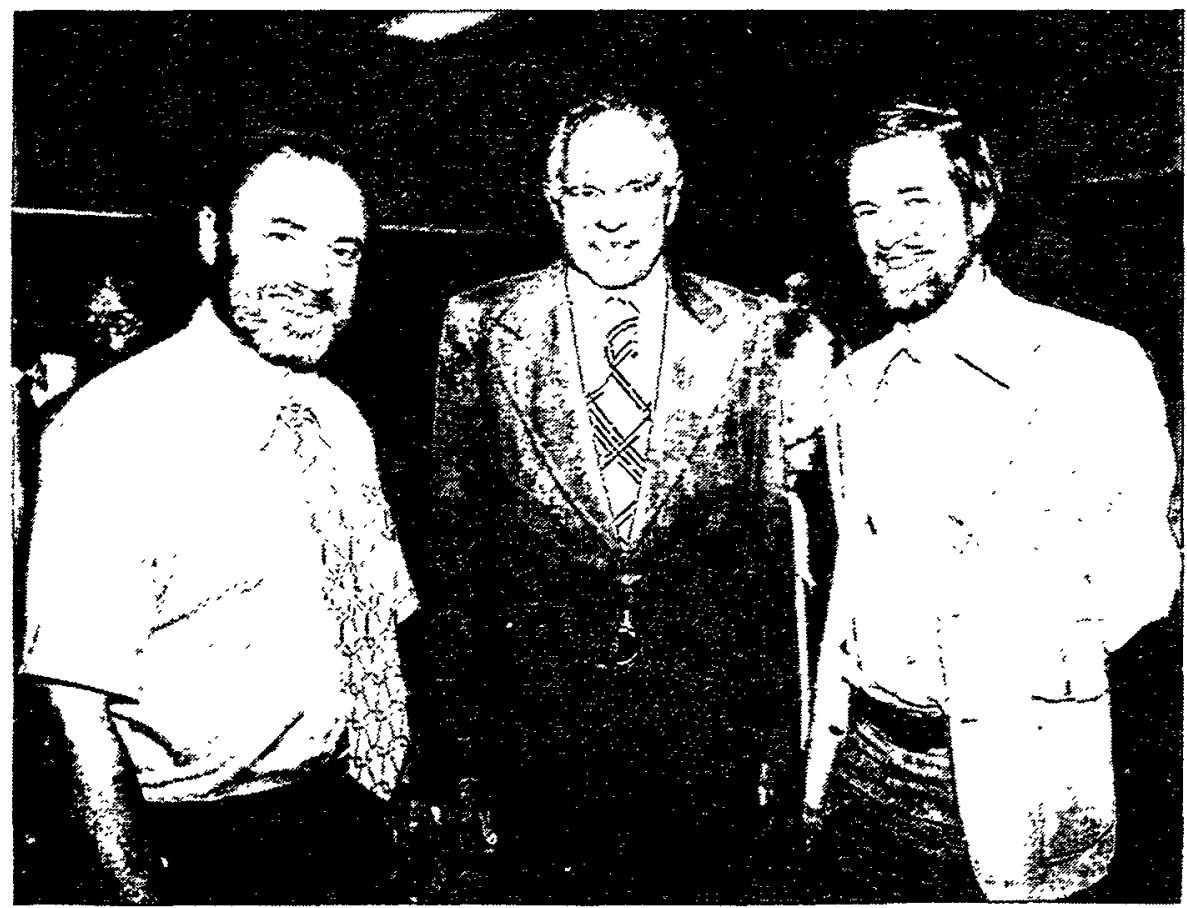


I made some remarks, describing how I met and convinced sheila to come to work with me, how I unsuccessfully tried to keep her a secret, her warmth, understanding and extraordinary competence, her friendly and helpful reception of all who have visited my office and her countrywide--and extending even to Europe--string of impressed acquaintances via the telephone. I wished her well in her new position and made several references to the helpful role for IBL that she will probably play in her position with the Regents. I introduced Pat Quinn, pointing out that she, like sheila, comes from Montana. I then asked sheila to come forward to cut the first pieces from the huge cake at the center table; the frosting was embellished with greetings to sheila.

Sheila responded with emotion, describing some of the delights, also some trials and tribulations, of working for me. She then cut the first pieces from the cake. After the party, Helen, who had come in on BART, drove down to Berkeley to do some shopping then drove me home. We stopped at Lafayette Reservoir so I could take a hike. We had dinner in the playroom, watching TV news.

Thursday, August 11, 1977 - Berkeley

I drove to my office in the Bonneville because Helen needed the station wagon.

I received a telephone call from Harrington Manville at USIA regarding my Warsaw trip. There was not enough time to make arrangements for me to speak, but he is willing to assist me in any way during my visit.

I received a very interesting letter (attached) from Jens Kratz and went by to discuss its contents first with otto and Morrissey, then with Nitschke. I also discussed the results from $U \cdot+U$ (Kratz et al. in the GSI annual report) in which they find the "goldfinger" peak shifted to thorium; this provides more hope that the deep inelastic process can lead to the observation of SHE and I suggested to otto, Morrissey and Nitschke that perhaps we should plan to bombard Cf or Es targets with $\mathrm{Pb}$ ions when they are available. Nitschke showed me measurements on his RAMA (Recoil Atomic Mass Analyzer); these look very encouraging. RAMA might be used, when completed 6-12 months from now, for the identification of SHE.

I also talked to Williams; she has analyzed her Bk decay dăta and sees a 45-minute component in the $\mathrm{Cm} x$-ray; this may be due to $242_{\mathrm{Bk}}$

When I returned to my office, Cynthia Lee came by and gave me a present of a bottle of wine, a 1969 Chateau Smith Haut Lafitte Martillac, from Bordeau, France.

At 11:30 a.m., I received a telephone call from Mrs. Nivens of Dowden, Hutchinson \& Ross, Inc. informing me that the Benchmark manuscript had arrived in excellent condition.

I had lunch with de Saint-Simon. He told me about the research groups at orsay and his plans to spend 3 months at Dubna. 


\section{DARMSTADT $\quad$ Dr. J.V. Kratz}

RECD AUG 101977

Dr. G.T. Seaborg .

Lawrence Berkeley Laboratory

University of California

Berkeley, California 94720

USA

August 4,1977

Dear Dr. Seaborg:

Thank you for sending some of your recent publications including the ${ }^{48} \mathrm{Ca}+{ }^{208} \mathrm{~Pb}$ preprint. In the latter work you refer to work by Ghiorso et al. (LBL - 5075). As you probably know, we have investigated $5.9 \mathrm{MeV} / \mathrm{A}{ }^{40} \mathrm{Ar}$ reactions with $\mathrm{Pb}$-isotopes using a rotating. wheel experiment through which thick target cross sections are obtained for spontaneous fission activities. In contrast to the results reported in LBL - 5075 we find the maximum cross section for the ${ }^{208} \mathrm{~Pb}\left({ }^{40} \mathrm{Ar}, 2 \mathrm{n}\right){ }^{246} \mathrm{Fm}$ reaction $\left({ }^{-} \sigma=6 \mathrm{nb}\right.$, if the s.f. branch is assumed to be $8 \%$ ), while the ${ }^{208} \mathrm{~Pb}\left({ }^{40} \mathrm{Ar}, 4 \mathrm{n}\right)$, ${ }^{207} \mathrm{~Pb}\left({ }^{40} \mathrm{Ar}, 3 \mathrm{n}\right)$ and ${ }^{206} \mathrm{~Pb}\left({ }^{40} \mathrm{Ar}, 2 \mathrm{n}\right)$ reactions yield integral cross sections of $i 0.5,1.6$ and $0.7 \mathrm{nb}$, respectively. Both ${ }^{246} \mathrm{Fm}$ and ${ }^{244} \mathrm{Fm}$ were identified via their $3.6 \mathrm{msec}$ and $1.2 \mathrm{sec}$ half-lives. I wonder if you could give an explanation for the apparent discre- . pancy.

In reading your interesting ${ }^{48} \mathrm{Ca}+{ }^{208} \mathrm{~Pb}$ article, I realized that in Fig. $1(a)$ and (b) a large number of data points lie above the curve $A+B+C+D$. I do not see how a least-squares procedure could result in such unbalanced data point distributions around 


p. 2 - Dr. G.T. Seaborg - $\quad$ August 4, 1977

the fitted curve. Since your main conclusion depends strongly on the magnitude of the fusion-fission cross sections, I find it troublesome to find a discrepancy of the order of a factor of two or so between the mass yield data points and the curve $A+B+C+D$. Could you help me to understand your analysis?

Finally, I wonder what are the prospects for the combined $\mathrm{Kr}+\mathrm{U}$ and $\mathrm{Xe}+\mathrm{U}$ paper. You had suggested that M:. Fowler might do the writing. I have not heard news from you since the beginning of this year about this matter.

Looking forward to hearing from you, cordially, (J.V. Kratz) 
At 2:00 p.m., I received a telephone call from Larry O'Donnell at General Atomics in San Diego. He called to bring me up-to-date on the HTGR reactor and to invite me to speak at a meeting of congressmen and others about its present status. I had to decline because of my Europe trip.

I proofread the placing of pictures in some chapters of Volume II, Travels in the New World. I also selected some more material for slides for my talk on John E. Willard at the Chicago, American Chemical Society meeting (August 30).

I had a talk with Sheila about her new job and the pangs she is feeling at leaving her present position.

I signed the statement of support, along with Melvin Calvin and Joel H. Hildebrand (as yet unsigned), for Dick Iemmon's re-election to membership in the ACS's national council and a letter of support for the appointment of Paul J. Karol to a tenured faculty position at Carnegie-Mellon University. I also sent correspondence to Volker Metag and Reinhard Brandt regarding my plans for visiting Marburg.

In the late afternoon, I went by to confer with otto and Morrissey about my answer to Kratz's letter.

The Bonneville developed a steaming engine on my way home so I left it parked on Grizzly Peak Boulevard, near the train ride area. Jeannette Mahoney came by and drove me to Grizzly Peak Stables. Here I called the $A A A$ in orinda to come and tow the car in to the orinda Union 76 garage, after which steve Young drove me home to Lafayette.

Helen and I had dinner in the playroom, watching TV news; we saw scenes of Sol Linowitz returning from Panama and in the cabinet Room of the White House reporting to President Carter on his and Ambassador Bunker's success in negotiating a revision of the US Treaty with Panama regarding the Panama Canal (which provides for US withdrawal by the year 2000).

Helen spent much of today making purchases for our wine and cheese party tomorrow evening for old-timer members of the LBI and ILI chemistry departments.

\section{Friday, August 12, 1977 - Berkeley}

I worked with otto and Morrissey on another contribution to the IBI Annual Report "Observations on the Mass Distribution from Heavy Ion-Uranium Reactions."

I received a call at 11:55 a.m. from Michael Crisp, Senator Howard Baker's Administrative Aide. He is working on a letter for Senator Baker regarding the Holifield Project and wanted to know the similarities between this project and the uranium high intensity uranium beam facility. Crisp feels confident that our project will be funded through a supplemental appropriation. He asked me to write a description of the implications of the loss of the beam facility for Senator Baker's presentation/information. I also agreed to write a few lines regarding the importance of the facility to the nation. 
At noon, I spoke with George Rogosa and he informed me that Jim Kane has approved placing the high intensity uranium beam project before the Holifield heavy ion accelerator on the FY79 Budget. He also told me that George Pake and Pief Panovsky are being considered for Head of an Office for Basic Research in the Secretary of Energy's Office.

After lunch, I went by room $203 / 70$ to talk to Morrissey about getting ideas to Fred Goldhaber and Harry Hickman for their Annual Review of Nuclear Science article on high energy interactions of nuclei. I also discussed with Baisden her calculations of yields of Th, Ac, etc. isotopes from her U plus $8 \sigma_{\mathrm{Kr}}$ bombardments.

I sent Mike Crisp the information (letter attached) he requested by phone this morning. During the course of the day, I wrote a reply (attached) to Jens Kratz's letter of August 4 and approved my Bio-Bibliographical supplement (attached).

At 4:00 p.m., we had a little farewell champagne party in the office area for Sheila. Pat Quinn, Kathy Van Der Haeghen, Sharon Date, Olivia Austria, Eileen Eiland, Bea Ramsay, Bernie Harvey, Art Poskanzer, Rollie otto and a few others were present. I said goodbye to Sheila, on this her last day, wished her well on her new job as I left my office to drive home at $4: 20$ p.m.

I stopped at Lafayette Reservoir for a hike on the way home. Helen and $I$.gave a wine and cheese, reception for our old IBL and LLI friends; this was a renewal of the annual (cocktail party) receptions we had for Rad Lab and Livermore Lab chemists from 1948-1960 and which were attended by nearly 200 people in the late 1950's. This affair was both a reunion and in honor of $I z$ and Lee Perlman. Alice Thompson came in the middle of the afternoon to help Helen make preparations. Iz and Lee arrived at 5:15 p.m. Also included were my undergraduate students who had not visited our home yet--Bonner Nishida, Cynthia Lee and Wayne Marsh--they were the first guests to arrive, at 5:30 p.m. Besides Helen, Dave, Eric and I, and Ty Jenkins, about 65 guests. attended.

After the last guests left, a little after 8:30 p.m., Helen produced a casserole dinner for the Perlmans, Alice Thompson, Eric, Dave, Ty and me, which we ate in the living room. This was followed by conversations, after which the Perlmans and Alice left at 10:00 p.m.

Eric has heard from Backpacker Magazine that they would like to receive an article on the EBRPD "Golden Loop" Trail, as suggested by him. Dave, Eric and Ty spent the night with us. Bill Jenkins called from Washington at 8:45 p.m. to extend his greetings.

Saturday, August 13, 1977 - Central Contra Costa County

Helen and I rode with Eric in our station wagon to the Union 76 station (AAA) in Orinda to pick up our Bonneville. (The repair con-. sisted of a heater core bypass--cost $\$ 2$ ). Eric continued on to Marin to complete his editing of a special newspaper The Marin Energy Examiner. He has been working on this full time during the last week. 
August 12, 1977

Mr. Michael Crisp.

c/o The Honorable Howard H. Baker, Jr.

4123 Dirksen Building

Washington, D.C.'20510

Dear Mike:

This is.in response to your request for information about the USERDA Division of Physical Research Project 78-12-b "High Intensity Uranium Beams, Lawrence Berkeley Laboratory, California". This will upgrade the present SuperHILAC and Bevalac (the Bevalac is the combination of SuperHILAC injecting heavy ions through a transfer line into the Bevatron for further acceleration up to relativistic energies). The present capability of the SuperHILAC is to accelerate heavy ions up to the mass of xenon or slightly beyond to-energies of $8.5 \mathrm{Mev} /$ nucleon. The present capability of the Bevalac is to accelerate heavy ions up to the mass or argon or somewhat beyond to energies of about $2 \mathrm{Gev} / n u c l e o n$. This $\$ 6 \mathrm{M}$ project, by furnishing a third injector for the SuperHILAC, by upgrading the connecting transfer line and by providing the Bevatron with a better vacuum, would give the capability of accelerating heavy ions in the SuperHILAC up to uranium with an energy of $8.5 \mathrm{Mev} /$ nucleon and heavy ions up to uranium at the Bevalac with an energy of about l-2 Gev/nucleon.

The present SuperHILAC and Bevalac are national facilities used by scientists from all over the United States to carry on basic research investigations in the field of heavy ion science. This is a field of increasing importance to the understanding of nuclear structure and the mechanisms of nuclear reactions and is being pursued vigorously in many countries: The improved facility would give the United States the possibility of staying abreast of the competition from accelerators in other countries and would also give the United States a unique capability in the relativistic energy, range. There is a high interest in the relativistic energy range because of the possibility of creating entirely new kinds of matter and of investigating some of the most fundamental problems in physics.

Heavy ion science oxiginated in the united States and U.S, scientists have been in the forefront but are now in danger of losing their preeminent position. There is a powerful 
heavy ion accelerator aixeady operating at Darmstadt in West Germany which is accelerating uranium ions to energies of about $8 \mathrm{Mev} /$ nucleon. An even more powerful facility is nearing completion at Dubna near Moscow. France is also building a powerful heavy ion facility neax Caen. England and Japan have plans for such a facility. A powerful incentive is the possibility of synthesizing super Heavy Elements $(\mathrm{z}=110-120)$.

The relativistic energy capability of the improved Bevalac (2 Gev/nucleon) also makes it unique as a facility that can make tests of the concept of heavy ion induced fusion which many scientists believe might prove to be superior to laser- or electron beam-induced fusion.

Phase I of the Holifield Heavy Ion Accelerator, at a cost of $\$ 18 \mathrm{M}$, will be capable of accelerating heavy ions up to mass 100 to energies of $6 \mathrm{Mev/nucleon}$ or to slightly higher mass (about 140) if it is coupled to ORIC (Cyclotron). Phase II of the Holifield Heavy Ion Accelerator, at a cost of about $\$ 25 \mathrm{M}$, will accelerate heavy ions up to uranium to an energy of $12 \mathrm{Mev} / \mathrm{nucleon}$ and ions up to about mass 40 to $100 \mathrm{Mev} / \mathrm{nucleon}$.

- We need both the improved SuperHIIAC and Bevalac and the Holifield Heavy Ion Accelerator Phases I and II in order that the United States might be able to keep its preeminent position in the increasingly important field of heavy ion science.

with best regaräs,

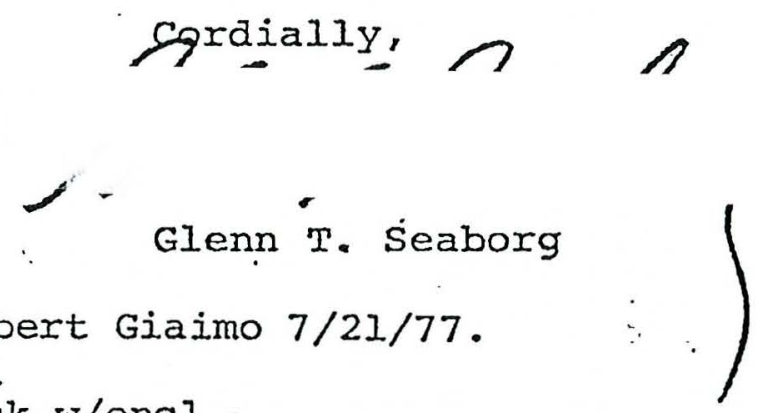

Enclosure:" D. Allan Bromley/Robert Giaimo 7/21/77.

bcc: Dr. Bernard Harvey w/encl.

Congressman Mike McCormack w/encl -.

- (Vancouver, Wash. and Wash.D.C.) -...-

John Andelin, McCormack's office, w/encl 
Augast 12, 1977

Dr. J. V. Pratz

Gesellschaft Fü Sairierionenforschung MBH

Postfach 541

6100 Damstadt 1, Viest Germany

Dear Jens:

Your letter of August 4, 1977 which I received hedresday, crossed in the mail with my letter to you of August 8, 1977. I will try to respord to your giestions.

I think the tho values for the cross section of the ${ }^{208} \mathrm{~Pb}\left({ }^{40} \mathrm{Ar}, 2 \mathrm{n}\right)$ $24 \mathrm{Fm}$ reaction can possibly be reconcilea as follows: parhaps the value for the s.f. branch of ${ }^{4} 6 \mathrm{Fm}$ is off by a jactor of 2 , that is it is actually 16:, tims lowering your cross section to $3 \mathrm{nj}$. This is easily possible and the upper limit reported in IBI-5075 coula actually be 3 nib. In fact, tinis upper linit is reported as $2 \mathrm{rb}$ in tine most recent cescription of tinis work (LEL-6534, enclosed), and this could be ofi by $50 \%$ - 1005. Yod might also note that in IBI-6534 the value of $3 \mathrm{nb}$ is reported for the cross section of the ${ }^{203} \mathrm{Fb}$ ( ${ }^{40} \mathrm{Ar}, 4 \mathrm{n}$ ) ${ }^{244} \mathrm{Fm}$ resction (creaitea to Kirn iriilliams), in contrast to your value of $0.5 \mathrm{nb}$. (She tells me her value is actually $2.5 \mathrm{nb} \pm 508$.) I am afraid tiat errors of this order of ragnitude are still a possibility in these kinds of erperiments. You reported $1.6 \mathrm{nb}$ in your Anmul Peport (page 72), in agreement with Dubna (JINR D7-8099).

With respect to your observation on our ${ }^{\circ 8} \mathrm{Ca}+{ }^{208} \mathrm{~Pb}$ ariticle, I an enclosing a revisea version as it was sent in for pubiication in Plysical Revies ietters. We think tinat tine best fit using ali hine cata points corresponds to cirve A but the error bars in Figire 2 are drawn so that the upper linits repxesent the cases in winich the conplete fusion-fission mass distribution is shifted upread so as to pass timough the points in the mass region $130-160$.

The have not had much luck in getting Malcolm Fowler or Tod Norris to co sare writing on our papar "Charge and Mass Distributions in the

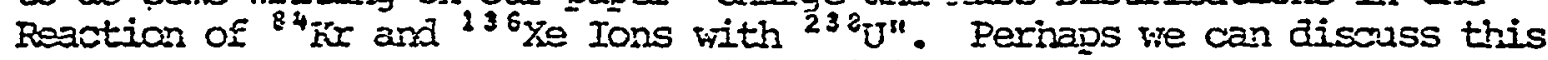
when I see you at GSI next month if a visit at that time should prove convenient to you.

With best regards,

cordially,

Glenn T. Seaborg

Attachents

GIS:pq 
AlI information refers to the period July 1, 1976 to June 30, 1977

\begin{tabular}{lll} 
NAME SEABORG, Glenn Theodore & \\
LEPARTMENT & Chemistry & \\
\hline
\end{tabular}

Date_August 12, 1977

ACADEMIC TITLE University Professor

CAMPUS Berkeley

Report changes in home address, academic degrees, citizenship, and marriage

I. TEACHING (incluđing University Extension teaching) *

1. Courses taught (including tutorials)

Chemistry IABC Laboratory (F-W-S) Chemistry 196 (F-W-S) Physics 295 (F-W-S)

Chemistry HI94 (W-S) . Chemistry 299 (F-W-S)

2. Ner courses devised and instituted

3. Systematic efforts undertaken to improve instruction

4. Master and doctoral theses completed under your chairmanship (give names of students and titles of theses)

Irwin Binder, "A Radiochemical Study of the Reactions of Heavy Ions with Gold"
5. Post-doctoral scholars supervised (give names) :
Patricia Baisden
R. Eric Leber
Roland J. Otto

\section{Academic advising activities}

II. PUBLICATIONS, RESEARCH, AND OTHER CREATIVE ACTIVITY*

List all research and creative accomplishments, including porks of art, musical compositions, and other activities of this nature. Cite only items not previously submitted.

Give a full bibliographical citation for each item, or an equivalent reference if the rork being cited is not represented in the form of publication. (Do not submit any material that is in progress or in press.) List separately publications for which you were supervisor but not co-author (indicate your role).

SEE ATTACHMENT PAGE 1

\footnotetext{
- If you need additional space please attach extra sheet.

Copy for Psesident's Offico, 681 University Hall, Barkeley
} 
III. COMUITTEE SERVICE*

1. Committees of the Academic Senate

2. Administrative oommittees

3. College, department or other University committees SEE ATTACHMENT PAGE 2

IV. PROFESSIONAL ACTIVITIES*

1. Invited lectures, papers at meetings and similar activities SEE ATTACHMENT PAGES 2-5

2. Service to editorial boards of scholarly journals or other publications SEE ATTACHMENT PAGE 5

3. Service to scholarly or professional societies SEE ATTACHMENT PAGE 5

4. Service to educational or governmental agencies SEE ATTACHMENT PAGES 5-6.

5. Service to University Extension

v. SPECIAL APPOINTMENTS*

Administrative posts (e.g., department officer, director of organized research unit, principal investigator)

Associate Director at Large, Lawrence Berkeley Laboratory

VI. ATARDS*

1. Prizes, honors, commendations

Daniel Webster Award, International Platform Association, July 29, 1976

2. Fellowships and extra-mural grants 
II. PUBLICATIONS, RESEARCH, AND OTHER CREATIVE ACTIVITY

\section{Monographs}

China Journal: Report of a Visit to the People's Republic of China. Berkeley: Iawrence Berkeley Laboratory, 1973.

Early History of Heavy Isotope Research at Berkeley: August 1940 to April 1942. PUB-97. Berkeley: Lawrence Berkeley Laboratory, June' 1976.

Editor, Proceedings of the Symposium Commemorating the 25th Anniversary of Elements 97 and 98 , Held on January 20, 1975. I.BL-4366. 'Berkeley: Iawrence Berkeley Iaboratory, July 1976.

History of the Met Iab Section C-I: April 1942 to April 1943. PUB-112. Berkeley: Iawrence Berkeley Laboratory, February 1977.

Travels in the New World: Volume I. PUB-113. Berkeley: Iawrence Berkeley Laboratory, April 1977.

\section{Articles}

Science: The Next 100 Years. San Francisco Sunday Examiner and Chronicle, July 4, 1976, p. A2.

Don't Shackle Science (with .. R. Corliss). Skeptic, No. 14, July/August 1976, pp. 30-31.

Chemistry--Key to Our Progress. Chemical and Engineering News, Vol. 54, September 13, 1976, pp. 31-36.

Criteria for the Discovery of Chemical Elements (with B. G. Harvey, G. Herrmann, R. W. Hoff, D. C. Hoffman, E. K. Hyde, J. J. Katz, O. L. Keller, Ir. and M. Lefort). Science, Vol. 193, 24 September 1976, pp. 1271-1272.

Toward an International Chemical Society. Chemical and Engineering News, October 11, I976, P. 4.

Towards an International Chemical Society. Trends in Biochemical Sciences, VoI. I, No. 10, October 1976, pp. 217-218.

New Signposts for Science. The Future of Science (T. C. I. Robinson, editor). New York: John Wiley and Sons, 1977, pp. 1-37.

Can We Solve Our Energy Problem? ASM News, Vo1. 8, No. 4, April 1977, pp. 4-5.

Knowledge--Principal Motive Force (in Russian). Technica-Youth, No. 2, 1977, pp. 20-22. 
ANNUAL SUPPLEMENT TO THE. BIO-BIBLIOGRAPHY 1976-77 SEABORG, Glenn Theodore

\section{COMMITTEE SERVICE}

3. College, department or other University committees

Chairman, Planning Subcommittee, Lawrence Hall of Science

Member, Advisory Comittee, Lawrence Hall of Science

Member, Executive Committee, Chemical Education Material (CHEM) Study

Advisory Council, History of Science and Technology in the Bay Area Project, The Bancroft Library

Scientific Program Council, Lawrence Berkeley Laboratory

Board of Delegates, University of California/Berkeley Foundation

Parents' Committee for Recreation Hall, University of California, Davis

Program Review Team, Chemistry and Materials Science Research Division, Lawrence Livermore Laboratory

IV. PROFESSIONAI ACTIVITIES

1. Invited lectures, papers at meetings and similar activities

1a. Papers and lectures at scientific meetings

"Chemistry--Key to Our Progress." Presidential Address, American Chemical Society, San Francisco, California, August 31, 1976.

"American Chemical Society Centennial Year." Dinner Remarks, Atlanta and Northeast Georgia Sections, American Chemical Society, Decatur, Georgia, October 25, 1976.

"Alchemy Revisited." Public lecture, Atlanta and Northeast Georgia Sections, American Chemical Society, Decatur, Georgia, October 25, 1976.

"The Heaviest Transplutonium Elements." Lecture, Inorganic and Nuclear Chemistry Symposium on Plutonium and Transplutonium Elements, 28th Southeast Regional Meeting, American Chemical Society, Gatlinburg, Tennessee, October 27, 1976.

"American Chemistry--Bicentennial." Remarks, Robert A. Welch Foundation Conference XX, Houston, Texas, November 8, 1976.

"Status Report on the Transuranium Elements." Lecture, Southeastern Texas Section, American Chemical Society, Houston, Texas, November 10, 1976.

"Modern Alchemy." Keynote address, CHEMAMERICA 100 Program and Exhibit, Northwest Region, American Chemical Society, Seattle, Washington, November 12, 1976.

"Stanley G. Thompson--A Chemist's Chemist." Address, Stanley G. Thompson Memorial Symposium, Division of Nuclear Chemistry and Technology, American Chemical Society, New Orleans, Louisiana, March 21, 1977. 
ANNUAI SUPPLEMENT TO THE BIO-BIBLIOGRAPHY 1976-77 SEABORG, Glenn Theodore

(IV. PROFESSIONAI ACTIVITIES, 1. Invited lectures, continued)

1b. Other scientific lectures

"The Energy Problem." Banquet address, International Platform Association, Washington, D.C., July 29, 1976.

"The Alchemists are Back." Lecture, Lawrence Hall of Science, University of California, Berkeley, California, August 5, 1976.

"The Energy Problem." Lecture, International Energy Agency, Paris, France, September 17, 1976.

"Energy Sources for the Future." Lecture, Executive Program, Graduate School of Business Administration, University of California, Berkeley, California, October 19, 1976.

"Modern Alchemy." Address, Harold Brunn Society, San Francisco, California, November 22, 1976.

"The Energy Problem." Lecture, Opinion Leaders Seminar, Touche-Ross and Company, New York, New York, January 10, 1977.

"Reactions of ${ }^{48} \mathrm{Ca}$ with Heavy Nuclei." Lecture, Nuclear Science Seminar, Lawrence Berkeley Laboratory, Berkeley, California, January 24, 1977.

"Can We Solve Our Energy Problem?" Keynote address, Ninth Biennial Golden Gate Welding and Metals Conference, San Francisco, Califorria, January 26, 1977.

"Transuranium Elements: Past, Present and Future." - Lecture, 'Iawrence Iivermore Laboratory, Livermore, California, February 3, 1977.

"Reactions of ${ }^{48} \mathrm{Ca}$ with Medium and Heavy Nuclei." Lecture, SuperHIIAC Users Meeting, Lawrence Berkeley Laboratory, Berkeley, California, February 19, 1977.

"A Scientist Looks at the Energy Problem." Remarks, Department of Economics Faculty, University of California, Berkeley; Berkeley, California, March 1, 1977.

"The Heaviest Chemical Elements." Lecture, Science Talent Search, Washington, D.C., March 5, 1977.

"Environmental Impact of Energy Technologies--The LBI Program." Lecture, Medical Staff, Alta Bates Hospital, Berkeley, California, March I4, 1977.

"The Energy Problem--Short and Long Range." Lecture, Round Table on Science and Public Affairs, Duke University, Durham, North Carolina, March I6, 1977. 
(IV. PROFESSIONAI ACTIVITIES, I. Invited lectures, continued)

"The Alchemists are Back." Public lecture, American Chemical Society, New Orleans, Louisiana, March 20, 1977.

"Environmental Effects of Energy Technologies." Lecture, Environmental Toxicology 10 Course, University of California, Davis, May 9, 1977.

"The Transuranium Elements." Keynote lecture, 28th International Science and Engineering Fair, Cleveland, Ohio, May 9, 1977.

1c. Other invited addresses and lectures

"ACS President's Evening and General Meeting." Opening remarks and introductions, American Chemical Society, Berkeley, California, August $30,1976$.

"Joel Henry Hildebrand." Introductory remarks, American Chemical Society, Berkeley, California, August 30, 1976.

"American Chemical Society Centennial." Dinner remarks, The Chemical

- Society, London, England, September 20, 1976.

"Joseph Priestley Revisited." Dedication address, Priestley Laboratory Restoration Project at Northumberland, Lewisburg, Pennsylvania, October 12, 1976.

"Arthur Kent Kerman." Introductory remarks, 45th Anniversary Symposium, Lawrence Berkeley Laboratory; University of California, Berkeley, California, October 30, 1976.

"Welch Foundation Conference Speakers." Introductory remarks, Robert A. Welch Foundation Conference on Chemical Research XX. American Chemistry Bicentennial, Houston, Texas, November 8-10, 1976.

"William 0. Baker." Introductory remarks, Charles Iathrop Parsons Award Dinner, American Chemical Society, Washington, D.C., December 3, 1976.

"Toward A Recycle Society." Dinner address, Upper Napa Valley Associates, Calistoga, California, December 10, 1976.

"Leon N. Cooper." Introductory remarks, Awards Banquet, 36th Annual Westinghouse Science Talent Search, Washington, D.C., March 8, 1977.

"Chemistry for the Future." Address, Dedication of Seeley G. Mudd Chemistry Building, Stanford University, Stanford, California, March 11, 1977.

"Hammarskjold House." Keynote address, Hanmarskjold House Tenth Anniversary, University of California, Davis, May 22, 1977.

"The Energy Problem." Remarks and press conference, National Writing Championship Contest, Journalism Awards Program, William Randolph Hearst Foundation, Berkeley, California, May 9, 1977. 
ANNUAL SUPPIEMENT TO THE BIO-BIBLIOGRAPHY 1976-77 SEABORG, Glenn Theodore

(IV. PROFESSIONAI ACTIVITIES, 1. Invited lectures, continued)

"A Scientist's View of the Arts in Education." Testimony, Joint Congressional Hearings on the Arts, Education and Americans, Washington, D.C., May 25, 1977.

"Some Reminiscences." Lecture, Chemistry Graduate Student organization, University of California, Berkeley, May 31; 1977.

2. Service to editorial boards of scholarly journals or other publications

Editorial Board, Encyclopedia of Chemical Technology Editorial Advisory Board, Journal of Inorganic and Nuclear Chemistry Ad Hoc Editorial Planning Committee, Annual Review of Energy American Heritage Dictionary Panel of Usage Consultants Honorary Editorial Advisory Board, International Encyclopedia of Physical Chemistry and Chemical Physics, Pergamon Press, Itd.

\section{Service to scholarly or professional societies}

American Chemical Society:

President, 1976

Past President, 1977

Chairman, Joint Board-Council Committee on International Activities

Board of Directors

Councilor

Council Policy Committee

Board Conmittee on Education and Students

Board Committee on Grants and Awards

Joint Board-Council Committee on Chemistry and Public Affairs

Screening Committee, Charles Lathrop Parsons Award

American Association for the Advancement of science:

Advisory Committee, Office of International Science

National Academy of Public Administration:

Standing Committee on International and Cross-Cultural Administration

Standing Committee on Environmental and Resource Management

National- Academy of Sciences:

Committee on Human Rights

General Committee, First International Conference on Chemical Research Applied to World Needs (CHEMRAWN) (Toronto 1978), sponsored by International Union of Pure and Applied Chemistry

4. Service to educational or governmental agencies

President, science Service, Inc.

Chairman, Robert A. Welch Foundation Conference on Chemical Research XX. American Chemistry--Bicentennial, Houston, Texas, November 1976

Chairman, Robert A. Welch Foundation Conference on Chemical Research XXI. Cosmochemistry, Houston, Texas (November 1977) 
ANNUAI SUPPLEMENT TO THE BIO-BIBIIOGRAPHY 1976-77 SEABORG, GIenn Theodore

(IV. PROFESSIONAL ACTIVITIES, 4. Service to educationl or governmental agencies, continued)

Chairman, Advisory Committee for the Nobel Conference, Gustavus Adolphus College Scientific Advisory Board, Robert A. Welch Foundation

Board of Trustees, Pacific Science Center Foundation

Science Advisory Committee, Pacific Science Center Foundation

Board of Trustees, American-Scandinavian Foundation

Board of Trustees, Swedish Council of America

Program and Policy Comnittee, Swedish Council of America

Advisory Council, Fellowships and Grants Activities, American-Scandinavian Foundation

Board of Directors, World Future Society

Board of Directors, California Council for Environmental and Economic Balance

.Energy Committee, California Council for Environmental and Economic Balance

Panel on Arts, Education and Americans, American Council for the Arts in Education

Board of Associates, Linus Pauling Institute of Science and Medicine

Advisory Board, San Francisco Bay Area Science Fair

Advisory Board, Nova University, Fort Lauderdale, Florida

Advisory Council, Future Studies Program, Kean College of New Jersey, Newark

Advisory Group, Goals for Global Society Project, State University of New York, Geneseo

Judge, 36th Annual Westinghouse Science Talent Search

Honorary Scientific Committee, International Congress on Phosphate Compounds, World Phosphate Rock Institute (Moscow 1977) 
Helen and I drove to Las Trampas Regional Wilderness and started a hike from the Bollinger Canyon parking lot at 11:00 a.m. We hiked Mahogany Trapline and Sulphur Spring Trails to Sulphur spring and found that work on my suggested trail to Corduroy Hills has not been started. We then hiked back on Sulphur Spring Trail, along Gooseberry Trail and stopped to have our back pack lunches at 1:00 p.m. We continued on Hiker's and Ridge Trails nearly to Las Trampas Peak, then back along Ridge, Grassland and Valley Trails to our point of origin, arriving at $3: 30 \mathrm{p} . \mathrm{m}$. Here we ran into Bob Daskam (who is sort of in charge of Las Trampas) and spoke to him about getting started to work on the trails from Sulphur spring to Corduroy Hills. He wants me to show him the route on a sunday sometime this fall.

Helen, Dave, Ty and I had dinner in the kitchen. Eric came back from Marin about 9:00 p.m. and had some dinner, then went out on a date with Ty.

\section{Sunday, August 14, 1977 - Berkeley}

Steve came by at 9:00 a.m. and stayed with us about an hour on his way from Sacramento to San Diego. He took E. Coli with him, along with his cat. He is going to register on Tuesday and start classes at San Diego State University on September 1.

I had an early Iunch, then rode in the station wagon with Ty and Eric, dropping them at their Oakland homes, and on to the San Francisco Airport to pick up Mike McCormack due in on United flight \#69. It turned out that the flight, which was late, also stopped in oakland. Because I thought Mike might get off there, I quickly drove to the Oakland Airport, arriving at the gate just as passengers were coming off the plane. I boarded and found Mike on board waiting to fly to san Francisco. I persuaded him to get off (making it necessary to pick up his luggage in San Francisco later) and drove him to LBI. We met Andy Sessler in his office. It was 4:00 p.m.; we were a halfhour behind schedule. We picked up Bernie Harvey, walked up to the HILAC Building, met Jose AIonso and Bob Stevenson and made a tour of the SuperHILAC, the Ghiorso experimental area and walked by some other experimental areas.

We walked along the connecting line down to the Bevatron and explained that this combination is the Bevalac. We went to the Bio-med area of the Bevalac where Tom Budinger and Jerry Howard (an engineer) described the heavy ion therapy experiments. We picked up Eric Leber along the way.

Sessler, Leber, McCormack and I then went back to Sessler's office where Terry Simkin explained the LBL program on radioactive waste disposal and Ken Mirk described the LBL geothermal energy program. Simkin said the LBI program involves cooperative work at the Stripa Mine at Storå, Sweden, about $80 \mathrm{~km}$ from Stockholm, (an abandoned iron ore mine).

McCormack, Leber and I then went to my office. In the course of the visit, McCormack and I discussed the High Intensity Uranium Beam project; he still hopes to get it in a FY78 supplemental budget. He thinks we should enlist the help of Dellums, Brown, Mineta, Goldwater 
(to help with Stennis) and Hayakawa. I said I would send him a copy of my letter to Mike Crisp. He will try to have olin Teague introduce the ERDA supplemental bill for our line item. Leber then drove McCormack to the Hilton Hotel in San Francisco. A LBL police officer went to the San Francisco Airport to pick up McCormack's luggage.

I drove home, arriving about 7:00 p.m. Dianne called about 9:00 p.m.; she is getting along fine and is starting to put 3825 Harrison Street into shape. Dave spent the night with us.

Monday, August 15, 1977 - Berkeley

The first thing this morning I went over my correspondence with Pat quinn. This is her first day in charge in her position with me.

I went by room $203 / 70$ to talk to otto and Morrissey about our Annual Report paper, "Observations in the Mass Ristribution from Heavy Ion-Uranium Reactions," Williams about her new $242 \mathrm{Bk}$ (I suggested she look for daughter $242 \mathrm{Cm}$ ) and Baisden and Thomas about scheduling their future bombardments. (I favor a $248 \mathrm{~cm}$ target. Baisden wants to continue with uranium.)

I went down to the scheduling meeting in building 88 with Baisden, Thomas ang Williams. Somerville was also present. We were scheduled for $40 \mathrm{Ar}$ on $\mathrm{U}$ and $15_{\mathrm{N}}$ on $248 \mathrm{~cm}$ for Thursday, August 25 (day, swing and then owl shifts), and ${ }_{\mathrm{He}} \mathrm{plu} \mathrm{y}_{5} 23 \mathrm{~J}_{\mathrm{U}}$ (to look for $238 \mathrm{Pu}$ ) and ${ }^{4}$ He plus 253 Es (for Hulet to look for 255 Md) for Monday, August 29 (swing) and Tuesday, August $3 g_{0}$ (owl). Somerville told me he has observed the 3.8-nanosecond ${ }^{240} \mathrm{Pu}$ from $23{ }^{\mathrm{U}}+{ }^{4} \mathrm{He}$, using his Decay-inElight (DIF) system at the $88^{\prime \prime}$ cyclotron.

At 11:45 a.m., I called Joseph Katz at Argonne National Laboratory and then talked to Donald stewart a few minutes later to make arrangements for my visit to ANL on Friday, August 26 . Stewart may be willing to help with my Met Iab section C-I history if he moves to the Bay Area after his retirement at the end of this year.

I had lunch at the table outside the lower level of the cafeteria with Dave Brown (visiting from Harwell), Norm Edelstein, Doug Cline (physicist from University of Rochester working with Diamond-stephens), Tom Bregante (undergraduate with Ken Raymond, going to USC graduate school), Barbara Fisher (undergraduate with Edelstein et.al. starting University of Rochester graduate school), Rod Banks and Fred Weidl, joined later by Mike Nitschke.

I went by room 209/70 to talk to de saint-simon about our paper on excitations functions of $40 \mathrm{Ar}$ on $U$ (iodine isotopes) and to the HILAC Building to talk to Yashita, Sebesta and then Ghiorso. Ghiorso may have an operation to correct a hernia soon.

About 3:00 p.m., I walked down to Latimer Hall to pick up my mail and stopped to talk to Dorothea Crane. I signed up to have my fall quarter laboratory section on Tuesdays. She will help to find me a competent teaching assistant since I will be in Uppsala the first week of the quarter. 
I stopped in to see Rollie Myers. He will be using College Chemistry by Mahan as the text for his class.

At 5:00 p.m., I went by to see de Saint-Simon again to discuss the paper he is working on (iodine isotopes from $40 \mathrm{Ar}$ plus U).

I took a hike at Lafayette Reservoir. Helen and I had dinner in the playroom watching TV news.

Tuesday-Wednesday, August 16-17, 1977 - Berkeley - London - Warsaw

Soon after my arrival at my LBL office, I talked with Morrissey about giving material to Fred Goldhaber for the Goldhaber-Heckman article for Annual Review of Nuclear Science on RHI reactions. We later mailed a letter (attached) to Goldhaber describing our efforts in this area of study.

I then talked with Margie Hollander about our Met Lab Section C-I history progress and was interrupted by a telephone call from Rodney Hader informing me that Herman Bloch suffered a mild heart attack a couple of days ago at his summer place in Michigan. Bloch's condition is stable but there is no hope he will recover in time for the Chicago meetings of ACS.

I sent a letter to the assistant editor of C\&E News, M. Mitchell Waldrop, in response to his request for my view of which of the talks in my session at ACS, Chicago meeting, is likely to be the most interesting to chemists and chemical engineers in general. I replied that M. Lefort's article ("What is Limiting Complete Fusion Between Complex Nuclei?") might be the most important talk in my session.

I sent in my Referee's Report (attached) on "Search For Superheavy Elements In The Meteorite Mundrabilla" to Inorganic and Nuclear Chemistry Letters (authors: H:-J. Becker, D. Molzahn and R. Brandt).

248 Baisden dropped in about 10:00 a.m. We decided to do 136 Xe plus $\mathrm{U}$.

The Intersectional Proposal for the Nomination of John Oscar Rasmussen for Academic membership in the Sections of Chemistry and of Physics of the National Academy of Sciences has been signed by the five proposers (Gerhart Friedlander, John R. Huizenga, Owen Chamberlain, John A. Wheeler and me) and was submitted today to Dr. David R. Goddard, Home Secretary, NAS. I also sent a letter of recommendation to the UC School of Dentistry for Glenn N. Hori, a student in my laboratory section in Chemistry 1B during the Winter quarter of 1975. I accepted an invitation to present a paper at the symposium on Nuclear Applications to Research in Chemistry at the ACS Spring meeting in Anaheim, California on research on the transactinide elements. Robb Grover, Brookhaven National Laboratory, extended the invitation.

I had lunch in the cafeteria with Michel de Saint-Simon. Shortly after lunch, I met Helen on Hearst Avenue, then she drove me in our station wagon to San Francisco International Airport, where I boarded 
Dr. Alfred S. Goldhaber

Builaing 70, Room 112

LBI

Dear Alfrea:

The are very pleased to receive your letter inviting us to contribute ideas for your AnnuaI Review of Huclear Science article. We look forward to seeing the full article because $i t$ seems that all of the information about relativistic heavy ion (KrI) interactions is spread throughout the literature and no single collection of cata and interpretations exists.

Using the methods we have developed at the superHILAC to study low energy heavy ion reaction products ne have begun a study of RHI interactions that focuses on the target residue. Such prodicts have been generally neglected by most researchers in the RirI field. This is apparent in the term "iarget-apectator" used in the "Fireball Hodel" to describe the target-like fragment producea in the interaction. Our method of identification of the induce $\bar{a}$ radioactivities by garnia ray analysis is particularly vieli suited to the study of the target residues. These fragments are slovi moving in the laboratory frame and, in general, do not escape from the target material. By carefully measuring the secondary contributions to the product distributions we can spen all the reaction processes from a single nuclear knockout to any which leaves a slow moving Eragment with $A>30$. That is we are sensitive to interactions that range from peripheral to those central coliisions wicin do not anninilate the target nucleus. So by careful measurement of the bean (not tririal at tine BEVALAC) ard of the secondary contributions we can determine exactly how many "central" collisions give rise to disintegration of the projectile and target nuclei.

Our first contributions to the Iiterature of the RHI field describe the target-iike production distributions from the interaction of 2.1 GeV/A $12 \mathrm{C}$ with $U$, Au and $P S$ targets. We have enclosed a copy of the phys. Rev. Iett; that describes the ${ }^{2} \mathrm{C}+\mathrm{v}$ work as well as a prepinit of an article describing the ${ }^{12} \mathrm{C}+\mathrm{Ail}$ and $\mathrm{Pb}$ work that has been accepted for publication in physics Letiexs. Longer versions of both these letiers which Cescribe the details of the iorle are presently being peepareä. The most striking new feature of the mass distribution of target like products that we observed was the appearance of 
an excess of products with $A \sim 170$ for the ${ }^{12} \mathrm{C}+\mathrm{U}$ interaction. This bump is clearly not present in the mass distribution of products from relativistic proton reactions with $U$ targets. In our work we have gone on to calculate the sinape of the product distribution for the ${ }^{12} \mathrm{C}$ interactions prior to the statistical nucleon evaporation-fission deexcitation process. We were quite pleased to see that all these prestatisticalequilibriun product distributions look similar for all tiree targets. We now hope to compare these distributions with those predicted by the various interaction models; however, these predictions for the target resiaue have not been forthcoming. It is clear to us, however, that the products we see cannot have survived with the excitation energies commonly talked about by the people studying tine emission of the prompt high energy particles.

Coräially,

Glenn T. Seaborg

GTS/KV

Enclosures 


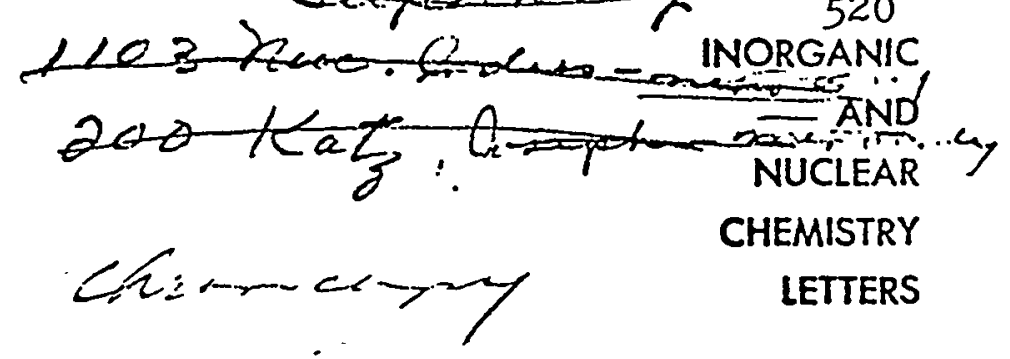

thor: H.-J. Becker, D. Molzahn and R. Brandt

tle:

GEARCH FOR SUPERHEAVY ELEMENTS IN THE METEORITE MUTDRABILIA

\section{$\underline{\text { Referee's Report }}$}

August 16,1977

I believe this is a fine plece of work and is worth publishing.

The possibility of the complete loss of superheavy elements $\therefore$ through volatility is a weakness in the research but the authors point that out.

The authors perhaps give too much credence to the clain for discovery of superheavy elements in the Allende meteorite by emphasizing the difierence in composition of the lundrabilla meteorite, but perhaps this is a Eroper conservative approach.

None of these coments suggest a change in the manuscript. 
TWA \#750, which left at 3:00 p.m. and arrived in Iondon (Heathrow Airport) at 9:15 a.m. on Wednesday, August 17. I took the transfer bus to Terminal 1. Here I met Dermot O'Sullivan, London representative of Chemical \& Engineering News. We boarded British European Airways flight \#804, which left London at 11:00 a.m. and arrived in Warsaw, Poland, at 2:30 p.m. I met Bob Parry as I was boarding the plane. He agreed to appear on behalf of IAC at the ACS Board Finance Committee meeting on Friday afternoon, August 26. We also discussed Bob Cairns's negative attitude on Ed Piret and the need to discuss this with Mariella and Cairns at the Chicago meeting next week. We discussed possible successors to Herman Bloch as Chairman of the ACS Board of Directors next year and tended to favor Mary Good.

After some confusion, in which a IUPAC hostess tried and failed to find Bob Parry, I rode in a IUPAC-arranged car (with a couple the hostess thought to be the Parry's) to the Grand Hotel. I checked into Room 624, went by Room 112 to pick up my allotment of zlotys (660, i.e. 220 per day; $\$ 1$ = about 30 zlotys) then went up to my room.

I then walked to the Palace of Culture and Science, the "Namiestnikowski" Palace (where I attended the Curie Symposium in 1967), about ten blocks away, where I picked up my IUPAC briefcase and packet of papers and met Bryant Rossiter, Jesse Hwa and Bill spindel. We talked about plans for the caucus of the U.S. National Committee (for IUPAC) at $7: 30 \mathrm{a} . \mathrm{m}$. in Room $O$ at the Palace tomorrow and the meeting of the ad hoc committee on the International Chemical Society of the chemical Societies Presidents on Saturday.

I walked back to the Grand Hotel with Hwa. The two of us had dinner in the hotel's restaurant, "Turkusowa," after which I retired for the night.

Thursday, August 18, 1977 - Warsaw

I walked with Parry and Hwa to the Palace of Culture and Science to attend a caucus in Room $O$ of the US National Committee (IUPAC) and young observers. Present were Chairman Bryant Rossiter, Charles Overberger, Robert Parry, Ronald Breslow, R. J. Fawcett, H. Winslow, William Spindel, Jesse Hwa and Dermot O'Sullivan, plus 4 young observers (Michael M. Fisher, Robert M. Gavin, Jr., William C. Harris and Darryl DesMarteau).

We went over the agenda items for the IUPAC Council meeting tomorrow in order to decide how to vote; the National Committee votes as a bloc in non-scientific matters. For membership in the IUPAC Bureau, we agreed to support overberger (US), D. Lavie (Israel), A. R. H. Cole (Australia), J. W. Barrett (UK), Lamberto Malatesta (Italy), J. Michalski (Poland) and C. N. R. Rao (India). We discussed a proposal to form a Division of Radiation Chemistry and I pointed out that this does not meet the requirements of those who want a Division of Nuclear and Radiochemistry. Rossiter said each member of the US National Committee should drop a paragraph to Bill spindel describing the value we found in attending the IUPAC General Assembly in Warsaw.

At 9:45 a.m., Rossiter, Hwa and I went up to the 26th floor to IUPAC President Bob Cairns's office to meet with N. M. Emanuel (Soviet 
Thursday, August 18,1977 (con't)

Union). We told him our plan to have Dzhermin Gvishiani (Soviet Union) as a speaker at the opening plenary session of the CHEMRAWN meeting in Toronto next JuIy. He suggested I phone him and invite him. I told Emanuel about my plan to invite Morokhov to speak at the September 1968 Salzburg Conference on "Internationalization as an Alternative to Proliferation" (he thinks this is a good idea), my plan to give him the medal, etc. for Semenov's ACS Centennial Fellow Award at Uppsala next month for delivery to Semenov (he agreed) and my idea to form an international chemical society (he was enthusiastic about this but thinks it should be an elitist organization). We failed to get the phone call through.

Rossiter, Hwa and I then returned to Room 0 , where Parry had been briefing the group on my idea of an international chemical society. I summarized my views and the three approaches. We found a generally favorable reception. Rossiter also reviewed the status of the Toronto CHEMRAWN meeting. We adjourned at 10:30 a.m.

Rossiter, Hwa, Parry and I went back up to Cairns's IUPAC office again and found that the call to Gvishiani could not be made because they cannot get his Moscow telephone number.

Parry, Hwa, O'Sullivan and I then had lunch in the Adria Restaurant. I briefed O'Sullivan on the dispute over naming of elements 104-105 and on the concept of an international chemical society.

After lunch, we went back to the Palace of Culture and Science, where Hwa went to work on the letter to Gvishiani that I will send inviting him to talk at the Toronto CHEMRAWN meeting. Parry and I then walked back to the Grand Hotel to drop our brief cases, then walked to Srodmiescie (Old Town). As was most of Warsaw, Srodmiescie was completely destroyed during World War II, then rebuilt using the original plans after the war. It is a charming section with many churches and a large town square.

We visited a cathedral, Katedra Domen Bozyon (rebuilt), which had the dates 966-1966 on a rock in front. We stopped to have some orange juice at the large outdoor refreshment stand, situated in the town square opposite the Restaurant Bazyliszek. It was a beautiful day and the place was full of people--every table was occupied.

Parry and I then walked to a nearby area outside of Srodmiescie to the Curie-sklodowska Museum (16 Freta St.). This is a museum with Madame Marie Curie's papers, letters, books, experimental equipment, medals, certificates, family pictures, etc. I visited here on its opening day, October 19, 1967. Parry and I signed the Guest Book, noting on page $1 \mathrm{my}$ signature, along with those of Albert Ghiorso, Arnold Fritsch and Abe Friedman. Although it was 4:30 p.m. when we arrived and the museum closes at 4:00 p.m., we managed to talk our way in. We were shown around by a charming girl, Anna Kroh. Anna has an uncle, George Kroh, who is on the staff of an institute in the field of radioactivity at Lodz. She gave us a packet of pictures. 
After our tour of the Curie-Sklodowska Museum, Parry and I walked back toward the Grand Hotel; we took a taxi the last few blocks. (The taxi driver offered us 110 zlotys per dollar.)

I dropped some things in my room, then took a taxi to the Palace of Culture and Science. Here I joined a CHEMRAWN group, Bryant Rossiter and others, and members: of the IUPAC Applied Chemistry Division, and we rode special IUPAC buses to--of all places--the Curie-Sklodowska Museum as our first stop. Here Anna Kroh led the group in a tour of the museum with explanations of its contents.

The group then rode in the bus to nearby Srodmiescie and walked to the Warsaw Historical Museum (Rynek Starego Miasta 42). Here we heard a concert of old romantic music. The performers consisted of a female pianist, a male violinist and 2 female and 1 male vocalists.

We then walked to the nearby restaurant Rycerska. I met and talked to Heinrich Zollinger of Switzerland (Technische Chemisches Iaboratorium der Eidgenossischem Technischen Hochschule Zurich), who is the incoming Vice President (1977-1979) of IUPAC (and will become President, 1979-1981). I discussed my concept of an international chemical society with him and he seemed favorably disposed. I also talked to W. G. Stoll (Vice Chairman of the Board, Ciba-Geigy AG, Basel, Switzerland) and he seemed favorably disposed toward ICS.

I also talked to Harold Egan of the UK (and President of IUPAC Applied Chemistry Division); he is an analytical chemist and gave me a reprint of one of his articles. He seemed to regard the concept of an ICS favorably. I àlso talked to A. Abou-EI-Azm of Egypt; he is an organizer of the ACS workshop to be held in Cairo in November.

The dinner was hosted by Professor Edward Grzywa, Director of the Institute of Technical Organic Chemistry in Warsaw. The dinner took place at a U-shaped table which included Grzywa, Rossiter and Egan at the head. I sat near Dr. and Mrs. Stoll, Mrs. Anna Frehse and Mr. Frehse (with the Bayer Company in Cologne, Germany), D. Raymond (with Nestle Co. in Switzerland), Ms. M. Wozniak (who works with IUPAC in Warsaw) and Bill spindel.

There was a small band and dancing in the same room, so conversation was somewhat difficult. After dinner, Rossiter, Egan and Grzywa attempted to make some welcoming remarks above the background of voices in another part of the room. Barrett and Hwa also made' some remarks of appreciation for the efforts of our Polish hosts in entertaining us.

The dinner ended at 11:00 p.m. We then rode back to our various hotels on the bus. It had begun to rain by this time. It was after midnight by the time I retired for the night.

Friday, August 19, 1977 - Warsaw

I had breakfast in the hotel dining room with Parry, Hwa and $C$. N. R. Rao (India). I then rode with Parry in a taxi in the rain to the Palace of Culture and science to attend the council meeting of the 29th General Assembly of IUPAC. We went to Warsaw Hall, where the 
Friday, August 19, 1977 (con't)

Council meeting was held. Here I met Georges Smets (Belgium--incoming President of IUPAC), A. R. H. Cole (Australia), Jan Michalski (Poland), J. Bernard (France), J. L. Brocart (France), Stig Claesson (Sweden), Sten Ahrland (Sweden) and Jack Barrett (UK, Negative on ICS, member ICS Committeee to meet tomorrow). Bob Cairns presided in his role as IUPAC President, sitting on the stage with Smets, Guy Ourisson (France-Secretary General), O. Horn (West Germany--Treasurer) and Maurice Williams (Executive Secretary). I sat in the first row with the US delegation--B. W. Rossiter (leader), Ronald Breslow, R. J. Fawcett, Charles overberger, Robert Parry and William Spindel (Secretary to the Delegation). Hwa sat nearby.

Cairns presided and followed the agenda. There was a dispute as to whether Derek Barton, recently moved from UK to France, is eligible to be added by the IUPAC Bureau (as he was) for re-election to the Bureau, this time as a representative of France; Cairns said he will rule on this later. In his "Report of the President" Cairns mentioned my proposal for the creation of an international chemical society, saying that existing national societies and international organizations do not look with favor on my proposal.

During the intermission, I talked to Bozo Tezak (Union of Yugoslav Chemical Societies), who favors the concept of an ICS and gave me a one-page manuscript suggesting liberalization of IUPAC copyright practices. I spoke to Dick P. den Os (Secretary, Royal Netherlands Chemical Society), who said the Royal Netherlands Chemical Society favors an ICS provided it is formed via IUPAC or the Chemical Societies Presidents' group. He said as a representative of FECS at the ICS Committee meeting on Saturday, he will be lukewarm to the ICS concept but as an individual he will support it.

I also talked to $\mathrm{K}$. A. Jensen (Denmark), explaining to him the status of the 104-105 controversy because of his role on the IUPAC Inorganic Division's Nomenclature Committee. I told him I disagree with his Committee's system for naming elements above 105 and described my method.

After the intermission, the meeting continued with the report of the Treasurer (Horn) and Finance Committee (Barrett).

We adjourned for lunch at $12: 30 \mathrm{p} . \mathrm{m}$. I went to Iunch with $A$. Bielanski (Chairman of the Committee on Chemistry of the Polish Academy of Sciences and Leader of the Polish IUPAC National Committee and Professor of Chemistry, Jagellonian University, Krakow--founded in 1364) and Boguslawa Jezowska-Trzebiatowska (a friend from my 1967 visit to Warsaw and wife of the President of the Polish Academy of Sciences). We rode, in a heavy rain, in a Polish Academy of Sciences' car (a Polish-built Fiat), to Srodmiescie (Old Town), where we had a typically heavy Polish meal in the Restaurant Bazyliszek (situated in the town square where Parry and I stopped for orange juice yesterday). We discussed her work on electronic structure of uranium, her visit to Cunningham in Berkeley in the 1960 's, my concept of an ICS (which they like), my proposal for designation of chemical symbols of elements beyond 105 using their atomic numbers, etc. 
Friday, August 19, 1977 (con't)

We returned to the Palace of Culture and science and joined the IUPAC General Assembly in Warsaw Hall, already in session, at $2: 30$ p.m. The presidents of the following commissions made their reports: Physical (R. N. Jones), Organic (Zollinger), Inorganic (Malatesta), Macro-molecular (Overberger), Analytical (West reporting for Tanaka), Applied (Egan) and Clinical (Per Lous).

During the intermission, I talked to Malatesta (he told me the problems of expense made the proposal for a Division of Nuclear and. Radiochemistry difficult to accomplish--he recalled his work with me at Berkeley in 1950), Glynn Michael (he is a member of ICs Committee that meets tomorrow who told me that the plans are to expand the Commission on Analytical Radiochemistry and Nuclear Materials, V7, of the Analytical Chemistry Division, to encompass Nuclear and Radiochemistry--I described the Interciencia Association to him), Georges Duyckaerts (colleague of Jean Fuger of the University of Iiege), Wolfgang Fritsche (he is a negative on the ICS, thinks this might take place in 10-15 years--I said I was flexible but not that flexible), Dieter Behrens (Secretary of the European Federation of Chemical Engineering--he is a negative on the ICS; he thinks action should only be taken on national levels by national chemical societies--I used the Djerassi proposal as an example of a desirable activity that couldn't be accomplished by this method).

We went back into Warsaw Hall and continued with the meeting. Ourisson gave the report of the Committee on Publications; Tezak talked on the need to liberalize IUPAC copyright restrictions (his proposal was referred to the Committee on Publications). The Canadian recommendation for the formation of a Commission on Radiation Chemistry in the Physical Chemistry Division was referred to an Ad Hoc committee for study and report. Cairns then ruled provisionally that Barton can be placed on the list of nominees for the Bureau. We adjourned a little before 5:00 p.m.

I talked further with Malatesta about the nomenclature for elements beyond 105 and described my idea (he said that the use of the atomic numbers gives trouble in indexing and abstracting) and about the concept of an ICS (he is worried about the cost).

We then had a caucus of our National Committee to discuss our vote (an abstention) on item 18, the ratification of minutes, etc.; we decided to change our vote to one in favor. We decided to substitute Barton for Lavie for our slate of seven candidates for the Bureau.

I walked in a heavy rain with overberger and Fawcett to the Forum Hotel, then took a taxi to the Grand Hotel, where I had a bite to eat in the dining room. (The waiter offered me 120 zlotys per dollar.) At 7:00 p.m., I boarded a special IUPAC bus to go to staszica Palace to attend a reception given by the Polish Academy of Sciences. Michalski and Bielanski. were in the reception line as hosts. At 8:00 p.m., we went into an adjoining room to hear a music program by the Warsaw Quartet--Maria Brylanka (first violin), Michael Trojanowski (second violin), Janusz Nosarzewski (viola) and zbigniew Liebig (cello). They played music by Mozart, Moniurzko and Bacewicz. 
Before and after the music program, I met and talked to a number of people. These included R. M. Kunz of Switzerland, who will be the organizer of the 1979 IUPAC General Assembly in Switzerland (he indicated approval of ICS), Tadeusz Urbanski (whom I met at the 1957 IUPAC Conference), S. Nagakura of Chemical Society of Japan and who will represent Japan on the ICS Committee meeting in Cairns's office tomorrow morning (he expressed himself in favor of ICS), Dick P. den Os (I told him about my ancestors who lived in the 1500's on warmoesstraat in Amsterdam), Ahmed Kamel of Egypt (whom I met during my visit to the National Research Council in Cairo in 1965), R. C. Kapoor (University of Jodhpur, Jodhpur, India), Sylviane Raimbault of IUPAC (who had me sign the letter of invitation to Gvishiani in Moscow inviting him to speak at the CHEMRAWN meeting in Toronto), Boris Myasoedov of USSR who has been working on IUPAC business (he said it is somewhat boring work), C. Simionescu of Romania (who was a recipient of an ACS Centennial Foreign Fellow Award, presented to him by Bill Bailey in Bucharest), C. Sandorfy of Montreal, Canada, (who occupied my Latimer Hall office during his stay at Berkeley in 1975), D. Lavie of Weizmann Institute of Science, Rehovat Israel (he reminded me that we met in New York at the ACS Centennial meeting), A. Kjaer of Denmark (he said he favors ICS), Maurice (Mo) Williams (Executive Secretary of IUPAC--whom I met at the 1973 IUPAC Conference in Hamburg) and Ann Troutin (Secretary in IUPAC office in Oxford, England).

Parry and I rode with Mrs. Jezowska-Trzebiatowska in the Polish Academy of Sciences' car back to the Grand Hotel, arriving there about $10: 30$ p.m.

\section{Saturday, August 20, 1977 - Warsaw - Lafayette}

I had breakfast in the hotel restaurant with Ron Breslow, then rode with him to the Warsaw Airport in the Polish Academy of Sciences' car (since my hotel bill was prepaid, I did not have to check out). After an extensive set of checks of passport, Us money report, luggage, etc., we boarded Polish Airlines (LOT) flight \#341, which left at $9: 30 \mathrm{a} . \mathrm{m}$. and arrived in London (Heathrow) Airport at 11:00 a.m. Here we transferred by bus to Terminal No. 3 and eventually boarded Pan American flight \#121, which left at a little before 5:00 p.m., about 4 hours late due to an air traffic controllers' slowdown.

Breslow introduced me to Professor and Mrs. Emanuel Vogel (University of Cologne) on the plane to attend a scientific conference in San Francisco that Breslow has arranged. We arrived at San Francisco International Airport at 7:15 p.m., a little more than 3 hours late. I went through passport and customs control and met Helen, who drove me home. She gave me the bad news that Don cooksey died yesterday.

Dennis Byrne and his friend, Jenny, were at our home. Eric and Ruthie olson had just gone out to pick up some tacos for dinner. They all had attended Clark Bailey-Tricia Nielson's wedding in Danville this afternoon. Dave came late last night and spent the night.

Sunday, August 21, 1977 - Iafayette - Asilomar

I took a hike on the Rim Trail (clockwise) around Iafayette Reservoir. Some 50 or more runners had just finished the "Rim Run" as 
I arrived. I had Iunch with Dave, Eric and Ruthie in the kitchen. Eric and Ruthie planned to go to Las Trampas to take pictures for his article on the Golden Loop Trail.

At a little before 1:00 p.m., Helen (driving) and I started, in the station wagon, for Asilomar, where I was scheduled to give the Keynote Address at the 19th Annual Asilomar Summer Conference of the California Association of Chemistry Teachers on "The Transuranium Elements:"

We arrived at 4:00 p.m. and checked into Room 20 of Whitecaps (Asilomar Conference Center) and immediately met Vic Schmidt, whom we had telephoned from Pacific Grove. We spent about one hour with him in our room. We then went to a reception in scripps where we met Janan Hayes, President of CACT, and a number of other participants in the Conference.: We had dinner with the approximately 160 participants and their families in Crocker Dining Room. We sat at a table with Janan Hayes, Dennis L. Fox and a number of children. Fox is a Professor of Marine Biochemistry (Emeritus) at Scripps Institution of Oceanography. He attended Berkeley as a Chemistry major during 1921-25 and knew all. of the chemistry faculty at that time. He told me that Charles Gilman was a storekeeper in Old Chemistry, Brooks the storekeeper in Gilman Hall, Harry N. Cooper, the curator with an office in old Chemistry, that Cummings had an assistant glass blower, Harold Betts, and that Nelson was in charge of the shops. He said that there is available somewhere an "old solution room book" with the. signatures of many of the people who worked in the College of Chemistry including him.

Among the other people that Helen and I met were Sister Agnes of Immaculate Heart College in Los Angeles (a friend of Yoshi Kadota that we met at the ACS San Francisco Centennial meeting), Robert Keller of the College of San Mateo, Bea Page of Antelope Valley College (who met me at the time of the dedication of the MMRD building in the summer of 1965), and Leigh A. Wilson, a Lynbrook High School teacher of Cupertino, California, who taped my lecture and asked if he might receive copies of my slides.. We also met George Goth who received his Ph.D. in 1971 (under Cerny) and who has been working as a post-doc on identification of element 118 with Art WahI at Washington University at St. Louis.

I was introduced by Janan Hayes for my lecture and spoke for an hour (8-9 p.m.), illustrating with 46 slides. My talk was very well received and was followed by a number of questions, both from the floor and by people approaching me afterward. Helen and I then drove home and arrived about 12:20 a.m. Dave spent the night with us.

Monday, August 22, 1977 - Berkeley

I went over my mail with Pat as soon as I arrived this morning at 8:35 a.m. I then attended the scheduling mepting at Building 88 . Williams was scheduled for $67-\mathrm{Mev}{ }^{1 I_{B}}$ plus $235_{\mathrm{U}}$ to 1 ook for $242 \mathrm{Bk}$ on swing shift Tuesday, May 30 . (She is visiting at oregon State University this week.) I discussed with otto my referee's report for Physical Review Letters on the paper "Reaction between $238_{\mathrm{U}}$ and ${ }^{238} \mathrm{U}$ at 7.24 Mev/Nucleon" by $K$. D. Hildenbrand" et al at GSI. 
I had Iunch in the cafeteria with Otto, Morrissey and de SaintSimon to discuss progress in writing, etc., during my absence in Poland.

At 2:00 p.m., I walked down to Gilman Hall to pick up my campus mail. Soon after my return to my LBL office, I received a call from Tom Martens, Contra Costa Times, requesting an interview for a story on me as a resident of Lafayette. This I agreed to and will meet him tomorrow at 2:00 p.m. I also returned a call from R. J. Alsmiller, who told me that Dr. H. W. Bertini (formerly of the Physics Division at ORNL) is on other work now and therefore Alsmiller will make the Monte Carlo calculations for us on the $25.5-\mathrm{GeV}{ }^{12} \mathrm{C}$ on $\mathrm{Pb}$ reaction (they cannot do the uranium target because their code doesn't handle fission). He will send me the output on this within a couple of weeks and then we can decide whether the information is useful enough for us to suggest that he continue with other systems.

Paul Fields called to say he has found, in Winston Manning's old files, some C-1 Met Lab papers covering the period 1944-46. These are with Robert Hewson in ANI security, bldg. 5, ANI. We made arrangements that I would drop by ANL on Friday, August 26th while I am in Chicago. He also told me that Don Webster is working in the Chemical Engineering Division of ANL.

I talked to Frank Oppenheimer, Director of the Exploratorium, about Jane Kingston's qualifications for a position with them.

I was invited to speak at the Open Forum of the Fourth International Congress of Cybernetics and systems to be held in Amsterdam in August 1978 by $J$. Rose (Blackburn College of Technology, Lancashire, England). Since I have another speaking engagement in California at the time scheduled for the Forum, I declined (Kamen symposium).

I talked to Bernard Harvey to get up-to-date on his contacts to try to get the High Intensity Uranium Beam Iine item into the DOE supplemental appropriations bill.

At 4:00 p.m., I attended the Nuclear Science Seminar in 70A (3377). Catherine Thibault of Orsay spoke on "Mass Measurements and Nuclei far from stability."

I took a hike at Iafayette Reservoir. Helen prepared my dinner and then went in to Berkeley for a YWCA affair. Eric and Ruthie went with her to Berkeley to have dinner with Janet Rosati, then went to Eric's place where Ruthie will stay until she leaves on Thursday to go home to Sanger. Dave returned to his Berkeley place today.

Tuesday, August 23, 1977 - Berkeley

I went by to see Otto and Morrissey to discuss progress on our writing program and to go over the draft of our paper on the search for SHE from the $136 \mathrm{Xe}$ plus $\mathrm{U}$ reaction and its relationship to the $136_{\mathrm{Xe}}$ plus $160_{\mathrm{Gd}}$ reaction.

I had lunch in the cafeteria with Baisden. We discussed the U plus $U$ work at GSI and its effect on her research program. 
Tuesday, August 23, 1977 (con't)

Tom Martens (Contra Costa Times) came to the office for our interview at 2:00 p.m. As background material, I gave him a copy of my biography, the C\&E News editorial "Towards an International Chemical Society" and my Saturday Review article, "Finding A New Approach to Energetics." We covered my work on trails for the EBRPD, my interest in an ICS and the energy problem (including President Carter's views on the breeder reactor, the time scale for the breeder reactor, nuclear fusion, solar energy and the current interest over the "Ioss of uranium"). After the interview, we went to Room 203, BIdg. 70, where Eric Rehkonen (photographer with the Times) took my picture along with Baisden and one with Baisden and Nishida in front of a chemical set-up in the hood. He took more pictures outside of BIdg. 70 and $70 \mathrm{~A}$ and in the office during the interview.

Dan Andes, LBI security, straightened out the misunderstanding regarding my security clearance at Argonne National Laboratory to examine documents pertaining to the Met Iab History. Two people in security at ANL, Mr. Hewson and Bill Shaw, discovered that, through a computer error my security clearance had been dropped. It is now reinstated.

I called Alexander zucker (ORNL) about the high intensity uranium beam project and gave him background on our attempts to get the item reinstated in the supplemental appropriations bill. He said that he will contact John Andelin and will make his approach on the basis of self interest of ORNL in Tennessee. He said that, worldwide, excluding the Soviet Union, there are now about \$250M worth of heavy ion accelerators projected.

During a conversation with Lew Keller (ORNL), I transmitted a message for him from Myasoedov whom I saw and talked with in warsaw. The message concerned information on waste disposal, and Keller believes their waste disposal site is near Dimitrograd (Melekess). I told him that Mrs. Balukwa at the Institute for Physical Chemistry is working on waste disposal. Keller will get word to Myasoedov, during a meeting they will both attend in Toronto, to give me the documents in Uppsala. Keller also told me that Elijah Johnson, of ORNL's Chemistry Division, has African contacts in Nigeria and Kenya who might be interested in an international chemical society.

President Saxon asked me for suggestions of people to nominate for the position of Head of the Office of Basic Research in the Office of the Secretary of the Department of Energy. We discussed a number of people and ways of presenting their names to Secretary Schlesinger. Saxon is a member of a committee of the Association of University Presidents that is concerned with this matter.

Gary Higgins (ILI) said that he would be happy to give a talk at the January 23, 1978 symposium for the 25th anniversary of Es and Fm.

At 4:30 p.m., I went by room 209/70 where de Saint-Simon was describing his research and writing program to Catherine Thibault, who is his boss at orsay. 
I took a hike at Lafayette Reservoir. Helen and I had dinner alone in the playroom watching the news on TV.

Wednesday, August 24, 1977 - Berkeley

next week.

I worked on the material for my talks at the Chicago ACs meeting

I called Tom Martens at the Contra Costa Times at 11:30 a.m. to ask him why the story on the front page of the Times this morning was so different from his stated objective of the interview with me. Tom said that his editor had extracted the portions of the interview that dealt with the missing uranium news story (to coincide with the recent release of news on this subject) and that another story would be run in the Sunday edition dealing with the broader content of our interview. He apologized for this situation and said that he intended to "talk to his editor about it."

Jerry Kent (EBRPD) called me to ask if I would be available to attend the public hearing tomorrow night regarding the Briones/Las Trampas Trail. I told him that I could not attend due to my trip to Chicago tomorrow. We discussed the trouble over the walnut Creek trails, opposition to the Briones/Mt. Diablo trail system, Proposition 2 funding and efforts to get the support of potential users of the trails to attend the hearing. I told Kent I would try to attend the september $\sigma$ hearing at BART headquarters in Oakland.

I declined an invitation from Philip Handler (President, National Academy of Sciences) to participate in discussions regarding the United Nations University on October 24-25, 1977, but suggested he contact Henry Hill.

During the morning, I wrote several letters about my European trip to Gunter Herrmann (West Germany) and Siv Lindkvist, Mr. and Mrs. Carl Tersmeden and Olaf Bloom in Sweden.

The regular biweekly meeting of the SHEIKS was held in my office. Present were Otto, Morrissey, Marsh, Diana Lee, Cynthia Lee, Nishida, Leber, de Saint-Simon, Yashita, Thomas, Sebesta, Somerville, Baisden, Gottstein. Somerville reported on his observation of the 3.8-nanosecond $240_{\mathrm{Pu}}$ from $23 \mathrm{U}_{\mathrm{U}}\left({ }_{\mathrm{He}} \mathrm{He}\right)$ determined by the Decay-in-Fight method. Morrissey reported on his correlation of data on 48 Ca bombardments of heavy targets ( $\mathrm{Ag}, \mathrm{Ce}, \mathrm{Tb}, \mathrm{Pb}, \mathrm{U}$ ); we decided to prepare a description of this for publication. Otto reported on the $U$ plus $U$ results from GSI and their optimistic implications for the production of SHE. I emphasized again the importance of our getting on with a $\mathrm{Pb}$ plus Cf bombardment to look for SHE.

At 3:00 p.m., Barbara Jacak, my student assistant for the freshman cluster group, arrived to talk about plans for the first meeting of the group for Fall Quarter 1977. Barbara will meet with the group in my absence on September 19th or 27th. My first meeting with the students will be on October 4 in the Latimer Hall Dining Commons. We agreed to meet again on september 8th to discuss further plans. 
At 4:00 p.m., I walked up to the HILAC Building to talk to Leber, Cindy Lee and Sebesta. I said goodbye to Leber, who is leaving for Washington in a couple of days to take up his AAAs Congressional Internship.

I went by room $203 / 70$ to talk to Nishida about her future plans; I will see if I can obtain funds to pay her to continue to work for me. She plans to start graduate school somewhere next year. I also talked to Baisden about her summary of transuranium yields found in heavy ion bombardments of actinide targets.

I took a hike at Lafayette Reservoir. Helen prepared a quick dinner for me, then drove to San Francisco Airport to pick up Ben Orlove. They came back at 9:00 p.m. and Ben spent the night with us.

Thursday, Aügust 25, 1977 - Berkeley - Chicago

Ben Orlove had breakfast with us and left soon after.

I talked to otto, Morrissey and Baisden soon after arriving at my office at 8:30 a.m. I spoke with them regarding preparation of slides for my talks at GSI and Marburg. Otto's calculations give optimistic outlook for production of SHE from Cf plus $\mathrm{Pb}$ ions.

Pat-told me about a call from John Fialka (Washington Star) who wants to interview me by telephone regarding the $\mathrm{Z}$. Shapiro/NUMEC episode which took place during my tenure as Chairman of AEC. She told Fialka that I was about to depart on a trip and would contact him in a couple of weeks: She asked him to put in writing the questions he wished to discuss and he will do so before my return from Chicago.

I received a telegram from Lennard Bickel, a writer living in Australia, who wishes to interview me in Paris for a book he is writing. I replied, setting the date on september 19th at the Hilton Eiffel.

I met with Williams at 9:30 a.m. to discuss progress gn her thesis research. She will continue to look for $24{ }^{\mathrm{Bk}}$ and $4 \mathrm{I}_{\mathrm{Bk}}$ from bombardments of $235_{\mathrm{U}}$ with ${ }^{1} \mathrm{I}_{\mathrm{Bk}}$. Her thesis title is "Radiochemical Studies of Actinide Isotopes."

I declined an invitation to speak at Monmouth College's Convocation on September 14, 1977, transmitted to me by President DeBrow Freed. I wrote to Gösta Rudstam (Swedish Research Council's Iraboratory, Nyköping, Sweden) to say that we would be pleased to have Kjell Aleklett come to work at LBL for a year if he should succeed in getting a fellowship to cover his needed support salary.

Eric and Ruthie dropped in at a little before noon and had lunch with me in the cafeteria. We were soon joined by AI Ghiorso. AI is recovering nicely from his hernia operation last week at Peralta Hospital. Eric was confronted with a stripped screw in the rewind mechanism as he was trying to rewind Dave's Nikon camera so we went down to Building 88 where Dick Perkins (a mechanic) succeeded in fixing it. 
I checked there with Ghiorso, Somerville and Yashita who were testing (they have 3 shifts at the 88" cyclotron) AI's new idea for a Gas Transport System (GTS) for collecting recoils from heavy ion reactions.

Eric, with Ruthie, drove by his apartment to pick up Ruthie's things, then we drove to San Francisco Airport where I boarded American Airlines flight \#248, which left at 4:15 p.m. (Ruthie left about an hour later to fly south to visit with her parents at their home in Sanger.) I arrived in Chicago at 10:00 p.m. After a 25-minute wait for my luggage, I took a taxi to the Palmer House. I went to the Towers where I was pre-checked into Room $2351 \mathrm{~W}$.

\section{Friday, August 26, 1977 - Chicago}

I went to Parlor $G$ (on the sixth floor) to attend the 7:15 a.m. breakfast meeting of the ACS C\&EN Editorial Board. Present were Robert Parry (chairman), Gardner Stacy, Bryce Crawford, Mary Good, Anna Harrison, Gordon Nelson, Ernest Eliel, Rodney Hader, Albert Plant, Michael Heylin, Edgar Piret, Charles Kimball (University of Edinborough) and Ernest Carpenter (C\&EN writer). Parry and I emphasized the need for more emphasis on international activities in C\&EN. We adjourned a little before 9:00 a.m.

Piret told me that, during his visit to Paris, he found Kaddoura (a physicist), Sidney Passman (a chemist, formerly of NSF) and Ingmar Eneberg (a chemist from the University of Gottenburg), all of UNESCO, are much in favor of an international chemical society.

I talked to Parry about the meeting of the Ad Hoc Committee on an International Chemical Society held in Warsaw last Saturday (attended by Cairns, Hwa, Parry, Barrett, den Os, Nagakura, Michael and Spindel). Parry said Barrett and Michael were strongly opposed, Nagakura was noncommittal and den os didn't speak. However, there was general agreement that there is a need for additional international cooperation in chemistry.

I then went to Parlor $C$ to attend the meeting of the Board Committee on Education and Students. Present were Gardner Stacy (chairman), Patricia Figueras, Gordon Nelson, Clayton Callis and Moses Passer. We voted to reaffirm to the board the proposed ACS statement on additional modes for scientific research. (I had mildly protested the inclusion of profit institutions but decided to approve the statement subject to further consideration by the full board). We endorsed and approved 1977 funding, up to $\$ 2,500$, for a conference in chemical education for high school teachers to be held in Philadelphia, August 20-27, 1978.

Ray Mariella dropped in to tell us that only $50 \%$ of university chemistry faculty who direct Ph.D. research are members of ACS. I suggested that Mariella give a list of non-ACS faculty members to an ACS faculty member at each university so the ACS faculty member could contact his non ACS faculty colleagues. Mariella will do this. Dave Wetstone joined us at 11:15 a.m. and we discussed the dispute over the role of inorganic chemistry as a part of the core material in the university chemistry curriculum. We adjourned at 12:30 p.m. 
I had Iunch with ACS Board and staff in Parlor B. I sat at a table with Robert Cairns, Robert Henze, Rodney Hader, John Crum, Francisco Marin-Price and others.

I then met Joe Katz on Wabash street and rode with him to Argonne National Iaboratory. In his office, I went over with him the status of the revision of "Chemistry of the Actinide Elements." We wrote to Ahrland of the University of Iund asking him to write Chapter XXI on "Solution Chemistry and Kinetics of Ionic Reactions."

Winston Manning joined us and we went to Don Stewart's office. Don gave me a xerox copy of the personnel records of everyone (in the file) who worked at the Met Lab before the middle of 1946 .

We then went to Paul Fields's office. Mel Friedman gave me a copy of a report by Bansaku Arakatsu on "Yield observation at Hiroshima on the Radioactivity Induced by Atomic Bombs" dated November 25, 1945. Fields, Stewart, Manning, Katz and I went over the AI Florin snapshots of December 24, 1943 to identify as many people as possible. Katz and Fields then drove me to Building 5 to the security area of documents where Guy Van Horn (extension 3803) showed me some documents from Manning's and my file of 1943-46. After Katz and Fields left, I picked out a number which Van Horn will mail to me. Katz then came and drove me back to the Chemistry 200 Building to his office. He gave me four old Met lab pictures which stewart had found for me. Stewart will send me some others. Katz then drove me back to the Palmer House where I arrived about 6:15 p.m. I learned from Parry and Bailey that our IAC items were approved by the Board Finance committee. this afternoon.

I went down to Parlor F (sixth floor) to attend the joint reception and dinner of the ACS Board of Directors and the Committee on Professional Training (CPT). I sat at a table with Polly Newman, Bob Fox, Pat Figueras, Brad Stanerson, Art Campbell, Ed Piret, Bob Neuman and steve Quigley.: Polly brought me up-to-date on the actions of the Committee on Grants and Awards. After dinner, ACS President Henry Hill made some remarks, including reference to the dispute over the CPT recommendation that inorganic chemistry be left out of the university chemistry core curriculum. Harry Gray asked ACS Presidential candidates Bryce Crawford and Gardner Stacy to describe their views on this dispute. E. E. McSweeney and Bill Bailey also made some remarks.

During dinner, Art Campbell told me that Robert Maybury (UNESCO, Scientific Office, Nairobi, Kenya) is in the process of trying to set up an African association of scientific societies and Dean Odhiambo of the University of Nairobi is helping him. He told me Odhiambo is Director General of UNESCO in Paris.

I took a walk in the loop area before retiring.

Saturday, August 27, 1977 - Chicago

I had breakfast in my room, then attended the meeting of the ACS Board of Directors in the Monroe Room (sixth floor). Henry Hill presided in the absence of Herman Bloch who missed the meeting as a 
Saturday, August 27,1977 (con't)

result of his recent heart attack. Present were all members of the Board (except Bloch) and a number of ACS staff and others. Charles Kimball of the United Kingdom also attended. We approved the statement on additional modes of scientific research. Polly Newman (Committee on Grants and Awards) reported that the new directions program (providing PRF research awards to chiefly young chemists engaged in new directions of research) has been started; the Committee recommends that the G. D. Searle Co. be invited to continue to fund the Nuclear Applications Award when the present arrangement expires in 1979.

Parry, in his report for the Publications Committee, said they are considering the possibility of the ACS's becoming a co-sponsor of the European Journal of Chemical Research.

I reported in my role as chairman of the International Activities Committee. My four items were approved:

1. policy with respect to political non-discrimination in international scientific activities (the Taiwan matter),

2. policy with respect to UNESCO,

3. invitation by ACS to serve as host for the 1979 Meeting of Presidents of Chemical Societies and

4. publication of Chemical Education Orientation Guides for Foreign Students (the Brasted proposal).

We adjourned at noon and went to Parlor $\mathrm{H}$ for the reception and luncheon of Board and staff and others. I sat at a table with Newman, Fox, Wetstone, Figueras and Fred Tate. I told Wetstone that Parry will recommend him to George Pimentel for a position with NSF and that I will respond to any questions that Pimentel might pose to me. During lunch, Mary Good gave humorous paper medal awards to Tim Hansen and Bill Butler for their success in getting a tax refund from the IRS.

After lunch, we went-back to the Monroe Room for the Executive Session of the Board. Board members (except Bloch), plus Cairns, and Hader, Wetstone, Mariella and Tim Hansen were present. We decided to submit additional names (besides Arthur Bueche) as candidates for membership on the NSF Board; we should send suggestions to Hader by September 15 .

President Harrison said she intends to work on ways that chemists can serve society, e.g., (1) role of regulatory agencies, (2) international affairs (especially regulatory) and (3) educational component (esperially students). Hill complained about his lack of support from headquarters' staff. Harrison also spoke of problems of dealing with the Department of Chemistry and Public Affairs. As a result of these remarks, I spoke strongly in support of the ACS staff and the fine support they have given me. Parry also took this point of view. others were less positive or less negative in their appraisals.

I then went up to suite 2400 (on the 24th floor), Cairns's apartment, for a meeting with Cairns, Mariella, Parry and vladimir Haensel to discuss the future of the US-USSR Cooperative program on research 
in catalysis. Haensel wants Maria snow to be the Program Administrator, reporting to Gordon Bixler. I told Cairns I will make a decision on this by Monday. This program is supported and administered by NSF through Oren Williams. Haensel is the Scientific Director (replacing Baldeschweiler), and the key members of his team are John stille and John Grubbs (U.C. man).

I then went with Parry to Parlor D, where we met with Bixler, Piret and Elizabeth Bull to discuss the agenda for Monday's meeting of the IAC. (Before this meeting I talked to Alan Nixon who said he will support my international activities program; I suggested enlisting the support of Attila Pavlath also.) We went over the agenda, item by item. I will appoint a subcommittee on the 1979 meeting of presidents of chemical societies--Bailey (chairman), Hwa, Bob Fox (non-member IAC) and Bryant Rossiter (non-member IAC). We also decided to appoint J. Roberto Ramirez (of the University of Puerto Rico) as an outside member of the ICS Subcommittee of IAC; he is connected with a Iatin American Association of Chemical Societies. We may also find tasks for Francis Bonner (Zurich), E. A. Matzner (Monsanto) and H. H. Irwin (Borg-Warner Chemical), who have offered their services.

After this, I met with Ed Piret. He realizes that his consultantship with ACS expires this year when Bob Cairns retires and seems resigned to it.

I had dinner in Miller's Pub (on Adams between Wabash and Mich-. igan) with Joe and Sonia Katz. We discussed some events of the Met Lab section C-I era. Joe and Sonia were married on October 1 , 1944 in Grand Rapids, Michigan (her home town). They met in the Met Lab Library in Eckhart Hall a year or so earlier. Sonia worked as Luther Arnold's secretary for a while, visited us by going through the air lock into New Chemistry (to see Joe) and worked in the same office as Hogness's secretary, who wasn't very busy: Thomas Drugstore was on the NW corner of 53 rd and Blackstone, next to the YMCA that was on the north side of 53rd street between Blackstone and Dorchester. The University Tavern was on the SW corner of 55th and University. Morton's was on the east side of Lake Park Avenue just north of 55 th and Schall's was on the east side a little further north. The Hitching Post (where Helen and I had sweet rolls) was on the north side of 53 rd Street; between Kimbark and Kenwood. on their second trip to Clinton to recover $\mathrm{Np}^{23}$, Magnusson reported to the police that Katz and Walter Beard were missing; actually, they arrived in knoxville on an earlier section of the train. Jonathan Dixon prepared plutonium acetylacetonate. Joe shared a cubicle in room 2 with Isabella Karle. Hagemann also worked in room 2. Katz made an early sample of plutonium iodide. We parted at a little before 9:00 p.m. I returned to my room at the Palmer House.

\section{Sunday, August 28,1977 - Chicago}

At 8:00 a.m., I attended the joint breakfast meeting of the Board Committee on Education and Students and the officers of the Division of Chemical Education in Parlor 5 (third floor). Present were Gardner Stacy. (who presided); Patricia Figueras, Gordon Nelson, Clayton Callis, Moses Passer, R: W. Ramette (Chairman, Division of Chemical Education and with Manufacturing Chemists Association), Henry Bent 
(son of my friend Henry $A$. Bent and at North Carolina State College, and Chairman-elect, Division of Chemical Education), Derek Davenport (incoming Chairman-elect of Division of Chemical Education) and James J. Hazdra (Chairman, Council Committee on Chemical Education). We discussed the proposed conference for high school chemistry teachers, to be held in Philadelphia in August, 1978. Jay Young joined us at 9:00 a.m. I made the suggestion that the ACS take the initiative to start additional annual regional meetings of high school chemistry teachers patterned after those of the California Association of Chemistry Teachers and the New England Association of Chemistry Teachers. I described my experience with the CACT last sunday at Asilomar and my favorable impression. We decided the soon-to-be-established ACS Commission on Chemical Education should take on this assignment. Henry Bent will be a member of this commission and will bring the word to them. I also suggested there should be some incentives for high school teachers to join ACS similar to the SANDS program for high school seniors. I was told the Council Membership Affairs Committee would oppose this. I then went up to my room to do some reading.

I had lunch in the coffee shop at the lower arcade level with Henry Hill. He described to me the piece he is publishing in C\&EN which proposes a $\$ 1$ contribution from ACS members toward an international chemical society. We discussed general progress and problems with the ICS. I also told him about my idea to give incentives to high school chemistry teachers to join ACS.

After lunch, I ran into Bob and Kay Cairns and passed on Helen's greetings to Kay (she will call Helen next Thursday evening while they are in San Francisco en route to Japan to attend the IUPAC Congress). I suggested they have lunch in the coffee shop and I joined them for dessert and tea. We discussed progress and problems with ICS. I then accompanied Bob and Kay to the Art Institute of Chicago where we viewed a Native American Heritage (Indian) Exhibit and French Impressionist painting.

I then walked to the Conrad Hilton Hotel to hear the first part of the so-called Public lecture (the analog of my New orleans lecture) by Theodore I. Cairns (du Pont) on "Surviving the Petroleum Shortage," in Parlor C (third floor). Only about 15 people were present in the audience. The Council Committee on Public Relations, who sponsors this lecture, doesn't know how to do it!

I walked to the Field Museum of Natural History. Here I viewed Bushman (for old times sake) and saw the extensive American Indian Exhibit, dinosaurs, the Chinese Exhibit, display of gems and rare minerals, numerous mounted animals, etc. I bought postcards of Bushman, souvenir rings and a souvenir pen.

I took a taxi back to the Palmer House and went up to my room. I called Howard $W$. Lange, who was curator of New Chemistry and Chemistry Annex in the Met Lab. He is now 70 years old. He started at the Met Lab in June 1942, worked in the pile group until December 1942, then moved to New Chemistry, moved to Chemistry Annex when it was completed 
and stayed there until the move to Argonne site. He remembers he was scheduled to move into the south end of Room 16 (when it was partitioned) but never was allowed to because it was needed for laboratory space; he thinks he. remembers that du Pont people used Room 16 as a training site before Ghiorso moved in. He has two pictures of Chemistry: Annex and will send me copies.

I rode with Stacy in a taxi to the Chicago Sheraton Hotel and went up to the seventh floor. to the general ballroom to attend the testimonial dinner in honor of Ray Mariella given by the Illinois Institute of Chemists and American Institute of Chemists. During the reception, I met and talked to Ernest Thiele (friend from Met Lab days), Warren Lowe (of Chevron Research who thinks he was in my Chemistry 1A laboratory section in 1944), Florence Wall (whom Helen and I talked to at the New Orleans ACS meeting), Helen Free and her husband ( $I$, gave her some tips on how to get people out to the ACS Public Lectures her Committee on Public Relations is sponsoring), David Roethel (AIC Executive Secretary), Ernest Gilmont (he wants some ideas for CSSP meetings)., Ben Luberoff (who said my article for Chem-Tech is being processed) and others. I sat at a table with Bob and Kay Cairns, Rod Hader, Milt Harris and Jim Schoffner (of the Chicago ACS Section). After dinner, Roethel, Hoylande Young and 0 . A. Battista spoke about Mariella-and his career of service, after which Battista presented him with the Illinois Institute Honor Scroll Award and the AIC Members and Fellows Scroll. Mariella then gave his address "Progress on the Professional Front," which was the 43rd AIC Members and Fellows Lecture. Afterward, I greeted Hoylande Young (she sent her greetings to Helen) and congratulated. Mariella, then took a taxi back to the Palmer House with Hader and Justin Collat.

I went to the staff-Board party in Cairns's suite. I talked to Patricia Morgan (Managing Editor of Chemistry who wants me to send her an article), Henry Hill and Polly Newman (who were collecting $\$ 1$ per person to launch the international chemical society), Dorothy Smith (who liked my article on ICS for the New York Journal of Commerce and has made it available to the news media), Art Poulos (who said the tapes on the Physical Chemistry Milestone Symposia, New York Centennial meeting, are selling well) and others. I retired for the night at midnight.

Monday, August 29, 1977 - Chicago

I had breakfast in my room, then walked to the headquarters of Illinois Bell Telephone Company (232 Washington Street). They told me they no longer have old telephone books and referred me to the Chicago Public library ( $425 \mathrm{~N}$. Michigan Avenue). I walked there, went up to the twelfth floor and looked up in microfilm copies addresses for Roy H. Beaton, Spofford G. English, the Hitching Post and Del Prado Hotel. I was interrupted by a fire which made it necessary for most visitors and staff to vacate the Sociology and History Department but I managed to get back in and continue my research. After, I took a taxi back to the Palmer House. I went to Room 783 to attend the luncheon meeting of the ICS Subcommittee of the IAC. Present were Stanley Kirschner (chairman), Minoru Tsutsui, Jesse Hwa, Robert Cairns, Robert Parry and I, plus Gordon Bixler, Edgar Piret and Raymond Mariella. We decided to test a sort of grassroots opinion about forming an ICS by writing 
Monday, August 29, 1977 (con't)

letters with enclosed questionnaire to 100 to 200 active research chemists throughout the world; I will sign the letters which will be prepared in the ACS International Activities office in Washington; the text of the letter and questionnaire will be worked out by Kirschner and Bixler; each of us is to send suggested names to Bixler.

I then went to Room 786, where I presided over the meeting of the International Activities Committee (IAC). Sixteen of the seventeen members were present--Ronald Breslow, Pauline Newman, Robert Parry, Cyril Ponnamperuma, Robert Brasted, Howard Gerhart, Vladimir Haensel, Milton Harris, Jesse Hwa, Stanley Kirschner, William Bailey, Glenn Brown, Ellis Fields, John Sheehan and John Wotiz. Also present for at least part of the meeting were President Henry Hill, Presidentelect Anna Harrison, Bob Cairns, Ray Mariella, Harry Szmant, Francis J. Bonner, David Wetstone, Dick Lemmon (who is acting as Iiaison with the Long Range Planning Committee), Aaron Wold, Fred Wilkes and numerous others. I followed the agenda, starting at 2:00 p.m. and finished at 5:15 p.m. (including a short executive session). We approved a cooperative program in solid state with France, a US-India workshop (like the forthcoming US-Egypt workshop) and a cooperative research program with Sri Lanka; I agreed to appoint Subcommittees for each of these. We approved the program recommended by the ICs subcommittee to write to get opinions of some 100-200 chemists around the world. On the assistance request for Romania, Bixler is to draft a letter for me to send to Ambassador Barnes or Scientific Attaché Sidney Smith to ask for more information as to what they could use that we can realistically send. We turned down a request from John Wotiz that IAC endorse a trip by him to The People's Republic of China to investigate their educational methods (because we do not believe this would be well received by the Chinese). We will draw up a suggested program for the 1979 UN Conference on Science and Technology for Development on the basis of what we learn from the US-Egypt Workshop to be held in Cairo in November (Parry, as chairman of this workshop, will work with Cairns on this program).

I attended the Presidents' Dinner, and preceding reception, in the Red Lacquer Room (fourth floor). President Henry Hill presided. I sat at the head table with Hill, President-elect Harrison, Charles Overberger, Inata Brubaker (ACS Chemistry and Public Affairs Fellow; she heard my seminar at ohio State University in 1961), Bryce Crawford, Raymond Mariella, Ellis Fields, Claude Lucchesi (Chairman, ACS, Chicago Section), Alan Nixon, Gardner Stacy, William Bailey, Pauline Newman and Jordan J. Baruch (Assistant Secretary of Commerce for Science and Technology). Hill gave his Presidential Address, "The ACS and Interactions with Government," illustrated with many historical slides. (In this connection there was, in the Red Iacquer Room, a gallery of large portrait photographs of ACS members who had, over the years, served the government in some capacity; my photograph was included). Hill then introduced Baruch who spoke rather humorously on the subject of "Science, Technology and Government." I sat between Harrison and Overberger and had a long talk with Harrison about what she should do for Presidents' Night next year at the fall ACS meeting in Miami. I suggested she try to get Mike McCormack as speaker, but, if she does, she should start now. She may want to have a science and 
Society symposium (afternoon) followed by a wine and cheese reception. I went up to my room after dinner and soon retired for the night.

Tuesday, August 30,1977 - Chicago

I had breakfast in my room, then walked to the Pick-Congress Hotel (Congress and Michigan Avenues) and went to the Windsor Room. Here I talked to John Willard, Bill Carnall, Dave Karraker, Dan Miller and others. Carnall presided over the opening session of the symposium, on Radiation Effects in Honor of John E. Willard, sponsored by the ACS Division of Nuclear Chemistry and Technology. After opening remarks by Carnall, he introduced me and I spoke for 20-25 minutes on "John E. Willard: Pioneer Nuclear Chemist," illustrated by 23 slides. My talk covered his Met Lab and Hanford days during the period 19421945, some comments on pre Met Lab correspondence with him, his June 1945 letter to me from the Olympic Hotel in Seattle and the Symposium on the 25th Anniversary of the Weighing of Plutonium (Sept. 10, 1967 ).

After my talk, I spoke further to John Willard (he wants copies of the letters. I showed on my slides) and to Dan Miller ( I asked him to try to get the LBL High Intensity Uranium Ion project into a FY78 supplemental). I also talked to Earl Hyde and Dick Hahn. I then went to the Buckingham Room and heard part of the paper by Joe Cerny on "Initial studies with the on-Iine Mass Analyzer System RAMA." Afterward, I walked back to the Palmer House. I met Peter Gray. He is now working with Phillips Petroleum in Bartlesville, oklahoma, in charge of analysis. His Aunt Dorice Brown lives in Detroit.

I went to Parlor $G$ to sit in on the last part of the morning session of the meeting of the council Policy committee. I then went to the Committee lunch in Parlor $\mathrm{E}$. I learned from Mariella that he has set aside some money in his budget for my use as chairman of IAC to cover travel expenses of special envoys, etc. I sat at a table with Hill, Cairns, Jay Young, William Sheppard, Pauline Newman and Fox. Newman told me that, as chairman of IAC, I will be asked to suggest names of 3 members, of which one will be chosen, for membership on the new ACS Science Commission; she thinks I should include my name among the three nominees.

I took a taxi to the Hyde Park area. At Hyde Park Boulevard (51st Street), just east of Blackstone, the closed Picadilly Theater is apparent, but there is no sign of Isbell's Restaurant (there is a restaurant just west of the Picadilly, the area east is occupied by what seems to be new buildings). I walked to 53rd street and Hyde Park Boulevard (which turns $90^{\circ}$ toward the south just east of the I.C. station) to check the Del Prado Hotel, which is on the SE corner of Hyde Park Boulevard and 53rd street; it is now a rather seedy place. I walked west on 53rd Street; on Harper Avenue, just north of 53rd Street on the west side of the street is the "Hyde Park Theater." This is apparently the former Harper Theater. The former Hyde Park Theater, on Lake Park Avenue, has disappeared because Lake Park has been widened to a boulevard with grassy areas on each side. I continued west on 53rd street, going one block to the corner of 53rd and Blackstone. There on the $\mathrm{NW}$ corner is "The Great Frame Up," a picture framing business, that looks as if it could have been the Thomas Drug store (it still has that kind of an entrance). I continued west on 
53 rd street and in the block between Blackstone and Dorchester, on the north side of the street, still stands the Hyde Park YMCA (1922 AD). I continued walking west on 53rd. Between Kenwood and Kimbark Avenues (nearer Kenwood) on the north side of 53rd, at the spot corresponding to 1342, is a parking lot for a McDonald's which is just west of the parking lot. The area between kimbark and Woodlawn on the north side of $53 \mathrm{rd}$ is now a wide Kimbark-Woodlawn shopping Center and Kimbark is blocked off. Also the area where Kimbark Avenue used to be between 53rd and 55th is now a huge Chicago City Park. I walked to Woodlawn Avenue, then south past 5418 woodlawn which is unchanged. I walked to Woodlawn and 55th street. OnIy the wartime store building on the NW corner still remains (a cleaning establishment). 55th street is now a wide boulevard with wide open space on each side and new tall buildings. I walked further south on Woodlawn, then took a taxi past 6128 Woodlawn (still there unchanged), the drugstore at 61st (?) 62nd (?) and Woodlawn (NE corner) is gone (open space at 61st, huge old-looking building at 62nd.) The taxi proceeded to $63 \mathrm{rd}$ street, then headed east; the remaining buildings here are all boarded up and by the time one reaches Dorchester the buildings have disappeared and it is all open space. However, the Elevated Train is still in operation.

I took the taxi to the Chicago Public Iibrary, where I found, in the Classified Directories (Red Book, on microfilm), under. Drug Stores, the entry "R.W. Thomas, 1426 E. 53rd," in the September 1943 and March 1944 editions; this address seems to correspond to 53rd and Blackstone. I looked up the Hitching Post in the March 1943 Classified and found the entry "Hitching Post, Waffle-omelet-flapjack-open all night," at address 1342 E. 53rd Street. However, there was no Hitching Post entry in the september 1943 Classified book, and, in the March 1944 and September 1944 classified books there were Hitching Post entries for $1552 \mathrm{E}$. 57th street but none for $1342 \mathrm{E}$. 53rd street (1552 E. 57th Street would be close to lake Park Avenue). I took a taxi back to the Palmer House.

I attended the reception for new members in the Chicago Room (lower level arcade), met many new members talked to John Nelson, whom I met when he was chairman of the Sierra Nevada ACS Section at Asilomar in January, 1975.

I had dinner at Miller's Pub (on Adams street) with Alan Nixon and Cheri $W$. Nelson (Ashland Chemical Co. and member of the ACS Younger Chemists's Committee). I described to Cheri my ICS proposal and my suggestions regarding high school chemistry teachers. She may bring these ideas to the attention of the Younger Chemists' Committee.

I spent the evening in my room going over my material for my talk to the Miller symposium tomorrow.

Wednesday, August 31, 1977 - Chicago - Lafayette

I had breakfast in my room, then went to the Ballroom to attend the meeting of the ACS Council. Before the meeting started, I checked with Bixler on my appointments to the three IAC subcommittees: (1) Cooperative solid state program with France (Sheehan, chairman, Aaron Wold of Yale and Neil Bartlett), (2) workshop with India (Ponnamperuma, chairman, Bailey and Brasted) and (3) cooperative research 
Wednesday, August 31,1977 (con't)

project with Sri Lanka (Ponnamperuma, chairman, Bailey and Brasted). Bailey has been informed and has accepted; the others will be contacted by Bixler. (I offered Bob Fox membership on the 1979 Presidents' meeting subcommittee of the IAC and he accepted). I also checked with Bixler on the appointment of Francis Bonner, Henry Hill and Bob Cairns to the ICS Subcommittee. We agreed to set september 14-15, 1979 as the date for the meeting of Chemical Society Presidents in Washington.

The Council meeting began at 8:45 a.m. President Hill presided and the agenda was followed. In his President's report, Hill referred to his visit to Cologne where he talked to Professor Vogel (after which, coincidentally, I met Vogel on the airplane on my way back home from IUPAC meeting in Warsaw). I stated that I had no oral report to add to my. written report (attached) as Past President which was printed in the council agenda. Mariella read a resolution of commendation for retiring Bob Cairns which was passed with a standing ovation.

I left the council meeting at 10:15 a.m., took some papers to Bixler in the International Activities office, for mailing to me in Berkeley, checked out of the hotel (by signing my bilI), took a taxi to the Pick-Congress Hotel, checked my bags and went to the Buckingham Room to hear the last papers in the morning session of the $J$. M. Miller Symposium on Nuclear Reactions. I talked to Leo Yaffe, agreeing to speak on the early history of fission, transuranium elements, etc., at the symposium in honor of Soddy at McGill University in November. I also saw Iuther Arnold, who passed on warm regards to Helen. He said his sister went to Russia as planned.

I. walked back to the Palmer House and went to the state Ballroom to join the sandwich Iuncheon of the council members. I sat at a table with Elliot Pierce, Bob Fox and Bob Cairns, joined later by Polly Newman. She wants me to consent to stand for election as Chairman of the soon-to-be-created science Commission. She said, if I would do this, she and Bob Fox would do as much of my work as I wished, I might have Deputy or Vice Chairman, a good ACS staff man could be assigned to the Commission (perhaps Mike Passer) and there would only be two meetings a year (at the time' of the national ACS meetings); I told her that, under these circumstances, there is a 50-50 chance I would accept if offered the position.

I talked to Peter Lykos who wants ACS IAC sponsorship of an ongoing but sporadic series of US-Soviet conferences on computer usage; I told him to send his requests to me via the IAC in the National ACS office in Washington. I then met with David Wetstone, this year's Vice Chairman of CPC, and Arthur Hale, former Vice Chairman of CPC; we constitute the statutory committee to nominate two candidates to be Vice Chairman of CPC next year; we chose Dick Iemmon and Bob Fox.

I then walked to the Pick-Congress Hotel and met Professor Hyuk $\mathrm{Yu}$ of the Department of Chemistry; University of Wisconsin, who wants a copy of my remarks on John Willard delivered yesterday; I don't have a written text but will send him copies of my slides. I then went to 
Page 1 of ITEM III, $C$

Past Pres.

Report

\section{REPORT OF IMMEDIATE PAST PRESIDENT}

I am reporting to you in a dual capacity today--as Immediate Past President of the Society and also as cheirman of the Joint Board-Council Comnittee on International Activities. The International Activities Committee's refort appears later. in these pages, and it is inevitable that there should be some duplication between that report and this one. However, here I want to emphasize chemistry's international nature and why and how we should improve international exchanges amorg chemists. Accordingly, I have chosen to discuss three of the committee's projects which also are covered formally in its report..

As I wrote in Trends in Biochemical Sc:iences last October, "I do not share the pessimistic viev: of the future that seems to be in fashion. It is a view trat skows too little faith in the power of knowlecige and in the potential for mankind. The world is demonstrably a better place than it was a century ago, and comparable progress can be made in the century to come. The key is broad aissemination ard humane, intelligent application of knowledge of all kinds. The achievement of such a goal in a world that is evolving steadily toward a social and physical whole will require international teamwork of many kinds at many levels. In fostering this teamwork and in building confiderce in the power of knowledge, the. worldwide technical commurity is in a sound position to take the lead."

Internaticnal cooperation among scientists produces both scientific and cultural benefits. In 1973 while chairman of the board of the American Association for the Acivancement of Science, I called for AAAS to expand its international activities. One concrete result was the formation that year of Interciencia Association, which is a federation of associations for the acivancement of science in North and South America. Last year, Interciencia Association began publishing a journal, Interciencia, in Spanisf, Portuguese, and English, and the Association in this and in other ways is increasingly fostering interchanges amorg scientists in the Americas.

Organizations such as Interciencia Association serve regions and many different disciplines. When we focus on chemistry, we also car see an impressive network of international ties. They range from multilatero.I ties through the International Union of Pure and Applied Chemistry to bilate:ral ties slich as those the ACS has with The Chemical Society anci the International

Dokumentationsgesellschaft für Chemie with resp:ect to Chemical Abstracts. What we do ncit yet have for chemistry, however, is an international organizotion based on individual membershi.ps. In recent months, therefore, I have beeri suggesting that formation of an International Chemical Society be ex:plored. The suggestion has evoked a generally favorable response, and I have been par- 
Report

ticularly pleased that last fall, tre ACS's International Activities Committee appointed a subcommittee to investigate and report on the possibilities.

This subcommittee, under the chairmanship of Dr. Stanley Kirschner of Wayne State University, has drafted proposals for several ways in which an International Chemical Society might be formed, including starting from scratch, building on the biennia meeting of chemical society presidents that Dr. Charles Overberger initiated when he was ACS president in 1967, and modifying the structure of the International Union of Pure and Applied Chemistry. The subcommittee's ideas have been discussed with the presidents of chemical societies, who met this past June, and with IUPAC officials during IUPAC's meeting in mid-August.

An International Chemical Society would certainly. number among its activities the publication of an international journal of chemistry and holding. international chemical conferences In addition to other typical scientific society activities, however, an especially effective activity would be for an Internationa Chemical Society to serve as a focal point for helping developing countries with projects that would hasten the development of chemical research and the application of chemistry in such countries.

Another project of the ACS's International Activities Committee is a prime example of such an international effort. Somewhat more than a year aজo, Prof. Carl Djerassi, in an article in the Bulletin of the Atomic Scientists, noted that scientific societies in developed countries have done very little to improve research in their disciplines in developing countries. He: also noted that the: gap in scientific research and competence between developed and developing countries is wideining rather than narrowing. He therefore propcsed that scientific societies in developed countries should join in a common effort, select a few developing countries as a start; ard each comrit itself to support for a meaningful period ore of its country's outstanding scientists to direct a research project jointly with an experienced scientist in the selected developing country or countries.

An IAC subcommittee, under the leadership of Dr. Pauline Newman of FMC Corp., is seeking to initiate such a program among. chemical societies of developed countries. The program it envisions would operate as follows:

1. Cooperating chemical societies in developed countries would seilect one developing country in which to start the program.

2. Each developed country cher:ical society would select the outstanding scientist from its country and secure his agreement to participate in the program. 
Page 3 of ITEM III,C Past Pres. Report

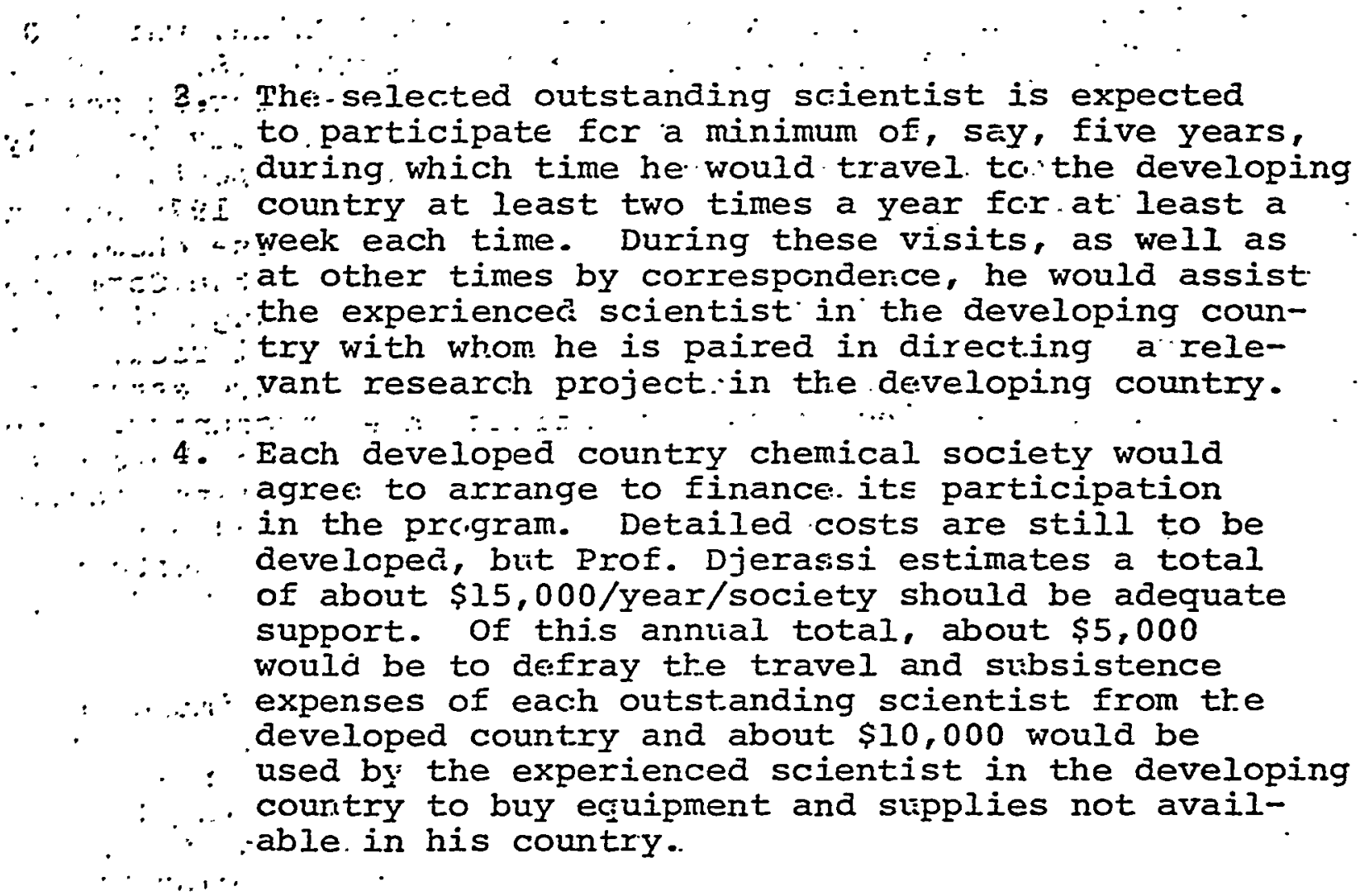

If there were an International Chemical Society, such project would be natural for it. Since no such orcanization ists, the ACS is attempting to form ari informal group of chemi-. 1.societies. to undertake the froject. . The main need at this ne is for a sufficient number of chemical societies in developed untries to commit themselves to. the program and to agree to rancie financial support. for their participation. Once those nmitments, and agreements have been made, the necessary next eps can then be taken to select the developing countries, to nd the outstanding chemists from developed countries who would ree to become part of the program, and to secure the cooperaon of universities in the selected developing countries.

Shculd the project succeed, there will be benefits bead those to the participating developing countries, since such ternational cooperation amorg chemical societies could well $t$ into the concept of an international chemical society.

In: another effort to improve international exchanges ong chemists, several of my colleague:s on the International ivities Committee and I have been working closely for some ne now with the Committee on Scholarly Communication with the Jple's Refublic of China to increase contacts between chemists the People's Republic and the U.S. I was fortunate in 1973 be a member of the first delegation of scientists who visited ina to discuss arrangements for future group visits under the ims of the agreement between this Committee and China's Scieniic and Technical Association. By the end of this year, 23 
groups of American scientists will have visited̀ China, while 30 groups of Chinese scientists will have visited the U.S. Chemistry has been represented twice in these 53 exchanges--steroid chemistry and biochemistry from the U.S. in 1976 and catalytic, polym! and analytical chemistry from China thj.s year. Prospects for having an American group of chemists included in the 1978 exchang' are promising in. light of this year's visit by Chinese chemists. Probably more important for the future, however, is the committee on Scholarly communication's plan to negotiate a change with the Chinese that would expand the: present program of reciprocal group visits to one in which cooperative relations are establishe and continue between individual scientists in each country. The reception and luncheon that IAC gave (as described in the committ report)-and indeed the hospitality the chinese chemists received throughout their month-long tour--should he.ve advanced our relationships with chemists in China a great deal, and substantive scientific cooperation between chemists in Chine: and the U.S. is now a much more likely prospect.

Forming an International Chemical Society, improving chemical research and competence in developing countries, and increasing contacts between chemists in the U.S. and in such countries as China are only three of the projects on the International Activities Committee's agenda. As I noted at the beginning, IAC's programs are discussed in more detail elsewhere among these reports to the council. They are part of the societ overall effort to fulfill its charter objectives, which may be generally summed up as to advance chemistry in all its aspects. Equally important, however, these and the society's other international activities complement the general U.S. national policy of improving understanding among countries and peoples. Much. of the national effort involves numerous assistance and exchange programs that function on a government-to-government basis. As the State Department's Bureau of Educational and Cultural Affais has observed in one of its publications; however, "The tone ar:d content of U.S. .... relations are set increasingly by the greatly expanded informal contacts which occur between American: and othe:r peoples. To an unprecedented degree, the problems which governments confront, the means they choose to resolve them, and the perceptions one country has of another evolve out side official channels." Cooperative rese:arch projects formed and administered by the ACS, programs of technical consultation using the experience and knowledge of ACs members, and fosterin the international exchange of chemical technology can each be numbered among such informal contacts and thus.contribute impor tantly to improved international-relations:

\section{Glenn T. Seaborg}


the Windsor Room and talked to John Willard. He told me Adelaide is with him here, but I missed seeing her. They, too, have no grandchildren yet. I also saw Leonard Katzin; they have four grandchildren.

I then went to the Buckingham Room where I was scheduled to be Chairman of the second, afternoon, session of the J. M. Miller Symposium on Nuclear Reactions. I started the session on time at 2:00 p.m. and followed the planned program (program attached). As the last speaker I spoke on "The Reactions of ${ }^{48} \mathrm{Ca}$ with Medium and Heavy Mass Targets," illustrated with 16 slides. The session ended at 5:15 p.m. I took a taxi to O'Hare Airport, boarded United Flight \#135, which left at 6:50 p.m. and arrived at San Francisco International Airport at 9:00 p.m. I was met by Helen and Dianne (who had just returned from Washington on United Flight \#57).

The three of us drove to Dennis Byrne's place (he is now in law school) in San Francisco to pick up Eric, who had had dinner with Dennis. Eric rode home with us. He has moved out of his Oakland apartment and will stay with us until his departure for Europe with me on September 12.

Helen told me that Jeanette called to tell us that David Clauss, 12-year-old son of Lloyd Clauss (son of my cousin Ethel Clauss), was killed on Thursday in an accident in Saudi Arabia. Dianne told us that, during her visit to Washington, she and Bob Puppa (20-year-old brother of Pete's friend, Bill Puppa) have fallen in love. Helen told me that Ty Jenkins returned home on a Monday night plane nearly a week ahead of schedule.

Thursday, September 1, 1977 - Berkeley

I went over my accumulated mail with Pat quinn upon arrival at my LBL office.

In the late morning, I went by room $203 / 70$ to show the letter from Harry Gove, associate editor for nuclear physics of Physical Review Letters, rejecting for publication our article "Lowered 5 usion Cross Section in the Quadruply Magic Heavy Ion System, ${ }^{4} \mathrm{Ca}+{ }^{208} \mathrm{~Pb}$." We also discussed progress in writing our papers, preparation of slides, etc. I talked to Baisden in room 204; she is finging, as a result of her analysis of data, some cross sections for ${ }^{248}$ Cf, etc., in old samples from heavy ion bombardments (48 $\mathrm{Ca}$ plus U). She is also preparing some summary slides for me giving yields of actinide isotopes from heavy ion bombardments.

Robert Silva started to work in the new Earth. Sciences Division today. I had lunch in the cafeteria with him, Nitschke and Baisden.

After lunch, I talked to Otto to suggest that Carolyne Gottstein, who has been working with him recently, should not take Chemistry 194H with me next quarter; she has not been working with the energy and enthusiasm consistent with continuation after so many quarters in the past.

I received a letter from Carl Johan Herrlander, Research Institute of Physics, Stockholm, Sweden inviting me to stay in the Insti- 
Division of Nuclear Chemistry and Technology

$$
\begin{aligned}
& \text { A. M. Poskanzer, Chairperson } \\
& \text {.T. T. Sugihara, Secretary }
\end{aligned}
$$

WEDNESDAY AFTERNOON

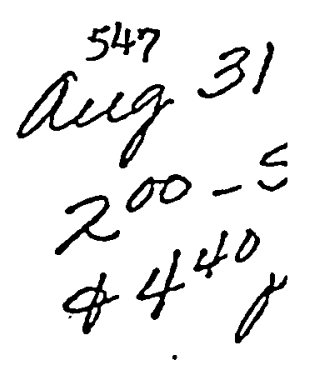

- Section A

J. M. Miller Symposium: Nuclear Reactions

G. T: Seaborg, Presiding

2:00 - 56. Charged Particles Emitted in Reactions of $720 \mathrm{MeV}$ ${ }^{86} \mathrm{Kr}$ with Au.. J. Miller, D. Benson, G. Catchen,

I. Kowalski, D. Logan, N: Lu, J. Alexander, T. Debiak,

M. Rajagopalan, M. Kaplan, M. Zisman.

2:25 - 57. Coincidence Studies for ${ }^{4}$ He and Heavy Products from Reactions of $720 \mathrm{MeV}{ }^{86} \mathrm{Kr}$ with Au. J. Miller, G. Catchen, D. Logan; M. Rajagopalan, J. Alexander,

$=$ M. Kaplan, M. Zisman.

2:45 - 58. Monte Carlo Calculations as Compared to Experiments for ${ }^{4} \mathrm{He}$ Emission. from Reactions of $720 \mathrm{MeV}{ }^{86} \mathrm{Kr}$ with Au. J. M. Miller, D. Logan.

3:05 - Intermission.

3:10 - 59. Formation and Decay of $194 \mathrm{Hg}$ at High Excitation Energy. J. Miller, D. Logan, G. Catchen, I. Kowalski, M. Mokiahä, M. Rajagopalan, J. Alexander, M. Kaplan, J. Ball, M. Zisman.

3:30 - 60. Coincidence Stuaies of Heavy Fragments Formed in Reactions of $720 \mathrm{MeV}{ }^{86} \mathrm{Kr}$ with Au.' J. Miller, D. Logan, I. Kowalski, G. Catchen, M. Rajagopalan, J. Alexandex, . M. Kaplan, M. Zisman. 
Wednesday Afternoon, Section A, continued.

3:50 - 61. What is Limiting Complete Fusion between Complex Nuclei? M. Lefort.

4:40 - 62. The Reaction of ${ }^{48} \mathrm{Ca}$ with Medium and Heavy Mass Targets. G. T. Seaborg, D. J. Morrissey, W. Loveland, R. J.- Otto, D. Lee. 
tute's guest apartment September 21-22 while I am in that city to lecture at the Institute. I wrote Dr. Herrlander to accept the invitation. I mailed the nominating letter for Sergei Polikanov for the 1978 Tom W. Bonner Prize in Nuclear Physics to Gerald T. Garvey, Argonne National Laboratory. I also wrote to V. Druin (Joint Institute for Nuclear Research, Moscow) to thank him for information on Polikanov.

At 4:00 p.m., I went up to the cafeteria to attend the reception honoring Raymond wakerling on his 35th anniversary of service to LBL.

Dick Diamond dropped in at 5:15 p.m. He has just returned from his seven-month sabbatical in Australia and his subsequent fifteen-day visit to The Peoples' Republic of China, on which he was accompanied by his wife, Marian, daughter, Cathy (who speaks Chinese), and John and Louise Rasmussen.

I took a hike at Lafayette Reservoir. Eric went to Marin. The Marin Energy Examiner (newspaper) appeared today. He is the co-editor and has worked on it off and on during the last month or two.

Friday, September 2, 1977 - Berkeley

I dictated several letters early this morning to: Sidney Passman (UNESCO, Paris) to get an appointment with him during my upcoming European trip; Leo Yaffe (McGill University, Montreal) regarding my speech during their Soddy Centenary in November 1977; Robert $H$. Maybury (UNESCO Regional Office of Science and Technology for Africa) regarding the establishment of an international chemical society, including reprints of articles on the subject of US/African cooperation; David Eckroth (John Wiley \& Sons, Inc.) with corrections for "Actinides and Transactinides;" Philip Powers (Purdue University) regarding my acceptance to membership on the Council of New Directions; and John Willard (with copies of letters containing information for the Met Lab history written in 1944 and 1945).

I spoke with Marian Reeve at 10:00 a.m. regarding the environmental impact report of the EBRPD. Sue watson is drafting a letter for me. Sue called me at 10:30 a.m.; Roger Reeve will stop by with the draft letter today.

At 11:00 a.m., I went to room 204/70 to talk to Baisden about her latest calculations of her data on actinide yields, then to room $203 / 70$ to talk to otto and Morrissey about a possible paper we might write correlating yields from the various kinds (quasi-elastic, deep inelastic, complete fusion) of heavy ion reactions, then to room $209 / 70$ to discuss with Williams her evidence for the new isotope $242_{\mathrm{Bk}}$, from $11_{\mathrm{B}}$ plus $235_{\mathrm{U}}$.

I had lunch with Pat Quinn. Roger Reeve came by at 1:30 p.m. with the draft letter from sue Watson. It was typed and mailed today.

At 2:00 p.m., Dave Templeton came by to pick up the extra gown I got from Public Ceremonies for his use at the Uppsala 500th Anniversary Convocation. 
At 3:00 p.m., I walked up to the HILAC Building to talk to Cindy Lee ( $I$ gave her some souvenirs from the Field Museum--a ring and pen), Sebesta and Nitschke.

At 4:00 p.m., Jerry Kent of EBRPD returned my call. He wants me to attend the EBRPD Board meeting next Tuesday afternoon to speak for the Land Use Development Plan for the Briones to Las Trampas Trail. on this matter, I sent a letter to K. D. McCloskey, Chairman, Environmental Committee, EBMUD, regarding the "Final--Environmental Impact Report on the Reclassification of the Temporary Emergency Distribution Facilities in the Oakland-Berkeley Hill Area," expressing the views of some of us in CUWA (attached). Copies were sent to Helen Burke, Roger Reeve, Thomas Bowman, Joyce Burr, Susan Watson, Robert Witser and Assemblyman Thomas Bates.

I was shocked to learn from Mrs. W. Q. Smith (when I placed a call to " $Q$ " to ask him a question regarding my Met Lab section C-I book), that " $Q$ " had been seriously injured in an automobile accident. He has been holding his own, and Mrs. Smith said that his vital signs were good.

At 4:15 p.m., I went to room $203 / 70$ to confer with: otto and Morrissey about oyr october bombardments at the SuperHILAC and the revisions of our ${ }^{48} \mathrm{Ca}$ plus $\mathrm{Pb}$, paper and progress on other papers; with Thomas about his chemistry to separate $\mathrm{Am}, \mathrm{Cm}$ and trans $\mathrm{Cm}$ fractions to look for new beta emitters from $248 \mathrm{~cm}$ plus heavy ion bombardments; with Baisden and Nishida about calculations and interpretations of yields of $A c, T h, U$ and trans $U$ isotopes from $U$ plus various heavy ions.

I took a hike at the Lafayette Reservoir. Helen, Eric, Dianne and $I$ had dinner in the kitchen.

Saturday, September 3, 1977 - Lafayette - Brookdale ?

Helen and I had breakfast at home. With Helen at the wheel, we left at 9:15 a.m. and drove, via Highways 680 and 17, to Los Gatos, then via Saratoga to the parking lot of Castle Rock State Park on Highway 35 (Skyline Drive). We hiked to Castle Rock and continued on Castle Rock Trail to the waterfall platform (the waterfall: was dry), then back to our car where we had our picnic lunch.

After lunch, we hiked on Castle Rock Trail to Castle Rock Camp, then on a road up to Highway 35 and across, finally on Summit Rock Trail (on Santa Clara county Park property) back to our starting place. This loop hike was a total of about six miles. Across Highway 35 from the Castle Rock state Park parking area there are a number of trails on Santa Clara County Park property. One of these is the Skyline Trail running parallel to Highway 35. About 2 miles south, Skyline Trail connects with Sanborn Trail which goes 3 miles down the mountains to Sanborn Park (a county park). To reach Sanborn Park by car, drive off Highway 9 on Sanborn Road; Sanborn Road comes into Highway 9 just opposite Saratoga Springs Resort which is about 1/3 the way, on Highway 9, from Saratoga to Highway 35. After our hike, we drove back to Highway 9, then on Highway 9 to Brookdale, where we checked into Brookdale Lodge (Room 30). 
Mir. K. D. Mccioskey

Chairman, Environmental Committee

P. O. Box. 24055

Oaklana, California 94623

Dear Hr. icCloskey:

This letter is to acknowledge the receipt of the document entitlad, "Final - Environmental Impact Report on the Reclassification of the Temporary Fmergency Distribution racilities in the oaklandBerkeley nill Area" by various nember grouss of Citizens for Urban wilderness Areas (CUWA).

At this time, we have met once on the subject of this Report and shall mest sevaral more times for consultation iith ourselves and with others before your scheduied hearing date.

Te are gravely concerned over the procalural irregularities and the slibstantive errors and inconsistencies contained in your documents entitled "Draft" and "final".

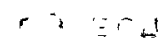

CurA and its menber organizations expect to be in further correspondence with you berore the hearing date and sizali speak at the hearing.

Sincerely,

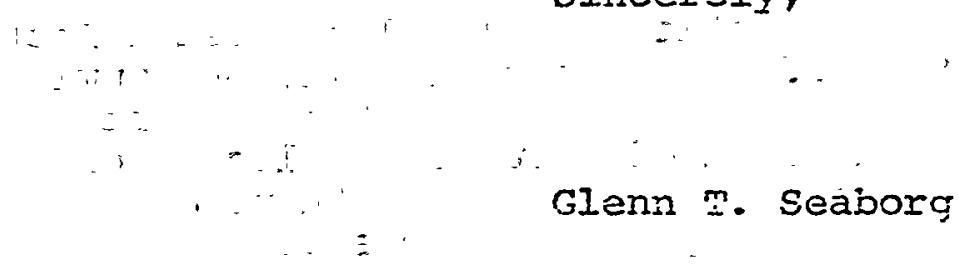

cc: Mr. John Harnett; General Manager, IBHUD

MIr. C. R. Hitchcock, Presilent, Boara of Directors, EBEUD 
We had dinner in the Lodge Coffee Shop - a very reasonably priced meal. After dinner, I dictated to Helen the text for my talk "John $E$. Willard - Pioneer Nuclear Chemist" to meet the request of Professor Yu of the Department of Chemistry, University of Wisconsin.

Sunday, September 4, 1977 - Brookdale, Santa Cruz Mountains

Helen and I had breakfast in the Brookdale Lodge Coffee Shop, then drove on Highways 9 and 236 to Big Basin Redwoods State Park. Here we hiked on Howard King Trail (about 6 miles including a good climb and several portions of the hike on the Hihn Hammond Road) on to Lower Berry Creek Falls (which had a good flow of water). McAbee Mountain Overlook (also called Carl I. Wheat Overlook) on the Hihn Hammond Road includes a view of the Pacific Ocean at the place where Spanish explorer Portola camped in 1769 (and was the first European to look up the Redwood-studded watershed).

We had our backpack lunch at Lower Berry Creek Falls, then hiked on the Berry Creek Falls Trail about 5 miles, back to our starting point at the parking lot. Helen bought some redwood bowls, etc., for use as gifts.

We drove back to Brookdale and managed again to find lodging at Brookdale Lodge (this time in Room 33). We again had dinner in the Lodge Coffee Shop. We spent the evening reading in our room. We had to rearrange the furniture in order to find adequate light from the single lamp.

[Today's Contra Costa Times carried the articles on me written by Tom Martens (copy attached).]

Monday, September 5, 1977 - Brookdale, Santa Cruz Mountains

We had breakfast in the Lodge Coffee Shop; this is in a room adjoining the Lodge Dining Room.

We drove south on Highway 9 to Felton to Henry Cowell Redwoods State Park. Starting at park headquarters, we first made the one-mile marked tour of Redwood Grove; this gives a very interesting and worthwhile view of a large assortment of redwood trees and other natural growth.

Next, we hiked on the River Trail (and Pipe Line Road), Eagle Creek Trail, North Powder Mill Trail and Ridge Trail to Observation Deck (which afforded a $360^{\circ}$ view of surrounding territory). We then continued on Ridge Trail, then Rincon Trail to Cathedral Redwoods, where we ate our back pack lunch. We then continued on down Rincon Trail nearly as far as Big Rock Hole. (There is a parking area on Highway 9 near here which would provide a good starting point for a hike on Rincon Trail, connecting to other trails.)

We then turned back, hiked on Rincon Trail, a service road, River Trail and Pipe Iine Road, through Redwood Grove, back to our starting point. We hiked a total of 6 or 7 miles. 


\section{Lafayette's Glenn Seaborg}

- There Is an Energy Crisis,

$\therefore$ B BYTMMARTENS

Dr. Glenn - Seaborg of Lafayette, the-Nobel Laureate who co - discovered plutonium in the early 19ios, re

$\because$ mains, at 65, a busy researcher, teacher and speaker.

$\because$ He was back in the news again re - cently when Washington, D.C.; newspapers reported missing uranium during his tenure, under the Kennedy administration, as chairman of the now defunct A tomic Energy Commission. $\because-$

Described by his wife, Helen, as an early riser who. works 14 hours a day, Seaborg addressed the American Chemical-Society in Pittsburgh, Pa., in late August. This month he will fly to Sweden as keynote speaker at Upsala University's 500-year anniversary.

A speaking tour taking him to Par$\because$ is, Brussels and other.European cit;ies-will-follow the Sweden engagement.

$\therefore$ "When I travel, I line up all the -speeches 'end" to end so there's' no :wasted time," he said in a recent in"terview. "I always try to carry a full $\therefore$ teaching load and consider my stu"denits first when trayeling."

$\because$ Seaborg, who was chancellor of the

University of California at Berkeley

from August, 1959, to January, 1971,

is an enthusiastic outdoorsman, foot-

- ball fan and conservationist.

As chairman of Citizens for Urban

Witderness Areas, Seaborg said he is

excited about development of an

: Eaśt Bay Regional Parks District

$\because$ trail that will form an 89-mile loop

through the hills of Contra Costa

County, linking existing parks.

$\therefore$ He often spends weekends walking

a alońg East Bay Parks trails with friends.

'I hope to see the day when hikers can walk along the park trails in two or" three day trips," he said. "Perhaps there will even be hostels some sort of overnight rest and : camping areas - along the way."

Seaborg, who helped write the East -Bay Parks' 20-year master plan, was referring to plans to establish the

"Golden Loop" hiking trail connect-

-ing Wildcat Canyon Park (adjacent

to Tilden Park), Briones Regional Park, Mt. Diablo State Park, Las Trampas Regional Wilderness Cha- bot Regional Park, a section of East Bay: hills, Redwood Regional Park and Sibley Regional Preserve.

$\because$ The park district's board of directors: will decide on funding for the $\because$ irst part of the trail - Briones to Las Trampas - on Tuesday.

- Seaborg also touched on the followingsubjects:
TENERgY CRISIS: President Carter, based on a Central. Intelligence Agency report, has proclaimẹd an energy crisis and declared war on it Tet a report by Stanford Research Iistitute and a study by United National both say the problem is in find-: ing existing energy sources. Is there really an energy crisis?

- - There definitely is an energy cri-. "sis: In the immediate future the country must slow from the current four per cent annual energy use growth to two per cent.

$\therefore$ 'The age of cheap energy is gone," he said. "We. will simply never be able to take energy for granted again."

Seaborg said scientists are study'ing separating hydrogen from water, which could be used to power generators, drive automobiles and for other energy-related uses.

"Hydrogen might be the substitute for natural gas," he said.

- SOLAR ENERGX்: Seaborg said there are two aspects of solar energy that must be developed in the next decade - the use of solar energy for heating and cooling.

"It's going to take a lot of research, but scientists must keep the energy balance. in mind at all times. You must know whether the cost of using energy to pump water through the system offsets the gain from solar energy."

- NUClear P0WER: President Carter has withdrawn support for breeder reactor research at Clynch River, Va. Will this decision, if supported by Congress, have any long - range impact on our nuclear research?

"I generally agree with Carter's stand on nuclear power," said Seaborg, who was pro - nuclear power during his AEC tenure, "and I don't think that slowing down the breeder program a year, two or three will have much effect on research."

Breeder reactors use enriched uranium as fuel, producing radioactive plutonium which is recycled through the reactor. Current reactors use uranium only once.

Compared to present reactors, though, the breeder would still produce more plutonium, which would have to be disposed.

"Carter has said, 'go slow,' and not make any more plutonium," Seaborg said. "He's worried about proliferation of the material. He wanted to use that decision as a model for the rest of the world to follow, but some countries must continue (with breeder research)." 


\section{Says Nobel Laureate}

- NUCLEAR fÚsION POWER: How far off is fusion power?

(Nuclear fusion power results from creating heat by joining, rather than splitting, radioactive elements like deuterium and tritium. Like current nuclear power plants, the heat is converted to steam, which runs generators).

"I'm not sure whether fusion nuclear energy is possible at all," Seaborg said. "And certainly, at the outside, it will be a minimum of 30 years before anyone will approach generating electricity.

"We are plainly just a long way off on fusion."

- NUCLEAR WEAPONRY: NewSpapers are reporting that South Afri$\mathrm{ca}$ is about to join some 30 conntries in producing an atom bomb. Are we heading for a nuclear doomsday?

"Oh, I'm a little more optimistic than those people (doomsday crit ics). I think we're going to survive," Seaborg said.
"On the Manhattan Project, scientists were concerned with developing the bomb before Hitler in Germany, where the atom was discovered." Seaborg worked with 12 other scientists in developing the atom bomb and said he signed a pact in June, 1945, which asked President Harry Truman to test the bomb on an unpopulated area to demonstrate its power.

"But our suggestion was not accepted," Seaborg recalled. "The world would have been better off, I suspect, without the atom bomb, but now we must work for international control of nuclear weapons.

"Getting all countries to sign the non - proliferation treaty is damned important in this age when war is so unthinkable."

Seaborg noted that even though many countries have nuclear power plants - and the capability of making atom bombs - none have used plutonium for weapons.

Plutonium can only be produced in a research reactor or as a by - prod: uct of a power plant.

"India's bomb was made with en: riched U-235 using a Canadian research reactor," Seaborg said. "That was possible because nuclear agreements were not tight enough."

- MUSSING URANIUM: You've been quoted as saying that uranium could have been missing during the 1960s. Any change in that position?

"There has always been a problem in monitoring nuclear fuel production because of the mechanics of the production process," Seaborg said, adding that a certain amount of loss of uranium during the enrichment process is always experienced."

Referring to the month - old report of missing fuel from a Hanford, Conn., processing plant, Seaborg said the uranium unaccounted for was probably due to administrative error.

"To hijack enough material for a bomb, you would have to spend an entire day working your way through locks," he said. "The material is guarded better than Brinks. There are always reports about uranium going to Israel. I can't imagine what Israel is doing with all that uranium.

"Why, they don't even have the capability to store the 100 tons of nuclear material that is supposed to be there."
- NEUTRON BOMB: President Jimmy Carter, who endorsed re search on the neutron bomb as a possible weapon to repel a Russian attack in West Germany, has been subject to seviere European pressure because of the decision. Is such a bomb a significantly new weapon?

"Not really," Seaborg said: "Research has been going on with these kinds of pieapons for some time. The current direction (in re: search) is to produce a bomb with minimum blast and maximum neưtron production.

"Others, it seems (referring to opponents of the neutron bomb), for some reason want-a little blast along with their neutrons. I think the weapon would work as a tactical weapon because it leaves the remaining structures free of radiation after a relatively short period."

The neutron bomb, a low - yield atom bomb, is designed to explode above the ground at a target and kill people, leaving buildings untouched.

- CURRENT RESEARCH: What research are you doing now?

"I'm currently working on an international chemical organization, sort of a group of elite chemists, to set up a mechanism of exchanging information," he said.

"In Warsaw, the idea was favorably accepted. At the (Lawrence Berkeley) lab, we are experimenting with finding more heavy elements. We are trying to find whether some have a half - life long enough to be declared elements."

In the future, Seaborg said he expects to see great advances in the use of computers as a research aid in biochemistry. He believes. the study of molecular and cellular structures, aided by computers, may lead to the creation of life, elimination of disease and the development of artificial eyes, ears and hearts. 
$\because$
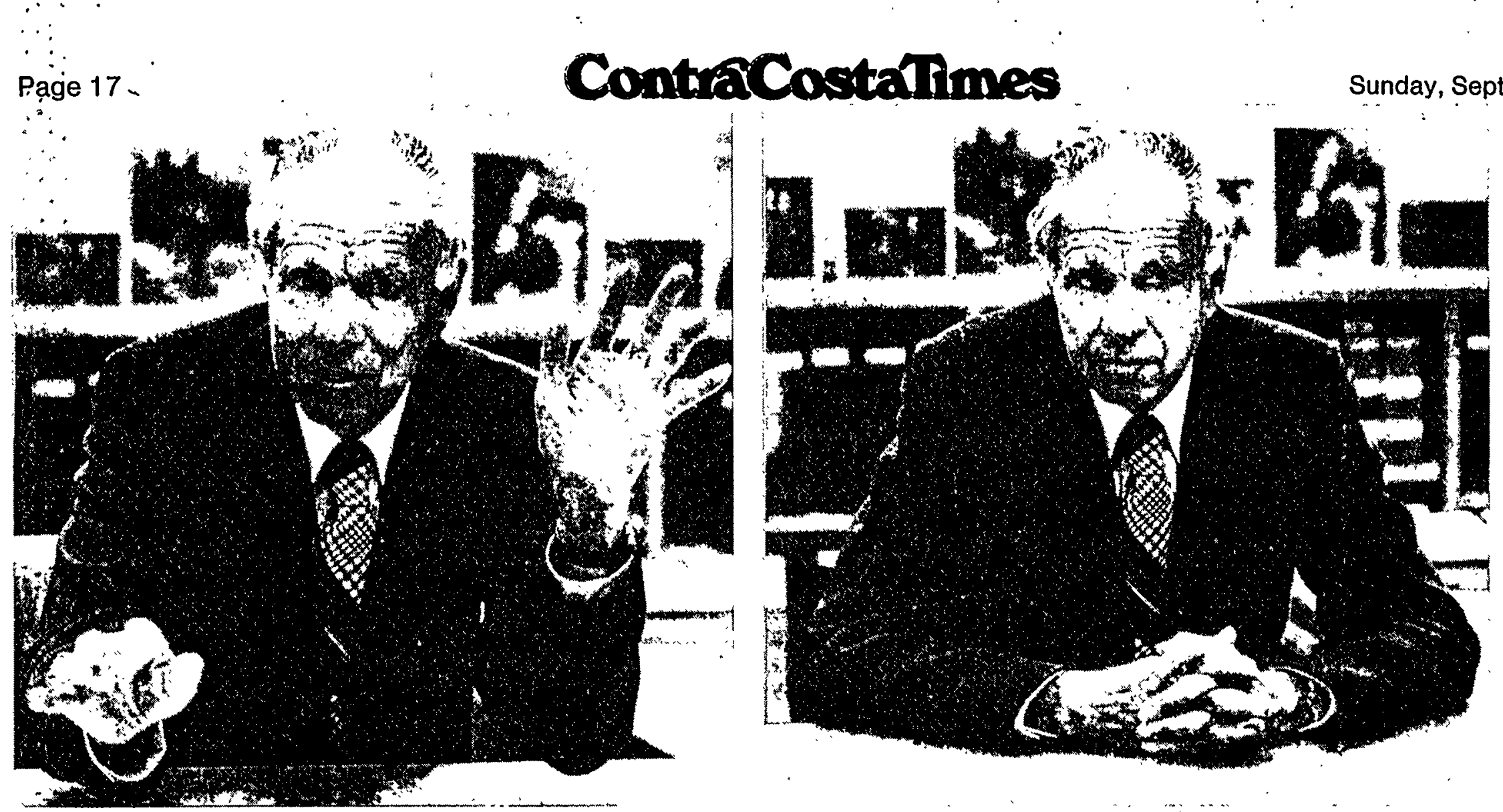

At age 65; Dr. Glenn Seaborg, the. Nobel Laureate who co-discovered plutonium, remains a busy researcher, teacher and speaker. He resides in Lafayette with his wife, Helen. 

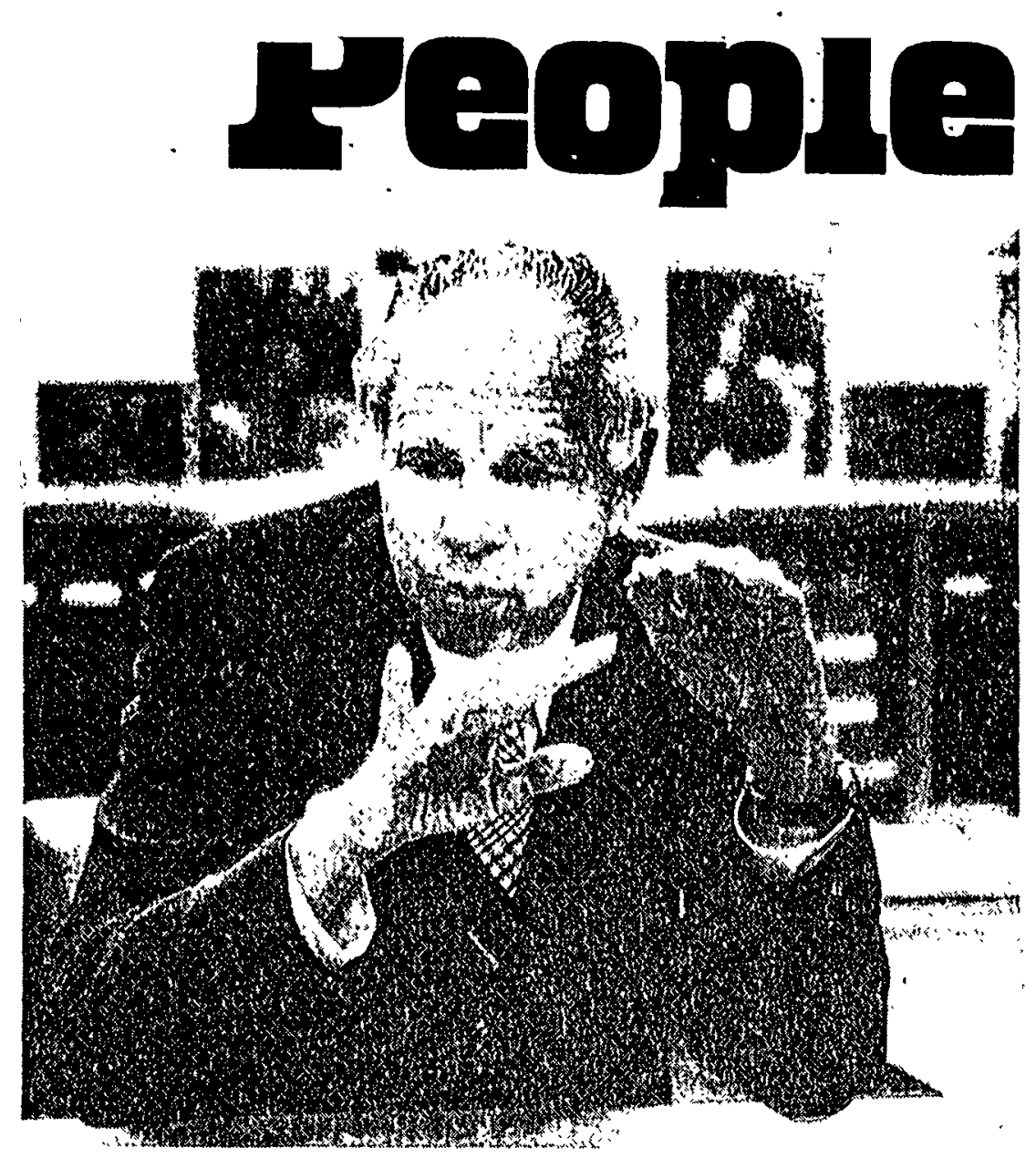

\section{Seaborg: His Credits Are Many}

Glenin T. Seaborg was born April California at Los Angeles in 1934 and 19,1912 , in the iron mining city of Ishpeming, Mich., the son of a machin-

His accomplishments fill 10 'inches. of double-column print in the Encyclopedia Britanica and eight inches of squinty-sized print in the $1976 \mathrm{edl}$. tion of Who's Who.

Here is a partial biography:

- He received an A.B. degree in chemistry from the University of was awarded a $\mathrm{Ph} . \mathrm{D}$. in chemistry from the University of California at Berkeley In 1937.

- In 1940-41, Seaborg co-discovered plutonium and the first 10 heavier-than-uranlum elements on the periódic chemical chart.

- During World War II he headed a research group that resulted in a chemical process for making pluton- ium in the super-secret Manhattan Project, which resulted in the first atom bomb.

- In 1951 he was awarded the No bel Prize for chemistry with. E.M McMillan for work. with transuranium elements.

- He served as chancellor of the Berkeley campus from 1958 to 1961 .,

- Appointed by President John F. Kennedy, he served as chairman of the now-defunct Atomic Energy Commission from 1961 to 1971. - Since 197 t he has worked as assistant: director of the Lawrence Berkeley Laboratory, teaches chem. istry in Berkeley. and has helped write the 20-year master plan for East Bä́y Reglonal Park District.

He lives in Lafayette with his wife, Helen. The Seaborgs have six children, most of whom are interested in biological sciences and conservation. 
We then went into the Gift Shoppe where Helen bought a number of redwood candlestick holders, vases, etc., trivet with embedded abalone shells, a descriptive brochure on redwood trees, etc., for use as gifts (such as on my forthcoming visit to Sweden). There is also a snack bar here (like the one at Muir Woods).

We then drove back to Felton, drove about a half-mile east in the Felton-Empire Grade Road to the parking lot for the Fall Creek Unit of the Henry Cowell Redwoods state Park. We hiked in about a third of a mile to the Fall Creek North Fork Trail, which leads to other trails. This is an interesting undeveloped unit (no buildings at the dirt parking lot), and the trails appear to be relatively level.

We left for home (with Helen still at the wheel) a little before 4:00 p.m. We drove on Mit. Herman Road (passing the region of the Lutheran Camp where Lynne spent a week in about 1959), then on Highway 17 (passing Santa's Village, where we took the kids when we came down to pick up Lynne). We continued on home on Highways 680 and 24, arriving at 5:30 p.m.

Eric and I hiked up Monticello Road, the water tank road and the road on Percy Jennings property up toward Lafayette Ridge so he could take some pictures of chaparral, trees, grass, etc., some including me as a hiker, for use in his article on the Golden Loop Trail.

Helen, Eric, Dianne and I had a waffle supper on our patio. I read the final Environmental Impact Report "Briones to Las Trampas" in preparation for tomorrow's EBRPD Board meeting.

Tuesday, September 6, 1977 - Berkeley

I made telephone calls regarding information for my Met Lab Section C-I history to: Roy Howard Beaton, Don Stewart (regarding Helen Peterson), Bernard Abraham (also regarding Helen Peterson) and Merlin Peterson (regarding his home address in 1943). I also talked with Alan Pasternak regarding his upcoming talk before the UC Berkeley Foundation at the Lawrence Hall of Science.

I sent St. Mary's Church in Oak Ridge a copy of my book, Nuclear Milestones (autographed) to be auctioned off at the "Fall Festival."

My correspondence today included a letter to Harrison Brown in reply to his request for me to make comments on his book. I said that I would not have time to do this until October (because of my Europe trip) but that I would be most happy to make some comments. I also wrote $A$. M. Dowden in regard to two changes in my manuscript on the transuranium elements. I sent copies of my talk, "Knowledge and Survival," which I will present at the 5 th Centenary Celebration of Uppsala University on September 31, 1977, to Torgny Segerstedt at Uppsala and Michael Heylin at the ACS.

At 9:05 a.m., I spoke with Hyuk Yu at the University of Wisconsin regarding my speech at the John Willard Symposium. He requested a copy of the text for publication in the alumni quarterly magazine. Although I did not have a prepared speech, I agreed to put something together and send it to him with pictures of the slides I used. 
Tuesday, September 6,1977 (con't)

I wrote to Frederick Seitz (President, Rockefeller University) a note explaining that I believe the formation of a Council on Science and Technology for Development is a good idea and gave him information about an international chemical society.

I attended the scheduling meeting for the 88" cyclotron in the Building 88 Conference Room from 10:30-11:00 a.m. Since the cyclotron had a water flooding accident last week, the users were re-scheduled for the next period, Williams was scheduled for $69-\mathrm{Mev}{ }^{1} \mathrm{I}_{B}$ plus U (to look for and study $242 \mathrm{Bk}$ ) for the day shift on Monday, september 12 .

I went by room 203/70 to talk to otto and Morrissey about the papers we are writing, my slides for my GSI and Marburg talks on september 14, 15, etc. I also discussed with Baisden some slides for these talks.

I had lunch in the cafeteria with Otto, Morrissey, de SaintSimon and Nitschke. We compared notes on Bay Area hiking (including Santa Cruz mountains), sailing on lakes and bay, other sports, etc.

I left the office a little before $3: 30 \mathrm{p} . \mathrm{m}$. to join Eric in front of International. House and he drove us to the Hayward City Hall (22300 Foothill Blvd.) where we attended the regular meeting of the EBRPD Board in the Hayward City Council chambers. We were interested in the agenda item concerned with the adoption of the Land Use Development Plan and Environmental Impact Report for the Briones to Las Trampas trail. All seven Board members were present--John Leavitt (Chairman), William Jardin, Howard Cogswell, Paul Badger, Mary Jefferds, Harlan Kessel and Walter Costa.

Bill Gries made the presentation for this agenda item after which its adoption was immediately moved by Costa and seconded by Badger. Costa then made some remarks in support of his motion. This was followed by a slide presentation by Jana Olson, showing many pictures of the whole route including alternate routes. Chairman Leavitt then took note of my presence and asked if I had any comments. I came forward and spoke in support of the resolution. I described my interest over the last six years in this project, my participation in many field trips with EBRPD staff and with the Lafayette-Moraga Trails Committee, indicated that approval of this section would close and complete the golden loop trail and said that, although I have had some different ideas as to the best route, I have come to the view that the staff has come up with the best overall route.

Following this, David W. Long, representing home owners on 4 th Street, spoke in opposition to the trail, followed by G. T. Duffy, owner of the property at the top of Elizabeth Street who also spoke in opposition to the trail going through his property and suggested alternate routes such as going through the Gelhaus property.

This was followed by effective down-to-earth pithy remarks by ken Brown, owner of property over which the trail would pass, strongly in favor of the trail and decrying the number of people with negative attitudes that have moved into Lafayette. Following this, Jeff Davis, 
who was a schoolmate of some of my children and is now an Oakland fireman, spoke in opposition to the trail in a rather long and tedious presentation that included suggestions of alternate routes, such as using the north side of Deer Hill Road, which did not seem very feasible. This was followed by remarks by Norm Sims, Kay Petersen and Lee Pfautch strongly in favor of the trail. Pfautch made the suggestion of a one sentence addition to the Environmental Impact Report which would promise to have attention given to the maintenance of environmental qualities of private lands near which the trail would go. Donn Black, attorney for EBRPD, then suggested an addition to the resolution, introducing some flexibility in the exact route of the trail. Following this, the resolution was adopted unanimously by a 7-0 vote.

The meeting adjourned shortly thereafter. I pointed out to Jana Olson, Wally Costa, Hulet Hornbeck, Jerry Kent and Paul Badger the desirability of a connection from the water tank road at the end of Monticello Avenue either through the Percy Jennings property or the panhandle to the west to the Lafayette Ridge trail. This would make the trail accessible to all the people in Happy Valley Glen and environs. Olson will look into this. Badger seemed especially interested and wants me to bring it to his attention later.

Eric and I then drove home, arriving about 6:30 p.m. Helen, Dianne, Eric and I had dinner on our patio. It was a warm evening, following a warm day.

Wednesday; September 7, 1977 - Berkeley

My correspondence today included a letter accompanied by a contribution to the Santa Cruz Mountain Trail Association and a congratulatory letter to Principal George $w$. Keatley of the Princeton High School in Princeton, West Virginia for receiving the annual Bellamy Flag award.

At 10:00 a.m., I received a telephone call from David Cristwell, Executive Director of the Lunar Space Center Proposal Panel in Houston, Texas. He inquired if I would review a proposal by Ed Anders regarding superheavy element origin. I agreed to do it in october (because of my trip to Europe).

We held the regular biweekly luncheon meeting of SHEIKS in my office. Present were Ghiorso, Nitschke, Thomas, Nishida, Nurmia, Baisden, Marsh, Gottstein, Morrissey, Diana Lee, Cynthia Lee, Yashita, Qfto, de Saint-Simon and Williams. Williams reported on her ${ }^{1} 1_{B}$ plus $235_{U}$ bombardment which seems to have yielded an 18-minute electron capture $242_{\mathrm{Bk}}$ (and/or $24 \mathrm{I}_{\mathrm{Bk}}$ ). Marsh reported on his computer work on the fireball model heavy residues from $12 \mathrm{C}$ (and $2 \mathrm{O}_{\mathrm{Ne}}$ ) Bevalac bombardments of $\mathrm{U}, \mathrm{P}, \mathrm{Au}$ and Ta. Morrissey reported on Diana Lee's and his work on the new computer terminal for gamma ray fitting and Baisden on her summary of data on actinide yields from heavy ion bombardments of heavy targets.

Otto came by at 3:00 p.m. to inform me that he would like to seek permanent employment at LBI. I made several suggestions where he might apply. 
I had to decline an invitation from Lt. General H. C. Donnelly (Ret.), of Presbyterian Hospital Center Foundation in Albuquerque, to attend their ninth annual awards dinner to take place when I am in Europe.

I made calls regarding the high intensity uranium beam facility line item to James Kane (Division of Physical Research in ERDA) and Michael Crisp (Senator Howard H. Baker, Jr.'s office).

Lars Ortgrem (Swedish Embassy, Washington, D.C.) called to inquire about the possibility of my giving a talk at the Royal Academy of Engineering Sciences in Stockholm during my stay there september 22-30. We agreed that I would speak on Thursday afternoon, September 22, and my topic is to be "Energy and The Environment."

I went by room 203/70 at 5:00 p.m. to talk to otto, Morrissey and Thomas about their work.

Eric came by, having spent some time at the UC library referencing his Hetch Hetchy article, rode home with me, stopping en route for a hike at Lafayette Reservoir. Helen, Dianne, Eric and $I$ had dinner in the patio.

I called Ken Brown to check on Reid Laitner as a possible realtor to handle our (Seaborg-Segrè) Orinda land. He gave no adverse comments. He is torn between selling his land to EBRPD for a low offer and selling through Reid Laitner for an offer more than twice as great; he hopes I can help him get a more equitable offer from EBRPD. I then called Emilio Segrè to suggested we go ahead with an agreement with Laitner.

Eric showed us his slides taken at Ias Trampas. Steve called from San Diego. He likes his apartment and finds his school work not too difficult but voluminous.

Thursday, September 8,1977 - Berkeley

Carolyne Gottstein dropped in to ask me if I would serve as a reference for graduate school (UCLA, UCSD, etc.); I agreed to do so.

Andrew Sessler came by at 9:00 a.m. and we discussed plans for the visit of the Prince of Wales on October 28th. IBI will have a 35-minute spot in the afternoon to describe our work on energy and environmental research. Speakers will include Bob Budnitz, Paul Witherspoon, Art Rosenfeld and Jack Hollander. Andy told me that Jack will return to LBL next month to be one-half time associate director for planning and one-half time on energy policy work.

Ken Hulet called to say that N. B. Mikheev will be here today and asked if I could find office space for him. I said that I probably could find space in $203 / 70$.

I wrote to A. M. Dowden regarding Flerov's refusal to sign permission forms covering his articles for the Benchmark volume. (This refusal affects articles 31 and 32 only since his and Zvara's other articles predate 1973.) 
I also wrote to F. C. Gallais (Centre National De Ira Recherche Scientifique in Toulouse, France) about meeting with him and Professor Horeau while I am in Paris.

Paul Lochak called from Paris to confirm some of our plans for the trip. He asked me to contact George MilIy and ask about areas of progress made by Geomet during. the year. (I tried to reach Milly today but he was on a field trip in colorado.)

I had Iunch at the table outside the lower level of the cafeteria with Norman Edelstein, Jerry Bucher, Rodney Banks, Bob Silva, Fred Weidl, Alex Avdeef, Allan Zalkin, Dave Morrissey and Michel de SaintSimon.

After lunch, I talked with Jane Kingston about her future program with me. This will be half-time after October 1, probably working on some writing project covering my AEC days. She is disappointed that she did not get the position at the Exploratorium.

At 4:00 p.m., I went over to see Otfo to discuss our paper, in preparation, on the search for SHE from $136_{\mathrm{Xe}}$ plus $238_{\mathrm{U}}$.

I ran into Neil Bartlett and invited him to accept membership on the US-France. IAC subcommittee on a cooperative program in solid state, which he accepted. I asked if he has written Professor Glemser (in Gottingen) about the ICS (he hasn't but will do so tonight).

I wrote a letter to Robert Fox regarding representation on the Science Commission for the Joint Board-Council Committee on the International Activities Committee. I sent a list of suggested names for appointment as the representative.

I spoke with Terry simkin in Engineering here at IBI regarding material for my talk to the Royal Swedish Academy of Engineering Sciences in stockholm which is coming up.

I took a hike at the Lafayette Reservoir. Eric and I had a quick dinner in the kitchen, preparatory to the party Helen is giving this evening for Lee and Iz Perlman and many of our mutual Lafayette friends. Dianne ate a few minutes later.

Present for dessert, coffee, tea and lemonade were Iz and Lee Perlman, Victor and Annamary Peery, Albert and Marjorie Alexander, Parker and Dorothy Haydon, Marty and Jane Duffy, John and Kay Bauer, John and Maryann Gilcrest, Harold and Mary Paige, Yehuda and Cathy Sherman and daughters, Yehudit and Tammy, Eric, Dianne, Helen and I. Iz and Lee stayed on a while after the others left; they will leave for their return to Israel about october 1 , so I won't see them again during this visit.

Friday, September 9, 1977 - Berkeley

At 9:25 a.m., I talked with Gordon Bixler on the telephone regarding several items of International Activities Committee business (subcommittee on ICS, 1979 meeting of Chemical Society Presidents, etc.). I also talked with George Milly who returned my call of 
Friday, September 9, 1977 (con't)

yesterday. Rodney Hader and I spoke on the phone regarding nominations for the National Science Foundation Board and I suggested Neil Bartlett and Melvin Calvin as new members. Shortly thereafter, Ben Loeb and I talked about our book on the limited test ban treaty. He has two readers lined up to go over our material. Later in the morning, I met with Candy Voelker and gave her material on the manuscript. I explained the rough draft nature of the material which she will pass on to Little, Brown \& Company. She suggested that I should meet Milton Johnson, San Francisco representative of Little, Brown \& Company when I return from Europe.

Pat Quinn called Lars Ortgrem at the Swedish Embassy in Washington to accept their invitation to speak to the Royal Academy of Engineering Sciences (September 22) and made further arrangements for my visit with them.

At 11:00 a.m., Reid Laitner brought in the two agreements ("exclusive right to sell") for our orinda property. These agreements are for a period of six months. One agreement is joint with Emilio Segrè for the fifty-one-acre parcel and the other agreement is joint with Helen Seaborg for the two-acre parcel. He then went to our home in Lafayette to have Helen sign the second agreement. We had discussed a couple of matters dealing with the property over the telephone last night. We agreed that the road that runs through the property should be moved to allow a better division of the property; we also agreed we could add the two-acre parcel in the NW corner of the property to fill out the offering to 10 acres.

Earl Bolton called to request that I grant an interview to his firm, which has a contract with IBM to do a study involving interviews with twenty-five distinguished scientists. I said that I would do this and will wait to hear from eastern offices of Booz, Allen \& Hamilton.

I had lunch in the cafeteria with Thomas, Morrissey and de SaintSimon, who will be finished with his draft of the iodine isotopes yield paper ( 4 Ar plus U) next week. Both Morrissey and I haye heard from walter Loveland. He wants to try to get our ${ }^{48} \mathrm{Ca}$ plus ${ }^{208} \mathrm{~Pb}$ paper published in Physical Review Letters despite Gove's rejection.

I talked to Frank Oppenheimer about a possible position for Jane Kingston at the Exploratorium.

I arranged to have Matti Nurmia put on my budget for $10 \%$ of his time (the remainder, $50 \%$, he will be on Al Ghiorso's budget) for FY78.

At 3:00 p.m., I met with Barbara Jacak, my student assistant for the Freshman Cluster Group. She will meet with the group the week of September 19th and I will meet with them for the first time on October 4. Since she is interested in doing research with me later (she is beginning her junior year), I took her around to meet Morrissey (who was her TA in Chem IA), Otto, Gottstein, de Saint-Simon and Marsh. 
I wrote to the Minister of Foreign Affairs in Prague, Czechoslovakia on behalf of Professor Drahoslav Iim at the suggestion of Philip Handler (NAS) and Jesse Hwa (copy attached). I also wrote to Senator Sam Hayakawa and Representative Barry M. Goldwater, Jr. to urge their support for our high intensity uranium beam facility budget item (copies attached). I answered an inquiry from Vitalii Goldanskii, saying that I would very much appreciate receiving an updated list of his selected papers including a self-survey article and suggesting means by which he might attend the Welch Conference in November 1977.

I then wrote to Pat Walsh (ANL) to ask her help in identifying some old photographs for my Met Lab section C-I history.

Norman Glendenning asked if I would serve as a reference for a Guggenheim Fellowship for him and I said that I would be happy to do so and would send a.strong letter of support.

Sheila called at 5:00 p.m. She is enjoying her new job.

I took a hike at Lafayette Reservoir. Helen, Eric, Dianne and I had dinner in the kitchen. I then read proof on the index of Volume III of Travels in the New world and on the typed version of my article "John E. Willard - Pioneer Nuclear Chemist."

Saturday, September 10,1977 - Iafayette.

Helen, Eric and I visited our land in orinda, then drove to Redwood Regional Park. We hiked Orchard, French and Stream Trails (a loop) and took a 20-roll of olympus and half a 36-roll of Nikon color slide pictures, including various combinations of the three of us, for possible use by Eric in his article on the Golden Loop Trail for Backpacker Magazine. We then drove to Tilden Park, eating our lunch en route and hiked on the Skyline National Recreation Trail, where we took more pictures with the olympus and Nikon cameras. It was quite foggy, which may or may not have led to good pictures. We returned home at 4:00 p.m. Eric, with the Nikon, and I, with the olympus, took pictures of Adolph Eriksson's (my grandfather) medal, awarded him in 1900 for his more than 25-years work with the Grängesberg Iron Mine. I am going to give the medal to Uncle Karl Adolfsson (my mother's brother) when I visit him in Kopparberg later this month, at his request. (Mother had bequeathed the medal to our son stephen but we are acceding to Karl's request.)

Sheila Saxby dropped by at 6:00 p.m. and spent an hour with Helen and me over coffee, tea and cake. She was on her way to have dinner with Beverly Liss in her apartment at Rossmoor.: Sheila is enjoying her new job.

Helen, Dianne, Eric and I had dinner in the kitchen.' In the evening, I worked on the final draft of our paper "Recoil Range Distributions of Heavy Mass Products in Deep Inelastic Reactions with Gold and Uranium Targets" and a draft 8 f "Search for Superheavy Elements Produced in the $136 \mathrm{Ke}$ plus $238 \mathrm{U}$ Reaction and An Upper Limit Cross Section for the Gd ( $\left.{ }^{136} \mathrm{Xe}, \mathrm{X}\right){ }^{212} \mathrm{~Pb}$ Reaction." 
September 3,1977

Minister of Foreign Affairs

Czechoslovak Socialist Republic

Prague, Czechoslorakia

\section{Excellency:}

I am writing on behalf of Professor Drahoslav Iim because I am concerned about him and his family. I have learned from mutual friends about his stay at stanford University as a visiting scholar and professor during the years 1971-74 and his excellent research performance.

These friends have told me professor Iim has not been alle to find employment to carry on his scientific research activities in Czechoslovakia. This is very surprising in view of the fact that he has an outstanding reputation in the field of Macromolecular Chemistry and especially in the bionedical aspects of this field.

Professor Iin has been offered research appointments in the United States. I strongly urge that he he allowed to leave Czechoslovakia to accept such employment. I man with his unusual ability should be in a position to contribute through his research to the overall benefit of mankind.

Sincerely,

Glenn T. Seaborg

Professor of Chemistry

and robel Laureate

GTS/sca

cc: Mr. John.C. Kornblum, U. S. Representative to Belgrade Conference on Fuman Rights

bcc: Professor Paul J. Flory

Dr. Philip Handler, NAS

Mr. J. C. E. Hwa 
The Honorable Sam Hayakawa

Onited States Senate

6221 Dirksen Senate office Buililing

Washington, D.C. 20510

Dear Senator Hayakawa:

I would like to draw your attention to a matter of great importance to our research in nuclear physics and chemistry at Lawrence Berkeley Laboratory.

The FY:78 President's Eudget for ERDA's Basic Sciences: Huclear Physics Program requested $\$ 6,000,000$ for construction of a high Intensity Jranilum Beams project at InL. I enclose a copy of the relevant part of the ERDA budget subnission. The project was authorized by the louse and Senate but to our great disappointment, no funds were appropriated for FY '78. It is my understanding that failure to appropriate was done "without prejudice."

Huclear research with heavy ions is field in shich LBL has led the world. Our position is now threatened by the-exiscence of a much more modern accelerator in Germany and by projects on the drawing boarus in Gemany, Japan, France and the USSR. This comes at a tine when new and exciting scientiric ideas are waiting to be tested with tise improved facilities that the Uranium Beams project would make available to U.S. science. Some flavor of the fascinating new possibilities comes through in the enclosed note by jr. Bernard Harvey, lead of the LBL hifulear Science Division. It is my own judgment that an early start on the Uranium Beans project is vitally important to maintaining moruentum in this vital research field.

I have spoken to Senator Howard baker about this and he has an interest tin reinstating this project in a Departnent of Energy supplenentary budget request for Fy' 78 .

Dr. Hiarvey or I would be happy to assist you or your stafe in any way that you would find useful.

sincerely yours,

Glenn T. Seaborg 
500 Nuc. Sci Budget

200 Goldwater, B.

Extension 5661, 5670

September 9, 1977

The Honorable Barry MGigolawater, Ir. House of Representatives

Washlngton, D.C. 20515

Dear Mr. Goldwater:

I would like to draw your attention to a matter of great importance to our research in nuclear physics and chemistry at Lawrence Berkeley Laboratory.

The FY'78 President's Buaget for HRDA's Basic Sciences: Nuclear Physics Program requested $\$ 6,000,000$ for construction of a Jigh Intensity Uranium Beams project at LiEL. I enclose a copy of the relevant part of the ERDA buaget submission. The project was authorized by the louse and senate but to our great disappointment, no funds were appropriated for $F Y$ '78. It is ray understanding that failure to appropriate was done "without prejudice."

Nuclear zesearch with heavy ions is a fiela in which LBI has led the world. Our position is now threatened by the existence of a much more modern accelerator in Germany and by projects on the drawing boards in Germany, Japan, France and the USSR. This comes at a time when new and exciting scientific ideas are waiting to be tested with the improved facilities that the Uranium Beams project would make available to U.S. science. Some flavor of the fascinating new possibilities comes through in the enclosed note by Dr. Bernara harvey, Head of the LBL huclear Science Division. It is ny own judgment that an early start on the Uranium Beams project is vitally important to maintaining momentum in this vital researcin fiela.

I have spoken to Senator Howard Baker about this and he has an interest in reinstating this project in a Department of Energy Bupplementary budget request for FY 173 .

Dr. Harvey or I would be happy to assist you or your staff in any way that you would find useful.

sincerely yours,

Glenn T. Seaborg

Enclosures 
Sunday, September 11, 1977 - Lafayette

I worked further on the two papers that I worked on last evening. In the afternoon, I took a hike, clockwise, around Lafayette Reservoir on the Rim Trail, including the wooded trail portion on the southeast side. I also organized my papers and slides for the European trip that Eric and I will start tomorrow.

We had a delayed high school graduation dinner for Dianne--Helen, Eric and. I with Dianne. Helen baked an angel food cake. We gave her a book of Robert Frost's poems for a present.

Monday, September 12, 1977 - Berkeley

Otto, Morrissey and I had a half-hour telephone conversation with Walter Loveland in Corvallis, Oregon, regarding revisions of our paper "Lowered Fusion gross Sections in the Quadruply Magic Heavy Ion System, $48 \mathrm{Ca}+208 \mathrm{Pf}$." We will revise it and submit for publication in Physics Letters.

I sent several letters urging support for our high intensity uranium beam facility line item; these went to: Representatives John J. McFall (copy attached), Yvonne Brathwaite Burke, Edward P. Boland and Edward Roybal. I also talked to Joe Overton, in Barry Goldwater's office, regarding this line item and alerted him to the arrival of my letter to Goldwater with the attached narrative description of LBL's uranium beam capabilities.

I answered a letter from Professor James E. Boggs (University of Texas) in which he offers his services to the International Activities Committee of ACS. I thanked him for his interest and referred his letter to Gordon Bixler for consideration when assignments to subcommittees are made. I also answered an invitation from Father Ted Hesburgh, Notre Dame University, for a dinner honoring Senator and Mrs. Hubert Humphrey on October 3, which I had to decline due to my trip to Europe.

Pat Somerville and I attended the 88" cyclotron scheduling meeting with Al Ghiorso at 10:30 $\mathrm{m}_{6} \mathrm{~m}$. We were scheduled as follows: Ghiorso for two shifts ${ }^{14} \mathrm{~N}$ plus $206 \mathrm{~Pb}$ to test recoil systems on September 26 and 27; Ken Hulet for alpha plus $254 \mathrm{Es}$ to study Md chemistry on September 21; and Somervilie for alpha plus ${ }^{23} \mathrm{U}$ to look for ${ }^{234} \mathrm{Pu}$ (S.F. isomer) on September 14 .

I had lunch in the cafeteria with otto, Morrissey and de SaintSimon. We discussed the content of Otto's NSD talk scheduled for Monday, October 3 .

In my office, Otto, Morrissey and I then went over the transparencies given me by Walter Loveland for use in my GSI and Marburg talks (covering $\mathrm{C}$ plus $\mathrm{U}, \mathrm{Pb}, \mathrm{Au}$ data).

N. B. Mikheev came by, with Ken Hulet, about $2: 15$ p.m. and I took him by room 209/70, where he could have a desk (in the room with de Saint-Simon and Williams). 
500 Nuc. Sci Budget 568

200 McFall, John

Extension 5661, 5670

September 12, 1977

The tonorable John J. MCFall

United States House of Representatives

2346 Rayburn Fouse Office Bullaing

Washington, D.C. is 20515

Dear Congressman McFall:

I would like to draw your attention to a matter of great importance to the future of research in Juclear science at Iawrence Eerkeley Laboratory.

The FY'78 Rresident's Burget contained a request for funds in the amount of $\$ 6,000,000$ for improvement of the capabilities of our SuperisInc and Bevalac accelerators. I enclose a copy of the relevant part of the ERDA Basic Sciences: Nuclear Physics budget request, where the construction project is described.

The requested fund were authorized by both rouse and senate, but no money was appropriated for FY'78. It is my understanding that this action was taken "without prejuaice."

I belleve this project to be of the utrost importance to our work at Lawrence Berkeley Lakoratory and, indeed, to the whole national effort in nuclear science research. Its tirnely conpletion will allow us to maintain our position of leaciership in the vital field of heavy ion physics, a position that is rapidiy being undermined by a new accelerator in Germany and further threatened by projects on the drawing boards or under construction in France, Japan and the USSR. The enclosed note by or. B. G. Earvey, gead of the LBL ivuclear Science Division, gives some flavor of the breakthroughs in research and technology that we anticipate from the upgrading of our accelerators here in Eerkeley.

If you or your staff would be interested in more information, I or Dr. Harvey would be more than willing to be of assistance.

sincerely yours,

Glenn . Seaborg

Attachments

GTS/sca

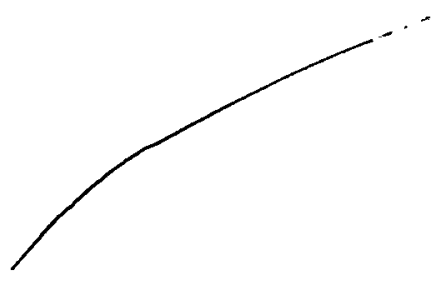


Eric and Dianne came by in the station wagon at 4:30 p.m. Dianne drove us to the San Francisco Airport. Eric and I boarded Pan American flight \#120 which left at 7:00 p.m., nearly an hour late. Mr. and Mrs. David Ridgway were aboard; he was on a trip that includes discussions in Gottingen regarding translation of the chem study text into German. I read material for my GSI and Marburg talks en route and Eric worked on his article on the Golden Loop Trail for Backpacker.

Tuesday, September 13, 1977 - London, England - Frankfurt, Germany

We arrived at London's Heathrow Airport at a little before 1:00 p.m. We were met by Paul Lochak, who helped us through passport control (there was a long line) and customs (our bags which we had checked to London were not inspected).

We then rode with Lochak in a UKAEA car to Stones Chop House on Panton street in the Haymarket district. (This is an old restaurant, extending back hundreds of years in this or other nearby Panton street location, is one of few that specializes in English type foods.) Here we met Paul's long time friend, Annabelle, and had a good lunch.

After Iunch, we took a taxi to 11 Charles II street, the headquarters of British Nuclear Fuels, Iimited (BNFI). (We went first to 11 Charles street, some distance away, because Lochak gave the taxi driver the wrong address, then returned to 11 charles II Street, which turned out to be just around the corner from stones chop House.)

We were issued our passes and went up to the 6 th floor to a conference room. Here Paul and I met with John Waddarns, BNFL Director of External and Technical Services, and Calvert W. Armstrong, BNEL Geologist. ( I also briefly greeted Donald Avery, Deputy Managing Director of BNFL, whom I met first in Washington, D.C., when he was Scientific Attaché at the British Embassy.)

Waddarns described to us the operations of BNEL. He told us BNEI is responsible, together with central Electricity Generating Board (CEGB), for the procurement of nuclear fuels. The procurement program contemplates diversification of supply--geographically, by many companies and in the time dimension. They have ongoing uranium supply contracts (e.g. with Australia), exploration contracts with mining exploration groups and want to be share holders in established mining ventures. They have been in business for three years. They want to undertake cooperative ventures with exploration groups and we said this is the way Geomet wants to operate. Under such ventures they would look at new, unexplored areas in the world (outside of North America, South Africa, Australia).

Waddarns and Armstrong then went on to describe an exploration arrangement they had two years ago with Urania which used Geomet as the contractor for exploration. This venture used the radon method in the Basinaud Range in California and Nevada, uncovered anomalies which, after substantial drilling proved to be barren. Neither lochak nor I had heard about this before. 


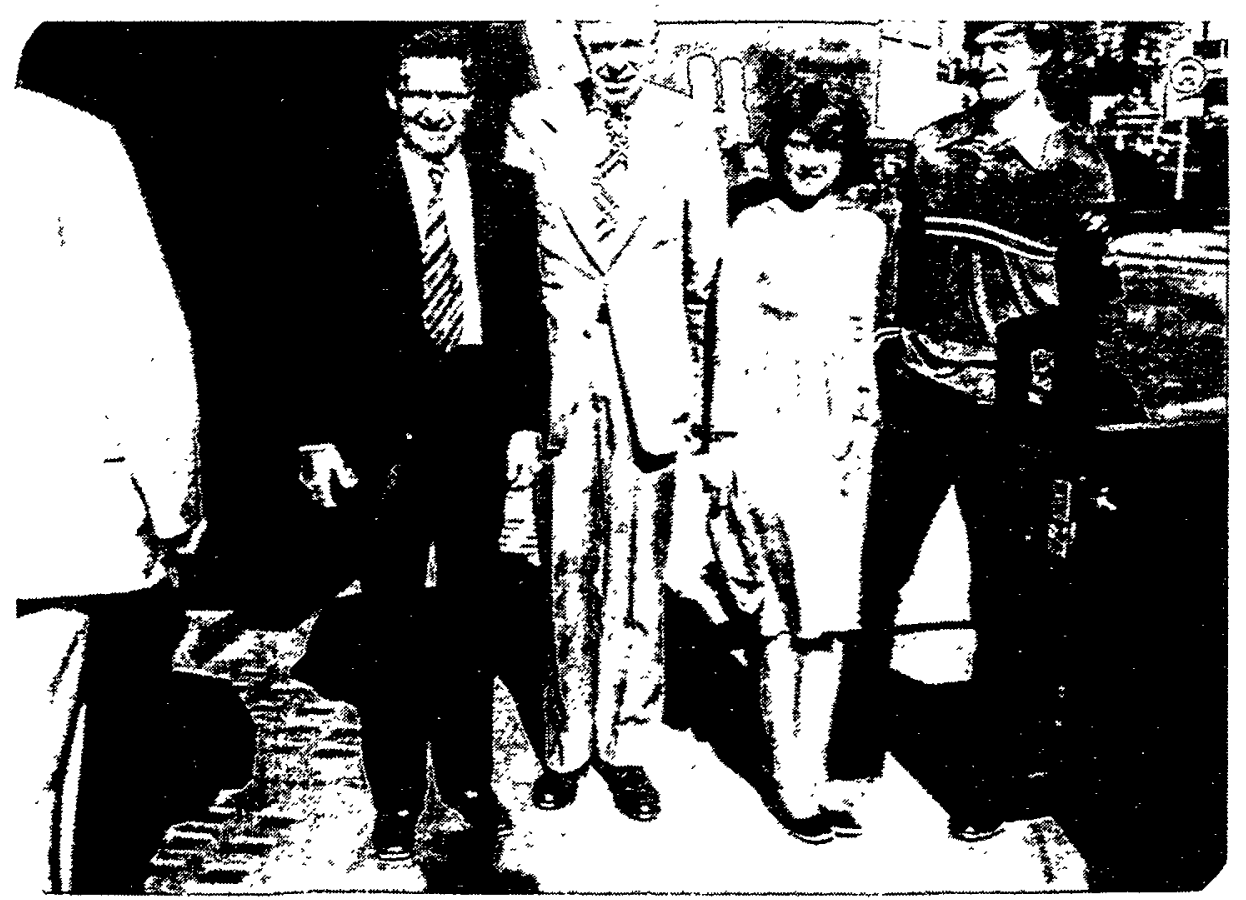

Paul Lochak, GTS, Annabelle, Eric Seaborg-entering taxi in front of Stone's Chop House.

Iondon, England--September 13, 1977.

GTS, Sir John Hill, Eric Seaborg--11 Charles II Street.

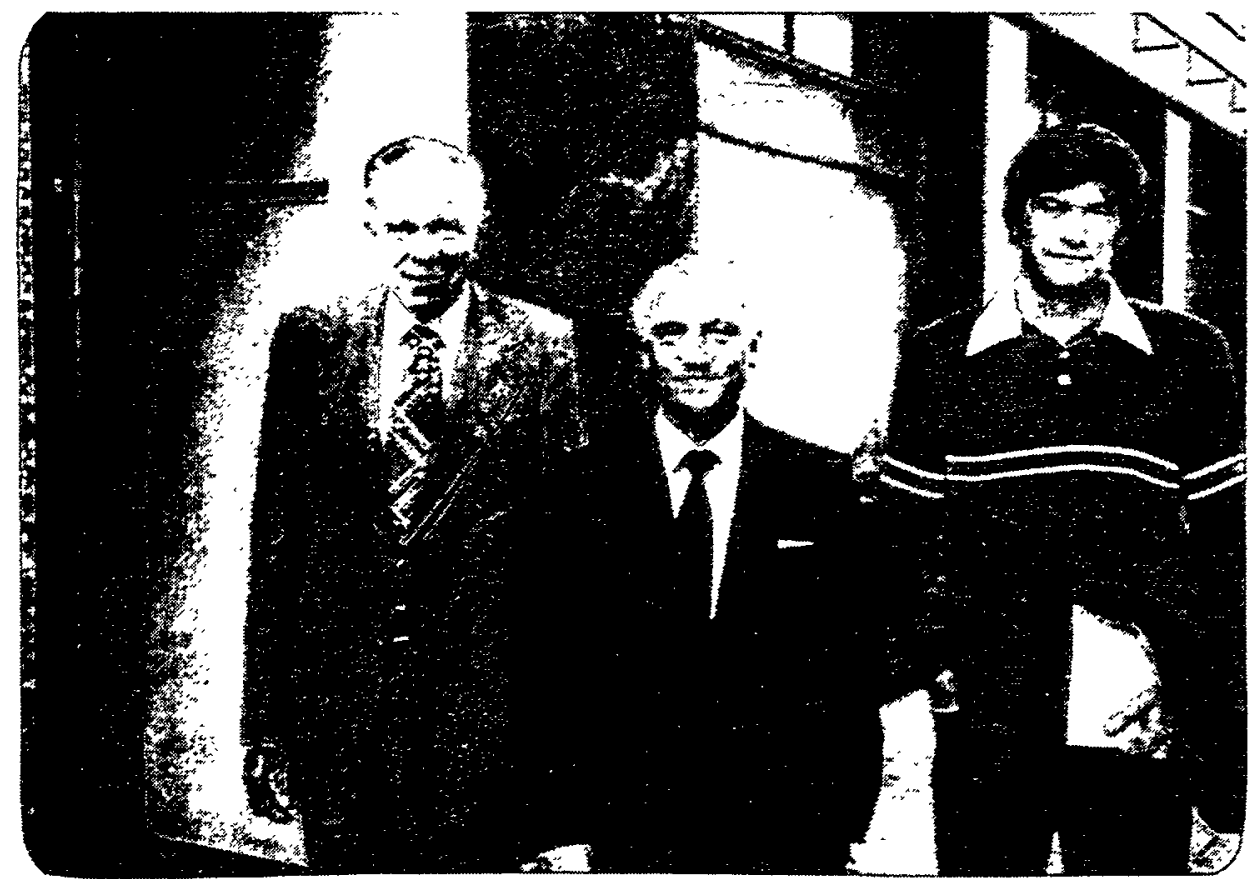


Tuesday, September 13,1977 (con't)

Lochak and I described the Geomet success at Crooks Gap, being exploited by Texas Gulf, and the apparent impending success foreseen by this summer's exploration northeast of Rawlins, Wyoming.

Iochak agreed to send Waddarns (with copy to Sir John Hill) a document describing the results of various Geomet explorations and outlining the terms for a joint venture between Getex and BNFI plus CEGB. Waddarns said he would welcome this, saying that an agreement for such a joint venture could be.consistent with BNFL (and CEGB) operations.

We then went to the nearby office, on the sixth floor, of BNEL Chairman, Sir John Hill. This is the same office where I met in the early 1960's with UKAEA Chairman Sir Roger Makins. UKAEA Chairman Sir William Penney also used this office. Craig Ash, Hill's executive assistant, joined us here.

Waddarns summarized the conversation he and Armstrong had just finished with Lochak and me and described the proposal that Lochak will make for a joint venture. Hill said he will look forward to seeing the proposal.

Hill and I then had a discussion of the status of nuclear power in the US, UK and worldwide. He thinks President Carter's recent emphasis on the need to tighten controls over plutonium and proliferation is a welcome and needed contribution, but his method for doing so is wrong and doomed to failure. He thinks the rest of the world must, and will, use plutonium as a nuclear fuel and develop nuclear fuel reprocessing. He thinks that all the talk by farter about developing an alternate fuel cycle, e.g., using thorium-U ${ }^{233}$, represents nothing new and holds little hope for improvement over the uranium-plutonium cycle in preventing proliferation; it signifies that it is the thinking of naive amateurs.

We also discussed the role of the fast breeder reactor. He thinks the UK program is doing well, is actually better than the French program and that the time scale worldwide is such that very little electric power (perhaps 4,000 MW) from fast breeders will be on the line by the year 2,000. However, such a program will put the world in a position for widescale use of the fast breeder at the time when the fueling of new light water reactors for their lifetime will be limited by the uranium supply.

He said that the development of practical electric power from the fusion reaction, although possibly it will be shown to be feasible from the standpoint of powering light bulbs within ten years, is proving to be extremely difficult and may, in fact, turn out to be impossible.

During these talks, Eric was in a neighboring room working on his article on the Golden Loop Trail.

Hill then accompanied Lochak, Eric and me, in his car with his driver, to the London Heathrow Airport. We continued our conversation 
on the nuclear power situation on the way. He fears that wars may very well result from the competition for the limited worldwide supply of oil, especially if oil-rich countries try to shut off the supply. He thinks Sigvard Eklund is doing a good job as Director General of IAEA, that he would be difficult to replace and it is good that he has agreed to serve for a fifth term. He mentioned again his interest in the radon method for exploring for uranium.

Hill saw us to the passport control and left us as we proceeded with Lochak to the boarding area. (Lochak was scheduled to fly to Paris on an Air France flight.) Eric gave Lochak his manuscript on the Golden Loop Trail, which Lochak will mail from Paris to Helen in Lafayette, after making a xerox copy.

Because our flight departures were delayed, Lochak, Eric and I had a bite to eat in the buffet area. Eric and I, a little later, boarded Iufthansa flight \#037, which left at 8:15 p.m. and arrived at Frankfurt Airport at 9:30 p.m.

We found that the handle on my three-suiter was pulled out when our baggage came, which made it difficult to bring our luggage out through customs. We were met by Günter Herrmann with a GSI driver and car and rode with him to the Weinmichel Hotel in Darmstadt. (I left my three-suiter with the driver to get it fixed tomorrow at the GSI Iab). Eric checked into room 306, I into room 402. I retired at $11: 00$ p.m.

Wednesday, September 14, 1977 - Frankfurt, Germany

Eric and I had breakfast in the Weinmichel breakfast room then rode with Jens Kratz to the GSI Laboratory. Here we met with Kratz, Herrmann, Helmut Ahrens, and later Heinz Gäggeler, in Kratz's office where they described to us the results from their experiments.

In the $\mathrm{Xe}+\mathrm{Au}$ bombardments, they separate $\mathrm{Au}$ isotopes into two charge dispersion curves: (I) quasi-elastic transfer, which includes $2^{-}$states, comes in below barrier and has $\approx 150 \mathrm{MeV}$ less energy than inelastic transfer (as observed by recoil range and angular distribution studieş and (2) inelastic transfer which includes $12^{-}$states (they use ${ }^{136} \mathrm{Xe},{ }^{13} \mathrm{Xe}$ and ${ }^{129} \mathrm{Xe}$ projectiles). The products at $\mathrm{Z}>2$ from $\mathrm{Xe}$ or $\mathrm{Au}$ show only deep inelastic distributions. They see products at $\left(z_{1}+z_{2}\right) / 2, \approx 50$ microbarns, that are due to deep inelastic reactions they are side peaked and do not follow 1/sine distribution). They see a few $\mathrm{mb}$ of isotopes $\mathrm{A}=80-100, \mathrm{Z} \aleph_{40}$, due to fission of $\mathrm{Au}$ which increases sharply with increasing Xe energy. The $Z$ distribution is perfectly symmetrical--hence no charged particle evaporation, only neutron evaporation. In the mass balance, they find a minimum of missing mass at $\mathrm{Xe}$, $\mathrm{Au}$ and strongly rising at greatest distance, e.g. Dy (66), Ho (62), indicating correlation of number of neutrons emitted with energy transfer in the deep inelastic process; this is for $5.9-\mathrm{MeV} / \mathrm{A}^{129} \mathrm{Xe}$-here they are only $25 \mathrm{MeV}$ above the barrier so loss of 15 neutrons must be due to deformation of fragments (i.e., lowering of coulomb barrier in this region of high deformability). Moretto has arriyeg at the same conclusion from counter data. Plots of $\mathrm{N} / \mathrm{Z}$ for $129 \mathrm{Xe},{ }^{132} \mathrm{Xe}$ and $136 \mathrm{Xe}$ bombardments demonstrate that there is complete $\mathrm{N} / \mathrm{Z}$ equilibration except for the region close to $\mathrm{Z}=$ 
Wednesday, September 14, 1977 (con't)

79, (due to too short a reaction time). Their recoil range and angular distribution studies show strong side peaking near $\mathrm{z}=54, \mathrm{Z}=$ 79 and still side peaking at point of symmetry $\mathrm{Z}$ 스. 68 .

Next we discussed the $U$ plus $U$ reaction. They have finally learned how to remove all $\mathrm{Ra}$ and $\mathrm{Ac}$ from the actinide fraction and can now do it in an hour (using high pressure chromatography). They look for $\mathrm{Z}=126, \mathrm{~N}=228$ in the actinide fraction--all negative results so far. Their 60\% QET - 40\% DIT may be due to the fact they are only $10 \%$ above the barrier (average energy) where QET predominates. In the goldfinger, there is an 8-neutron evaporation at $A u$ and 2-neutron evaporations at Th as shown on the mass distribution çurve. For

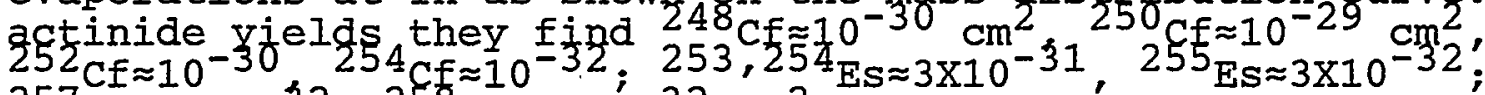
257 Fm<2.10-32; $258 \mathrm{Md}<2.10^{-32} \mathrm{~cm}^{2}$.

They compared their actinide yields with sikkeland $\Gamma n / \Gamma f$ values and found good agreement. Heinz Gäggeler made these calculations using the mirror extrapolation of the goldfinger to get the number of neutrons emitted in the primary reaction and the consequent excitation energy. They will publish the U plus U mass distribution (perhaps in Physical Review Letters); here they will only mention the actinide yields. Their fimit on the 150-day S.F. activity from $136 \mathrm{Xe}$ on $U$ is $10^{-36} \mathrm{~cm}^{2}$ (2X1017 particles total for two runs at $\left.7.5 \mathrm{MeV} / \mathrm{AMU}\right)$. They found zero counts in 80 days for both chemistries. The kinds of chemistry were: (1) wet chemistry with bromide complexing and diethyldithiophosphoric acid extraction (Baden Baden paper) and (2) Eichler volatilization chemistry. The Marburg group also did chemistry with Cds precipitation with a limit of $10^{-3} \mathrm{~cm}^{2}$.

Gäggeler, who just came from a visit to Dubna, said Dubna now has 29 S.F. events (without chemistry), for a total flux of $10^{17}$ and 6.2MeV/Amu over 350 days, which decay with a half of $150+200-60$ days. This means GSI should have seen only 4 events in 60 days. Oganessian claims that their lower energy is the key factor because the production has a narrow energy window. Dubna finds, in 11 events, 5 events with 0 neutrons, 3 with 1,2 with 2 , 0 with 3, 1'with 4 and 0 with 5 with $23 \%$ efficiency for detection of all neutrons, corresponding to $\bar{\nu}=4.5 \pm 1$. . In $\mathrm{Xe}$ on $U$ recoil fragment measurement (titanium catchers with mica detection) they find a mean range from 8 events of $5 \mathrm{mg}$ per $\mathrm{cm}^{2}$, which corresponds to a mean total energy of $185 \mathrm{MeV}$. They claim it is not Cf because, in the early experiment, they found 6 S.F. in $C d S$ and 1 in actinide fraction. It appears that this can be explained by the production of $254 \mathrm{Cf}$ which has a measured cross section of $10^{-34} \mathrm{~cm}^{2}$.

Gäggeler gajye me the fol $\frac{1}{3}$ owipg yields of açinides frim $U$ plus $U$

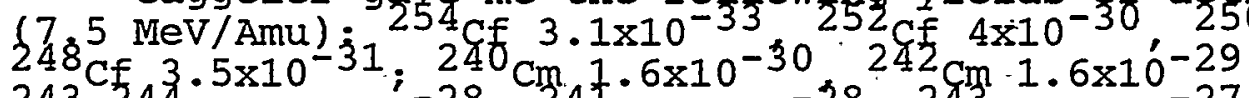
$243,24{ }^{3} \mathrm{Cm} 4.3 \times 10^{-28} ; 24 \mathrm{I}_{\mathrm{Am}} 5 \times 10^{-28}, 243 \mathrm{Am} 6 \times 10^{-27} \mathrm{~cm}^{2}$. He also gave me a copy of Flerov's Tokyo talk on superheavy elements.

I then made a tour of radiochemistry laboratories, with Herrmann, Kratz, Ahrens, Gäggeler and Eric. I saw Kratz's high pressure ion 
Wednesday, September 14, 1977 (con't)

exchange system; this uses $30 \mathrm{lbs}$. pressure. Gäggeler next showed us his high temperature volatility apparatus for separation of SHE based on the Zvara-Eichler system. I met Mrs. Heidi Gäggeler, who works with her husband. I next saw the electroplating and molecular plating (from organic solvents) apparatus; they plate all their samples for final S.F. and alpha counting.

We went to a room upstairs where Kratz has moved his counting apparatus; neutrons from Unilac bombardments interfered with his previous counting room location. They have eight solid state counters for actinide alpha and S.F. detection and four double-chamber (coincidence) counters for S.F. detection of SHE mounted on vyns foils. Gäggeler mounts his samples from high temperature separation on thin-nickel foils for coincidence counting.

We went to another room where an equal number of alpha and S.F. coincidence counters are being set up in transparent chambers so the samples can be seen as they are being counted.

Eric and I went to meet Christoph Schmelzer, then had lunch with Schmelzer, Herrmann, Ahrens, Gäggeler, Kratz, Reinhard Brandt and Herman Wollnik (who is from the University of Giessen, works with Brandt on the He jet apparatus) in the GSI cafeteria. We discussed the Dubna work on SHE; there was much skepticism voiced.

After Iunch, I visited the He jet set-up with the Giessen-Marburg group. Erich Georg, Peter Lemmertz and Rainer Foss, all from the University of Giessen, and Hartmut Jungclas and Reinhard Brandt from the University of Marburg showed me the system and described it to me. (They will give me some diagrams and data charts tomorrow when I visit Marburg.) They have a collection efficiency of $\approx 60 \%$. Aumann (of Munich) uses this for his work on volatile products. They also showed me their apparatus in the neighboring room to measure alphas and time of flight of alpha recoil nuclei to get the mass within $10 \%$. With the He jet transport, they have used the ${ }^{86} \mathrm{Kr}$ plus $103_{\mathrm{Rh}}$ reaction to find new alpha emitters and delayed proton emitters in the new neutron deficient TI region.

Next Peter Armbruster and Ernst Roeckl showed me their mass separator apparatus. They have used this up to $\approx 213_{\mathrm{Fr}}$. From $58_{\mathrm{Ni}}$ plus 58 they find a new region of alpha and delayed proton emitters around $110_{I}$ and $108 \mathrm{Te}$.

Herrmann and Armbruster showed me "Das Heidelberg Fass;" a huge vacuum tank about 3 meters in diameter and 3 meters high, with a huge scattering chamber for use in high geometry detection of S.F., alpha, etc. This will be applicable to more than 2 particles in coincidence.

After a short stay in Herrmann's office, I went with him down to the entrance area for the pre-seminar tea, coffee and cookies. Among the group here was Volker Metag, who came over from Heidelberg. He said he could work with me at LBL for a $1 \frac{1}{2}$ year stay starting sometime between October 1978 and March 1979. He and Habs cannot leave Heidelberg at the same time and Habs plans to come to Berkeley next spring 


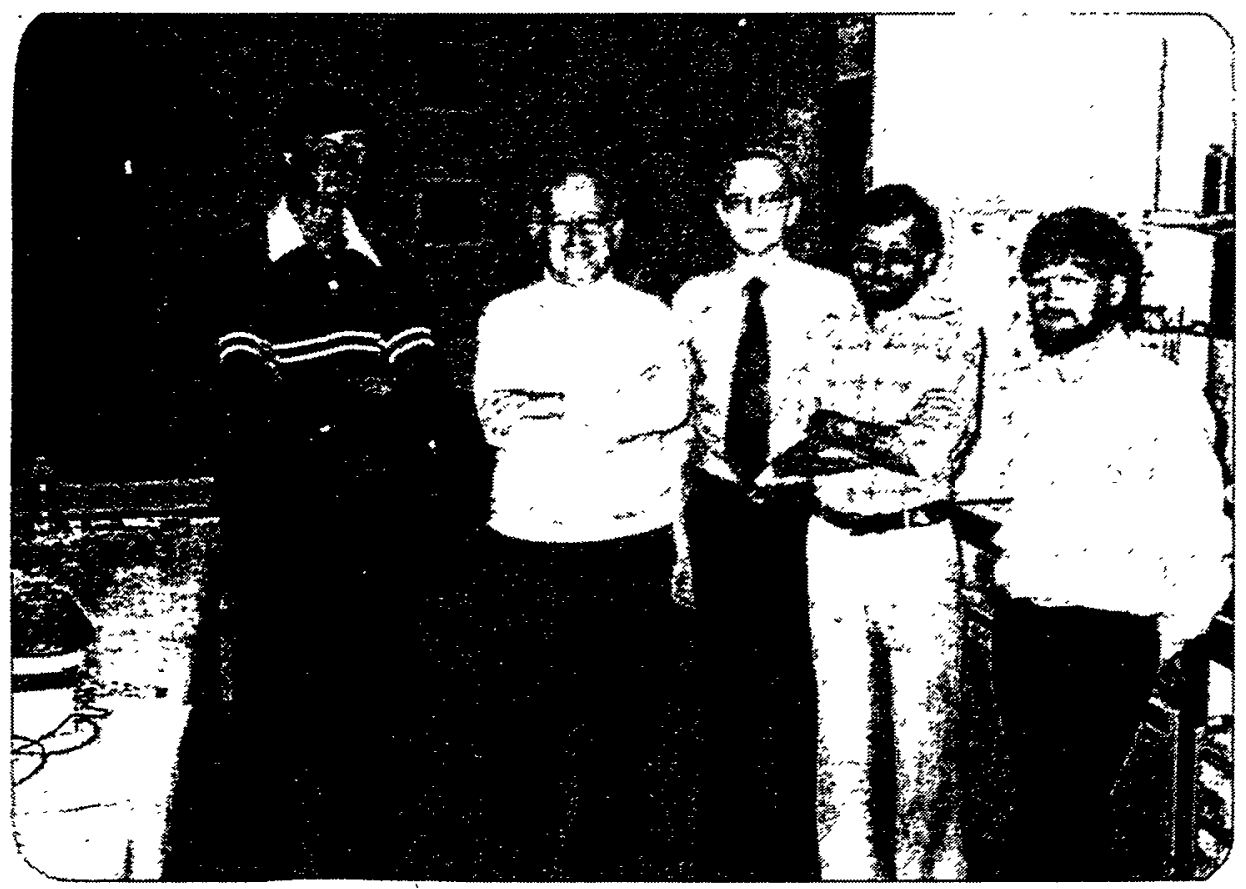

Eric Seaborg, Günter Herrmann, Helmut Ahrens, Jens Kratz and Heinz Gäggeler, GSI, Darmstadt, Germany--September 14, 1977.

Eric Seaborg on the second level of Eiffel Tower, Paris, France--Septémber 16, 1977.

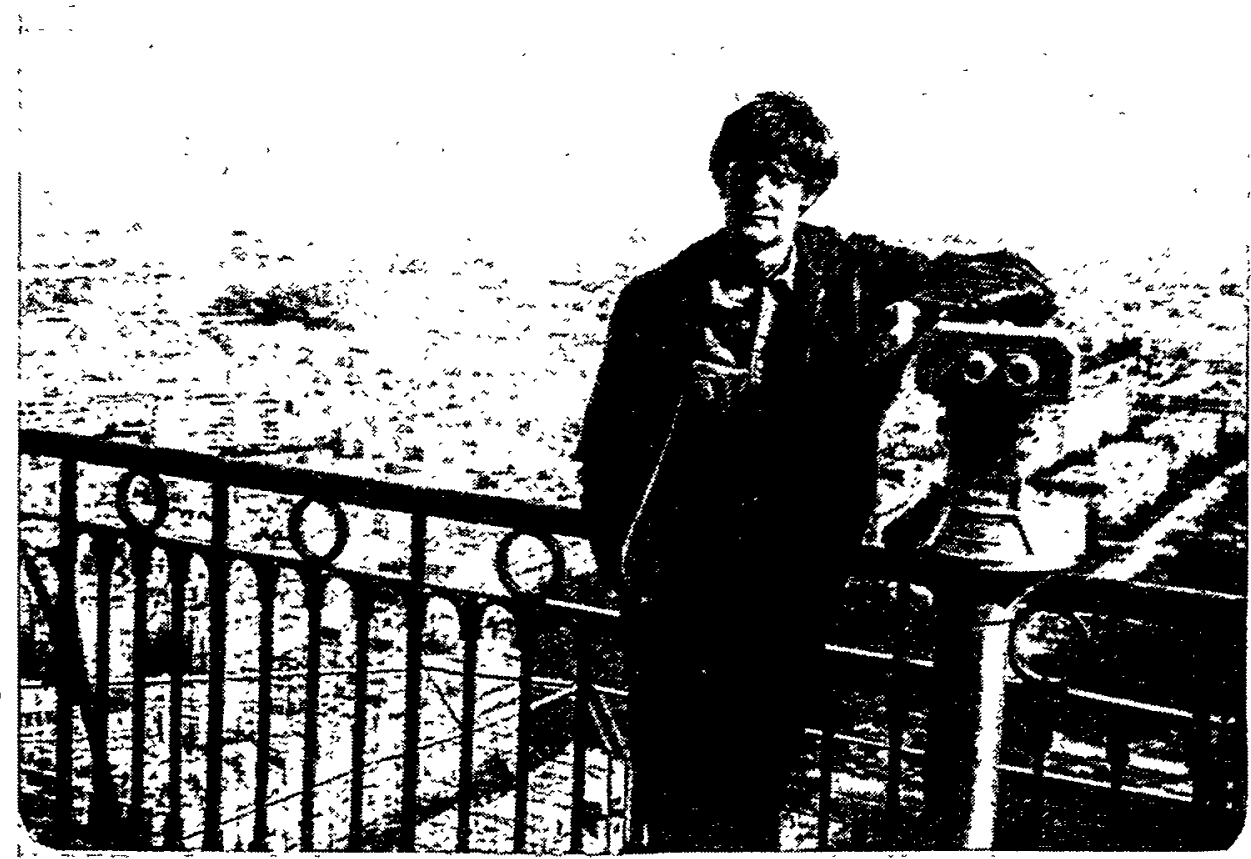


Wednesday, September 14,1977 (con't)

(perhaps to work with Diamond and Stephens). Habs is at the University of Heidelberg and Metag at the Max Planck Institute; both work for Hans Specht who is Professor at Heidelberg and needs at least one of them to help run his classes. I also talked to Manfred Dietrich; he now believes his explanation for our recoil range results is untenable--he was quite interested, however, in the two component range in the ${ }^{136}$ Xe plus 197 Au results.

We then went to the full, neighboring auditorium where Herrmann introduced me for my talk on radiochemical investigations with heavy ions and search for superheavy elements. I used the 29 slides (but no transparencies). The talk was followed by a question-and-answer period. There was interest in the lowered fusion cross section of $48 \mathrm{Ca}$ plus $208 \mathrm{~Pb}$.

After my lecture, I talked to Wolfgang Nörenberg. He will send me his latest calculations on nucleon exchange in deep inelastic scattering. He is interested in finding a shell structure effect. (Kratz told me he finds a small shell structure effect at $\mathrm{z}=50$ and $\mathrm{z}$ $=82$ from Xe plus Au.)

Metag tolg me about his interesting results that seem to confirm
our ${ }^{48} \mathrm{Ca}$ plus $20{ }_{\mathrm{Pb}}$ results. He has bombarded $48_{\mathrm{Ca}}$ with $238_{\mathrm{U}}$ near the barrier and finds an asymmetric distribution of fission products with peaks at $\mathrm{z}_{1} \stackrel{\wedge}{=} 82, \mathrm{z}_{2} \stackrel{\underline{\mu}}{3} 3$, peak to valley ratio $\approx 3$, which he believes to be due to fusion-fission, using counter ( $E-\Delta E)$ techniquej zt higher energy this distribution becomes symmetric. However, with $208 \mathrm{~Pb} \mathrm{plus}$ ${ }^{4} \mathrm{Ca}$ near the barrier, or higher energies, he finds no products close to $Z=50$, indicating no fusion-fission within accuracy of his experiments. Metag gave me 4 reprints.

Eric had walked back to our hotel after lunch. Ahrens, with Herrmann, drove me back to our hotel. We picked up Eric, then drove to Herrmann's home in Mainz. Here the dinner group consisted of Dr. and Mrs. (Ellen) Herrmann, and their daughter, Eric and me, Dr. and Mrs. Kratz, Peter Armbruster, Dr. and Mrs. Ahrens, Dr. and Mrs. Norbert Trautman, Dr. and Mrs. Gäggeler, Dr. Schmelzer, Dr. and Mrs. RoeckI, Dr. and Mrs. Helmut Ringsdorf (he is a polymer chemist at the University of Mainz) and Dr. and Mrs. Klaus Beyermann (he is head of Chemistry Department at University of Mainz, in charge of translating Chem Study text and films into German, which are used at College freshman level in Germany).

Gäggeler told me Zvara can't get any bombardments at Dubna; he surmises he is unhappy and may leave. He and his wife spent $1 \frac{1}{2}$ years at Dubna, living in a one-room apartment. He said that Flerov insists that all bombardments be directed toward SHE and other transuranium elements.

Kratz said he would be glad to come to Berkeley for another stay, starting about 2 years from now. He and Herrmann said Metag is an extremely good man, maybe the best in Germany in his field in his age group (he is a physicist). 
Eric and I rode back to our hotel with Dr. and Mrs. Jens Kratz. He told me he will send me a copy of their latest chemical separation scheme which finally separates Ra and Ac and the German address of a source of cation exchange resin that is as good as Dowex-50 used to be. Krat; gave me $\xi_{3}$ opies of the Hildenbrand article on "Reaction between $238_{\mathrm{U}}$ and $238 \mathrm{U}$ at $7.42 \mathrm{MeV} / \mathrm{N}$ " and his article "Charge Asymmetry Equilibrium in Reaction of Xe with Au near Interaction Barrier" both submitted to Physical Review Letters. I retired at about midnight. Thursday, September 15,1977 - Frankfurt, Germany - Marburg, Germany -
Paris, France

Eric and I had breakfast in the Weinstube, then checked out. I paid for our room ( $\$ 228.50$ marks, to which I applied the 200 marks I received for my lecture yesterday). We then rode with a University of Marburg driver in the president's Mercedes along with Dr. Hans Joachim Becker and Brandt to the University of Marburg. Eric then went sightseeing in Marburg with Mrs. Marie-Lou Esterlund.

On the way. to Marburg, we discussed the planned stay of Becker at IBI to work with me. He will apply for a NATO fellowship to start in August 1978. The University of Marburg will support him. 2-3 months before that and, if he comes still earlier, LBI will support him $(\approx \$ 1,100$ a month). His coming is contingent on his not getting a tenure job in industry. His NATO fellowship will.give his research project ti.tle as "Radiochemical Investigation of Reactions Induced by Relativistic Heavy Ions (RHI)." He will also work on superHILAC bombardments. He will learn gamma spectroscopy and He jet technique before leaving Marburg.

Brandt gave me 350 marks for my talk. We then had tea, coffee and cookies with the staff in the commons room.

I met with Bob Esterlund, Anna Marie Haberstadt, Alex Boos, Wolfram Westmeier and Paul Patzelt in Esterlund's office. I will add

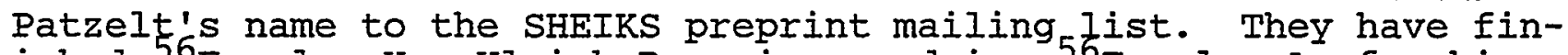
ished ${ }^{56} \mathrm{Fe}$ plus $U$. Ulrich Reus is now doing $56 \mathrm{Fe}$ plus $\mathrm{Au}$ for his Ph.D. thesis. (Bombardments done at Manchester.) 56 They gave me a

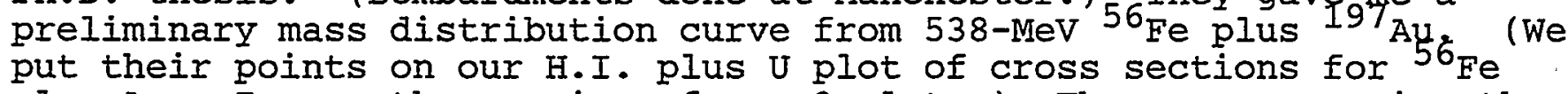
plus Au. I gave them copies of our 3 plots.) They are now using the Unilac at GSI. They have done 3 bombardments of $132 \mathrm{Xe}$ on nat $\mathrm{Fe}$ (599, $779,944 \mathrm{MeV})$ and have processed data for $779 \mathrm{MeV}_{132}$ They haye done angular distributions for $944 \mathrm{MeV}$. For $779 \mathrm{-MeV} 132 \mathrm{Xe}$ on $56 \mathrm{Fe}$, they get $\approx 50 \mathrm{mb}$ for $\sigma_{\mathrm{ER}}$. Here they have the problem of separating the fusion-fission component from the deep inelastic components--the peak yield is $A \approx 88, \mathrm{Z} \approx 40$. The charge (mass) dispersion curves at $A \approx 180-185$ (for evaporation residues) are very narrow (FWHM<1.5 mass units). Westmeier is working on $132 \mathrm{Xe}$ plus ${ }^{56} \mathrm{Fe}$. They may do Ti on U (to fill in between $A r$ and $F e$ on $U$ ) if the SHEIKS do not plan to do this; I said we do not plan to. Also, they may begin to bombard thin, rather than thick, targets; here they may do Fe plus $U$ at near barrier and higher energies. They would like a suggestion for someone to come to work with them for a year (e.g., on a von Humboldt fellowship). They will mail me a gamma ray catalog ( up to $A=140$ ). I promised to send them Binder's gamma ray table. 
Thursday, September 15, 1977 (con't)

I then went to Heinz Duschner's office to discuss with him the work of Kurt Starke's group. Duschner worked with Born in Munich in 1970-1975. John McMinn joined us. He worked with Hans Ihle at Julich on the search for element 114 in nature. (He gave me a reprint on this.) Duschner described his work in analytical chemistry and McMinn his work on the search for element 114. (McMinn will send me his thesis describing this in detail.)

Duschner then took me on a tour of some laboratories. He showed me a gas analysis laboratory where I met Wiendt and Schorr. We then went to the neutron generator area where Karl Heinz Hellmuth (who worked with Valli in Finland) showed me his jet system, which involves separation with a centrifuge, and the Phillips neutron generator. McMinn also works here on neutron activation analysis.

We went to lunch in a commons room. Here I met Mrs. Becker, Professor Reinhard Helmbold (a source of giant halo micas for Brandt) and a number of others--a total of some 20-30 people. We had a typical German lunch (brockwurst, etc.) with beer. This is the room in which the members of the Kernchemie Institut (Nuclear Chemistry Institute or group) have tea every day at 10:30 a.m.

There are only three tenured members (Starke, Patzelt, Brandt), some postdocs, graduate students, technicians, etc. Professor wilhelm Walcher (who worked at CERN on the isotope separator and is an expert on gas jet transport) joined us for Iunch. Eric and Mrs. Esterlund also joined us.

Brandt wants me to send him our SHEIKS preprints and wants a copy of our ${ }^{48} \mathrm{Ca}$ plus ${ }^{208} \mathrm{~Pb}$ paper; he also wants to be put on list for Nitschke preprints.

Esterlund gave me several pages of Equations from KINEW (Kinematics from Esterlund and Westmeier) for applications to our problems and copies of mass distribution from $538-\mathrm{MeV}{ }^{56} \mathrm{Fe}$ plus $238_{U}$ and correlations of \% Fusion-Fission vs. $\mathrm{z}_{1} \mathrm{z}_{2}$ and vs. acrit-ainj and calculation of ${ }^{48} \mathrm{Ca}$ plus ${ }^{248} \mathrm{Cm}$ critical parameters.

I gave copies of three LBL SHEIKS reports to Brandt (LBI 6509, $6527,6534)$ so he could make xerox copies. Becker gave me a copy of his thesis, "Kernreaktionen Induziert von ${ }^{136} \mathrm{Xe}$ in Uran." Esterlund took a picture of me at the blackboard for their speakers file.

After lunch, I went to Brandt's office. The group at various times included Hermann Wagner, Walcher, Becker, Brandt, Torgeir Lund, Vater, Peter Gottschalk, Helmbold, Dieter Molzahn, Gerhard Tress, Hartmut Jungclas, Amal Mazumdar and Wilhelm Werner.

Wagner described the He jet coupling to an Isotope separator (responsibility of Professor Walcher). He works one day a week at the TRIGA reactor at the University of Mainz. Wagner gave me 3 reprints.

Becker next took me to the "Holy Cow," the neutron detector used to look for SHE. Here he looks for SHE from CdS from ${ }^{136}$ Xe (925-1140 
Thursday, September 15, 1977 (con't)

MeV) plus U, Allende meteorite, etc. No S.F. with neutron coincidences have been observed. They set a limit on yield of the 150-day S.F. of $10^{-35} \mathrm{~cm}$; this includes work at Flerov's Xe energy and Flerov's low beams. so no difference in loss of SHE due to volatility should exist. Iund then showed me his laboratory where Allende meteorite is dissolved and chemistry is done (sulfide is precipitated after dissolution).

Next, we went to Molzahn's laboratory where he is working on giant haloes. They find some haloes have no detectable radioactivity in the inclusion. He has found ng S.F. counts during four months counting of giant halges. For $242 \mathrm{Cm}$ from 136 Xe plus $U(8 \mathrm{MeV} / \mathrm{N})$, they get $3 \times 10^{-30} \mathrm{~cm}^{2}$, for ${ }^{254} \mathrm{Cf}$ they get less than 1 event/70 days (but chemical yield of $\mathrm{Cf}$ was not too high). They have excellent detection apparatus for long S.F. and alpha counting.

In a neighboring room, Vater showed me some giant haloes under microscopes. He showed me a 4-prong fission track from $U$ plus $U$ (they use $10^{6} \mathrm{U}$ ions per $\mathrm{cm}^{2}$ directed into mica with $U$ on surface, $\approx 1$ $\left.\mathrm{mg} / \mathrm{cm}^{2}\right)$.

Then we went back to Brandt's office where Peter Gottschalk described his treatment of time sequence in sequential fission (he works with Professor Grawert). In a 3-prong $\mathrm{Kr}$ Plus $U$ event, he concludes that the U fission occurs in $>3 \times 10^{-21}$ seconds after the time of closest approach of $\mathrm{Kr}$ to $\mathrm{U}$ (this was a quasi-elastic collision).

Next, we went to an applied nuclear technology laboratory where Tress showed me the production of Mica-sieves produced by heavy ion irradiations. These can be used to clean air. Perhaps production cost will be competitive with Nucleopore-Micropore of California (made with fission fragments). Such sieves are used heavily in the U.S. for medical purposes. Flerov makes such sieves as well.

Next we went to Jungclas's laboratory. He is working on a Timeof-Flight Mass Analyzer for Bio Molecules (like McFarlane of Texas $A \& M)$; he intends to use laser pulses for ionization.

We then went back to the commons room for tea, coffee and cookies preceding my talk. Most of the luncheon group was there. I talked with Hans Becker. He worked $3 \frac{1}{2}$ years for his $\mathrm{Ph} . \mathrm{D}$. and built the "Holy Cow," based on the S. G. Thompson system. The Beckers have a 1-year-old daughter. He gave me three papers: (1) A xerox copy of their Physical Review Letters paper "Study of Heavy-ion Induced Reactions on Uranium with Use of Mica Detectors," (2) a manuscript "Search for Superheavy Elements in the Meteorite Mundrabilla" and (3) a reprint of "Search for Eka-Gold and Eka-Lead in Nature Using the spinner-Techniques."

$209_{\mathrm{Bi}}$ and and $136_{\mathrm{Xe}}$ plus $23{ }_{\mathrm{U}}$.

We went to an auditorium in a nearby building where I gave my talk "Recent Experiments in Nuclear Chemistry Using Heavy Ions and 
Searching for Superheavy Elements," using the 29 slides (no transparencies). There was time for only one question (on predicting chemistry of SHE).

After my talk, Brandt said he doesn't agree that there is a deep inelastic (third) component in the iodine isotopes from $4 \mathrm{Ar}_{\mathrm{Alus}} \mathrm{U}$ and gave me a reprint "The Production of Iodine and Bromine Isotopes from Uranium at High Proton Energies;" which he thinks contradicts our interpretation.

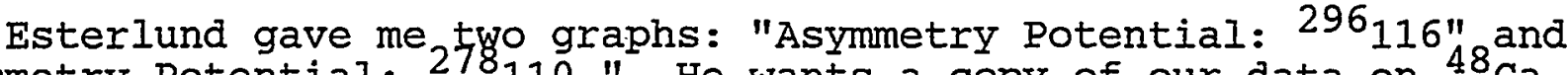
"Asymmetry Potential: $278110 . "$ He wants a copy of our data on $48 \mathrm{Ca}$ plus Ce because they form the same compound nucleus (Pt) another way.

I met Eric, who had spent the afternoon sightseeing in Marburg with Mrs. Esterlund, using the University of Marburg's president's car. She presented Eric and me each with a box of Marzipan candy from her aunt (mother's sister) who was visiting her.

Eric and I said goodby to our hosts, then rode to the Frankfurt Airport with the driver in the University of Marburg Mercedes. The bent frame of Eric's back pack (caused by Iufthansa) was fixed at the University of Marburg.

We boarded Air France flight \#747, which left at 7:30 p.m. and arrived at Paris DeGaulle Airport at 9:10 p.m. We were met by Roxanne Goldsmith and took a taxi to the Hilton (Eiffel), where Eric and I checked into room 319. I retired at 11:00 p.m., Eric a little later.

Eriday, September 16, 1977 - Paris, France

Eric and I had breakfast in the hotel in Ie Coffee Shop. Roxanne joined us there. She told me she has had a falling out with Paul Lochak, is now actually on sick leave. She drove us to SIT (at 61 Rue des Belles Feuilles) and returned home. Eric talked to Paul awhile, then left to explore Paris.

Olivier Giscard d'Estaing joined Paul and me. We discussed Olivier's forthcoming book Social Capitalism in which he quotes from Man and Atom on nuclear power problems.

At 10:15 a.m., Simone Gregori and Giuseppe Laurenti of Agip, the Italian Oil and Uranium Exploration Company, joined us (Agip, with 90\% exploration in oil and $10 \%$ in uranium, is associated with Italian ENI, National Agency for Hydrocarbons). Olivier left us after about 15 minutes. Paul recapitulated the results of his negotiations on a joint uranium exploration in the U.S. conducted during the last two days with Gregori and Laurenti. The proposed agreement between Getex and Agip for a five phase uranium exploration program in the U.S. is as follows: (1) Exploration to cost $\$ 700,000$, funded $30 \%$ by Getex and $70 \%$ by Agip; (2) continued exploration to cost $\$ 475,000$, funded $40 \%$ by Getex and $60 \%$ by Agip; (3) exploration and discovery drilling to cost $\$ 3-5,000,000$, funded $50 \%$ by Getex and $50 \%$ by Agip; (4) development and (5) production. If, in phases 4 or 5, one party (Agip) elects to proceed alone the other party (Getex) can reenter by paying $50 \%$ of cost to date plus interest on this $50 \%$, plus $15 \%$ additional interest. 
They expressed some concern as to whether the U.S. government might change its present policy. of allowing export of uranium discovered in the U.S. by a foreign country some time in the future; this question could not be answered.

Pending some remaining problems concerning Getex obligation under phase 3, the agreement might be approved by the Italian government within a few weeks and signed by Agip and Getex soon thereafter (after october 20). The exploration will probably be in Colorado, Wyoming, Arizona, or. New Mexico, and could begin before the end of this year.

Eric returned at noon, then we rode with Paul to Cercle du Bois de Boulogne (a private club) where the three of us had lunch at an outside table in somewhat chilly weather, with Paul's parents, Boris and Rose Lochak.

Paul, Eric and I returned to SIT for a while. I wrote a note to otto and Morrissey about Metag's confirmatory work on $48 \mathrm{Ca}$ plus $208_{\mathrm{Pb}}$ (no observable fusion-fission) and Eric sent his "Golden Loop Trail" manuscript to Helen.

Iater in the afternoon, Eric and I walked to the Eiffel Tower and climbed to the second level. I did some more climbing by going down to the first level twice--a total of about 1,500 steps.

I took a taxi back to SIT while Eric did some more sightseeing. I discussed with Iochak the text of letters I might write to the President of Brazil, President of Brazilian Nucleblas and Akbar Etemad (Chairman Iranian AEC) regarding possible uranium exploration programs in cooperation with Getex.

Eric came soon thereafter and we drove to Paul's apartment. Francine Caland, joined us for drinks. We then went to Le Western at the Hilton, where we were joined by Claud Morel and the five of us had dinner. I met Francine when steve and I visited in september 1973. claud is an architect who was involved in the design of the new, high Hilton Hotel in Paris.

\section{$11: 30$ p.m.}

After dinner, Eric and I went up to our room ánd retired at about Saturday, September 17, 1977 - Paris, France - Athens, Greece

Eric and I checked out of our room, checked our two big suitcases, two suits and his pack in the check room at the Hilton (with considerable difficulty) and joined Paul in a taxi to orly Airport. Here we boarded Air France flight \#600, which left at 9:15 a.m. and arrived in Athens, Greece, at 1:00 p.m. We were met by Anthony Delyannis, President of the Greek AEC, and rode with him and his driver to the King's Palace Hotel, where Eric and I checked into room 406, Paul into room 411 .

We walked to the nearby king George Hotel and had lunch in the restaurant on the 7 th floor (with a view of the Acropolis). After a brief return to the King's Palace Hotel to pick up my cameras, Paul, Eric and I took a taxi to the Acropolis. Here we walked up to the top 


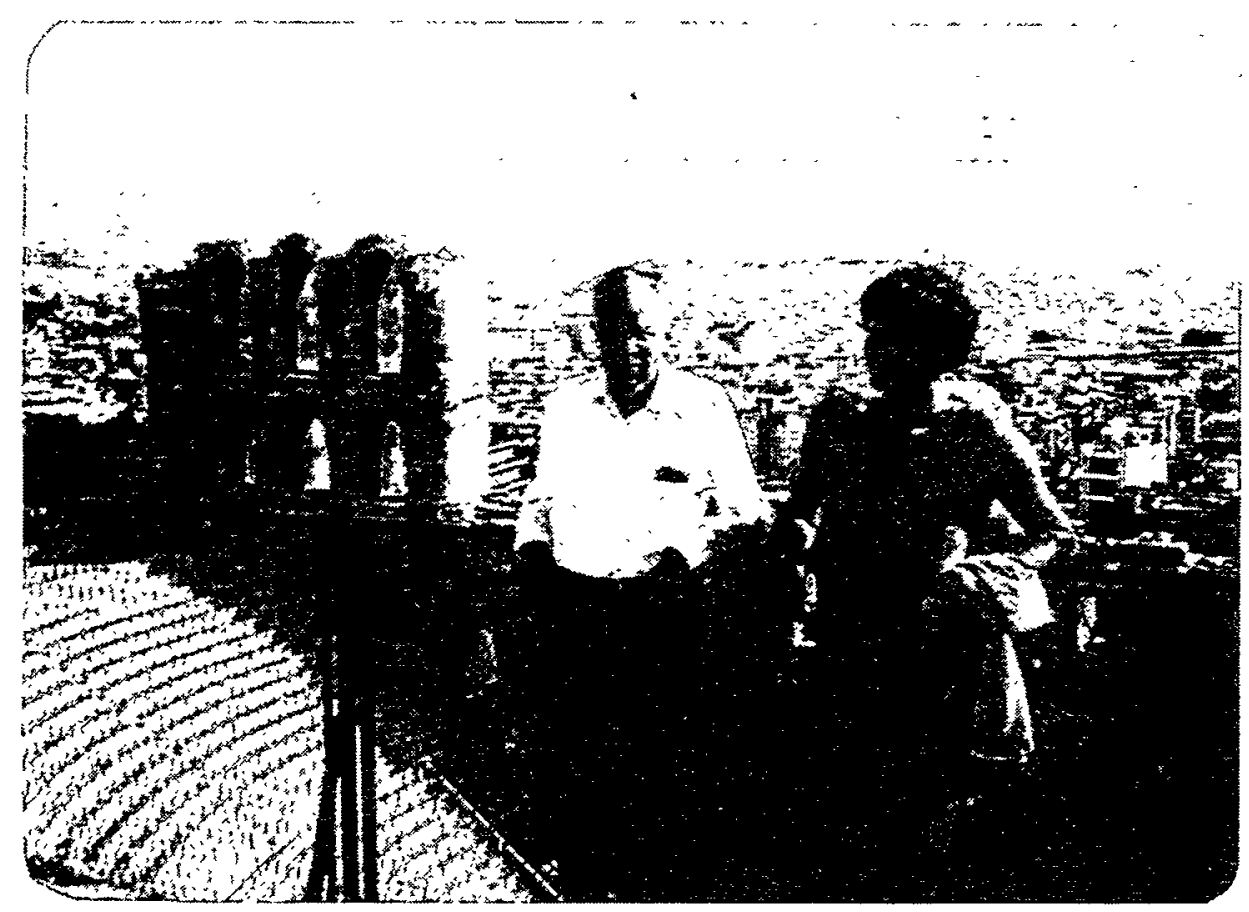

GTS and Eric Seaborg at the Parthenon with second century amphitheater in background.

Athens, Greece--September 17, 1977.

Eric and GT Seaborg at the Parthenon.

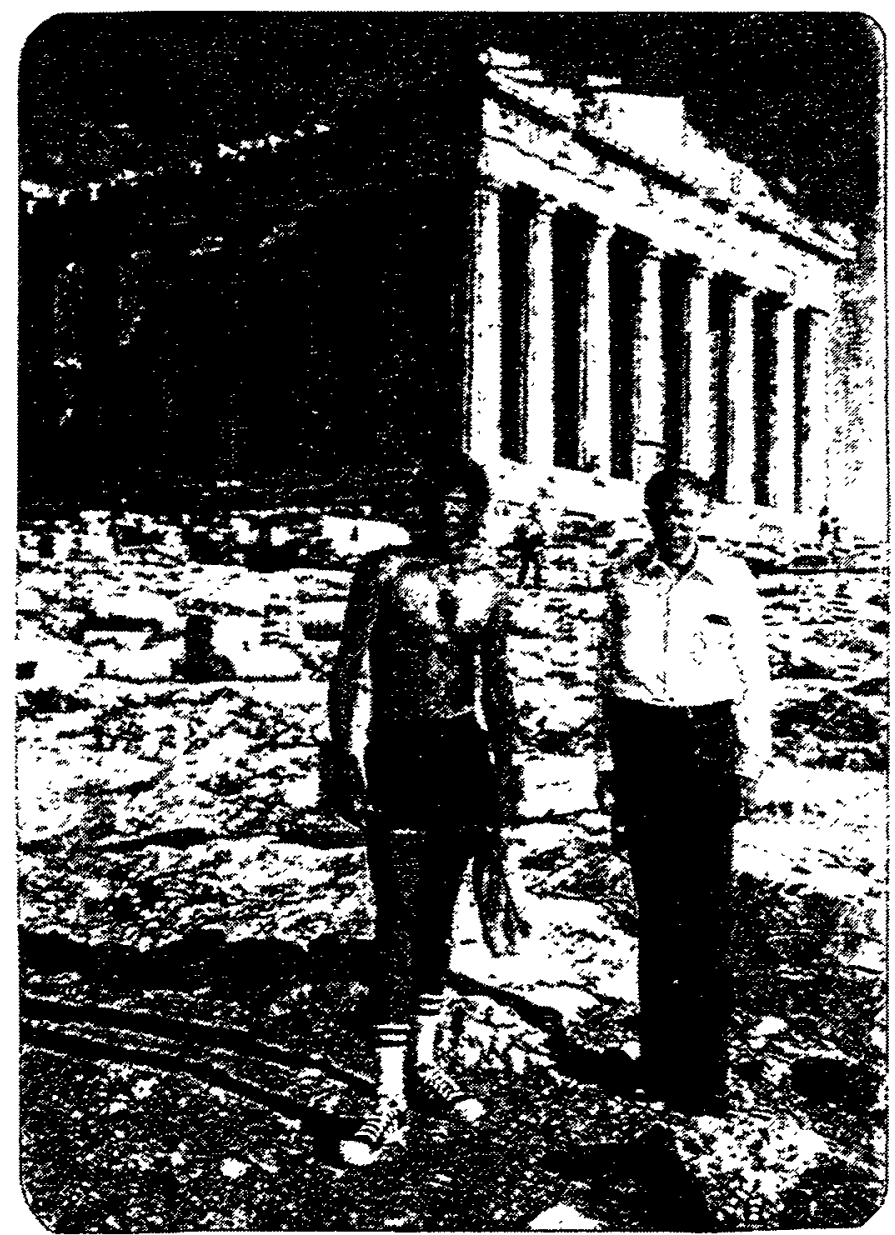


of the hill, walked around the whole area and especially around the Parthenon. Paul returned to our hotel at 5:45 p.m. Eric and I walked down the path to Ancient Agora, viewed the market place ruins, the Church of the Apostles (restored in the 11th century), Temple of Hephaistes and the foyer of the Agora Museum.

We then walked back to the Kings Palace Hotel and Paul, Eric and I rode with President Delyannis's driver to Valsilenas Tavern in Piraeus for dinner hosted by Anthony and Eurydike (Mrs. Anthony) Delyannis and also attended by Dr. and Mrs. Roger Morse (he is doing solar energy research at the Commonwealth Scientific and Industrial Research Organization, CSIRO, Melbourne Australia). Delyannis is a chemical engineer, specializing in water desalination. The owner of the restaurant, Vasilenas, was a chemical engineer, one of Delyannis's students. Delyannis is professor-emeritus at Technical University (Institute of Technology) in Athens. He is going to a conference on moving icebergs from Antarctica (First International Conference on Iceberg Utilization), sponsored by Prince Faisal of Saudi Arabia, at Iowa state College from October 2 to $6,1977$.

Delyannis was the expert in desalination that met with us when Jim Ramey and I met with the people at the Pan Hellenic Bank in Athens in september, 1965. I told him about my idea for an international chemical society; he thinks it is a good idea and will suggest it to Behrens, executive officer of the European Federation of Chemical Engineers, of which he.(Delyannis) is a leading participant.

We had a 20-course dinner that ran until after 11:00 p.m. This is a famous (although primitive) restaurant, at which people such as Churchill have eaten. Paul, Eric and I rode back to the King's Palace Hotel and retired at 12:15 a.m.

\section{Sunday, September 18, 1977 - Athens, Greece}

Eric, Paul and I had breakfast in the hotel restaurant, then took a taxi to the National Museum. We made a tour with guide Sophie Soldaton (neè Voyadjozlen). We began with the Mycenaean age (16th to 11th century B.C.) and proceeded through rooms covering later times, more or less in chronological order. In the Mycenaean rooms, we saw gold crowns, masks, goblets and jewelry, including the gold mask thought to be that of Archaean King Agamemnon ( 16 th century B.C.). We saw vases of all sizes, beads, engraved ivory, some of the 250 known tablets with syllabic script, including the earliest, from the 14th century B.C. We saw the findings, in 1927, of King Gustavus of Sweden, including swords, rings and necklaces found in Beehive Tomb, corresponding to the 14 th century B.C. The Mycenaeans Iived on the Peleponnopoles Peninsula.

We went through the rooms corresponding to the Geometric Period, the beginning of the iron age, the 11 th to 8 th centuries B.C. These include iron, and primitive marble, sculptures. Next, we came to rooms representing the Archaic Period, the 7 th century to 470 B.C., and viewed the improved marble sculptures. We saw the marble statue of Christ, taken by the Germans during World War II and returned to Athens after the war--this dates from the end of the Archaic Period. 


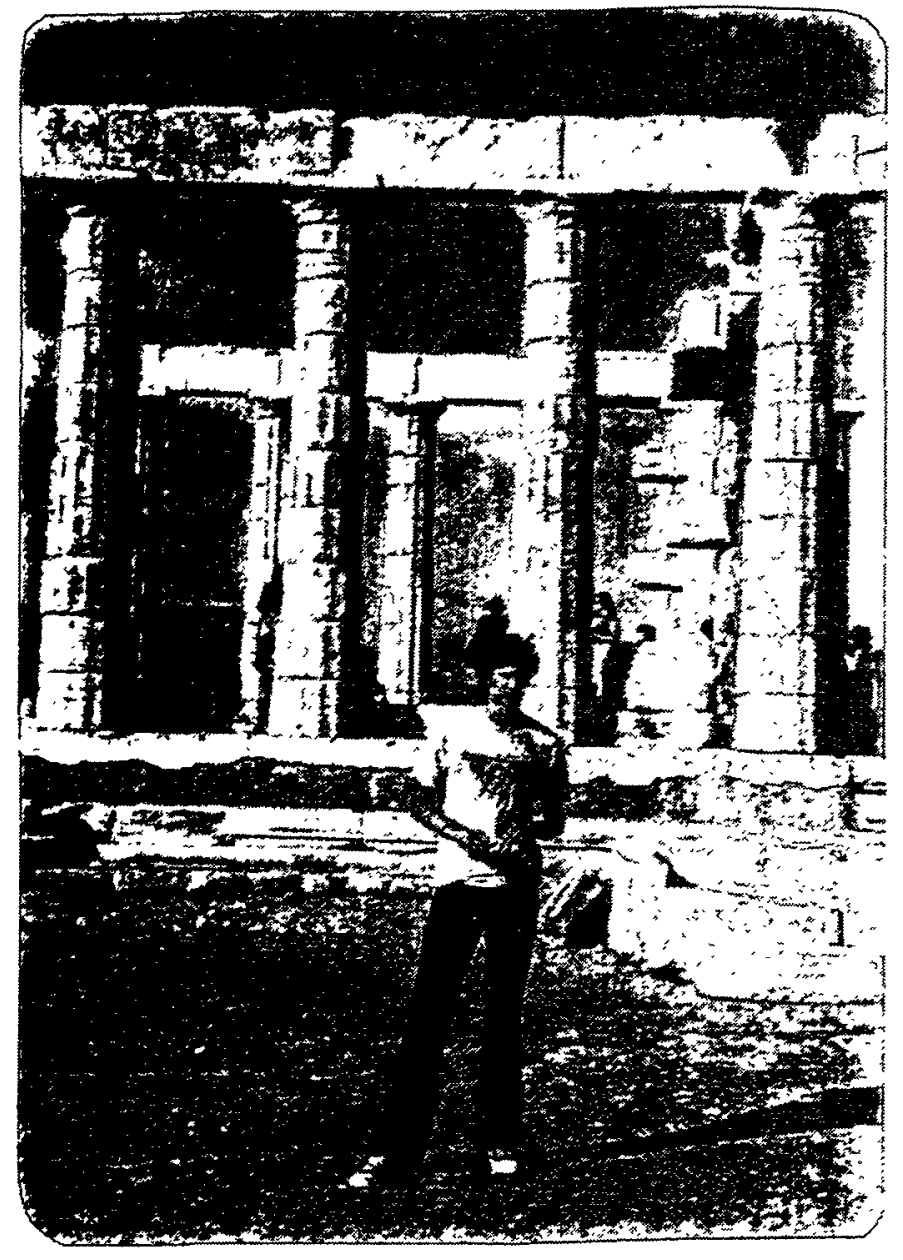

Eric Seaborg in front Poseidon Temple on the Attica peninsula of Greece: September 18, 1977.
GTS, Anthony Delyannis \& Eric Seaborg on top of Filopapos Hill with the Acropolis in the background--Athens, Greece-september 19, 1977.

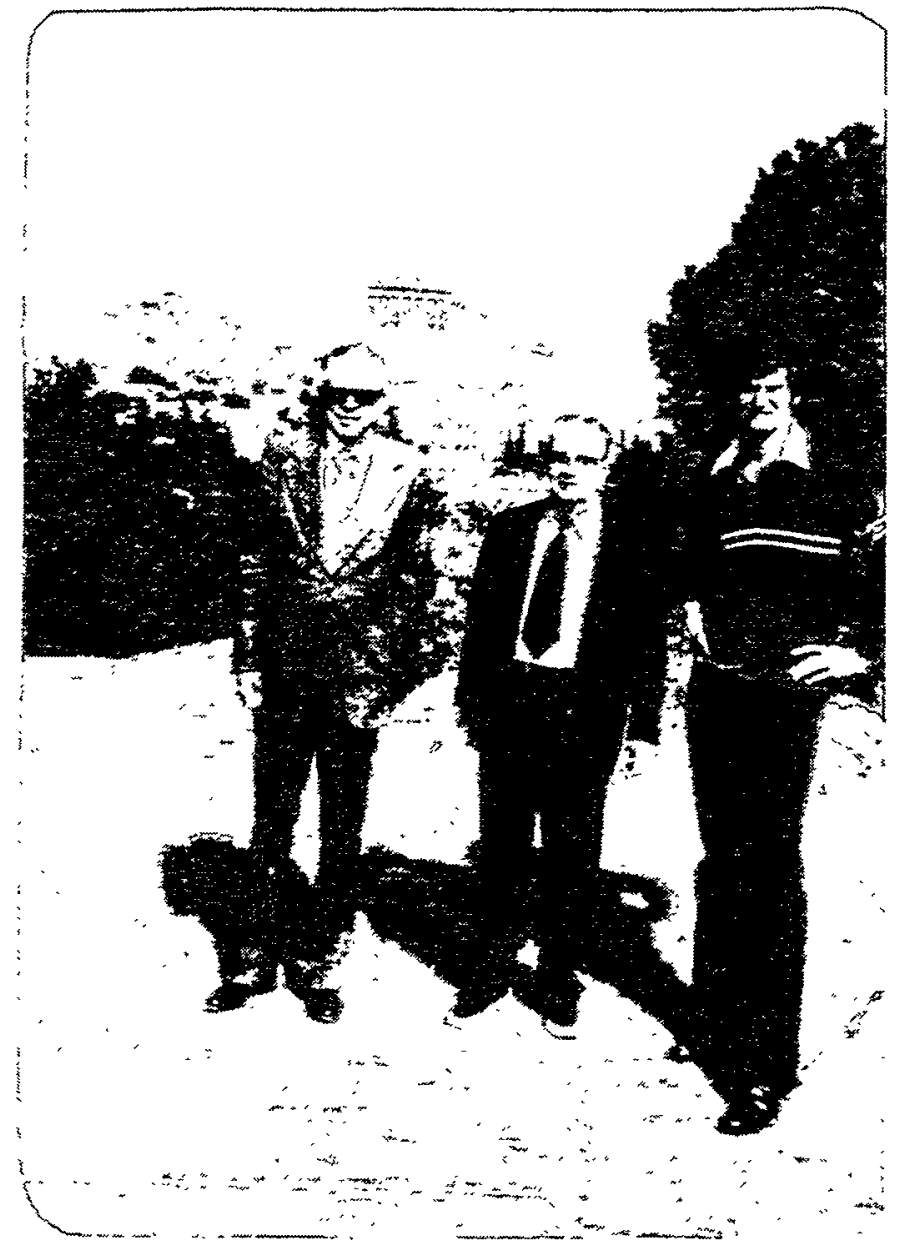


We next went through many rooms of marble statuary corresponding to the Preclassical and Classical Periods and into the Hellenic Period (which started 284 B.C.). We went.through the room of marble funeral monuments. We saw increasing mounts of bronze sculpture. We saw sculpture from the area of the Thermopylae, made of bronze or iron.

We visited a room devoted to display of surgical equipment, including tools for dentistry. There was evidence in statuary that operations for breast cancer were performed in the B.C. era. Caesarean operations were also performed. I bought a booklet describing the exhibits of the prehistoric (Mycenaean and pre-Mycenaean era).

We took a taxi back to our hotel area, then had lunch at Zonar's, a restaurant across the street from the King's Palace Hotel, at a sidewalk table.

After lunch, Paul went for a swim in the pool at the Hilton, while Eric and I took a bus tour to Cape Sounion (site of the Poseiden Temple), located on the Aegean Sea about $70 \mathrm{~km}$. from Athens. The ride went through Piraeus, along the Sea past a number of resort towns to the tip of the Attica peninsula. We visited the Doric columns of the temple built by the Athenians in $444 \mathrm{~B}$. C. and dedicated to the sea-god Poseidon. About 15 columns remain standing. It was a beautiful clear day (as was yesterday). We also walked around on the peninsula.

We returned to the King's Palace Hotel, arriving at 6:45 p.m. We joined Paul and had dinner at Corfu restaurant, around the corner from King's Palace Hotel. After dinner, I had a session with Paul in his room to discuss our meetings scheduled for tomorrow morning with Professor Michael Angelopoulos, Governor of Public Power Corporation of Greece, and with the Minister of Industry.

Monday, September 19, 1977 - Athens, Greece - Paris, France

Paul and I had breakfast in the hotel restaurant. (Eric had breakfast later, then went sightseeing in Athens.) Paul and I then rode with a driver furnished by Delyannis to the building housing the Greek Public Power Corporation. We were accompanied by George zis, Public Relations Officer of the Public Power Corporation. He accompanied us to the office of Professor Michael G. Angelopoulos, Governor of Public Power Corporation (PPC). (He is professor of nuclear engineering at nearby Technical University of Athens and is still teaching there.) We met with Angelopoulos, D. N. Simeon, General Manager (PPC), and toward the end, Anthony Livieratos, Deputy Governor (PPC).

I described my connection with SIT and the role of Gibbs and Hill, after which Paul described the qualifications of Gibbs and Hill for the role of engineering firm for the 600-800 MW power reactor proposed for Greece. They told us the reactor is planned for operation by 1986, at a time when Greek electrical capacity will be about $6,000 \mathrm{MW}$ (it is now about 3,000 MW). Paul asked if the PPC would like Gibbs and Hill to include a European engineering firm as a partner. Angelopoulos replied that this is not a factor, but they would like to involve PPC engineers (about 20 would be available). Simeon gave some indication that inclusion of a European partner could have some value. The meeting lasted nearly an hour, from 9-10:00 a.m. 
Monday, September 19, 1977 (con't)

Paul and $I$ then rode to the building housing the Ministry of Industry and Energy (which shares some of its responsibility with the Ministry of Coordination). Here we joined Anthony Delyannis and met with Minister Constantine Conophagos (who is serving as Minister of Industry and Energy while on leave of absence as Professor of Metallurgy at National Technical University, where he has served as Rector). I described the Gemex process for uranium exploration, after which Paul and Minister Conophagos discussed, in French, the financial details under which a cooperative arrangement between Getex and Greece might be made along the lines of the letter Paul wrote. Conophagos said that Greek law forbids a royalty arrangement for uranium (oil and salt are also in this category). A fee arrangement is possible and he suggested that Paul get in touch with him with such a proposal in some 4 or 5 months, i.e., after the national election in November. (We also talked to Conophagos's daughter, who is serving as his political officer; she said the present party in power--that of Premier Constantine Caramanlia--controls 220 out of the 300 seats in Parliament and is expected to win in November.

After the meeting, which lasted about 30 minutes, I gave Delyannis a copy of my New York Journal of Commerce article on an ICS which he will forward to Behrens.

Paul, Delyannis and I then met with Dimitros Christophilopoulos (of PPC), whom I had met at an American Nuclear Society meeting in Washington in the 1960s. Paul continued meeting with him, and I rode with Delyannis to Democritos Nuclear Research Center (which I visited in september, 1965). Delyannis told me that T. Kanellopoulos, who was Director of Democritos at the time of my visit, left his position a year or so later and is now a Professor at the University of Göttingen. I met first with George Papadatos (whom I met in 1965), Director of Administration and Technical Branch (Democritos does not have a Director at present); Delyannis has his office here.

Delyannis then took me to the building housing the Tandem Accelerator, where I met George Vourvopoulos, Director. He worked with the Tandem Accelerator at Florida State University from 1967-1974 and returned to Democritos to supervise getting the Tandem operating. It started operating in 1975, was purchased from High Voltage Engineering and has a capacity of $5.5 \mathrm{MV}$. He showed me the control room, the Tandem itself and the four beam lines with scattering chambers, particle and gamma ray counters, etc. (there is a room for three more beam Iines).

Vourvopoulos described his present work with $21-\mathrm{MeV}{ }^{12} \mathrm{C}$. He is studying subcoulomb fusion in the $C$ plus $C$ reaction using gamma ray detection. They handle their data with a PDP15 (and auxiliary PDP11) computer system. He gave me a copy of their 1976 Annual Report (which Delyannis will presumable forward to me). Democritos Kossionides described to me his work on the production of 20 -hour $28 \mathrm{Mg}$, via the ${ }^{2} 3_{\mathrm{Na}}\left({ }_{\mathrm{Li}}, 2 \mathrm{p}\right)$ reaction, to be used for medical applications.

Delyannis then took me to the Computer Center where the Director, Dr. Condos, showed me their Control Data 3300, acquired in 1968. We 
then went upstairs in their building where Delyannis and the librarian showed me the library.

Delyannis and I then rode to the Dionysos Restaurant where we met Paul and Eric for lunch. This restaurant has a marvelous view of the Acropolis. Delyannis told me that Irene Dilaris, an organic chemist at the University of Athens, is President of the Association of Greek Chemists; he will convey to her my request for support for an ICS and give her a copy of my New York Journal of Commerce article. He told Paul that he doesn't think it is necessary for Gibbs and Hill to have a European partner in order to help them compete for the engineering contract for the Greek reactor. Paul suggested that Eric, while he is in Europe, might interview a broad range of European chemists to get material for a book on their. view on the influence of U.S. chemistry on the development of European chemistry; Delyannis thinks this is a good idea and would be glad to help Eric make the necessary contacts in Athens.

After lunch, the four of us rode to the top of Filopapos Hill, where we had a spectacular view of the Acropolis. (Filopapos erected a monument on this hill in the B.C. era). Eric and I bought a book of Greek stamps (perhaps a gift for Bengt Adolfsson), a card of old Greek coins and a blue scarf (perhaps to be used for gifts in Sweden).

We then rode with Delyannis to the Athens Airport, where we boarded Swiss Air flight \#355, which left at 5:45 p.m. and arrived in Zurich, Switzerland at 8:15 p.m. (Paul reminded me that olivier Giscard d'Estaing is head of the European Commission for International Cooperation). We boarded Swiss Air flight. \#708, after the x-ray supervisor insisted on putting my olympus camera through the $\mathrm{x}-\mathrm{ray}$ machine (because the rules require this) and left at 7:00 p.m. (Zurich time is two hours earlier than Athens time) and arrived in Paris (Orly Airport) at 9:00 p.m. (Paris time is one hour later than Zurich time). We took a taxi to the Hilton (Eiffel) Hotel, where Eric and I checked into room 316 and retired a little after 11:00 p.m.

Tuesday, September 20, 1977 - Paris, France

Eric and I had breakfast in the hotel coffee shop with Iennard Bickel (of Australia) who started to interview me about early days of plutonium for a book he is writing on uranium. Bickel, Eric and I then took a taxi to SIT where Bickel continued his interview of me, on tape, for about 15 minutes. He covered my early life and early days at Berkeley up to the discovery of fission. Bickel has written a number of books, one about Norman Borlaug and at least one in the Book of the Month category.

Eric then left to spend the day seeing Paris (he hoped to visit the Louvre). I met with Lochak, olivier Giscard d'Estaing and Norbert Beyrard. Beyrard described his progress in creating a fund through bankers and others to support uranium mining and then exploration and further mining. This fund may be centered in France, Switzerland, Belgium or, most likely, Luxembourg. Part of the money acquired from mining would later be used to do research to extend the Milly process to improve the efficiency of underground uranium mining. The fund, which would first be used to acquire some mining companies, would be 
Tuesday, September 20, 1977 (con't)

about $\$ 40,000,000$ ( $\$ 40 \mathrm{M})$. About $20 \%$ of this would immediately go to exploration (in connection with Getex or TEAM). The first mining company to be acquired is a French manganese mining company (with some uranium interests) for which control (30\%) can be acquired for \$10-\$15M. Then control of two other mining companies would be acquired with the remainder of the $\$ 32 \mathrm{M}$ in other countries. The connection with Getex or TEAM would be through a Management Company centered in Switzerland (probably), and the Fund would be centered in Iuxembourg (probably). The Fund should increase to $\$ 100 \mathrm{M}$ within about three years. The Fund will come about 25-33\% from bankers, 25-33\% from insurance companies and perhaps $33-50 \%$ from the public. First there will be 2-3 bankers, then insurance companies, then the public (if this is decided). Perhaps the first two financing stages will raise $\$ 25-40 \mathrm{M}$. As the program progresses, increasing amounts of money (beyond the initial \$8M) would go into exploration and research to improve the Milly process and extend it to related fields.

I rode with Francine to the Societe Chimique de France (250 Rue Saint-Jacques), in the College de France region. Here, I had lunch with Professor P. Horeau (President, Societé Chimique de France), Professor F. C. Gallais (President-elect), Robert Guillamont (Secretary) and J. Bernard (past President of IUPAC). I described to them my idea for an international chemical society and the three possible methods for proceeding. They are all in favor of the idea, provided we don't start from scratch. Bernard is most strongly in favor and wants to start with the world biennial meeting of Chemical society Presidents (or the FECS), with some connection to IUPAC. I showed them the proposal Jack Barrett mailed me, "An Alternative To A New International Chemical Society," namely, associate membership in IUPAC for national chemical societies. I gave Bernard and Horeau copies of my New York Journal of Commerce article. They are not much impressed by Fritsche's opposition to ICS; they regard him as merely a clerk of FECS. Horeau and Gallais will present the concept to the meeting of the Council of the Societe Chimique de France next month (about 30 of the 50 members usually attend) and give me the results. Horeau and Gallais think membership in ICS should be contingent on membership in a national chemical society, otherwise, for example, a young French chemist would join ICS in preference to Societé Chimique de France. I told them about the impending ACS invitation to the chemical society presidents to meet in Washington, D.C., September 14-15, 1979.

Guillaumont and I discussed the present visit of Francois David and Samhoun to the United States. I took a taxi back to SIT, where Bickel continued his interview of me for another 40 minutes. He based much of his questioning on the copy of "Early History of Heavy Isotope Research at Berkeley--August 1940-April 1942" which I gave him this morning and which he had been reading during the interim.

He was interested in my reaction at key moments of discovery, my recognition of the physiological hazards of plutonium, the early production at Oak Ridge and Hanford, my feelings at that time about its potential use as a weapon and my feelings today about the problems of its use as a nuclear fuel. I promised to send him a copy of my Met Lab Section C-I history. 
At 4:00 p.m., I met again with Beyrard and Lochak, joined by Roger Godino, to discuss further the Fund, Management Company, etc., for the uranium mining, exploration, etc., program. Beyrard has talked to Banque Lazard (Paris, London, New York) and Banque Rivaud (Paris) and they are interested. We discussed the pros and cons of including money from the public in the Fund ( $I$ expressed some opposition to this), and the relationship between the Management Company and the Fund.

I walked back to the Hilton and found an envelope of mail sent by Pat (the third I have received at the hotel during the last few days). I wrote a note to her responding to a number of questions that have arisen. I phoned Bernard Harvey who brought me up-to-date on our efforts to obtain the $\$ 6 \mathrm{M}$ Iine item for FY78 (the High Intensity Uranium Beams facility) and $\$ 6 M$ addition to the FY78 national nuclear physics budget. Prospects look somewhat good for the latter and not so good (but not hopeless) for the former.

Eric and I rode with Paul and his parents to the Beyrard home. Here we had dinner with the Beyrards, their daughter Nicolette and son Jean Pascual, Olivier Giscard d'Estaing and Roger and Carol Godino. Paul suggested to Roger and Carol that they employ Eric at Les Arcs (their ski resort in the Alps) for a few months during Eric's European stay, and they showed some interest. Nicolette' sent her best regards to Steve. Arrangements were made for Eric to have lunch with Jean Pascual and some friends tomorrow.

Paul, accompanied by his parents, dróve Eric and me back to the Hilton Hotel and. We retired at 1:00 a.m.

Wednesday, September 21, 1977 - Paris, France - Stockholm, Sweden

Eric and I had breakfast in the hotel coffee shop and then checked out. Eric rode part way with Paul and me, then went on to the Louvre, which he couldn't visit yesterday because it was closed (he visited Notre Dame yesterday). Paul and I stopped for some breakfast for him. He told me about his disagreements with Roxanne Goldsmith and that she may leave SIT. I.told him that I prefer to be on an advisory board for the proposed Beyrard mining and exploration Fund or Management Company, not on the Board of Directors.

Paul and I continued to SIT. I met with Francois Kertesz, who is returning to Oak Ridge (as a consultant) after a two-year stay with SIT in the nuclear safety documentation section. I told him I will arrange for him to be associated: with the ACS Committee on International Activities.

I sent a wire of regret in response to Cyril Ponnamperuma's wire inviting me to be a Nobel Lecturer at the University of Maryland December $1-5$.

I worked with Lochak to begin to prepare letters from me to Amir Hoveyda (Minister of Court, Iran; copy: of letter attached), Akbar Etemad (President, Atomic Energy Organization of Iran), Nogueira Batista (President Nuclebras Corporation) and General Ernesto Geisel (President of Brazil; copy of letter attached) concerning possible 


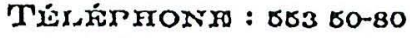

Ad). TíL. Sitré Paris

T直LSX 8302100
61. RUm Des Bhlles Fedillas

$\therefore \quad$.76782 PARIS CEDDX 16

FraAco

September 21, 1977

Mr. Amir Abbas Hoveyda

Ministex of the Imperial Court.

Tehran

Iran

Dear Mr. Hoveyda :

My friend Paul Lochak has told me about his interesting visit with you in Tehran in August. I recall with pleasure my own visit with you in 1970 .

I understand that you found your discussions with $M r$. Lochak of value and that you have initiated further discussions with Mr. Akbar Etemad, President of your Atomic Energy Organization. I hope that this will lead to a collaboration which will be of value to your country's energy program.

Cordially yours,

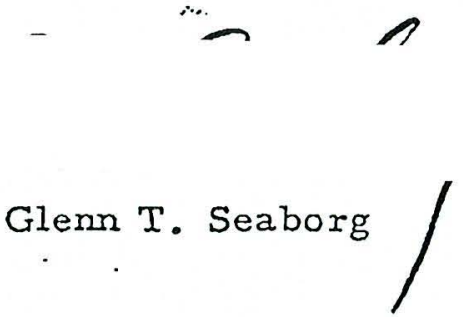


TSETPRTONAN : 503 50-80

Al). 'I'É. SITEO PARTB

Tíntex 0302mo

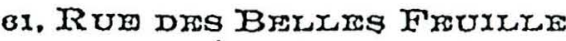
76782 PARIB CEDEX 18 FraNCE

September 21, 1977

His Excellency General Ernesto Geisel

President of the Republic of Brazil

Brasilia

Brazil

Dear Mr. President :

I have asked General Buchalet, whose long attachment to your country is well known to you, and who is a Director-founder of GETEX S.A., one of the GETEX associated companies, to inform you of the possibilities of a new technology which has recently been developed for uranium exploration.

This technology is an intertwining of radiochemistry and micrometeorology and permits an efficient and economical detection of totally buried uranium deposits. The technology is described at some length in document GX/TB-3 which General Buchalet has available.

This technology is the exclusive property of GEMEX and is available to GETEX. Both companies include and are managed by eminent scientists and technicians whose names appear in the document referred to above.

I wish by this letter to bring my recommendation concerning the serious ness of this technology and its effectiveness. We believe that it is particularly well suited. to a country the size of Brazil and that it should allow rapid and economic exploration of vast land areas.

I hope that this process will interest the Nuclebras Organization and can lead to a fruitful collaboration between Nuclebras and GETEX.

Please accept, Mr. President, the expression of my highest consideration.

Sinserely vơtis,

Glenn T. Seaborg

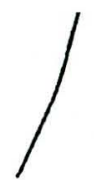


Wednesday, September 21,1977 (con't)

cooperative uranium exploration programs in Iran and Brazil. I also wrote a letter of appreciation to Michael G. Angelopoulos for his hospitality when we visited him last Monday in Greece.

I then met with Norbert Beyrard, Olivier Giscard d'Estaing, Roger Godino and Paul Lochak to discuss further the new mining and exploration organization proposed by Beyrard. Paul explained my desire to be on an advisory board and not on the Board of Directors and my reluctance about public participation in the financing. This organization (Fund and Management Company) will be given names yet to be decided. In the interim the Management Company might be called "M," the Fund called "F." The Management Company is a Norbert Beyrard Company (led by him). In addition, SIT or a new French company such as Getex SA (SA means French company) will serve as a service company. The stock in the Management Company will be 50\% with Beyrard and 50\% with TEAM. The meetings of Beyrard, Lochak, Olivier and Godino with bankers to explore this concept will begin next Wednesday.

In the Management Company, I will be president of the scientific advisory board (perhaps Francis Perrin will be the other member) and a member of the investment advisory board (of which olivier will be president). For the Management Company, Beyrard, Godino and Lochak will be on the Board, plus three bankers. Some percentage (to be determined by negotiation) of the Management Company stock will be held by the bankers, and of the remainder, $50 \%$ will be held by Beyrard and $50 \%$ by TEAM (of which I am a member). The Fund Board will consist of bankers, insurance people, people like Boris Lochak, ex-ministers of countries like Belgium, etc.

At 1:00 p.m., we all went to lunch at Cercle du Bois de Bologne, where we continued our discussion.

Beyrard explained that the Management Company would receive 5-10\% of the profits from the $80 \%$ ( $\$ 32 \mathrm{M})$ investment and this would be mostly consumed in expenses for the first few years; greater profits, at a different percentage, would come later, from the uranium exploration activity which would be initially financed by the $20 \%$ (\$8M). The remainder of the profit would go to the owners of the Fund 190-95\% from the $\$ 32 \mathrm{M}$ ) and some different percentage of the profits from exploration (based on \$8M investment). The TEAM (Swiss Company) ownership is Lochak $40 \%$, Godino $40 \%$, SIT $11 \%$, GTS $5 \%$, Olivier $3 \%$ and Jim Gill 1\%. This will become effective in 1978, perhaps in January. (The value of my share can be established for income tax purposes sometime in 1978--Lochak will inform me.)

Olivier told me that E. Ernest Goldstein (Coudert Bros., 52 Champs Elysees, 75008 Paris) wants me to speak to the American Club of France (Paris), of which he is president.

Lochak and I returned to SIT and we prepared and I signed letters, concerning proposed cooperative arrangements for uranium exploration, to Amir Hoveyda (Minister of the Imperial Court Iran), Akbar Etemad (President of the Atomic Energy Organization of Iran), General Ernesto Geisel (President of Brazil) and Nogueira Batista (President 
of Nuclebras Corporation in Brazil). A letter about and concerning their proposed nuclear power reactor was sent to Professor Michael G. Angelopoulos (Governor of the Public Power Corporation in Athens, Greece).

Kertesz then drove me to the headquarters of UNESCO (on the left bank near the Eiffel Tower), where I met, in his office, with sianey Passman, Ingmar Eneberg (from Halmstadt, Sweden, with UNESCO for the last 5 years or so) and Jacques Richardson (Editor of the UNESCO journal, Impact of science on Society). I described my concept of an ICS and they agreed with the idea. Passman said he will send me information on a number of international organizations, including individual membership organizations, some copies of Impact of science on Society and some other UNESCO literature. When I told them about my idea of seeking financial backing for an ICs in sweden, they reminded me of the International Federation of Institutes for Advanced Studies (IFIAS), supported by and with headquarters in stockholm, with Sam Nilsson as Executive officer, the international interests of olaf Tandberg (Secretary of the Swedish Academy of Sciences) and the international interests of Carl Heden (Carolinska Institute); all are friends of mine.

Eneberg told me that he will accompany A. M. M'Bow (the Senegalese Director General of UNESCO) to Uppsala next week (where M'Bow will receive an honorary degree) and that IFIAS will hold a widely advertised seminar on the human prospect at Ulriksdal slott (near stockholm) next sunday and Monday.

I rode back to SIT with Kertesz. Eric was there; he had visited the Louvre and had Iunch at a club with Jean Pascual and a friend of his. Lochak phoned Godino and learned he is prepared to employ Eric at Les Arcs.

Lochak drove Eric and me to DeGaulle Airport. En route, he told me that Charles Gottschalk, whom I knew as engaged in public information work at AEC, is a candidate, backed by the U.S. UNESCO Committee, for the position of assistant to the director of UNISIST (in UNESCO), world information system for transmission and dissemination of information for growing and developing countries; M'Bow will make the appointment.

Eric and I boarded Scandinavian Airlines flight \#568, which left at 7:00 p.m. and arrived in Copenhagen Airport at 7:45 p.m. We then boarded Scandinavian Airlines flight \#556, which left at 8:40 p.m. and arrived in Stockholm (Arlanda) Airport at 9:45 p.m. We were met by Carl Johan Herrlander, Director of the Research Institute of Physics. Eric's samsonite suitcase was lost so we had to fill out a report form so a search can be made for it. Herrlander drove us to the Research Institute for Physics where he showed us our rooms and breakfast facilities. I called Siv Lindkvist and we tentatively arranged to meet on Friday.

Thursday, September 22, 1977 - Stockholm, Sweden

Eric and I put together a breakfast with the facilities in our apartment area. We then joined Herrlander who helped me make phone 
Thursday, September 22, 1977 (con't)

calls to Karin Möller (in Borlänge) and Olaf Bloom (in Stockholm) to make arrangements for our visiting schedule. Olof told me he is moving to No. 76 (fifth floor) of the same street and will retain the same phone number.

I then had a tour of the Research Institute under the guidance of Herrlander, Hugo Atterling and Wilhelm Forsling. We visited the Beam Foil Spectrometer (also isotope separator), which was described by Lennart Lunden (Iongtime assistant to Manne Siegbahn, who is still alive at 91 and lives on the Institute ground) and Leif Liljeby. We next visited the "vascatron," an electron accelerator based on high frequency deflection technique for application to atomic and molecular spectroscopy. Finally, we visited the isotope separator (a follow-on to Ingmar Bergstrom's machine--he was out of town at a meeting), which was described to me by Manuel Braun.

Their little cyclotron has been dismantled and its magnet will be used for a beam separator in a new underground building (they waited 20 years for this) connecting the building housing their larger cyclotron and the Research Institute building. I toured this area as well and saw their cyclotron (the one they used in 1957 on their work on element 102); this is being renovated somewhat (but will still not be an isochronous cyclotron) and will furnish $C, N$, and $O$ ions at 10MeV per nucleon.

I returned to our apartment and joined Eric, who soon set out for some sightseeing in Stockholm, travelling by subway (a station is near the Research Institute). I spent some time going over my material for my talks today.

I had lunch with Herrlander, Atterling and Forsling at nearby Skarpskylten ( $a$ club). After lunch, we visited nearby Lillaskuggan (near the former village of Husarby) and saw the Fishing Home of Charles XI (about 1680). Queen Christina (born 1628, daughter of King Gustavus Adolphus) had a barn, still standing here.

We drove back to the Research Institute and, at 2:00 p.m., I gave my talk on "Forty Years in Transuranium Elements," illustrated by 62 slides. The lecture hall was nearly full. I was introduced by Herrlander, and my talk, which lasted exactly an hour, was followed by a short question and answer period.

After my lecture, I talked to Kjell Aleklett (Gösta Rudstam's protégé). He wants to work on SHE with me at LBL, is a physicist, can start July 1, 1978, is seeking support from Swedish organizations and Rudstam and may need some additional support from me. I told him to write me describing his financial balance of support and deficit and that I could arrange for LBL to pay him a per diem (perhaps $\$ 10$ per day). He is married and has one small child. I also talked to Börge Johansson, a friend of Leo Brewer, who works at FOA in theoretical considerations of solid state of actinides, which he considers the most interesting group in the periodic table. 
Thursday, September 22, 1977 (con't)

I had tea and cookies in Herrlander's office with Herrlander, Atterling and Forsling. I called Sam Nilsson, Executive Officer of IFIAS, and told him I couldn't accept his invitation to attend their conference on the human prospect. I told him about my ICS concept. He likes the idea and will pass it on to Alexander King, a chemist from France who is now working $50 \%$ of his time as chairman of the Board of Trustees of IFIAS (since he left OECD). He will be in stockholm a week.

Atterling showed me the room (now divided into 2 offices) in which Lise Meitner worked when she came to the Institute from Germany in september 1938; she stayed at the Institute until 1945, then went to the Institute of Technology.

I rode with Herrlander to the Royal Academy of Engineering Sciences IVA (Grev Turegatan 14). I gave my talk "Energy and the Environment," illustrated by six slides, and, for the portion describing the nuclear waste disposal project at the Stripa Mine, eight transparencies (furnished to me by Terry Simkin in the Engineering Department at LBL). I talked for about an hour, followed by a question and answer period. The session was presided over by Erland Waldenström, chairman of IVA and long time president and chairman of Grängesberg Company (Gränges), now retired. Present were Göran Borg (ex-Dean of the Royal Institute of Technology), Herrlander, Lars Högberg (Swedish Board of Energy Research), Gunnar Jancke (Swedish State Power Board), Ingvar Jung (Professor of steam technology at the Royal Institute of Technology), Gunnar Ieman (State Delegation for Energy Research), Bo Lindel1 (Professor Radiation Physics, Carolinska Institute), Dick Lundqvist (ASEA), Valfrid Paullsen (Director General of the National Swedish Environment Protection Board and Undersecretary of State to Prime Minister Tage Erlander, 1964-1967, in which capacity I knew him), Ernest Sohns (Scientific Attache at the U.S. Embassy), Torbjörn Westermark (professor of radiochemistry at the Royal. Institute of. Technology and a long-time friend), Ingvar wivstad (state Power Board), and, from IVA staff, Gunnar Hambraeus, Allan Carlsson, Folke Hjalmers and Leif Olausson.

Eric joined us toward the end of the question and answer period. He had spent the day walking around Stockholm, including a visit to old Stockholm (Gamla stan). After Hambraeus left, the remainder of us went to a dining hall in the building for dinner. I sat between Waldenström and Westermark. Westermark gave me a copy of a paper, in Swedish, describing a method for providing a scrubber tower for an underground nuclear plant, with provisions for absorption of the volatile products, for use in case of a meltdown accident. (He had described this earlier, after my talk; Wivstad responded that he thought this would be impractical.)

Waldenström opened the dinner with the traditional welcoming toast and $I$ responded with a toast near the end of the dinner, making reference to the impending visit of Eric and me to Dalarna, the friendship of my great grandfather and the svedbergs' grandfather at Hällefors (and the consequent source of my middle name Theodore), etc. 
During dinner, Waldenström told me of his long connection with Gränges and said he would contact a Gränges official to suggest he show us around Grängesberg tomorrow.

On the way back to the Research Institute, Herrlander drove us by the Opera House, Opera Kallerin, Grand Hotel, the King's Castle (Slottet), the City Hall and the Malaren, to give Eric an opportunity to see these. We returned to the Research Institute. I tried unsuccessfully to reach Siv Iindkvist to tell her our schedule tomorrow precludes our visiting skansen with her as planned. Eric and I retired at 10:00 p.m.

Friday September 23, 1977 - Stockholm- Eröve - KopparbergIjusnarnsjö - Grängesberg - Borlänge, Sweden

Eric and I had breakfast in our apartment, then met Herrlander (who had recovered Eric's suitcase) and rode with him to the Stockholm Railroad Station. Herrlander said he would call Siv to tell her of our travel plans.

Eric and I boarded the train to Fröve, which left at 8:05 a.m. and arrived at Fröve at 11:00 a.m.; here we changed to a train that left at 11:10 a.m. and arrived at Kopparberg at noon. (I travelled for half fare, a privilege for those who have reached the age of 65.) We were met by Karl and Bengt Adolfsson and rode in Bengt's car to Karl and Jenny's apartment. Here Eric and I had lunch (meatbalis, different breads, Iingonberries and apple pie) with Karl, Jenny, Bengt and Irene.

We exchanged gifts. Karl and Jenny gave Eric a Ljusnarsbergs Kyrka Kopparberg thermometer and gave us a hand-made (by Jenny) doily for Helen. We also received a package from Bengt and Irene for Helen, a card with a picture from Jenny to Helen and a bottle of lingonberries from Jenny. I gave a trivet to Jenny, a redwood burl to Karl, Greek stamps to Bengt and book of etchings of big trees to Karl.

Eric and I then rode, passing on the way the house the Adolfsson's lived in for 33 years, with Bengt and Karl, to Bengt and Irene's summer place at Ljusnarnsjö. This is a very nice, comfortable place, fronting the large lake.

They told us the 100-year old carnival held in Kopparberg at the end of september each year will draw 75,000 people this year. (The population of Kopparberg is 3,000 or less.) We drove back to Karl and Jenny's place. (Bengt and Irene's place is only a couple of kilometers away.) on the way back, we stopped at the site of Iaxbrostugan and passed by old Kopparberg church.

At Karl and Jenny's, we had tea, coffee, cakes and cookies. Karl showed me a book with a picture of Laxbrostugan in Kopparberg taken in the 1860's ("Ijusnars-Kopparberg, Enhembygdsbok" published by Nya Kopparbergs Bergslags Hembygdsförening--Oriel Blombergs Nya Aktiebog Iindesberg 1960); the caption states that Laxbrostugan was moved to Skansen in 1895. 


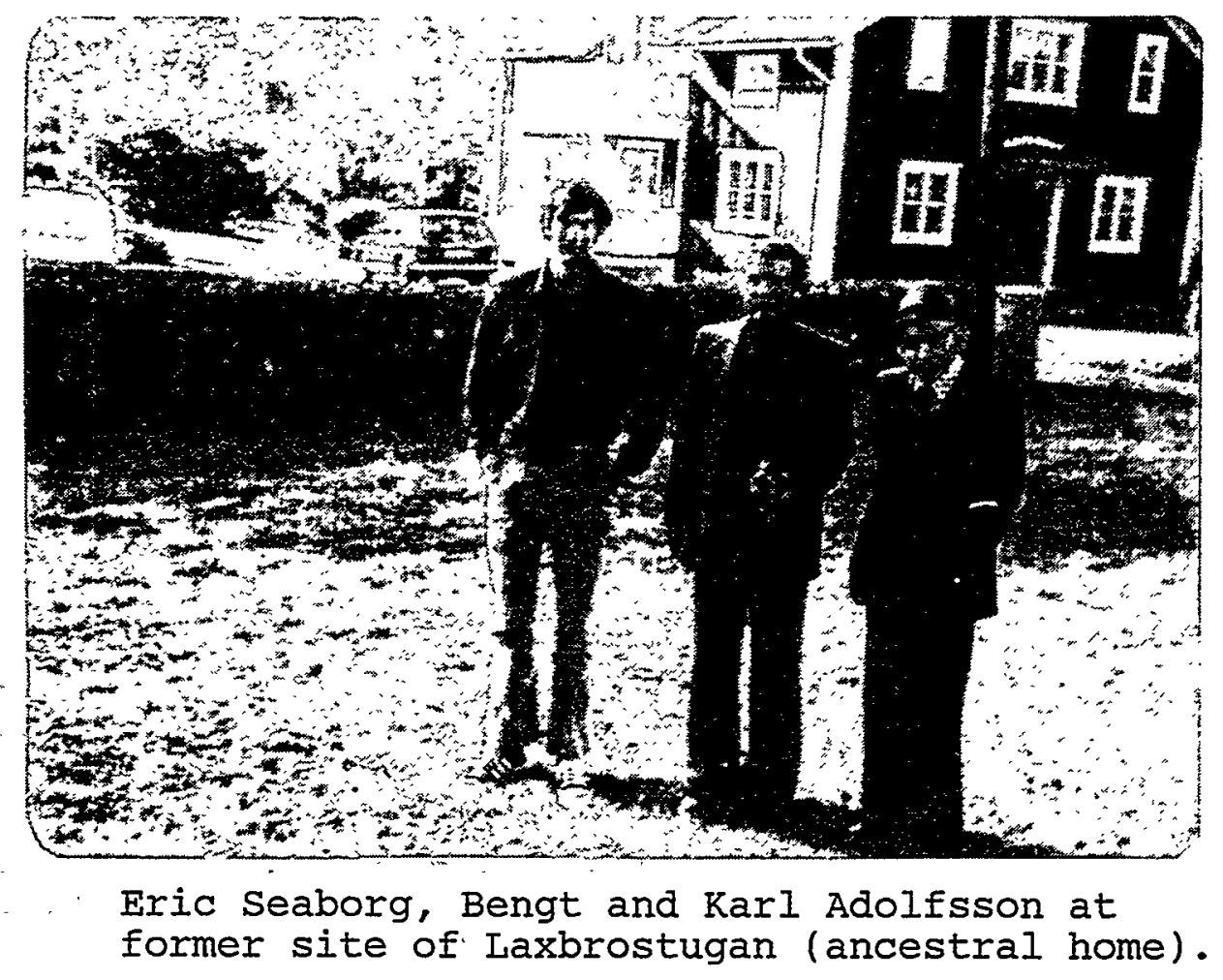

Kopparberg, Sweden: September 23, 1977.

Karl and Jenny Adolfsson, Eric Seaborg and Irene and Bengt Adolfsson in Karl and Jenny's living room.

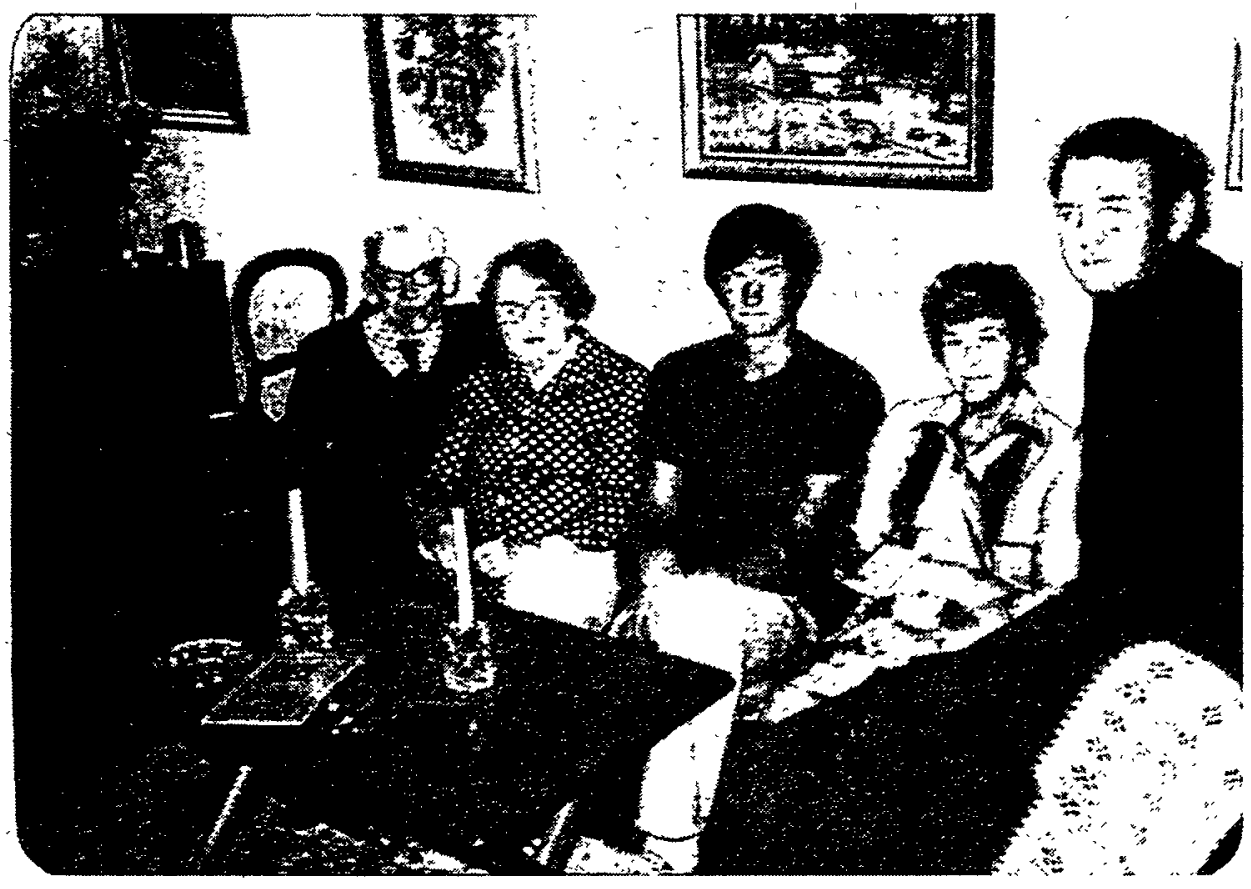


We gave a redwood burl to Irene. Karl showed us his photo album covering his 1959 U.S. trip (he said he kept a day-by-day diary) and his album covering my visits to sweden.

Jenny and Irene took the train to Borlänge, while Eric and I rode with Bengt and Karl, stopping en route at Grängesberg. We stopped first at the old Kopparberg copper mine, "Finn Gruve," started around 1600. We rode by the house of our ancestor Lars Bengtson in Skarptägt, where he lived around 1700 (this is shown in the genealogy given me by Karl; Bengt will send me a picture of this house).

We drove on to Grängesberg, to the offices of Grängesberg Mines, where we joined Boris Serning, retired President. (He succeeded Fredenberg in 1957, the man whom I met and at whose home I had dinner in 1949.) Serning's daughter, Eva, is an opera singer, sings under name of Eva Serning in America. He accompanied us to Karl's and mother's family home in örntorp, which was built in 1900, replacing the smaller home (one room and a kitchen) which stood a few feet away. No one was home so we couldn't visit inside. We then drove around Örntorp to show Eric the various areas inhabited by my mother, her sister Hilda, brother Oscar, Karl, etc.

We then drove on to Borlänge to the Möllers' home. We had a. typical Swedish dinner with Karin and Per Möller, with Karl, Jenny, Bengt and Irene. After dinner, I gave Karin a trivet and Per a redwood burl. I also gave my grandfather's (Adolph Eriksson) medal back to Karl and Jenny as they had requested during my visit with them a year ago. Mona and Bo Forssling came and we went upstairs to the charming den room. I gave the Forssling's a redwood vase. Karin gave Eric a birchwood ladle (made by Per) and Helen and me a birchwood woven basket (made by Per and Karin).

I called Siv Lindkvist to tell her about our plans to visit Laxbrostugan on Tuesday afternoon. Pavel Kurfurst of the Stripa Mine called to invite me to visit the mine but, because it is back south of Kopparberg and not open Sunday, I couldn't accept.

Saturday, September 24, 1977 - Borlänge - Stora-Skedvi, Sweden

We all had breakfast--Karin, Per, Bengt, Irene, Karl, Jenny, Eric and $I$. Karin returned to me the Nobel symposium briefcase left by Lynne on the train last September; Karin said she had mailed Lynne its contents.

In the late morning, we all had coffee, tea, cakes and cookies. Karl told me Jeanette wanted one of his paintings (of flowers, eye glasses and a book) which Mother had; he thinks Jeanette should inherit this. Another of his paintings is of the örntorp house, which Karl thinks I should inherit; another pair of pictures is painted on wood (in the shape of an ellipse) and Mother also had a painting of the Lindås house and the painting of Elmer, Jeanette and us. Mother had all of these. Karl wants me to write him if I find these and also tell him who will inherit them. Eric wants one of these paintings.

Göran Möller and Marie Ivars arrived at 12:30 p.m. I gave Göran the book California Redwoods and Marie a redwood burl. 


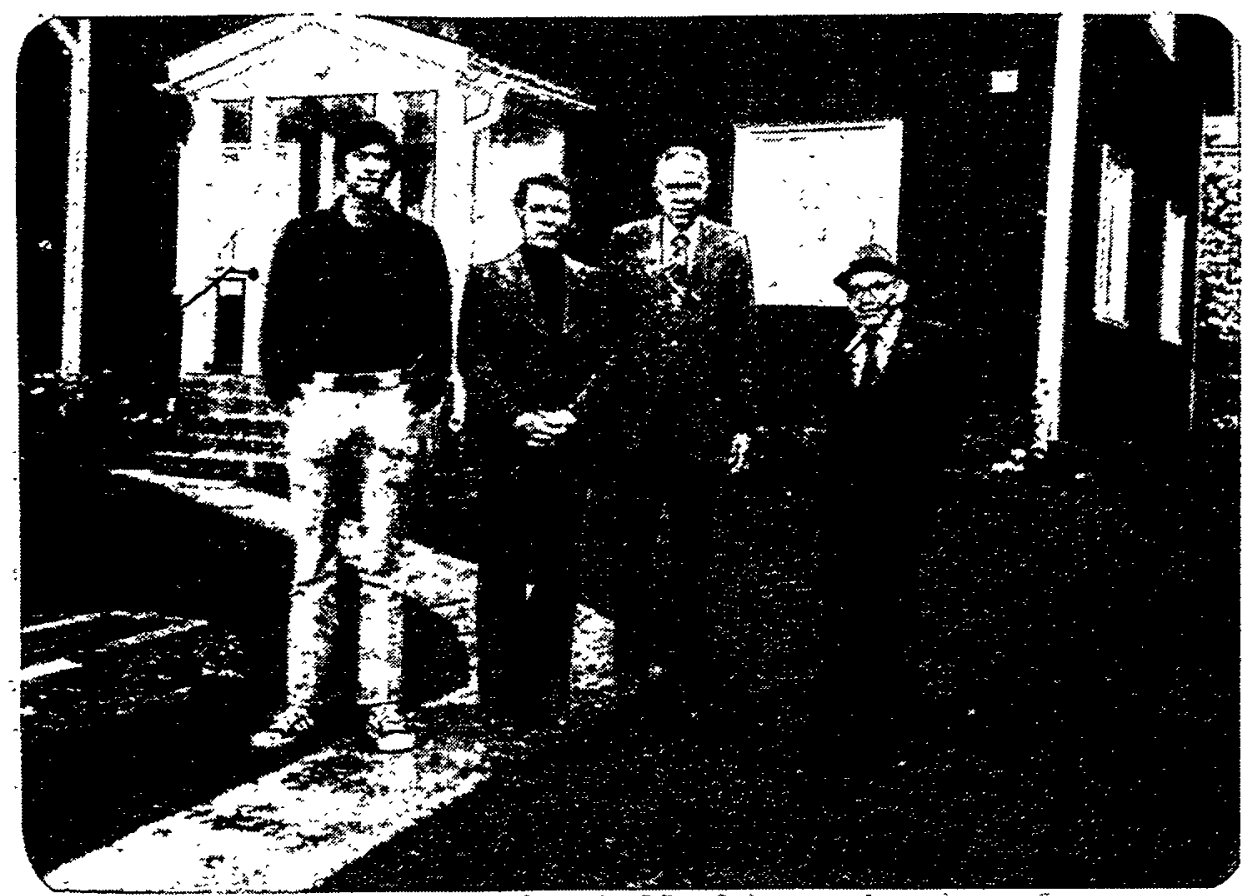

Eric Seaborg, Bengt Adolfsson, GTS \& Karl Adolfsson in front of family home Karl Adolfsson and Selma Adolfsson Seaborg in örntorp, Grängesberg, Sweden, 9/23/77.

Bengt Adolfsson, Eric Seaborg, Per Möller, Irene Adolfsson, Karin Möller, Mona and Bo Forssling and Karl and Jenny Adolfsson-Möller home, Borlänge, Sweden--9/23/77.

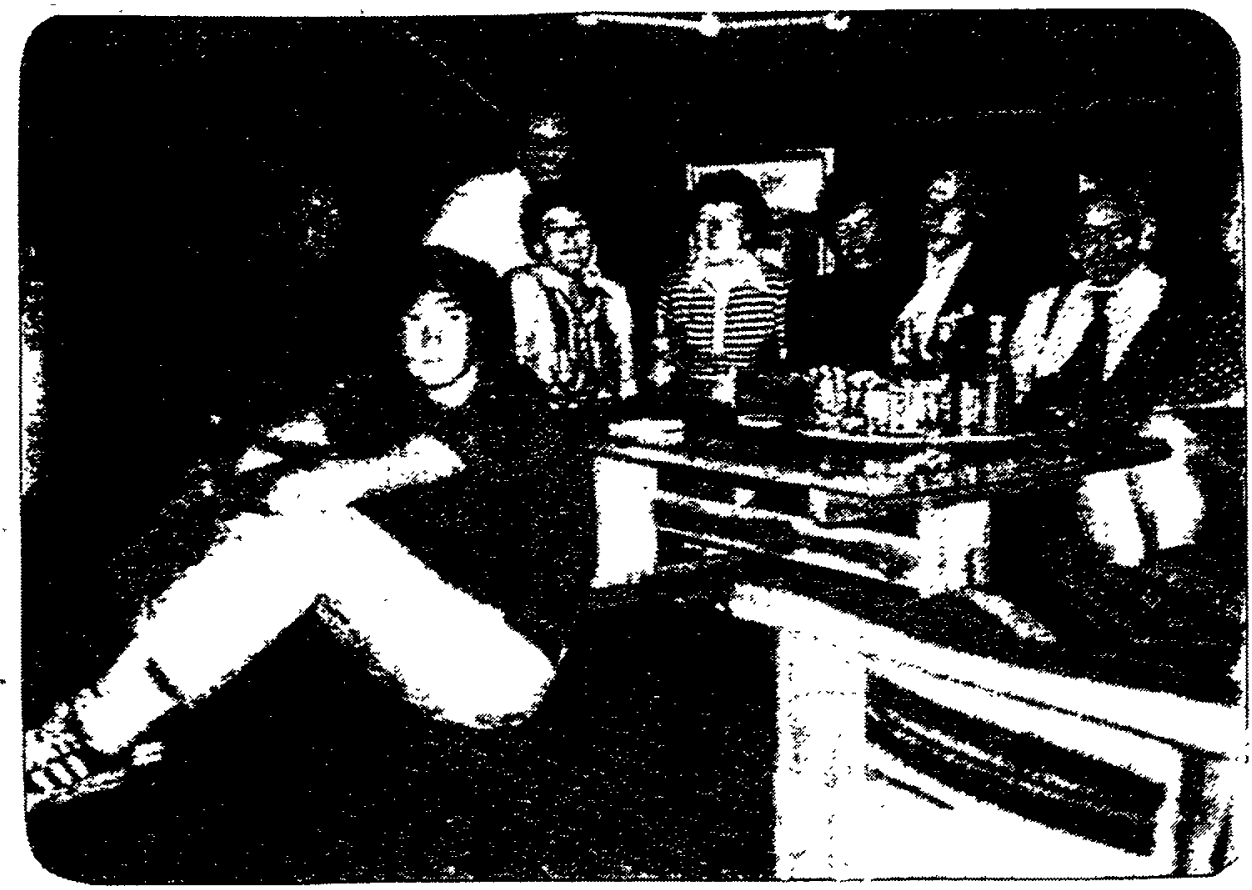


Saturday, September 24, 1977 (con't)

We drove down to Stora-Skedvi. I rode with Per and Karin, Eric with Göran and Marie, and Karl and Jenny with Bengt and Irene. We went to Värdshus, with the people gathering in front and inside as they arrived. Gustav Eriksson came in his rebuilt 1926 chevrolet touring car. I took movies of the group before we went inside for our Smorgäsbord dinner which started a little after 2 p.m. Attending were:

\author{
Jenny and Karl Adolfsson \\ Bengt and Irene Adolfsson \\ Gösta and Irene Adolfsson \\ Lena Adolfsson (daughter of Gösta and Irene) \\ Per and Karin Möller \\ Göran Möller \\ Marie Ivars (fiancee of Göran Möller) \\ Sven and Karin Lindås \\ Lars Iindås (Sven and Karin's 30-year-old son, who is single) \\ Gunvor Iindås (Sven and Karin's 24-year-old daughter) \\ Kerstin Lindås (Sven and Karin's 27-year-old daughter) \\ Lars Forsner \\ Sven Forsner \\ Gustav Eriksson \\ Karl-Eric Eriksson \\ Göran Eriksson \\ Arne Ahlström \\ Barbro Ahlström \\ Maja Lindås (Sven's sister) \\ Gunhild Lindås (Sven's sister) \\ Timo Lindås (Gunhild's adopted son, who speaks some English; he \\ is Finnish and is divorced) \\ Johan (13), Sara (19), Mats (14) (children of Timo Iindås) \\ Britt Marie Lindås (wife of Timo Lindås) \\ Nils Lindås (Sven's brother) \\ Erik and Ingrid Andersson (husband and wife who live in Ludvika-- \\ where mother visited them in 1957) \\ olof Andersson (Eric and Ingrid Andersson's son who lives in \\ Solna near Stockholm) \\ Stig and Margareta Eriksson (husband and wife who Iive in \\ Grängesberg; my mother's birthplace) \\ Carl and Monica Tersmeden \\ Sanda Strängnäs (daughter of Albert Eriksson of Näshulta)
}

The dinner had a tremendous choice of food for all courses. In the course of the afternoon, I gave presents as follows: Greek coins to Gösta, a redwood vase to his wife Irene, a redwood candlestick holder to Lena and a redwood burl for her sister, Eva, a redwood candlestick holder to Gunhild, a redwood vase to Maja Lindås, a redwood vase to Kerstin and a redwood burl to Gunvor Iindås.

After the dinner, Sven Iindas announced that there would be more coffee, etc., at the Lindås home in Stora-Skedvi (Hasmats). I made a short talk of thanks, reminded them of Steve's and Iynne's visits, pointed out Eric's progress in learning Swedish and said perhaps Helen and Dianne will come with me next year. 


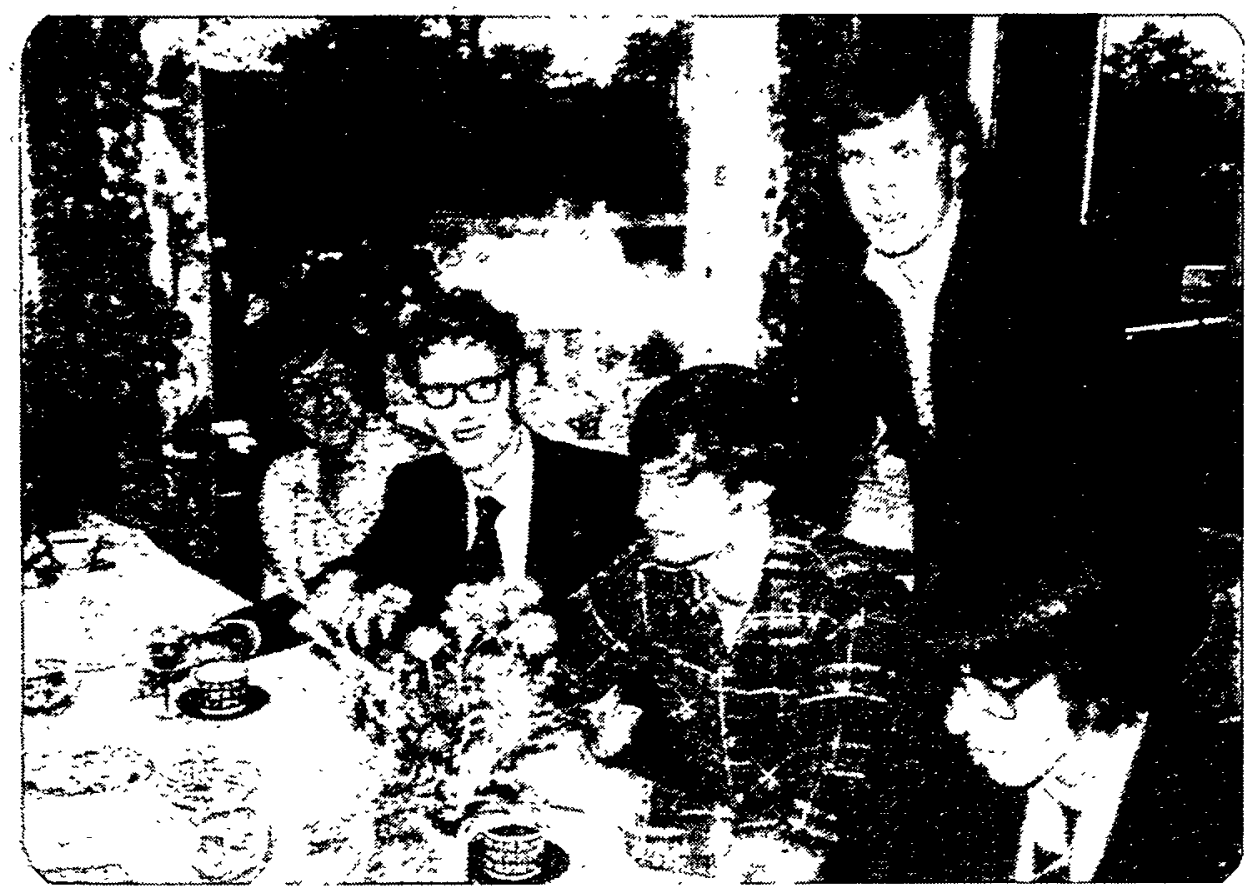

Monica and Carl Tersmeden, Eric Seaborg, Göran Eriksson (standing) \& Göran Möller --dinner at Värdhus, Stora Skedvi, Sweden.

Gustav Eriksson, Karl-Eric Eriksson, Sanda Strängnäs, Maja Iindås, Nils Lindås, Kerstin Iindås \& Gunvor Iindås--dinner at Värdhus, Stora Skedvi, Sweden--September 24, 1977.

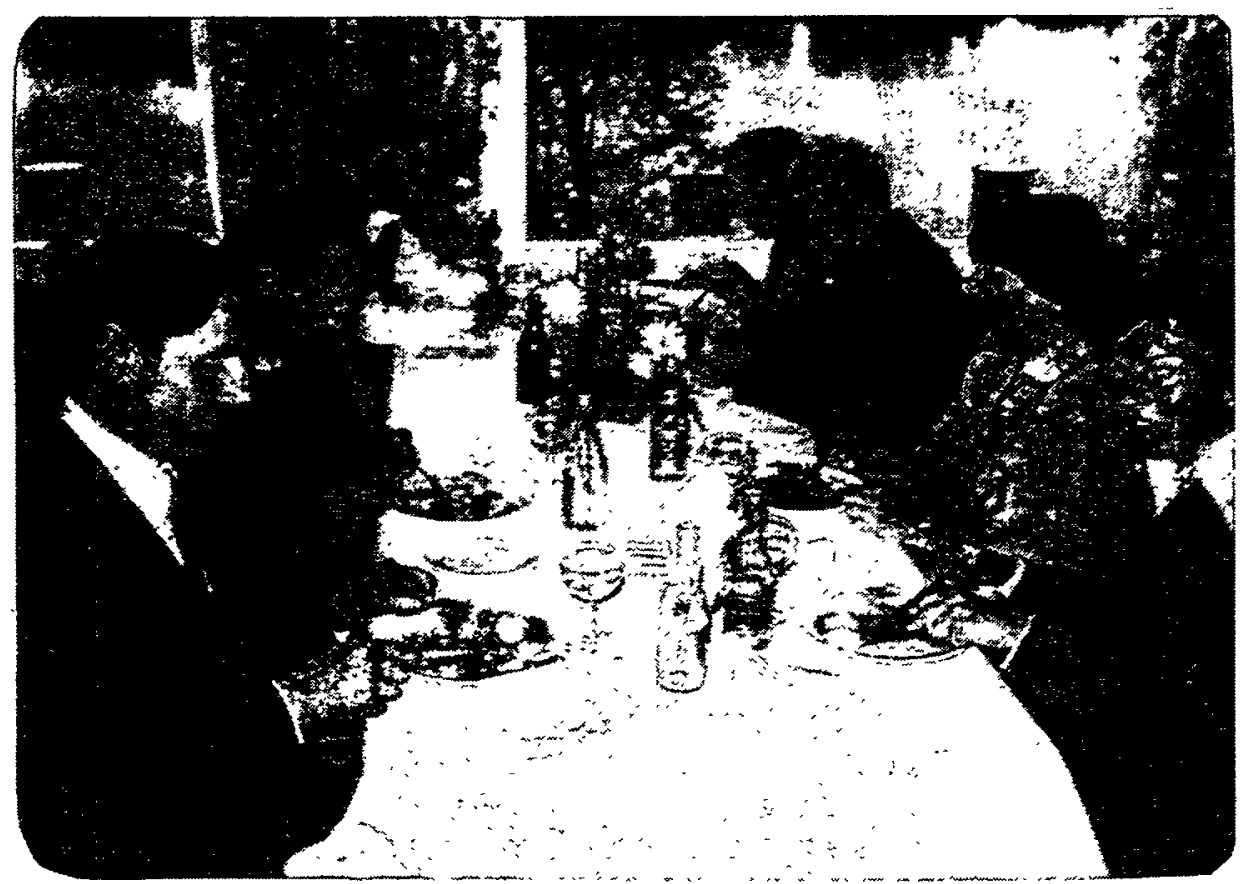




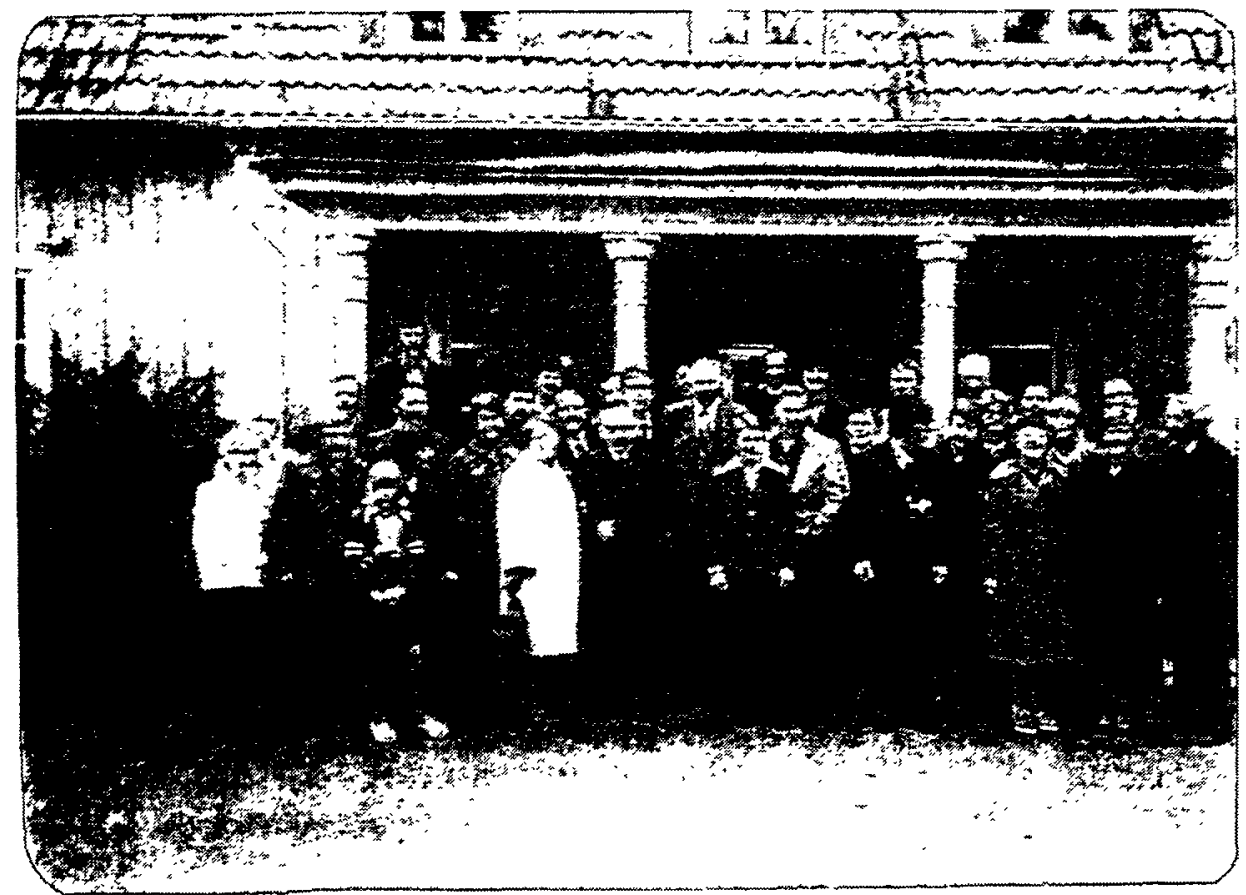

Relations in front of Värdhus, Stora Skedvi, Sweden--September 24, 1977. 
Göran Eriksson gave me a hand painted (on cloth) picture of the stora-Skedvi church (in a tube container).

We then all rode to nearby Hasmats (except Carl and Monica Tersmeden, Göran and Marie, Karl, Jenny, Bengt and Irene, all of whom returned home).

We had coffee, tea, cakes and cookies, extending over a couple of hours. Eric and Lars Iindàs went rowing on Dalalven after dark. Lars gave Eric a replica of an old Säter coin (Säter Klipping). Margareta Eriksson gave me a sheet of genealogical information on my mother's mother's side of the family.

Eric and I then rode with Per and Karin back to their home in Borlänge. Lars, Kerstin and Gunvor Iindås followed in one car, Gösta, Irene and Lena in another. We all spent the remainder of the evening in the upstairs den room, having coffee, tea, bread and cheese, cold meats, etc. The party broke up at 10:30 p.m., with the Lindases and the Gösta Adolfssons driving to their homes. Eric and I retired at $11: 30$ p.m.

Sunday, September 25, 1977 - Borlänge - Falun - Lake Flädran Svärdsjö - Borlänge - Uppsala, Sweden

Eric and I had breakfast with Karin and Per. I gave the shawl we bought in Greece to Karin. We then drove to Falun (in their simca), where we stopped to see the stora Kopparberg copper mine. There is $a^{\text {. }}$ huge pit ( 400 meters by 350 meters and 90 meters deep), where a cave-in occurred in 1680. We also drove through old sections of Falun where very old houses, preserved or reconstructed, on very narrow streets are found. This is a sort of model preservation project for Sweden.

We then rode northeast about 15 kilometers to their summer place on Lake Flädran, a house rebuilt by Per.with nice wood finishing inside and set in beautiful woods. We then drove on to svärdsjö, on a country road, to the old school where we saw the bronze bust (with no identification) of Gustav Daniel Sjöberg (brother of my grandfather). He had a mustache, long curly hair and a winged collar.

We drove on to the church (where Daniel played the organ) and went into the social hall on the grounds where a luncheon (refreshments serving) was in progress. We met Anna Bergstrom (neè Backland), who was a pupil of Daniel in the third through sixth grades around 1898 to 1902 (she was born 1890). (Daniel taught grades 1 through 6 when he first came to svärdsjö, then grades 3 through 6.) She said she "loved" Daniel; he was strict but fair, and a look from him was enough to cause a pupil to behave. We were served coffee, sandwiches, cookies and cakes as we talked to Anna.

Anna took us to the Geijer home next door loverlooking Svärdsjö Iake). Here, through an incredible coincidence, we met Erik and Doris Geijer who, on a whim, were visiting from their home in Gävle. Mother and I, with Per, had met them (and Erik's Mother) in 1957. Erik Geijer is the son of Ossian Geijer (1864-1955), a brother of Betty (another brother was called Mauritz), the wife of Daniel Sjöberg. The 
parents of Betty, Ossian and Mauritz were Carl and Mathilda (neè Salling) Geijer. We went in the house and saw a duplicate (in plaster) bust of Daniel on the mantle in the living room. We went upstairs where Daniel and Betty lived when he retired (from 1910 to 1922). They had lived in an apartment at the school before this. We observed a stove and small wooden cabinet with some utensils they used and a small wooden rocking horse that they had.

The Geijer house was built in 1827. Erik Geijer, although he was only five years old when Daniel died, remembers him very well. Daniel regarded him as his protégé, insisted that he accompany him on fishing expeditions on svärdsjö, taught him about nature (Daniel was a naturalist) and asked him to stand by when he played the organ (sometimes Erik sang and continued singing when Daniel stopped playing). They told us Daniel had an original mind, perhaps even could be classed as stubborn. When it was time for him to play the organ, he sometimes was a little late, saying they couldn't start until he came so why should he hurry. He was a rather rugged outdoorsman.

We went out of the house and walked to the nearby grave in the churchyard. The headstone included information on several Geijers and Daniel sjöberg (1845-1922) and Betty Sjöberg (1857-1946). Doris Geijer told us she was born in Oakland, California and remembers the address as $2243 \mathrm{E}$. 22nd street. The Geijers may not be able to keep the family home much longer--it stands empty. They said they heard my talk on the transuranium elements in Iund in October 1949.

We drove back to Borlänge and had sandwiches at Per and Karin's, then drove to Erikslund to visit the Erikssons. We saw Albert and Maria Eriksson, their sons Göran, Karl-Eric, Stig, and also nephew Daniel and his friend Margaret (who live in Falkenberg). Karl-Erik and Stig played the dragspel and we had coffee, tea, cookies and cake. Albert, who is 85, is becoming mentally confused and Marie is suffering from diabetes. Dan received his bachelor's degree in ethnology two years ago at the University of Lund.

At 6:00 p.m., we drove to Uppsala. We arrived at Hotel Gillet at 8:30 p.m., where I checked into room 330, Eric into 332. Eric and I then had dinner with Karin and Per in the hotel restaurant (they were our guests). They left at 10:00 p.m. for the drive back to Borlänge.

Monday, September 26, 1977 - Uppsala

Eric and I had breakfast with David and Iilo Templeton in the hotel Brasserie. Eric and $I$ then walked across the Fyris River (formerly Sala River) to nearby Uppsala University and to the University Main Building. We went to the registration office in the entrance area, picked up our folders of programs, badge, tickets and booklets in a special 500th anniversary portfolio and an anniversary plate. Eric then went sightseeing in Uppsala. Before he left, I introduced him to Stig Claesson, Gösta Rudstam and others.

I went with Rudstam to the Aula (auditorium) in this building. Here, J. Porath (Uppsala) introduced C. H. Li who spoke on "Chemical Messengers of the Interior Pituitary: Human Somatotropin and Iipotropin." During the intermission, Stig Claesson suggested I talk to 


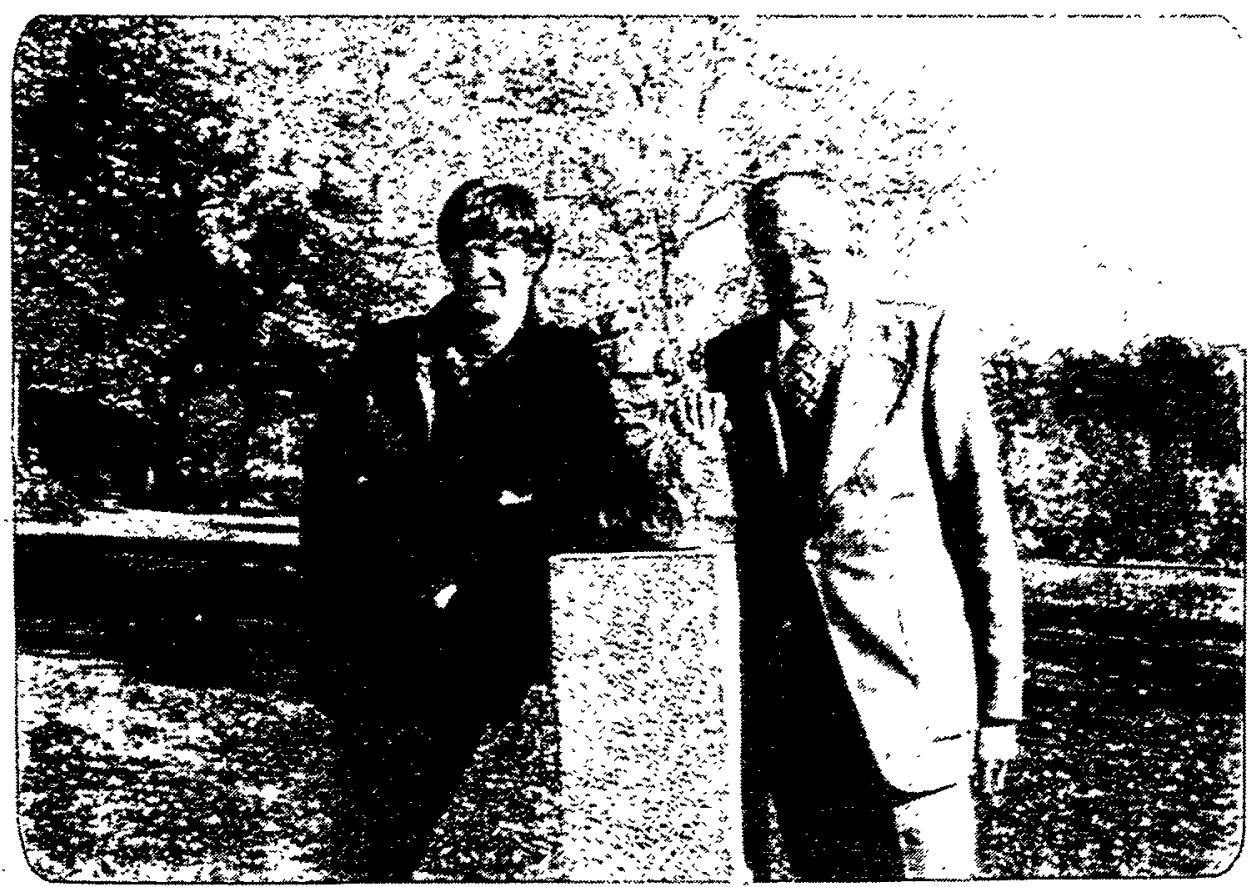

Eric and Glenn Seaborg with bust of Daniel Sjöberg, Svärdsjö, Sweden--September 25, 1977.

Erik and Doris Geijer,

Eric Seaborg, Karin Möller \& GTS at the Geijer house where Daniel and Betty Sjöberg lived, Svärdsjö, Sweden--September 25, 1977.

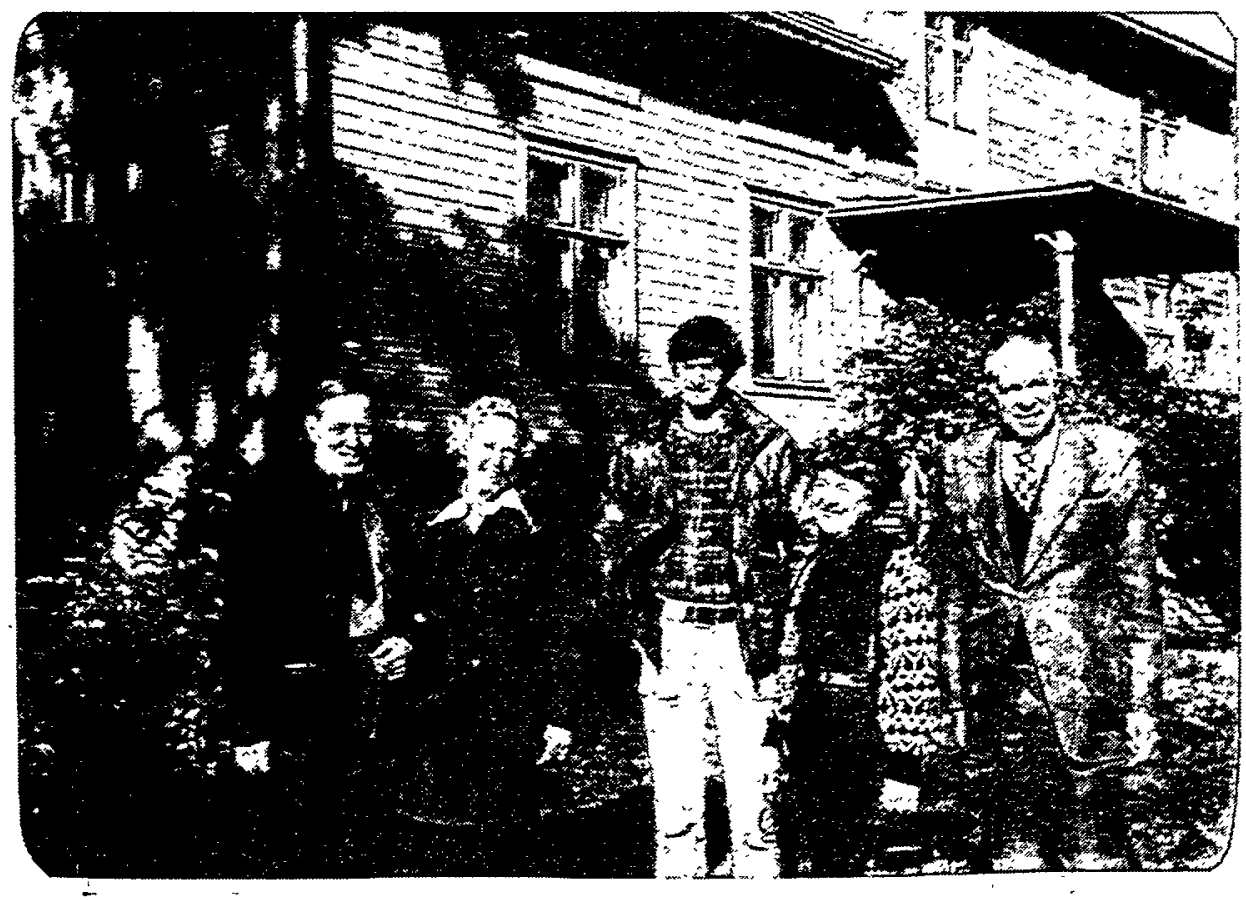


Monday, September 26, 1977 (con't)

the representatives of Swedish chemistry about my concept of an ICS. I agreed and he called to arrange for Ragnar Ohlson, President of the Swedish Chemical Society, to come to Uppsala to meet with me. I raised with stig the possibility of centering the ICS in sweden; he will give this some thought.

I called Pavel Kurfurst to investigate the possibility of visiting the stripa Mine, driving up tomorrow afternoon; he will let me know. Gunilla Lind gave me 240 kronors for expenses in Uppsala and a check $(\$ 1,097)$ to cover travelling expenses. I talked to Nikolai Emanuel about my invitation to Gvishiani to talk at our CHEMRAWN meeting in Toronto; he will check and let me know.

I returned to the Aula where J. Olovsson introduced Dave Templeton who spoke on "Symmetry and Disorder in Crystal structures." I talked with Stig Claesson and he will try to arrange for an Uppsala University car and driver for our visit to the Stripa Mine.

I went by with Gösta Rudstam to pick up my white tie and tails at the rental place (Widens Hogtidskläder, around the corner from the Hotel Gillet). I then had lunch with Gösta in the Brasserie of the Hotel Gillet. We discussed his ideas on radioactive waste disposal and his mass separator identification of short-lived isotopes at studsvik.

After lunch, I went up to my room to work on my slides and text for my talks tomorrow and Thursday. I met Clark Kerr in the hotel lobby; he arrived late last night, coming directly from Berkeley. We went to the nearby jewelers, Guld smed, to pick up our doctor's gold rings.

I walked to Uppsala University and went to the Main University Building. I met Rector Torgny segerstedt; he lived in säter and knows Karl-Eric Eriksson. I went to the Aula and heard Ilya Prigogine's lecture on "Fluctuations in Chemical Reactions and Non-equilibrium Phase Transitions." I saw stig claesson and he told me he has arranged for a student, Rolf Bergman, to drive Eric and me to the Stripa Mine tomorrow. I visited the cathedral near the campus.

I joined Eric at the Hotel Gillet and went with him to widens Hogtidskläder to rent white tie and tails for him. We changed for dinner and walked to Uppsala Castle, where, after a reception, we had dinner in Rikssalen. This is the room in which queen Christina abdicated in 1654. I sat at a table with Gösta Rudstam, Iars Melander, Mrs. Gunnar Hägg, K-A. Engdahl, Mrs. B. Flemström, Arne Fredga, Mrs. C. H. (Annie) $\mathrm{I}_{i}$ and B. Pederson. Eric was at a table with C. H. Li, K. Arrhenius, K. Hermansson, H. P. Lundgren (from Davis campus), K. O. Pederson, Mrs. I. Pederson, J. Porath, J. Tegenfeldt and Iilo Templeton. There were about 110 people present. We had reindeer meat for the main course and hjortron berries for dessert. At the beginning of dinner, Lars-olof sundelöf gave welcoming remarks and proposed a toast; after dinner, G. Wijkman (executive officer at Uppsala University) responded. We went upstairs to another room for coffee. Eric and $I$ walked back to the Hotel Gillet. 
Tuesday, September 27, 1977 - Uppsala - Guldsmedshyttan - Herrgård

Eric and I had breakfast in the hotel Brasserie. We ran into Margaret Mead and I introduced Eric to her.

We walked to University Main building and spoke to a number of people. We then went to the Aula, where Gösta Rudstam introduced me for my talk "The Periodic Table of Today." He gave a survey of the discovery of chemical elements at or in connection with the University of Uppsala (22 elements), then a rather complete description of my career including my Swedish background. I opened my talk with reference to my visits to Sweden, my present visit with Eric (who wants to remain in Sweden), the connection of my name with that of The Svedberg and the goal of discovering as many elements as Uppsala people have done (22). I illustrated my talk with 33 slides and spoke about 50 minutes. The Aula was nearly filled with people. Rudstam made a few remarks of thanks following my talk.

I met Lena Gäfvert, a cousin and a student at Uppsala University. Her mother's name is Mrs. Gurly Gäfvert. Her aunt's name is Mrs. Emma öhrn; she was a cousin of mother's. :Her mother corresponded with both mother and Mrs. Esther Wells; Lena will send me xerox copies of these letters.

I introduced Eric to Sir Frederick S. Dainton, who recalled his meeting Lynne at the Chemical Society dinner last September. Eric and I remained in the Aula to hear Dainton, introduced by Stig Claesson, speak on "What is Science For Anyway?" He spoke critically of the way Sweden requires her scientists to perform (i.e., lack of free choice) in return for financial support. He advocated the pursuit of scientific truth wherever it leads. He pleaded for a wider dissemination of scientific literacy.

After his talk, Stig claesson made come concluding remarks for the Symposium on Structure and Dynamics in Chemistry.

Eric and I returned to Hotel Gillet. I found two mail envelopes sent by Pat. We had lunch in the Brasserie.

At 2:15 p.m., we set out for the Stripa Mine (located at Guldsmedshyttan, between Lindesberg and Kopparberg) in a Uppsala University car, with Rolf Bergman, a graduate student in chemistry, driving. We arrived at Stripa Mine about 5:15 p.m. and went to the main building of the rather large complex to met Pavel Kurfurst. Pavel described the operation to us using models, then he, Thomas Doe and Richard Thorpe, all of LBL, took us on a tour of the surface operations of the radioactive waste disposal test--the drilling of holes, etc. We then joined Per Axel Halén a Swedish mining engineer on the project, who worked for years with the Stripa Mine when it was mining iron ore (iron ore mining stopped last March--the mine started about 1640). Eric, Rolf and I, under the guidance of Halén, Kurfurst, Doe and Thorpe then donned rain garb and went down the mine shaft via elevator to the 330-meter level, where we travelled by train some 700 meters through the granite tunnel to the area where the waste disposal test project is. located. We saw the various side bores, the proposed sites for the heaters and the computer room (just erected during the last 
few days). We returned up to the 220-meter level and saw an abandoned iron ore mining area. We then returned to the surface by elevator and all drove to the nearby Herrgard. Here Eric, Rolf and I checked into our rooms (nos. $7,8,9$ ), then joined our tour guides and others for dinner at Matsalen. Present for dinner were Halén, Kurfurst and his wife Dana and $3 \frac{1}{2}$-year old son David, Mr. and Mrs. Doe, Thorpe, Mr. and Mrs. Ulf Jacobson, Lars Jacobson (Ulf's brother), Håkan Sellden, Karl-Eric Alhén, Gösta Millberg and Craig Forster. We had a marvelous dinner with extraordinarily good apple pie (made from fresh home-grown apples.)

After dinner, we retired to salongen for coffee and tea, where we spent until 10:00 p.m. in pleasant conversation. Pavel's wife and son had just arrived on saturday for a week's visit. The other LBI representative is Björn Paulsson, in Berkeley at present. Ulf told me that Gästgiveri in Grythyttans, near Hällefors, is an excellent place to eat.

Today we had beautiful weather on the drive from Uppsala to Guldsmedshyttan, with striking fall colors on the abundant trees along the route.

Wednesday, September 28, 1977 - Guldsmedshyttan - Hällefors -
Skansen - Uppsala, Sweden

Eric, Rolf and I had breakfast with Pavel, Dana and David Kurfurst in Matsalen. We learned we were guests of IBL during our visit (rooms and meals). We then headed for Hällefors and spoke to the woman in charge of the office at the police station, asking if she could ascertain where the Johan Eric Sjöberg family lived in about 1870. She knew of a Carl sjöberg who lived in Hällefors at about that time and phoned one of his descendants named Anna but she knew of no connection with Johan Eric. She gave us directions on how to reach the old iron mine area and said everything, including the office building I visited in 1949, has been torn down. We drove to this area near the railroad track and near the river (Svartälven). Here, I believe I recognized the general area where the Sjobberg house stood in 1949 near the edge of a disappearing lake. (The old map at the police station showed a lake here with the name Klockersjön). In 1949, I visited the mine office headquarters, received some photocopies of Sjöberg accounts of purchases from the mining company, walked to the nearby sjobberg home at the edge of a disappearing lake and talked to an old resident of the home who apparently knew the sjöbergs had lived there.

We then headed toward Stockholm, stopping en route in Gyttorp, at Nitro Nobel $A B$, to talk to Bertil Enoksson, Director of Research. I told him of mother's correspondence with sigard Nauckhoff and his role in tracing our Swedish genealogy and establishing the connection with Laxbrostugan. He told us about Nauckhoff's fundamental work on the melting point of nitroglycerin mixed with impurities, for which he received a gold medal from the Swedish Royal Academy of Engineering Sciences. He said Nauckhoff left the Grängesberg dynamite company, run by his father, about 1905 to join Nitroglycerin Nobel. 
Wednesday, September 28, 1977 (con't)

Enoksson gave me two of his reprints "Gummidynamitvärldens första explosiva gelantin" and "Syneresis of cellulose nitrate gels." He is a part-time (20\%) professor at Uppsala University and introduced Professor Weil, one of the speakers in the Symposium on structure and Dynamics in Chemistry.

We stopped for a quick lunch in Eskilstuna. We were again favored with fine weather today and saw many beautiful fall colors among the trees, but, as we approached stockholm, the weather darkened. We drove on to skansen and met our guides, Breata Holmgvist and Ulla Svensson, at the church at a little before 3:00 p.m. We then went to nearby Laxbrostugan, went in and looked it over, with explanations and description by Breata. 'She gave us a copy of the brochure "The Iron-Master's House.": Eric bought a dalahest for Ruthie. We then drove on to Uppsala and the Hotel Gillet where we arrived at about $4: 30$ p.m.

At 5:00 p.m., Dr. Ragnar Ohlson, President of the Swedish Chemical Society, came by and we went down to the hotel bar for a drink. I told him about progress on the ICS and my idea that perhaps it could be centered in sweden. He is very interested in this possibility and will talk to a number of people in sweden to explore it further--Sam Nilsson, Lars-olof Sundelöf, Carl Heden, Olaf Tandberg, Ingmar Eneberg (UNESCO, Paris), etc. He has been President of the Swedish Chemical Society for seven years and wants to retire from this position, but I urged him to stay on. He will write to keep me informed of progress. He may look for sources of financial support. He plans to visit a colleague in Burlingame, California, next year and give some speeches in the U.S.; he will visit me in Berkeley if possible, but, unfortunately, he may come in May when I could be in China.

I gave him a copy of my New York Journal of Commerce article on the ICS; he already had the material Bixler mailed out to Chemical Society Presidents, signed by me.

Eric and I walked to the University Main Building where we attended the buffet dinner for the participants in the Uppsala University 500 years anniversary celebration. Hundreds of people were present. We sat next to Margaret Mead and Anna Briget Rooth (a Swedish ethnologist who spent some time, at Berkeley around 1964 ).

Eric went on with Margaret Mead to attend her meeting with some students and meet me later in my room. I walked back to Hotel Gillet.

Since Eric has heard from AI Iindstrom that he and Richard sproul are arriving. October 5, Eric will stay in sweden a few extra days. I phoned Gösta Adolfsson and arranged for him to visit them Saturday and Sunday. I also phoned Siv Lindkvist to arrange for him to stay with her Monday night. He will fly to London on Tuesday.

I went up to Nikolai M. Emanuel's room in the Hotel Gillet to deliver the ACS Centennial Foreign Fellow Medal and certificate for Semenov. I also reminded him to check with Gvishiani about his CHEMRAWN speech invitation. 


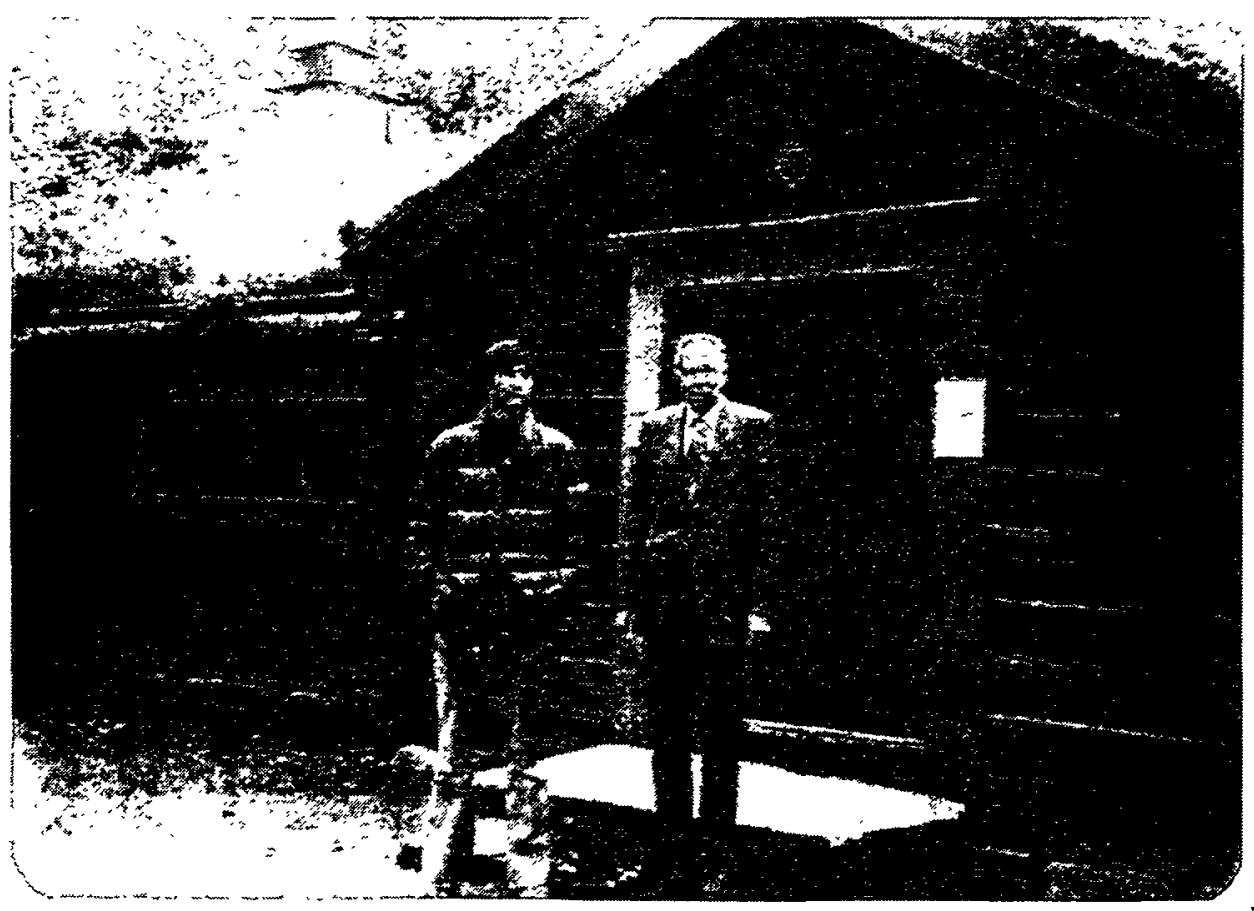

Eric and Glenn Seaborg in front of Iaxbrostugan, Skansen, Stockholm, Sweden, September 28, 1977.

Eric and Glenn inside Laxbrostugan.

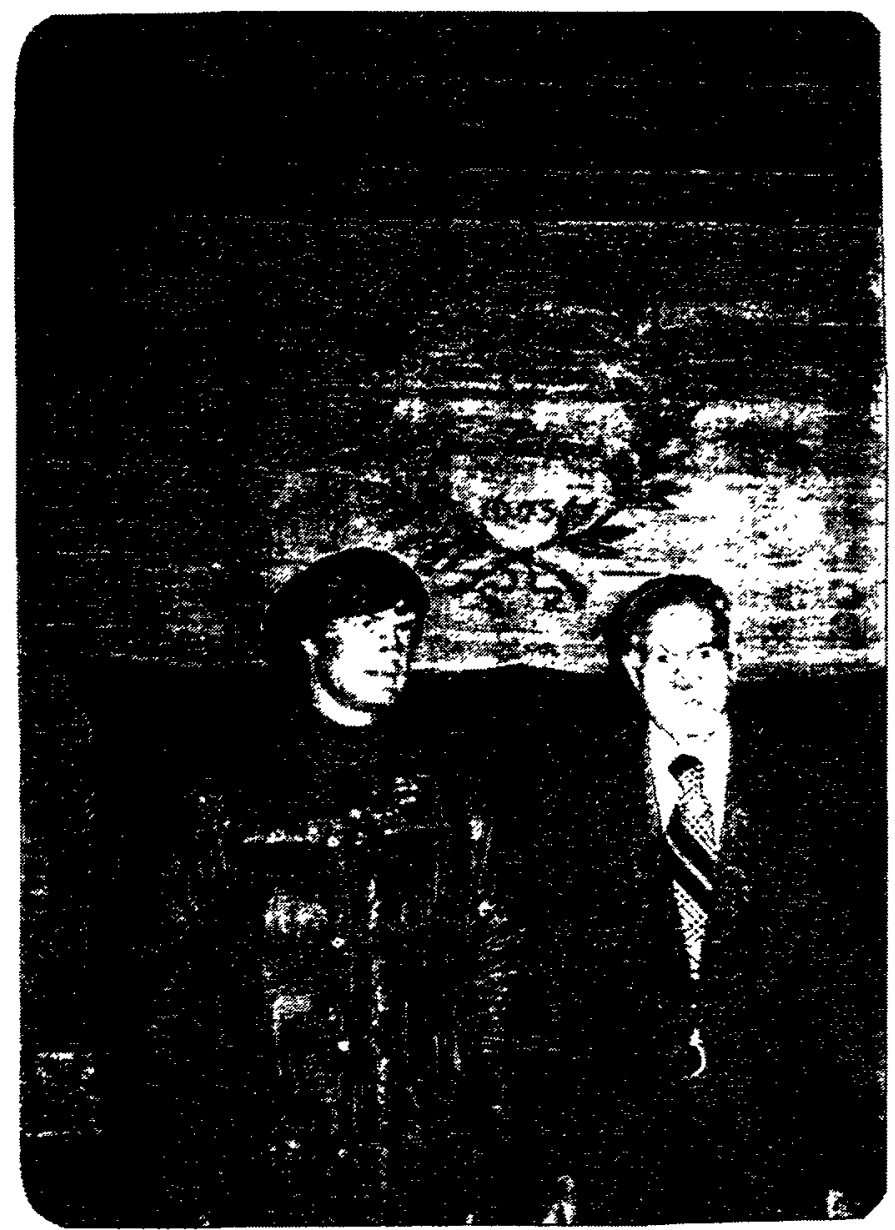


Thursday, September 29, 1977 - Uppsala

Eric and I had breakfast in the Brasserie, then walked in a light rain to the University Main Building. Here we entered the Aula. Eric took a seat and $I$ proceeded to the stage and donned my academic gown (the one worn by Robert Gordon Sproul), hood and cap. After some opening remarks, by Rector Magnificus Segerstedt, interspersed with music by the orchestra, I gave my address "Knowledge and Survival" (shortened from the prepared text to about 20 minutes). It was well received by the people in the full Aula. I sat near Carl Gustav Bernhard of the Swedish Royal Academy of sciences and told him of my concept of an ICS and my hope that sweden could play a key role.

After my address, the representatives of the University of Paris-Sorbonne (Maurice Gravier) and University of Copenhagen (Rector lange) extended greetings. This was followed by representatives of academies and universities from all over the world, about 75 in all, coming forward and extending their greetings and presenting to Rector Segerstedt various diplomas, old documents, antiquities, etc. Rector Segerstedt, Pro-rector Holmdahl and Executive Officer Gunnar Wijkman stood during this ceremonial session, which lasted more than two hours, to receive the various documents and gifts. (It is a shame that the University of California was not represented.) The representative of the Wallenberg Foundation announced the gift of 4,000,000 kronor to Uppsala University to build housing for visiting scholars.

After this ceremonial session of the Jubilee Day of the 500th Anniversary (today is the actual anniversary day), Clark Kerr, Eric and I walked to the Hotel Gillet to drop off my gown and pick up our tickets. (The third envelope sent by Pat to Uppsala had arrived.) We then continued on to the castle, entered the wrong door and ran into the king and his party, then left to enter by the correct door (for us) and went to Rikssalen (State Room) for the lunch given by the City of Uppsala. About 650 people were present (completely filling the room). Eric sat, by assignment, at the same table as clark Kerr; I was at the very long head table, across from and a few places removed from the King. I sat across from Amadou Mahtar M'Bow, Director General of UNESCO. He was familiar with my visit to UNESCO headquarters in Paris (having heard from Eneberg) and expressed interest in my concept of an ICS. I mentioned that Charles Gottschalk, a candidate for assistant to the Director of UNISSIST, is known to me; M'Bow seemed to be familiar with this. I also mentioned the ICS to the nearby Minister of Education, Jan-Erik Wikström.

The lunch began with a formal declaration by the Mayor of Uppsala, Brita Nordlander, a very impressive person. At the end of dinner, she again spoke, some in Swedish, much in English, giving the background of the relationship and history of the University and city of Uppsala. As the final act, the King made a statement, in Swedish, ending with a toast; he included a joke about king Charles XIV having to pay for a similar dinner, expressing the hope he wouldn't have to do the same.

Eric and I then walked with Dr. and Mrs. Walter shelley to the University Main Building; they will visit London next week and offered to give him a bed in their hotel room if needed. 
Thursday, September 29, 1977 (con't)

Eric bought four 500th anniversary stamps, and had them canceled, in the post office at the registration office.

We went to the Aula and sat with Gösta Rudstam and his son Sven (who works for Control Data Company in Sweden) and David and Lilo Templeton, in our assigned seats. The king and queen entered in a processional. We then viewed the continuing Jubilee Ceremony. There were speeches by Rector Segerstedt, Minister of Education Jan-Erik Wikström, Chancellor of the Swedish Universities Hans Löwbeer and the Rector Magnificus of Lund University Carl-Gustav Audrén. They spoke in Swedish, but we were given a booklet with their speeches in English. This was followed by a special musical program, the first performance of Allan Pettersson's 12th Symphony with the Stockholm Philharmonic Choir and Orchestra, and the Uppsala University Chamber Choir, conducted by Carl Rune Larsson. We were given a booklet describing this symphony No. 12 entitled "The Dead on the Square," which includes the text of this production.

The king and queen left and then the other people on the stage left in a processional. Eric and I walked back to the Hotel Gillet. Eric went to the Travel Agency across the street to try to change his ticket to London to next Tuesday morning, but they couldn't reach the airlines office by phone (closed).

Eric and I donned our white tie and tails and rode on the bus to Fyris Hall (the gymnasium) to attend the Jubilee Banquet. I talked to Sundelöf about the ICS concept and its possible location in sweden and said that Ragnar Ohlsen will talk to him about it; he thinks it is a good idea. I also told him to discuss it further with Francis Bonner, whom I had a chance to see only once (after my talk on Tuesday) during my stay in Uppsala. Sundelöf told me he was pleased with both of my talks.

As we walked to the banquet rooms in Fyris Hall, I talked to Carl Djerassi and his friend Diane Middlebrook. I told him about the progress on his "Modest Proposal" (to help developing countries through joint research projects).

I sat at the head table a few places removed from the king and Prime Minister Torbjörn Fälldin; I had a few words of a purely social nature with Fälldin and exchanged nods of recognition with the king. I sat next to Mrs. Birgit Wijkman (wife of the executive officer of Uppsala University) and Lady Gunborg Sutherland (who was born and spent her youth in Sweden) and near Mayor Brita Nordlander and Governor (of Sodermanland) Mats Lemne. Eric sat at a table next to Carl Djerassi (Eric reminded Carl of the sea cucumber story). Professor Rector and Mrs. Bengt Pernow sat at the neighboring table but Eric didn't meet them.

There were about 1,400 people in the two halls ( $A$ and $B$ ); Eric and $I$ were in Hall B. We each received a 500th Anniversary medallion at our dinner place. The dinner began in the traditional manner with the blare of trumpets and a toast by Rector segerstedt. During the dinner, following introduction by trumpets, there were short talks by 
Rector Segerstedt (in Swedish), Prime Minister Fälldin (in Swedish), UNESCO Director General M'Bow (in English) and the king (in Swedish), ending with his toast (which brought the dinner to a close).

Eric and I then proceeded by bus to the Castle where there was dancing in the Rikssalen. We viewed this in the Rikssalen and from the room above (where we had our coffee Monday night). Here we joined a table where Dr. and Mrs: C. H. Li and Dr. and Mrs. Jerker Porath were sitting. I learned that Porath's parents are originally from stora-Skedvi, which led to the remark that we might be cousins. His mother's name is Iidman (from Lidmans-gården) in Vika Dalarna. Fredga joined us; his mother was a sister of Ingve öhman's mother.

I left at about midnight and walked back to Hotel Gillet. Eric stayed on a while; he danced with Mrs. Porath (who claims she has a beautiful daughter, aged 21, that Eric should meet).

Friday, September 30, 1977, - Uppsala

Eric and I had breakfast in the Brasserie--he then went to the Travel Bureau to change his airplane ticket.

I rode to University Main in the Porath car driven by Mrs. Porath, with Porath, C. H.'Ii, and Yuriy Anatoliyevich ovchinnikov for the rehearsal of the Conferment Ceremony for honorary doctors to take place this afternoon. I told them about my ICS idea and they all approved of the idea. All the 95 or so honorary doctorates recipients went through, a rehearsal in the Aula for this afternoon's Conferment Ceremony.

After the rehearsal, I talked further to Eneberg about the ICS, then joined Clark Kerr. Kerr and I went with Porath and Sundelöf to the chemistry building where they showed me the lecture hall in which I made my talk on the transuranium elements in October 1949; the interior has been rebuilt somewhat. Porath wants to escort me on a visit to Ytterby next year.

Sundelöf told me that Uppsala has a program called International Seminar in Chemistry (also one in Physics) in which fellowships are given each year to 15 post-Ph.D. students from developing countries to come to Uppsala University to do cooperative research for one year. Sundelöf said this is much in line with my ICS idea, which he will discuss with Ragnar. Ohlson. I told him about the Djerassi proposal; I willsend him a copy of the Bulletin of Atomic Scientists article.

Kerr and I then visited a number of the student Nations buildings, including Södermanlands, Göteborg and Västmanlands-Dala. These are really nice places. Each student must join one of these student "clubs." Västmanlands-Dala has 3,000 members. They were preparing for tonight's banquets and student balls. Kerr and I then walked back to Hotel Gillet.

Eric and I had Iunch in the Brasserie at a table with Dr. and Mrs.. C. H. Ii. Eric then went shopping for a bag that I can use to carry the extra things (books, pamphlets, etc.) I have picked up during our"visit to Europe. He bought a little suitcase for $\$ 25$. 
Friday, September 30,1977 (con't)

I rode on a bus to the University Main Building to participate, in the Aula, in the Conferment Ceremony, at which we were to receive our honorary doctorate degrees. About 95 degrees were conferred, 30 in the sciences. Eric walked to the University Main Building, bringing the cameras with him. It was raining although not very hard. our bus was delayed by Uppsala student and other demonstrators marching on the central Uppsala street in which the bus travelled.

Demonstrators were also assembled in front of University Main so Eric had some trouble working his way through them. Many police were in evidence and the area was cordoned off. For this, as for the other functions, a special card was required for admittance. The focus of the demonstrations was the representative from Iran, Seyyed Husain Nasr.

The academic procession into the Aula began at 3:00 p.m. (I greeted Finnish President Urko Kekkonnen, an honorary degree recipient, recalling our meeting in Finland some 8 years ago.) Eric tried to take an olympus picture but the flash didn't work (batteries down). The procession included University officials, student leaders, honorary degree recipients, faculty delegates from universities and academies, promotores, and other dignitaries.

We entered to orchestral music and choir singing, with four trumpets in the gallery adding their contribution. The ceremony was interwoven with a cantata, with choir, soloists and orchestra, written by Ingmar Milveden, and including excerpts from statements of Rector Segerstedt and Iinnaeus, with the theme of academic freedom. Honorary doctorate degrees were also conferred on a number of people who received their doctor's degrees at Uppsala University 50 years ago-Doctores jubilares.

The science doctorates were conferred last and I was no. 80 in the sequence. Each recipient stepped forward to the rostrum and the "promotor" conferred the degree. In the case of science doctorates, we received a laurel wreath, placed on our heads, a ring placed on our finger (symbolic gesture because we were already wearing our rings) and our diploma. A cannon outside boomed as the wreath was placed on the recipients head. Some recipients bought the empty shell afterwards. Stig claesson was our "Promotor" and made his individual pronouncements, and opening and closing remarks in latin. He became somewhat confused on several occasions in trying to remember his Latin words as he conferred individually the 30 honorary degrees.

Ninety-year-old Hans von Kantzow (Bruksdisponent, Hallstahammar) violated protocol, making some kind of a statement which resulted in some merriment in the audience. As we left the rostrum, we stopped and bowed to the king. Following the degree conferments, there were short talks by Frederik Täckholm, Chairman of the Student Union, and Urko Kekkonnen, who spoke on behalf of the honorary degree recipients. The program ran until 6:30 p.m., an hour over the scheduled time. We left in an academic processional, with the orchestra and choir again augmented by the four trumpets from the gallery. I greeted Baron stig Ramel, of the Nobel Foundation, on the way. 
Friday, September 30,1977 (con't)

Eric and I walked back to Hotel Gillet in a light rain. We quickly donned our white tie and tails ( $I$ again wore my centennial Swedish king's medal.) We then rode with the sundelöfs, together with Prigogine, to the "Västragöta Nations" Student Ball held at their 17th century house. We met a number of lively and interesting students. I was assigned to escort Mrs. Amadou Mahtar (Raymonde) M'Bow to the table in the festively decorated dining room with murals on the walls. Eric was assigned to Britta Isen, of Västerås, a pretty, vivacious law student with whom he spent the rest of the evening, also in the company of some other pretty girls.

At dinner, I sat next to Mrs. M'Bow and Mrs. Jacqueline Mislow (her husband is at Princeton University) and near Frederik Täckholm, Chairman of the Student Union, who spoke as representative of the students at the Conferment Ceremony this afternoon, and Professor John-Eric. Thun, the "Inspector" (house master) of the Västragöta house. (Thun is a nuclear physicist, in charge of the tandem accelerator at Uppsala University.)

The dinner began at 9:00 p.m. and lasted until after midnight. It was punctuated by many toasts, remarks by student leaders of Västragöta house, Inspector Thun, $M^{\prime} B o w$ and others and comedy singing to guitar and piano accompaniment by a couple of Uppsala faculty members. There was much singing of students' songs, one standing on our chairs: All of this was led by an attractive "Mistress of Ceremonies," who thumped the floor with a huge wooden staff in order to quiet the assemblage to the point we could hear her announcements and introductions.

We went back upstairs for coffee. I sat at a table with the M'Bows and Georg and Greta Borgström (he is an environmentalist at Michigan State University consulted by Prime Minister Fälldin and other Swedish officials; they were both born in Sweden and went to Michigan state some 20 years ago.) Ingmar Eneberg joined us, again urging me to keep him and UNESCO informed on progress on the ICS because they (including M'Bow) want to be involved. When I told him of Eric's interest in Sweden, he told me he might get a job (writing on environmental problems in English) with the newly established Stockholm international research institute on environmental issues, which has support from the Swedish government. It will be headed by Gordon Goodman. Eneberg will discuss this possibility with Goodman and Eric should call him at UNESCO when he gets to Paris late in October.

I left at 1:30 a.m., soon after the dancing started; Britta and Eric were on the dance floor; Eric stayed until about 5:30 a.m.

I walked back to our hotel in a light rain and packed-my various bags. I received a call from a student at södermanlands Nation house inviting me to come over and join them, but I had to regret to his tremendous disappointment. I retired at 2:30 a.m. 


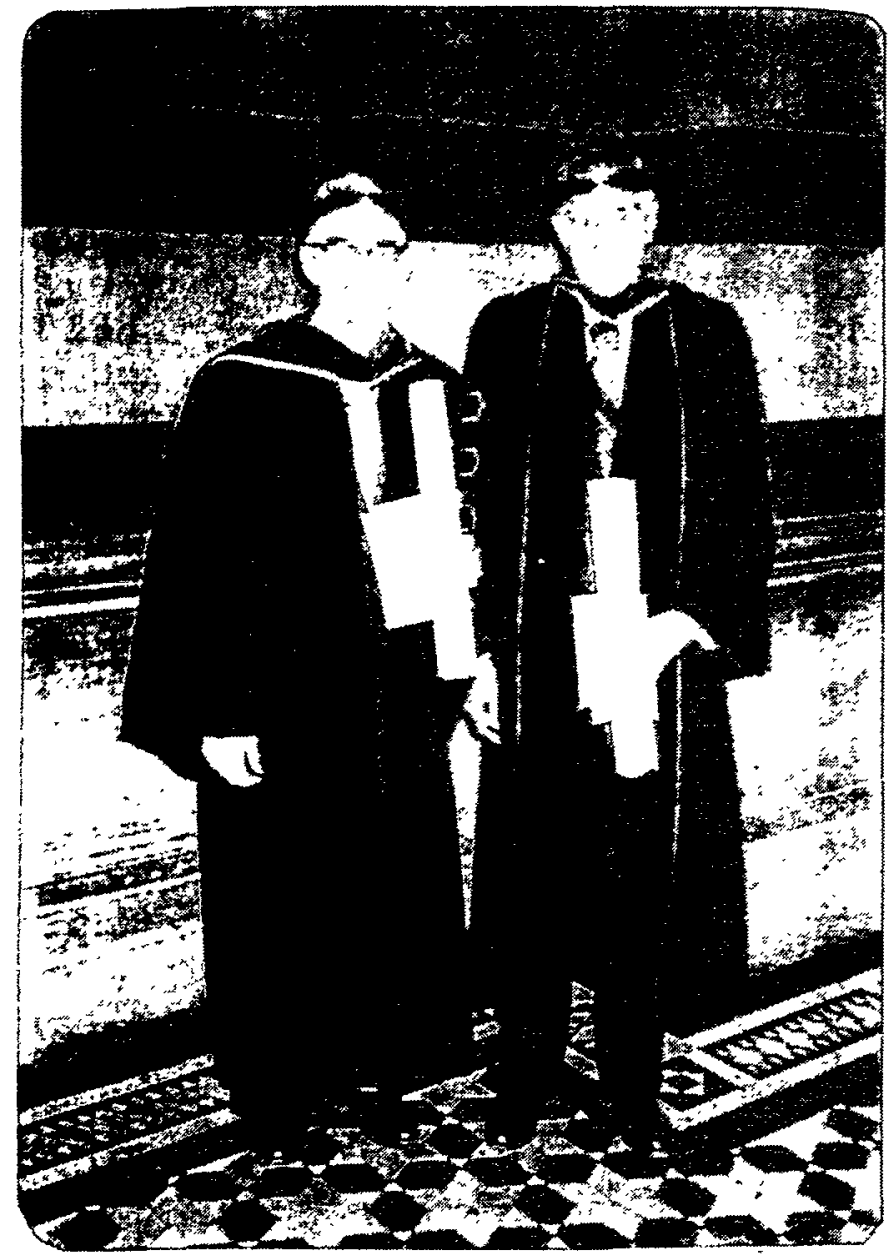

616

David Templeton and GTS after receiving honorary degrees at the 500th anniversary of Uppsala University, Uppsala, Sweden, September 29, 1977.

Eric Seaborg at the Hotel Gillet, Uppsala, Sweden: September 30, 1977.

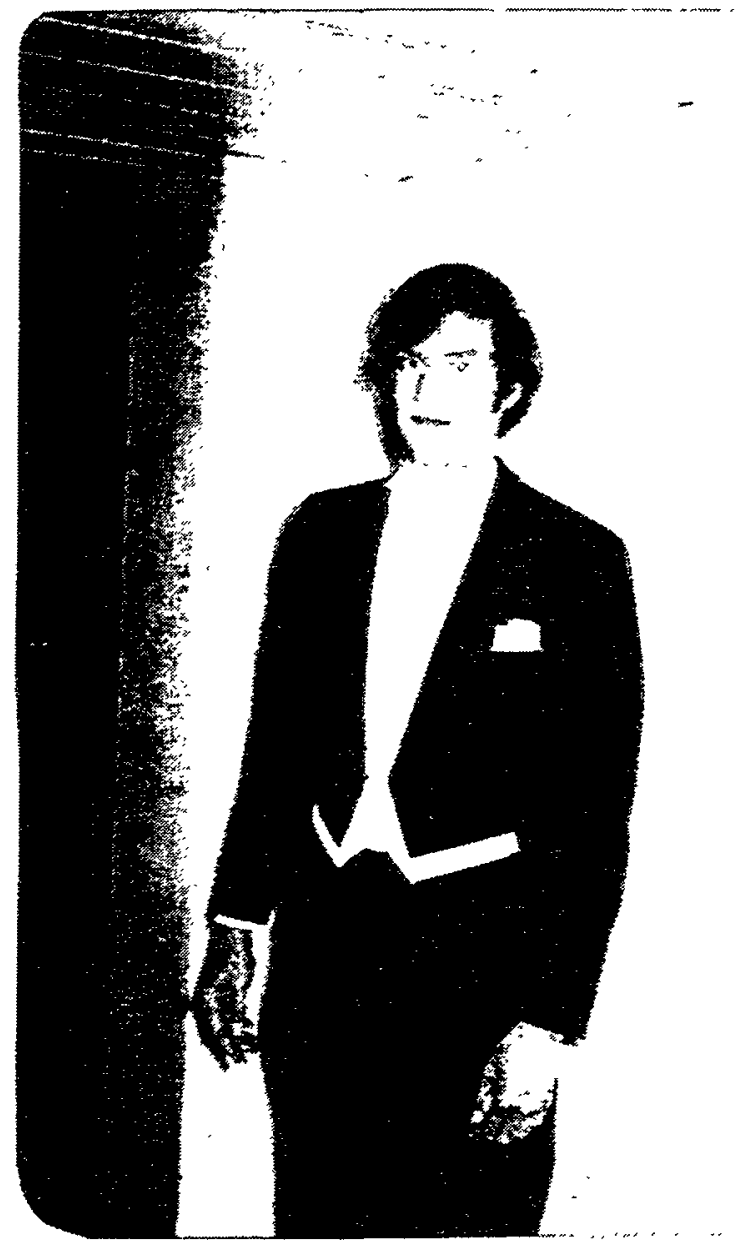


Saturday, October 1, 1977 - Uppsala, Sweden - Copenhagen, Denmark Seattle, Washington - San Francisco

I phoned Jack Barrett at his home in Bourton-on-the-Water and made arrangements for Eric to store his suitcase at the Chemical Society headquarters at Burlington House (where Lynne and I had dinner last September) in London during his travels in England. Jack may also look into the whereabouts of youth hostels in the Iondon area.

Eric and I had breakfast in the Brasserie at 8:00 a.m. He had only an hour or two of sleep. (I loaned him $\$ 240$ for use if he runs out of money.) I told him about my talks with Ingmar Eneberg last night (concerning the contact with Gordon Goodman's environmental organization) and with Jack Barrett this morning. Eric will go by train to Eskilstuna, via Stockholm, as soon as he gets his suitcase and backpack packed. He will be met there by Gösta Adolfsson and spend Saturday and Sunday nights with the Adolfssons, then he will probably contact Siv Lindkvist and spend Monday night at her home, first visiting the Vasa ship and Skansen again on Monday. He will then fly to London on Tuesday morning and meet AI Lindstrom and Richard Sproul at London Heathrow Airport early Wednesday morning (October 5).

I checked out of our hotel rooms, paying a bill of 412.60 kronor which covered our dinner with Per and Karin Sunday night, our lunches and telephone calls.

I then bade farewell to Eric, boarded a special bus and rode to Arlanda in the rain. Here I boarded Scandinavian Airlines flight \#911, which left at 11:00 a.m. and arrived in Copenhagen at noon. At Copenhagen, I boarded Scandinavian Airlines flight \#933, which left at 1:15 p.m. and arrived at seattle Airport at 3:00 p.m. I read draft articles and other material sent to me by Pat, en route. I talked to Carl Djerassi and Diane Middlebrook, who were also aboard, about progress in ICS, my itinerary on the present trip, their itinerary (they left home on August 23), etc.

We travelled on three trains at seattle Airport to reach the United Airlines area, where we boarded United flight \#275 which left at 4:40 p.m. and arrived at San Francisco at 6:20 p.m. Helen met me and drove me home. She told me that Dianne has started her freshman year at Davis and seems to be getting. along all right. Dave is home with us recuperating from a cold before he starts his next boardand-room job. I spent the evening reading some of the huge stack of papers which accumulated during my absence.

\section{Sunday, October 2, 1977 - Iafayette}

I spent most of the day and evening reading the accumulated material.

In the afternoon, Helen and I took a hike at Las Trampas Regional wilderness: From the parking lot we hiked to the start of Mahogany Trail. We hiked Mahogany Trapline, Gooseberry, Chamise, and Mahogany Trails, then returned to the parking lot. 
In the evening, Reid Laitner came by and Helen and I signed a purchase contract to sell our 2-acre Orinda land relating to an offer from Phillip S. Wirthman to purchase it for $\$ 20,000$ and our counter suggestion of $\$ 25,000$.

Monday, October 3, 1977 - Berkeley

I worked with pat on my accumulation of mail and papers. I received the following note from Bernard Harvey apprising me of the latest developments of the High Intensity Uranium Beams project:

"Here's the position on Capitol Hill:

1. IINE ITEM Things look bad for FY'78. House and senate Appropriations are both saying "after you." The D. of $E$. supplemental seems to be genuinely only for "emergencies" i.e. moving to the Forrestal Bldg.

The last hope is cranston/Forcier. They probably haven't done much yet since the senate is all tied up with Gas Deregulation. I suggest calling Goldschmidt and Forcier MON a.m.

2. 6M OPERATING. Apart from Minetta's and Andelin's calls, nothing has happened. If we can't even get the line item. I see no hope on an Operating Add-on, so I've done nothing to move this along. I suggest you call Andelin or Leber.

I've really worked on all this, but can't think of anything more that could be done. You might want to follow up on the Goldwater-Bellmon connection by phoning Joe overton. I'm not optimistic though. No word from Hiyakawa!"

I also dictated a letter to stanley Schneider to let him know that my Uppsala address for the 500th Anniversary Jubilee was very well received and enclosed a check for $\$ 1,000$ as a token of my appreciation for his work on the speech ("Knowledge and Survival"). I sent A. M. Dowden the biographical sketch for the transuranium elements volume and a copy of the author's permission letter and informed him that we do not have a publishers permission form on file in my office. I replied to Professor Mansel Davies in regard to his inquiry of my having seen the Bury paper before ( $I$ had not).

At 9:55 a.m., I received a phone call from Professor Allan Bromley. He will be in the San Francisco area and wants to meet with Bernard Harvey and me. He will come to the Laboratory at 10:30 a.m., Monday, October 31, 1977.

At 10:30 a.m., I attended the scheduling meeting for the 88" cyclotron along with AI Ghiorso, Pat Somerville, Ken Thomas and Kim Williams. Someryille was scheduled for the owl shift, Thyrsday, October 13 (for ${ }^{\mathrm{He}}$ plus $235_{\mathrm{U}}$ to look for S.F. isomer of ${ }^{234} \mathrm{Pu}$ ); Williams was scheduled for the swing shift, Friday, October 14 (for ${ }^{1} 1_{B}$ plus $235_{U ;}$ Ghiorso was scheduled for the swing shift, Saturday, october 15 and the owl shift, October 16 (for ${ }^{14} \mathrm{~N}$ plus $\mathrm{Pb}$ ); and $\mathrm{K}$. Hylet and $N$. Mikheev were scheduled for the swing shift, October 14 ( 254 Es plus ${ }^{4}$ He for chemistry of 256 Md). Mikheev has had one experiment on Md chemistry and is pleased to get started. He will be at IBL for 3 months. I signed somerville's study list and discussed his most recent results-he has found a $30-$ n.s. S.F. from ${ }^{3}$ He plus $235_{U}$. 
Gordon Halstead dropped by to give me a copy of his thesis to read in my capacity as a member of his. Ph.D. committee:

Barbara Jacak dropped by to bring me up-to-date about her meetings with the cluster student group for which I am the advisor and to have me sign some study lists.

I called Pete Goldschmidt, John Andelin, Dan Dreyfus (Senator Jackson's office), Jim Forcier (Senator Cranston's office) and Jack Ford (Burgener's office) about the status of our High Intensity Uranium Beams project.

I attended the luncheon of the Chemistry Department faculty in the Latimer-Lewis Room. Rollie Myers, who is giving the lectures in Chemistry 1A, and Sam Markowitz, who is leader of laboratory section 3 (Tuesday afternoons), brought me up-to-date on the start of classes last week.

At 3:30 p.m., I attended the Nuclear Science Division seminar in 70A-3377. Rollie otto spoke on "New Insights into Heavy Ion Reactions from Radiochemical Studies".

I attended a reception in the cafeteria, from 4:30-5:00 p.m., held in recognition of art work done by $L B L$ employees which was on display. Andy Sessler spoke and then I spoke about my involvement with the Arts in Education Panel and their output, "Coming to our Senses".

Sheila called to inquire about my European trip and to bring me up-to-date on her work in the Regents' office.

I took a hike at Iafayette Reservoir on the way home. Helen and I had dinner in the playroom and were joined by Dave. We watched Monday Night Football--Oakland Raiders vs. Kansas City Chiefs. The Raiders won $37-28$.

Tuesday, October 4, 1977 - Berkeley

Helen drove me to my LBL office so she could take the station wagon to Berkeley Tire Company to purchase some new tires.

I continued to work with Pat to get caught up on my correspondence. I dictated a letter to Professor Samuel Devons expressing my regret and declining his invitation to attend the symposium on the occasion of the 50th Anniversary of the Pupin Laboratory, at Columbia University, due to a previous commitment to the Welch Foundation in Houston, Texas. They will also include recognition of Professor Isidor Rabi's fifty-year association with Columbia, so I wrote:

"I have had the privilege of being associated with Professor Rabi in a number of ways during the last thirty years, including our membership in the First General Advisory Committee of the Atomic Energy Commission, and in our mutual involvement with the International Atomic Energy Agency. I have found $\mathrm{him}$ to be a man of extraordinary vision and wisdom and have benefitted much from my associa- 
Tuesday, October 4, 1977 (con't)

tion with him. He has played a notable role in the overall development of science policy in the United States and throughout the world. I would like to join his many friends in paying my respects and expressing my affection for him. I am sure that he will continue to make important contributions during the second fifty years of association with Columbia University."

I sent a check $(\$ 100)$ to Benjamin Loeb for his distribution to Walter Leight and Francis Duncan ( $\$ 50$ each) for their analysis of our draft on Test Ban negotiations. I replied to Robert Weast, Editor-inChief of CRC Press, Inc. in Cleveland, Ohio regarding competing claims of the discovery of elements 104 and 105 between Berkeley and Dubna. I informed Bernard Abraham that a search committee had been formed and that I was supporting his nomination as Head of the Energy and Environment Division. I also dictated a short thank you note to Arthur Norberg, in the General Library, for the four stamps commemorating the centenary of the Royal Institute of Chemistry he sent to me.

I went by to see Rollie otto in room 203/70. He told me he has been offered a position in the LBL Earth Sciences Division. We will have to discuss further when he might start, to be consistent with our planned bombardment schedule and paper writing program.

I gave Otto and Dave Morrissey the reprints and other data I gathered during my visits to GSI and Marburg on September 14 and 15 to read and return to me. We also discussed plans for Wayne Marsh; he will do undergraduate research with me this quarter (his last before graduation). He will do graduate research with Professor Prussin.

I learned that Kim Williams got a pretty good $10_{B}$ plus $235_{U}$ bombardment at the 88" cyclotron on the swing shift yesterday. I discussed with Patricia Baisden her plans for a $4 \mathrm{Ar}_{\mathrm{Ar}}$ plus $\mathrm{Pb}$ (to study $\mathrm{X}$ ) and a ${ }^{136}$ xe plus ${ }^{248} \mathrm{Cm}$ bombardment (to study heavy isotopes) at the Superhilac.

I discussed with Olivia my tentative FY 1978 budget allotment, pointing out the additional requirements for salary support.

At 10:40 a.m., I received a telegram from Dzhermin Gvishiani declining (with regret) my invitation to attend the Conference (World Conference on Future Sources of Organic Raw Materials-CHEMRAWN).

From 11:10 a.m. to 12:00 noon, I attended the Chem $1 \mathrm{~A}$ lecture in PSL given by Professor Rollie Myers.

I had lunch at the Faculty Club at a table with Alexander Pines, Leo Brewer, Donald Noyce, Andrew Streitwieser, Neil Bartlett, Joel Hildebrand, Robert Connick, William Dauben and others.

I attended the pre-lab section 3 meeting of Chemistry $1 \mathrm{~A}$ instructional staff in Latimer 328 , then met my laboratory section in room $B$ from 1:10-1:50 p.m.; we gave them a quiz. I have Pat McGaughey as a Teaching Assistant in Room B, James A. Roe in Room C, Steve Treon in 
Room $D$ and David Goodin in Room $E$. I covered these rooms untiI 3:00 p.m., when I was relieved by Barbara Garrison.

From 3:10-4:10 p.m., I met, in room 444, Iatimer, with 20 students in my cluster group for whom I am serving as advisor. We had a satisfactory discussion on superheavy elements, nuclear structure, etc., in addition to philosophy of undergraduate research, etc. Two of the group, Don Ino and Richard Davis walked up the hill with me and visited briefly in my LBL office.

I met Pat somerville in room $203 / 70$ and arranged to have his $235_{U}$ target isotopically analyzed by Maynard Michel; I also gave him some reprints on delayed S.F.- isomer work.

Helen and I had dinner in the playroom watching the National League baseball playoff game between the Los Angeles Dodgers and Philadelphia Phillies. Alice Thompson joined us; after a while, Alice and Helen went to Berkeley to attend a club meeting on investment techniques. The Phillies won--7-5.

Wednesday, October 5, 1977 - Berkeley

I called Bryant Rossiter at 8:45 a.m. to inform him about the telegram I received from Dzhermin Gvishiani declining our invitation to participate in the CHEMRAWN Day I panel. Rossiter suggested Professor Dieter Behrens from Frankfurt as a replacement. I agreed to contact Behrens and extend the invitation.

I walked down to the campus to attend the Chem $1 \mathrm{~A}$ lecture by Rollie Myers in PSL. I then attended the meeting of chem 1A teaching staff at which Robert Connick and Leo Brewer went over the laboratory work in room 124 Lewis.

As I was entering my IBI office, after walking back up the hill, I received a phone call from Bill Bevan: I agreed to write a letter (attached) of recommendation to Norman Hackerman recommending Bill for appointment to the National Science Board.

We held the regular meeting of my research group (SHEIKS) in my office from 12-1:15 p.m. Present were Nikolai Mikheev, Bob Silva, AI Ghiorso, Dave Morrissey, Rollie Otto, Trish Baisden, Michel de SaintSimon, Diana Lee, Bonner Nishida, Kim Williams, Saburo Yashita, Ken Thomas and Pat Somerville. Somerville reported on his observation of

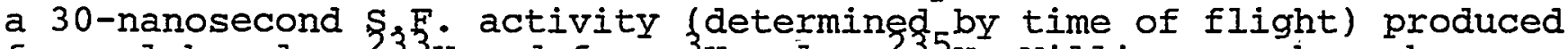
from alpha plus $233_{U}$ and from $3_{\text {He plus }} 235_{U}$, williams on her obser vation of a $18.3 \pm 2.5$-minute electron-capture activity (due to $242{ }_{\mathrm{Bk}}$ or $241_{B k}$ ) from $11_{B}$ plus $235_{U}$ (observed via $\mathrm{Cm} \mathrm{K}_{\alpha}$ and $\mathrm{K}_{\beta} \mathrm{x}$-rays), otto ${ }_{4}$ plans for SuperHILAC bombardments ( $\mathrm{Pb}$ plus $\mathrm{Pb}$ or $\mathrm{Bi}{ }^{\beta}$, and ${ }^{4} \mathrm{Ca}$ plus $248 \mathrm{Cm}$ to look for SHE and actinides), Baisden on her plot of actinide yields and other heavy isotope yields from HI on heavy targets and Morrissey on recoil behavior of products from $400-\mathrm{MeV} /$ nuclear $2 \mathrm{Ne}_{\mathrm{Ne}}$ plus Ta (with x-ray detection).

At 1:30 p.m., I received a call from Tim. Moder with GASP asking me to chair an active campaign support committee. My schedule would not permit me to spend a great deal of time on it, but I said I would 
October 11, 1977

Dr. Norman Hackerman.

National Science Board

National Science Foundation

Washington, D.C., 20550

Dear जงorman:

I am writing in support of Professor William Bevan of Duke University for appointment as a member of the National Science Board.

Bill Bevan is 7 illiam Preston Few Professor of Psychology at Duke University. The is an experimental psychologist with an outstanding record of publications in the fields of perception and other cognitive processes, vision and other sensory processes, and human engineering and human factors research.

I became very veil acguainted with Bill during the three years (1971-73) in which I served as President-elect, President and Chairman of the Board, and during whicin he served as Executive Officer of the Mnerican Association for the-Advancenent of Science. I have also participated in the Rouna Table on Science and Pubijc iffairs which he initiated and implemented so successfully at Duke University.

On the basis of my opportunity to watch him in action, I believe that 3 ill ievan is very vell qualified for nembership on the rational scicnce Boarä. ïe possesses a tare conbination of scholarly background, execurive ability and anministrative experience with a special interest and competence on the questions of sociclogy and national policies for science and technology. He is a very dynamic person, energetic, very articulate, has a pleasant personality, reíates well to people.

Bill Bevan has been very active in a nunber of scholarly and scientific Fssociations. These include the Arerican fissociation for the Advancement of Science (where he serves on the Comittee on Scientific Freedom and Responsibility), Anerican Council on Education, Anerican Psychological Essociation, American Psychological Foundation, Association for the Advancement of Psychology, National Institutes of Health, National Institute of Mental liealth, and others. He has been active 
in the National Science Foundation and is currently serving on the National Science Board Task Force on Science Applications.

I believe that Bill Bevan is very well qualified for a position on the IJational Science Board, and I feel I can give him the highest recommendation.

Cordially yours,

Glenn T. Seaborg

GTS : pq 
consider being a co-honorary chairman with Iinus Pauling on the advisory committee. He agreed to send me a description of the duties that would be required of me.

At 3:00 p.m., the Nuclear Science Division staff had a birthday party for Bernie Harvey. In attendance were Sharon Date, Kathy Van der Haeghen, Pat Quinn, Eileen Eiland, Olivia Hansen, Frances Mann, Wanda Smith, Paula Bjork, Harvey and $I$.

Kenton Moody, an incoming graduate student in Chemistry from the University of California at Santa Barbara, came by at 3:40 p.m. to discuss my research program as a possible choice for his Ph.D. research. I described my program, gave him some reprints and took him to building 70A to meet Morrissey, Thomas, de Saint-Simon and Lee, to the HILAC Building to meet Ghiorso, Nitschke and Sebesta and to see our equipment (FAKE, FAMSY, etc.).

I dictated a letter of support for the admission of Richard Sankary to the Bowman Gray School of Medicine in Winston-Salem, North Carolina.

I went to Baisden's office to discuss her research program.

I took a hike at Lafayette Reservoir. Helen, Dave and I had dinner in the playroom, watching on TV the second National Ieague baseball playoff game--the Dodgers won, 7-1.

Thursday, October 6, 1977 - Berkeley

I dictated to Pat a response to A. DeVolpi at Argonne National Laboratory on his comments on New Directions and a letter to Paul Lochak in France, indicating the amount of $\$ 2,336$ as my travel expenses (my recent Europe trip) for which I would like reimbursement.

At 9:10 a.m., I spoke with W. O. Milligan with the Welch Foundation about several matters in connection with the foundation and the upcoming conference.

I had lunch in the cafeteria with Michel de Saint-Simon.

Reinhard stock has just returned from a visit to GSI and CERN, during which he tried to arouse interest in providing funding for relativistic heavy ion capability at CERN.

I worked with otto and Morrissey on the revision of our ${ }^{48} \mathrm{Ca}$ plus ${ }^{208} \mathrm{~Pb}$ paper for submission to Physics Letters because of its rejection by Physical Review Letters.

I went down to Building 88 to talk to Mikheev, Hulet and Baisden, busily at work on mendelevium chemistry in preparation for their bombardment on Monday ( ${ }^{4}$ He plus ${ }^{254} \mathrm{Es}$ to produce ${ }^{256}$ Md for tracer).

At 3:00 p.m., Michael Crisp of Senator Baker's office returned my call of yesterday. He told me that the markup would be made next Wednesday (October 12). He suggested I contact Kathryne Bruner (Senator Hayakawa's office) and Jim Forcier (Senator Cranston's 
office) to have them attempt to have each senator contact key (or alI) members of the Appropriations Committee to enlist their support for the High Intensity Uranium Beams facility and request that it be added to the Senate Appropriations Bill. I told Crisp that I had spoken to Dan Dreyfus (Senator Jackson's office) and suggested that Crisp call him to encourage his help.

I dictated a letter of appreciation to Aristides Pinto Coelho for sending me a copy of his book, "Energía Nuclear." I then walked down to Latimer Hall and back to pick up my mail.

When I arrived home we received a call from Iynne, who was in Moline, Illinois, with Bill at his mother's home. She said she did well in defending her Ph.D. thesis plan before her 4-man committee at Purdue in Iafayette, Indiana, earlier this week. Bill has had an interview for a possible internship at Vanderbilt, with Iowa state coming up. They are coming to California next week; Lynne to arrive here on Monday and Bill a little later following some interviews at West Coast schools.

Helen, Dave and I had dinner in the playroom. We watched the American League baseball playoff game between the New York Yankees and Kansas City Royals. After dinner, as usual, I worked in the study. Friday, october 7, 1977 - Berkeley

At 8:30 a.m., I spoke with Kathryne Bruner (Senator Hayakawa's office) on the telephone regarding the High Intensity Uranium Beams Project and its inclusion in the supplemental budget appropriation bill. Mike Crisp (Senator Baker's office) suggested that I contact her and request senator Hayakawa to send a letter to members of the appropriations committee in support of its inclusion in the bill. She agreed to make sure this was done and if necessary have it hand delivered (Bellmon was the only name she mentioned). She said that Ann Wray is the most influential person in Senator Cranston's office (Crisp mentioned James Forcier who, as it turns out, is Ms. Wray's assistant). Bruner agreed to call wray prior to my calling her, and I informed her that I would try to reach Ms. Wray before 9:00 a.m. our time.

I called Ann Wray at 9:00 a.m. She said that Forcier was the person handling the staff work and that a letter has gone out from Senator Cranston to the Chairman of the full Senate Appropriations Committee with copies to all members voicing his support for the project and urging restoration of the funds. She will talk to Cranston to ascertain the best senator to approach on offering the amendment or resolution to the senate Bill to restore this item in the budget. She will keep in touch with me.

At 9:50 a.m., I walked down to Latimer Hall and held my office hour from 10-11:00 a.m. in my office, room 446. I then taught my Chemistry $1 \mathrm{~A}$ discussion section (students from section 3 laboratory room B) in room $E$ from $1: 1: 10 \mathrm{a} . \mathrm{m}$. to noon. Pat McGaughey, my teaching assistant, was present. 
Eriday, October 7, 1977 (con't)

I walked back up the hill and had lunch at the table outside the lower level of the cafeteria with Ghiorso, Nitschke, Diamond, Bucher, Edelstein and Banks.

At 2:30 p.m., I spoke to John Fialka, a reporter for The Washington star. I had previously received a letter from him inquiring about the NUMEC Corporation and the missing enriched uranium during the mid 1960's (during my tenure as Chairman of the Atomic Energy Commission).

In today's mail I received a copy of a letter from senator Alan Cranston to Senator John C. Stennis, dated October 4, 1977, supporting the High Intensity Uranium Beams facility project and urging senator Stennis to support and urge restoration of the funds.

Edelstein dropped in at 3:00 p.m. He told me that Banks finally succeeded yesterday in obtaining an $x$-ray diffraction pattern on protactinium borohydride.

A little before 4:00 p.m., I walked down to Iatimer Hall where, in room 120, I attended the weekly Inorganic Chemistry Seminar. Ken Raymond spoke on "Microbial Iron Transport".

I walked back up to my LBL office and learned that Bonner Nishida signed her consultant's contract today to start research work, for a 6-month's period, at LBL with Trish Baisden.

I went to room 203 where otto and Morrissey were talking by phone with Walt Loveland. I also talked with him and told him about some of my conversations at GSI and Marburg. We discussed progress on writing our papers.

I also discussed with otto and Morrissey my conversation with Rasmussen earlier today regarding the possibility that I might participate with him in the teaching of Chemistry 123 next quarter. Otto told me he would like to have a freshman chemistry student work with him to help prepare vyns films, etc.; I said that one of my "cluster" students might be interested.

The operators at the SuperHIIAC are attempting to get a ${ }^{208} \mathrm{~Pb}$ beam and we have a target of ${ }^{208} \mathrm{~Pb}$ ready to be bombarded.

My correspondence today included letters to G. N. Flerov and Yuri Oganessian in regard to Flerov's refusal to allow us to include some of their papers in the Benchmark volume on Transuranium Elements (letters attached) and I also sent Amadou Mahtar M'Bow some reprints of articles regarding my visits to scientific research establishments in Africa in January 1970.

Helen, Dave and I had dinner in the playroom while watching on TV the American League baseball playoff game of the New York Yankees vs. the Kansas City Royals--the Royals won, 6-2. They are now leading the series, 2-1. The Dodgers won this afternoon, 6-5, and now lead the Phillies $2-1$ in games. 
Professor G. N. Flerov

Joint Insticute for ivuclear Research

Post Office Eox 79

101000 YKoscon, USSR

Deax Professor Plerov:

This is in response to your letter of June 1977 which. we have just receivea and which followeä your telegram of September 2, 1977 in wich you refused permission to include some of your papers in the Benchnark volume on pransuranium Elements for which permission for publication vas requested in my letiers to you of March 28 and April 26, 1977.

Actually, since the USSE entered the International Copyright Asreanent on sal 1,1973 , it is oniy necessary to recuest permission for the use of Russiat material publishea since that caite.

The book was already in procuction when I received your letter. It will include the reprints of 12.3 articles anó so, in eny case, it would have jeen cifificult to adjo aōaitional reprints.

Forever, I includea references to your work in adcition to the reprints. For exanjie, on element 102, I refer to the article in SOV.AT.JIFEGY 22, 33 (1967). I also cite tine paper by zvare, et al cealing with the chemical properties of element 10. SOV.RADIOCIIEM,14,.115 (1972), and papers by Zvara et al on the chemical propexties of elenist 105, JILR report

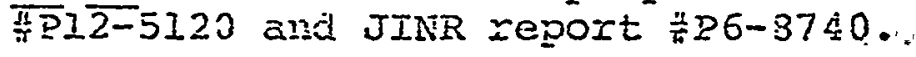

sincerely yours,

Glenn T. Seaborg

G:S:PQ

CC: Dr. J. Kaufman

Dr. Ko. Kos?i

Dr. Y. T. Ogaizessian 
1008 Benchmark/Trans.Elements

300 USSR Joint Inst. Nuc. Sciences

200 Oganessian, $Y . T$.

Cctober 7, 1977

Professor $Y$. T. Oganessian

Joint Institute for :Tuclear gesearch

post Office 20x 79

101000 HísCOW, USSR

Dear Professor Oganessian:

This is in reply to your letter of June 1977. In view of the telegrain ixom trofessor irlerov of september 2 , 1977, refusing permission fo: tise publication of your two articies is tise Jercinark book on tire Fransuranian Elements Ior whicin permission was rerdestea in my letter to you of Auril 26, 1977, the plulishers miy decide that these tro articles shoulu not ba inciuced. In this case, I shall inclase a statement in tire book indicating that Elerov refised to grant vernissior to do so, but will cite in the text referonces to Jipr Iet:. 20, 265 (1074) and JEpT Iett. 23. $277(1976)$. (These are tine two papers for wijich I woild have inciuded reprints had permissior been granted. space rould not perait the inalusion of papers as long as your lecture notes for elentat 106 or yul. Piys. I.273, 505 (1975) for alement 107.)

The book is already in production but, in any case, I would not sibnit the text to you for editing.

Sincerely yours,

Glenn T. Seatorg

GIS : pq

CC: Dr. J. Kaũman

Dr. 诵. Kosti

DI. G. N. Elerov 
Reid Iaitner called to inform us that he showed our 2-acre orinda land to the potential buyer (a plumber) who appeared very interested; he will call me with his decision Sunday night. This buyer also has associates back east who might be interested in the 51-acre Segrè-seaborg land.

\section{Saturday, October 8, 1977 - Lafayette - Santa Cruz}

Helen and $I$, with Moses, drove to the Forest of Nisene Marks state Park. We tried to enter at the Santa Rosalia Ridge by going off Highway 17 via Summit Road and Highland Way but we missed the turnoff and drove on through Corralitos and Aptos to the main entrance.

We all hiked on the Center Loop Trail, then took a new trail along the stream to the end of the trail, turned back, climbed up a hill and had our backpack lunch. We then hiked back to the Center Loop Trail, hiked along to China Camp, then up to the West Ridge Trail and back to our parking place (near the Porter Picnic Area).

We then drove to Santa Cruz and checked into room 15 of the Mardi Gras Motel (on Riverside Avenue). We had dinner in the Coffee shop of the Surf Bowl (bowling), then took a walk along the Santa Cruz Beach Boardwalk at the waterfront.

\section{Sunday, October 9,1977 - Santa Cruz - Lafayette}

Helen and I had breakfast in the Surf Bowl's Coffee shop (across from the Casino), checked out of our motel and drove on soquel old san Jose Road and Olive Springs Road. We parked our station wagon at olive Spring Quarry; then Helen, Moses and I started our hike going down the dirt road across olive springs Road a few hundred feet beyond the Quarry.

We intended to hike directly into Forest of Nisene Marks State Park, but, by mistake; we took the road to the right, which turned out to be on private land. We hiked this road to its end (it had obviousIy been improved to permit logging operations), then further on up along a swarth cut by bulldozers until we reached the top of the west ridge of the Park, where we bushwhacked our way (about a half-mile) through underbrush until we managed to find the West Ridge Trail. We followed this trail to Trail Camp, where we found a water faucet. We hiked to sand Point overlook, then about a mile on Aptos Road toward Santa Rosalia Ridge and then back to Sand Point Overlook, where we had our backpack lunch. After lunch, we hiked down Aptos Road about a mile, hiked a side trail a few thousand feet toward what we thought might be White Lagoon, then hiked back to Trail Camp and then on down the dirt road to. Olive Springs Road, where our station wagon was parked. We crossed a creek (Soquel ?) four times as we approached the end of our hike.

We then drove home, with Helen at the wheel, along olive Springs Road, Laurel Glen Road, Mountain View Road, Vine Hill Road and Highways 17, 580 and 24. We arrived home at 5:30 p.m. Helen, Dave and I had dinner in the playroom. 
We watched on TV, during and after dinner, the fifth American League playoff game-the Yankees won, 5-3 and thus won the series and the American League pennant, 3-2. The Dodgers won the National League pennant yesterday, beating the Phillies for the third time.

Monday, October 10, 1977 - Berkeley

I attended Rollie Myers's Chemistry 1A lecture in PSL from 9:10$10: 00$ a.m.

I walked back up to my LBL office and found that Kathryne Bruner (Senator Hayakawa's office) had called to say our attempt to reinstate the High Intensity Uranium Beams facility is now hopeless because Dave Lohman, Minority Counsel for the Senate Appropriations Committees, feels he cannot support it.

I went down to Building 88 to attend the scheduling meeting. Ghiorso is scheduled for $103-\mathrm{MeV}{ }^{14} \mathrm{~N}$ plus $\mathrm{Pb}$ on the swing shift on Tuesday, October 18 and the ow 7 shift on Wednesday, October 19; Hulet and Mikheev are scheduled for ${ }^{4} \mathrm{He}$ plus ${ }^{254}$ Es on Friday, October 21 from 8:00 a.m. to 12:00 p.m. I talked to Ghiorso and he thinks maybe we should look for SHE in geothermal waters to check Dubna results. Matt Renkas took my picture for inclusion of the Building 88 picture gallery. Mikheev told me about the results of their last experiment.

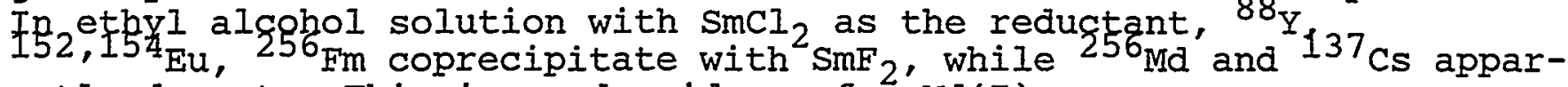
ently do not. This is good evidence for Ma(I).

1 met with George Moynihan, Bill Davis (the new LHS Director for Development) and Mac Laetsch (in his LHS office) for lunch. We discussed plans for the formation of a Development committee for IHS.

Jim Forcier (Senator Cranston's office) called and relayed to Pat that the reinstatement of funds for the Uranium Beams project looks very bleak.

At 1:45 p.m., I called Roger Reeve, CUWA, to discuss setting up a planning group of EBRPD members working on a shoreline trail plan. Roger will keep in touch with me.

From 2-3:00 p.m., I met with Rose Marie McFarland, an incoming graduate student from the college of Idaho. I explained our research program, gave her reprints, and took her to meet Otto, Morrissey, Thomas, williams, Marsh, Lee and de Saint-Simon in Building 70, Somerville in the HILAC Building (where I showed her the SuperHILAC and our experimental area) and also Edelstein and Banks in room $70 A / 1145$.

Today I received a reply from Dieter Behrens--he agreed to participate on the panel for CHEMRAWN, Day $I$.

At 3:00 p.m., I met with Joseph H. Penrose, Jr., Vice President of Booz Allen \& Hamilton, who was in the Bay Area interviewing forty outstanding scientists on behalf of IBM to get their opinions of IBM and its contributions to research. In terms of contributions to basic research, I rated IBM in the upper $25 \%$ of industrial firms. I have a 
high regard for the quality of their research personnel but said they would do better if IBM were diversified. I told him that I had not been particularly impressed, with the lack of help from IBM while I was Chancellor and trying to set up a computer center on the Berkeley campus. I suggested that IBM might provide grants for post-doctoral students and graduate students (and particularly for their equipment).

From 3:30-4:00 p.m., I met with incoming graduate students Michael D. Cable (from Iowa State University) and Lee D. Sobotka (University of Michigan) to explain my research program and gave them some reprints. I'll see them again a week from tomorrow.

At 4:00 p.m., I attended the NSD seminar in Building 70A conference room where Professor Walter Meyerhof of Stanford spoke on "Positrons from Heavy Ion Collision".

Today I dictated a letter to Richard Merrill, Mt. Diablo Unified School District, urging him to accept membership on the Advisory Committee of the Lawrence Hall of Science.

I took a hike at Lafayette Reservoir. Lynne arrived at San Francisco Airport this afternoon; she was met by her. friend Nathan Loucks, who had dinner with us and spent the night. Steve called from San Diego; he is getting along fine, but needs some money.

I did my usual reading of papers after dinner, then at 10:00 p.m., Helen, Lynne, Nathan, Dave and I gathered in the living room to look at slides that Dave took during his visit to Yosemite last month; he had some very good slides.

\section{Tuesday, October 11, 1977 - Berkeley}

At $8: 35, a . m .$, I started making a number of phone calls regarding the High Intensity Uranium Beams facility project. I first called James Forcier (Senator Cranston's office); he agreed to call senator Magnuson's Office. At 8:40 a.m., I spoke with Jack Ford (Representative Clair Burgener's office); he will also call Magnuson's office. He also agreed to get in touch with Mike Crisp (Senator Baker's office). I spoke with Crisp at $8: 45 \mathrm{a} . \mathrm{m}$. and he agreed to ask Baker to speak with Senator Henry Bellmon before the markup meeting and to ask Sasser who could make such an amendment to put the project in the Appropriations Bill. Crisp suggested that. I contact Mike Walker in Jim Sasser's office. I called Forcier again at 9:00 a.m. and related my conversation with Ford; we discussed the possibility of Cranston's also talking to sasser this morning.

In between calls, at 10:00 a.m., Michael Cima, one of my Cluster Group students came in to discuss his program with me.

I spoke with Mike Walker (Sasser's office) at 10:45 a.m. I described the history of the uranium beam project and he will request a "fact" sheet on the project. from Crisp. He will contact me after he receives the information and has had a chance to go over it. I called Crisp again at 10:55 a.m. and he will see that the informational material is prepared and hand delivered to walker today. 
At 11:30 a.m., I called Bryant Rossiter to tell him that Professor Dieter Behrens has accepted our invitation to be a panel member on Day I of CHEMRAWN in July. The National Committee of the IUPAC met (October 8) and discussed the ICS concept. Rossiter appointed a subcommittee to investigate the possibility of IUPAC reorganizing to fill the need for ICS. Rossiter and I agreed Bob Parry is the best person to Chair the Committee.

I met Kristen Jean Johnson, Pat's 18-year-old daughter.

I had lunch at my desk, then walked down to Latimer Hall to attend the Chem $1 \mathrm{~A}$ pre-lab session at 1:00 p.m. in room 328 . I then went to room $C$ to give the quiz and the pre-lab discussion and circulated among rooms $B, C, D$ and $E$ until relieved by Barbara Garrison at 3:00 p.m.

I met with my cluster advising group in room 71 Evans Hall. About 10 students showed up. I answered questions on superheavy elements and the modern periodic table and gave them copies of the AEC "Nuclear Milestones" pamphlet and modern periodic table (up $Z=$ 168). After my meeting with the group, Simon Chin, Andrew Shapiro and Don Ino accompanied me back up the hill, visited my LBL office and went with me to Building 70 to meet otto and Morrissey. Chin may do some research work with Otto.

At 4:00 p.m., I met with H.R.H. Prince Mohammed Al Faisal in room 154 of Building 50. Also in attendance were the following: Iuis Alvarez, John Harte, Edward Lofgren, Arthur Rosenfeld, James Alvarez, Richard Muller, Andrew Sessler, Hermann Grunder; and from Saudi Arabia: Prince Faisal; Haten Azzam, Aide; Salah Galal, Science Chief Editor of Al Ahram. Prince Faisal spoke informally about his idea of moving icebergs from the antarctic to places like singapore to give a source of fresh water. He made it seem technically and economically feasible.

My dictation today included a letter of recommendation for William Bevan of Duke University to Norman Hackerman of the National Science Foundation for appointment as a member of the National Science Board. I also wrote a letter to Russell W. Peterson, President of New Directions, thanking him för some miscellaneous material he sent me.

From 5:30-6:15 p.m., Helen and I attended the reception marking the opening of "An Exhibition on Peru: The Archaeological Work of Max Uhle" at the Lowie Museum of Anthropology in Kroeber Hall.

Helen, Dave and I ate dinner in the playroom and watched on TV the first World Series baseball game--the New York Yankees beat the Los Angeles Dodgers, 4-3, in 12 innings. Lynne and Nathan went to Davis to visit with Ben Orlove and Dianne.

Wednesday, October 12, 1977 - Berkeley

I went by to see Morrissey and learned that it has proved impossible to accelerate $\mathrm{Pb}$ ions at the superHILAC so we cannot have $a \mathrm{~Pb}$ plus $\mathrm{Pb}$ bombardment as planned. 
Wednesday, October 12,1977 (con't)

I attended Rollie Myers's Chem 1A lecture in PSI from 9:10-10:00 a.m. I then went to room 124 Lewis to meet with Chem 1 A laboratory instructional staff from 10:10-10:45 a.m.

At 10:45 a.m., I spoke with Gordon Bixler about a number of items pertaining to the International Activities Committee, including the following: summary of my discussions in Europe regarding the International Chemical Society, the IAC questionnaire, the Egyptian Workshop, Thailand Workshop, Yugoslavia Workshop, Peter Lykos's suggestion for institutionalizing of conferences, Bixler's acknowledgement to William T. Watson, Puerto Rico Conference, 1979. Presidents' meeting, India Chem-Tech Exhibition, wotiz letter, Brasted proposal, IAC membership Iist, Francis J. Bonner regarding ICS, Emanuel Vogel letter, Richard Lemmon letter regarding China Trip, India Workshop and Japan Meeting.

At 11:20 a.m., I met with S. K. Runcorn, a planetary astronomer from the United Kingdom. We discussed his interest in the theory of primeval melting of the moon and the effect of radioactive elements and possibly superheavy elements on this. He gave me two reprints: "The Ancient Lunar Core Dynamo" and "Primeval Melting of the Moon." I agreed to send him a copy of my Annual Review of Nuclear Science article when it becomes available ("Chemistry of the Transactinide Elements").

I had lunch at my desk, had a short look at the solar eclipse, then attended the Actinide Chemistry seminar in room 191/70. Present were Norman Edelstein, Kenneth Raymond, Andrew Streitwieser, Allan Zalkin, David Templeton, Gordon Halstead, Jerome Bucher, Charles Eigenbrot, Rodney Banks, Neil Bartlett, Patricia Durbin-Heavey and others. Durbin-Heavy spoke on experiments to remove plutonium from physiological systems, performed in Donner Laboratory. She told me she started working with Joe Hamilton in July, 1946.

At 2:00 p.m., Patrick McGaughey, incoming graduate student from Augsbery College in Minnesota and my T.A. in Chem $1 \mathrm{~A}$ laboratory room $B$, came by to discuss my graduate student program with me. I described my research program, gave him some reprints and took him by Building 70, the HILAC building and Building 88 .

Wayne Marsh told me he has been admitted to graduate school in the UCB Department of Nuclear Engineering to work under Stanley Prussin, possibly doing his research with me. Sebesta told me he is terminating next June at the Masters degree level to accept an industrial position. This raises the question of whether we should have some other graduate student from the Chemical Engineering Department carry on his work with FAKE. I talked to otto and Morrissey about our publiçations plans. The article on the search for 150-day SHE from U plus $136 \mathrm{Xe}$ will be issued as LBL 7104 and submitted for publication in Journal of Radiochímica Acta; the article "Calculation of Primary Product Mass and Charge Distributions from a Stochastic Fireball" will be issued as IBI 657.9 and our revised article "Lowered Cross Section in the Quadruply Magic Heavy Ion System" will be issued as LBL 6539 Rev. and submitted to Physics Letters. 
At 3:30 p.m., I met with Joan Warnow of the American Institute of Physics. She was visiting here from the AIP Archival Project regarding starting an Archival Project at the ERDA National Laboratories. I agreed to help if an archival project is started at LBI and I showed her my Met Lab volumes, Met Lab records, my records and my journals for the last 15 years.

During the course of the day I talked with Bill Davis at the Lawrence Hall of Science to inform him that Luis Alvarez has declined my request that he serve as chairman of a LHS development committee.

I also spoke with Paul Witherspoon regarding my visit to the Stripa Mine on september 27, 1977 and told him that Pavel Kurfurst is doing a marvelous job.

I wrote to Alan Nixon, Project SEED Decennial Celebration Committee, and agreed to serve as a sponsor of the Celebration.

I took a hike at Lafayette Reservoir. Helen, Iynne, Dave and I had dinner in the playroom and watched on TV the second world series game in which the Dodgers beat the Yankees, 6-1.

Thursday, October 13, 1977 - Berkeley

I talked to Dave Morrissey from 10:00-10:45 a.m. about a schedule for finishing his Ph.D. program. It may be feasible for him to finish by next June. This will raise a problem with respect to overlap of my key people if otto and Baisden both leave next summer as planned.

I went to talk to Baisden and Thomas about their research program and will meet with them later today. I also talked to williams about her program and will meet with her again soon to discuss it further.

I had Iunch at the table outside the lower level of the cafeteria with Hyde, Edelstein, Bucher, Diamond, Stephens, Banks and Avdeef.

I attended the meeting of the IBI Scientific Program Council from 2:10-3:45 p.m. Present were Andrew Sessler, Earl Hyde, Alan Searcy, Hermann Grunder, Frederick Goulding, David Scott, Edward Bennett, Luis Alvarez and others. Sessler told us the Laboratory Program Panel of the Office of Basic Energy Sciences will meet at LBL on November 10 and 11. Gert Friedlander is chairman and John Deutch, new head of the DOE Office of Basic Energy Sciences, will attend.

Sessler called for a discussion of general problems or ideas concerning the operation and future of IBI. We discussed the problem of controls on equipment funds and whether we might approach DOE to have these controls removed. Goulding reviewed the problem of how to use Director's Funds for new projects. Grunder spoke about the problems attendant with choosing people for senior scientist status. scott described the problems caused by moving illustrators (who prepare slides) off the hill down to Berkeley. The meeting was still in progress when I left.

I met in my office from 4-5:00 p.m. with Baisden and Thomas to help plan their forthcoming bombardment at the superHILAC. I then 
went by to see otto in 203470 to discuss his planned bombardment at the superHILAC ( ${ }^{48} \mathrm{Ca}$ plus $\left.248 \mathrm{Cm}\right)$.

Cathy webb dropped in to my office at $5: 15 \mathrm{p} . \mathrm{m}$. to request a letter of recommendation for a Fulbright Fellowship to spend a year studying German Iiterature in Germany.

I stopped at Lafayette Reservoir for a hike on the way home. As usual these days I hiked up toward the Rim Trail and on to sunset Reservoir and back.

Bill, who had been to San Diego for an interview at UCSD Medical School, was home when I arrived; he had dinner with steve last night and the night before spent the night with him--he said steve is getting along fine. Ben orlove was also at the house. Helen, Lynne, Bill, Dave, Ben and I had dinner in the patio; it was a balmy evening.

Kay Petersen called to invite me to explore a trail connection between the Panorama Way entrance to Lafayette Ridge across Lafayette Reservoir via the Rim Trail to the Lafayette-Moraga Trail on Sunday morning, October 23; I accepted.

Friday, October 14, 1977 - Berkeley

At 9:05 a.m., I called Darleane Hoffman at Los Alamos. She. told me she has applied for a Guggenheim Fellowship and I am one of her references. The fellowship is to help support her stay at LBL, (9-12 months beginning the Fall of 1978. She has accepted an invitation from Dubna to attend the Conference on heavy ions in December. She agreed to make some Calculations on actinide isotope concentrations in regard to Flerov's claim of reported discovery of superheavy elements in geothermal waters.

I went by to see Morrissey and otto before I walked down to the campus; we went over some suggestions for their experiments. I suggested a recoil experiment for ${ }^{4} \mathrm{Ar}$ plus $U$ to distinguish the mechanism of formation of the iodine isotopes near the barrier. I also talked to Thomas, suggesting he consult with Bob Silva about his actinide chemical separation procedures.

I walked down to campus and held my office hour in room 446 Latimer from 10-11:00 a.m. I then taught my chem 1A discussion session from 11:10 a.m. to noon in Room E, Latimer Hall.

I walked to the Alumni House for the UC Berkeley Foundation Board of Delegates Annual-Meeting and luncheon. I sat at a table with $S$ is Collins, Guy D. Manuel, Louis H. Heilbron and others. - E. Morris Cox, President, gave a report to the Delegates and introduced Vice Chancellor Heyman who talked on the Berkeley Academic PIan.

I walked back up to my LBL office, where I met with Thomas to discuss his research program and with Morrissey and otto to discuss revisions to our article "A Search for Superheavy Elements....," submitted for publication in the Journal of Inorganic and Nuclear Chemistry. 
Friday, October 14,1977 (con't)

Simon Chin, a freshman from my Cluster Advisory Group (and a native of Burma) started to work with otto this afternoon as a laboratory assistant.

At 4:30 p.m., I met with Irena Radunskya (accompanied by Noel Bransford) in my office. She represents publications such as PRAVDA and will write an article about me. I took them to the Bevatron where Fred Lathrop and Dave Morrissey met them and showed them around. She requested a picture of me which will be used with her article.

I went by to see otto and Michel de Sajpt-Simon to check on progress on writing and made plans for our ${ }^{4} \mathrm{Ar}$ plus U recoil experiment to help clarify mechanisms of production of iodine isotopes from

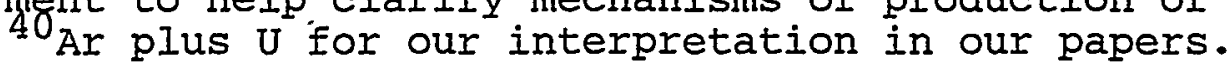

At 6:00 p.m., I went down to Building 88; I found Ghiorso, Hulet, Lougheed, Wilde, Baisden and Mikheev working on the Md chemistry experiment and Ghiorso, Nurmia, Williams and Thomas working on Williams's $235_{U}$ plus $10_{B}$ bombardment (to look for $242{ }_{\mathrm{Bk}}$ plus $241_{\mathrm{Bk}}$ ). Madrid.

We learned that Bing Crosby died today on a golf course in

My correspondence today included letters to Joseph Katz at Argonne with additions to our article "A Search for superheavy Elements with Half-jijves Bętween a Few Minutes and Several Hundred Days, Produced in the ${ }^{48} \mathrm{Ca}+{ }^{248} \mathrm{Cm}$ Reaction," Patricia Walsh, also at Argonne, expressing my appreciation for her help on the illustrations for the Met Lab section C-1 History and to Harold Kirby regarding his book "History of Uranium."

Helen came by at $6: 30 \mathrm{p} . \mathrm{m}$. and we went up to the cafeteria to attend the UC Berkeley Foundation reception and dinner. After the reception, we sat at a table with Mr. and Mrs. Hugh McGuire (he was the UCB quarterback on the 1955 football team), Ludy Langer and Dick Erickson. After dinner, Erickson made a number of introductions, including three who have received the Alumnus of the Year Award (Don Mclaughlin, Rudy Peterson and me). He then called on E. Morris Cox, President of the UC Berkeley Foundation, who introduced Amelia (Segrè) Terkel for a few remarks (as a representative of Emilio Segrè); she spoke on her work at the Lawrence Hall of Science while in Berkeley on a sabbatical leave from her professorship at Tel Aviv. Cox then called on the Nobel Prize winners present to describe their present activities--Luis Alvarez, Donald Glaser, Edwin McMillan and me. I began by referring to the illuminating talks by Alvarez, Glaser and McMillan, my interesting conversation with Hugh McGuire and my experiences as UCB Faculty Athletic Representative including my trip with the football team to the 1954 game with Ohio state at which Hopalong Cassidy was instrumental in beating us, my reentry as a professor at UCB in 1971 after an absence from teaching of more than 13 years, the present role of IBI in heavy ion research and my part in this program with graduate students and post doctorates and the continuation of work in the transuranium elements including our present search for "superheavy elements." 
Helen and I drove home, arriving a little before 11:00 p.m. Ben Orlove was there and spent the night with us. Dianne had come with him and was visiting at the Sherman's.

Saturday, October 15, 1977 - Lafayette

Bill, at the wheel, Iynne, Ben, Dave, Helen and I drove to Big Basin Redwoods State Park. (Dianne stayed home.) We hiked the Howard King Trail, stopped at the Carl I. Wheat overlook for our backpack Iunch. We continued on to the Lower Berry Creek Falls, then hiked the Berry Creek Falls Trail back to the parking lot. We drove home, arriving at $7: 30$ p.m.

Helen; Lynne, Bill, Ben, Dave and $I$ had dinner in the dining room. A telephone call came through from Bob Puppa (at Hobart College in New York) for Dianne and she spent about an hour on the phone with him.

I had a talk with Dianne as she was eating her dinner in the playroom. She is enjoying her life at Davis and seems to be doing well. She works four hours a week in her co-op dormitory and says she likes it.

Ben Orlove spent the night with us.

Sunday, October 16, 1977 - Lafayette

Ben Orlove drove home to Davis at 9:00 a.m. I read accumulated papers from my LBL office and read proof on the final version of June, 1943 for my Met Lab C I history and summaries of lab work, etc.

Steve Quigley called me at about noon to say that Bob Cairns is in the process of firing him and plans to announce this tomorrow afternoon. He says Cairns will not disclose the reason and therefore he is asking for "due process." He is calling all members of the ACS Board of Directors. I was noncommittal and told him I have heard complaints about the way he runs his office and his relations with his office staff. He told me there is much more behind these complaints than I know and he actually has done very well in this and other aspects of his job.

I watched on TV the football game between the Oakland Raiders and Denver Broncos; the Broncos won, 30-7.

Iynne, Bill and I took a hike at Lafayette Reservoir on the wooded trail on the southeast side and back on the Rim Trail.

Helen, Dianne, Iynne, Bill, Dave and I had dinner in the dining room. Helen left at 9:30 p.m. to drive Dianne back to Davis.

Monday; October 17,1977 - Berkeley

Bill, accompanied by Iynne, went to UCSF for an 8:00 a.m. appointment this morning for interviews in connection with his application for an internship. They will spend the day and evening there and in Palo Alto (with Nathan). 
Monday, October 17, 1977 (con't)

I had Pat send a message to G. K. Skriabin, Chief Learned Secretary, USSR Academy of Science, declining his invitation to attend the 60 th anniversary of the Great October Socialist Revolution.

I attended Rollie Myers's Chemistry 1A lecture in PSL from 9:1010:00 a.m., then went to a scheduling meeting in Building 88 with Kim Williams and Ken Thomas. Williams was scheduled for ${ }^{1} I_{B}$ plus ${ }^{23} 5_{U}$ for the day shift on Monday, October 31.

I talked to Joe Cerny, in his capacity as chairman of the Chemistry Department, about the advancement of Dave Shirley and Bruce Mahan to above scale salary status. I also discussed the possibility of Dave Morrissey's finishing his Ph.D. in 3 years. (He sees no problem with this.)

At noon, I attended the weekly Iuncheon meeting of the Faculty of the Chemistry Department in the Lewis/Latimer Room of the Faculty club. I discussed Vitalli Goldanskii's nomination as a foreign member of the National Academy of Sciences with Bill Dauben.

I returned a call from Walter Loveland (at Oregon State). He will come down to confer with us during each of the next two weekends. He also plans to spend next summer at LBL. We discussed the problem of the continuity of our research program when otto and Morrissey (if he does) leave next summer.

At 1:25 p.m., Henry Hill called to advise me of the possibility of a special meeting of the Board of the ACS regarding the recent firing of Steve Quigley by Bob Cairns. I voted in favor of having such a meeting.

I returned Gordon Bixler's call at 1:35 p.m. We discussed a written or oral report to the ACS Board meeting in December and the expenditure of approximately $\$ 2,500$ toward a reception and dinner during the Egyptian Workshop.

At 1:40 p.m., I received a call from Arthur Livermore at NSF regarding Senate Bill 991 which provides for the establishment of a Department of Education in the Cabinet and would thus transfer Science Education from NSF to the new department.

I received a call from Dorothy Schriver at 1:55 p.m. regarding her upcoming visit to San Francisco. She said everything looks fine for the December 2 Board meeting in Washington.

At 2:30 p.m., I went by to see Morrissey; I told him that June 1978 is a good target date to finish his Ph.D. I suggested Moretto and Price for his committee. I told him that it may be possible for him to stay on here awhile as a post-doctorate if he doesn't find a satisfactory position elsewhere. I also talked to Diana lee to let her know about the various post-doctoral and sabbatical people who may join us next year. I had a short session with Baisden to tell her about Darleane Hoffman's plans to work with us next year and about Walter Loveland's plans. 
At 3:00 p.m., Paul Lochak called to discuss some items regarding GEOMET and my affiliation with them.

I dictated a letter today to Leonard Dreher to be enclosed with three snapshots taken at the Met Lab section C-1 Christmas Party of 1943 and asked him to help me to identify some of the people and a letter to Harry Drickamer regarding Vitalli Goldanskii's proposed nomination for membership in NAS on an Intersectional basis.

I attended the NSD seminar at which Marie Deleplanque spoke on "Nuclear Spins at High Angular Momentum."

After the seminar, Rose Marie McFarland said she would like to do her graduate work with me; she wants to work in the nuclear field but perhaps start in inorganic chemistry. I said I would consider this possibility.

I took a hike at Lafayette Reservoir on the way home. Helen and I had dinner in the playroom and watched part of Monday night football--Cincinnati Bengals vs. Pittsburgh Steelers.

We received a postcard from Eric today. He told us he visited the Gösta. Adolfssons at Eskilstuna, spent a night with Siv Iindkvist and met Richard Sproul and $A I$ Iindstrom in London and they went to Scotland and visited the Isle of Skye, Loch Ness, etc.

Tuesday, October 18,1977 - Berkeley

Bernard Harvey dropped in to talk about the problem of finding a scientific leader for the Bevalac program--such names as Arthur Poskanzer and David Hendrie were discussed.

At 10:00 a.m., Lee Sobotka and Michael Cable, incoming graduate students, dropped in to discuss my research program to ascertain their interest in working with me. After talking in my office awhile, I took them to Building 70, to the HILAC Building and to Building 88 . We finished our tour at 11:45 a.m.

I had lunch at my desk, then went to room $191 / 70$ to hear Richard Diamond and John Rasmussen give a talk on their recent visit to the Peoples Republic of China.

I walked down to the campus to attend the pre-lab session in Latimer 328 from 1-1:10 p.m. I then went to room D (Steve Treon, teaching assistant), to help administer the quiz, give the discussion and circulate among rooms $\mathrm{B}, \mathrm{C}, \mathrm{D}$, and $\mathrm{E}$ until $3: 00$ p.m.

From 3:10-4:00 p.m., I met, along with Barbara Jacak, with my freshman chemistry students cluster advisory group in room 71 Evans. Seven students were present and we talked in general about chemistry courses, planning of curricula, etc.

I then walked up the hill to my LBI office. I dropped by Building 70 to see Baisden, Nishida and de Saint-Simon at 5:00 p.m. 
During the course of the day, I dictated letters to William J. Davis, at the Lawrence Hall of science, regarding suggestions for members of the LHS Development Committee and Bill Perkins acknowledging receipt of a copy of Russell Peterson's speech at the Second Alternatives To Growth World Conference. I also mentioned my disagreement with New Directions' policy on plutonium.

I took a hike at Lafayette Reservoir on the way home. Helen, Dave and I watched the sixth game of the world series on IV in the playroom during dinner. The Yankees won, 8-4, and hence won the Series, 4 games to 2. Helen left before the end of the game to go to her class on antiques. Iynne and Bill spent the day in Davis and had dinner at Ben Orlove's apartment with Dianne also present.

Wednesday, October 19,1977 - Berkeley

I attended Rollie Myers lecture from 9:10-10 a.m. in PSL. At 10:10 a.m., I attended a meeting with $1 \mathrm{~A}$ instructional staff in 124 Lewis. This meeting concluded at 10:40 a.m.

I walked back up the hill to my LBL office, then went to $204 / 70$ to talk with Ken Thomas about his progress on developing a chemical method of separating Am from heavy ion bombardments of actinide targets.

The regular SHEIKS' lunch was held at noon In my office. Present were Ghiorso, Nitschke, Nurmia, Otto, Thomas, Morrissey, de SaintSimon, Baisden, Lee, Somerville, Williams and Nishida. Pat McGaughey alsso attended. Williams feported on her production of 20-minute $241,242_{\mathrm{Bk}}$ from $235_{U}$ plus $1_{\mathrm{B}}$; Ghiorso on $\mathrm{his}_{\mathrm{S}} \mathrm{S}$. TKE photomultiplier tube apparatus which he has tested with $242 \mathrm{~m}_{\mathrm{Am}}$ from $242_{\mathrm{Pu}} \mathrm{plus} 15_{\mathrm{N}}$ and used to look for $20-\mathrm{m} . \mathrm{s} .260_{104}$ from $24{ }^{\mathrm{Bk}}$ plus ${ }^{15} 5_{3}$; and somerville on his fission isomers from $U$ isotopes plus ${ }^{4} \mathrm{He}$ and ${ }^{3} \mathrm{He}$.

After the meeting, at 1:00 p.m, all except Nurmia and McGaughey stayed on to discuss plans for our $248 \mathrm{~cm}$ plus ${ }^{48} \mathrm{Ca}$ bombardments schedule for November 11, 12, and 13 .

Ted Vermeulen and Ed Sebesta dropped in to discuss Sebesta's Master's thesis covering his work on FAKE. He will write up his work, which will also be issued as an LBI report. Vermuelen, I and one other (Donald Hanson, Scott Lynn, Edward Grens or Malcom Williams) will be on his thesis committee.

I went by to see Otto, Morrissey, Thomas, and Williams on my way down to the campus to address the participants in the Executive Program in the Graduate School of Business Administration in the Iipman Room. The title of my address was "Energy Sources for the Future." The participants, who came from various parts of the world, were very interested in the subject.

Helen, Bill, Iynne, Dave and I had dinner in the kitchen and spent the evening in conversation. 
Thursday, October 20, 1977 - Berkeley

Helen drove Iynne and Bill to the San Francisco Airport where they set off by plane for Moline, Illinois to visit Bill's mother over night. Tomorrow and Saturday they will drive back to washington in their Volvo, which they left at Moline on the way out to California.

William Laidig, incoming graduate student from UCSB, dropped in at 10:30 a.m. to discuss my research program and thus determine his interest in it. I described my program, gave him some reprints and took him to Building 70 and to the HILAC Building. I showed him our experimental areas and equipment.

Walter Ioveland arrived at 1I:30 a.m. I brought him up-to-date on our program, writing, planned bombardment, etc. We then joined Morrissey and went to the cafeteria to have lunch there at a table
with Lougheed and Nitschke to discuss plans for our ${ }^{2}{ }^{8} \mathrm{Cm}$ plus ${ }^{4} \mathrm{Ca}$ bombardments.

I met with Elizabeth Rauscher at 1:30 p.m. She gave me her thesis outline and abstract. She said her thesis is about halfwritten.

I joined Loveland, Morrissey and otto in room 203/70 from 3-4:00 p.m. for the discussion of our writing program, plans to give papers and for bombardments. I also talked to Williams and suggested she calculate her yield of ${ }^{24} \mathrm{Bk}$ from ${ }^{23}{ }_{\mathrm{U}}$ plus ${ }^{11_{\mathrm{B}}}$.

I went by Building 88 , where Baisden was preparing for tomorrow's bombardment to continue the study of Md chemistry.

I walked down to Gilman Hall to pick up my mail.

My correspondence today included letters to Frederick Goulding of IBI regarding the upgrade and expansion of TI-960A based MCA system for my group here at the Lab and Richard Frankel, President of Kevex Corporation, along with copies of articles about me which appeared in Time and Newsweek in 1961.

There was a farewell party in the office for Bea Ramsay who is leaving to take a new position in the Personnel Division. Today is her final day in the Nuclear Science Division.

Helen helped Dave move to his new live-in (board-and-room) job in Oakland today.

At 6:30 p.m., I attended the dinner honoring former Regents and Officers of the University of California. UC President David and Shirley saxon hosted the dinner at their home, Blake House. I sat next to David Saxon at the dinner. Also at the'same table were Emil Mrak, Vilma Martinez, Bernard Sisco, Angus Taylor, Joseph A. Moore, Robert Reynolds, Elmo Morgan, DeWitt A. Higgs, Owsley B. Hammond, Robert M. Underhill and Michael S. Salerno. (A total of 58 people attended.) 
Friday, October 21, 1977 - Berkeley

I went by Building 70 to discuss with Loveland, Otto, Morrissey and de Saint-simon progress on writing data treatment.

On the way down to the campus, I stopped at the 88" cyclotron to watch Hulet, his post-doc Robert Franklin, Delano Lundqvist (from Sweden) and Baisden prepare for this morning's experiments on the chemistry of Ma.

I held my office hour in room 446 Latimer. Richard Davis, one of my cluster students, dropped in. He wants to work with me on a volunteer basis this summer. I gave him a periodic table and "Nuclear Milestones" pamphlet.

I taught my Chemistry $1 \mathrm{~A}$ discussion section in room $\mathrm{E}$, Latimer from $11: 10 \mathrm{a} . \mathrm{m}$. to noon.

I walked back up the hill to attend the luncheon meeting of the NSD Program Committee in room 191/70 from 12:20-2:00 p.m. Present were Bernard Harvey (Chairman), Earl Hyde, Arthur Poskanzer, Luciano Moretto, Norman Glendenning, John Rasmussen, Joseph Cerny, David Scott, Hermann Grunder, David Hendrie, Frank Stephens, Dick Diamond, Homer Conzett and Wanda Smith.

We elected Poskanzer Scientific Director of the Bevalac; we learned from Glendenning that the UCB Department of Physics is likely to appoint Stephen Koonin, a nuclear physicist from Cal Tech, to a tenure position and therefore we voted to invite him to be a Faculty Senior Scientist in NSD; we discussed the plan to choose a chairman of the NSD (internal) Advisory Committee at the next meeting of the NSD Program Committee (November 18); we also discussed the forthcoming meetings of the national Nuclear Science Advisory Committee on December 12, 13 and on January 26, 27, 1973 (the latter at LBL), plans to choose members for the NSD Visiting Committee at the next NSD Program Committee meeting (November 18) and voted to invite Herb Steiner and Lee Schroeder to accept indefinite appointments in NSD.

At 3:00 p.m., I went to Building 70 to visit with Loveland, Otto and Morrissey and to help write abstracts for the six papers we are going to give at the American Physical Society meeting in San Francisco in January. I also discussed with de Saint-Simon a title for his talk to the NSD seminar on Monday, November 7.

I went down to the 88" cyclotron and found Hulet, Jerry Landrum, Jgygheed, Baisden and Mikheev busy trying to reduce the Md from their 254 Es plus 4 He bombardment with $\mathrm{Sm}^{+2}$; they were having some trouble with oxidation of $\mathrm{Sm}^{+2}$ to $\mathrm{sm}^{+3}$. I asked Nicolai Mikheev to talk at our Actinide Chemistry meeting on November 23 and he accepted.

I went back to Building 70 and talked to Simon Chin (busy at work), Diana Lee, Ken Thomas and Kim Williams (who is haying trouble

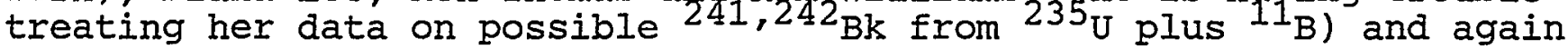
spoke with Loveland, Otto and Morrissey on their APS abstract writing. 
I dictated a letter to Edward Anders thanking him for sending me copies of preprints covering the work of Flerov's group on their searches for superheavy elements.

I took a hike at Lafayette Reservoir on the way home. Helen and I had dinner in the playroom. We are alone in our house for the first time since a few days last summer.

Saturday, October 22, 1977 - Lafayette - Berkeley

Helen and I met Kay Petersen at the end of Cambridge Road; we hiked up Quail Ridge and on to Highway 24 to explore the proposed "Wally Costa Trail." We hiked back by a more westerly route on an alternate route for the trail.

We then left Kay at Happy Valley School, parked our station wagon and hiked up Panorama Drive and on into the McKee Property (Live Oak Park). We hiked along the fire road to the top of the ridge and then along the ridge above the Petersen home. (which fronts on Deer Trail Road). Here, under 2 oak trees overlooking Happy Valley and more, we had our Iunch. We then hiked along the ridge to the point where Iafayette Ridge Trail connects (near the entrance to Briones Regional Park). We hiked back on the road at the east end of the McKee Property, past Valory Reservoir, on down to Panorama Drive and on to Happy valley School. We then drove home, arriving at 3:30 p.m.

A little before 5:00 p.m., we drove to the Bernard Harvey home in Berkeley ( 95 Plaza Drive) to attend his reception for Nuclear Science Division staff. Here we met Pat Quinn, her attractive daughter Celeste Johnson and Celeste's boyfriend, Bert Schurr. We left after about an hour and drove home to Lafayette.

Helen and $I$ had dinner in the playroom. After dinner, we listened on the radio to the UCB-UCLA football game played in Los Angeles. UCLA won, 21-19.

Sunday, 'october 23, 1977 - Lafayette

I went on a trail exploration with Kay Petersen, Mr. and Mrs. Wally Costa, Barbara Langlois, Lavaughn Craig and Don Good. We met at 9:00 a.m. at the Mormon Church, just off Moraga Road. We hiked through the Sky Hy development on to the Lafayette-Moraga Trail across Boise Cascade property. We then hiked back to, our starting point. This will be a leg of the trail from Happy Valley School, via Lafayette Reservoir, to the Lafayette-Moraga Trail. I then continued with Don Good on into the Lafayette Reservoir area to explore this portion of the trail link.

I returned home at 1:00 p.m. I had lunch, then spent the rest of the afternoon working on our paper on iodine isotopes from ${ }^{23}{ }_{\mathrm{U}} \mathrm{Plus}$ $40 \mathrm{Ar}$ and reading chemistry $1 \mathrm{~A}$ material.

Helen and I had dinner in the playroom; we watched the TV program "60 Minutes." I read more articles and papers in the evening. 
Monday, October 24, 1977 - Berkeley

At 9:15 a.m., I attended the meeting of LBL Associate Directors. Present were Andrew Sessler (Chairman), Earl Hyde, James Bassham, Edward Alpen, George Pappas, Robert Birge, Raymond Wakerling, Mike Wahlig, Luis Alvarez, Robert Hinckley, Conway Peterson, Bernard Harvey, Edward Lofgren and Karl Olson (representing Paul Witherspoon.

Sessler reported that the DOE meeting of Laboratory Directors was attended by most of the Laboratory Directors and most DOE officials who had program responsibility--Thorne was absent; Liverman present only briefly. There will be a Research and Development Coordinating Council chaired by John Deutsch. Sessler said it was a good meeting. John Deutsch showed his Office of Energy Research breakdown: Bateman, Deputy Director; Adler, Assistant for Administration; Dave Israel, Field and R \& D Coordination; Roger LeGassie, Program Analysis; Joel Snow, Research Policy; and James Kane, Basic Energy Sciences, including Nuclear Physics, High Energy Physics. IBL will report broadly through Joel snow. There are rumors Joe La Grone will be appointed Manager of SAN. Even "informal" visits by dignitaries should involve the Director's office.

Attendance at the IBI Colloquium should be improved. Requests for Program Development Funds that go directly to the Director will be discussed with Division Directors before the money is allotted. Earl Hyde is serving as interim Director of NRCC. I left the meeting at $10: 25$ a.m.

I went down to Building 88 for the scheduling meeting for the 88" cyclotron with Williams, Thomas and Mikheev. Each of them received bombardment time. Mikheev gave me copies of two of his papers that he has in preparation for me to read.

I went to Building 70 and discussed with williams the results of her experiment, with Thomas, his results, and with Otto and Morrissey progress on our writing of meeting abstracts.

I walked down to the campus to attend the regular luncheon meeting of the Chemistry Department faculty in the Lewis-Iatimer Room.

I walked back to Latimer Hall with Joel Hildebrand. John Rasmussen and I went to Hildebrand's office where he showed us his latest results on the correlation of fluidity and viscosity of molecules in the liquid through gaseous range; this will be published in the Journal of Molecular Physics.

I went by building 70 to see otto and Morrissey about a letter to Jens Kratz and Robert Esterlund concerning treatment of errors in our radioanalytical data. I also discussed our APS abstracts (Jan 1978 San Francisco meeting).

At 3:00 p.m., we had a birthday party for Pat. I presided over the NSD seminar at which physics graduate student Michael Robel (working with Glendenning) spoke on "Fermi Jets in Heavy Ion Collisions." The seminar was held in the conference room of $70 \mathrm{~A}$. 
My correspondence today included the following: to J. B. Rhine, Executive Director, Foundation for Research on the Nature of Man, declining his invitation. to attend their annual dinner meeting because of my plans to be in Texas; a letter (attached) to Kenzo Sugimoto thanking him for forwarding to me the summary report and full report describing the NUMATRON accelerator in Japan and expressing my support for the NUMATRON proposal; a letter (attached) of nomination of Professor Gregory. Choppin for a "Senior U.S. Scientist Award"; a letter to Tony Gabriel regarding the Monte carlo calculations of the product distributions from the reaction of $25.2-\mathrm{Gev}{ }^{12} \mathrm{C}$ ions with $\mathrm{Au}$; a reply to Tina May walton who requested biographical material and personal answers to a few questions; a cover letter to Iynne and Bill to accompany a copy of my journal covering the European trip with Eric; and letters to go with copies of Volume II of my Travels in the New World to Sheila Saxby, Arthur Norberg, Iynne Cobb, Keith Glennan, Howard Brown, Arnold Fritsch, Justin Bloom, Myron Kratzer, Gerald Tape, Stanley Schneider and Herman Pollack.

I went by to see Baisden, otto and Morrissey in Building 70 as I was leaving. I stopped at Lafayette Reservoir for a hike on my way home.

I had dinner in the playroom watching the first half of Monday night football, the Los Angeles Rams vs. the Minnesota Vikings. Helen went to Berkeley to attend a YWCA dinner meeting.

Tuesday, October 25, 1977 -: Berkeley

At 8:45 a.m., I received a telephone call from Eric Leber in Mike McCormack's office in Washington, D.C. He called to request a recommendation for Thomas Pigford, Nuclear Engineering professor at UC Berkeley, as a possible replacement for Kent Hansen in the Nuclear Regulatory Commission.

During the course of the morning, I sent a contribution (\$100) for the I. I. Rabi Chair at Columbia University to Samuel Devons.

At 9:50 a.m., I spoke with William Dauben regarding Vitalii Goldanskii's nomination to membership to NAS. He suggested that someone in the Physics Section be asked to nominate Goldanskii. At 10:00 a.m., I called Harry Drickamer at the University of Illinois. He agreed to contact Hans Frauenfelder who may be willing to nominate Goldanskii in the Physics Section.

Pat McGaughey came in at 10:00 a.m. to discuss further the possibility of doing his graduate research with me. I again took him by room 203/70 to talk to Otto, Morrissey and Thomas. He then told me he has decided to work with me on Bevalac research.

I had lunch in the cafeteria with de Saint-Simon, Nishida and Diana Lee; I then walked down to Latimer Hall to meet in room 328 for the pre-lab session for Chem 1A from 1:00-1:10 p.m. I then helped administer the guiz and gave the pre-lab talk in room $E$ (where the T.A. is David Goodin). I circulated among rooms B, C, D and E until 3:00 p.m. 
October 24,1977

Professor K. Suginoto

Physics Departinent

Osaka university

Toyonaja, Osaka

JDPRANT

Dear Professor Suginoto:

I appreciated very much receiving the surnmary report and the full report describing the INUIA riRON accelerator which you hope to build in Japan. I have looked at these reports and found the project to be very well conceived, and, in fact, very exciting.

The field of heavy ion nuclear science, and especially that aspect winich incluales relativistic heevy ions, is one of the most important areas of nuclear science today. I believe that many important discoveries will be made in this field which is now the center of attention of laboratories in many of the countries who are the leaders in scientific research. I believe that the capability to accelerate ions as heavy as uraniun, which the rivingor will be able to do, offers the opontunity to work at the very forefront of nuclear scierce.

I strongly endorse the riminnon proposal and would very mich lite to see this accelerator built and put into operation.

Sincerely yours,

Glenn T. Seaborg

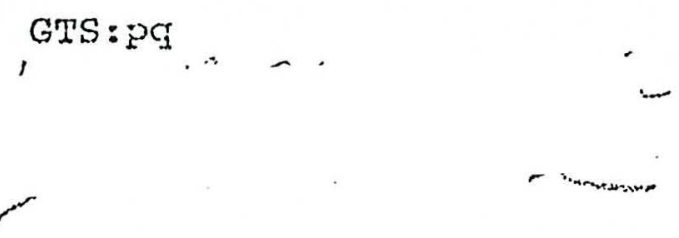


october is, 1977

Dr. Eeliriut Eanle

Alexancer Von Fumbolat-Stifrung

Schijleistrasse iz

D-5300 ronn - Bad Godiesbery

Fiest Germany

Dear DE. Fanie:

I am writing in support of tine nomination of professor Gregory R. Choppin for a "Senior U.S. Scientist ziward.".

Professor Cloppin has a distinguished record of accomplishment in tire $f i \equiv j$ of nuclear chemistry and inorganic chemistry and has specialized in investigations of the actinide and lanthariae elenents.

I have know din since 1953 when he started a three year study with us as a nemier of the Nuclear Chemistry Division in the Radiation Laboratory of the University of California, Derkeley. He did outstanding work on nong of the heavier transuraniun elements. Ferhaps his greatest contribution was as co-discoverer of the element, fencelevium, wich is the transuranium element with the ztomic number 101. This element was produced and identifies on an aton-by-atom basis, the First element for which this vas done. Tis involved the introduction of important new technicues, intch heve served as the basis for the discorery of ail tie transuraniun alenents jeyond mendeleviun in tire periodic system.

Professor Choppin was also involved in the program of intense neutron jomberinent of plutonin that les to the production of the important isotope, berkelium-2An, and the important caijionsum isotoses; californitur-249, californinn-250,

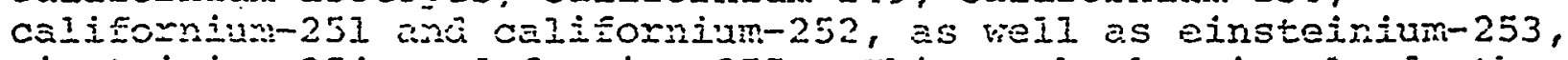
einstejnium-254, and fermiun-255. This worle also involved otiner intsiresting heavy transureniun isotopes, and included the neasurenent of radioactive and other nud lazr properties of most of these isctopes. ïe also participated in the first definitive worl ori tise stuay of the chemical properties of einsteinium and Eerminm.

Te has mace particulaxyy inyortant contributions in the ion exchange beiravior of the actinise elements, and played a key role ju developing the important oluting agent. alpho-hydroxy isotutyric acia. This has been a key chenical peagent in the 
separation of the chemicaily very similar actinide elements from each other. His work on the thiocyanate complexes of the actinides and lanthanides has also played an important role in the chemistry of these elements.

Frofessor Choppin has displayed a great versatility in his experimental progras, both in the chemical and in the nuclear aspects. This has continued in his program of research at Florial State University where he has been on the faculty since 1956, and has held the title of professor since 1963. Fe has carried on a strong research program of investigation of the thermodunamic stabilities of complexes of the tripositive lanthanide - and to a lesser extent actinide - ions. Professor Choppin's approach has bミen based upon a combination of ion exchange, potentionetric and calorimetric techniques for obtaining Free energy, enthaipy, and entropy data, using a number of simple methods.

He has an impressive list of publications among which are four widely used tertbooks, "Introductory Chemistry," "Experimental suclear Chemistry," "Nuclei anä Radioactivity," and "Chemistry, Science of Matter, Energy and Change."

Professor Choppin has played an important role in the professional aspects of cinemisiry. He served for nine years as Chairman of the Chemistry Department at Florida state Uni-. versity; he has served on the Eäitorial soard of the Journal of the emerican Chemical societr, os Sparetary-ireasurer of the

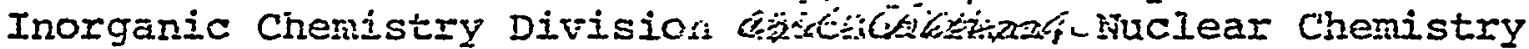
ana Technology Djvision of the American Chemical Society; and he has servea as a member of the Comitzes on Nuclear science and Chairman of the Subcontithee on Reajochenistry of the National Research Council-Naticral academy of Science.

Professor Choppin is very articulate and has an unusual ability to write clear. concise and understandable soientilic articles. He has a pleasant personality and is well likea by his co-workers and coliezgues.

I believe that Professor Choppin is very well qualified to receive a Senior U.S. Scientist Award fron the Alexander von Humbolät-Stiftung.

Glenn ri. Seaborg University. Professor and Rssociate Director Iekrence Berkeley Laboratory 
I met with my cluster advisory group from 3:10-4:00 p.m. in room 71 Evans Hall. After the meeting, I happened to meet Jean Severinghaus who asked to use my name as a reference for her job with the U.S. Geological Survey Radiocarbon Dating Laboratory in Menlo Park. She was in my Chem IB laboratory in the winter of 1975. I agreed to serve as a reference.

I went by to see Baisden and Nishida. The former expressed her concern with the lax monitoring of radioactive spills in the area in which she works in the HILAC Building. I expressed that I also am disturbed with this situation.

I took a hike at Iafayette Reservoir on the way home. I had dinner in the playroom. Helen went to a meeting of her Antiques Class at Acalanes High School. As usual, I spent the evening in the study reading and working on my briefcase of papers.

Wednesday, October 26, 1977 - Berkeley

I met with John Rasmussen to discuss the outline and distribution of lectures (between us) for Chemistry 123 for next quarter when I will share the teaching with him.

I walked down to the campus with Luciano Moretto and went to PSI to hear the Chem 1A lecture by Rollie Myers from 9:10-10:00 a.m. I attended the meeting of Chem $1 \mathrm{~A}$ laboratory instructional staff in room 124 Lewis from 10:10-10:40 a.m. I then walked back up to my LBL office. Betty Robinson from the Executive Program of the School of Business Administration came to my office at 11:45 a.m. to get my signature on the certificates (31) which will be given to the participants of the Executive Program.

I had lunch at my desk, then attended the biweekly meeting of the Actinide Chemistry group. Present were Edelstein, Raymond, Templeton, Bucher, Conway, Shalimoff, Avdeef, Mikheev and others. Eigenbrot reported on his work on $5 f$ orbital bonding in $U$ compounds with $C p$ and William Smith on attempts to synthesize organo-uranium compounds.

I talked with Rodney Banks. He will give me a copy of his JACS letter describing his work on actinide borohydrides.

Mikheev came by and I gave him copies of the following papers and miscellaneous material he requested; some of this for his son: a press release from ERDA dated July 24; 1975 regarding nuclear generating units in the U.S; The Nuclear Industry-1971; Peaceful Uses of Nuclear Energy; Nuclear Milestones; Plowshare; Heavy Element Properties.

At 3:00 p.m., Roger Parry came by to discuss with me his forthcoming talk on "The Study of Neutron-Deficient Holmium Alpha-Emitters with RAMA" at the Graduate Research Seminar.

I sent a copy of Volume. II of my Travels in the New World to Betsy McFadden today.

I went to Building 70 to talk to Morrissey and Thomas. On the way home, I stopped at the HILAC Building to talk to Ghiorso, Somer- 
ville and Yashita, who are getting ready for their ${ }^{40} \mathrm{Ar}$ bombardments at the SuperHILAC starting on Friday.

I took a hike at Lafayette Reservoir. Helen and I had dinner in the playroom.

Thursday, October 27, 1977 - Berkeley

I went by to see Morrissey, Thomas and Williams at 11:00 a.m. Walter Loveland arrived soon after to start his weekend with us.

I had Iunch in the cafeteria with Ghiorso, Otto, Morrissey, de Saint-Simon and Loveland.

David Goodin, an entering graduate student from the University of Oklahoma, came by at 1:00 p.m. I described my research program to him and gave him some reprints, then took him to meet everyone.

I went by room $203 / 70$ to talk to Otto, Loveland, Morrissey, Thomas and Williams. Williams finds that my suggestion of the use of $\mathrm{Hg}^{+2}$ as a catalyst for dissolving $\mathrm{Al}$ in $\mathrm{HNO}_{3}$ works very well. She uses $\mathrm{Al}$ to catch her $\mathrm{Bk}$ recoils from ${ }^{235} \mathrm{U}$ plus ${ }^{1 I_{B}}$.

During the course of the day, I received a telephone call from Dan Bornstein, a journalism student at UCB. I declined his invitation to appear in a documentary on the Berkeley smoking ordinance due to lack of time. He also inquired into my affiliation with "GASP."

My correspondence today included the following: a letter to Dean Homer Neal declining the invitation to speak at Indiana University; an acknowledgement to Jim Heneghan expressing satisfaction with his translations; a reply to Russell Peterson of New Directions regarding his grant application letter; a letter to Robert Maybury of UNESCO Regional office of Science and Technology of Africa regarding my visit to the UNESCO headquarters in Paris; and a reply to Robert Budnitz, of LBI, regarding his interest in visiting the People's Republic of China. I also continued to send copies of Travels in the New World, Volume II to various friends as follows: Harry D. Smyth, Robert E. Hollingsworth, Marie Janinek, Isidor I. Rabi, Rev. Theodore M. Hesburgh, Richard G. Hewlett and Julius H. Rubin.

On the way home, I stopped by the HILAC Building to watch Ghiorso, Yashita and Somerville prepare for their Ar bombardments.

I had dinner with Helen in the playroom and spent the evening in the study reading mail, articles and Chemistry $1 \mathrm{~A}$ material.

Friday, October 28, 1977 - Berkeley

I called Rod Hader at Washington ACS. He has heard nothing about the Steve Quigley matter.

I went by Building 70 to talk to Morrissey, Thomas and Williams.

I dictated letters to Jens Kratz (letter attached) and Robert Esterlund requesting feedback on our current research. 
October 28,1977

Dr. Jens V. Kratz

Geselischafi fur

Schiverjonen Eorschung $\mathrm{mbH}$

6100 Darmstadt 1

Postfach 541

Darmstadt

Federal Republic of Germany

Dear Jens:

Our group has receritly been concerned about the accuracy and precision of product liass aistributions measured by rąiochemical and räioanaly ical techriques. He are trying to devise an impartial, statistically valid means of estimating the uncertainty in any cotal nass yield inferred from the measurement of an indepenaent or cumulative radicnuclide yield. Fe are very interested in hearing how you and your colleages treat these problems.

Our approach to thjs probiem in the past has not been, totaliy satisfactory. The have assumed the fractional uncextaintiz in the yield of any riass is merely equal to the rracional uncertainty in tre measured radionuciade inciependent or cunulative $y$ iela fxom whicin the mass yiela vas calculated. This procedure, of course, underestimates the wroertainty in any nass yield because it neglects any uncertainty cortriblited by the correction of the measured. Yielas for precursor cecay, the fiting of charge aispersions to trie cajcuiated independent rabionudide yields, and tire integration of the charge äispersion curves to yield mass yielis.

In recent years, ve actemptea to impxove upon this proceiure by fitimg the cata witis several aiternative charge dispersion curves winich were jusged to give "acceptable" Fits to tise catal ana using tile resulting variation in the ceduced mass yiejas anc their uncertainties as a neasure of the true uncertainty of tie mass yiela vaiue. 
In all cases, the cieduced true fractional uncertainties are larger than the fractional uncertainties in the measurea radionuclice ylejas. Unfortunately this profiz cecure is not rigorous and is subjective because it depenas upon a derinition of what is an "acceptable" fit to the charge aispersion data.

Very recentliy we have done a fully rigorous propagation of exrors treatment of these uncertainties and the resu?is of such a treatment do rot seem reasonable, aithough they are ratienatically correct. We find that if re assume that the most probable fragment charge, $\mathrm{Zp}$, is uncertain to $0.1 \mathrm{z}$ linits and the Eaussian wictin paxameter, $\sigma$, is uncertain to $0.1 \mathrm{z}$ units, that a ijgorous propagation of errors treatment assigns extremely large uncertainties to the mass yields of nucilies whose $z$ is far different from $Z$ p. This results in finding that the only statistically meaningrul mass Yieids are those deauced from radionuclides at or near to.

We are very interesteci in your thoughts on these matters and we would appreciate it very much if you ccule tell us hoy you and your colleagues treat this problem of estimating the wincertainties in mass yields.

We have recenty recalculated mass yields from the measursa racianicijas yielas from the reaction of 40 Ar + $33 \varepsilon_{U}$ pubisisea in Phys. Rev.C 13, 2347 (1976) using our caiculation prccecurss (see ersclosed data) and io are puzzled by the restilts. Oux values of the isobaric yields egreed vitin experinenial uncertainty iil most (but not aIi) cases with those you reported, jut he are unable to understas the discrepancies in the uncertainties in the riass yielas. In particular, we cennot unoerstand how eny mass $Y$ ield (stich as the $A=161$ Yiaic) can have a smailer uncertainty (7\%) than the measured ricionucilde Fieid ascertainty (50\%) upon which it is based. we would feel tiat no smooting or averaging procecure can result in a reanction. in the uncertainty of tine datia. Does the anstrer lie in an incaeased uncertairity in the mass number associated with the smoothed or areraged mass yield? cuestions.

We lock formard to hearing your thoughts on these 
I enjoyed very much my visit to G.S.I. Iast month and wish to express my appreciation for the hospitality shown by you, Gunter Hermann and the others.

Cordially,

\author{
Glenn T. Seaborg
}

GTS/kV

Enclosures 


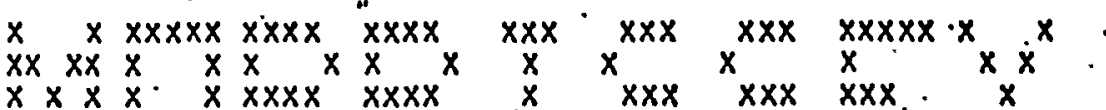

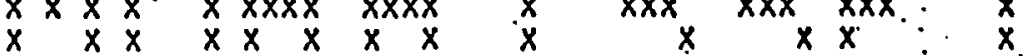

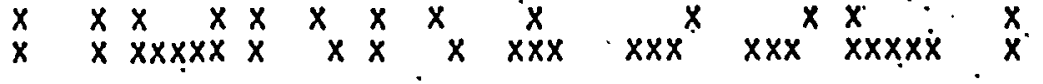

$462201 \ldots . . . . . . . . . . . . . . . . . . . . . . .462201$

$x x x x x x x x x x x x x$.

$x \times x^{x \times x}$

$x \times x$

$x x x x x x x x x x x x x$

$x \times x \times x \times x \times x \times x$

$\begin{array}{ll}x \times x \times x \times x \times x x \\ x & x \\ x & x\end{array}$

$x \times x \times x \times x \times x \times x$

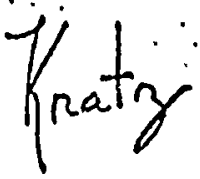

$A^{4}{ }^{40}+$

238

$\operatorname{lix}_{x \times x}^{x} x^{x} x^{x} x^{x \times x} x$

with $T_{\text {sep asgiven by } R J O}$

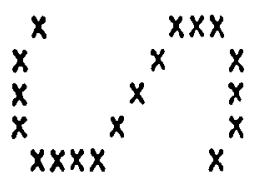

$x^{x x x x x}$

$x x x x x x x$

$x \times x \times x$

$\dot{x} x x x x$

$x_{x \times x \times x x x}^{x}$ $x \times x x x^{x}$

$x_{x}^{x} x_{x x x^{x} x^{x x x x} x_{x}}^{x}$
$x_{x}^{x}{ }_{x x x}^{x} x^{x^{x}} x^{x x x x} x$

$x \times x \times x \times x \times x \times x$

$\begin{array}{ll}x & x \\ x & x \\ x & x\end{array}$

${ }^{x} \underset{x \times x \times x \times x \times x x}{x}$

$x \times x x x x x x x x x x x$

$x \times x$

${ }_{x \times x}^{x \times x}$

$x \times x$
$x \times x \times x \times x \times x \times x x$

vi 
TIME DF BRMPARDMENT * $=$.DOOOE+02 MIN

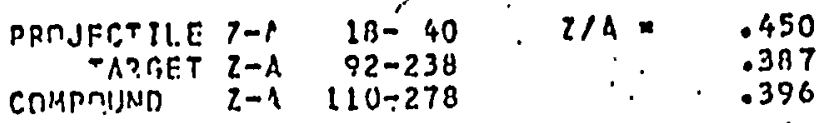

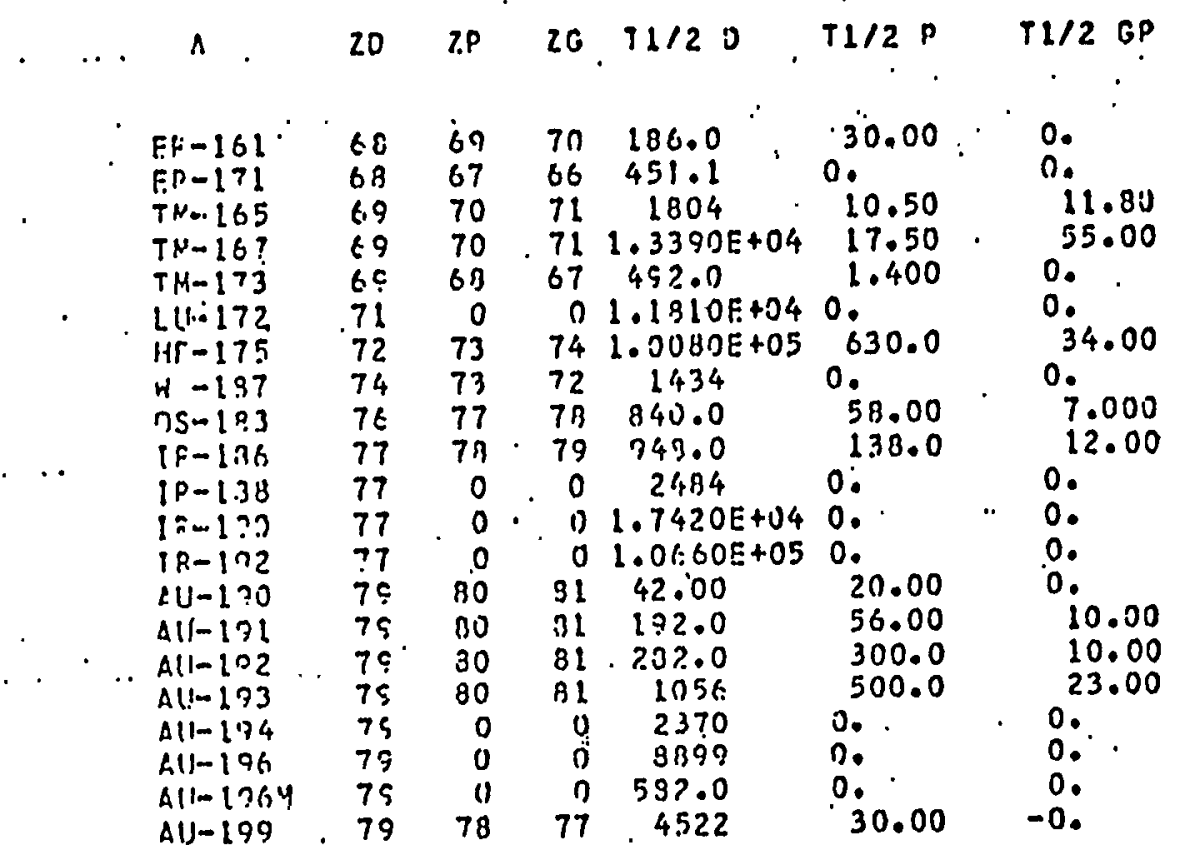

CROSS SECTIDNS

48

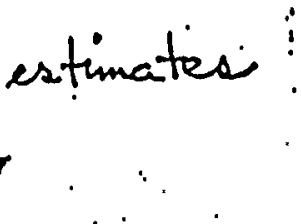

.7200
.1700
1.150
3.330
.2100
1.870
1.890
.2700
.6200
.6300
1.780
1.600
2.150
.2200
.3400
.8200
1.270
1.560
1.410
.9900
.1500

$\begin{array}{ll}+1- & .3400 \\ +1- & 400000 \mathrm{~F}-02 \\ +1- & .2900 \\ +1- & .7000 \\ +1- & 7.0000 \mathrm{E}-02 \\ +1- & .6100 \\ +1- & .4600 \\ +1- & .1200 \\ +1- & .3900 \\ +1- & .1100 \\ +1- & .5800 \\ +1- & .8100 \\ +1- & \vdots 2700 \\ +1- & 4.0000 \mathrm{E}-02 \\ +1- & .1900 \\ +1- & .1100 \\ +1- & .1000 \\ +1- & .2100 \\ +1- & .1100 \\ +1- & 0.0000 \mathrm{E}-02 \\ +1- & 6.0000 \mathrm{E}-02\end{array}$

RITIST TIME

45.07

45.07

45.07

45.07

45.07

.45 .07

45.07

60.05

60.05

60.05

60.05

60.05

60.05

60.05

60.05

60.05

60.05

60.05
60.05

.9900

.1500

$+1-6.0000 E-02 \quad 60.05$ 
PREGRAH MASSY

TEST OF ALSSY ON THE KRATZ 1P-40 + J-2.38 DATA IWITH TSEP BY RJDI CALCIILATE GPNWTH AND DECAY COR.RECTION FACTORS

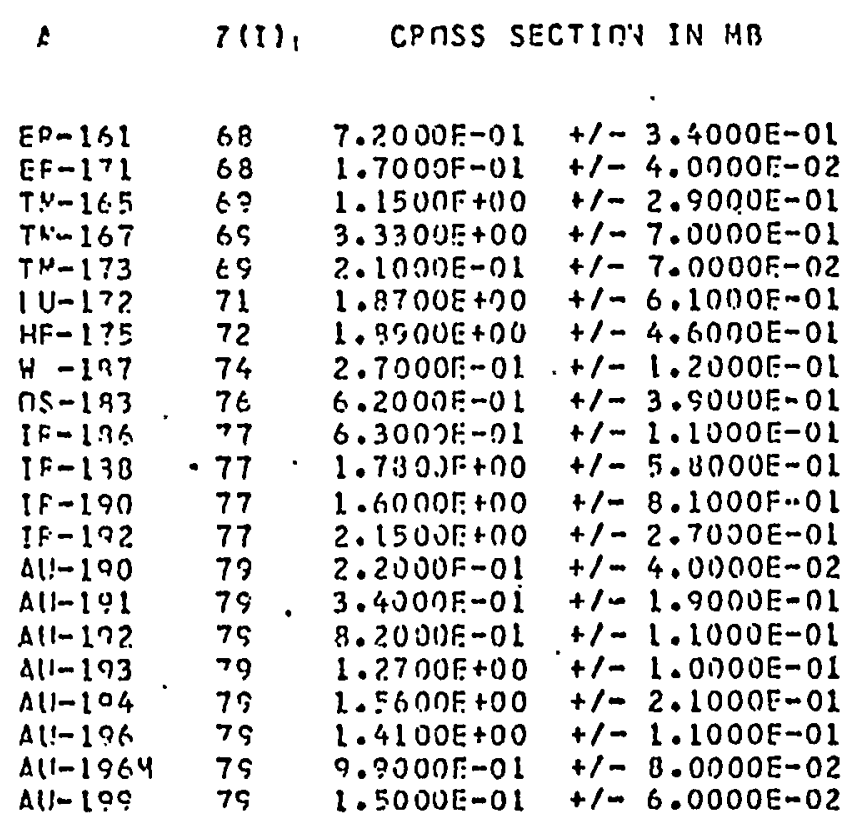

CORRECTION FACTORS

$$
\begin{aligned}
& 6(1.1) \\
& 70.58 \\
& 86.50 \\
& 96.42 \\
& 99.51 \\
& 87.54 \\
& 99.44 \\
& 99.93 \\
& 94.83 \\
& 91.35 \\
& 92.29 \\
& 96.99 \\
& 99.56 \\
& 99.93 \\
& 18.18 \\
& 67.59 \\
& 76.50 \\
& 93.05 \\
& 96.84 \\
& 99.15 \\
& 87.77 \\
& 98.33
\end{aligned}
$$$$
\begin{array}{ll}
C(2,1) & c(3,1) \\
44.85 & 22.89
\end{array}
$$$$
0 .
$$$$
82.03
$$$$
74.89
$$$$
85.89
$$$$
0.501
$$$$
0 .
$$$$
\text { 0. } 38.47
$$$$
19.96
$$$$
0 .
$$$$
\text { 0. }
$$$$
14.89
$$

$0(4,1)$
0.
0.05
65.97
28.07
0.
0.
2.335
0.032 .44
32.55
14.55
0.
0.
0.
23.94
6.518
3.435
0.
0.
0.
0.

$C(5,1)$

0 .

12.95

14.04

0 .

- 7188 0.

4.395

0.

0.

0.

0. 553

1.356

1.349

0 .

0 .

0. 
CHARGF DISTR?PUTY DV IIIPUT DATA FOP. TRIAL ${ }^{\ell}$

TFST RIF VISSY ON THE KRATL AR-40 + IJ-238 DATA (WITH TSEP BY RJOI

EYPFPIRLL ZIA

SITMA $=(* .300 E-03) A(1)+(1.636)$

$Z N P=(3.000 r-01) 1(1)+13.100)$

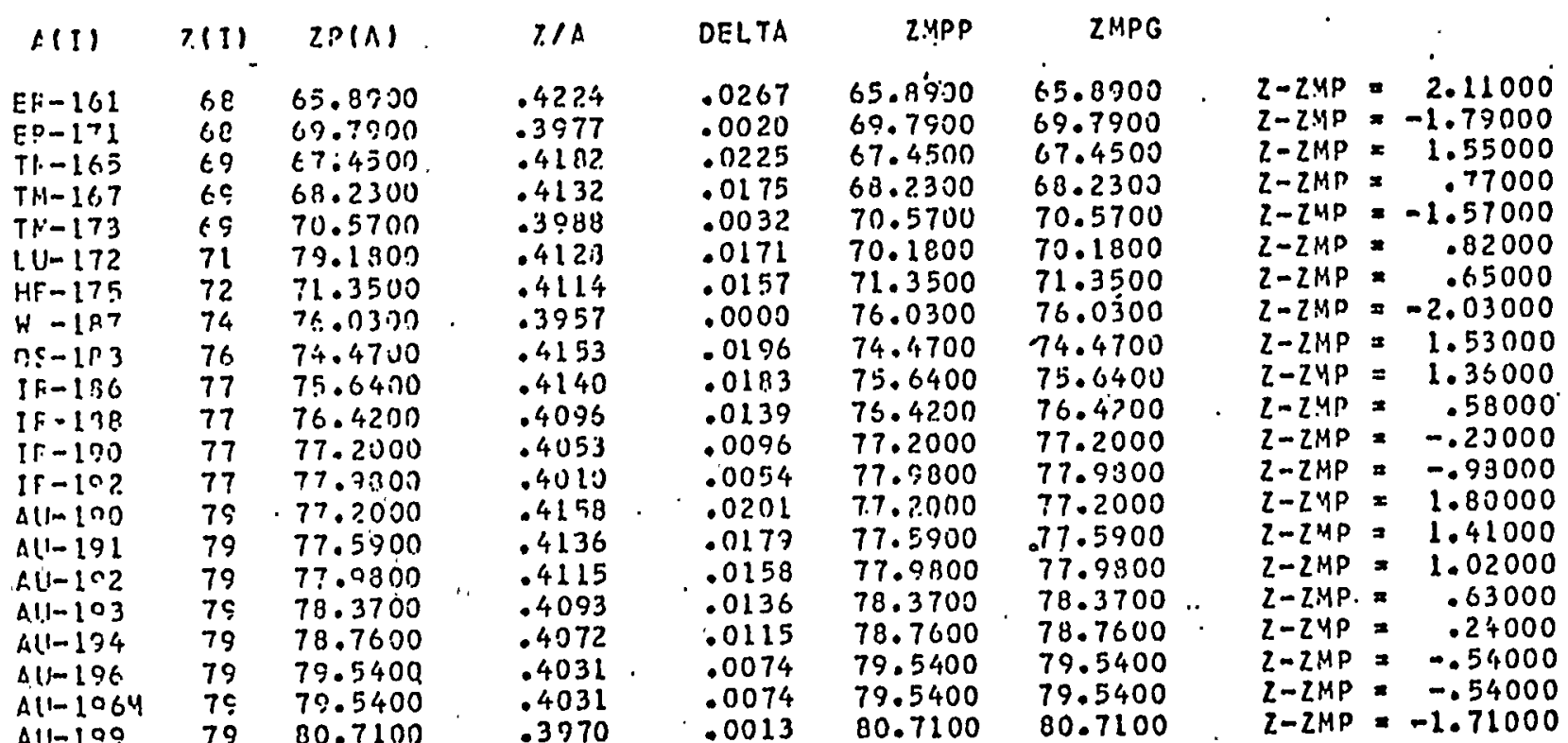

NEUTS OUT

18.000
2.000
15.000
12.000
3.000
12.000
11.000
1.000
14.000
13.000
10.000
7.000
4.000
14.000
13.000
11.000
10.000
8.000
6.000
6.000
1.000

SIGMA (MB)

7. $200 E-01$

1.70OE-01

1. $150 \mathrm{E}+00$

3. $330 E+00$

2. $100 E-01$

1. $870 E+00$

1. $890 E+00$

2. $700 E-01$

$6.200 E-01$

$6.300 E-01$

$1.780 E+00$

1. $\triangle O O E+O O$

2. $150 E+00$

2. $200 E-01$

3. $400 E-01$

8.200E-01

1. $270 F+00$

1. $5.60 E+00$

1. $410 E+00$

9. $900 E-01$

$1.500 E-01$

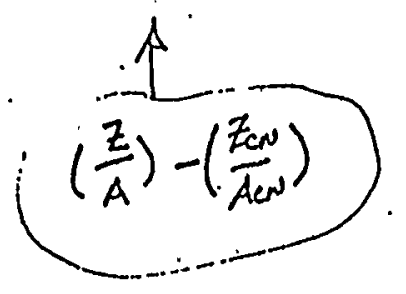

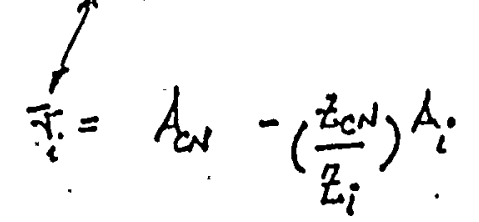

$$
\frac{A_{i}}{z_{i}}=\frac{A_{C N}-\bar{\gamma}}{Z_{C N}}
$$


CHAQRE nISTRIRUTIJV INAUT DATA FOR TRIAL

PHARGE DISTEPAITIJIN DATA AFTER O URGLSES

TFST JF MASSY ON THE KRATL AR-40 + U-238 DATA (HITH TSEP BY RJO)

\section{CALCULATED RATFS}

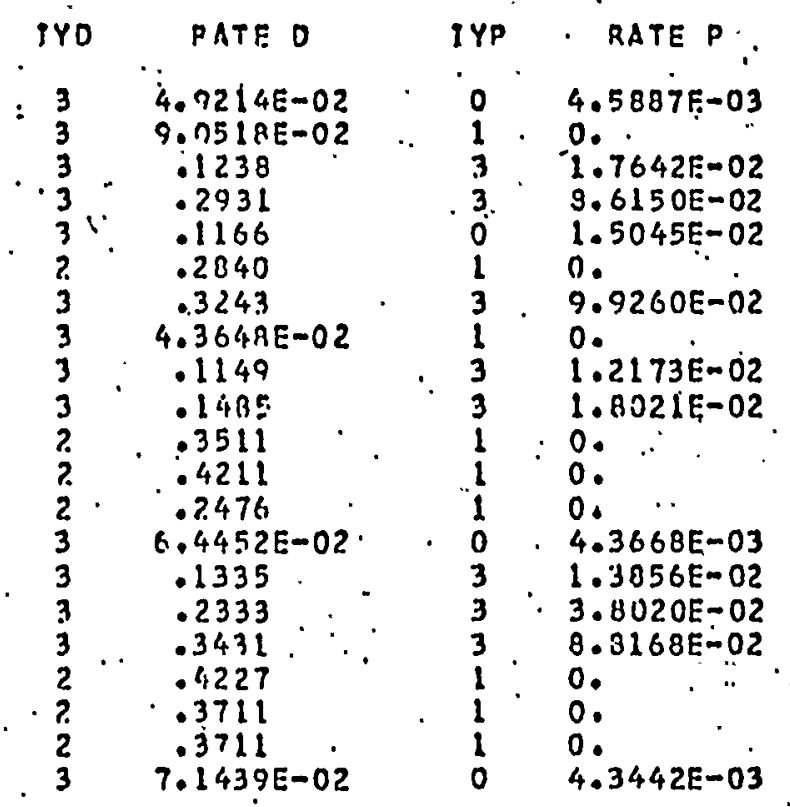

\begin{tabular}{|c|c|}
\hline $\begin{array}{l}0 . \\
0 .: 1 \\
9.7804 E-04 \\
9.9980 E-03 \\
0 . \\
0 . \\
1.1184 E-02 \\
0 . \\
4.2119 E-04 \\
6.9469 E-04 \\
0 . \\
0 . \\
0 . \\
0 . \\
4.3021 E-04 \\
2.8600 E-03 \\
6.8490 E-03 \\
0 . \\
0 . \\
0 . \\
0 .\end{array}$ & $\begin{array}{r}E R-161 \\
E R-171 \\
T M-165 \\
T M-167 \\
T H-173 \\
L U-172 \\
H F-175 \\
H-187 \\
O S-193 \\
I R-186 \\
I R-188 \\
I R-190 \\
I R-192 \\
A U-190 \\
A U-191 \\
A U-192 \\
A U-193 \\
A U-194\end{array}$ \\
\hline
\end{tabular}

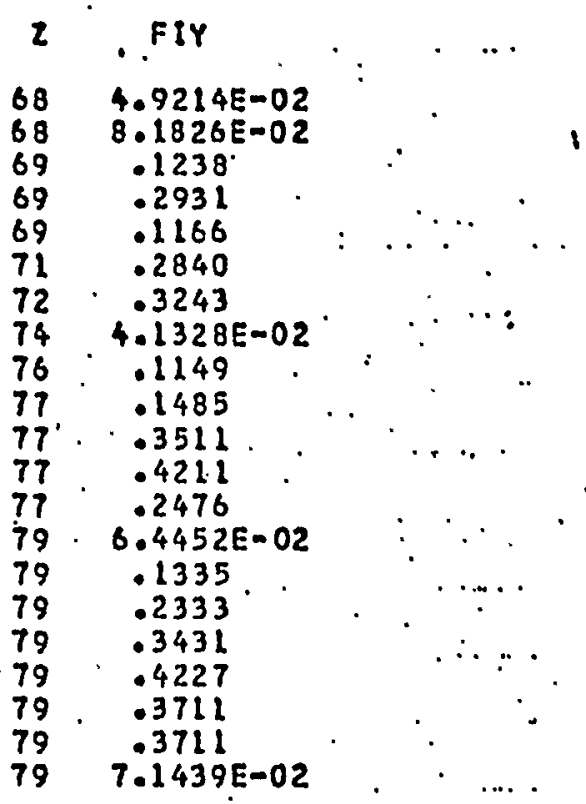


PESULTS R:F TRIAL 1

AFTEQ ONRGLSFS

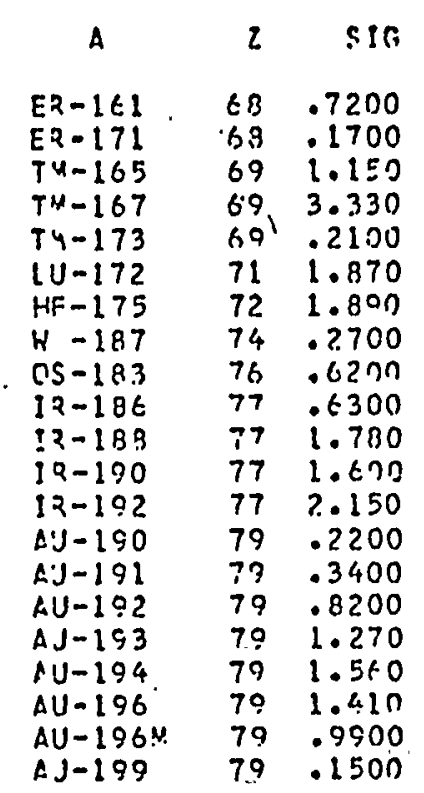

MEAS

\begin{tabular}{|c|c|}
\hline $\begin{array}{l}\text { EASIIRED } \\
\text { ESIS }\end{array}$ & FC \\
\hline $\begin{array}{l}.3400 \\
4.0000 \mathrm{E}-02 \\
.2900 \\
.7000 \\
7.0000 \mathrm{E}-02 \\
.4100 \\
.4600 \\
.1200 \\
.3900 \\
.1100 \\
.5800 \\
.8100 \\
.2700 \\
4.0000 \mathrm{E}-02 \\
.1900 \\
.1100 \\
.1000 \\
.2100 \\
.11100 \\
8.0000 \mathrm{E}-02 \\
6.0000 \mathrm{E}-02\end{array}$ & $\begin{array}{r}.9179 \\
1.0000 \\
.8706 \\
.7714 \\
.8854 \\
1.0000 \\
.9696 \\
1.0000 \\
.9261 \\
.9493 \\
1.0000 \\
1.0000 \\
1.0000 \\
.9054 \\
.9184 \\
.9599 \\
.9630 \\
1.0000 \\
1.0000 \\
1.0000 \\
\$ 9477\end{array}$ \\
\hline
\end{tabular}

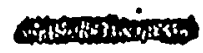

\begin{tabular}{|c|c|c|c|}
\hline SIGC & - ESIGC & & RO \\
\hline $\begin{array}{l}.6609 \\
.1700 \\
1.001 \\
2.569 \\
.1359 \\
1.870 \\
1.833 \\
.2700 \\
.5742 \\
.5930 \\
1.780 \\
1.600 \\
2.150 \\
.1992 \\
.3123 \\
.7871 \\
1.223 \\
1.560 \\
1.410 \\
.3900 \\
.1422\end{array}$ & $\begin{array}{l}.3121 \\
4.0000 E-02 \\
.02525 \\
.5399 \\
6.1981 E-02 \\
.6100 \\
.4460 \\
.1250 \\
.3612 \\
.1044 \\
.58100 \\
.8100 \\
.1700 \\
3.6215 E-02 \\
.1745 \\
.1056 \\
9.6301 E-02 \\
.2100 \\
.1100 \\
8.0000 E-02 \\
5.6864 E-02\end{array}$ & 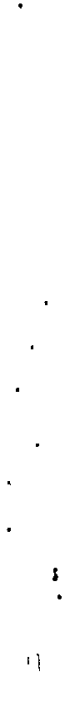 & $\begin{array}{l}.0492 \\
.0905 \\
.1238 \\
.2931 \\
.1166 \\
.2840 \\
.3243 \\
.0436 \\
.1149 \\
.1485 \\
.3511 \\
.4211 \\
.2476 \\
.0645 \\
.1335 \\
.2333 \\
.3431 \\
.4227 \\
.3711 \\
.3711 \\
.0714\end{array}$ \\
\hline
\end{tabular}

CALC. Y Y A SIGA. ESIGA

13.43

1.878

8.086

8.763

l. 595

6.584

5.651

6.186

4.999

4.027

5.070

3.759

8. 685

3.090

2.340

3.373

3.565

3.601

2.668

. 1.990

6.341

.4419

2. 039

1.842

.5315

2.148

1. 375

2. 749

3.144

.7031

1.652

1.923

1.091

.5619

1.307

.4525

.2807

.4968

.2156

.2964

PCY BETA

PCY`BETA

PCY-RETA

PCY-BETA

PCY-BETA

$$
\text { IY }
$$

PCY-BETA

PCY-BFTA

PCY-IETA

PCY-RFTA

IY

IY

PCY-BETA

PCY-RETA

PCY-BETA

PCY-BETA

IY

IY

PCY-BETA 


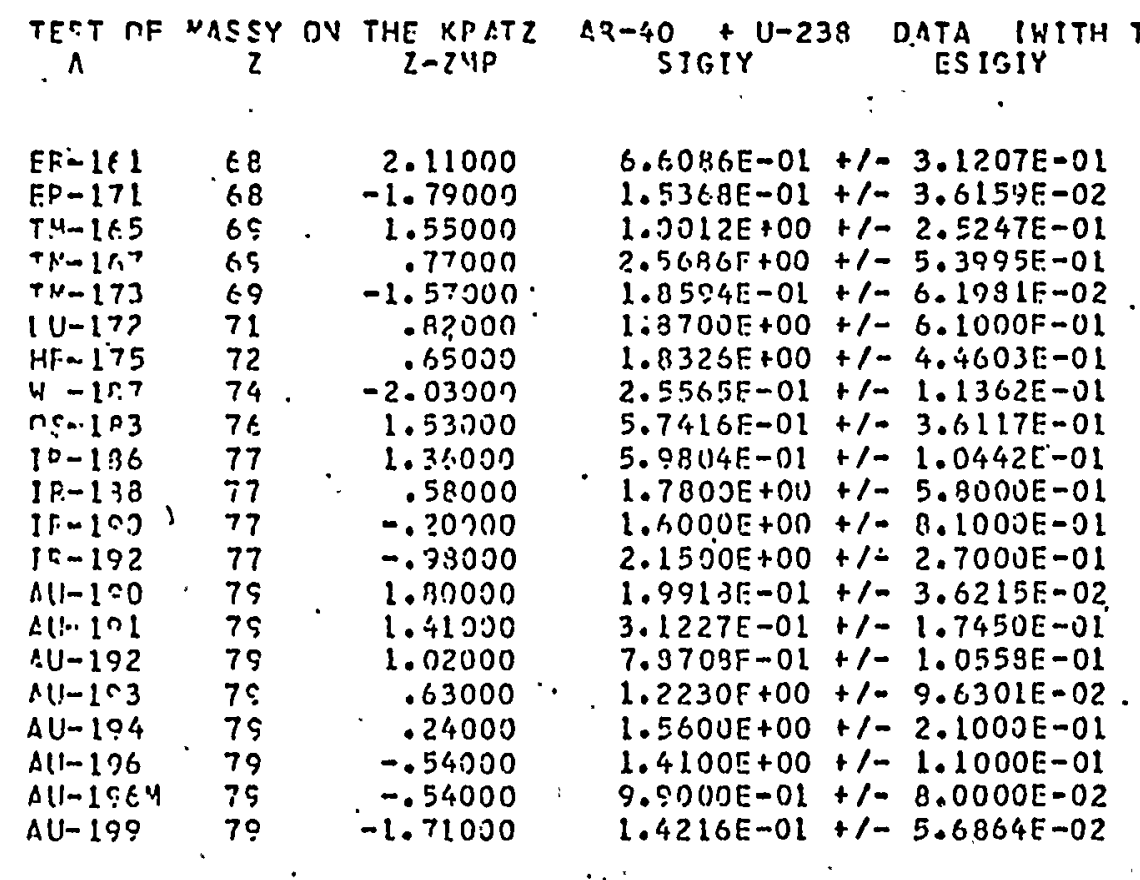

BY RJU

FACTOR

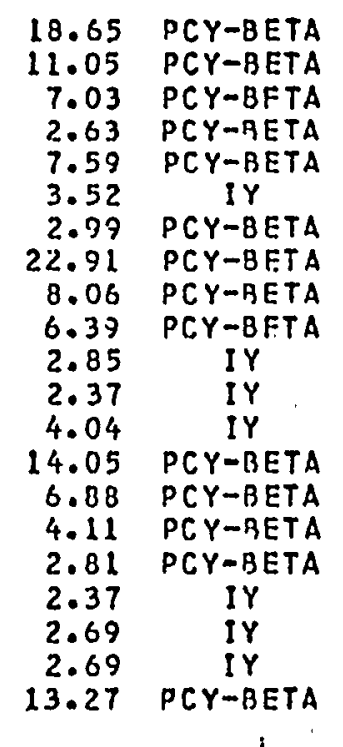

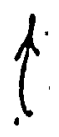

D. F. $\equiv$ Calculated Mass Yic $/$ measurad Yield 


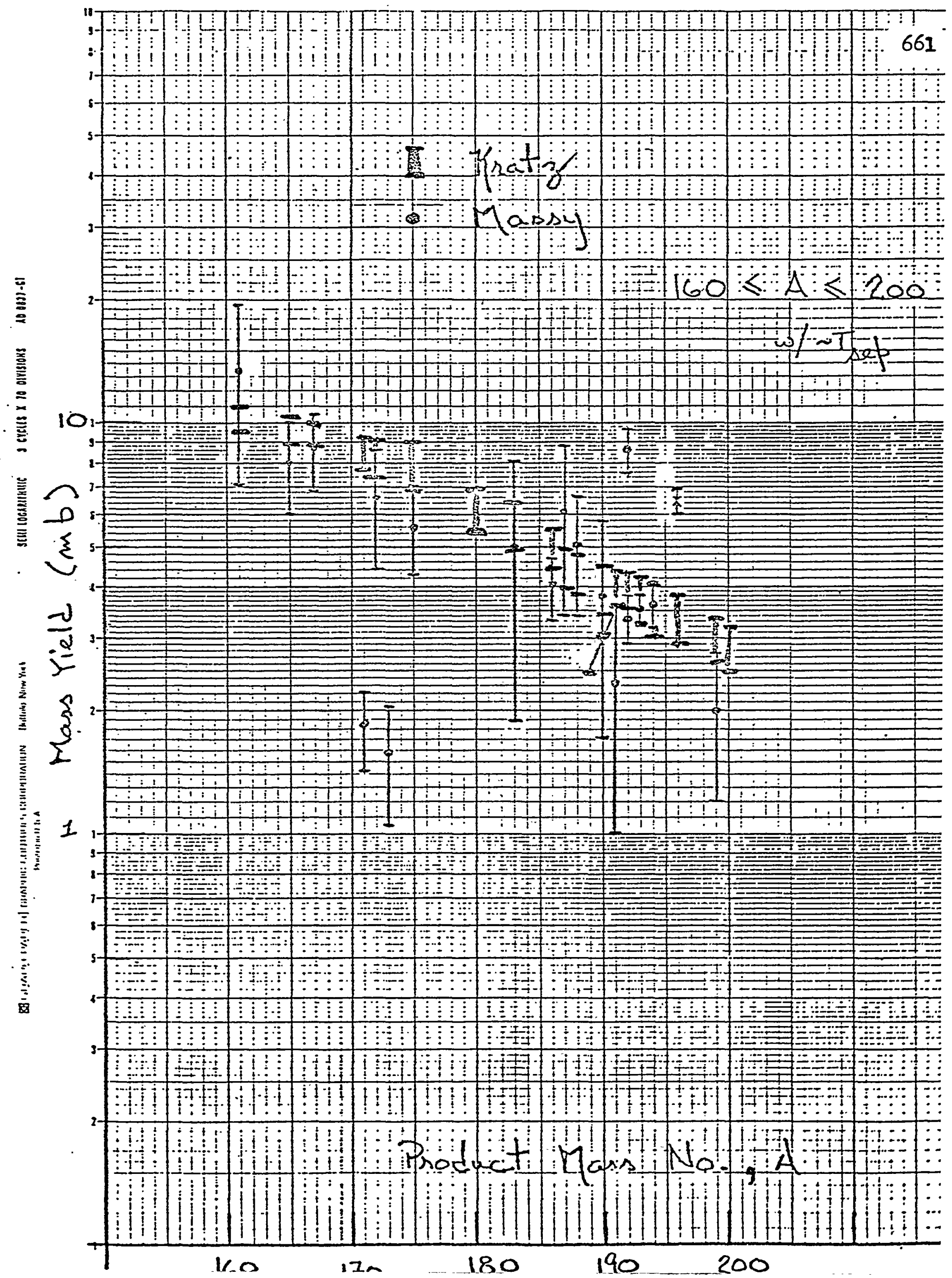


$+\because$

1.?

(1)

662

-

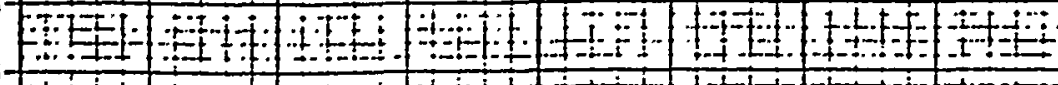

10 fot

$1 \frac{1}{1}$

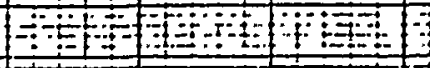

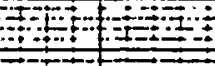

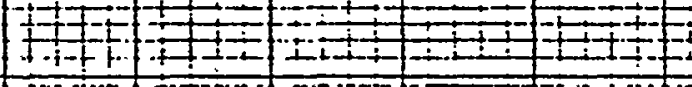

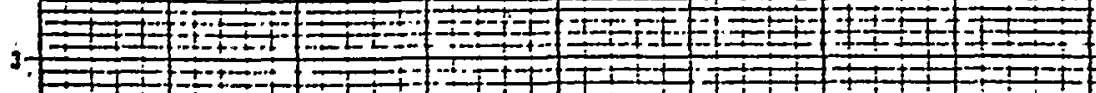

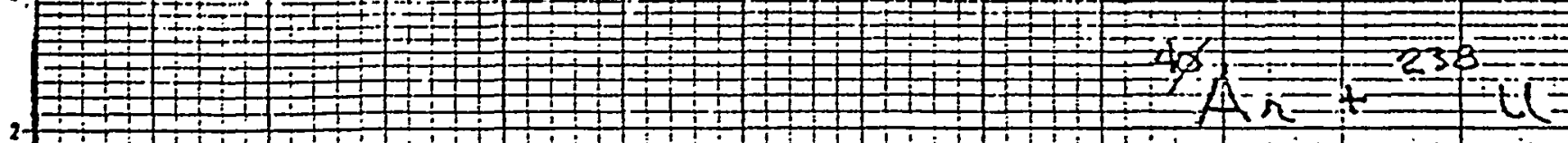

$2-$

ititim

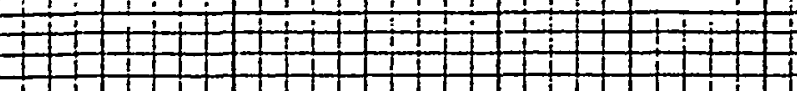

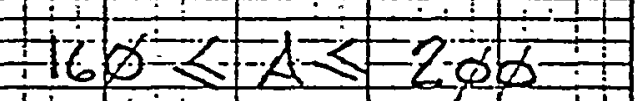

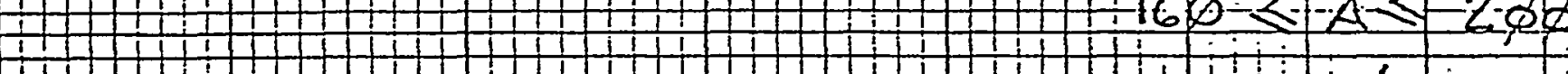

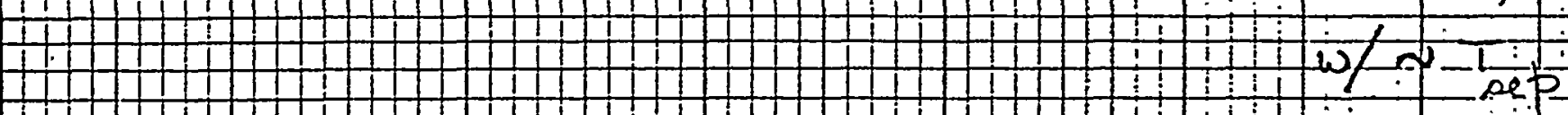

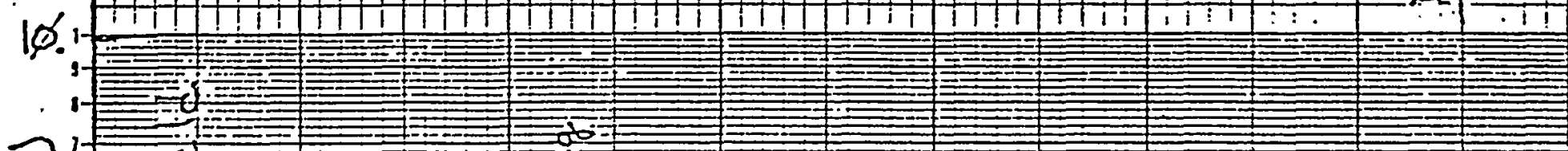

క̊․

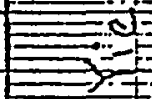

$b_{1}$

2

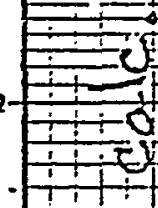

en

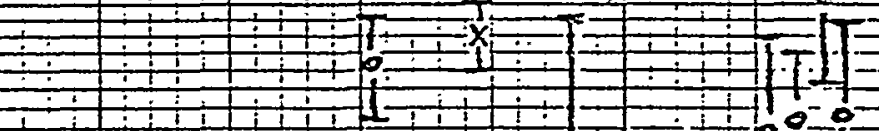

$\stackrel{5}{3}$

1

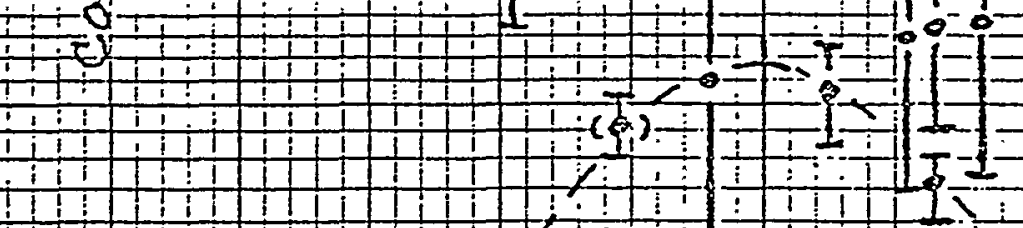

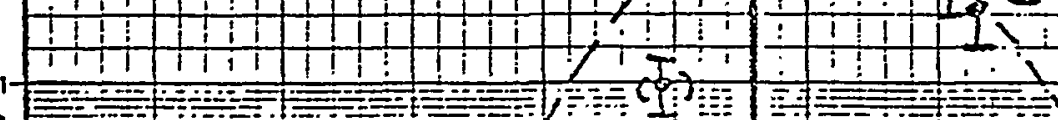

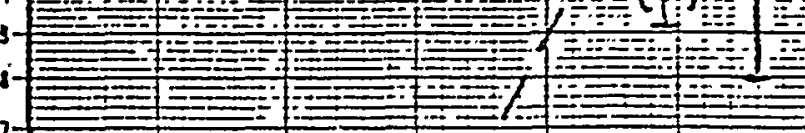

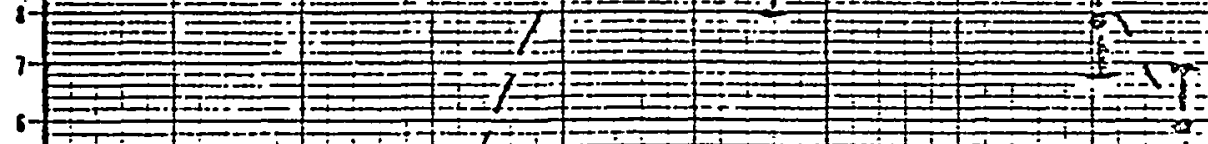

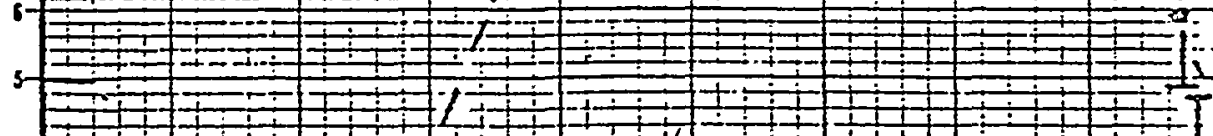

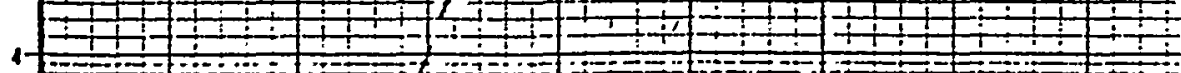

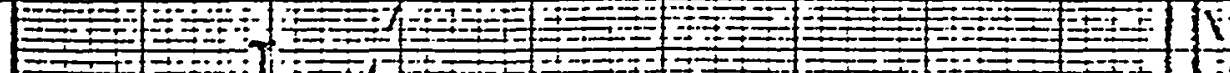

, 19010

3 PIf

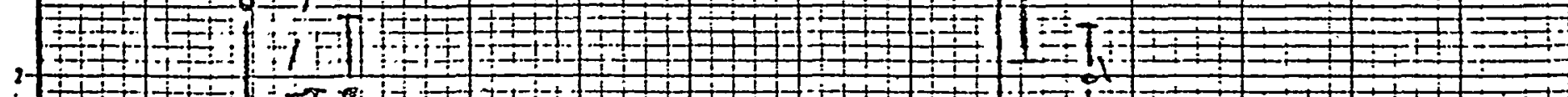

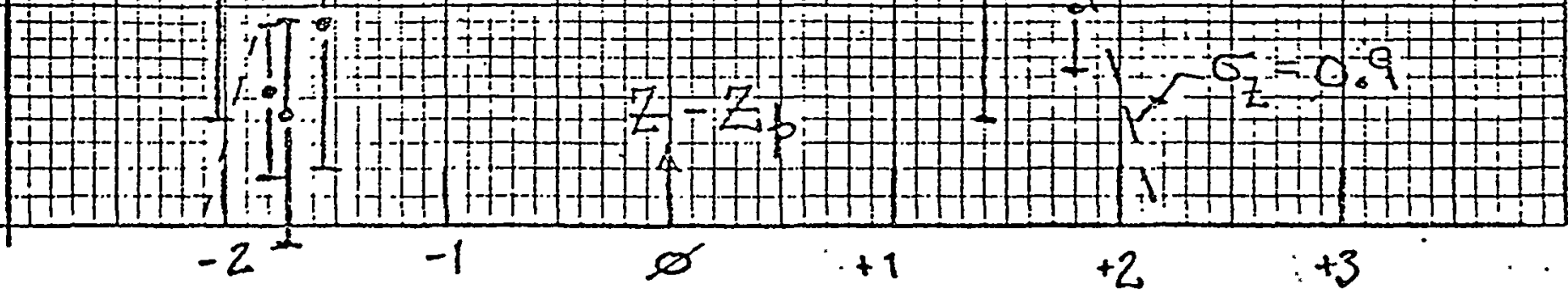

0.1 $-2$

$+1$

$+2$ 
Friday, October 28,1977 (con't)

I walked down to campus for my office hour in my -Iatimer Hall office (446 Latimer) from 10-11:00 a.m.

During the course of the day, I also dictated a memo to Kenneth Raymond approving the draft of a proposed inorganic information letter and a letter to: G. Melese-d'Hospital, Office of the Executive Vice President, General-Atomic International, declining an invitation to participate in a seminar in honor of Peter Fortescue's 65th birthday, as I shall be out of the country.

Joe Engbeck called and invited me to attend a field trip on the Claremont Canyon Project on Saturday, November 12; I accepted.

I taught my Chemistry $1 \mathrm{~A}$ discussion section in room E Latimer from $11: 10$ a.m. to $12: 00$ p.m.

At 12:30 p.m., I went to the University House where I met Helen and we conversed with a number of the 100 people who had been invited to have lunch with Prince Charles (the Prince of Wales). We talked to a number of people, including Trudy Martin (President of ASUC), Don and Sylvia McLaughlin, Mayor and Mrs. Iionel Wilson (Oakland), Don Mulford (Chief of Protocol of the City of Oakland), Leslie Iipson (Political Science Department), Regent Joseph Moore, Regent william Coblentz, Garff.Wilson, Vice Chancellor Michael Heyman, Vice Chancellor Robert Kerley, Provost George Maslach and Gene Trefethen.

The Prince arrived at 1:00 p.m. and went around and shook hands with each of us individually and talked to many. He and I discussed my tenure as Chairman of the US Atomic Energy Commission, my friendship with Sir John Hill (UKAEA), my work on transuranium elements and the planned briefing for him on energy this afternoon.

We went downstairs to Iunch. I sat at a table with Doris Hough, Sue Hone.(vice Mayor of Berkeley), Regent Moore, Jim Hart, Mike Heyman, Sylvia McIaughlin and Lady Moreton.

As the Iunch was completed, Chancellor Bowker made some welcoming remarks to the Prince alluding to-Sir Francis Drake's visit to the Bay Area in 1579, the effects of the visit (the Drake Plate) and then proposed a toast to Queen Elizabeth; for which we all stood. Bowker presented a "Golden Bear" tie to the Prince. "Prince Charles then responded, in a humorous vein, alluding to the convenience he finds in the common language between the United Kingdom and America, perhaps aided by Sir Drake's discovery of the Bay Area. In general, he is satisfied with his visit to America. He mentioned that he has been elected Chancellor of the University of Wales (he defeated a Communist miner in the election); the position resulted from nepotism, since his father had preceded him.

Prince Charles left at this point and went upstairs with Chancellor Bowker. They then left immediately out the front door of University House. Andy Sessler and-I caught up and followed a few feet behind them. The entire walk to California Hall was accompanied by many students chanting slogans such as "Charlie get out of Ireland." 
Eriday, October 28, 1977 (con't)

When we arrived at California Hall we went to the Chancellor's Conference Room. Here Chancellor Bowker sat at the head of the table with Prince Charles on his left and Andy sessler on his right. Others on the right were Bob Budnitz, Paul Witherspoon, Wulf Kunkel, me and Jack Hollander. On the opposite were Lady Moreton, Sir John Moreton, Mrs. Kinnear and Mr. Kinnear. Continuing down the table on both sides (each was full) were members of the United Kingdom entourage. Garff Wilson and others sat on the side.

Chancellor Bowker called on Sessler, who said that the program would consist of a discussion of conservation and energy. Sessler gave a brief history and description of Lawrence Berkeley Laboratory. He then called on Bob Budnitz who spoke about 5 minutes on conservation, illustrating with projections the importance of this in a home for saving energy and money. Paul Witherspoon spoke next on "Nuclear Waste Isolation and Storage" and described the joint US-Sweden waste storage project at the Stripa Mine in Sweden. Kunkel spoke on "Controlled Fusion Energy" with projections to illustrate the nuclear reactions involved.

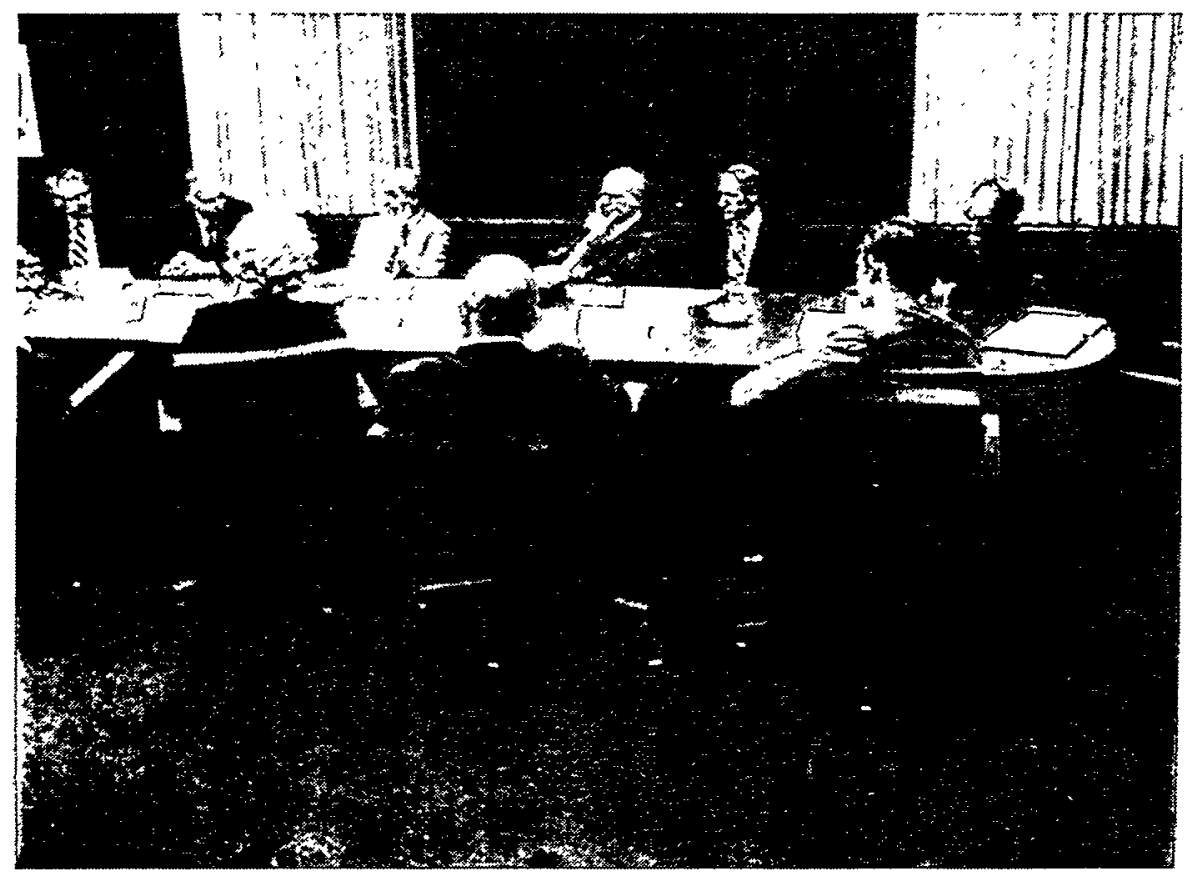

Left to right: Jack Hollander, GTS, Lady Moreton (back to camera), Wulf Kunkel, Sir John Moreton (back to camera), Paul Witherspoon, Bob Budnitz, Prince Charles (back to camera) and Andy Sessler.

Because Prince Charles made an inquiry about the fast breeder reactor, I described the role of the nuclear breeder and how it relates to conventional nuclear power and to nuclear fission. I said that development of the breeder will increase our available nuclear fuel resources so that nuclear power could be used for thousands of years. 
Jack Hollander then gave a summary of our energy supply problems between now and the year 2020. He explained that the fuel supply may not be adequate even with stringent conservation measures. Prince Charles: asked intelligent questions throughout the presentations.

After the meeting with the Prince, sessler and I went by the new office facilities (off-site) at 1947 Center street and 2000 Hearst street. I looked over the facilities and returned to my LBL office after stopping by my Latimer Hall office.

I went to the HILAC Building at 6:00 p.m. and found that Ghiorso and Nurmia had just finished a ${ }^{40} \mathrm{Ar}$ plus U bombardment and Baisden had chemically isolated $\mathrm{X}$, which was brought down to Building 70 for Maynard Michel to make a mass spectrometer determination.

Helen drove to Davis after the lunch with Prince Charles, picked up Dianne and drove her home to Lafayette.

Dorothy and oliver Schriver came by and Helen and $I$ had dinner with them at the Norsemen Restaurant (Smörgåsbord) in Lafayette. It was raining.

\section{Saturday, October 29, 1977 - Lafayette}

Helen and I took a hike up to Lafayette Ridge via the Jennings property to check on this route as an access trail. We then drove to. IBI where I went to room 203/70. I found Loveland and Morrissey at work on the measurement of gamma rays of the gold region (recoil range measurements) from U targets bombarded with $40 \mathrm{Ar}$ ions over a range of energies. I went by Maynard Michel's room and found that the mass spectrometric measurement of " $X$ " failed because the sample was not properly inserted. I went by the HILAC Building where Ghiorso was working on the detection apparatus for his test of the TKE measurements of fission products using oxygen bombardments.

Helen and I walked down to International House and attended the luncheon of Robert Gordon Sproul Associates. We sat at a table with Rose Mary Shepard, Myer and Sally Kahn and Sherry Warrick.

We then went to Memorial Stadium to see the UC Berkeley--USC football game. The stadium was a "sellout," the first non-Big Game "sellout" since the 1953 UCB-USC game. Berkeley won 17-14.

We walked back up to IBL. I went by room $203 / 70$ and found Loveland and Morrissey still working. They seemed to be finding the gold region products have recoil ranges corresponding to deep inelastic and not compound nucleus reactions.' I went up to the HIIAC Building and found Ken Hulet and his crew busy testing their apparatus for detecting gaseous SHE, to be collected together with radon products from $\mathrm{Pb}$ plus $\mathrm{O}$ reactions.

Helen and I drove back home to Lafayette and found Dianne on the phone talking to Bob Puppa. Helen and I had dinner in the playroom. Dianne ate later. Helen drove in to pick up Dave who is moving back to live with us because his live-in board-and-room job didn't work out. 
Sunday, October 30, 1977 - Lafayette

I went on a trail scouting expedition at Lafayette Reservoir from 9:00 a.m. to noon with Kay Petersen and Barbara Langlois. Starting at the parking area of the dam, we hiked on the Rim Trail about 3/4 of a mile to the cutoff point to head for the Mormon Church. We hiked to Rheem Reservoir, then along the top of Rheem (Campolindo) Ridge to the Point just above Campolindo High School. We hiked back along the top of Rheem, then along its side to the Rim Trail of Lafayette Reservoir, and then back to our starting point.

In the afternoon, Helen and $I$ went to a reception at the home of Horace and Joyce Burr in El Cerrito to celebrate our success in getting EBMUD to turn down the request for the use of the emergency water tanks on Skyline Drive in Oakland for use in a housing development in that area. Present were Hans and Jean Jenny, Roger and Marian Reeve, the Paul Badgers, Mary Lee Jefferds, Helen Burke, Tom and Marge Bowman, Ed and Elsie McMillan, the Sills, the Grossenbacks and the Reid Inddenhams (UC Psychology Department).

Helen and I had dinner in the playroom. Dave ate in the kitchen and Dianne ate later because of her displeasure at Dave's moving back home. Helen drove Dianne back to Davis.

Monday, October 31, 1977 - Berkeley

My morning dictation included correspondence to Iennard Bickel in regard to a number of questions he posed in a letter regarding events during my tenure at AEC.

I went by Building 70, room 203 and found that the Loveland-ottoMorrissey recoil experiments (U plus $40 \mathrm{Ar}$ ) over the weekend seem to be successful; the gold region products seem to be due to deep inelastic reactions. The ${ }^{4} \mathrm{Ar}$ beam is at a high intensity (several microamperes) so Thomas's experiment (U plus $40_{\mathrm{Ar}}$ to look for Pu isotopes) and Baisden's experiments (to jdentify $X$, etc.) are planned for today. Williams also has her U plus $11_{B}$ bombardment (to look for $242 \mathrm{Bk}$ ) today.

I attended Rollie Myers's Chemistry 1A lecture in PSL from 9:1010:00 a.m., then walked back up the hili.

At 11:15 a.m., Allan Bromley came by and Bernard Harvey and I met with him in my office until noon. I then took him by Building 70 to meet Morrissey, Thomas, Williams and Marsh. We then went to the cafeteria and had lunch with Harvey and Dick Diamond. Bromley told me he is serving as Vice President of IUPAP. I again took Bromley by room 203/70 where we gave him copies of a number of our mass yield curves for use in two talks he will give next year. Diamond and I then walked with him up to the HILAC Building where we showed him the Diamond-Stephens experimental setup and the various experimental setups in the Ghiorso-Nitschke area.

I attended the NSD seminar in the Building 70A conference room where Gordon Wozniak spoke on "Evidence for Angular Momentum Fractionation in $86 \mathrm{Kr}$-induced Reaction on $107,109 \mathrm{Ag}$, $165_{\mathrm{Ho}}$ and ${ }^{197} \mathrm{Au}$." 
After the seminar, Kenton Moody (of UCSB) came into my office to tell me he would like to do his graduate work with me; I indicated I might accept him.

The Stanley Thompson. (2 volume set of reprints--6 copies) appeared today.

I received a telephone call from Minoru Tsutsui of the Department of Chemistry at Texas A \& M University. We discussed my ideas for an International Chemical Society.

I also received a call from George Milly of GEOMET inquiring if it would be possible for me to visit the Dennison Mines in Toronto, Canada to meet stephen B. Roman. He will try to arrange a visit for me to coincide with a Board meeting.

During the course of the day, I dictated correspondence to: Francois David at Oak Ridge acknowledging receipt of two preprints he sent me, O. Bertrand Ramsay at Eastern Michigan University thanking him for a copy of his "Periodic Table That Might Have Been,..." and J. R. Grover forwarding the abstract for my talk "Research on: the Transactinide Elements" for the ACS National Meeting in Anaheim in March, 1978.

I went by to see Baisden and Michel de Saint-Simon in Building 70. They had just come from the alpha counter and had found that " $X$ " (10.3-MeV, 11.6- MeV and 6.28-MeV alphas) can be assjgned to mass no. 212, hence to $212_{\mathrm{Bi}}$. It was produced from $U$ plus $4 \mathrm{Ar}$ this afternoon at the SuperHIIAC and put through Michel's mass spectrometer.

Helen and $I$ had dinner in the playroom and watched the first half of Monday night football (New York Giants vs. St. Louis Cards). Dave took care of handing out the treats to the kids that came around for "Trick or Treat."

Reid Laitner came by at 9:30 p.m. and Helen and I signed the necessary papers for the sale of our 2-acre orinda land to. Wirthman for $\$ 25,000(\$ 5,000$ down, 4 annual payments to follow, 10\% interest).

November 1, 1997 - Berkeley

At 8:30 a.m., I received a call from Milo Dowden regarding the Flerov articles for my volumes on the transuranium elements. We decided to delete articles 31 and 32 . The proofs should be ready in approximately 6-8 weeks.

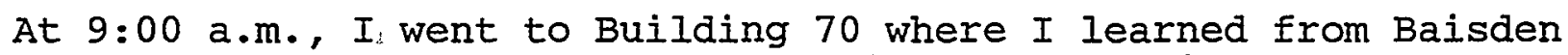
that they made two more mass spectrometric determinations of $X$ $(A=212) ;$ I suggested she report this result at the ACS Anaheim meeting in next March. Morrissey showed me Marsh's analysis of iodine isotopes yield from our $0.4-\mathrm{GeV}$ per nucleon $2 \mathrm{Ne}_{\mathrm{Ne}} \mathrm{U}$ bombardment; these will help us interpret our data.

At 9:30 a.m., Ray Commerford came by with correspondence from my secret files at SAN so I could refresh my memory on the NUMEC uranium loss case. 
Rod Banks dropped in at 11:45 a.m. to give me a progress report.

I received a telephone call from Minoru Tsutsui in the Department of Chemistry at Texas A \& M University. We discussed the possibility of encouraging forty or so individual chemical societies in various countries to support my idea of an international chemical society.

I had lunch in the cafeteria with Morrissey. I then walked down to Latimer Hall to attend in room 328 the pre-lab meeting of Chem IA instructional staff. After the quiz had been given, I circulated among my laboratory rooms $B, C, D$ and $E$ (on the second floor of Latimer Hall) until 3:00 p.m.

I met with my cluster group of chemistry freshmen in room 71, Evans Hall from 3:10-4:10 p.m., then I walked back up the hill.

I discovered that Abraham Friedman is no longer in Mexico and that he has been transferred to West Germany. I redirected a copy of Volume II of my Travels in the New World to him.

At 5:15 p.m., I went to Building 70 to talk to Thomas, Williams, otto and Morrissey.

At 5:30 p.m., I received a call from Joseph Hamilton, Vanderbilt University, regarding my upcoming visit to present the first Francis slack Lectures. We discussed the title of my speech and the arrangements which had been made for my visit on November 30-December 1 .

Wednesday, November 2, 1977 - Berkeley

I dropped by Building 70 to see Morrissey and Thomas on my way down to the campus. Morrissey told me the $220-\mathrm{MeV} 4 \mathrm{Ar}$ on $\mathrm{U}$ experiment seems to have yielded measurable yields of gold region isotopes-this is the important energy, near the barrier, for distinguishing between the fusion-fission and deep inelastic mechanisms in these recoil range experiments.

I attended Rollie Myers's Chem 1A lecture in PSL from 9:10-10:00 a.m. I then attended the meeting of Chem 1A lab instructional staff in room 124 Latimer until 10:40 a.m.

I walked back up the hill and met in my office with Nils wessell of the Swedish Council of America at 11:00 a.m. We discussed three main items: (1) membership of the committee I have agreed to join, (2) the newsletter they want to start publishing and (3) his retirement as chairman and inquiry into my becoming chairman.

At noon, Cyril Ponnamperuma called regarding information he had sent me for the Welch Conference. We also discussed the India workshop.

I held the Iuncheon meeting of my research group in my office from noon-1:15 p.m. Present were Morrissey, otto, Somerville, de Saint-Simon, Diana Lee, Cindy Lee, Nishida, Williams, Thomas, Baisden and also Pat Qyinn, Pat McGaughey and Bob Silva. Morrissey reported on our U plus $40 \mathrm{Ar}$ bombardments that took place over the weekend. The 
recoil ranges for gold region products for 221, 237, 250-MeV $40 \mathrm{Ar}$ are consistent with deep inelastic, not fusion, type reactions. 40 This is a very significant result! Control experiments with $259-\mathrm{MeV}: 40 \mathrm{Ar}$ on $\mathrm{Au}$ shows gold region products due to deep inelastic and rare earth products due to fusion reactions followed by fission. Otto spoke on the interpretation of these and related results. Baisden spoke on the mass spectrographic and chemicgl identification of "X," over the weekend (produced from $U$ plus $4 \mathrm{Ar}_{\mathrm{H}}$, 6-minute $11,6-\mathrm{MeV}$ alphas and 25minute $10.3-\mathrm{MeV}$ and $6.28 \mathrm{-MeV}$ alphas, as due to $212 \mathrm{Bi}$ and decay produfts. Somerville reported on his practice experiment, $248 \mathrm{~cm}$ plus $40 \mathrm{Ar}$, at the 88" cyclotron, to test the Decay in.Flight Detection Systems.

After the meeting, I discussed with otto and Morrissey plans for the early publication of our U plus 4 Ar recoij data and with somerville our abstract on the. S.F. isomer work ( $228 \mathrm{~Np}$ or $228 \mathrm{~Np}$ and $23{ }_{\mathrm{Bk}}$ ) for presentation at the APS meeting in San Francisco in January. I talked with Diana lee about some of her thoughts concerning transfer to a group in the Energy and Environment Division and assured her that she is needed in my group. I also told Morrissey I want him to stay on for a year as a post doc after he gets his degree in June and he agreed to do so. I then had a talk with Baisden about various interactions within my group.

I spoke with Pauline Newman, FMC Corporation, regarding the Petroleum Research Fund Initiative, the Japanese session planning meeting in Honolulu and the meeting of the Grants and Awards Committee in Washington on December 1 or 2 .

Today I dictated letters to A. M. Dowden at Dowden, Hutchison \& Ross, Inc. and enclosed with the letter the biographical sketch he requested for my, volume on the transuranium elements and Mansel Davies replying to his inquiry if I had previously seen the Bury paper. I replied that I could not recall seeing it.

At 3:15 p.m., I met with Mac Laetsch at the Lawrence Hall of science to prepare for the Advisory Committee meeting. I opened the meeting in the Conference Room at 3:45 p.m. Present were committee members Marian Diamond, Sherwood Washburn, David Schlegel, Keith Sexton, David Gale, David Miller, Donald Savage, David Auslander, Richard Merrill, Stuart Linn, E. Lee, David Cudaback, Laetsch and I. Also present were staff members Robert Karplus, A. Laubmann, Herbert Thier, George Moynihan, Bill Davis and Moira Kinney. We discussed the Executive Committee I appointed (Sherwood Washburn agreed to serve on it), the Development Plan for LHS and the NSF grant excluding funds for evaluation. I requested members to send me comments on the annual report. We then went to the auditorium to view the film, "Spaceborne" (1977), by Philip. Dauber, edited by Tom Valens.

Thursday, November 3, 1977 - Lafayette - Waco, Texas

Helen drove me to San Francisco airport where I boarded United Airlines flight \#1054, which left at 10:15 a.m. and arrived in Dallas at 3:00 p.m. I was met by Kenneth Busch, who drove me to waco, where I checked into the Sheraton Inn at 5:15 p.m. 
At 5:50 p.m., Kenneth Busch and his wife Maryanna came by and drove me to the nearby Baylor University campus where Kenneth and I went to the Student Union to attend a dinner preceding my GoochStephens Lecture. Present at the dinner were W. O. Milligan, Dr. and Mrs. W. R. Stephens (one of those whom the Gooch-Stephens Lecture honors), with me at the head table, and Dr. and Mrs. John Belew (he is Dean of Arts and Science and an organic chemist), Dr. and Mrs. William Toland (he is Dean of the Graduate School and a philosopher), Dr. and Mrs. Willie Lunsford (he is a biochemist), Dr. and Mrs. Jack Bond (he is Chairman of the Chemistry Department), Dr. and Mrs. Garrett Hill (retired, he used to work for American Cyanamid Company), Jim McAtee (x-ray chemist), Dr. and Mrs. Tom Franklin (he is an electrochemist), Dr. and Mrs. David Pennington (he is an inorganic chemist), Malcolm and Francis Dole, Leone Cockerell (retired from the chemistry department) and Dr. and Mrs. Virgil Tweedle (he is an organic chemist).

After dinner, I walked with Milligan to the Marrs-McLean Chemistry-Physics Building, where we went to the lecture hall, which was full (about 300 people). Busch made some welcoming remarks, then Milligan introduced me and I spoke, for about an hour, on "The Energy Problem," illustrated with 27 slides. I started with reference to my talk at Baylor ten years ago and my contact with Baylor in the 1950's when their football team came to Berkeley and beat us with players such as Cotton Davidson. My lecture was well received.

Just before my talk, I spoke with Dolores Coker (professor of Education at Baylor), sister of Luis Muga. My talk was followed by a question and answer period of about twenty minutes. We then went upstairs where refreshments were served and talked to a number of people and signed a number of autographs. Busch then drove me back to the Sheraton Inn where I spent the night.

Eriday, November 4, 1977 - Waco - Houston, Texas

I had breakfast in the Coffee shop and checked out. I then rode with Kenneth Busch to the Chemistry-Physics Building where I held a press conference in the conference room. There were questions on: our energy supply, short and long range; nuclear and its safety; danger of high-jacking; and nuclear proliferation. Present were Jack Thornton (Office of Public Affairs, Baylor University), Doug Williamson (Waco Tribune Herald), Darleane Lewis (radio station WACO), Iinda Solomon and Rush Field (KCEN-Channel 6) and Ben Blalock and Rich Bradfield (KWTX-Channel 10). I made individual statements for Channel 6 (Linda Solomon) and Channel 10 (Ben Blalock).

I then went up to W. O. Milligan's laboratory area where he has about six rooms. He showed me his excellent electron microscopes, $x-$ ray diffraction apparatus and $x$-ray fluorescence equipment (including a recently acquired Kevex detector). In his office, he has an extraordinary collection of early editions of books (non-scientific), including one of the world's best collections of Lewis Carroll.

We then went to the Student Union where I had lunch with a group on the second floor dining room (the same room as last night). Present were Baylor University President Abner McCall (president since 1961), Albert Pincus (organic chemist at Baylor), Gordon Teal (Texas 
Instruments), Malcolm Dole, Brian Slimp (a McAtee student now in industry), Dr. and Mrs. Garrett.Hill, William Toland, Willie Iunsford, Jack Bond, Tom Franklin, Leone Cockerell, David Pennington, Maryanna Busch and Charles Ruder (Chemistry Department). I sat next to Dole and Teal. In my conversation with President McCall, we talked about Baylor and UCB football fortunes.

I then walked with Bond and Teal to the Marrs-McLean ChemistryPhysics Building and visited the library awhile. Then we proceeded to the auditorium. Milligan introduced me for my lecture "Modern Alchemy," which was illustrated with 45 slides. Again the auditorium was full and my lecture was very well received. Afterward, Busch presented me with a plaque inscribed "Glenn T. Seaborg, Gooch-Stephens Lectures, Baylor University, 1977."

Busch drove Milligan and me to the Waco-Madison Cooper Airport. Here Milligan and I boarded a small Texas Aero plane (a twin-motored Cessna), with Garry Tarpley and Mr. Weaver as co-pilots. We left at 4:00 p.m. and arrived at Houston Air Center at Houston Hobby Airport at 5:00 p.m. We then rode in Milligan's car to Houston and went to the Houston Club, Governor Hogg Room, to attend the dinner of the Scientific Advisory Board of the Welch Foundation. Present were George Beadle, Carl Marvel, E. J. Corey, W. O. Miliigan and I. (Henry Eyring and William Baker were absent, Eyring talking to the local Sigma Xi group and Baker scheduled for later arrival.)

After dinner, the five of us walked to the Bank of the Southwest Building and went to the 20th floor, Welch Foundation, for the meeting of the Scientific Advisory Board. We went over the renewal proposals and voluntary proposals in a preliminary way. .After the meeting, Milligan drove us to the Shamrock:Hotel, where I checked in.

\section{Saturday, November 5, 1977 - Houston, Texas}

I had breakfast in my room, then rode in a taxi with $W .0$. Baker and Henry Eyring (Marvel, Corey and Beadle were in another taxi) to the Bank of the southwest Building. Here the six members of the SAB met at the Welch Foundation Headquarters with Milligan; beginning at 8:00 a.m. A photographer took some pictures of the board members in Jack Josey's office.

We considered further the renewal proposals and voluntary proposals to cut out some of the former to accommodate some of the latter.

We then walked to the nearby Lamar Hotel to have Iunch in the San Felipe Room. We stayed awhile after lunch to reminisce about historic people in science, political figures of now and previous times, etc. We then walked back to the Bank of the southwest Building and continued the meeting of the SAB with Milligan. We discussed speakers for the next Welch Conference (Nov.11-13, 1978):"Chemistry of Future Energy Resources," to be chaired by Eyring, topics for future Welch Conferences (chemistry in medicine, suggested by me, chemical structure by x-ray diffraction and other methods) and completed discussion of renewal and voluntary proposals. 


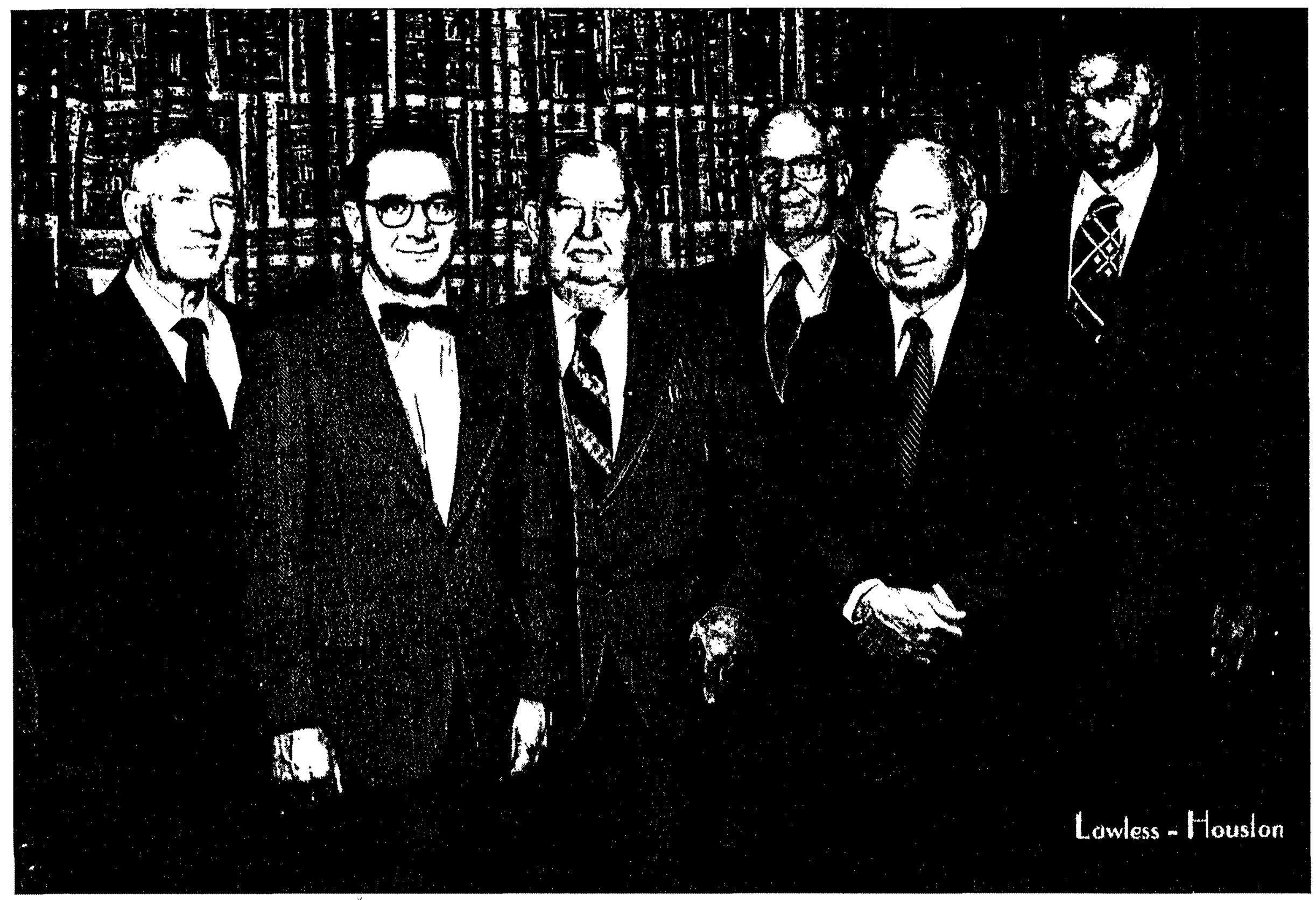

Robert A. Welch Foundation, Scientific Advisory Board: left to right-George Beadle, E. J. Corey, Carl Marvel, W. O. Baker, Henry Eyring and GTS: November 5, 1977. 
The seven of us had dinner at nearby Massa's Restaurant (on Rusk Street), then the board members returned by taxis to the Shamrock Hotel. I spent the evening in my room reading Chem 1A material.

Sunday, November 6,1977 - Houston, Texas

I had breakfast in the Terrace and Pavilion Restaurant with E. J. Corey. I later rode in a taxi with Henry and winifred Eyring and Bill Baker to the Houston Club. (I met Mrs. Baker [Frances] and their son Joe as we were coming out of the Shamrock Hotel.) At the Houston Club, in the Bluebonnet Room, we held the joint meeting of the SAB with the Welch Foundation Board of Trustees. Present were the six members of the SAB, Milligan and Trustees Jack Josey, Roger Wolfe, E. L. Wehner, Marvin Collie and Robert Doherty and Secretary-Treasurer Robert Wise. We presented our written report to the Trustees and it was accepted.

Wehner showed me a letter from Texas A \& M University Executive Vice Chancellor John C. Calhoun, Jr. requesting money from the Welch Foundation for renovation of equipment and upgrading of their $88 "$ cyclotron. Wehner said they are considering annual grants of $\$ 200,000$ for each of five years to come out of the 15\% of Welch income which is controlled by the Trustees. Josey joined us and I told them both that I support such aid.

Josey asked me if he should write Baron Stig Ramel to inquire about the status of attendance of the Collies and Dohertys at the Nobel Ceremony this year and I said yes.

After the meeting, we went into the dining room to pick up our food which we brought to the Bluebonnet Room. (The Eyrings left toward the end of the meeting to fly to Puerto Rico where Henry is scheduled to give the Union Carbide Curme Lectures.) Mrs. Elva Josey, Mrs. Nancy Collie, Mrs. Ada Doherty and Mrs. Jo Alice Wehner joined us for brunch.

After our brunch, Corey and I walked back to the Shamrock Hotel-about 4.5 miles--in an hour and 20 minutes. During the afternoon, I read Chem IA material and other work papers.

At $6: 30$ p.m., I took a taxi with Corey, Marvel and Beadle to the Esso (Humble) Building, then went up the 43 rd floor to the Petroleum club. Eyring and Baker didn't attend. Here there was a reception and dinner for the Trustees, Regents and grantees, and their spouses, of Rice University and the University of Houston, given by the welch Foundation. About a hundred people were present. From the University of Houston were Dr. Philip Hoffman, Dr. and Mrs. Jerome Peschke and Regents Mr. and Mrs. Leonard Rauch, Mr. and Mrs. J. Davis Armistead, Mr. and Mrs. Robert Lee Grainger and Mr. and Mrs. Willie Wells. The grantees from the University of Houston present were Dr. and Mrs. Ivan Bernal, Dr. and Mrs. Stanley Deming, Dr. and Mrs. Douglas Dyckes, Dr. and Mrs. Joseph Eichberg, Dr. and Mrs. Russell Geanangel, Dr. Karl Kadish, Dr. and Mrs. A. P. Kimball, Dr. and Mrs. Harold Kohn, Dr. and Mrs. Donald Kouri, Dr. and Mrs. R. I. Matcha, Dr. Simon Moss, Dr. and Mrs. J. Wayne Rabalais, Dr. James Richardson, Dr. Randolph Thummel, Dr. Marvin Vestal, Dr. and Mrs. Steven Welch, Dr. W. W. Wendlandt, Dr. 
and Mrs. Wayne Wentworth and Dr. and Mrs. Mark Willcott. Present from Rice University were Norman and Gene Hackerman, Dr. and Mrs. Frank Vandiver and Trustee E. D. Butcher. Grantees from Rice University present were Dr. and Mrs. John Allan Stewart Adams, Dr. and Mrs. C. D. Armeniades, Dr. Jorge Awapara, Dr. W. E. Billups, Dr. and Mrs. Philip Brooks, Dr. and Mrs. Robert Curl, Dr. and Mrs. Graham Glass, Dr. Paul Engel, Dr. and Mrs. J. L. Franklin, Dr. Joe Hightower, Dr. Huey Huang, Dr. and Mrs. Neal Lang, Dr. and Mrs. Edward Lewis, John and Mary Lou Margrave, Drs. Kathleen and Randall Matthews, Dr. and Mrs. Rex Mclellan, Dr. and Mrs. John Olson, Dr. and Mrs. Graham Palmer, Dr. and Mrs. Florante Quiocho, Dr. and Mrs. Frederick Rossini, Dr. and Mrs. Frederick Rudolph, Dr. George Schroepfer, Dr. and Mrs. R. E. Smalley, Dr. and Mrs. R. F. Stebbings, Dr. and Mrs. Frank Tittel, Dr. and Mrs. James Walker, Dr. and Mrs. Frederick Wall, Dr. and Mrs. Ernest Wenkert and Dr. Ion Wilson. Elva Josey, Nancy Collie, Ada Doherty, Jo Alice Wehner and Mr. and Mrs. Robert Wise were also present.

I sat at a table with Rice President and Mrs. Norman Hackerman, Houston President Philip Hoffman, Dr. and Mrs. Leonard Rauch and Dr. and Mrs. R. F. Stebbings (he is a space scientist at Rice).

Josey made a few welcoming remarks; he called on Wolfe, Doherty, Collie and Milligan for brief remarks. He then called on Wehner, who introduced Beadle, Marvel and Corey who made brief remarks. After dinner, Wehner called on me to give the address of the evening. I recalled my 1940 visit to Houston and Rice University, my attendance at the 1957 Welch Conference (when I joined the SAB), the growth of and present role of the Welch foundation in supporting basic chemistry in Texas (so that Texas is now the envy of the country), the importance of basig research practical applications of some of my basic research (Co68, TC ${ }^{99}$, I 131 and $238 \mathrm{Pu}$ and its use in cardiac pacemakers, potential power source for an artificial heart, source of power on the moon, $\mathrm{Am}^{241}$ in thyroid diagnosis, $\mathrm{Cf} 252$ in analysis, cancer therapy, etc.), my talk at the 500th Anniversary of Uppsala University on "Knowledge and Survival" and many examples from that talk on the need for knowledge and ending with a statement about the contributions of Welch-supported research in Texas to this needed knowledge bank.

I talked to Dr. and Mrs. Randy Rapaport (he was a Rapoport Ph.D. student in the late $1960^{\prime} \mathrm{s}$ ), who asked me to give their greetings to Rapoport. I rode back to the shamrock Hotel in a taxi with Corey (who is returning home tomorrow morning) and Beadle.

Monday, November 7,1977 - Houston, Texas

I had breakfast in the Nile Room with the speakers and discussion leaders for Welch Conference XXI, "Cosmochemistry." Present were Claude Arpigny, William Fowler, Cyril Ponnamperuma, John Reynolds, Richard Atkinson and John Wood--all speakers. Charles Townes, one of the scheduled speakers, was absent. Also present were Edward Anders, Jean Audouze, A. G. W. Cameron, A. H. Delsemme, Fred Hoyle, Richard Lemmon, Arno Penzias and G. J. Wasserburg who comprised the table discussion leaders group. Hans Mark was not in attendance. Also present were W. O. Milligan, Robert Wise, George Beadle, Raymond Mariella, Carl Marvel, Melba Gibson and Milligan's people who run the slide projectors, etc. Anders gave me a copy of his letter to Lew 
Monday, November 7,1977 (con't)

Keller suggesting that ORNL (especially stoughton and his neutron counter) work on verification of Flerov's report of SHE in meteorites and geothermal water.

I went to the ballroom, where I met Vitalii Goldanskii and we made arrangements for him to make some comments following Ponnamperuma's talk tomorrow morning.

The conference started at 9:45 a.m. with comments by Milligan and Wolfe. I then made my introductory remarks, using my prepared text, and introduced the first speaker, Claude Arpigny, who spoke on "On the Nature of Comets." Since his talk ran until noon, I postponed the discussion of it until after Fowler's talk this afternoon.

I talked to Oscar Sarabia about my talk to Houston area high school teachers and students which couldn't be arranged this time; he wants me to schedule this for a future trip to Houston.

I went to the Venetian Room to attend the Iuncheon for speakers and discussion leaders. Present were those lat breakfast this morning, plus Vitalii Goldanskii and staff working for the Welch Foundation to help with the conference. I talked to 26-year-old Maria Pessier, a chemistry-biology major at St. Thomas University (located about two miles from Rice University).

I sat next to Anders and Reynolds at lunch and we discussed the interpretation of Xe isotopes in meteorites. Anders wants to check Flerov's results on SHE in the Allende meteorite. I told him that Maynard Michel might make a mass spectrometric separation of a chemical fraction produced by Anders and Ghiorso might use this for heavy ion scattering. Anders will make a chemical separation and will be in touch with Michel and Ghiorso.

For the afternoon session, I introduced William Fowler, who spoke on "Nuclear Cosmo Chronology." He said the age of the solar system is $4.8 \times 10^{9}$ years. The time element synthesis is about $6-7 \times 10^{9}$ years, so the age of the galaxy is about ' 12 x $10^{9}$ years. "Fowler's talk was followed by a period of comments, questions and answers, lasting about an hour-and-a-half, until 5:30 p.m.

Vitalii Goldanskii came up to my room and we had an interesting talk lasting about an hour. We discussed the Flerov situation, my Benchmark book on the transuranium elements and the Harvey-seaborg Benchmark book on nuclear chemistry (he will send some reprints), information to be used in my nomination of him for membership in the National Academy of Sciences, etc.

I attended the dinner in the Nile Room for speakers and discussion leaders. The Welch Foundation Trustees (except Wehner), Mrs. Josey, Mrs. Collie, Mrs. Doherty, Mrs. Wise, Milligan, Baker, Marvel, Beadle, Mrs. Anders, Mrs. Milligan and Goldanskii were present. During and after dinner, Josey called on the Trustees, SAB members, many speakers and discussion leaders, Milligan, Wise and Goldanskii to make some remarks. Fowler and Wasserburg made very critical remarks 
about the way the Welch Foundation distributes its research funds. They said the funds should be used to create centers of Excellence. They also criticized the way the University of Texas is operating. Josey responded with some rather harsh language. In my remarks, I defended the concept of helping a broad spectrum of educational institutions; I said we have also used some funds to build up Centers of Excellence using the Texas $A$ \& $M$ cyclotron as an example. Goldanskii spoke humorously, making reference to Russia's conspiracy in selling Alaska to the U.S. 110 years ago so that Texas would become the second largest state (or even the third largest should Alaska split in two). He suggested a bilateral treaty between the soviet Union and Texas so they could share some of the money.

I watched on TV in my room the second half of Monday night footbal1. The Baltimore Colts beat the Washington Redskins, 10-3.

Tuesday, November 8,1977 - Houston, Texas

I had breakfast in the Pavilion and Terrace Room with Paul Bartlett (now at the T.C.U.), George Beadle and Carl Marvel. I then went to the ballroom to preside over the welch Conference. I introduced Cyril Ponnamperuma, who spoke on "Cosmochemistry and the Origin of Iife." This stimulating talk was followed by short remarks by Dick Iemmon and Vitalii Goldanskii (who spoke on his low-temperature tunneling readings and their application to the origin of life out in space at low temperatures).

I had lunch in the Belvedere Room at a table with John Reynolds, Claude Arpigny, W. O. Milligan and Melba Gibson. Carol Triebel, a straight-A, junior year, chemistry major from Baylor was also present. Melba Gibson told me that the Welch Foundation has heard from Stockholm that the Collies and Dohertys can attend the Nobel Ceremony in 1978 (not this year).

I started the afternoon session at 1:30 p.m., a half-hour early, because of the many requests for time to speak as discussants and the need to vacate the ballroom at 4:00 p.m. to make ready for tonight's dinner. For the first half-hour, I held the discussion of Ponnamperuma's talk of this morning. Fred Hoyle, Edward Anders, A. G. W. Cameron, Arno Penzias, Jean Audouze and some audience members made comments. I then introduced John Reynolds, who spoke on "Isotope Cosmochemistry: The Rare Gas Story and Related Matters." He said he does not believe Anders's theory that the enormously high concentration of xenon isotopes in the Allende meteorite is due to an extinct SHE. After Reynolds's talk, I called on Anders (who defended his idea on SHE), Oliver Manuel (who attacked Anders's idea), Clayton Cameron (Rice University), Audouze, Wasserburg and Fowler.

After we stopped at 4:10 p.m., I talked with Andy Suttle, who told me that, partly on the basis of my luncheon meeting with them a year ago (with Helen), they have decided to buy a 42-MeV proton accelerator costing $\$ 6-7,000,000$.

I attended the reception (in the foyer) and conference dinner in the ballroom. About 1,030 people were present. I sat at the head table with Robert and Ada Doherty, Roger and Mrs. Wolfe, Jack and 
Elva Josey, Frances and William Baker, George and Marion Beadle, E. J. and Claire Corey, Henry and Winifred Eyring, Carl and Alberta Marvel, Robert and Mrs. Wise, Claude and Mrs. Arpigny, William and Ardiane Fowler, Cyril Ponnamperuma, John and Ann Reynolds, Richard and Rita Loyd Atkinson, Charles and Frances Townes, John and Mrs. Wood, Edward Anders, Jean Audouze, A. G. W. Cameron, A. H. Delsemme, Fred Hoyle, Richard Lemmon, Hans Mark, Arno Penzias and G. J. Wasserburg. Josey introduced the welch Trustees and their wives and the SAB members present. Milligan introduced the speakers and discussion leaders and then introduced Richard Atkinson, Director of the National Science Foundation, who spoke on "Research and Development and their Impact on Economic Progress." It was a good speech.

I talked to Anders and Wasserburg about Runcorn's preprint on the melting of the moon by a SHE; they don't agree with this. I told Anders that I don't want to sign his letter to Lew Keller urging ORNL to work on checking Flerov's report of a SHE in the Allende meteorite; I said I will talk to Michel and Ghiorso about working on his chemical concentrate of the meteorite. I also talked to Donald clayton (and his wife Annette) of Rice University. He did his work with willie Fowler and has been at Rice since about 1963. I spoke to Anne Bogel of Houston, a long-time friend of Anna Carlson (of Ishpeming) beginning with her stay in Charlestown, West Virginia.

Wednesday, November 9, 1977 - Houston, Texas - Lafayette

I had breakfast in the Pavilion and Terrace Restaurant with Vitalii Goldanskii. We agreed that I might send Alexandrov, the President of the soviet Academy of sciences (his term ends in November 1979), a telegram on the occasion of his 75th birthday on February 12, 1978. Goldanskii told me that Khokhlov, at that time Rector of Moscow State University, was in line to succeed Alexandrov as president, but died on August 8, 1977 as the result of an overly ambitious attempt to scale and ski on a very high mountain. Goldanskii hopes that I will accept an invitation to visit the Soviet Union as a guest of the Academy of Sciences during Alexandrov's presidency. He told me that Alexandrov and Markhov are very interested in Flerov's claims to the discovery of heavy elements including SHE.

I went to the auditorium where I introduced Charlie Townes for his talk "Isotopic Abundances in the Galaxy of the More Common Elements." His talk was followed by comments from Penzias, Audouze, Cameron and Wasserburg, some of whom spoke several times with responses by Townes, Dieter Heymann (of Rice University) and Goldanskii.

I had lunch in the Belvedere Room. Present were the speakers and discussion leaders and Wolfe, Wise, Milligan, Mrs. Anders, Goldanskii and members of the Welch Foundation staff and people helping run the conference. I visited the exhibit of guinea pigs and the exhibit of rabbits of the Rabbit Growers Association, who were holding a meeting at the Shamrock Hotel this week.

I checked out of the hotel and went to the auditorium where I introduced John Wood who spoke on "Ancient Chemistry and the Formation of the Planets." He citted results of Wasserburg's that indicate the presence of excessive ${ }^{2} \sigma_{\mathrm{Mg}}$ in some Allende inclusions proving that 
this meteorite came from a supernova of the order of a million years ago (because of the presence of one-million year radioactive $26 \frac{\mathrm{A} I \text { ). }}{\mathrm{a}}$ After the talk, there were comments by Cameron, Anders and Manuel. I made some closing remarks, thanking the participants and suggesting the conference was interesting and successful.

I took a taxi to the Houston International Airport with Charles Townes. We discussed the claim by Gould to the laser patent. We also discussed the University Professor situation and decided that they should meet once or twice a year to discuss ways in which we can give advice to President Saxon. Townes was scheduled for an American Airlines flight. I boarded National Airlines flight \#117, which left at 5:15 p.m. John Reynolds was also aboard. We arrived at San Francisco Airport at 7:00 p.m. Helen met me and drove me home. I spent the rest the evening reading the large stack of papers from my LBI office.

Thursday, November 10,1977 - Berkeley

I went over my accumulated mail with Pat and then went to the opening session (in Room 4205, Building 50B) of the Nuclear Science Program Advisory Committee meeting on the Bevalac/Bevatron program. Arthur Kerman, chairman of the committee, presided and members present included Fred Goldhaber, Bogdan Povh, Reinhard stock, C. J. Waddington and I. S. Schroeder. Bernard Harvey made the opening remarks and announced the appointment of Arthur Poskanzer as Director of the Bevalac/Bevatron research program. Poskanzer then spoke and described the bombardment schedule that has been worked out in cooperation with the bio-medical research group. After all the other competing claims for time had been allotted, about 2,000 hours of time for nuclear science remained for the fifteen groups. Therefore, he asked the committee to review the already scheduled bombardments. George Igo, Chairman of the Bevalac Users Association, then made a report on behalf of the association. Hermann Grunder then reported on Bevatron/Bevalac development. He mentioned design work on the third injector (low beta, not really a wideroe) and the low vacuum in the Bevatron $\left(2-4 \times 10^{-10} \mathrm{~mm}\right)$.

I went by Building 70 to talk to Morrissey, Thomas, de SaintSimon, Diana Lee and Matti Nurmia. Morrissey told me that de SaintSimon was attacked by Reinhard stock et al. after his talk at Monday's NSD Seminar. Nurmia described their successful identification of " $X$ " as $212_{\mathrm{Bi}}$. I also saw Maynard Michel and told him Ed Anders will get in touch with him regarding mass spectrometric separation of SHE from the Allende meteorite.

I attended Rollie Myers's Chem IA lecture in PSI from 11:10 a.m. to noon. At 12:30 p.m., I talked with Pete Goldschmidt. He called me to inquire if I would be willing to loan my "Spirit of St. Louis" award to the Medallic Art Company so they could design a new cast. He said I would be contacted by Ray Ruete. Pete also advised me that, since the first breeder reactor bill was vetoed, we would have to start all over with authorizations with the Department of Energy. Ray Ruete called later; I agreed to loan the award to them. 
I had lunch at the lower level of the cafeteria with the members of the Basic Energy Sciences Panel of the Department of Energy and others, including Leo Brewer, Gus Donough, Gerhart Friedlander (Executive Secretary), Richard Taschek, Alex Zucker, Martin Blume, Kenneth Kliewer, Albert Narath, Michael Nevitt and Julian Nielsen, plus James Kane, Daniel Miller, James Coleman, Elliot Pierce, George Rogosa, Ryszard Gajewski, and Earl. Hyde, Joe Cerny and David Shirley.

Kenton Moody came by to get signed up to work with me as my graduate student.

I met with Ken Thomas in my office for about an hour to disguss his Ph.D. thesis research program. He will emphasize ${ }^{238} \mathrm{U}$ and ${ }^{248} \mathrm{Cm}$ targets bombarded with $\mathrm{Kr}$ and $\mathrm{Xe}$ ions to get yields of actinides produced by deep inelastic reactions, at the same time looking for new beta-emitting isotopes produced mainly by quasi-elastic reactions. We also discussed interpersonal relations within my group.

Walter Ioveland and Robert Kraus arrived by car from gregon State University at 4:00 p.m. to participate in this weekend's ${ }^{48} \mathrm{Ca}$ bombardment experiments.

My correspondence today included: a letter (attached) to Joe Cerny in support of the advancement of David Shirley to Professor, Step VI; a letter to Francis Bonner regarding my visit with Ragnar Ohlson, President of the Swedish Chemical Society, about the formation of an international chemical society; a letter to Lincoln Constance indicating that I would not be able to attend a meeting (November 30 ) of Faculty. Mentors of the Freshman Cluster Program as $I$ will be lecturing at Vanderbilt University; and a letter to $S$. K. Runcorn saying that $I$ had received the manuscript he sent me.

I attended a. reception in the director's office and then dinner at the Inn Season Restaurant ( 1921 Grove Street) for the members of the Basic Energy Sciences Panel of the Department of Energy. Frank Asaro and the same people as those at lunch were present (with the exception of Joe Cerny). I sat at a table with Gerhart Friedlander, Daniel Miller, James Coleman, Alex Zucker, Michael Nevitt, Kenneth Kliewer and Frank Asaro.

Friday, November 11,1977 - Berkeley

I conferred with Margie Hollander about Met Lab Section C-I history questions.

At 9:00 a.m., I attended, in the Building 70A conference room, the Round Table Discussion of the Bevalac/Bevatron Program Advisory Committee. Arthur Kerman, Fred Goldhaber, Bogdan Povh, Reinhard stock and $C$. J. Waddington as PAC and Round Table members were introduced by Arthur Poskanzer. Doug. Greiner first gave a summary of heavy ion peripheral collisions, then Andres Sandoval spoke on heavy ion central collisions.

I walked down to campus for my office hour from 10-11:00 a.m. in 446 Latimer Hall. I taught my Chemistry 1A discussion section in Room $E$, second floor of Latimer, from 11:10 a.m. to noon. 
In Strict Confidence

November 10,1977

\author{
Professor Joseph Cerny, Chairman \\ Department of Chemistry \\ University of California \\ Berkeley, California
}

Dear Professor Cerny:

I am writing to sppport the advancement from Professor step VI to professor, special salary as a promotion for David A. Shirley.

Professor Shirley has been a pioneer in using hyperfine interactions of radioactive nuclei to study nuclear, solid-state, and chemical properties, employing weak, strong, and electromagnetic interactions. He played a major role among American scientists in the development of low-temperature nuclear orientation, Mössbauer spectroscopy, and perturbed angular correlations of gamma radiation. Shirley and his coworkers extended low-temperature nuclear orientation throughout the periodic table of the elements by the introduction of novel approaches such as quadrupole coupling, pseudoquadrupole coupling and the sternheimer effect. They oriented transplutonium nuclei for the first time, using the lanthanideactinide similarities.

Shirley and his associates discovered and explained the systematic variation of induced hyperfine fields at solutes in ferromagnets including the dramatic sign reversal in p shells. They determined many excited-state nuclear magnetic and quadrupole moments. Among nuclear symmetry properties, they were the first to observe alpha particle anisotropy from oriented transplutonium elements, conversion-electron anisotropies, and parity-violating asynmetry by inner bremsstrahlung. They developed gamma-ray thermometry near absolute zero. The method of nuclear magnetic resonance on oriented nuclei was first developed at Shirley's laboratory, leading to the discovery of constant relaxation times in metals at $10^{I^{2}}$ deg Kelvin and their theoretical explanation.

Shirley was the first chemist to do Mössbauer spectroscopy, and he explained the isomer shirt in terms of detailed nuclear theory. His definitive article on isomer 
Shifts has been widely quoted. Shirley, with his associates, discovered relaxation in Ferrichrome $A$ and explained it using the Bloch Equations and they developed its large isomer shifts.

Shirley logged many "firsts" in gamma-ray perturbed angular correlations. meexnd his associates discovered the random-fields effect. They developed the digital analysis method, a very early application of digital Fourier transform methods in spectroscopy. They were the first to observe magnetic resonance via $\mathrm{PAC}$ and later extended it to in-beam nuclear reactions. In collaboration with J. D. Baldeschwieler, Shirley first applied PAC to biological systems. The most profound keoretical insight of shirley and his group in the PAC area appears in their NMR paper which generalizes the Torque Equation to arbitrarily high inultipolarity and explains nultipole splitting. With Haas, Shirley presented an experimental tour de force of PAC applied to chemistry, answering many long-standing questions. More recently, his group has used PAC to study supertransferred hyperfine structure.

His contributions have been widely recognized by numerous requests to present invited talks at international conferences. In 1967 he organized, together with E. Matthias, the important International Conference on Hyperfine Structure and Nuclear Radiations, and co-edited the Proceedings. This was the first conference that brought together the practitioners of nuclear orientations, Mossbauer spectroscopy, and angular correlations, and it has proved to be the first in a series of such conferences.

In 1966, Shirley's laboratory became the second in the world, after Siegbahn in Uppsala, to do x-ray photoelectron spectroscopy (ESCA). He has maintained the leadership position in this field among American scientists. He and his group introduced the study of valence-band density of states in metals by $x$-ray photoemission, an extremely important and widely-used method. Later he extended it to high-resolution studies and to studies of important insulators and semiconductors, such as diamond; silicon, and germanium.

Shirley's group first observed multiplet splitting in photoemission from solids and applied it to observe local spins above the Curie point of iron. Later they observed correlation states directly. They were also the first to compare ESCA shifts with rigorous theory. Later they played a leading role in developing accurate "potential model" theories for these shifts. They first showed that reliable atomic charges can be derived from ESCA shifts and they discovered the important relation between ESCA shifts and acidity. 
Dr. Shirley single-handedly organized the first major international conference on photoelectron spectroscopy in 1971 and later introduced ultra-high vacuum methods to $x$-ray photoemission, using it to determine densities of states of atomically clean surfaces, including the definitive electronic structure study in amorphous semiconductors.

A major advance was Shirley's discovery of large "extraatomic relaxation" energies in condensed phases and adsorbates. This effect greatly enhances the value of core-level binding energies and, incidentally, renders all past tabulations conceptually obsolete.

As his entree into ultraviolet photoemission, Shirley introduced high-temperature techniques $(10008 \mathrm{C})$, which allowed him to make the first direct observation of peaks due to "Initial-state configuration interaction" (i.e.) electron correlation), affording unique, new insight into the major problem of quantum chemistry.

Sensing the need for laboratory photon sources at energies between the conventional ultraviolet and $x$-ray sources, Shirley and comorkers have employed the active metals sodium and yttrium as anode materials. This has allowed them to study energy-dependent cross-sections of molecular orbitals in small moleculeg and determine their ( $s$ or p) atomic orbital symmetries directly.

Most recently, Shirley has turned to synchrotron radiation at the stanford electron storage ring. Again he and his group is pleying a pioneering role, this time in the use of photon beams of energies from $20 \mathrm{eV}$ to $200 \mathrm{eV}$ and above. They have studied absorption and fluorescence in atoms and molecules, anglemresolved photoemission from solids, and molecular orbitals of absorbed molecules. They have shown that carbon monoxide "stands up" when absorbed on the catalytic metals

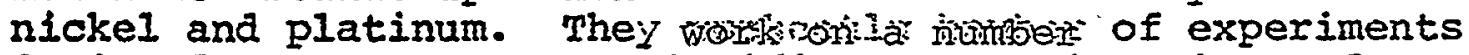
designed to answer other significant questions in surface chemistry and physics.

David Shirley is recognized as a brilliant and productive scientist of broad dimensions. I believe that he is richly deserving of a promotion to special salary status.

sincerely,

Glenn T. Seaborg

GTS : pq 
Friday, November 11,1977 (con't)

I then walked back up the hill and attended the closing moments of the Bevalac/Bevatron PAC Round Table Discussion.

I had lunch in my office with Walter Loveland, Dave Morrissey, Rollie Otto and Bob Kraus in preparation for Otto's report scheduled for 1:15 p.m. at the Bevalac/Bevatron PAC meeting. We then went to Room 4205, Building 50B, where otto presented to the PAC our Proposal \#422H, "Mass Yield and Recoil Range. Distribution Measurements with Relativistic Heavy Ions and Heavy Target" and described our Bevalac results obtained over the last year.

I agreed to write a letter of support for Bob Kraus's application for an NSF Fellowship. He will send me a copy of his application.

From 2-2:20 p.m., I met with Nikolai Mikheev. He gave me three books related to the 60th Anniversary of the Communist Revolution: USSR Science Over the 60 YearS, USSR 77 Sixty Soviet Years and Bolshoi's Young Dancers. I gave him the names of some people he might contact regarding actinide chemistry (Norman Edelstein, Kenneth Raymond, Neil Bartlett, Andrew Streitwieser and Bob Silva). He expressed his interest in attending the meeting of the American Nuclear Society in San Francisco, November 27-December 1 . I will try to arrange an invitation for him.

Patrick McGaughey came by to fill out his papers and to start work with me as a graduate student.

I went by Building 70 and the HILAC Building to see Otto, Morrissey, Loveland, McGaughey, Kraus, Thomas and Baisden in connection with their preparation for $48_{\mathrm{Ca}}$ bombardments now getting under way.

Williams showed me her results: She finds a definite 6-7-minute $\mathrm{Cm} \mathrm{Ka}$ X-ray decay component in her last $235_{\mathrm{U}}$ plus $1 \mathrm{~B}_{\mathrm{B}}$ bombardments, apparently due to $242 \mathrm{Bk}$ ! She will report on this at her NSD Seminar on Monday, November 21.

At 4:15 p.m., I met with Cliff Flower and Mike Gryszkowiec of the General Accounting office regarding the allegation that large amounts of highly enriched uranium-235 were diverted to Israel by zalman Shapiro of the Nuclear Materials and Equipment Corporation of Apollo Pennsylvania during the 1960's. A summary of our conversation is attached.

My correspondence for today included: a letter to Joseph Dietrich requesting him to arrange to have an invitation to the American Nuclear Society meeting in San Francisco sent to Nikolai Mikheev; a letter to Berta Karlik regarding Gerhard Winkler's desire to spend a year at Argonne--I said that I was not sure I could be of much help since most of my contacts in the Department of Energy have left the organization; a letter to Elliot Berman at the Center for Energy Studies at Boston University regarding his letter to me referring to an ad in Business Week by a number of eastern utility companies in support of nuclear power in which I am listed as one of the supporters--in my reply I indicated (although my specific consent was not 
November 11, 1977

MEMO TO THE FILE

Subject: Appointment with Cliff Fowler and Mike Gryszkowiec November 11, 1977 4:I5 p.m.

From 4:15 to 5:15 p.m. I met with Cliff Fowler and Mike Gryszkowiec of the General Accounting office who wanted to talk to me about allegations that Dr. Zalman Shapiro of the Nuclear Materials and Equipment Corporation of Apolio, Pennsylvania, diverted large amounts of highly enriched uranium 235 to Israel in the 1960's. They gave me a list of questions (attached) which I answered for them approximately as follows:

(1) I answered that I had rather complete knowledge and participated in many discussions.

(2) I believe that there is no evidence whatsoever that Zalman Shapiro diverted uranium to Israel. The losses were due to the intracacies of chemical processing and relaxed attitudes towards losses in waste streams because they felt the need to save money in order to have a profitable operation. Losses from one job were charged to a subsequent job until it all caught up with them on the Westinghouse job in the, 1960's.

(3) I said I met many times with Richard Helms to discuss many agenda items and recall only one meeting at which tine NUMEC matter was discussed. This was probably in the late 1960's. Helms seemed to be convinced of the theory that Shapiro was diverting material to Israel. When $I$ asked if he had evidence in addition to that which I had, he said that he did not.

(4) I said that I never met with a President on this matter but I did discuss it with Attorney General John Mitchell and National Security Advisor Henry Kissinger. This was at a later stage in 1969, 1970 and 1971 when the Department of Justice opposed a requested upgrade of Shapiro's clearance required because Shapiro was changing jobs. This led to a difference of opinion between John Mitchell and me. My talk with Kissinger was in order to appraise him of this difference of opinion. I also talked with secretary of state william Rogers because of the international implications involving US/Israeli relations.

(5) My answer to this question was "no".

(6) My answer to this question was "no".

(7) My answer to this question was "no". 
$1.2-$

(8) I said I did not know whether the AEC was getting all' the relevant information, certainly the Department of Justice was drawing different conclusions than the AEC. The AEC Commissioners were always unanimous in their position of disagreement with the Department of Justice.

(9) There was insufficient evidence to pull Dr. Shapiro's security clearance and he, was regarded by the AEC as innocent until proven guilty.

(I0) There were three reasons why the AEC continued to grant contracts:

1. There was insufficient evidence to prove any wrong-doing;

2. Dr. Shapiro and his co-workers were very competent in handling complex jobs, and

3. In some cases, NUMEC was the sole source of supply for the services.

(1I) I said I feel that a comprehensive and thorough investigation was made by the AEC.

Fowler and Gryszkowiec said that they are also planning to interview John Mitchell and Richard Helms. I urged them to interview Dr. Shapiro. They said that he is being represented by Edward Bennett Williams. I told them that Williams was representing Shapiro during our discussions with Attorney General Mitchell and that I had talked with Williams by telephone a couple of times. They said that $\mathrm{Dr}$. Shapiro refuses to have a meeting with them. I.indicated that I would be willing to help get in touch with Shapiro or Williams to try to convince them that such a meeting would be to Shapiro's benefit.

They said that they will let me check for accuracy their transcripts of our interview today.

Glenn T. Seaborg

GTS : pq

Attachments 


\section{QUESTIONS FOR DR. GLENN SEABORG}

re: NUMEC Incident

1. Could you please discuss your knowledge and involvement in the NUMEC matter during your tenure as Chairman of the Atomic Energy Commission?

2. What are your beliefs regarding the alleged NUMEC diversion?

If you can recall, what specific evidence supports your beliefs?

3. About when did your meeting with Richard Helms, Director of the Central Intelligence Agency take place? Could you please discuss what when on at that meeting?

Was there only one meeting or more? Specifics:

4. Did you have any discussions or meetings with any other top level Government people about the NUMEC matter (e.g., President, Attorney General, National Security Advisor)? If so, please discuss specifics: 
5. To your knowledge did any officials of the U.S. Government ever attempt to Timit the scope of investigative work being done by the CIA, FBI, or AEC into the NUMEC matter? Specifics?

6. Did you ever have any indication that (1) the U.S. Government acqui in any with a diversion of nuclear material at NUMEC or (2) that the NUMEC facility was a conduit for getting nuclear material to Israel?

7. Did you ever have any indication that the NUMEC facility was an Israeli backed organization established to get meterial to Israel?

8. Did you feel that the AEC was getting all of the relevant infomation on NUMEC from other Government sources like the FBI, CIA, and the White House? Specifics? 
9. Why didn't the AEC ever question or pull Dr. Zalman Shapiro's security clearances?

10. Why did the AEC continue to grant contracts involving weapons grade nuclear material to NUMEC in the. face of the questions and problems surrounding the facility and its President, Mr. Shapiro?

11. Do you fee] that a comprehensive and thorough investigation of the NUMEC diversion possibilities has even been done? Specifics?

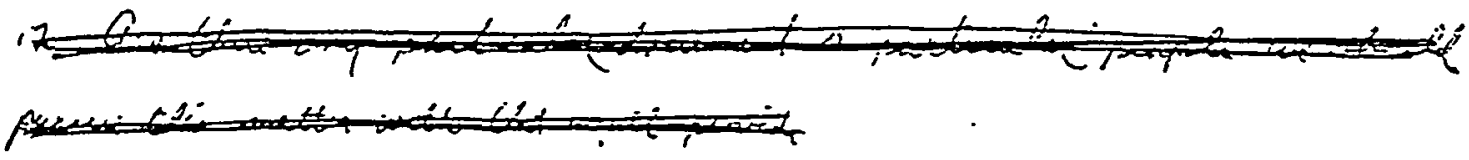


given for this ad) that I support all forms, "including nuclear energy," that will have to be used to solve our energy problem. I also sent to spencer Weart, Director of the Center for History of Physics, copies of the following: "Early Heavy Isotope Research at Berkeley, August 1940 to April, 1942" and "History of Met Lab Section C-I, April, 1942 to April, 1943." I also wrote that I did not know the whereabouts of Fermi's notebooks.

On the way home, I went by Building 70 and found Morrissey, Loveland, Kraus, Moody, McGaughey and de Saint-Simon watching the gamma ray spectrum from a successful, just completed, $\mathrm{Au}$ plus ${ }^{48 \mathrm{Ca}}$ bombardment at the SuperHILAC. I then went by the HILAC Building where Baisden was getting a U plus $48 \mathrm{Ca}$ bombardment to look for more $\mathrm{Bi}$ isotopes and Thomas was about to get a U plus $48 \mathrm{Ca}$ bombardment to look for $\mathrm{Np} 4 \mathrm{Pu}$, possibly $\mathrm{Am}$, isotope yields. I learned that we will now get a $248 \mathrm{~cm}$ plus ${ }^{48} \mathrm{Ca}$ bombarament to look for sHE. Hulet et al. were getting ready for a ${ }^{248} \mathrm{~cm}$ plus ${ }^{48} \mathrm{Ca}$ bombardment to look for short-lived volatile SHE.

I had dinner in the playroom with Helen. Dave returned home ill from Davis where he has been spending a couple of days.

Saturday, November 12, 1977 - Berkeley

Eric called at 8:30 a.m. from Paris (Roxanne Goldsmith's apart-ment). He said his friends Richard Sproul and AI Iindstrom have returned home to the U.S. He will see Roger Godino about a possible job at his ski resort next Wednesday and then go visit his friend in Switzerland. He, Richard and Al spent some time at the Goldsmith house in southern France. He has been getting along very well.

George Cardinet called about my talk on trails at the course he is organizing for Davis on March 9 and 10; we agreed to schedule my talk for the afternoon of Thursday, March 9 .

Helen and I drove to Berkeley; near the Claremont Hotel, to join a group to explore a possible Claremont Canyon Park. Present were Joe Engbeck, Fred Weekes, Tony Sargent (who works with Tom Budinger in Donner Lab), Robert Hotzapple, Harlan Kessel (EBRPD Board member), Karen Faircloth, Hulet Hornbeck and Hugh Richmond (UCB English Department). We hiked up the east side of the canyon and walked on to near the Marg home. We walked to the Chaparral Hill area and walked on University of California and State of California property (leased to EBRPD) to a hill overlooking the California school for Deaf and Blind, where we met Judy Haensel (and her 16-year old daughter and Weekes's son) who had a buffet lunch set up on card tables with wine, coffee and tea for us. (En route we had views of the Jordan trail, or fire road, in the strawberry Canyon area.)

I told Joe Engbeck and Harlan Kessel I would talk to Chancellor Bowker about getting University of California's cooperation in including University property in the claremont Canyon Park concept if they would get, with the help of Hulet Hornbeck, a written definition.

Helen and I walked with Joe Engbeck down a fire road to Stonewall Road and then on to Claremont Avenue where our car was parked. 
We drove to LBL where in Building 70 I found Otto, Morrissey, Kraus and Loveland. They told me their $\mathrm{U}$ plus ${ }^{48} \mathrm{Ca}$ recoil experiment was successful and showed that the products in the gold area are due to deep inelastic reactions not fusion-fission reactions. Bob's mother and father were also there visiting with Bob. (Williams was also there working on her data).

I went up to the HILAC Building and found Nitschke and Hulet and his people busy looking for S.F. from SHE from volatile fraction from $248 \mathrm{Cm}$ plus ${ }^{48} \mathrm{Ca}$; no S.F. have been observed but the bombardment was proceeding.

Helen and I then drove back down to the campus and stopped at Memorial Stadium where we saw the last few minutes of the UCB-USF soccer game, which USF WON, 3-2, in overtime. We then drove back home to Lafayette.

I had dinner with Helen in the playroom while watching news on TV. Dave, still ill, had dinner in his room. During the evening, I read proof on Met Lab Section C-I history (September 1943) and worked on the de Saint-Simon, Otto, Seaborg paper, "Iodine Isotopic MassDistributions from $212-340-\mathrm{MeV}$ Ar Induced Reactions on a Thick ${ }^{23} 8_{\mathrm{U}}$ Target."

Sunday, November 13, 1977 - Lafayette

In the morning, I worked on the de Saint-Simon "Iodine Isotopic Mass-Distributions from 212-340 MeV Ar Induced Reactions on a Thick 238 U Target" paper.

In the afternoon, Helen and I took a hike at Las Trampas Regional Wilderness. We hiked on the Mahogany Trail in the loop to the Chamise Trail, the Hiker's Trail, the Grassland Trail and the Valley Trail back to the parking lot.

Dianne called to make arrangements for Helen to pick her up at Davis Friday night to spend the weekend with us, including going to the Big Game at Stanford on Saturday.

During the evening, I worked on the final version of our paper "Search for Superheavy Elements Produced in the $136 \mathrm{Xe}+238 \mathrm{U}$ Reaction and an Upper Limit Cross section for the nat $\mathrm{Gd}\left(136_{\mathrm{Xe}} \mathrm{X}\right){ }^{212} \mathrm{~Pb}$ Reactions" and the manuscript for one of my Slack Lectures.

Monday, November 14, 1977 - Berkeley

I met with otto to discuss the papers I worked on over the weekend. Otto told me that he, Baisden and Diana Lee have chemicgally separated a SHE fraction from recoils from the long $248 \mathrm{Cm}$ plus ${ }^{48} \mathrm{Ca}$ bombardment over the weekend. I also met with Simon Chin.

I attended the 88" scheduling meeting from 10:30-10;50 a.m. Hulet and Mikheev were scheduled for Ma chemistry on the swing shift Monday, November 28 and Williams for $235_{\mathrm{U}}$ plus ${ }^{11_{B}}$ on the owl shift Tuesday, November 29. 
At 11:00 a.m., Norm Edelstein and I met with Robb Grover to discuss with him his beam work on astatine chemistry. I introduced Grover to Morrissey. Grover and I then walked down to the campus and attended the Chemistry Department Iunch in the Lewis-Latimer Room of the Faculty Club. Here Grover talked with Neil Bartlett and Kenneth Pitzer about radon and astatine chemistry planned for his atomic and molecular beam apparatus.

Grover and I walked back up the hill. I regeived a phone call from Darleane Hoffman and we discussed whether $250 \mathrm{Cm} \mathrm{S.F.} \mathrm{from} \mathrm{the}$ Mike Test can account for the S.F. the Dubna people observe in geothermal water and attribute to SHE; we decided this is possible.

Otto came in at 2:45 p.m. and we discussed his termination as a post doc with me sometime next spring. He wants to stay on at IBL in the Energy and Environment or Bio-Medical Division and this seems possible.

I talked with williams in my offige from 3:15-4:00 p.m. about her results (observation of a 6-7-minute $241,242 \mathrm{Bk}$ ) and her plans to discuss this at next Monday's NSD Seminar. We also discussed her plans to look for a position--she plans to get her Ph.D. next spring or summer.

I attended the NSD Seminar at 4:00 p.m. Alfred Goldhaber presented a talk on "High Energy Collisions of Nuclei: Bang or Burst?"

The Executive Committee of the Advisory Committee to the Lawrence Hall of science has been formed. Members of the committee are Iuis Alvarez, Martin Covington, Sherwood Washburn, Stuart Linn and $I$.

My correspondence today was composed of the following: I sent $W$. o. Milligan expense information in connection with my trip to Texas for the Welch Foundation Conference and SAB meeting and a corrected version of my introductory remarks for Charles Townes; I accepted an invitation to give the plenary lecture at the Actinide separations Symposium at the Pacific Chemical Congress in Honolulu in April 1979 in a letter to James Navratil at Rockwell International; and I wrote to I. F. O'Donnell at the General Atomic Company, declining an invitation to participate in a seminar in honor of Peter Fortescue's 65 th birthday, as I shall be out of the country.

Helen and I had dinner in the playroom and watched the Dallas Cowboys-st. Louis Cards football game. St. Louis won, 24-17. Dave ate in his room.

Tuesday, November 15,1977 - Berkeley

I wrote to Alexandr Gussev at the Soviet Encyclopedia Publishing House in Moscow with a slight alteration in my article on einsteinium for inclusion in the Great Soviet Encyclopedia. I sent six copies "Scientific Progress, the Universities, and the Federal Government" to Robert wise. I received today a number of letters from Robert Brasted which had been prepared for my signature. The letters were sent to the following coordinators and referees for the development of the "Chemical Education Orientation Guide-A Resource "for Foreign students 
Tuesday, November 15, 1977 (con't)

Studying in the United States:" Douglas Skoog (Chemistry, Stanford University; letter attached), Robert Osteryoung (Chemistry, Colorado State, Fort Collins), Lockhart Rogers (Chemistry, University of Georgia, Athens), Albert Lehninger (Physiological Chemistry, Johns Hopkins), David Metzler (Biochemistry and Biophysics, Iowa state, Ames), Emil Smith (Biological Chemistry, UCLA), Theodore Brown (Chemistry, University of Illinois at Urbana-Champaign), W. T. Lippincott (Chemistry, University of Arizona, Tucson), Emil Slowinski (Chemistry, Macalester College, St. Paul, Minnesota), F. A. Cotton (Chemistry, Texas A \& M University, College Station), James Huheey (Chemistry, University of Maryland, College Park), Stuart Tobias (Chemistry, Purdue University, West Lafayette, Indiana), Donald Cram (Chemistry, UCLA), Joseph Bunnett (Chemistry Board of Studies, UC Santa Cruz), Leallyn Clapp (Chemistry, Brown University, Providence, Rhode Island) and William Eberhardt. I also wrote Bob to let him know that I had done so.

I dictated a letter to John Bellama, Department of Chemistry, University of Maryland, in reply to his letter asking me to make an evaluation of Henry Heikkinen (for his possible promotion to Associate Professor). I said that I could not make an evaluation because of time constraints and therefore was returning the supporting material. I composed a letter to Daniel Wilkes at Lawrence Livermore to thank him for sending me the Jon Brenneis picture. I wrote a letter to Ionel Purica stating the I did not feel that I was well versed enough to express my opinion on the contents of his book the Laws of Modal Thought on Which Are Founded the Experimental Sciences. A letter was sent to N. N. Semenov, Academy of Science, Moscow, regarding the nomination of Britton Chance, Vitalii Goldanskii and Hans Frauenfelder for the Nobel Prize in Chemistry. I said that I think they are good candidates and that I shall make my opinion known to the Nobel committee. The last of the correspondence was to Joseph Berg at the National Research Council regarding the exclusion of Science News reporters from the Periodical Press Galleries. I wrote that I am asking Ted Sherburne to put it on the agenda for discussion at the next board meeting.

Baisden came in at 10:00 a.m. to discuss her research program and its deviation from my interests.

At 11:00 a.m., I went to room 203/70 and talked with Otto, Morrissey and Thomas about location of desks for our three new graduate students. We will add a desk to each of rooms 203 and 209, making a total of four in each room. Otto, Morrissey, Thomas and Rose Marie McFarland will be in room 203 and Williams, Marsh, Pat McGaughey and Ken Moody will be in room 209.

Pat Quinn drove me up to the Lawrence Hall Science where I met Harvey White, George Moynihan, Bill Davis and Mac Laetsch in Laetsch's office over a sandwich lunch. I asked Harvey to serve, at least for the first year, as the chairman of the LHS Development Committee that we are putting together. After considerable persuasion by Laetsch, Davis, Moynihan and me, he accepted. I then rode with Davis down to the campus; he was driving Laetsch to the San Francisco airport. 


\section{American Chemical Society}

INTERNATIONAL ACTIVITIES

COIviRATTEE
1155 SIXTEENTH STREET. N.W.

WASHINGTON. D.C. 20036

Phone (202) 872-4600

November 15, 1977

Douglas A. Skoog

Department of Chemistry

Stanford University

Stanford, CA 94305

\section{Dear Professor Douglas'A. Skoog:}

As an action of the American Chemical Society, a combined Council and Board Cominittee on International Activities was established a few years ago. It is my privilege to serve as Chairman of this Committee. One of our subcomittees is charged with investigating various facets and aspects of education of foreign students in this country. This subcomititee is chaired by Professor Robert $C$. Brasted of the University of Minnesota.

Many of us interested in and heavily involved with the education of young people from abroad have been concerned for the student who is admitted to either undergraduate or graduate programs in chemistry in this country, inadequately prepared or even worse, misinformed. The student may be unaware of the chemical, as well as mathematical and physical prerequisites of courses, there may be a lack of understanding of the intensity of study that is required to master materia he or she may know little of the actual duration of courses, there may be confusic by our different and often unique instructional methods, there may be a lack of familiarity of the role that the laboratory plays in certain of our courses, he or she may be unfamiliar with the problem solving, technique that is part of our usual chemistry course, there may be confusion in the grading practices (the differences between our literal and numerical systems). I have mentioned only a few of the factors. You, yourself may think of others.- Although a student may obtain some of this information from the myriad of catalogs and bulletins usually available upon request from our colleges and universities, I think you would agree that many of our students find such bulletins less than lucid. To expect a student fros another country to have at hand and to interpret properly, scores of these documents is unreasonable. Therefore, a recent action of the American Chemical Society's Board of Directors provided the necessary funds to produce a "Chemical Education Orientation Guide==a Resource for Foreign Students Studying in the United States." Hereafter, I'm going to refer to this document as "Guide".

Several points should be stressed before I attempt to explain the mechanics and what I sincerely hope will be your part in this production. First, this document will in no way attempt to describe or otherwise infer a "system" of education adaptable to or suggested for other countries. The introduction to this Guide will make this point perfectly clear. It is for those students who on their own, or at their own country's suggestion, are considering chemical edu= cation in the United States. Its utility should be evident whether the student desires a major in chemistry or in a curriculum that includes chemistry among the several prerequisites. Second, the International Activities Committee would like 
to think of this document as a service and a help to our friends abroad on behalf of the Anerican Chemical Society. ACS funding is therefore more appropriate than funds from a government or industrial source (as welcome as such funds might be for other purposes), to prevent foreign governments, ministries of education, or universities from feeling that the document is other than a truly altruistic gesture: One scientific society, the American Chemical Society, providing something helpful to the societies or educational systems of other countries. Finally, we feel that such a document potentially can diminish the number of students coming from abroad who do not have the proper prerequisites for our chemistry curricula. A better prepared and oriented student would be a happier student while here, and perhaps as important, one who will return to his or her own country with a warmer feeling for the United States, its people, and its educational system.

You as a distinguished educator, known for your expertise not only in the United States but abroad, realize that one of our strengths in education, in a sense, lies in the lack of regimentation from one institution to another. We do, however, strive for a certain commonality within the disciplines. It is these similarities that the Guide will attempt to portray for the foreign student.

An introduction by Professor Brasted, Editor of the Guide, will include some of the major philosophies of chemical education, at both undergraduate and graduate levels, similarities and differences found in the various tertiary education institutions (the two year colleges, liberal arts colleges, colleges and universities both private and state supported) will be briefly described. Suggestions will be included regarding application procedures, fees, assistantships, etc. Obviously we will not go into minute detail in any of these areas.

The classical subareas of chemistry will each have a Coordinator whose responsibility will be to produce the material according to a general outline. He or she will be aided by two Referees. The Referees will serve in part as editors, but more specifically, to supplement, suggest, and if needed, supply information that might have been omitted by the Coordinator. I am asking that you serve as a Coordinator*. We have planned in the format that each of the so-called subdisciplines would use approximately the equivalent of eight to ten printed pages. The total document we envision to be 120 pages approximately. The format will be an $8 \times 11$ with approximately 1100 words per page. Graphics are not now planned to be a major effort. Tabulations of data would be considered where you feel such to be the most efficient way of presenting data. It is quite possible that one or more of the subdisciplines will require fewer pages, a few might require more. The outline that follows obviously may be modified depending upon the requirements of the particular subdiscipline. If you feel compelled to carry the modification to extremes, however, I would hope that you would consult with Professor Brasted for obvious reasons of continuity. There would also be variations between the undergraduate and graduate programs, though in general, the format of the two should resemble one another.

I stress the fact that the same Coordinator and Referees will produce the undergraduate as well as the graduate programs for the same subdiscipline. I feel that this is necessary to maintain the degree of continuity and conciseness that would not otherwise easily be obtained.

* $\quad 0 \hat{I}$ Analytical and Instrumental Chemistry 
We are budgeted also to provide a multifold brochure that will serve as a reans of advertising this Guide. 'Professor Brasted will have the responsibility for the brochure's preparation with the help of the American Chemical Society's staff. This brochure will be given wide circulation, thus students not receiving the Guide directly, could be made aware of its existence and request one.

\section{UNDERGRADUATE EDUCATION IN CHEMISTRY}

More for the sake of organization than recognizing any unanimity of thought, I have designated six subdisciplines of undergraduate chemistry. These are: General Chemistry; Inorganic Chemistry; Organic Chemistry; Physical Chemistry; Analytical and Instrumentation; and Biochemistry.

\section{NARRATIVE SECTION}

a. Identify the year in which the subdiscipline is most likely to fit on the assumption that we are describing a four year curricula. That is to say, is it likely to be a freshman, sophomore, junior, or senior course?

b. What prerequisites would usually be expected, not only in chemistry, but almost equally important in the areas of physics, mathematics, or possibly biology?

c. What are the major subtopics that are part of this subdiscipline? This part of the document would not simply be a quoting of chapter headings of textbooks, but rather a somewhat more indepth description.

d. Under what conditions might we find major or even subtle differences in course offerings for persons pursuing chemistry as a major objective as contrasted to students using this particular subdiscipline, but perhaps a different course in preparation for another curriculum? (e.g. I think of the possible ancillary areas of agriculture, engineering, physics, etc.)

e. How does this undergraduate offering coordinate or mesh with graduate courses? Is it likely to be only one of several courses needed as a graduate prerequisite?

f. Are there unique features in problem solving as necessary learning techniques? Are there unique mathematical expectations that might not have been thought of in another system of education? I can speak from experience, as can other members of the committee, that often for instance, a student expecting to pursue organic chemistry does not realize that both at the undergraduate and graduate level, a reasonably high state of development is necessary in mathematics.

g. Is a laboratory usual in accompanying this course or subdiscipline? Is it an integral part of the course or is it pernaps a separate course offering? (A case in point might be "Mechanisms of Organic Reactions" as contrasted to "Analytical Instrumentation". The latter would be highly laboratory oriented). 
$h$. What fraction of the undergraduate curriculum does this subdiscipline occupy? I would assume that a meaningful fraction would total credits in chenistry= fraction

\section{GRADUATE EDUCATION IN CHEMISTRY}

The same subareas would be used in Graduate Education as for the Undergradual section with the obvious exception of General Chemistry. In some subdisciplines, upper division undergraduate courses are subscribed to by first year graduate students. If such is usual, mention sinould be made. The mathematical rigor of graduate level courses in areas often considered essentially non-mathematical in the home country is one of the less well understood requirements on the part of the entering foreign students as $I$ have mentioned just above. Again, from personal experience on the part of myself and members of the comittee, I would feel that this could be one of our major services provided to the foreign student.

One of the major differences of one university and another would be in the course requirements in graduate school. The iact that one university has an apparent lower course load than another does not negate the fact that a holder of an advanced degree from such a university would know less of that discipline because of this discrepancy. It would be expected that the narrative section would make mention of the course expectations in our graduate education.

I shall not reproduce the several subsections under Undergraduate Education, but only suggest that the section on "Graduate Education in Chemistry" follow the same general outline. Obviously there would be significant differences in the "narrative" section, and the Bibliography section which is described below would be considerably different as would the "Problems and Examination Questions" section reflecting a more indepth preparation.

\section{BIBLIOGRAPHY}

This section would be quite brief and would include only

- the essential but major texts used in the United States for the various subdisciplines in both undergraduate and graduate chemistry. No "modesty" is expected since you have been chosen because of your contributions to the literature, especially in well received texts. Large reference volumes or journals would not ordinarily be included unless they really, in your opinion, represent major (almost daily) learning resources.

III. REPRESENTATIVE PROBLEMS AND EXAMINATION QUESTIONS

This section should be one of our major contributions to our foreign friends' understanding and expectations of the nature of our course presentation in chemical education in the United States. It is one thing to recognize a topic that might be covered in a course and still another to be able to solve problems that are an inherent part of that discipline. I believe that most of us feel that the problem solving is essentially "the proof of the pudding". A variety of questions should be included in this section; multiple choice (since I 
find that this is often quite unfamiliar to foreign students), straight forward arithmetic problems, as well as those that we consider involve a reasonably high degree of sophistication in reasoning. The Coordinator and Referees would hopefully contribute equally to this section, with, of course, the Coordinator acting in the already designated role of editor for this section.

Finally, an appendix is planned with brief vitae of the Coordinators and Referees. Professor Brasted will compose this section, however, he would wish to have an input from you as to what you yourself would like to have included in this vitae. Other appendices are contemplated such as certain prerequisite non-chemist: subjects that might be important in the chemical education at both undergraduate al graduate levels such as certain physics, mathematics, or biological science course: that might be necessary for the appreciation of the chemistry courses.

I am fully cognizant of the length of this letter, but I believed it better to give you as much information as possible through this medium to help you decide on whether you can lend your support. An honorarium will be provided fully recognizing that we can never recompense you completely for the expertise and time that will go into this Guide.

I believe that the positive effects of this document will be considerable, not only in good will for our country and the American Chemical Society, but more importantly in terms of a better oriented student at the beginning of his or her training, and a more successful chemist, a more useful citizen in his or her own country at the end of the training. Another benefit could be a shorter training period because of diminishing the time to make up prerequisites, failures in cours work, and repetition of work that might have already been completed.

If you are willing to participate, and I certainly hope you are, please contact Professor Brasted directly at the address noted below. He is most anxious to complete the several panels for each of the subdisciplines so that they in turn may begin their work. In the committee's judgment, it seemed reasonable that the document can be constructed with your help and with Professor Brasted's editing without the so-called face-to-face meetings or working sessions even though such might provide opportunity for free exchange of ideas and information. We would prefer that the operation be undertaken essentially by mail with phone communication whenever such is needed. If Professor Brasted can provide more information, I hope-that you will feel free to call or write him.

Hoping for a favorable response, I remain,

Sincerelv yours.

Glenn T. Seaborg

Associate Director

Lawrence Berkeley Laborghory

University of California, Berkeley

Chairman - International Activities Com: American Chemical Society

Professor Robert C. Brasted

Department of Chemistry

University of Minnesota

209 Smith Hall

207 Pleasant St. S.E.

Minneapolis, $\mathbb{N} 55455$

612-373-2350 
I went to room 328 Latimer Hall to attend, from 1:00-1:10 p.m., the pre-lab meeting of the Chem $1 \mathrm{~A}$ instructional staff. During the quiz, I visited rooms B, C, D and E and later I circulated among them until 3:00 p.m.

At 3:15 p.m., I met ten of my cluster group students and Barbara Jacak at Hearst and Gayley Roads and rode in a bus with them to the HIIAC Building. I showed them the superHILAC and our experimental areas. I introduced them to sebesta and Yashita. Lee Davenport joined us and we showed them the connecting line and then walked down to the Bevatron Building where we showed them the Bevatron model and a view of the Bevatron. We then went to the Building 50 foyer where we showed them a cloud chamber. We finally went to Building 70 where I introduced them to Baisden, Nurmia, Nishida, otto, Thomas and Morrissey. Simon Chin, the freshman member of the group, showed them where he is doing his work. The group walked back down to the campus.

Wednesday, November 16, 1977 - Berkeley

I talked to Margie Hollander about Met Lab Section C-I history. I then attended Rollie Myers's Chem 1A lecture in PSI from 9:10-10:00 a.m. After, I went to the meeting of the Chem IA instructional staff in 124 Lewis from 10:10-10:30 a.m. I then walked back up the hill to my LBL office.

At 11:00 a.m., I spoke by phone with Glenn Sweitzer regarding the Council on Science and Technology for Development. He and/or Charles Dennison will come out to discuss possible Hewlett Foundation funding with Roger Heyns if a meeting can be arranged. They hope to get grants from three foundations, totalling $\$ 500,000$ over three years. I then spoke by phone with Roger Heyns who seemed to be pessimistic about the Hewlett Foundation's supporting the council but agreed to meet with Dennison and Sweitzer. I then called Charles Dennison and conveyed Heyns's pessimism in the possibility of funding from the Hewlett Foundation but Dennison was glad that I was able to arrange an appointment.

I went to Building 70 to discuss with Morrissey and Thomas some research projects for Pat McGaughey and Ken Moody (who will work on Bevalac and SuperHIIAC problems) and Rose Marie McFarland (who will work on chemistry of actinides to determine yields).

I held the regular biweekly luncheon meeting of our research group in my office from 12-1:15 p.m. Present were Ghiorso, Nitschke, de Saint-Simon, Baisden, Otto, Marsh, Morrissey, Diana Lee, Thomas, Silva, Nurmia, Williams, Somerville, Nishida, McGaughey, Moody and McFarland. We began with a champagne toast to de saint-simon, who is leaving to return to Paris this Saturday. An LBL photographer took a number of pictures of the assemblage and some of these included Bernard Harvey, Pat Quinn and Sharon Date.

I began the meeting by describing some of the calcylations Darleane Hoffman and I have made which indicate that $250 \mathrm{~cm}$ from the Mike explosion can account for the "SHE" reported by Dubna to exist in ground water. Then, Otto reported on the separation of a superheavy element fraction made by him, Baisden and Diana Lee last sunday from 
Wednesday, November 16,1977 (con't)

the forward recoils (caught on filter paper) from the ${ }^{48} \mathrm{Ca}$ plus ${ }^{248} \mathrm{Cm}$ (3.5-microamperes hours) bombardment. Nitschke reported on the search for volatile SHE by Hulet, John Illige and him during the same ${ }^{48} \mathrm{Ca}$ plus $248 \mathrm{Cm}$ bombardment; they found no SHE S.F. yet but found radon isotopes of mass numbers 219-224. The cross section for SHE is less than $0.2 \mathrm{nb}$. Baisden reported on her further work on the identification $8 \mathrm{f}$ the new $212_{\mathrm{B}}$ issomers ("X" complex). Morrissey reported on his $48 \mathrm{Ca}$ plus $\mathrm{Au}$ and ${ }^{48} \mathrm{Ca}$ plus U results showing $\mathrm{Au}$ region products due to deep inelastic and not compound nucleus reactions. Somerville reported on the observation, in his Decay-in-Flight apparatus, the detection of S.F. (?) tracks, from ${ }^{248} \mathrm{Cm}$ plus Ar, with half-life of $<2 \mathrm{~ns}$ and cross sections $270 \mathrm{mb}$.

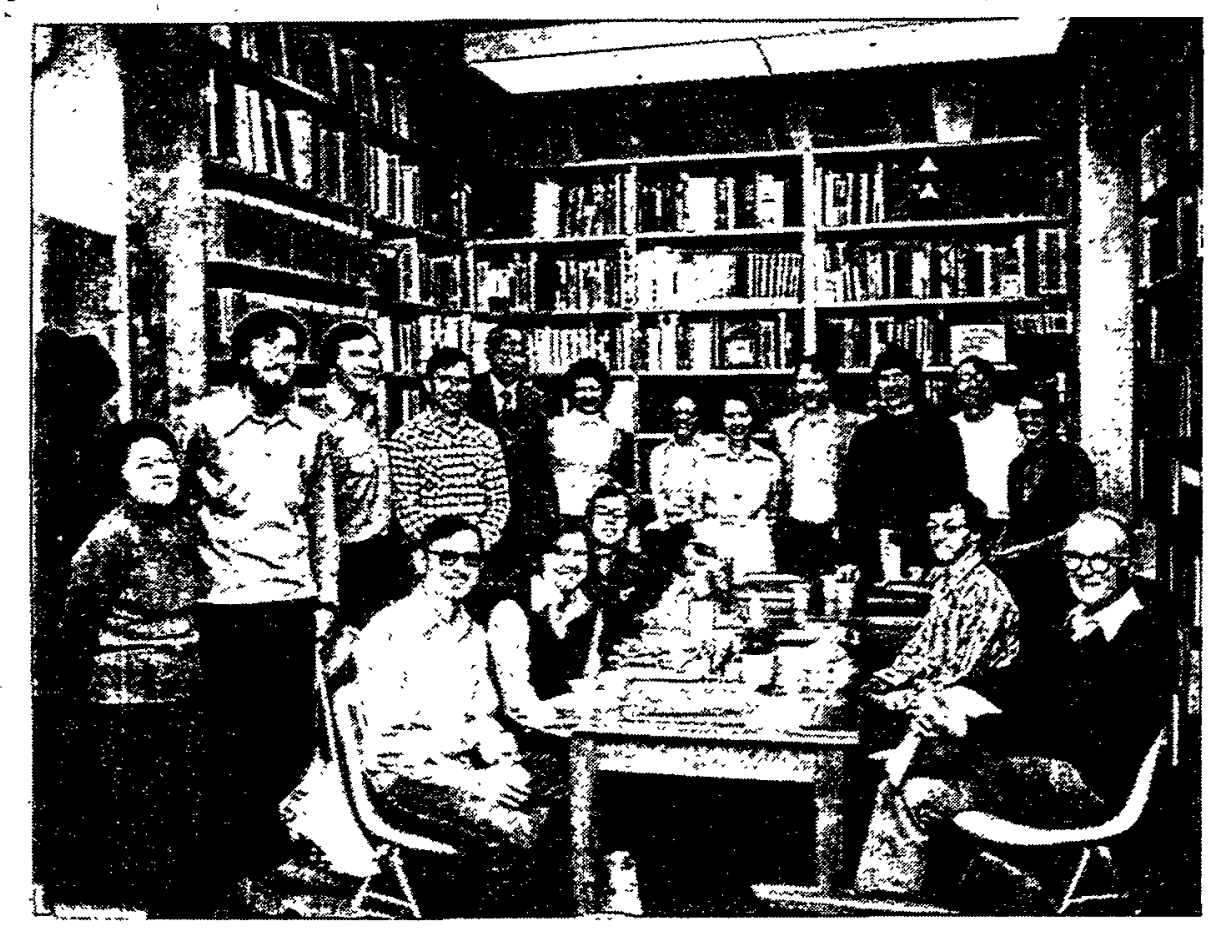

Farewell party at SHEIKS meeting for Michel de Saint-Simon. Standing from left to right: Sharon Date, Ken Moody, Mike Nitschke, Michel de Saint-Simon, GTS, Pat Quinn, Bonner Nishida, Diana Lee, Dave Morrissey, Roland Otto, Wayne Marsh and Trish Baisden. Seated from left to right: Ken Thomas, Kim Williams, Pat Somerville, Pat McGaughey and Bernard Harvey:

After the meeting, I talked to Ghiorso. We agreed that he, Dick Hahn, Darleane Hoffman and Gunter Hermann should write letters in support of the appointment of Matti Nurmia as a senior Scientist under the new LBL policy. Ghiorso also gave me the surprising information that Mikheev, Hulet, Lougheed and Baisden et al. are not finding evidence for Md(I) in their $254_{\mathrm{ES}}$ plus ${ }^{4} \mathrm{He}$ bombardments. This is leading to a problem because Mikheev refuses to accept such a result and interprets the data in favor of $\mathrm{Md}(I)$. 
Dick Frankel came by and I rode with him to the Kevex Corporation Building (in Foster City) to attend and preside over the annual Kevex Stockholders and Board of Directors meetings. President Richard Frankel, Edward Woo, Richard Cushing, Gary Kramer, John Colby and Rolf Woldseth sat at the table in front of the stockholders' group. We elected Kramer to the Board of Directors to replace Woo, who is retiring from Kevex.

Afterward, we went to Frankel's office to hold the meeting of the Board of Directors--Frankel, Cushing, Kramer and I. We elected Cushing a Director of Kevex International and Frankel as Treasurer to replace Woo. We also agreed to retain Woo as a consultant to Kevex, for a five-year period, at a stipend of $\$ 10,000$ a year, plus payment for medical insurance, plus travel expenses.

I visited among some Kevex people for a while and then rode with Ron Musket back to LBL. Ron told me that Isotope Products in Los Angeles (Carl Amlauer, President), prepares the $244 \mathrm{Cm}$ sources for their Alpha-X product.

I went to Building 70 to talk to otto and de Saint-Simon regarding our iodine isotopes paper, to Morrissey and Otto about McGaughey's research program, to Williams about her data and to Simon Chin.

During the course of the day, I dictated a letter to John Tuthill, Salzburg Seminar in American Studies, in response to his memorandum regarding Faculty and Guest Lecturers for Session 186. I said that the time I would be available to participate in their program would be while I am in Washington from March 3-6.

Thursday, November 17, 1977 - Berkeley

At 8:30 a.m., I spoke with Eric Leber in Congressman Mike McCormack's office in Washington regarding the reinstatement of the high intensity uranium beam line item in January 1978. He was not sure and said he would check and call me back. We arranged for Eric, and perhaps Mike McCormack and John Andelin, to join me for lunch on December 2 .

I met in my office with David Ridgway, Executive Director of CHEM Study, at 9:30 a.m. We discussed the Annual CHEM Study Report. I suggested that CHEM Study contribute $\$ 3,000$ to the Stanley G. Thompson Memorial Fund. Ridgway agreed to take the necessary steps to secure approval of my suggestion. He also agreed to send me a copy of the CHEM Study film "The Transuranium Elements" for my library.

At 10:10 a.m., I spoke with Richard Lemmon regarding his suggestion of a change to Sec. 3 of the Constitution of the American Chemical Society, Under Article II.

Arfin Lodhi called me at 10:15 a.m. to ask me to serve on the advisory committee for the symposium on superheavy elements, March 1011, 1978, at Texas Tech University. I agreed to serve on the committee but said that I could not participate. I suggested invitations be sent to Mike Nitschke, Lew Keller, Gunter Hermann and Sven-Gösta Nilsson. 
Thursday, November 17,1977 (con't):

At 11:00 a.m., I met with otto in my office. We decided to modify our request for equipment and put as the first priority a disk system for data processing with our pulse analyzers (cost about $\$ 8,000)$; this would replace our request for chromatographic equipment (cost about $\$ 15,000$ ). We also discussed further our iodine isotopes paper and his negotiations with Sidney Phillips of the Energy Division regarding a position to start sometime next spring.

My lunch at my desk was interrupted by a call from Lew Keller at ORNL. He and Dick Hahn are interested in hiring either Williams or Baisden if they are available in time (within six months). I also told him about Darleane Hoffman's and my consideration that show $250 \mathrm{~cm}$ or $240 \mathrm{Pu}$ might account for the S.F. observed by Dubna and attributed by them to SHE in ground water. I told him I had declined to sign the letter circulated by Ed Anders asking Keller to have ORNL look for SHE in the Allende meteorite to check on Dubna results.

I then went to room $191 / 70$ to attend a meeting to discuss new accelerators for LBL. Present were Dave Hendrie (chairman), Bernard Harvey, Hans Gutbrod, Dick Diamond, David Scott, Mike Nitschke, Hermann Grunder, Reinhard Stock, Lee Schroeder, Frank Stephens, Frank Selph and others. Committees under Gutbrod (high energy) and Scott (medium energy) were created to make suggestions for the types of physics that could be done. Stephens will work with Scott, Schroeder and Nitschke with Gutbrod. These committees will report to the main group which will meet once a month, the next meeting perhaps on December 15.

Joseph Hamilton, Vanderbilt University, called regarding plans for my visit on November 30-December 1.

My correspondence today included the following: a letter to Professor Charles Townes with ideas to help Vitalii Goldanskii's nomination as a Foreign Associate in the National Academy of Sciences; a letter to $\mathrm{H}$. G. Drickamer updating the information for Goldanskii's nominations next year by the Divisions of Chemistry and Physics; $a$ letter to Richard Erickson regarding the Stanley G. Thompson Memorial Fund, with a copy of the endowment record sheet (copy attached); a letter, approving the publication of one of my articles and inclusion of my picture on the cover of Revista Chilena de Education Quimica, to Rene Salame Martin in Chile; a letter to Bertrand Goldschmidt regarding his non-receipt of my history of the Met Iab; a letter of regret to J.P. F. Sellschop declining his invitation to me to attend and speak at the International Conference on "Dynamical Properties of Heavy Ion Reactions;" and a letter to F. B. Malik thanking him for calling to my attention his paper indicating very short half-lives for superheavy elements.

I went by room $203 / 70$ to talk to Thomas and Morrissey aboyt the possibility of having a target area for radioactive targets $\left({ }^{248} \mathrm{Cm}\right.$, etc.) in the direct Iine at the SuperHILAC. 
PURPOSE:

To assist deserving undergraduate students enrolled at the University of California at Berkeley. The scholarship is open to men and women, regardless of race, creed or national origin.

\section{CRITERIA:}

Recipients of The Stanley G. Thompson Scholarship, in addition to demonstrating academic ability, shall be selected from those students enrolled in the Department of Chemistry. The Fund will be administered as a Grant-in-Aid.

\section{SELECTION:}

The prospective scholarship recipients will be provided, screened and selected by the Department of Chemistry. The amount of the award(s) wi 17 be flexible and be dependent upon the individual need and available funds.

\section{ADMINISTRATION:}

Funds in the scholarship will be administered by the University of California, Berkeley Foundation, in accordance with established Foundation policy. The principal of the scholarship shall remain intact. Earnings from said funds will be used to award scholarships (Grants-in-Aid) under procedures and criteria hereby esitablished.

\section{CAPITALIZATION:}

$\$ 10,055$ September 13,1977

\section{AUTHORIZATION:}

Terms and provisions of the scholarship and its capitalization having been accepted by the Chemistry Department and the University of California, Berkeley Foundation through Secretary-Treasurer, Richard E. Erickson, The Stanley G. Thompson Scholarship is hereby established.

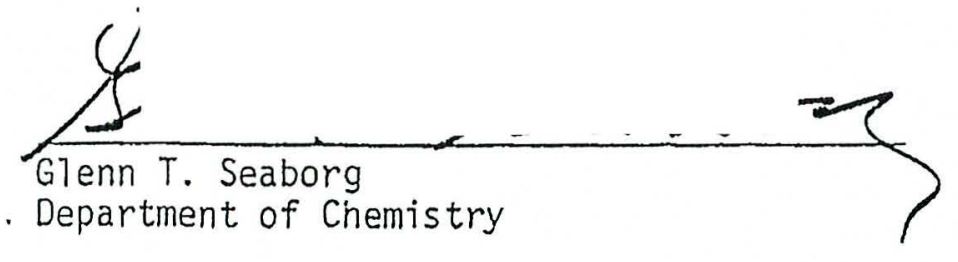


I walked down to the campus and went to room 444 in Latimer Hall to participate in the administration of the Ph.D. qualifying examination of William I. Smith as a member of his committee. The other members were Paul Bartlett, Richard Andersen, Alan Bearden (Medical Physics) and Robert Connick (chairman). I asked him some question about plutonium chemistry. He passed with a fairly satisfactory examination.

I walked back up to my LBI office. Pat Somerville dropped in to discuss his next experiments at the 88" cyclotron. He will measure alphas and $x$-rays from 1.9-hour $207_{\text {At produced }}$ from $206_{\mathrm{Pb}}$ plus $10_{\mathrm{B}}$ in preparation for doing the same for $234 \mathrm{Am}$ from $233 \mathrm{U}$ plus $10_{\mathrm{B} \text {. We }}^{\mathrm{P}}$ discussed membership of the Physics Department Ph.D. Qualifying Committee. He will try to get P. B. Price, H. M. Steiner, Al Ghiorso and me.

Friday, November 18, 1977 - Berkeley

My morning correspondence included a letter (copy attached) to Darleane Hoffman regarding our conclusions pertaining to "SHE" in ground water as reported by Dubna and a reply to Nils Wessell to say I plan to attend the meeting of the Swedish Council of America scheduled for March 1 in Washington, D.C.

I spoke with Ken Hulet at Lawrence Livermore about Francois David's visit and expressed my regret that I would not be available to meet with him since I will be in Montreal and Washington at the time of his visit (November 21 or 22 ). I said that I would be glad to have him work at the 88" cyclotron should be decide to move his apparatus to LBL.

At $8 ; 55$ a.m., I spoke to Stanley Kirschner regarding his subcommittee and suggestions for a list of "rank and file" chemists who will also receive the questionnaire. Kirschner read his list of names and I was able to add a few suggestions (Gordon, Koshland, Calvin, Campbell, Bloch and Bartlett). The full list now consists of the following names: analytical chemistry--Laitinen and Elving; environmental chemistry--Glen Gordon and Jack Winchester; biochemistry--Dan Koshland, Melvin Calvin, Davidson and Valley; organic chemistry--Djerassi and Breslow; physical--Bill Bailey and George Pimentel; chem education--Art Campbell, Jay Young and Bob Parry; industrial--Rossiter and Herman Bloch; and inorganic-Neil Bartlett.

Williams came by at 9:00 a.m. and I talked to her for about 45 minutes in preparation for her NSD Seminar next Monday afternoon and the schedule for completion of her Ph.D. thesis, job opportunities, etc.

I walked down to my campus office and held my office hour from 10-11:00 a.m. Iynn Eisenbrand came in and met with me for most of the hour. She is a student in Laura Nader's Anthropology 3 class and is writing a term paper on the questions of University of California's operation of the nuclear weapons laboratories. We covered the whole field of "public interest" protest groups and their role in trying to stop the nuclear arms race and the problems with their methods. 
November 18,1977

Dr. Darleane C. Foffman

Los Alanos Scientific iaboratory

P.O. Box 1663

Ios F.lanos, New Mexico 87544

Dear Darleane:

Is a follow up to our telephone conversation the other day, I thought I would summarize our conclusions (using some better values for the parameters).

If there were $10^{19}$ atons of $25^{\circ} \mathrm{Cm}$ proanced in the Mike explosion and if 10 of of these have been spread unifcrmiv over the earth's surface in the northern hemisphere ( $10^{8}$ square miles), we should have $10^{20}$ atoms of $250 \mathrm{~cm}$ per souare mile. If the Dubna scientists are observing 5 S.F. per day from their isolated chemical Eraction Erom ground water, this corresponds to about $2.5 \times 10^{7}$ ators of $25{ }^{\circ} \mathrm{cm}$ for a S.F. half life of $10^{4}$ years. Thus, the Dubna S.F. rate would correspond to collecting the $250 \mathrm{~cm}$ from an area of $2.5 \times 10^{-3}$ square miles.

Another possibility worth considering is the worldwice distribution of $5,000 \mathrm{Kg}$ of Pu produced from atomic bomb testing. If we assume that this is $18240 \mathrm{Pu}$, this corresponds to $10^{26}$ atoms of $24{ }^{\circ} \mathrm{Pu}$ which in turn corresponds to $10^{28}$ atoms of $24^{\circ} \mathrm{pu}$ per souare mile. Since the S.F. half Iife for $240 \mathrm{Pu}$ is $10^{7} \mathrm{x}$ that of $250 \mathrm{Cm}$, this would mean that the $10^{18}$ atoms of $240 \mathrm{pu}$ are equivalent to $10^{12}$ atoms of $250 \mathrm{~cm}$. Thus, the S.F. rate of $240 \mathrm{Pu}$ would be ten times that due to $25^{\circ} \mathrm{Cm}$. However $\bar{v}$ for $2{ }^{\circ} \mathrm{Pu}$ is 2.25 which isn't much better than that for natural U winich. I presume, is present as a more intensive source of S.F.

In order to thus account for the Dubna S.F. rate, we woula have to assume that the ${ }^{25}{ }^{\circ} \mathrm{Cm}$ or $2{ }^{\circ}{ }^{\circ} \mathrm{Pu}$ 1) reached the ground water sometime during the last thenty-five years; 2) dissolved and remained dissolved in the ground vater; and 3) was at least in part, separated on and recovered from the anion exchange resin that they used. 
The $25{ }^{\circ} \mathrm{Cm}$ (or $24^{\circ} \mathrm{Pu}$ or natural D) should, of course, pass through an anion exchange resin and herce be separated from Dubna's final fraction. Rowever it is aifficult to juage the efficiency of their process. Perhaps you can learn nore about this when you visit Jubna nert month.

With best regards,

Cordially,

Glenn T. Seaborg

GIS/sca

bcc: A. Ghiorso

11. Nitschke

R. Otto

D. Morrissey

P. Baisden

:. Nurmia 
I talked to the Chem $1 \mathrm{~A}$ Section in Room B on the second floor of Latimer Hall from 11:10 a.m. to noon.

I walked back up the hill to attend the NSD Program Committee meeting in 191/70. The luncheon meeting lasted until 12:50 p.m. Present were Bernard Harvey (chairman), Arthur Poskanzer, Albert Ghiorso, David Hendrie, Hermann Grunder, Frank Stephens, Homer Conzett, David Scott, Luciano Moretto, Joseph Cerny, Earl Hyde, John Rasmussen, Norman Glendenning and Wanda Smith. The committee reviewed with Conzett the future of his Polarized Particle Research--Harvey believes this should be phased out in view of budget stringencies and the committee didn't disagree. We elected Frank Stephens chairman of the NSD Advisory Committee and Sugihara chairman of the NSD Visiting Review Committee.

Rasmussen and I left the meeting and walked down to the campus to attend the physics qualifying examination of John Ioannou-Yannou. The committee consisted of Geoffrey Chew (chairman), Kinsey Anderson, John Rasmussen, Buford Price and me. Ioannou-Yannou passed with a below average performance. I asked him to describe deep inelastic heavy ion reactions, which he could not do.

I walked back up to my LBL office. Michel de Saint-Simon came by at 4:30 p.m. to say goodbye and I went with him to Building 70, where I spoke further with Williams about her Monday talk. I also talked to Nishida, who was working on Baisden's gamma ray data from her U plus $48 \mathrm{Ca}$ bombardment.

Simon Chin dropped in to seek my advice. He is having back pains and missed last week's Chem $1 \mathrm{~A}$ quiz. I suggested he cut down on his heavy extracurricular schedule (dormitory president, running for ASUC Senate, work in our lab, etc.). He will stop his work at IBI for a while if he wins the senate election.

Bernie Harvey dropped by to tell me about a potential danger in producing high density nuclear matter.

In the evening, I read proof on the final copy for October of History of the Met Lab, Section C-I. At 9:00 p.m., Helen drove to Davis, with Dave, to pick up Dianne. Dave stayed in Davis to attend, among other events, a party tomorrow night. Helen, Dianne and I watched on TV as Anwar Sadat arrived in Tel Aviv and was greeted by Begin.

Saturday, November 19, 1977 - Lafayette

At 10:00 a.m., Dianne (driving), Helen, Cathy Sherman and I rode to Palo Alto in our station wagon to attend the Big Game. As usual, we had our picnic lunch in the park of the Lucia Stern Palo Alto Community Center. Due to an overselling of tickets resulting in people in the aisles, etc., we didn't reach our seats until near the end of the first quarter. We sat just behind Ed Manske (Chicago Bears end of the late 1930's and end coach under Pappy Waldorf at Berkeley at the time of our Rose Bowl teams, 1948-50 and later) and his wife. Stanford beat Berkeley, 21-3, in a rather decisive fashion. 
With Dianne driving, we arrived home at 5:45 p.m. Helen and I had dinner in the playroom while watching IV news. Dianne ate later. In the evening, I worked on February 1944 of the Met Lab history.

Sunday, November 20, 1977 - Lafayette-Montreal, Canada

Helen drove me to the San Francisco airport. At breakfast, and on the way to the airport, we listened on the radio to the talk of President Anwar Sadat of Egypt to the Israeli Parliament in Jerusalem and part of the response of Prime Minister Menachim Begin. Sadat offered complete recognition of Israel.in return for complete withdrawal of Israel from occupied Arab lands.

I boarded American Airlines flight \#220, which left at 8:15 a.m. and arrived in Montreal at 5:30 p.m. During the stop in Chicago, I ran into Harold Lohr, who obtained his $\mathrm{Ph} . \mathrm{D}$. with our nuclear chemistry group during 1947-50. He was: at Argonne until 1954 and then left to work with the Iutheran Church. He is now Associate Executive Director, Division for Professionali Leadership, Lutheran Church in America, in Philadelphia, Pennsylvania. His friend Harold Johnson, also with the Iutheran Church, was with him.

In Montreal, I was met by Adi Eisenberg, who was on the faculty at UCIA (physical polymer chemist) from 1962-67 and came to McGill University in 1967. He drove me to the Four Seasons Hotel, where I checked into room 1111. I had dinner in La Paneterie in the hotel. I then took a walk in downtown Montreal. Many Christmas lights were in evidence.

Monday, November 21, 1977 - Montreal

I had breakfast in La Paneterie. I watched on TV the departure of Egyptian President Sadat from the Tel Aviv airport in Israel. Prime Minister Begin was there to see him off.

Adi Eisenberg came by and we walked, in the rain, a couple of blocks down Sherbrooke Avenue to the McGill University quadrangle and then to the Otto Maass Chemistry Building. Here we went to the Ruttan Room where I met with some Chemistry Department faculty over coffee and tea. Present were John Harrod (chairman), Jack Edward, Arthur Grosser, Arthur Perlin, Bill Chan, Rod Robertson, Jim Hogan and others. "I told them about some of my experiences with students problems as Chancellor, how I got started working with John Livingood, etc.

At 10:30 a.m., I went to the nearby office of Jim Hogan ( I visited: this area of the Otto Maass Building during my visit in June 1977). Hogan got his Ph.D. with Nathan Sugarman. He and his group are working on $p, \alpha \times n$ reaction yields, using radiochemical techniques, and have some interesting problems of interpretation. I mentioned to him the possibility of his taking a sabbatical leave in Berkeley and working with me on heavy ion reactions.

Hogan then took me to his nearby office, shared with Leo Yaffe and some of their co-workers, where I talked to Yaffe's post docs, Drs. J. I. Galinier and M. Diksic, and his graduate students, Cary Burns 
Monday, November 21,1977 (con't)

Philip Beeley (first year) and Chien Chung and his technician Riva Kaplan (she is working on an archeological project with Yaffe). They described their work and gave me a reprint on "Nuclear Charge Distribution, etc." by Dalmier and Yaffe (Journal of Inorganic and Nuclear Chemistry) and a preprint on "Nuclear Charge Dispersion Studies, etc." by Galimer, Diksic and Yaffe. They use the Monte Carlo deexcitation method of Bertini, Frenkel and Dostrovski, and one other and will compare the results in a forthcoming paper of which Yaffe will send a reprint.

Diksic then walked with me to the nearby McDonald Physics Building to the room housing the Rutherford collection which was shown me by F. Richard Terroux, the curator. Terroux worked at Cavendish Laboratory with Rutherford from 1927-31. He has been curator of the Rutherford collection since it opened in 1967 and is responsible for putting it together. There are 65 pieces of Rutherford apparatus, plus Rutherford books, pictures, notes, medals and letters. Rutherford was at MCGill from 1898 to 1907 . He was elected a Fellow of the Royal Society in 1903 and had his picture taken for Nature (for the Royal Society) with Otto Hahn's cuff links in 1905. He and his family (wife and one daughter) lived at 152 ste Famille street nearby in Montreal (the house is still there) from 1900-1907. His daughter married a physicist, Ray Foster, and they had four children. I signed the guest register.

I walked to the nearby McGill Faculty Club with Eisenberg, where I had lunch in the Harbour Room with Bernard Belleau, Edward, Yaffe, S. G. Mason and Don Patterson. We talked about the sadat visit to Israel and the nuclear work at the University of Montreal during the war, which I visited in September, 1944 and December, 1945. Yaffe said the building is still there (a wing of the main tower building) but the entrance to the wartime nuclear laboratory wing (now used for other functions) is closed off with a plaque containing the names of the workers at that spot.

I then walked with Eisenberg to the John Stuart Foster Radiation and Cyclotron Laboratory. I knew Foster through his many visits to Berkeley; he is the father of my friend Johnny Foster. The building was occupied (the first part of it) in 1946, the 82" synchro-cyclotron started operating in 1949. We went to the office of S. K. T. (Tommy) Mark, Director of the Laboratory since 1969. Foster was director until 1960 (he died in 1964); Robert E. Bell (now Principal and Vice Chancellor of McGill University) was director from 1965-69. Mark took me on a tour of the cyclotron, which produces $100-\mathrm{MeV}$ protons and recentIy 50-MeV deuterons.

John Crawford then came by and we walked to the nearby Rutherford Physics Building (it was still raining). We went to the Iounge Room where I met with Harry Iam (chairman of the Physics Department), Crawford, Bill Martin, Bob Sharp, Bob Gaskell, Andy Contogouris, Doug Stairs, Bernie Margolis (who asked me about IPA), John Robson and others. I told them about my experiences with the Fermi Award, Presidents Kennedy, Johnson and Nixon, my initial contact with John Kennedy, the background for my role in IPA, etc. 
Eisenberg came by and drove me to the University of Montreal where I saw the closed off entrance (with plaques listing the names of the wartime scientists who worked at this nuclear research laboratory).

Eisenberg then drove me back to the Four Seasons Hotel where I got ready for dinner and my scheduled talk this evening. Yaffe came by and I walked with him to the McGill University Faculty Club where I had dinner with Yaffe, Robert Bell, Eisenberg, John Harrod, Jim Hogan, Tommy Mark, Sven Orvig ( $a$ dean) and $W$. Shea. I sat next to Hogan and talked further about his spending his sabbatical with me at IBL next academic year. He has discussed this with his wife and they are considering it seriously. His sabbatical comes with full salary so he would need only travel expenses for himself and family (wife and three children). He told me that Eric Schneider, who just finished his Ph.D. with Vic Viola and who did undergraduate research with Herb Clark at Rensselaer in Troy, New York, would be a good post doc.

After dinner, we walked to the otto Maass Chemistry Building and went to the auditorium (the same one in which I talked at the time of my 1966 visit). It was full, despite the Metro and bus strike. Eisenberg made a few opening remarks after which Robert Bell described the background of tonight's lecture (it is called the Pervis Lecture) and the decision to dedicate it this year to Frederick soddy on the occasion of the 100th anniversary of his birth. Bell introduced me and I spoke for 50 minutes on "Reminiscences on Radiochemistry, Fission and Transuranium Elements," using 62 slides. I opened, on the basis of Bell's introduction, with comments on my voluntary relinquishment of my Berkeley Chancellorship and my Ishpeming-Negaunee story. MY talk was followed by a question-and-answer session. Bell then made some "thank you" remarks. Because he referred to next Sunday's Canadian football championship game of the Montreal Alouettes, I responded by describing my hiring of Marv Ievy (the :Alouettes' coach) as the football coach at Berkeley, and also, in response to his suggestion of naming transuranium elements after me, the New Yorker story about the naming of elements 97 and 98 . My talk was very well received.

Tuesday, November 22, 1977 - Montreal, Canada - New York

I took a taxi to the Montreal airport where I boarded Eastern Airlines flight \#173, which left at 7:10 a.m. and arrived at the new Baltimore-Washington International Airport (under construction) at 9:30 a.m. Dick Allen met me and I rode with him to GEOMET headquarters in Gaithersburg to attend the meeting of the board of directors, which began at 10:45 a.m. Present were George Milly (chairman), Charles Judkins, Richard Allen, Robert Campbell and Robert Trevisani. We voted to expand the number of directors by one member. We then voted to elect Henry luce, III, as a director. Iuce joined us at 11:00 a.m., having flown down from New York. We discussed further whether the American Health Systems Laboratory should be moved from Pomona to Boulder--this should be decided before June 30, 1978 and the move completed by December 31, 1978 .

MilIy reported on GEOMET exploration. In the exploration near Rawlins (Sage Creek, etc.), they have found anomalies which so far 
Tuesday, November 22, 1977 (con't)

show only $0.04 \%$ uranium, but acquired rights to about 100 square miles; Phillips Petroleum is doing some close-spaced drilling nearby. At Crooks Gap, Wyoming, Texas Gulf is doing some drilling as close as 100 feet grid spacing. Glenn Culver says Texas Gulf may soon announce the discovery of $7,000,000 \mathrm{lb}$. of uranium reserves here (up from $4,000,000 \mathrm{lb}$.$) , but intimates the possible presence of 30-40,000,000$ 1b. Texas Gulf is short of cash and wants to join with a utility as a financial partner but Leo Miller, Vice President for Exploration, wants to wait for more confirmation before moving in this direction. Presumably Fogarty, chairman of the board, would have to approve this. Gemex Associates will receive, by contract, $15 \%$ of net profits.

With respect to the utility combine: Philadelphia Electric is ready to go; New England Electric Power would go with GEOMET-Machta but wants to exclude Energy Associates, Ltd. (John Gray's Company); and General Public Utilities would join if a total of three utilities would cooperate as a combine. However, New England Electric wants Machta to put up all the money, with their furnishing none. Philadelphia Electric is willing to go it alone with GEOMET but would include Energy Associates, Itd.

The Italian AGIP should sign by early January, 1978. (total is about $\$ 1,200,000)$.

Negotiations are continuing with Dennison Mines and Steve Roman (Roman Corporation) of Toronto. Talks are also underway with Doug Tirex (Viet Nam) and French Schneider Atlantique Fund (German Investment Fund) and Saarburg (German Coal Company) are also interested.

GEOMET also has an exploration team in the Placerville area. They are acquiring land rights (about fifty claims of twenty acres each, so far). The Toronto people are interested in some specific property (might invest about $\$ 6,000,000$ ) and perhaps the Placerville property might be interesting to them.

Milly said Olivier Giscard d'Estaing has visited South Africa and found an interest there in possible uranium exploration with GEOMET. I reminded them of the widespread feeling against any South Africa investments and White House concern about the South African nuclear weapons intentions.

I talked briefly with Lee Odin, Milly's secretary, and Peggy Etzler, Allen's and Judkins's secretary.

We adjourned the board meeting at 1:45 p.m. Allen drove me to Dulles Airport, where I boarded United flight \#585, which arrived in San Francisco at 6:30 p.m.

Helen met me at the airport and we drove to University House to attend a dinner hosted by Chancellor and Mrs. Albert Bowker in honor of the Chinese High Education Delegation. We arrived late (7:15

p.m.). 
Tuesday, November 22,1977 (con't)

The delegation consisted of the following:

Yang Ting-pao (delegation leader)--Deputy to the Fourth National People's Congress, Vice Chairman, Revolutionary Committee of Nanking Engineering College, Professor, and former Vice Chairman of the Council, International society of Architecture. Specialty: Architecture.

Chang Wei (deputy leader, we met him at Tsinghua University)--Vice Chairman, Revolutionary Committee of Tsinghua University and former member of the Executive Bureau of UNESCO, Professor. Specialty: Mechanics.

Shen Ke-Chi (secretary-general, we met him at a luncheon at the Peking Duck restaurant)--Vice Chairman, Department of Physics, Peking University, Associate Professor. Specialty: Physics of Metals.

Kao Shang-yin--Vice Chairman, Revolutionary Committee of wuhan University, Professor. Specialty: Virus Microbiology.

Tsai Chi-jui--Vice Chairman, Revolutionary Committee of Shamen University, Professor. Specialty: Theory of Catalysts.

$\mathrm{Ku}$ Chao-hao--Professor, Department of Mathematics, Futan University. Specialty: Differential geometry and mathematical equation in physics.

Shih Ming-cheng--Associate Professor, Chiaotung University in Hsian. Specialty: Theoretical Mechanics.

Chin Han-fang (female)--Lecturer, Department of Education, Shanghai Teacher's University. Specialty: Education.

Yu Fu-tseng (interpreter)--Cadre, Bureau for Foreign Affairs, Ministry of Education of the People's Republic of China.

Ii San-Ii--Computer Sciences Department, Senior Lecturer Tsinghua University.

Also present were Albert and Rosedith Bowker, Jack and Carolyn Service, Ellis and Hilda May McCune (he is President of Hayward state University), Frederic and Carolyn Wakeman (Center for Chinese studies, and she teaches Subject $A$ ), Robert and Dee Scalapino, Joyce and Edward Kallgren (Center for Chinese Studies), Yuen and Buwei Chao, ShiingShen and Shih-Ning Chern, Jan,Berris (U.S. National Committee on U.S.China Relations), Mr. Hu (People's Republic of China Liaison Office in Washington, D.C.) and Andy Andreasen (a Graduate student at Stanford University in Chinese Studies).

I sat at a table with Shen -Ke-chi, who recalled meeting Mrs. Seaborg and me at the Iuncheon at the Peking Duck Restaurant, Ii SanIi, who is a senior lecturer in Computer Sciences at Tsinghua University, Mrs. Wakeham, Mrs. McCune and Andy Andreasen. Shen Ke-chi told me that whereas they used to admit students to the university who had 
Tuesday, November 22, 1977 (con't)

only a middle school education and based the admission on criteria other than examinations, now with the downfall of the "gang of four" they require a high school education and a rigid examination so that at his university only 700 were admitted out of 200,000 who took the exam.

After dinner, Chancellor Bowker made some welcoming remarks, including references to their forthcoming visit to Stanford University--a place that had treated us so badly this last weekend. Bowker then called on me, prefacing his remarks with the statement that $I$ would lead a delegation for the Scholarly Communication Committee in 1978 .

I opened my remarks by commenting that, while plans have not been formalized as yet, it is my hope to lead a U.S. delegation of chemists to the People's Republic in May 1978. Because of some laughter concerning my opening remarks (apparently due to a mistranslation), I took advantage of this and accused the translator (Andy Andreasen) of attributing something to me that I had not said. I explained that the same thing had happened to me during our visit to the People's RepubIic of China in 1973 when some translators took two to three times as long as I had taken to deliver my remarks to translate them. Both of these comments had the desired effect of evoking laughter. I then went on to speak seriously about the visit of Mrs. Seaborg and me to the People's Republic in 1973, expressing delight at meeting again an old friend like the distinguished vice Chairman of the Revolutionary Committee of Tsinghua University. I mentioned many of the People's Republic universities and research institutes that we visited and noted that this had resulted in a useful exchange of information.

After my talk, Yang Ting-pao gave a cordial response to Chancellor Bowker's and my remarks and expressed strongly the hope that I would indeed lead a delegation of U.S. chemists to China next year. He presented a hand-painted silk screen scroll (a landscape) to Bowker, then proposed a toast to our friendship. This was followed by remarks from Jan Berris expressing delight with the arrangements made at Berkeley for the visit and also proposing a toast. Then, finally, Chancellor Bowker made some concluding remarks and presented a book of photographs of the university to Yang Ting-pao.

The dinner was then concluded and Helen and I had an opportunity to meet each of the members of the delegation and had a warm meeting with Chang Wei and then Kao Shang-yin, who told me he worked with Wendell stanley and cordially invited me to visit wuhan University.

The members of the delegation left at 8:45 p.m. to proceed down to Stanford. Helen and I stayed on for a night-cap with the Bowkers, the Wakemans, the Scalapinos and the Kallgrens. There was an interesting discussion of the change in attitude in China toward education, etc., following the downfall of the "gang of four." Helen and I then drove home, arriving a little after 10:00 p.m. 
Wednesday, November 23, 1977 - Berkeley

I went over my accumulated mail and phone calls with Pat. My correspondence included: a letter to John McMinn at the Fachbereich Physikalische Chemie in West Germany, regarding the possibility of his visiting IBL the next time he visits the San Francisco area and also to thank him for sending me reprints of his publications; and a letter to Sam Teague declining his invitation to attend a dinner at the Chemist's Club at which time Herman Mark and Max Tishler will be awarded honorary membership.

At 9:30 a.m., Francois David dropped by my office to discuss with me his unsuccessful attempts to do mendelevium chemistry experiments at ORNL. He will apply for an exchange fellowship so he can come to IBL next summer to do the experiment in collaboration with Ken Hulet and me.

At 9:40 a.m., Bogdan Maglich called from Princeton to let us know that he had received a telegram from Professor Savitch of Belgrade regarding the scheduling of the Dubrovnik symposium. It has been set for september 17 through september 23, 1978 to accommodate my schedule.

I called Robert Stevenson, LBL, at 9:55 a.m. to discuss the possibility of arranging direct line bombardments. I explained the importance of these bombardments to our program. He said that the next shut-down will be in mid-April.

At 10:30 a.m., I met with Baisden to plan her next bombardments. She and Thomas will have U Plus ${ }^{136} \mathrm{Xe}$ bombardments on December 8 . "In January, she will have a ${ }^{24} \mathrm{Pu}$ plus ${ }^{136} \mathrm{Xe}$ bombardment to determine the yields of heavy actinides.

At 11:00 a.m., I met with Ed Stephenson to try to advise him whether he should go through with his move to Argonne (as a postdoctoral) or stay on at IBI somehow to work on his ${ }^{14} \mathrm{C}$ detection method at the 88" cyclotron (for archeological research). I suggested he assure himself of support, e.g. in the Earth Sciences Division, if he remains at LBI, which would interest him more than Argonne.

I went by to see Otto who told me that he, Morrissey and Marsh got two unexpected shifts of Bevalac bombardments on Monday. They had 25-Gev ${ }^{12} \mathrm{C}$ and bombarded $U$ (did iodine chemical separation), Ta (did recoil measurements) and Al (yield measurements of light nuclei to serve as a monitor).

Jorge Tamayo of San Juan, Puerto Rico, dropped in to ask me some confused questions about $250 \mathrm{Fm}$ for use in medicine as predicted from his theories of the periodic table.

Rose Marie McFarland dropped in to discuss the relationship between inorganic and nuclear research in her program.

Dave Hendrie came by to request me to serve as a reference for his application for a professorship at the University of Maryland to be in charge of their cyclotron. 
I attended a special luncheon meeting of the NSD Program Committee to discuss the possibility of diverting money from general plant, director's funds, equipment funds, AIP, to start this year on the SuperHILAC third injector. Present were Bernie Harvey (chairman), Earl Hyde, Art Poskanzer, Dave Hendrie, Lee Schroeder, Homer Conzett, Al Ghiorso, Frank Stephens, Dick Diamond, Hermann Grunder, David Scott, Mike Nitschke, John Rasmussen, Luciano Moretto, Joe Cerny, Richard Eggers and Herbert steiner. Following an hour-and-a-half of discussion, Ghiorso, Stephens, Diamond, Grunder, Scott, Nitschke, Rasmussen, Moretto, I and one other voted in favor of doing so.

During the course of the day, I received a call from Sheri Hadley of the Graduate Student Organization of the Department of Chemistry, asking me for suggested names of persons who might be willing to speak at their winter meeting and a call from John Gaustad in the Astronomy Department inquiring if I might be willing to write a letter of recommendation for David Cudaback. Iater in the day, Pat called Gaustad back to explain that I was not well enough acquainted with Cudaback or his work to write a letter.

I went to rooms 203 and 209 in Building 70 to talk to Williams (her talk on Monday went well), Thomas, McGaughey and otto.

I walked down to Latimer Hall to meet in room 444 to administer Roger Parry's Qualifying Examination. Iuciano Moretto (chairman), Samuel Markowitz, Schmuel Weiss (a year's visiting professor from Israel) and stanley Prussin are the other members of his committee. Parry has been working with Joe Cerny. He did poorly in our questioning on nuclear fundamentals. We decided to ask him to appear again for an examination during the spring quarter after he has taken Chemistry 123.

Helen drove to Davis this afternoon to pick up Dianne to drive her home for Thanksgiving. (Brian O'Konski came along for the ride to Lafayette.)

We received a letter from Eric from Switzerland where he is staying with his friend, Nils Eric Sorensen. He has arranged to start work on December 15 at Arcs, Godino's ski resort, to stay at least two months.

\section{Thursday, November 24, 1977 - Lafayette}

Thanksgiving Day.

I worked on papers in my study and then in the late morning I took a hike up to Iafayette Ridge. Jeanette and Ray Edwards came by during my absence to deliver two mince meat pies that she made for us. They were on their way to Union City to have dinner with Ray's son Keith and wife and sue Mathew.

We had our Thanksgiving turkey dinner in the dining room at 2:00 p.m. with neighbors the Shermans (Yehuda, Cathy, Yehudit [8] and Tamar [6]), Nat Iaks (Lynne and Bill's friend), Julie Nadich and Irving Furst (Dave's friends), Dave, Dianne, Helen and me. 
We called Pete, who was visiting his friend Ann Woodhouse in Newark, Delaware. Ann is getting a master degree's in American Culture at the University of Delaware (while working at Winterthur), which will be in addition to her Ph.D. in history from stanford.

We also called Lynne and Bill who were having their Thanksgiving dinner with the Roths at their home near Baltimore.

Jeanette and Ray arrived at about supper time and they, Julie, Irving, Helen and $I$ ate in the dining room. Dianne ate later. Jeanette and Ray spent the night in their camper in our driveway.

Friday, November 25, 1977 - Lafayette

Helen and I had breakfast with Jeanette and Ray. They left about $10: 30 \mathrm{a} . \mathrm{m}$. to return home:

I worked on checking placement of illustrations for volume III of Travels in the New World.

Helen, Dianne and I had lunch in the playroom. We watched part of the Oklahoma-Nebraska football game which oklahoma won by a large margin.

In the afternoon, Helen and I took a hike at Las Trampas Regional Wilderness. We hiked on the Chamise, Trapline, Gooseberry, Hiker's, Ridge, Grassland and Valley Trails. We met Al. Rothman of Lawrence Livermore Lab.

Dianne went to San Francisco in the afternoon and returned before dinner time.

Helen, Dave, Dianne and I had dinner in the playroom and watched on TV the USC-UCLA football game. USC won, 29-27, with a field goal in the last two seconds.

Saturday, November 26,1977 - Lafayette

I worked on my remarks "Reminiscences on the Discovery of Einsteinium and Fermium" for delivery at the symposium commemorating the 25th anniversary of elements 99 and 100 to be held in Berkeley on January 23, 1978. Helen and I had lunch in the playroom watching football on TV.

Helen went shopping with Dianne in the afternoon in Lafayette and Dave went to a meeting in San Francisco. I took a hike up to and along Lafayette Ridge.

I listened on the radio to the football game played at Toomey Field in Davis, in which Davis participated in a quarter final playoff for the NCAA Division II championship vs. Bethune-Cookman College of Florida. Davis won, $34-16$, and will play its next semi-playoff game next Saturday against Lehigh University at Davis. 
Sunday, November 27, 1977 - Lafayette

I took a hike around the rim trail at Lafayette Reservoir.

Helen and I had lunch in the playroom and watched on TV the Dallas Cowboys-Washington Redskins football game. The Cowboys won, $14-7$.

After the game, we called steve. He is getting along fine and will have his last final exam on December 19 and then will drive home for Christmas.

Helen, Dianne and $I$, and Dave a little later, had dinner in the playroom and watched the TV news, CBS's "60 Minutes," etc. Helen then drove Dianne back to Davis.

Monday, November 28, 1977 - Berkeley

Mac McSweeney called at 8:35 a.m. to inquire if I would be willing to fill a vacancy on the ACS Board of Directors from the west, to replace Gardner Stacy, for a one-year period. I replied that I could not as my schedule is so over committed that I could not take on any new duties or responsibilities and that I regretted having to decline his invitation.

Gardner Stacy called at 9:25 a.m. regarding my decision about the upcoming board chairman of ACS. I responded that I had not yet made up my mind. In particular he inquired as to my feelings about Mary Good and Bill Bailey, the two most likely candidates for the office (in his opinion).

At 10:10 a.m., I spoke with Rod Hader regarding my conversation with Gardner Stacy. He informed me that Stacy won the presidential election by a sizable margin. We also discussed the Quigley matter and the upcoming board meeting.

At 11:00 a.m., I went to Building 70 and talked to Otto, Morrissey, Thomas and McFarland, in room 203, and Williams and McGaughey, in room 209. I discussed the relevance of the work at McGill (Yaffe and Hogan) to our charge dispersion work here.

I spoke by phone with Dorothy Schriver at 11:50 a.m. She called to inform me that the General Motors Foundation has granted $\$ 500,000$ to Science Service to be awarded in five increments of $\$ 100,000$ each. This grant will make possible the "Glenn T. Seaborg Award," which will enable two students to attend the Nobel Ceremonies in Sweden. Dorothy suggested that Stig Ramel be invited to attend the Grand Award Banquet, where the first awards will be announced. I expressed my delight at the grant and the award.

I had lunch in the lower level of the cafeteria with Bob Brasted and David Ridgway. Brasted was here to attend, during the last three days, the meeting in the Unity of Science, etc., sponsored by Reverend Moon in San Francisco. 
Monday, November 28, 1977 (con't)

Dick Hahn, in the Bay Area for the ANS-AIF meeting in San Francisco, dropped in to see me at 1:00 p.m. Bob Silva joined us. I described to them my considerations with Darleane Hoffman to explain the Dubna SHE claims as due to $250 \mathrm{Cm}$ or $240 \mathrm{Pu}$.

In the mail today, I received a huge computer printout of gammaray data from Paul Patzelt of the University of Marburg and passed it on to Otto and Morrissey.

I called Gerald Garvey at ANL and learned that the Tom Bonner Nuclear Physics Prize will be given to Sergei Polikanov (whom I nominated) and V.M. Strutinski. I agreed to accept the award on their behalf if they cannot attend the New York APS meeting next April and to help pay their travel expenses by arranging for them to give talks at LBL if they can attend. Ghiorso and I discussed the helpful implications of this award for Polikanov in view of the way he is being treated by the authorities in the Soviet Union.

At 2:30 p.m., I spoke with John O'Brien who called me in an attempt to make some contacts for employment. He was with the Canadian Museum of Man. I suggested that he talk to Ed Cornish who maintains a bureau of futures research locations.

My correspondence today included the following: a letter to Vitalii Goldanskii, along with a picture, inquiring if he might be able to help me identify people in the picture; a letter to william Miller, Department of Chemistry, regarding his expressed wish to visit the People's Republic of China; a short cover letter returning a copy of a taped interview (made in 1965) to Hugh Oliver, managing editor of Interchange, The Ontario Institute for Studies in Education, Canada, and granting permission for its publication with the indicated changes made; a letter to G. J. Wasserburg thanking him for the reprints he sent me covering the results that he presented at the Welch Foundation meeting; a letter to Rear Admiral W. O. Gallery in response to his invitation to be the guest of honor at a Friday Recruit Graduation Review at Great Lakes explaining that my schedule would not permit my participation; and a letter to Pauline Newman regarding her contacts with international activities.

I went to the Nuclear Science Seminar in Room $3377 / 70 A$ presented by Gary Westfall titled "Energy Spectra of Nuclear Fragments Produced by High Energy Protons."

I went down to Building 88 to talk to Mikheev about the problem of extending his visa to stay an extra month (Soviet authorities gave delaying action) and his reaction to the disappointing results (from his point of view) that they are finding in Md chemistry; they are finding there is no Md (I) state. Bombardments (254 Es plus He) are scheduled for tonight. I also talked to Hulet about LLI hiring Baisden when her post doc with me is finished next summer, and collaborating with my graduate student, Rose Marie McFarland, on a program of studies on the chemistry of transuranium elements. I also talked to Baisden about her work on Md chemistry, etc. 
Helen and I had dinner in the playroom and watched part of the Monday night football game (the Oakland Raiders beat the Buffalo Bills). Dave was attending a speech by Eccles.

Tuesday, November 29, 1977 - Berkeley

I went by room $210 / 70$ and found walter Loveland there (he arrived last night) working with Diana Lee and Dave Morrissey on the pulse analyzer he brought down from oregon State University by van.

I also learned that Williams apparently had successful ${ }^{235} \mathrm{U}$ plus ${ }^{11_{B}}$ bombardments last night (this morning) in her work on Bk isotopes. on the other hand, Hulet, Mikheev, Baisden et al. did not have successful bombardments ( ${ }^{25} \mathrm{Es}$ plus $\left.{ }^{4} \mathrm{He}\right)$ for continuation of their Md chemistry experiments. They had planned to do fused salt distribution experiments to look for $\mathrm{Md}(I)$.

I held the regular luncheon meeting of the SHEIKS (usually held on Wednesdays) in my office. Present were Rollie otto, Walter LoveIand, Dave Morrissey, Pat McGaughey, Richard Eggers (post doc with Ghiorso-Nitschke), Saburo Yashita, Pat Somerville, Bob Silva, Diana Lee, Cynthia Lee, Bonner Nishida and Trish Baisden. Morrissey reported on the results to date on our recent $2.1-\mathrm{Gev} /$ nucleon ${ }^{12} \mathrm{C}$ plus $U$ and Ta bombardments. We are especially interested in the two distinct peaks in the distributions of iodine isotopes. He alş talked about our bombardment planned for tomorrow--2.1Gev/nucleon $20 \mathrm{Ne}$ plus $U$ and Ta. With $U$ there will be three targets for gamma analysis and one for iodine chemistry and gamma analysis. With Ta there will be targets for gamma and $x-r a y$ analysis and provisions to measure $F / B$ rations. Otto commented on the large ${ }^{4} \mathrm{He}$ yield from $\mathrm{U}$ plus 2-Gev protons and the relevance to our results. He also reports the observation of one $110-\mathrm{MeV}$ S.F. event from the SHE fraction from our ${ }^{248} \mathrm{Cm}$ plus ${ }^{48} \mathrm{Ca}$ bombardment earlier this month.

I walked down to the campus with McGaughey and Williams; the latter was pleased with her bombardments last night. McGaughey and I went to the pre-lab meeting of Chemistry $1 \mathrm{~A}$, section 2 instructional staff in room 328 Latimer from 1-1:10 p.m. We gave the students their last quiz for the quarter; I visited rooms B, C, D and E during the quiz and, later, during the laboratory working time until 3:00 p.m.

I walked back up to by IBI office and met, at 3:30 p.m., with Nikolai Mikheev. We discussed the failure to observe the Md(I) state. He thinks this is because they are working in alkaline solutions which cause Md(I) to precipitate as the hydroxide. He hopes to have his stay extended, but, if not, he will leave here on sunday to return to the Soviet Union.

My correspondence today included the following: a request for reimbursement for my trip to McGill University to Leo Yaffe; a letter to accompany the stenotype transcription of the Proceedings of Conference XXI to W. O. Milligan; a letter to Rene Salame Martin transmitting a manuscript for publication in Revista Chilena de Educación Quimica; and a letter to Randall sutherland forwarding an autographed picture and bank note and answering a few questions he posed to me. 
On the way home, I stopped by room $203 / 70$ to talk to Morrissey about interrelationships within our group. Walter Loveland came back from giving his talk at the ANS meeting in San Francisco and joined us at $5: 40$ p.m.

Wednesday, November 30,1977 - Lafayette - Nashville, Tennessee

Helen drove me to the Oakland airport where I boarded TWA flight \#442, which left at 7:00 a.m. and arrived in St. Louis at 1:30 p.m. We stopped at San Jose Airport (about the same size as Oakland Airport) en route. At St. Louis, I boarded Ozark flight \#918, which left at 2:15 p.m. and arrived in Nashville at 3:00 p.m. I was met by Joseph Hamilton, Physics Department, Vanderbilt University and rode with him to the Holiday Inn-Vanderbilt, where I checked in.

Hamilton arove me to nearby Vanderbilt University. We went to the Stevenson Center-Lecture Halls. I was interviewed on tape by Greg Anderson of radio station WKEA, on President Carter's plutonium policy; however, Anderson was so confused that this couldn't be a very useful interview. I also met Charles Campbell of the Associated Press and gave him a copy of the text of my talk "Our Energy Problem;" he stayed to hear my talk.

I also met Bill Dibble a former neighbor of ours in Lafayette. He is now 32 and is a photographer in the Nashville area. His brother David is a lawyer in New. Hampshire. His parents live in Hanover, New Hampshire.

Before my talk, Hamilton showed me the exhibit of early physics equipment in Stevenson Center, purchased in Germany and France about a hundred years ago by Landen $C$. Garland, Vanderbilt's first chancellor (a physicist).

My talk was in the main auditorium. Chancellor Alexander Heard (for a while) and President Emmet Fields (appointed a year ago) attended my lecture. The lecture hall was full, including many faculty that I met later at the reception and many students. President Fields first made some introductory remarks setting some background for this, the first, Francis G. Slack Lecture in Physics; he included some description of my honors. He then called on Joseph Hamilton, who introduced me with a thorough recital of my career.

I opened with an expression of appreciation to be the first Francis:Slack Lecturer, commendation of Slack's pioneering work in the nuclear fission reaction, reference to my voluntary termination of my Berkeley chancellorship and my role in the breakup of the Pacific Coast Conference. I gave my talk "Our Energy Problem," illustrated with 27 slides (shown by Gary Bomar, Hamilton's graduate student), followed by a question-and-answer period (with rather friendly, reasonable questions on my view of President Carter's energy policy, the safety of nuclear power, the possible degree of energy conservation, etc.). I talked about fifty minutes. My lecture was very well received.

After talking to a number of people who came down to see me, Hamilton took me up to the top floor of Stevenson Center to see the 
Edward Emerson Barnard Telescope, with which the Barnard Star was discovered nearly a hundred years ago by Edward Barnard.

I then rode with Hamilton to the Faculty Club where President and Mrs. Fields hosted a reception attended by many science faculty. Dr. and Mrs. Harvey Branscomb (parents of Lewis Branscomb; he is a former Chancellor of Vanderbilt) were present. I talked to Salim Bauna (an assistant professor who got his Ph.D. with David Shirley two years ago), Jod Tellinghuiser (who got his Ph.D. with Leo Brewer about eight years ago) and John Wikswo (an assistant professor working in medical physics--with an interest in artificial heart development work).

After the reception, I rode with Hamilton to nearby Julian's restaurant where I had dinner with him, Roy Albridge (who got his $\mathrm{Ph} . \mathrm{D}$. at the Radiation Laboratory, working with Jack Hollander in our nuclear chemistry group from 1956-1960), Charles Roos (a high energy physicist), A. V. Ramayya (high energy physicist) and Tom Pinkston (nuclear theorist). We talked about many nuclear chemists who did their Ph.D. work at Berkeley and I told them about some of my experiences in Washington as AEC Chairman. After dinner, Hamilton drove me to the Holiday Inn-Vanderbilt where I spent the night.

Thursday, December 1, 1977 - Nashville, Tennessee - Washington, D. C.

I had breakfast in the Inn's coffee shop. I found an excellent article in this morning's Tennessean, by Kathleen Gallagher, covering my talk yesterday.

Joe Hamilton came by and I checked out. I then rode with him to the Stevenson Center to a commons room. Here $I$ met with a number of people from the physics department. I was interrupted by a phone call from Iinda Pearlstein, a reporter from the Oak Ridger in Oak Ridge. She wanted to ask me some questions about charles Campbell's AP dispatch covering my talk yesterday. She read me the dispatch which included my statement that the Clinch River Breeder prototype reactor is overpriced. I responded that I had said this but had also said that I believe that, nevertheless, it should be built. I also clarified my statement that more support should, in addition, be given to other breeder reactors. In answer to another question, I told her I am talking today on superheavy elements and their place in the periodic table; this led to questions about the claim last year for the discovery of element 126 and $I$ explained why $I$ think this was an erroneous claim.

I returned to my meeting with physics department faculty. Present were John Barach, P. Galen Lenhert, Akunuri V. Ramayya and Stephen Reucroft. Then, at 10:15 a.m., students began to arrive until some 20-30 were present. For an hour we had a discussion about nuclear power, the prospects for employment for those present when they get their degrees, the most interesting fields of research today and in the future, etc. Included were graduate students Hans Kruse, Gary Bomar, Bill Nettles and Steve Jones and undergraduate students John Frazier, Deb Galloway and Fred Nixon. At 11:15 a.m., Hamilton came back and took me on a tour of his research area on the third floor of stevenson Center. He introduced me to a couple of his postdoctoral students (one from Portugal and one from Algeria). 
Thursday, December 1, 1977 (con't)

I then walked with Hamilton to Rand Hall where I attended a luncheon in a dining room hosted by Chancellor Alexander Heard. Present were James Surface (Executive Vice President), Dean Clanton (responsible for Academic Planning and Science Development Program), Melvin Joesten (Chairman of the Chemistry Department), Stanley Tarbell (chemistry professor), Joe Hamilton, Medford Webster (Chairman of the Physics Department), Oscar Touster (Chairman of Molecular Biology Department and Chairman of the Board of Directors of Oak Ridge Associated Universities), Lewis Silberman (representing Graduate Faculty Council, Professor of Jewish Literature), Bob Panvani (physicist) and Charles Maguire (nuclear reaction physicist). We had a wide-ranging discussion about the emerging problems of the Carter administration (energy problem, science advisory apparatus, mistaken approach to prevention of nuclear proliferation, etc.) and possible reasons for their ineptitude.

I walked back to Stevenson Center with Hamilton and others and went to the Lecture Halls to deliver my second Francis G. Slack Lecture in Physics in the main. lecture hall. The hall was nearly full with faculty and students. I was introduced by Joseph Hamilton.

I started with my reference to Ishpeming and Negaunee, described the relationship of what I was going to say to the early work of Francis Slack on nuclear fission, and gave my talk "Superheavy Elements and their Place in the Periodic Table," illustrated with 41 slides. Again the slide projector was operated by Gary Bomar, one of Hamilton's graduate students. I talked about an hour and my lecture was well received. It was followed by a question-and-answer session including questions on working with single atoms, the report of the discovery of element 126 and the production of quasi-molecular nuclei of high atomic number in the SHE region, etc.

After my lecture, I talked with some students. I then rode to the Nashville Airport with Hamilton. We passed by the new Grand opry House where the Grand Old Opry performances are staged on Friday and Saturday. nights, which Hamilton invited me to attend with him sometime to meet Minnie Pearl and the other performers.

Hamilton told me that Walter Greiner will be the second Francis G. Slack Lecturer in Physics next spring (moved up from next fall because Greiner will be at Vanderbilt on sabbatical leave). He said slack and his wife are on a world tour (he is 80 years old) so that is why he missed my lectures.

I gave Hamilton copies of my talks for publication as slack lectures. He asked me to send him some figures to go with "Our Energy Problem." He gave me some reprints covering his work. He may come to LBI for a collaborative experiment with Diamond and Stephens at the SuperHILAC next spring and Maguire may come to LBL for an experiment at the 88:" cyclotron a little earlier. I asked Hamilton to let me know about any post docs (with financial support) who might want to work with my group. 
Thursday, December 1,1977 (con't)

I boarded Braniff flight \#116 (the ticket agent said I had no reservation due to an oversight by my travel agent), which left at 4:20 p.m. and arrived at National Airport in Washington, D.C. at $6: 40$ p.m. I took a taxi to the Capital Hilton Hotel. Here I met my friend Jack Young who is now Deputy Undersecretary of the Department of Energy (Assistant to Myers). I checked into room W735.

I met the Gerson Goldhabers who told me they were on the way to the opening of the Accelerator Exhibit in the Museum of History and Technology in the Smithsonian. I decided to attend the opening also and took a taxi there. I talked to Bogdan Maglich and I told him I will attend the international conference on energy and environment in Yugoslavia and agreed to serve as head of the American delegation. Other members of the delegation that he has already contacted include Tihomir Novakov (of LBL), Alvin Weinberg, Schwenk (Director of Research at NASA, who would speak on the high temperature vortex uranium-fueled reactor) and Eugene Wigner; I also suggested Jack Hollander and he mentioned John Deutch (head of the Office of Basic Energy Research at DOE).

I spoke with John Deutch and told him about the episode by which Isabel displaced our High Intensity Uranium Beams facility. I also talked to Will Smith (Professional Staff Member, Senate Committee on Energy and Natural Resources). He said the actions of the New York people of putting the pressure on to fund Isabel so angered Senator Stennis that he insisted on dropping the uranium facility to teach the high energy physicists a lesson. He said that stennis may take over Senator McClellan's committee chairship, in which case senator J. Bennett Johnston of Louisiana would replace him as Chairman of the Subcommittee on Public Works; in that case, Johnston might be amenable to adding the $\$ 6 \mathrm{M}$ as a supplemental. Smith asked me to call him in mid-January to check on this possibility. He said the authorization for the uranium facility still is effective. I described our plan to shift funds to get started on the uranium facility and he said this is within his jurisdiction on the senate committee and it is okay with him. (Smith is a solid state physicist. He did his work at Washington University in St. Louis.)

I talked with Joe Kearney of OMB (he now holds Fred Schulz's job, which has cognizance over the DOE research budget--he was trained as a nuclear engineer at MIT) and Doug Pewitt (who works with Kearney at OMB--he a physicist from Florida state). Both Kearney and Pewitt assured me that the uranium facility is in the FY 1979 budget. They also assured me that intralab transfer of funds at LBL has their approval; in fact they commended such an action because it demonstrated a concrete step toward recognizing a priority item. (Kearney is the brother of the Kearney I met at Manhattan College).

Smith, Kearney and Pewitt all expressed indignation at the action of the New York group, recommending strongly that I inform the Brookhaven high energy physicists that the result of their action was the loss of our uranium facility. Greg Canavan, a White House fellow from DOE, also participated in these conversations and agreed with the conclusions. 
I talked to Ms. Elira Orly of Senator Hayakawa's office; I told her that I had learned that the lack of interest by members of the California congressional delegation made possible the action of the New York people in displacing the uranium facility. This disturbed her very much and she will look into it and talk to Katherine Bruner.

I explained to Henry Meyers (of Mo Udall's office) the background of the allegation of enriched uranium diversion by the shapiro firm. I said the allegation is absurd. He said Udall feels compelled to make an investigation.

I talked to Spencer Weart, Joan Warnow and Allan Needell of the AIP history project. Weart is writing a history of the French contribution to the atomic bomb project: Warnow said they hope to get financial support from DOE and a person at IBI to work on history.

I told Dave O'Kelley I will send him a copy of the letter I wrote to Darleane Hoffman regarding the alternate explanation of the Dubna SHE claim. He is doubtful that Lew Keller should undertake to check. this.

I talked to Ed and Elsie McMillan and Ed Lofgren and Raymond Birge and had my picture taken with them at the model of the Berkeley 27". cyclotron.

I talked to George. Temmer, now at Rutgers University--he left Florida state about 15 years ago. I also spoke with Ed and Mrs. Epstein (he is in the UCB political science department), who are in Washington, D.C. on a sabbatical. I then talked with Jim Kane, DOE, who told me our uranium facility has first priority in the FY 1979 budget. I told him what $I$ have learned about the Isabel displacing our uranium facility. He said the reprogramming of funds to get an early start in the uranium facility is okay with him.

[Back at IBL, Rollie otto sent Doug Greiner the equipment request form (copy attached) for our research group.]

Friday, December 2, 1977 - Washington, D. C.

I attended the breakfast meeting of the Chemical \& Engineering News Editorial Board in the Michigan Room. Present were Robert Parry (chairman), Herman Bloch, Bryce Crawford, Mary Good, Gordon Nelson, Gardner Stacy, Ernest Eliel, Albert Plant, Ernest Carpenter, Rodney Hader, Michael Heylin, Anna Harrison (later) and Raymond Mariella (later). The circulation of $\mathrm{C \& EN}$ is now about 130,000 . We adjourned at $8: 40$ a.m.

I then went to Caucus Room I (No. 509) to attend the meeting of the Committee on Grants and Awards. Present were Pauline Newman (chairman) Henry Hill, Bradford Stanerson, Patricia Figueras, Ray Mariella (part time), William Bailey, Robert Fox, Paul Smith, Robert Henze, Justin Collat and Warren Niederhauser (later). G. D. Searle Company has decided to discontinue sponsorship of the ACS Award for Nuclear Applications in Chemistry, as communicated to the ACS by retiring Searle president John Kuranz and Searle president Richard $E$. Schmidt. We agreed to change the name to the ACS Nuclear Chemistry 


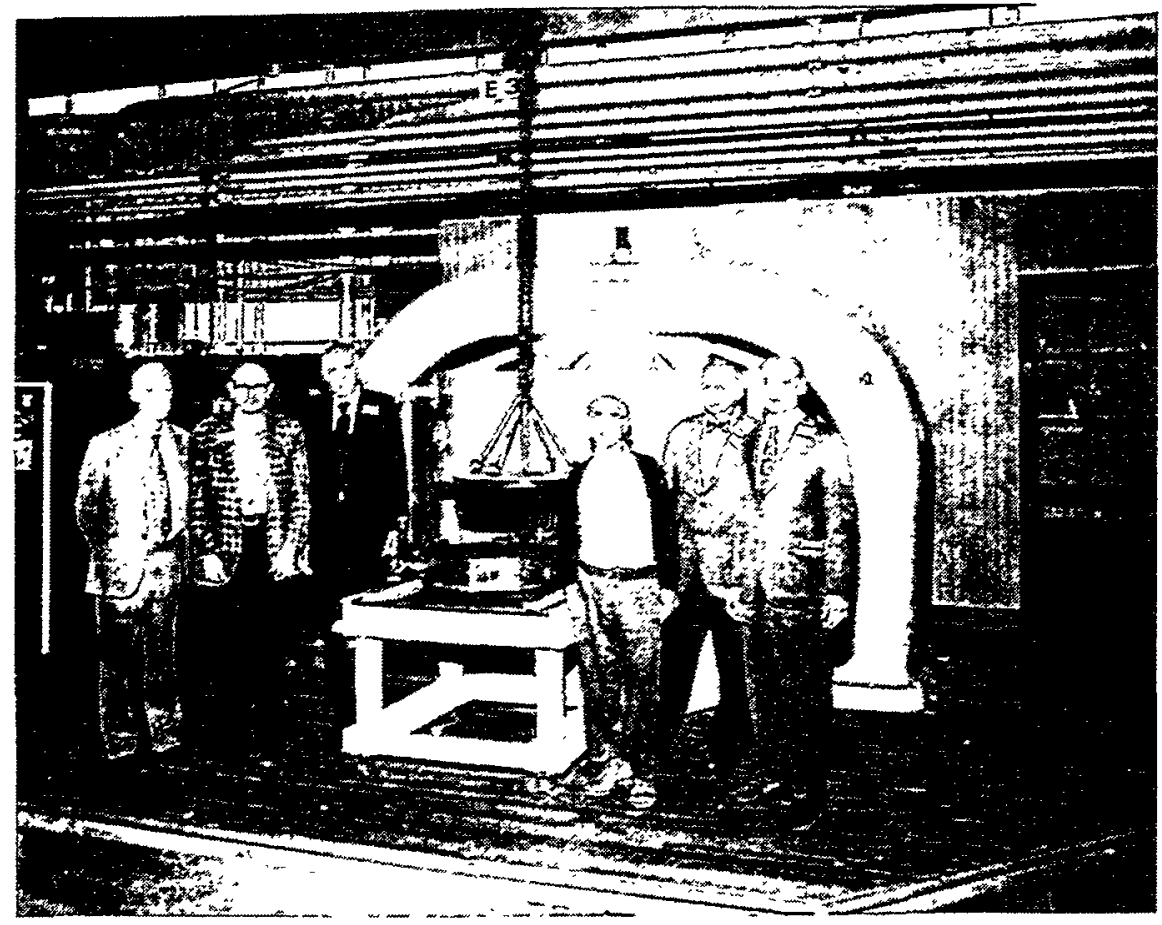

William Brobeck, Edwin McMillan, GTS,

William Baker, Cornelius Tobias and Edward Lofgren.

Accelerator Exhibit, Museum of History and Technology, Smithsonian, Washington, D.C.: December 1, 1977.

Edward Lofgren and GTS.

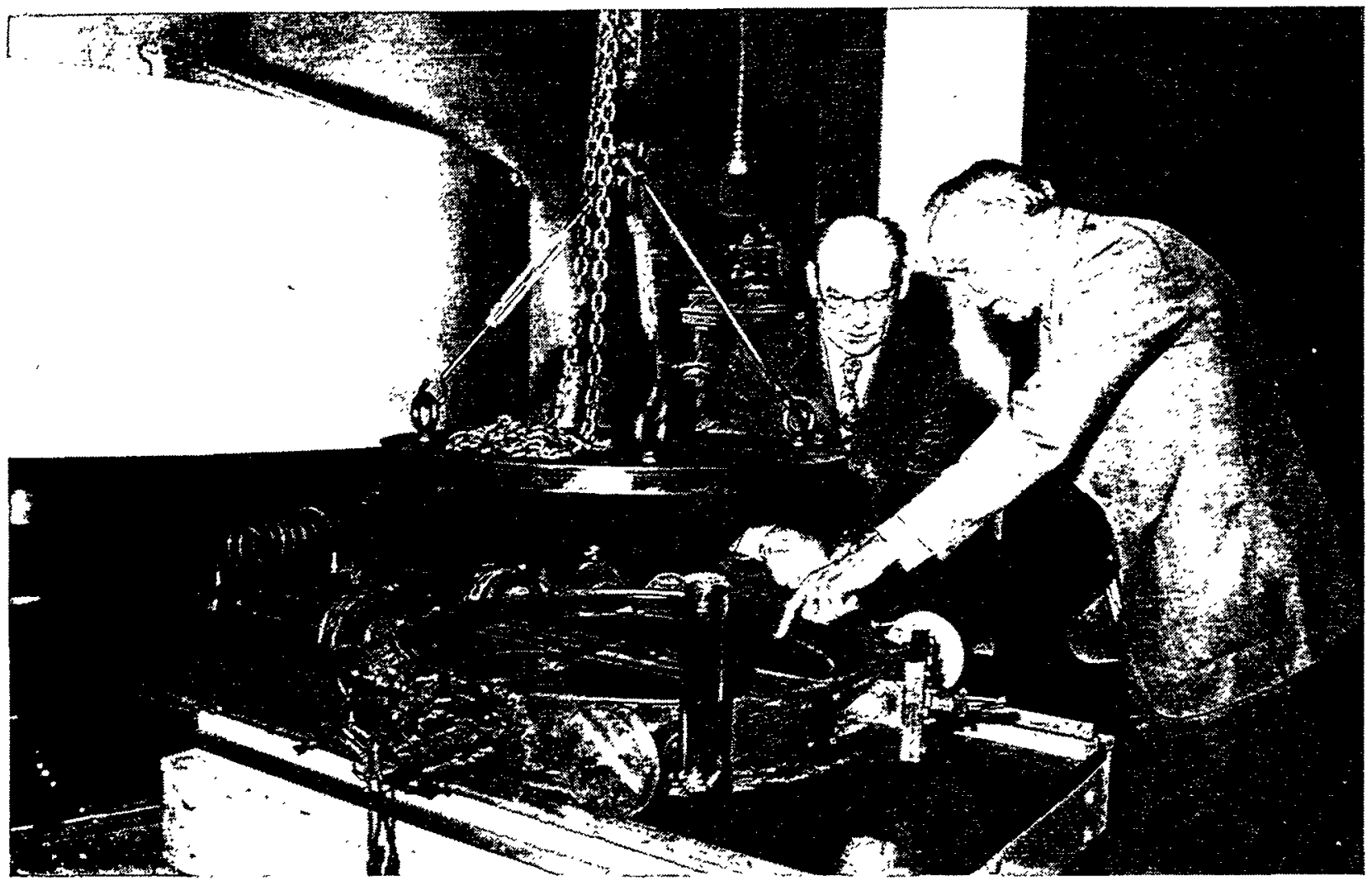




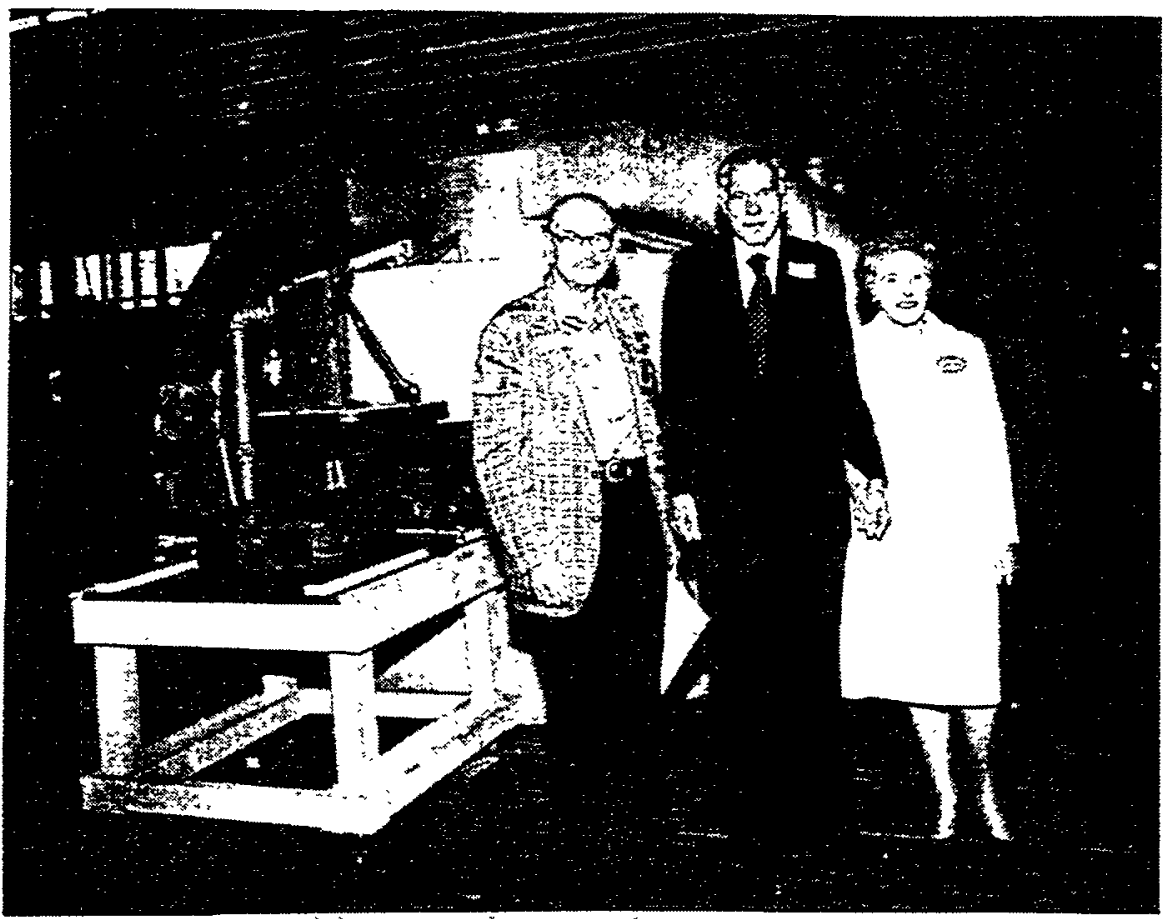

Edwin MCMillan, GTS and Elsie McMillan.

Accelerator Exhibit, Museum of History and Technology, Smithsonian, Washington, D.C.: December 1, 1977.

GTS and Raymond Birge.

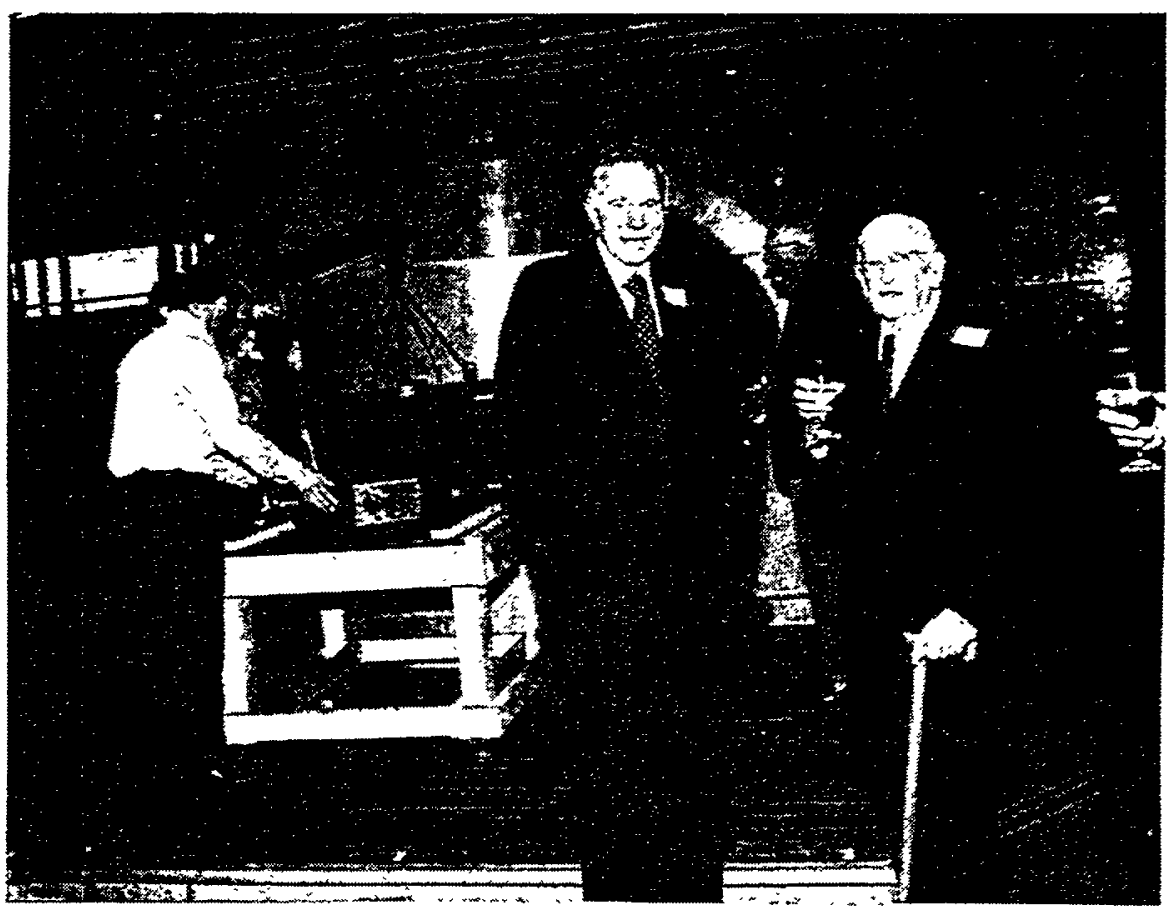


TO: DOUG GRENIER

EQUIFMENI RECUEST FORM FOT G. T. SEABORG GROUP

- Revised Decenker. 1, 1977

1. MAGNTIC DISK DATA HANOTITIS SYSTEI

Disk $\$ 6,000$

controller 5,000

Hardware. 1,000

Terminal 1,000.

$\$ 14 ; 009$

2. TOTAI, KINETIC FNETRGY DETECTION

SYSTEY,

4 Sxontanecus fission

wincidence systems.

TORAL REXUEST

$\$ 10 ; 000$

$\therefore 24000$

1. The conputer based multichannel aralyzer systers are heing majifisd so that tho to four times as many experiments can be carriea out similtaneously. This improvement requires more sophisticated data storage and handling devices. Ine addition of disk storace rould . not only allow superior data storage capabilities but also make online data analysis possible ana feasible.

2. It is anticipated that up to 6.spontanecus fission samples will ilave bejen prepared for coincidence fission counting in the near future. At the present time oniy two coincidence sirstems are availabie. It least 4 more systens are needed for planned future experirients winen the length of the counting times (1-2 years/sampla) is taken into account.

ce: Dr. Bernard Harvey

Dr. M. Nitschke

D. Morrissey; et al

Rolaind J. Otto

for: Glenn $T$. Seaborg 
Friday, December 2, 1977 (con't)

Award. I agreed to discuss with the Division of Nuclear Chemistry and Technology possible new sources of financial sponsorship of this award. The annual cost for this $\$ 2,000$ award is about $\$ 5,000$.

We discussed ACS nominations for the 1978 Robert A. Welch Award and I urged that we nominate two strong candidates. The previous ACS nominees were John Sheehan and Carl Djerassi and these should be considered for re-nomination. We decided to nominate Charles Price for the 1979 Perkin Medal. We determined to keep in mind nominations for the next National Medal of Science; the ACS Board may be canvassed for suggestions.

We discussed methods of increasing the visibility of the Petroleum Research Fund awards. Newman described the meeting she attended at LBL set up by me (with Shirley, Calvin, Dauben and Budnitz), which led to her "New Directions" project. I and others suggested additional new initiatives, such as a large award (similar to the Welch Award), symposia, etc. Newman will convene some small groups to discuss these ideas further prior to a discussion at the meeting of the Committee on Grants and Awards at the Anaheim ACS meeting.

We agreed to recommend that members of award selection committees know the identity of the other members on his/her committee and to consider further whether the membership of the award selection committees should be made public.

I took a taxi to the Longworth office Building and went to the office of Congressman Mike McCormack (room 1202). Here I met Mike, Eric Leber and Ezra D. Heitowit (who works with John Andelin on McCormack's Subcommittee on Advanced Energy Technologies. We went to the restaurant in the House of Representatives where we joined Mrs. McCormack for Iunch. I told Mike about the background on Isabel that led to stennis's punitive action on our uranium facility--this was news to him. He says he will talk to John Deutch to see if DOE can reprogram some funds to get at least the third injector started. - Leber will work with McCormack on this. Mike will also try to get the funding for the uranium facility in a supplemental, perhaps talking to Bennett. Johnston as soon as the senate committee situation is clarified. He will also try to get the $\$ 6 \mathrm{M}$ operating funds as a supplemental. I agreed to send Leber background information on our equipment and foreign travel problems.

We went back to McCormack's office after Iunch and I autographed a plate for the McCormacks' collection. Mike told me Kitty Shirmer wrote President Carter's veto message on the Clinch River Breeder.

I took a taxi to the Washington Hilton Hotel to attend the American Law Institute-American Bar Association Course of Study on "Investment Companies: The Changing Role of Outside Directors." I went to the Lincoln Foyer to receive my badge and packet of materials. I then went into the Lincoln-Monroe Room and joined about 75 people to hear a panel discussion on "Distribution of Mutual Fund Shares." The panel was chaired by David M. Butowsky (Gordon, Hurwitz, Butowsky, Baker, Weitzen \& Shalov) and was composed of Joel Goldberg (Special 
Friday, December 2, 1977 (con't)

Counsel to the Director, Division of Investment Management, SEC, Washington), Brian Brooks (Coopers \& Lybrand, Boston), Douglas Mercer (Ropes \& Gray, Boston), Meyer Eisenberg (Lawler, Kent \& Eisenberg, Washington) and James I. Walters (Wellington Management Company). Eisenberg spoke first. He discussed the propriety of using mutual funds assets for advertising and cost of distribution of the fund. Should each of the funds in a complex pay for marketing on a proportional basis? In this case should there be special directors (not the common directors) to deal with the problem? The Securities and Exchange Commission rules seem to prohibit such use of funds. Mercer spoke next on the meaning of SEC regulations. The question of charging trust accounts in banks to cover advertising was discussed. Brooks discussed the costs of distribution. The costs--rent, legal, filing, fees, advertising--of doing business are getting higher. SEC wants to reduce windfall to investment advisor. He discussed allowable and unallowable costs. A number of mutual funds are in the process of getting increases in their advisory fees.

We took a coffee break at 3:30 p.m. I left and walked to Science Service headquarters ( $1719 \mathrm{~N}$ Street). (I tried to find the headquarters of the American Hiking Society [1740 N Street] but found no sign of it there.) Here I presided, starting at 4:00 p.m., over the meeting of the Board of Trustees. Present were Deborah Wolfe, Gerald Tape, Allen Astin, Aaron Rosenthal, Edward Bliss, Julius Duscha, O. W. Riegel and Milton Harris, plus Edward Sherburne, Dorothy Schriver, Donald Harless and Bob Trotter (Editor, Science News).

I announced the contract with General Motors $(\$ 100,000$ a year for 5 years) to support ISEF and the Glenn T. Seaborg Nobel Prize Visit Awards. I appointed Tape and Duscha to help Sherburne, Schriver and Harless to revise the by-laws. In executive session, we voted for an 8\% across the board salary increase (including Sherburne, Schriver and Harless) and an additional $\$ 12,000$ discretionary fund for Sherburne's use to raise individual salaries; he is to report back to the board as to how he allocated the $\$ 12,000$. We adjourned at 6:00 p.m.

I signed a letter to Stig Ramel inviting him to talk at the Anaheim ISEF meeting and letters to Senator Howard Cannon (copy attached), Speaker Thomas O'Neill (copy attached) and Dale Taft to request entrance for Science News reporters to the Periodical Press Gallery. After the meeting, I told Tape about Stennis's action in deleting our uranium facility as retribution for the pressures to put Isabel in the FY 1978 budget and expressed my indignation at the whole episode. I suggested he tell the Brookhaven high energy physicists about my reaction.

I walked back to the Capital Hilton and attended the reception preceding the board dinner for ACS directors, staff members and wives in the New York and Pan American Rooms. Bob Cairns and Ray Mariella told me that Dr. Schlattman, President of the Netherlands Chemical Society, and Dr. Ijakutu, head of pollution control activities in Nigeria, are interested in supporting Carl Djerassi's proposal (Schlattman) and organizing an ACS-Nigerian workshop like the ACSEgyptian workshop (Ijakutu). Mariella also told me that Dick Lemon 
December 2, 1977

Senator Howerd \%. Cannon

Chairman, Conmittee on Pules and Administration

305 Russell Senate orfice Building

Washiraztor, D.C. 20510

\section{Dear Senator Cannon:}

This letter is a reguest for the reporters of science riews to be accredited by the Periodical Fress Gallery. Their exclusion is a handicap not only in reporiing scientific ne:ts in its correct context by not having congressional press cards, but also it excludes thern from obtaining White rouse press credentials. I am sure that this is not the intent of the gallem miles, and a vaiver to rectify this situation would be appreciated.

Science rews has been published by science service, Inc., (a private nomprofit or enizaion) For.the past 65 jears. The ojiectives of science Inews are: dissewination of scientific infornation; aidins in a general uncierstanoing of science; and ebcouraging the scientiric efiort of young scientists in particular.

Nominations to membership on the Board of Trustees of Science Service are derivea from several sources; including the rational Acadeiry of sciences, which is a private corporation. The Board advises the Jirector of sicience Service on the manacement of science niers sut does not exert any direct influence on the editorial content of icience netis.

Currently, science liews has a veekly jistribution of 165,000 copies. Indivicual reporters hare received national recognition for their abilities in providing unoiased scientilic news to the public andto the scientific community.

I urge you to help provide better scientific news coverage by accrediting reporters of Science Jiews to the Pericaicel sress GaIlery.

\section{Sincerely,}

Glenn T. Seaboxg

For the Board or Trustees

GIS:el

Science Service, Inc. 
December 2, 1977

Honorable Thomas P. O'Neill, Jr. Offices of the Speaker

Room $4-204$,

The Capitol

Washington, D.C. 20515

\section{Dear Speaker 0'Neill:}

This letter is a request for the reporters of Science News to be accredited by the Periodical Press Gellery. Their exclusion is a handicap not oniy ir reporting scientific news in its correct context by not having congressional press cards, but also it excludes them from obtaining White Louse press credentials. I an sure that this is not the intent of the gallery rules, and a waiver to rectify this situation would be appreciatec.

Science ievs has been published by Science Service, Inc., (a private nonprofit organizationj for the past 55 years. The objectives of science - News sre: dissemination of scientific information; aiding in a general understanding of science; and encouraging the scientiric effort of young scientists in particular.

Irominations to membership on the Board of Trustees of Science Scrvice are derived Irow several sources, incluaing the riational facademy of sciences, Which is a grivate corporation. The Board advises the Director of science service on the manegenent of science jievs but does not exert any direct influence un the ecitorial content op Science itows.

Currentity, fcience itews has a weekly distribution of 165,000 copies. Indiviaual reporters nare raceived national recognition for their abilities in providing unbiased scientific news to the public and to the scientific community.

I urge you to help provide beiter scientific news coverage by accrediting reporters of Science News to the Periodical Press Galiery.

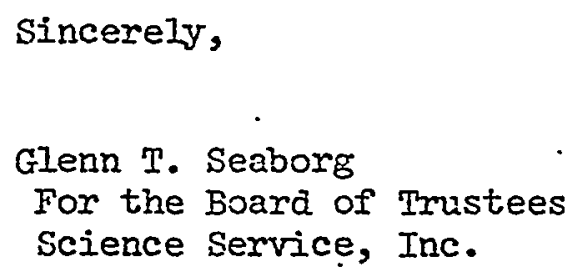

Gis:el 
will run for ACS Director to replace Gardner stacy and I said I will support him. Henry Hill talked to me about Sharon Johnson (discharged University of Pittsburgh biochemist with a two-year NSF or NIH grant with no place to use it) and to enlist my support of him or William Bailey for chairman of the ACS Board.

At dinner, I sat at a table with Rod and Lottie Hader, Herman and Judy Bloch, Bob and Kay Cairns and Bob Parry. After dinner, Bloch presided over a program featuring the four retiring members of the board of directors--Bryce Crawford, Bradford stanerson, me and Bob Cairns. Following remarks by Bloch in each case, the four of us were featured in the order listed. Dale Baker was in charge of the ceremony for Crawford, Justin Collat for Stanerson, Hader for me, Bob Henze for Cairns. In each case the four sponsors, and in some cases others, spoke and each of the retirees responded--all in a humorous vein with some serious remarks as well.

In his remarks about me, Hader gave a sort of talk on the transuranium elements, including as illustrations transparencies of my island of stability and "HILAC tank on the way up the hill," pictures made from slides furnished by Pat Quinn with Sheila Saxby's help. He presented me with a deer skin KAYAK (Klystron Attenuated Yagi for Applied Kinematics), a piece of rope (symbolic of the rope in my HILAC picture), a centennial ACS key and an ACS retiring president's pin. I responded with a description of my apprehension trying to guess what would be said about me, commented on Hader's transuranium speech (said some of it was correct), described Harry Whitmore's call inviting me to be a candidate for the ACS presidency (he made the job seem deceptively easy) and said I have been a member of ACS since 1938 and a member of the California, Chicago and Washington sections (sometimes two at a time). I ended by saying I will miss my official connection with ACS.

During his talk about Cairns, Henze said it was illegal for me to belong to two ACS Sections and I stood up and responded "I knew that!" Bloch presented a nice bouquet of flowers to Kay Cairns. Jack Barrett was present. He told me that he didn't see Eric during his visit to England, but apparently Ruck keene of The Chemical Society did see and help him. The dinner and program ended at 10:40 p.m., at which point I went up to my room for the night.

[Back at IBI, Rollie Otto șent our revised manuscript entitled Recoi] Range Distributions of Heavy Mass Products in Deep Inelastic Reactions with Gold and Uranium Targets to Gerard Dreiss, associate editor of Physical Review C (cover letter attached).]

Saturday, December 3, 1977 - Washington, D.C.

I joined Anna Harrison and Gardner stacy for breakfast in the coffee shop. Harrison wanted to talk about ACS international activities. Stacy pledged support for these. I described the various approaches to an ICS and expressed hope for centering it in sweden. she has some doubts about the IUPAC approach. She is going to visit Bangkok January 14-17 which may offer the possibility of exploring interest in international activities. 
901 Recoil Range Distri. of Heavẏ Mass Products in Deep. Inelastic Reaction: w/Gold \& Uranium

Mr. Gerard J. Dreiss

Bssociate Editor

Physical Review $C$

Brookhazen National Iaboratory

Long Island, New York 11973

Dear Mr. Dreiss:

We are returning, with revisions our mañuscript CK.1005, entitled Recoil Range Distributions of Heavy Mass Products in Deep Inelastic Reactions with Gold and Uranium Targets. In corapliance. with your rules we have revised the title page and acknowledgments to eliminate the footnotes in the title and the author list. One of the private communications has been eliminated (ref: 21 ) and the date of the communication (ref. 16) has been removed. We would prefer to keep this reference because of the specific nature of the information. Furthermore, we have revised: the tables and figures so that C.M.-rather than C.M.S. is consistently used throughout the paper.

- We would like to thank the referee for his comments. We had not appreciated the fact that both the projectile and one fragment from target would be moving backivards $\left(\sim 180^{\circ}\right)$ in. the center of mass system. Although this does not change our conclusions that the final range of the heavy target-like fragments must have very small laboratory ranges we have made the appropriate corrections. Possibly more important is the observation that a further search for evidence of the fission-fusion mechanism could be done by selectively looking at the charge dispersion curves of "gold finger" products with the short laboratory ranges. since the charge dispersions in this recion are normally broad $\left(\sigma_{z} \approx 1.0\right)$ and centered at $\mathrm{N} / \mathrm{A} \approx 1.48$ (19. $\mathrm{Au}$ for instance). some neutron excessive products may be expected with very low yields (200 Au for instance). Yields for neutron prodscts above those expected from deep inelastic transfer reactions could be taken as an indication that the fission-fusion mechanism did in fact occur in some of the low impact parameter reactions. 
Mr. Gerard j. Dreiss

$-2-$

December 2,1977

733

In accordance, with the referee's comments we have made appropriate changes on page 22 and have replaced this page with a revised version in the manuscript.

We hope that you will find these revisions. satisfactory.

sincerely,

RiJO/KV

Roland J. Otto.

Enclosures 
Saturday, December 3, 1977 (con't)

I went to the South American Room to attend the meeting of the ACS Board of Directors. Chairman Herman Bloch presided and all members of the board were present including Bob Cairns and also Ray Mariella, Jack Barrett, Arthur Hanson, Rodney Hader and numerous staff. We voted to permit the ballots for election of chairman of the board to indicate one choice, or first and second choices, or first, second and third choices. Bailey, Figueras, Good, Newman and Parry were candidates. On the first ballot, I voted for (1) Good, (2) Parry and (3) Newman. The board election returns, on a basis of 3 points for first choice, 2 points for second choice and 1 point for third choice, were: Good - 23; Bailey - 19; Newman - 19; Parry - 8; and Figueras - 7. Therefore, Good was elected Chairman of the Board.

In her report, President-elect Harrison pledged support of ACS international activities. In his report, Cairns reported on the ACS-Egyptian workshop, the impending ACS-Nigerian workshop and ACSBangkok negotiations. In the course of Newman's report for the Grants and Awards Committee, I emphasized the value of ACS nominations for the Welch Award and the hope to enliven the PRF program with new initiatives such as a prestigious ACS Award, symposia, etc. We adjourned at 12:30 p.m. for a reception and Iunch in the Massachusetts and Pan American Rooms. I sat next to Newman, Parry and Charles Overberger so we could discuss international activities, including the status of the ICS and Djerassi proposal. Newman has told T. H. GIynn Michael of Canada about the two proposals. I described my discussions in Sweden. Newman discussed her talks with the Japanese; they would probably be ready now to join with the ACS for a joint chemical society.

I talked separately with Jack Barrett to allay any fears on the part of IUPAC people that we want to dominate them; he made the surprising comment that perhaps IUPAC should be shaken up.

In the afternoon session, I gave my report on the International Activities Committee by giving highlights of subcommittees' work, including reference to opposition to the ICS concept by establishment people in England and West Germany. Following my report, a resolution of commendation for my service as ACS President, Board member, etc., was passed by the board. Similar resolutions were passed commending Crawford, stanerson and Cairns at appropriate times in the agenda.

Chairman-elect Good announced the following appointments made together with President-elect Harrison: Finance--Newman; CASI--Bloch; Publications--Eliel; Grants \& Awards--Parry; and Education and Students--Figueras. We then voted on the three other members for the Board Executive Committee. I voted for (1) Bloch, (2) Parry and (3) Newman. We adjourned at 3:30 p.m., then met in Executive Session.

The results of the Executive Committee election were: Bailey--23; Newman--19; Hill--17; Bloch--12; Parry--10; Figueras--4. Therefore, Bailey, Newman and Hill were elected. At the end of the meeting, Bailey brought up the matter of the discharge of steve Quigley by Cairns. After much discussion there was no disposition to 


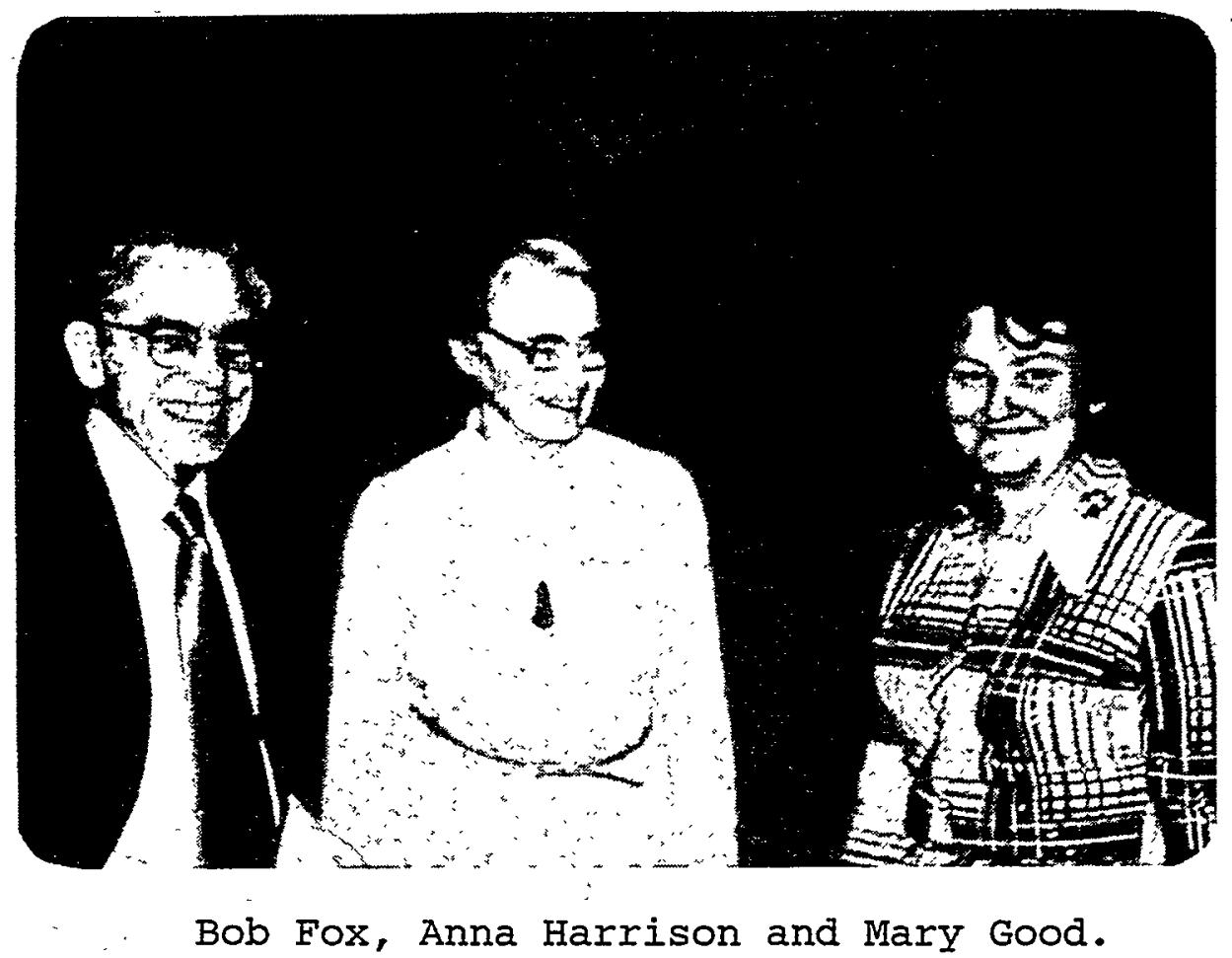

American Chemical Society Board Meeting--Washington, D.C.--12/3/77.

Polly Newman, Mike Heylin, Warren Niederhauser, Paul Smith and Bob Fox.

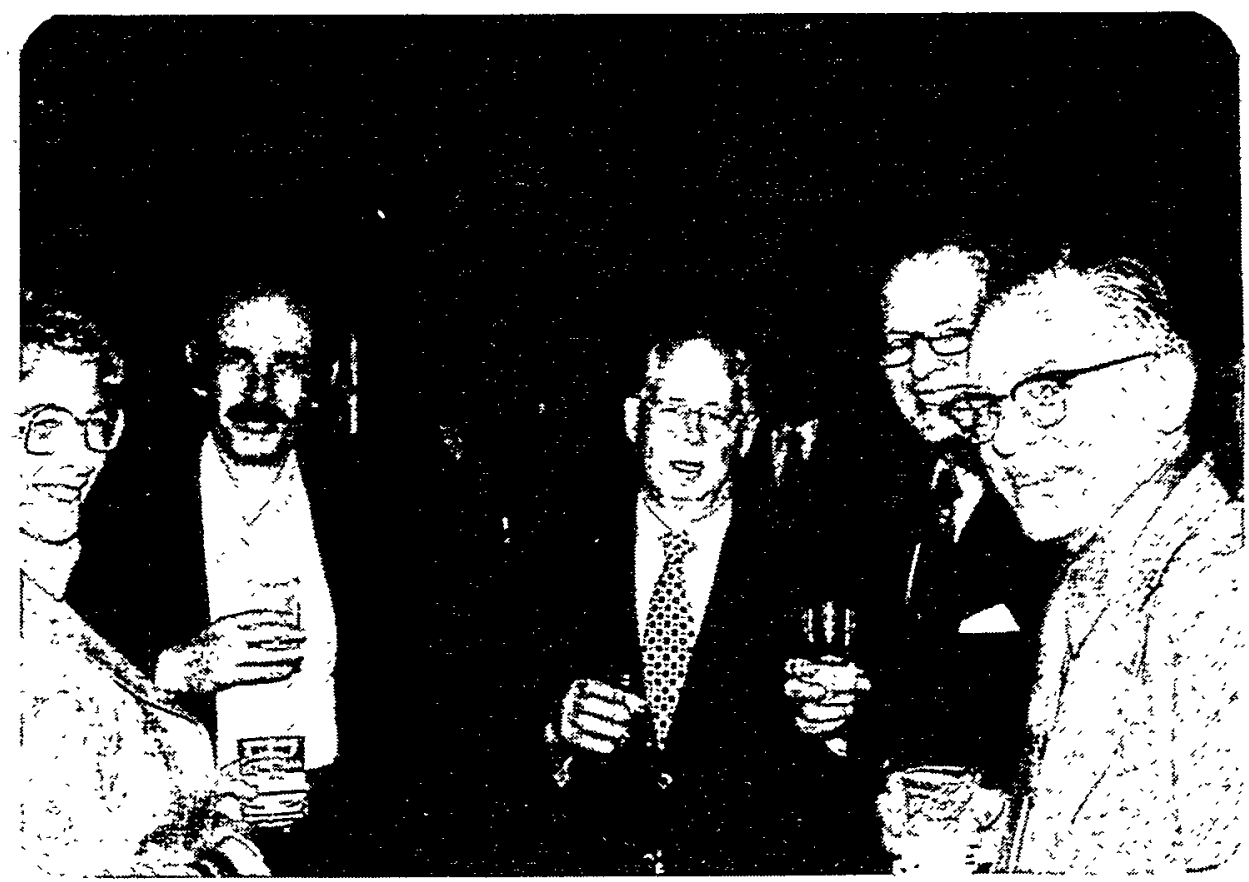




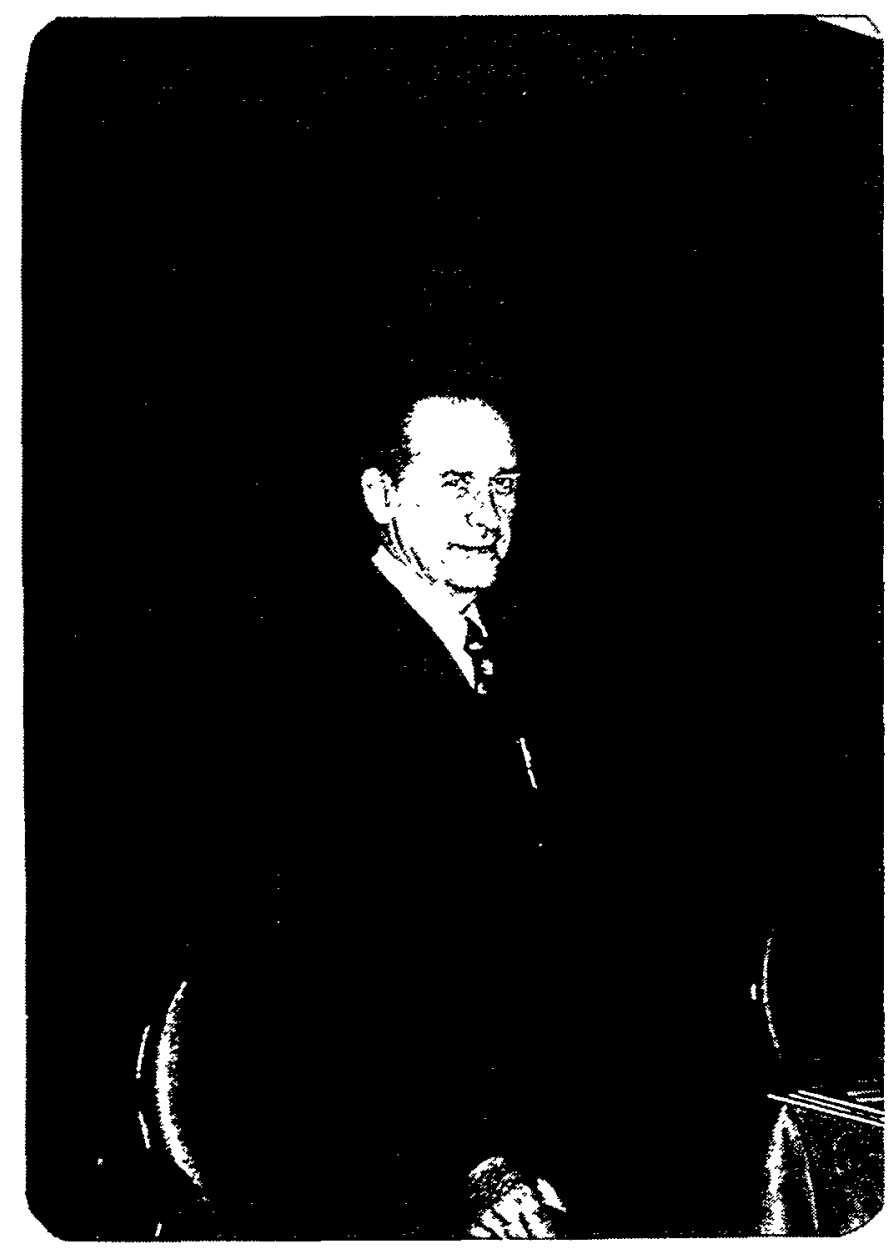

Rodney Hader, American Chemical Society Board Meeting:12/3/77. 
reverse Cairns's action, but it was decided to again offer Quigley a nine-months' terminal leave with full pay. The meeting adjourned at 5:30 p.m.

I took a taxi to the Cosmos Club where I joined Paul Lochak and then Lynne and Bill, Jack Barrett and Dr. and Mrs. Melvin Day for a drink. (Day is the Director of the National Library of Medicine. He worked at Y-12 starting in 1944 and was a long-time ORNL employee. Mrs. Day is a first cousin of Waldo Cohn.)

I met John Teem, who is now President of the Association of Universities for Research in Astronomy at Tucson. He had a serious operation to remove a tumorous kidney.

Paul, Iynne, Bill and I then had dinner in the cosmos club. We then rode to Iynne and Bill's place (5033 36th Place, Hyattsville), where we spent the night.

Sunday, December 4, 1977 - Washington, D.C. - New York - New York

Paul and I had breakfast with Iynne and Bill then rode with them to Nethers, Virginia to hike up OId Rag. We started at 10:30 a.m. and hiked up over the rock-scramble route (i.e., clockwise) to our favorite overview spot on top where we had our backpack lunch at about 12:40 p.m. We then continued on down going on the trail past Byrd's Nest and old Rag Shelter, then along weakley Hollow Road back to the parking lot where the Volvo was parked.

We rode back to Washington to National Airport, where Paul and I boarded the 6:00 p.m. Eastern Airlines Shuttle to La Guardia Airport in New York. Paul and I had dinner at Howard Johnson's across from the Commodore Hotel on 42 nd street. We discussed my financial arrangements with S.I.T. and Getex. Lack of funds prevents paying me the suggested stipend $(\$ 20,000$ per year) by Getex. Therefore, the present arrangement will continue with me dividing my annual one week in Paris between S.I.T. and Getex business. If I put in any additional time, I will receive compensation on a percentage basis from any future profits. I said any additional per diem for such work would not be feasible and I probably could not make an additional trip to Europe in 1978. I expressed some concern over lack of uranium discoveries by Gemex. Paul will formalize my stock in Getex or Team so I can pay income tax on it. I told him emphatically that I will not allow myself to be involved in any uranium exploration for south. Africa and advised him strongly to convince the others of the folly of this. Paul told me that Andrea (Lascelles) Hodges, from England, is taking Roxanne Goldsmith's place and Roxanne may rejoin him after her present responsibilities (visit to her mother in the U.S., etc.) are completed. I returned to spend the night at the Chemists' Club.

Monday, December 5, 1977 - New York - Berkeley

I had breakfast in the inner dining room, checked out and took a taxi through a light rain to the General Motors Building to attend a meeting of the Board of Directors of the Dreyfus Third Century Fund at the Dreyfus Corporation in the conference room on the 35 th floor. We first had a short meeting of the Board to accept the resignation of 
Michael Glass (he has been appointed General Counsel of the U.S. Information Agency), the appointment of Mark Jacobs (who has been with SEC for five years and is Assistant General Counsel of Dreyfus Corporation) as Secretary (to replace Glass) of the Dreyfus Third Century Fund and to elect John McCloy, Alice Jones and me as members of the Dreyfus Third Century Audit Committee. Present were Mccloy, Jones, George Harrar and me, plus Kenneth Oberman, Lawrence Greene, Mark Jacobs, Allen Eisenser (of S. D. Leidesdorf \& Company, Certified Public Accounts) and Margaret Evans.

We then held a meeting of the Audit Committee, starting with all the above present except oberman. Eisener made a presentation on behalf of S. D. Leidesdorf \& Co., the audit firm for Dreyfus Third Century Fund. He described the settlement between Leidesdorf and the SEC regarding the audit work of Leidesdorf for Tidal Marine International Corporation which was convicted of perpetrating a fraudulent scheme. We continued the meeting with only Eisener, Mccloy, Jones, Harrar and me. Eisener told us the conduct of the officers of Dreyfus Third Century Fund have been exemplary. Leonard Leiman (of Reavis \& McGrath, counsel to Dreyfus) joined us during the discussion. We approved the continuance of Leidesdorf as the audit firm for the Dreyfus Third Century Fund.

We then held the meeting of the Board of Directors. Present were the four directors, Oberman (who presided), Greene, Leiman, Evans, Jacobs, Elizabeth Paull, E. Hamilton Friedman, Jerome Hardy and

others. We approved the favorable report of our Audit Committee. I made a short report on the Course of study on The Changing Role of Outside Directors that I attended last week at the Washington Hilton Hotel. I suggested 10:00 a.m. Monday, March 6, 1978, as the time of the next meeting of the board and this was accepted.

I rode in a London Town Car sedan to Kennedy International Airport, where I boarded an American Airlines flight, which left at noon and arrived at San Francisco International Airport at 3:00 p.m. Pat Quinn met me. She was meeting her daughter, Debbie, and Debbie's boyfriend, Greg storrs who had just flown in from Washington. She drove me, with Debbie and Gregg, to IBI. I spent a few minutes in my office, then walked down to Latimer Hall where, in room 466, at 4:30 p.m., I met with the Chemistry $1 \mathrm{~A}$ instructional staff preparatory to giving the final examination. I walked down to Harmon Gymnasium where I helped administer the final examination which began at 5:00 p.m. in the main room (room 100). I left at $6: 40 \mathrm{p.m}$. and walked up to my LBI office where I met Helen who drove me home. I had dinner with her in the playroom, then went to the study to read accumulated mail.

Tuesday, December 6,1977 - Berkeley

I went over my accumulated mail and papers with Pat Quinn. At 9:30 a.m., Morrissey came in to see me to discuss our paper writing schedule, a possible Bevalac bombardment next week and his role in my group as a postdoc next year. He told me we did not get our scheduled $20 \mathrm{Ne}$ bombardments at the Bevalac last Wednesday due to problems with the Bevalac. 
Tuesday, December 6,1977 (con't)

Joseph Weneser, Brookhaven National Iaboratory, called in his capacity as a member of the American Physical Society, to ask about the symposium on superheavy elements being planned by Arfin Lodhi at Texas Tech University for March 10-11, 1978. I told him that I was on Lodhi's advisory committee for the symposium but that was the extent of my involvement. My role has been to merely suggest names of possible speakers.

I answered a request from Lawrence Lustig, ARETE Publishing Company in Princeton, New Jersey to prepare six articles for a new reference work. I declined this assignment due to a heavy schedule and suggested he ask Lew Keller of Oak Ridge.

I also had to decline an invitation to participate in Virginia Polytechnic-Institute and State University's Distinguished Visitors Program in 1978, replying to Mujaddid Ijaz, Department of Physics.

I wrote to Andy Sessler (copy of letter attached) to bring him up-to-date on the people I had visited with in Washington regarding the high intensity uranium beam facility.

I. was quite unhappy to learn upon my return to the office that the speed-up of the third injector will not go forward. I think this is a mistake and wrote a memo to the NSD Program Committee to that effect.

I went by to talk to Williams at 11:00 a.m. in room 209/70. She got a good ${ }^{235_{U}}$ plus ${ }^{11_{B}}$ bombardment last week and established a good excitation function for the production of our new seven-minute $242 \mathrm{Bk}$ (by the $4 \mathrm{n}$ reaction). I also talked to otto about our changed equipment budget), his revisions to our recoil paper and progress in the other papers he is working on.

I had Iunch in the cafeteria with Morrissey and Marsh. We discussed the latter's program for his master's degree in the nuclear engineering field. The requirements are 30 units plus a research thesis (which he will do with my group); he hopes to finish in 18 months (i.e., in June 1979).

I.talked to Al Ghiorso who told me that Nikolai Mikheev received permission from Moscow to stay an extra month; he still finds it difficult (almost refuses) to accept their failure to find any evidence for Md(I). I told Ghiorso about my discussions in Washington, D.C. concerning the uranium facility last week.

At 2:00 p.m., I attended the meeting of the Board of Directors of the East Bay Regional Park District at BART headquarters, 800 Madison Street, Oakland. Hulet Hornbeck sent me a letter suggesting that it would be helpful if I would attend in view of a number of land acquisition agenda items. Present were Chairman John Leavitt, Directors Mary Jefferds, Paul Badger, Howard Cogswell and William Jardin and General Manager Dick Trudeau, Assistant General Manager Jerry Kent and Attorney Donn Black. Also present on the podium were Hulet Hornbeck 
December 6, 1977

Dr. Andrew Sessler

Building 50A, Room 4133

LBL

Dear Andy:

During my recent visit to Washington I had the opportunity to discuss with a number of people our problem with the funding of the High Intensity Uranium Beams facility (Uranium facility).

Joe Kearney of OMB (who has cognizance over this item) and his associate, Doug Pewitt, have no problem with the proposed reprogramming of IBL funds to cut a year off the schedule for building the third injector. In fact they said LBL would deserve commerdation if it would be willing to set a priority in this fashion. They said the Uranium facility is in the FY 1979 OMB budget for DOE.

Will Smith (Professional Staff Member, Senate Committee on Energy and Natural Resources) said he would have no problem with such reprogramming of IBL funds and indicated that this is such a minor matter that it could be handled in the senate at his level. He was quite unhappy, as were Kearney and Pewitt, that Brookhaven and the New York Congressional people had so aroused that ire of Senator Stennis' by their actions on pushing Isabel that Stennis decided to delete the Uranium facility as a retribution. (Smith - suggested that we make sure that the Brookhaven people learn about this serious result of their actions.) He also said there is a small chance, if Senator J. Bennett Johniston (of Louisiana) replaces Stennis as Chairman of the Senate Subcommittee on Public Works (as the result of Stennis taking over McClellan's Chairship), that the Uranium facility can be put back in as a supplemental.

As a result of Will Smith's suggestion I told Jerry Tape, President of Associated Universities, Inc., about the action of Stennis and the reason therefor. Tape said he will look into this. Perhaps you should also inform the Brookhaven people of your knowledge of this situation.

Kearney, Pewitt and Smith indicated that.we would not have lost the Uranium facility had we received more support from the LBL leadership and key California Congressional members.

Jim Kane indicated he would have no problem with the reprogramming of LBI funds to.cut the year off the schedule. He indicated the Uranium facility has the top priority in the FY 1979 DOE budget. I told both Kane and John Deutch about the action of. Stennis in deleting the Uranium facility and the reason therefor. 


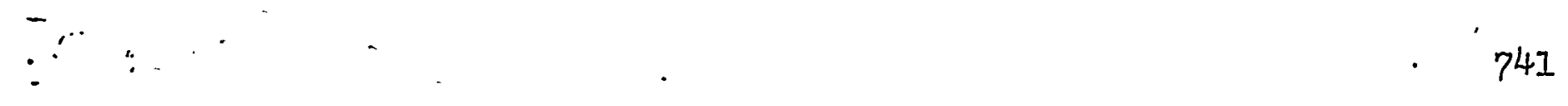

Andrew Sessler $\quad-2-\quad . \quad$ December 6, 1977

Mike McCormack was quite concerned about the axing of the Uranium facility by Stennis and will talk to Senator. Johnston about restoring it in a supplemental should Johnston replace stennis. However this would be difficult and must be considered to be $a$ long-shot possibility. Mike, as did Smith, said it would not have to be re-authorized. Mike said he will talk to Deutch to ascertain whether there could be some reprograming within DOE to allow a start of at least some portion of the project in FY 1978. He has discussed this possibility with Proctor Jones, who claims this can't be done because this is not an "on-going project" but Mike is not sure this is a correct interpretation.

I talked to a few other people but this summary covers my more important conversations.

Sincerely,

Glenn. T. Șeaborg

GTS/scd

P.S. I wrote this on the airplane on my way home before I learned of the decision to not implement a year's speed-up of the third injector, but thought it contains enough information to make it worth sending to you anyhow.

cc: Earl Hyde

Hermann Grunder.

Bernard Harvey 
and Lori Griggs, Hornbeck's niece who also talked in favor of acquiring Ken Brown's property. I spoke in favor of the purchase of the Brown property, elaborating somewhat on the history of the property and the fact that it is a key element in the trail link from Briones to Las Trampas and from Briones to Mt. Diablo. The directors voted unanimously to make the acquisition. Ken and Ada Brown arrived after the vote and Ken made a statement of appreciation including the comment that he was selling to EBRPD at a lower price than he could have obtained from a developer because of his interest in having the land available for use by the public. Among the other agenda items of interest to me was the authorization to purchase 1.76 acres to add to Huckleberry Regional Preserve. I left the meeting at $4: 15 \mathrm{p} . \mathrm{m}$. and drove back to my LBL office, arriving at 4:45 p.m.

On the way home, I went by Building 70 to falk to otto about our iodine-isotopes paper, Thomas about our U plus ${ }^{3}{ }^{4} \mathrm{Xe}$ bombardment scheduled later in the week, Nishida about her preparations for the $U$ plus ${ }^{136} \mathrm{Xe}$ bombardment and Williams about her data.

Wednesday, December 7, 1977 - Berkeley

Baisden dropped in at 10:30 a.m. to discuss our U plus ${ }^{136} \mathrm{Xe}$ bombardment scheduled for Friday and the Md chemistry experiments, with Nicolai Mikheev, scheduled at the 88" cyclotron for tomorrow and next Tuesday.

I called Joe Katz at 11:30 a.m. to discuss Fritz Weigel's letter to him of November 22, 1977 regarding Chapter VII, "Plutonium," of our revision of "Chemistry of the Actinide Elements;" Weigel is making excellent progress. We also discussed Lester Morss's progress on Chapter XVII "Thermodynamic Properties."

I discussed publicity plans for the symposium commemorating the anniversary of the discovery of elements 99 and 100 with Chuck Hurley of the IBI Public Information office and will send him a copy of my presentation, "Reminiscences," plus other information he may use in preparation for press releases, etc.

Berta Karlik of the Radium Institute in Vienna wrote that her colleague, G. Winkler, is applying for a temporary foreign appointment to work with Alan Bowen Smith in the Applied Physics Division at Argonne National Laboratory. She asked that I write on his behalf, which I did today, addressing letters to Robert G. Sachs, Director of ANL, and Smith.

I replied to Nils William Olsson that I did not have any leads as to how to raise another $\$ 3,000$ for a newsletter for the swedish Council of America. I told him, however, that I planned to attend the March 1 meeting of the council in Washington.

I wrote a memo to Bernie Harvey about my luncheon conversation in Washington with Mike McCormack, Eric Leber and Esra Heitowit (who works with John Andelin on McCormack's Subcommittee on Advanced Energy Technologies), telling him that I brought up the problem of funding for equipment and foreign travel. Mike said that he will try to do something about this and asked that $I$ have someone give Eric Leber the 
necessary information and ammunition that he would need. I told Bernie that I also discussed with Mike the possibility of adding the \$6M for increased operating funds for Nuclear Physics to the Supplemental that apparently is scheduled for about March 1978. Mike said that he will be alert to this possibility. A copy of my note to Bernie went to Earl Hyde for his information.

Frederick Seitz, the President of Rockefeller University, and Director of the Council on Science and Technology for Development, wrote to ask if I would continue to participate as a charter member of the council. I replied that I would do so but I could not give much time to meetings.

I had lunch in the cafeteria with Hyde and Morrissey. I told Earl about my discussions in Washington last week concerning our uranium facility.

Lew Keller called at 2:00 p.m. to tell me that he has received 100 reprints of our Annual Review article and will send me a supply. We will keep a list of those to whom we send copies of "Chemistry of the Transactinide Elements."

At 3:00 p.m., I walked down to Latimer Hall, went to room 406 for the grading session of instructional staff for Chemistry $1 A$.

At 4:00 p.m., I walked down to the Alumni House to attend the memorial for Ruth Hart who died a few days ago after a long bout with cancer. Rabbi Fein spoke, then called on Ruth Plainfield of the YWCA, Charles Muscatine and Vice Chancellor Ira Heyman for remarks, then concluded with more of his own remarks. Helen also attended.

I walked back up to Iatimer Hall, met further with the group engaged in assigning grades to Chemistry $1 \mathrm{~A}$ students, then walked up the hill to mY LBL office.

I found a note waiting for me from Bernie Harvey saying he is withdrawing as a co-author with me of the Benchmark Book on nuclear chemistry.

Lynne called to ask us to invite her friend, Peggy Willig, for Christmas dinner and to stay with us as a house guest. Helen prepared dinner for me which I ate in the playroom. She then drove to Davis to pick up Dianne who has finished her first quarter there.

Thursday, December 8, 1977 - Berkeley

Bernie Harvey dropped in to discuss (1) his decision to drop out of the editorship of the Benchmark book on nuclear chemistry, (2) his decision to drop the speed-up of the third injector, (3) his version of why Stennis axed the uranium facility and (4) the request of IAEA that we do some measurements on heavy isotopes.

Lester $R$. Morss had written to ask for a letter of recommendation for him in connection with a National Science Foundation Science Faculty Professional Development application. I replied that I would be delighted to do so and that it was good news to know that he would 
Thursday, December 8, 1977 (con't)

be working with Jean Fuger at the University of Liege. I also told him that I would call to the attention of Norman Edelstein, Bill

Carnall and others that his undergraduate student, Daniel Nocera, is looking for a summer research appointment to work in actinide chemistry.

I replied to Max Tishler that I would be happy to chair Day I of the CHEMRAWN meeting next July in Toronto.

Oliver K. Manuel, Department of Chemistry at the University of Missouri, had sent a manuscript to me to review. I replied that I believed it suitable for publication.

Regarding Bevalac argon requirements for our SHEIKS group, I wrote to Fred Lothrop and Lee Schroeder and outlined our requirements.

Paul Flory, Stanford University, called to ask me a few questions regarding my appraisal of the job as president of ACS. He has been approached and wanted to know how much time is required and what the possibilities are for doing something worthwhile. I told Paul that I thought there would be opportunities for him to accomplish worthwhile things and that the ACS needed him, particularly in view of their current efforts at reorganization, the creation of a Science Commission, etc. I did tell him that the job was time consuming and we reviewed the meeting schedule and other requirements.

Pete Goldschmidt called to tell me about a recent conversation he had with Norman Minetta saying that Minetta is ready to help on the uranium beam project. Goldschmidt also has heard that lack of support from sessler had hurt us very badly in this regard.

Jesse Hwa called early in the day to discuss changes to be made in the letter to participate in CHEMRAWN DAY I. We agreed on the format of the letter. We also discussed the ICS material being prepared by Stanley Kirschner and the China trip in 1978. He will call Kirschner and make suggestions for changes in the format of that particular letter and questionnaire. He said that Pat Tsuchitani told him that a chairman for the China delegation will be picked by January 5 (they hope) and that the delegation has now been formally approved by China. She also told him that the chairman of the delegation will be influential in choosing the delegation.

I had lunch in the cafeteria with Rose Marie McFarland to discuss her research program. I suggested a program combining nuclear with inorganic chemistry, e.g., chemistry of lower oxidation states of the heaviest actinides, etc. She would work on chemical separation procedures with Thomas and Baisden as well. She will be an observer at today's and Tuesday's Md(I) experiments at the 88" cyclotron and at Baisden's and Thomas's U plus 136 Xe experiments tomorrow. She will take chemistry 123 and an inorganic chemistry course and will attend both the SHEIKS and Actinide Wednesday noon meetings. I gave her a copy of the LBL "Job Openings" announcement sheets for use by her husband in finding a job. 
Bernie Harvey came in and said he is canvassing NSD members to get approval for advertising for a senior scientist or divisional fellow position in NSD, with the view of hiring Ralph DeVries of the University of Rochester. 'I agreed. He would do Bevalac work.

Leonard Dreyfus dropped in at 2:00 p.m. to ask me to help find a one-year work-study job in economics next academic year in the Bay Area for Johan Stahlhammar. He is 21 years old and a second-year economics student at the Stockholm School of Economics. I said I will think about it.

I told Art Poskanzer about the decision of Searle Corporation to end (after 1979) its funding of the ACS Nuclear Applications in Chemistry Award. He agrees we should try to find a new sponsor and will speak to members of the Executive Committee of the ACS Division of Nuclear Chemistry and Technology about it.

At 3:30 p.m., I went by room 203/70 to talk to Morrissey and otto. Otto gave me the latest draft of the Saint-Simon-otto-Seaborg paper on iodine isotopes yields to read.

At 4:00 p.m., I took Rose Marie McFarland down to the 88" cyclotron to meet Ken Hulet. We spent about an hour there as the crew tuned up the He beam. McFarland went home for dinner but will return tonight with Baisden so she can watch the work on Md(I).

I went by Building 70 to talk to Baisden, Thomas and Nishida about getting ready for tomorrow's bombardment and to give williams some reprints. Pat McGaughey, Kenton Moody, Pat Somerville, Kim Williams, Ken Thomas are going home over the Christmas holidays.

Helen and I had dinner in the playroom. Dianne ate later; Dave ate in his room. Helen drove Dianne to San Francisco Airport where she took an 11:45 p.m. plane to Rochester, New York, via Chicago, to meet Bob Puppa.

\section{Friday, December 9, 1977 - Berkeley}

I went by room $203 / 70$ and found that our ${ }^{136}$ Xe bombardments of $U$ are underway as scheduled. - Baisden will get two short (one-hour) bombardments and a two-hour bombardment and Thomas will get a one-hour and a four-hour bombardment. Baisden, with help from Nishida, will study " $\mathrm{X}$ " and other isotopes below $U$ and transplutonium $Y i e l d s$. Thomas will look for beta emitting Th, U, Np, $\mathrm{Pu}$ and transplutonium isotopes.

Doug Greiner came by to see me to protest the building of Velsep at the expense of Bevalac research capability.

Noah Johnson (ORNL) and Frank Stephens came by to tell me about their failure to obtain approval from the Board of Governors for the 1979 Gordon Conference in Nuclear Structure. I will help them obtain approval later on if it turns out to be necessary.

I talked to otto about the Saint-Simon-otto-Seaborg iodine isotopes paper, based on my reading of the latest draft last night. 
Eriday, December 9, 1977 (con't)

Otto will send it to Saint-Simon (back home at orsay, Paris) for his further input. I also talked to Morrissey, Otto and Diana Lee about writing of two papers describing the methods used in our heavy ion radiochemical research.

I wrote to President Terry Sanford, Duke University, that I would very much like to be their commencement speaker and to receive an honorary degree from Duke on Sunday, May 7, 1978, but until the China trip is scheduled I cannot give a firm answer.

Father Ted Hesburgh, President, University of Notre Dame, wrote to thank me for Travels in the New World, and I answered his nice letter, mentioning his participation in the 20th anniversary of the IAEA in Vienna this year, and our continuing dialogue with RusselI Peterson of NEW DIRECTIONS. I suggested Hesburgh send Peterson a copy of the memorandum which Sigvard Eklund prepared for him.

I sent more names to Gordon Bixler in response to Stanley Kirschner's memorandum of November 23, 1977 requesting names of nuclear chemists to whom a letter and questionnaire regarding ICS might be sent.

A letter and identifications of a photograph were received from Professor Ioan Ursu, National Council for Science and Technology, Bucharest 1, Romania. I wrote to thank him for the time and effort he spent on complying with my request, especially in view of the disastrous earthquake recently suffered in Bucharest.

I attended a Iuncheon meeting in Room 4205, Building 50B, chaired by Richard Diamond and including Bernard Harvey, Mike Nitschke, Frank Stephens, Phil Eggers, Franz Plasil, Chip Britt, Doug Greiner, John Alexander, Luciano Moretto, Earl Hyde, Joe Cerny and Hermann Grunder. The purpose was to hear Britt and Plasil make a case for diverting equipment money, etc., to the building of Velsep (the Velocity separator apparatus for use at the SuperHIIAC). Nitschke and Alexander also spoke in favor of it. Moretto spoke somewhat in favor, Cerny was skeptical and Greiner spoke against it. I said I was against this use of funds which displaces the plan to speed-up the construction of the third injector for the superHILAC.

Wayne Marsh dropped in to see me about the possibility of his getting a paid position (regular graduate student research assistantship) next quarter. I told him about my budget limitations but said I would look into it.

I went down to see Norman Edelstein about a number of items concerning our actinide research program. Ken Raymond wants to have Fred Weitl for a permanent position.

At 4:00 p.m., I walked down to the campus to Latimer Hall Commons to attend the College of Chemistry Christmas party. From 4:30-5:30 p.m., a number of graduate students and some faculty (Paul Bartlett) put on a number of humorous skits. 
I visited room 203/70 again, as I did many times throughout the day, $\Varangle 9$ watch progress on the chemical separations following the $U$ plus $136 \mathrm{Xe}$ bombardments. Baisden, Thomas and Nishida were busy, with McFarland watching. I also discussed further with otto and Morrissey our writing program.

Saturday, December 10, 1977 - Iafayette

Helen and I took a hike in Mt. Diablo state Park, about three miles up the Mitchell Canyon fire road and back. We had lunch in the playroom, while watching the Washington Redskins-st. Louis Cardinals football game, which the Redskins won, 26-20. After, I worked on January 1944 of my Met Lab Section C-1 history.

Helen and I picked up BilI and Muriel Giauque and drove to the Swedish Consulate in San Francisco to attend the celebration of the Nobel Prize Ceremony being held. in Stockholm (and Oslo) today. We met and talked to many people, including Kurt Adler, Don Mulford, Walter and Mrs. Danielson (he is the former--for 39 years--Swedish Consul; honorary title: Consul General in Ios Angeles), Carl Djerassi and Diane Middlebrook, Elmer Rasmussen (former head of the National Bank of Alaska; former--for 22 years--now honorary title--Swedish Consul General for Alaska), Veikko Huppunen (Finland's Consul General and dean of Consul Generals in San Francisco), Frokinan (Swedish Consul for Portland), Ingel Anderson (Swedish Consul for Phoenix), Adeline Simeons (Consul General in San Francisco for Belgium) and Mr. and Mrs. Nikoline (she is the head of the Ladies Society of Jenny Iind in Oakland). Our hostess, Swedish Consul General Cecilia Nettelbrandt, made a talk, explaining the background of the consulate (former Matsanhorne) and the beginning of today's date. She then conferred, on behalf of King Carl Gustaf,' the Royal order of North Star Commendor on Mrs. Nikoline (who has presented the bust of Jenny Iind which was in their Oakland headquarters, now sold, for years, to the San Francisco Swedish Consulate), Consul Frokinan and Consul Rasmussen. She then called on each of the Nobel Prize winners, in the order of their award years--Giauque, Seaborg, Iinus Pauling, William Shockley, Emilio Segrè, Owen Chamberlain and Burton Richter-to come forward so she could pin a carnation on each of us. About a dozen girls and ladies in white gowns, with candles, participated in a Iucia ceremony. We had a Swedish buffet meal. There were about 75 people present, including Oakland Mayor Lionel and Mrs. Wilson. We drove back to Berkeley, to drop the Giauques, and to Lafayette, arriving home a little after 10:00 p.m.

\section{Sunday, December 11,1977 - Lafayette}

In the morning, Helen and I, with Kay Petersen and Iavaughn Craig (Lafayette Planning Commissioner) hiked up through the Jennings property to Lafayette Ridge to show Kay and Lavaughn this as a potential entry to the Lafayette Ridge Trail. Activity to preserve this entrance is required because there are indications it may soon be developed as home sites. We also tried to locate the 20 acres of Albardan property off Glen Road which is up for development.

Helen and I had lunch in the playroom, while watching the Oakland Raiders-Minnesota Vikings NFI football game, which Oakland won, 35-13. 
I worked on December 1943 and March 1944 of my Met Iab section C-1 history. Dave went out and bought us a Christmas tree. Helen went to a showing of China slides at the Algo and Jean Henderson's in the late afternoon.

Monday, December 12,1977 - Berkeley

I dictated to Pat letters to Charles Browne (copy attached), Sherman Fried, Gary Higgins, Albert Ghiorso, Roderick Spence and Paul Fields on the symposium commemorating the 25th anniversary of elements 99 and 100.

I went by to see otto, who gave me a revised copy of our iodine paper ("Relative Thresholds for Production of Iodine Isotopes from Fusion and Transfer-Induced Fission Reactions"); he is sending a copy to Michel de Saint-simon for his input.

I walked up to the HILAC Building and talked to AI Ghiorso and Saburo Yashita about their tests of SASSY (through scattering of $20 \mathrm{Ne}$ ions), as a prelude to its use to $100 k$ for $\mathrm{SHE}$ (from ${ }^{48} \mathrm{Ca}$ plus $248 \mathrm{Cm}$ ). I talked to Bob Stevenson and Jim Haley about plans for a target containment area for our use in bombarament of highly radioactive targets ( $248 \mathrm{~cm}, 249 \mathrm{Cf})$ in the direct-beam line.

I wrote to Boris Myasoedov at the Laboratory of Radiochemistry, Institute of Geochemistry and Analytical Chemistry, Academy of . Sciences in Moscow, to thank him for sending me a copy of the Proceedings of the All-Union Conference on the Chemistry of Transplutonium Elements held at Dimitrovgrad, June 29-July 1, 1976. I asked for any reprints of papers that might have appeared in English.

I prepared letters to CHEMRAWN Day I speakers, Dieter Behrens, Maurice Strong, Roberto de Oliviera Campos, Herbert Grünwald, Irving Shapiro, Kenneth King, King Hubbert and M. K. Tolba, outlining requirements connected with the conference on July 10, 1978 in Toronto.

Igor Sobolev, American Chemical Society, California Section, · asked if I would accept the chairmanship of the Education Committee of the California section, and I declined, saying that I could not take on another assignment of any kind.

I had Iunch in the cafeteria with Baisden and McFarland.

I attended the NSD Seminar in Room 3377 (70A) at 4:00 p.m. Norman Glendenning spoke on "Can the Hadronic Mass Spectrum be Discovered through High Energy Nuclear Collisions?"

After the seminar, I met in my office with Franz Plasil (chairman of this year's Gordon Research Conference on Nuclear Chemistry, Heavy Ion Reactions) to discuss representation of my group at the Gordon Conference. We agreed Dave Morrissey should give a regular talk, and Kim Williams or Trish Baisden might give a short talk. 
University of California

Berkeley, California 94720

Telephone 415/843-2740

December 12, 1977

Dr. Charles I. Browne

Los Alamos Scientific Laboratory

P. O. Box 1663

Los Alamos, New Mexico 87545

Dear Charlie:

I am enclosing the Program for our Symposium Commemorating the 25th Anniversary of the Discovery of Elements 99 and 100, to be held on Monday, January 23, 1978 at the Lawrence Berkeley Laboratory, Nuclear Science Building 70A, Conference Room 3377, commencing at 9:30 a.m.

Our symposium group will have lunch together in the room at the lower level of the IBI cafeteria on January. 23, and will have dinner in the O'Neill Room of the Faculty club at 6:00 p.m. that evening.

We plan to publish a proceedings as we did for the symposium commemorating the anniversary of the discovery of elements 97 and 98 in 1975 (LBI-4366). To help in this, we will tape-record the presentations. However, you may want to prepare a manuscript with glossy prints of tables, figures, etc.

Could you send me some biographical information.about yourself for my use in introducing you.

I look forward to seeing you on January 23. Please call me or-my administrative assistant, Pat Quinn, if we can be of any assistance in any way. In the meantime, best wishes for a happy holiday season.

Cordially,

Glenn T. Seaborg

GTS/kV

Enclosure 
Tuesday, December 13, 1977 - Berkeley

At 10:00 a.m., I went up to the HILAC Building with Baisden, Williams and McFarland. Franz Plasil joined us in the room where Williams and Cindy Lee are doing their work on target preparation by electrospraying; they will prepare a paper for publication on this. Plasil talked to Baisden, Williams, McFarland and Lee, and also Pat Somerville. He is interested in the applications of Baisden and Williams for positions at ORNL and in their possible participation in the Gordon Conference this June.

I wrote to Vitalii Goldanskii and asked him for six reprints of his published works that I will need to renominate him for the ACS Award in Nuclear Applications in Chemistry. I also sent letters on the 25th anniversary of elements 99 and 100 to William Carnall, John Huizenga, Donald Ferguson, Richard Hoff, Joseph Peterson, Darleane Hoffman, Ken Hulet, Norman Edelstein and John Conway.

Don Stewart's secretary called to tell me that his retirement party will be December 15th at ANL and asked that I send a letter of congratulations. I sent the following mailgram:

"I have vivid recollections on my indoctrination briefing of a young Don Stewart on March 6,1944 when he started at the Met Lab 33 years ago. Your contributions from then until now have been outstanding. Helen and I extend best wishes to you and Dorothy for an equally rewarding retirement-hopefully in the San Francisco Bay Area."

Gordon Bixler called mid-morning and we discussed many pending items having to do with the International Activities Committee and ICS. We discussed the Kirschner sub-committee on ICS and progress on the letter and questionnaire, Anna Harrison's visit to Bangkok, invitations to the presidents of chemical societies for September 1979 and the India and Egyptian workshops.

Bogdan Maglich called regarding the East-West Symposium on Energy and the Environment he is helping to coordinate to be held september 1978 in Dubrovnik, Yugoslavia. I gave him the topic of my contribution to the symposium, "The Energy Problem in the United States." He is at present working on the funding for the symposium.

I had lunch in the cafeteria with Morrissey, Phil Eggers and Mike Nitschke. I discuss with Nitschke the third injector for the SuperHILAC and problems with Pat Somerville's lab technique; he recently ruined an expensive Ge detector.

Barbara Jacak dropped in to discuss her scholastic record (all A's last quarter) for use in my recommendation of her for an ARCS scholarship. She plans to do research with me next spring and summer; we also discussed plans for our cluster advisory group next quarter ( $I$ will meet with them at 3:00 p.m. on Tuesdays).

Morrissey and I read proof on our "Search for Superheavy Elements" article being published in the Journal of Inorganic and Nuclear Chemistry. 
I attended the meeting of the LBI Scientific Program Council. Present were Andy Sessler, Earl Hyde, Luis Alvarez, Sam Berman, Jack Hollander, Denis Keefe, Milt Klein, Ken Mirk, David Scott and others. Keefe reported on the LBI program on Heavy Ion Inertial Fusion, and AI Levy and Sabei Ergun reported on the Status of the Fossil Energy Program.

I dropped by Building 88 where I found Ken Hulet preparing for tonight's experiment in Md chemistry to be conducted with Mikheev, Baisden and others. Last Thursday's experiment (carrying with rubidium chloroplatinate) showed no carrying and thus again showed no evidence for $\mathrm{Md}(I)$.

Wednesday, December 14, 1977 - Berkeley

I called Don Hanson, of Chemical Engineering Department, about Bonner Nishida's application for admission to graduate school; he will let her know within a week.

I sent: Michel de Saint-Simon pictures of his goodbye party held in my office on Nov. 16th, 1977. I also wrote to Fritz Weigel at the Institut Fur Anorganische Chemie, Universitat München, West Germany, to thank him for the copy of Chapter VII of our revision of the Chemistry of the Actinide Elements, and for the reprint he sent. I told him that Joe Katz and I had conferred with respect to his revision of Chapter VII and we are pleased with it. I also told him that I would probably not be able to attend the Grenoble Conference, August 31-September 3, due to my schedule, and mentioned to him the Urbino, Italy conference on "Organometallics of the f-elements."

I held my regular biweekly luncheon meeting of my group. Present were Williams, Cynthia Lee, Baisden, Nishida, McFắl̆and, Morrissey, Diana Lee and sebesta. Wilitiams reported on her $242 \mathrm{Bk}$ studies, Baisden on her results from her recent U plys ${ }^{13}{ }^{3} \mathrm{Xe}$ bombardment, Morrissey on his analysis of his ${ }^{4} \mathrm{Ca}$ and ${ }^{5} 6_{\mathrm{Fe}}$ plus rare earth data and sebesta on his work on drop drying for FAKE experiments.

I called Walter Loveland to discuss Jim Hogan's request to spend next year with us on sabbatical leave. He said $\mathrm{S}$. Biswas of $\mathrm{N}$. $\mathrm{T}$. Porile's group (Purdue University) would also like to work with us.

I joined Helen and Justin and Robbie Bloom in the cafeteria at 1:00 p.m. They were finishing Iunch. Justin described to us his critical role in effecting a compromise, through Ambassador Mike Mansfield's cooperation, between the Japanese and President Carter's people on the plutonium reprocessing plant in Tokai Mura. The original position of President Carter was unbelievably stupid. We went back to my office, where I gave Justin a reprint of my article, "Chemistry of the Transactinide Elements."

I went by room $203 / 70$ to talk to Morrissey about the planned sabbatical of Jim Hogan with us. I walked, in the rain, up to the HILAC Building where Williams and Baisden were working on the Electrospray apparatus to make a ${ }^{235} \mathrm{U}$ target; Baisden is learning how to make a ${ }^{24} \mathrm{Pu}$ target. McFarland and Cindy Lee had just left. I learned that Somerville succeeded in getting his ${ }^{206} \mathrm{~Pb}$ plus ${ }^{10_{B}}$ bombardment 
last night to make ${ }^{212} \mathrm{Fr}$ to test his apparatus. I also went by to see Nitschke who was working on his GASP (gas jet apparatus).

I drove home via Berkeley, through the rain; it took me 1-1/4 hours to get home due to the fog. Helen was in Berkeley to attend a YWCA dinner so I had a casserole dinner that she prepared.

Thursday, December 15, 1977 - Berkeley

I talked to Eddie Brown about bringing the isotope tables up-todate for our revision of Chemistry of the Actinide Elements. He agreed to do this starting in about two months when the Table of Isotopes group will have summarized the data on the heavy isotopes.

I called Ted Vermeulen to discuss Ed Sebesta's timetable for finishing his MS degree.

Sylvia Kihara dropped in at 11:30 a.m. to say hello.

Bernie Harvey dropped in to tell me about his meeting with Procter Jones to discuss our uranium facility and funding problems and his discussion with Jim Forcier of Senator Cranston's staff.

I wrote a letter of recommendation (copy attached) for $\mathrm{kim}$ Williams to E. M. Vendley, ORNL.

I had lunch at the table outside the lower level of the cafeteria with Nitschke, Morrissey, Norman Edelstein, Alex Avdeef, Jerome Bucher and others. I discussed with Nitschke the research progress of Ed sebesta and we made plans to meet with him to discuss his MS thesis timetable. In this regard I called Vermeulen and then Mike again and we set an appointment time of February 3, 1978 in my office at 4:00 p.m.

I walked up to the HILAC Building to talk to Ghiorso about his progress on SASSY. He and Yashita are using the highly available 20 Ne, as a by-product from their use by the medical group at the Bevalac, to make a number of tests. I also spoke to Yashita.

Eric Leber called Bernard Harvey to report on Mike McCormack's talk with John Deutch today; Mike broached the subject of reprogramming funds to get started on the uranium facility and Deutch said he will think about it. Leber suggested we write a letter to someone in Congress to make our case for the need to get the line item six months earlier than the FY 1979 budget.

I stopped by the HIIAC Building on the way home to see somerville. He believes his run at the 88" cyclotron during the early morning hours Yesterday was successful. He collected successfully the $212_{\mathrm{Fr}}$ from $206_{\mathrm{Pb}}$ plus $10_{\mathrm{B}}$.

Friday, December 16, 1977 - Berkeley - Lafayette

Baisden dropped in at 9:30 a.m. to discuss the results on Md chemistry. There is no evidence for Md(I). 


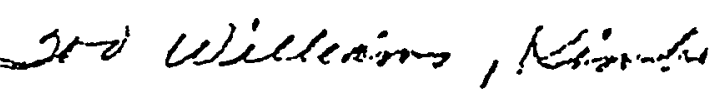

Mr. E. M. Vendley

Personnel Department

Oak Ridge National Laboratory

Post Office Box X

Oak Ridge, Tennessee 37830

Dear Mr. Vendley:

I'am writing to give you my evaluation of Rimberly $E$. Williams in connection with her application for a position with the Oak Ridge National Laboratory.

$\mathrm{Kim}$ is in the process of completing under my direction her graduate research work for the Ph.D and should have her thesis completed and written by summer. She has had a broad range of experience during her graduate career at the Lawrence Berkeley Laboratory. She was first involved in the work of the Ghiorso group to attempt to confirm or disprove the existence of 100 millisecond ${ }^{260} 104$, decaying by spontaneous fission, reported by Flerov and co-workers of the Dubna Laboratory in the Soviet Union. She played a key role in the identification of a $20 \mathrm{millisecond} \mathrm{spontaneous}$ fission activity produced by nuclear reactions where the production of 230104 might have been expected. She also has carried out a research with Nurmia which has set upper limits on the half-lives of neutron deficient new isotopes of curium, plutonium, and californium for decay by spontaneous fission.

Her main thesis problem has been on the identification of the new isotope ${ }^{2}{ }^{2} \mathrm{BK}$ and anomalies in the yields of. actinide isotopes produced by bombardments with light heavy ions. This has required rather careful and meticulous work in view of some of the small yields observed.

She has built an electro-spray apparatus for the preparation of radioactive actinide targets to be used in heavy Ion bombardments and has used this to prepare such targets for her own work and for many members of my research group. 
She has assisted in the teaching of an undergraduate course "Chemical Methods in Nuclear Technology," an Interdepartmental studies course (Departments of Chemistry and Nuclear Engineering) in a very satisfactory manner.

Her research experience has made her quite knowledgable in chemical separation methods for the actinide elements and thus she would fit in quite well with any program in this field.

Kim has the potential to be a:productive scientist. She has good knowledge of the fundamentals of nuclear science, good judgment on how to conduct experiments and exhibits initiative in her work. She willingly helps her colleagues and works well with a group. She has an excellent attitude toward her work, has a likeable personality, presents a good appearance and can be guaranteed to liven up any research group. She writes and speaks clearly and effectively.

sincerely yours,

Glenn T. Seaborg

GTS $/ k v$ 
Friday, December 16, 1977 (con't)

I went to room 203/70 at 10:30 a.m. to discuss our U plus Ar results to try to unravel the question of fusion-fission in deep inelastic reactions to account for iodine isotope and gold region yields.

I met in my office from 11:00 a.m. to noon with Nikolai Mikheev to discuss the disappointing results on Md(I). He still claims that Md(I) exists. I said I now doubt that Md(I) exists under the conditions of their experiments and that he and Spitsyn should write an article suggesting they may have been in error in reporting its existence. I said I will no longer refer to Md(I) in my publications.

Gordon Bixler called and we went over the agenda for the March ACS IAC meeting.

I wrote to Göte Klingberg, 'University of Göteberg, Sweden, to thank him for the new appendix (copy attached) to the van Gent paper No. 1. Letters of invitation to the symposium on January 23 (for elements 99 and 100) went to Ronald Lougheed (LLL), John Wild (LLL) and Leon. Leventhal (LFE Environmental Analysis Laboratories, Richmond). I also wrote to James Hogan and responded to a number of his questions regarding our current research efforts at LBL. I also sent him several pertinent reprints. Regarding funding for the Lawrence Hall of Science, I was asked by Director Laetsch and William Davis to write to Owsley Hammond to see what could be done to generate greater income for the hall, which I did.

I signed and mailed several letters prepared by Robert Brasted, chairman of the IAC subcommittee on the education of foreign students in this country. The letter is on behalf of the Foreign students "Guide" and is sent to prospective coordinators and referees for the development of the Guide and a descriptive pamphlet.

The NSD Program Committee meeting was held today at noon in Building 70, Room 191. Attending were Bernie Harvey (chairman), Luciano Moretto, Art Poskanzer, Richard Diamond, Frank Stephens, David Scott, David Hendrie, Hermann Grunder, Homer Conzett, Joe Cerny, Norman Glendenning, John Rasmussen and Wanda Smith. We decided to look for a divisional fellow through a search committee of Art Poskanzer (chairman), David Scott, John Rasmussen and one outside member; Ralph DeVries is the leading prospect. We voted to let Doug Greiner sit in at Program Committee meetings in place of Harry Heckman during Heckman's absence. The NSD Visiting Committee for 1978 is John Huizenga (chairman), Allan Bromley, Thomas Sugihara, Malcolm Macfarlane, Rayford Nix and P. Stelson. They will meet here March 29-31, 1978 .

I walked down to Latimer Hall to pick up my mail, then went by Building 70 and talked to Baisden and Morrissey about superHILAC time allotments. I found that Blair Jarrett was there installing our new pulse analyzer equipment. This should be working in about a month.

At 4:30 p.m., I went to the Christmas reception in the director's area. Elizabeth Rauscher told me her thesis is three-fourths written. 


\section{ADDENDUM TO THE VAN GENT PAPER NO 1}

THE ANCESTORS OF. MARRITGE JANSDR VAN BINCKHORST, KARRIED TO ARENT HENDRIKSZ VAN GENT (BORN 1568)

On p. 2 of this paper it was said that we do not have any information of Marritge Jansdochter van Binckhorst other than that she appears in her and her husband's will of January 16, 1625 and that she is mentioned as Maria van Binckhorst resp. Binckhorsten in a receipt given by her grandson Pieter van Gent on July 13, 1667 (p 5). A suggestion by Dr. Vink, that the family van:Binckhorst may belong to the The Hague - Delft district was also stated.

In $J_{u}$ ne $1977 \mathrm{Dr}$. Vink reported that. he was informed by a Mrs C.J. Kuiper of Zaandam, that she had a Iijsbeth Binckhorst from Leiden among her ancestors. This Iijsbeth had a sister, Hayken, and her father was a notary at leiden with the name of Jan. Dr. Vink thinks it highly probable that we have here the father of the wife of Arent van Gent. The name variants, Mayken, Marritge, Maria has no significance as they are forms of. the same name. In fact a daughter of Lijsbeth was called Marigje. Jan Janszoon Bilkhorst was sworn in as notary at Leiden on June 1, 158I. In the same year he is found in a register of inhabitants together with his wife and three children (Bevolking Reg. 1581, fol. 273). The family was then living in the Haarlemmerstraat.

Jan Janszoon Binckhorst mat of course, as Dr. Vinks thinks, have come to Leiden from The Hague (where the registers of births and marriages begin too late, however). It seems very probable that Arent van Gent learned häs trade as a notary at theloffice of his father-in-law in Leiden (the archives of Jan Binckhorst are lost, however).

The name of the wife, Vilvoorde, is the name of a town (Vilvorde) abput ten kilometers north-east of Brussels.

It may be of interest to note that the Swedish Maria van Gent thus seems to have derived her name from her father's mother's mother as well as from her father's mother.

Thefenealogical table should be as follows: JAN JANSZOON BINCKHORST, notary at Leiden from 1581, married to MAIJKEN GRIMMELIERS VAN VILVOORDE children:

\section{Xxix}

MAIJKEN, b before 1581, presumably married to Arent gan Gent before 1604
Lijsbeth, b before 1581, married March 7,1611 to Jeroen van der Tuyn, a meker of trousers and a dyer. Child: Marigje
Jan, b before 158 ? a government cler! buried May 9, 162 ? in the Hooglandscie Kerk 
I drove home through the rain. Helen and I, with Dave attending, held our Christmas reception for my research group and office staff and friends from 7:00-10:30 p.m. Attending were Kim Williams, Trish Baisden and her friend Bear Bechtel, Dave and Debbie Morrissey, Pat Quinn, her daughter Debbie and friend Greg storrs and daughter Celeste and friend Bert Schurr, Cindy Lee, Bonner Nishida, Simon Chin, Rose Marie McFarland, Nikolai Mikheev, Sam and Sondra Markowitz, Barbara Jacak, Mike Nitschke, Saburo Yashita, Sharon Date, Kathy and Steve Van der Haeghen, Jane Kingston and Dave Richards and Margie Hollander.

As we finished eating, I suggested that those from foreign countries present descriptions of how Christmas or its equivalent is celebrated in their countries, or was celebrated in their homes as they grew up. I began by describing the Christmas customs of Sweden; I described the Lucia Festival and my participation in the one held in Stockholm on December 13, 1951, our New Year's Eve dinners, etc. Nicolai Mikheev described the customs in the Soviet Union, Mike Nitschke in Germany, Bonner Nishida and Sharon Date in Japan and their homes here, Kathy van der Haeghen and Cindy Lee in China and their homes here, Simon Chin in Burma, Barbara Jacak and Debbie Morrissey in Poland and their homes here, Sam Markowitz in Israel, Trish Baisden in West Virginia and Kim Williams in New York. It was a very convivial evening and everyone seemed to enjoy it.

Saturday, December 17, 1977 - Lafayette

Helen and I watched the NFI football game between the Washington Redskins and the Los Angeles Rams. (Dianne and her friend Bob Puppa attended the game in Kennedy Stadium in Washington, D.C.) The Redskins won, 17-14, barely hanging on at the end. They could now have the "Wild Card" spot in the playoffs if either the Minnesota Vikings (tonight) or the Chicago Bears (tomorrow) lose their last regular season game.

I walked and jogged on the paved path (clockwise) around Irafayette Reservoir ( 33 minutes). Although it was not raining at the time, the path was covered with water in many places.

During the day, I worked on final drafts of February and March 1944 of my Met Lab Section C-I history.

During and after dinner, Helen and I watched the NFI football game between the Minnesota Vikings and the Detroit Iions. Minnesota's win, 30-21, diminishes the Redskins chance for a playoff spot.

Sunday, December 18, 1977 - Lafayette

I read nuclear science material off and on during the day in preparation for my Chemistry 123 lectures next quarter.

Helen and I watched, over the lunch hour, the San Francisco 49ers/Green Bay Packers NFI football game which the Packers won, 16-14. We learned that the Chicago Bears beat the New York Giants, 12-9, thus eliminating the washington Redskins from participation in the playoffs. 


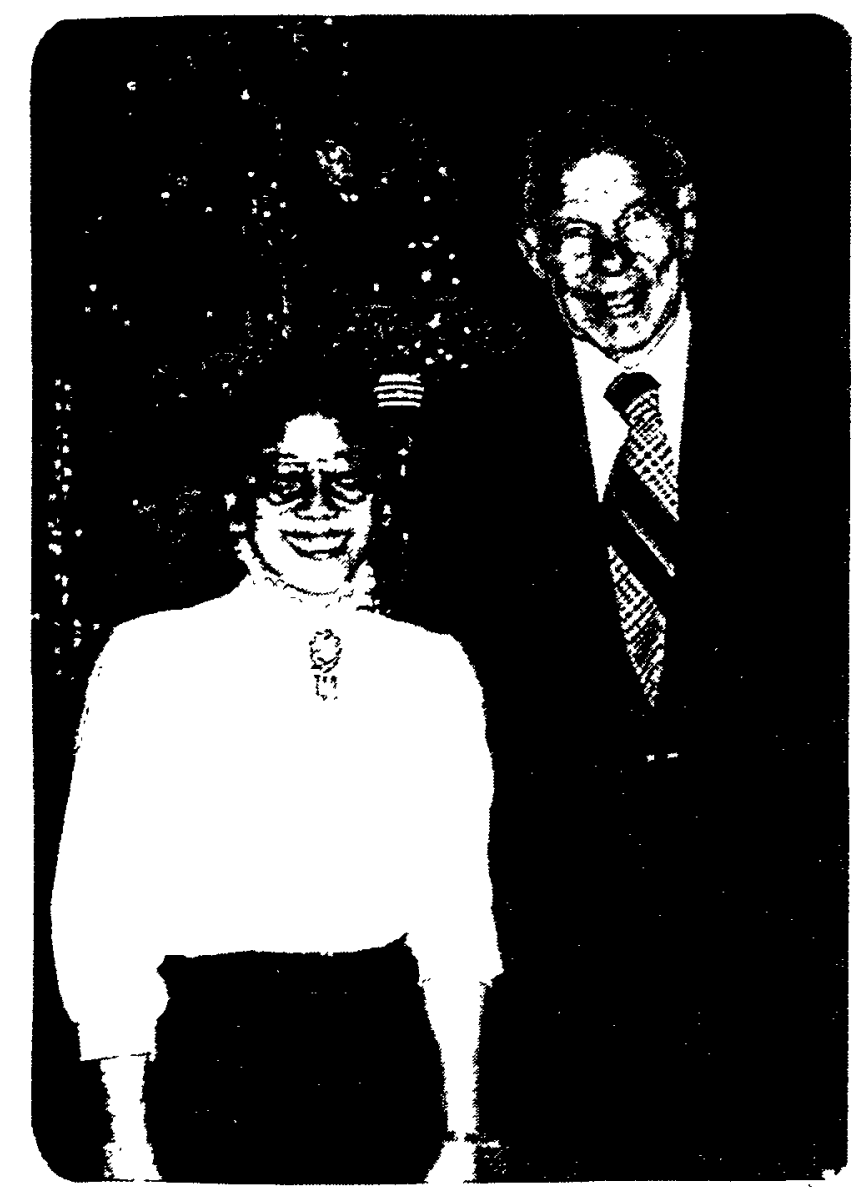

Sharon Date, GTS

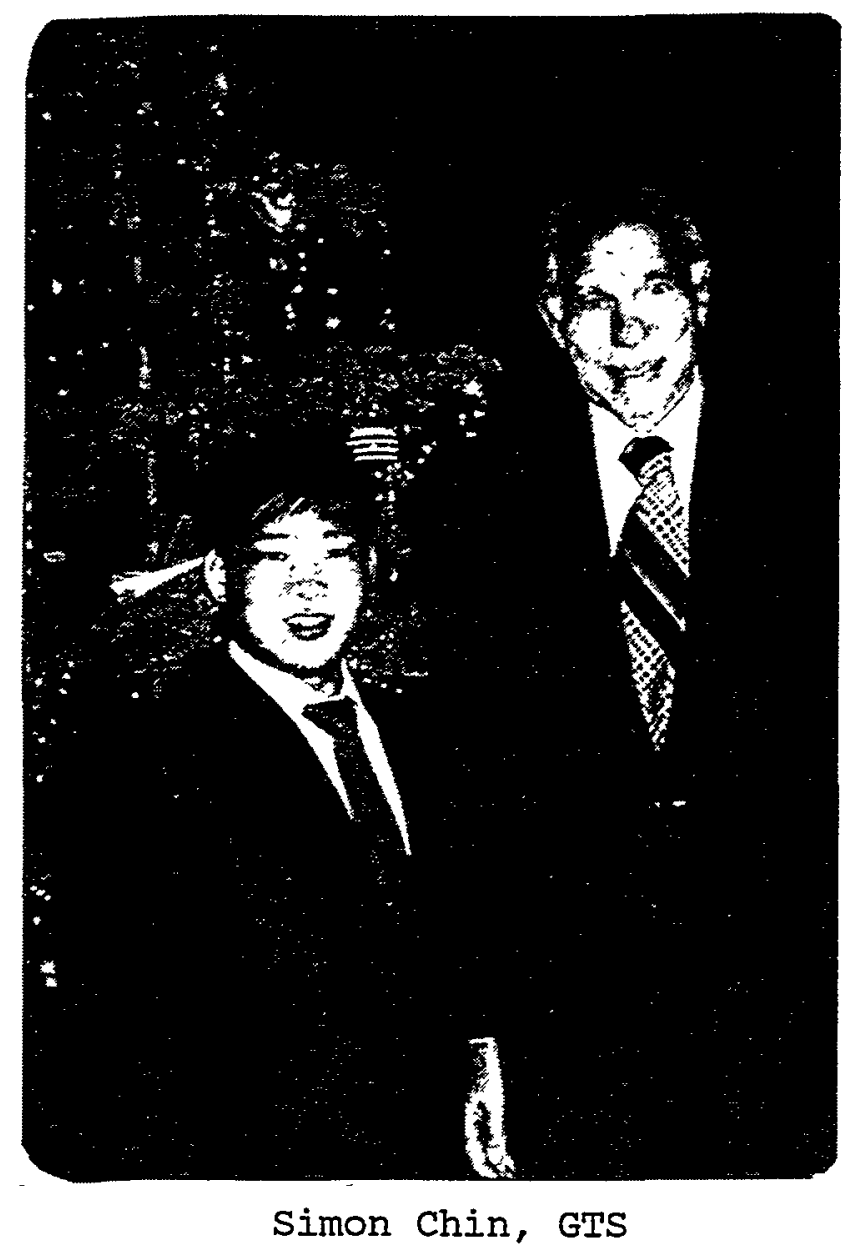

Christmas Party, Lafayette: 12/16/77.

Bonner Nishida

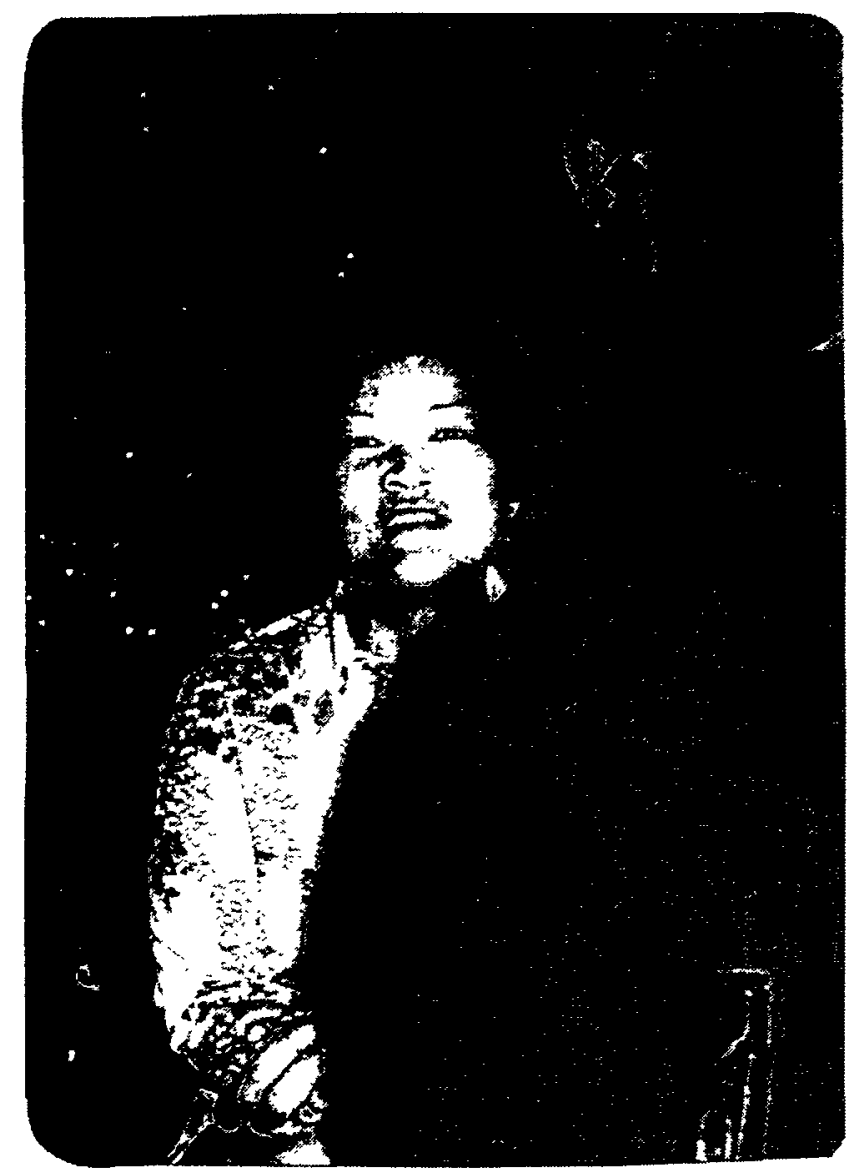

Cindy Lee, GTS

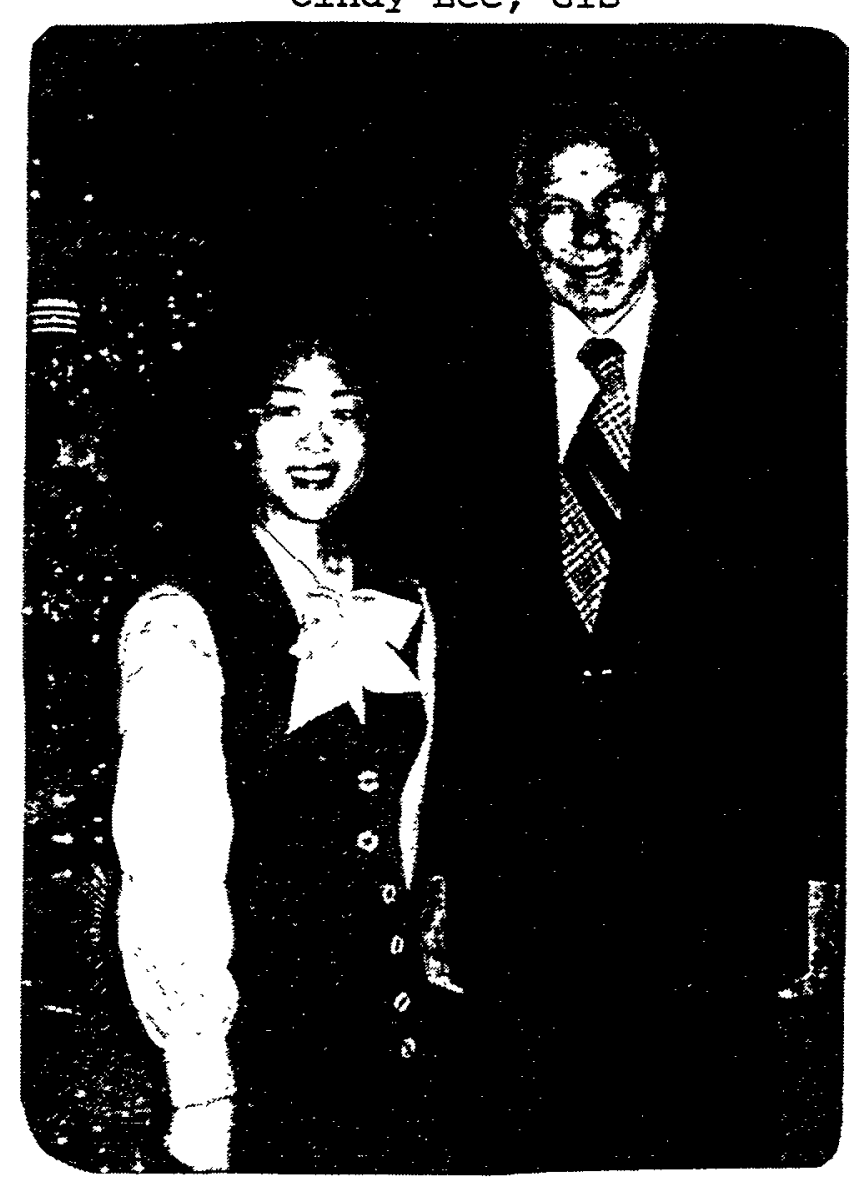




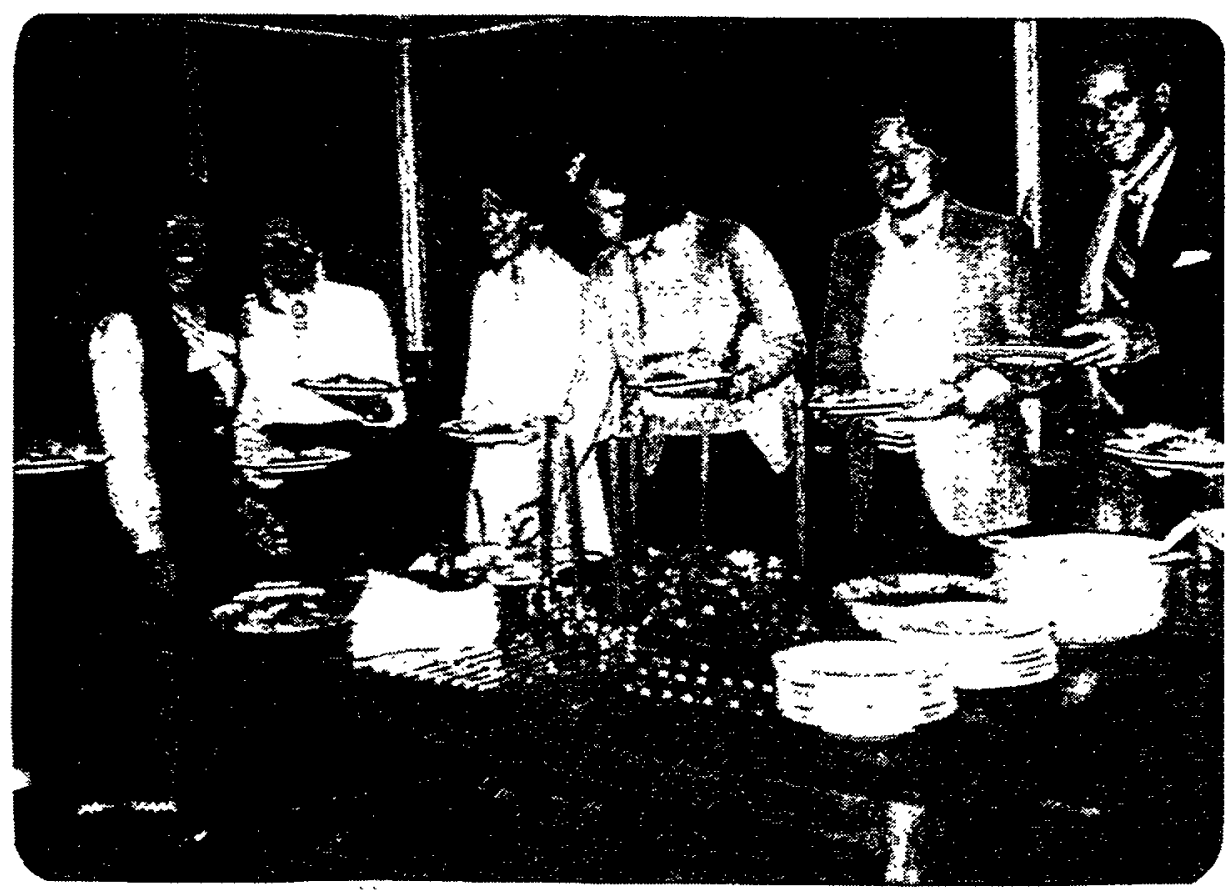

Cindy Lee, Sharon Date, Barbara Jacak Debbie \& Dave Morrissey and Sam Markowitz.

Christmas Party, Lafayette: 12/16/77.

Celeste Johnson, Steve Van der Haeghen, Sam Markowitz, Kim Williams, Pat Quinn, Debbie Johnson, GTS, Dave Seaborg, Mike Nitschke, Trish Baisden, Sharon Date, Dave Richards, Bear Bechtel, Cindy Lee, Nikolai Mikheev and Dave Morrissey.

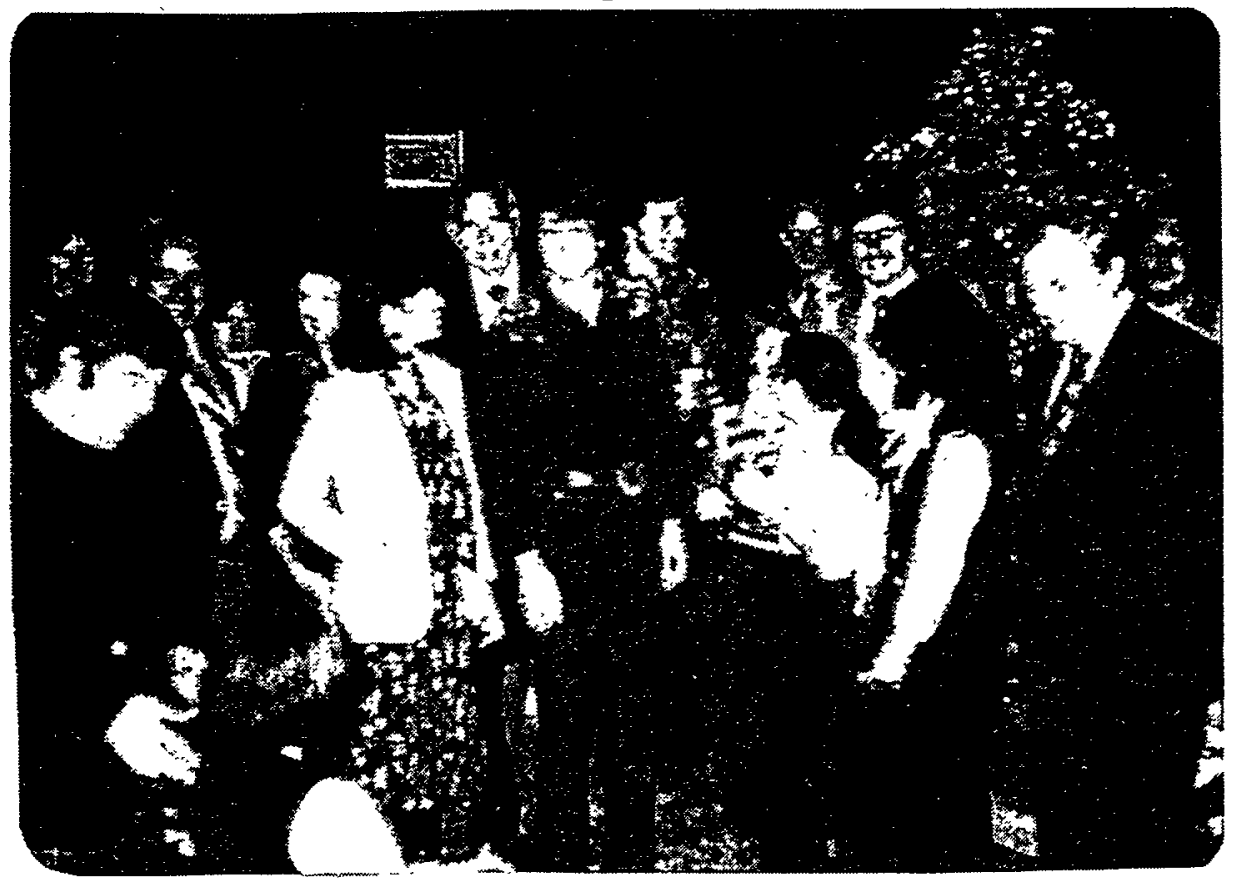


In the afternoon, we watched the Oakland Raiders/Kansas City Chiefs AFI football game which the Raiders won, 21-20. The Raiders will be the "Wild Card" in the AFI playoffs.

I went to Lafayette Reservoir where I jogged and walked (clockwise) around on the paved path ( 31 minutes).

Bill and Ann Chilcote came by at $6: 30 \mathrm{p} . \mathrm{m}$. and I signed his petition for his candidacy for the city council of lafayette.

Monday, December 19, 1977 - Berkeley

I called Joe Cerny regarding possibilities of James Hogan's teaching during his sabbatical here. Cerny said he might get $\$ 3,000$ per quarter (one or two quarters) to teach four hours of lab and two Chem 1 discussion sections. He can decide in February or March.

Iuis Alvarez dropped in at 10:00 a.m. to tell me he has decided to retire from his LBI position as of December 31, 1977.

Williams and I went down to the scheduling meeting in Building 88; we did not request any bombardment time but will want some at the January 3, 1978 meeting.

I had an hour-long meeting with otto and Morrissey in room 203/70 to go over Rollie's large backlog of heavy ion data, some of which can be processed by our new graduate students. I told Marsh that I will put him on the LBL payroll for the winter quarter.

I sent invitations to our symposium commemorating the $25 \mathrm{th}{ }^{\circ}$ anniversary of the discovery of elements 99 and 100 to Robert Silva, Earl Hyde and Lew Keller.

I had lunch in the cafeteria (it was too cold to eat outside) with Norman Glendenning (for awhile), Al Ghiorso and Dave Morrissey. Ghiorso told me about his interesting results with Yashita in the variation in ignization of heavy elements (Ta to $\mathrm{Cm}$ ) elastically scattered by 20 ions. I talked to Bill Carnall at ANL about his experiments on Md(I);
he found it absorbed on zirconium phosphate like Cs (and that Eu did not).

I Iistened to tapes of "Voices of the Past" for use in my Chemistry 123 course next quarter.

I went down to the Bevatron Building to attend a Christmas reception of Bevalac researchers hosted by John Rasmussen. I talked to Rasmussen about our plan for Chem 123. I also talked to Bernard Harvey about a possible letter to Mike McCormack to urge a reprogramming of funds for the uranium line item. Harvey is leaving for France tomorrow to spend Christmas at his summer house. 
Tuesday, December 20, 1977 - Berkeley

I worked on a letter to Mike McCormack (and others via carbon copies) from Earl Hyde and me, to request a supplemental of $\$ 800 \mathrm{~K}$ in FY 1978 to get our uranium beam facility started. I called Eric Leber and Hyde about this.

I went by to see otto and Morrissey to discuss the proximity force concept of $\mathrm{J}$. Blocki et al. McFarland was there.

At noon, Pat and I went up to the HILAC Building to attend the annual SuperHILAC Christmas party. Ben Mottelson was there; he and his parents are visiting his sister in San Francisco over Christmas. I described to him a broad range of our heavy ion experiments, the status of superheavy element experiments (including my idea for their production via the deep inelastic reaction), my views on the Dubna claims for SHE in meteorites and ground water, etc.

I talked to Hermann Grunder. He is getting some design work done on the third injector despite the decision to not transfer LBI funds for this. He thinks he can support (fund) the building of a direct beam area for actinide targets. I arranged with Bob stevenson to have a meeting on this at 2:00 p.m. Thursday. We had our lunch (hamburgers, punch, etc.) at the party in the area above the target area, then went into the Conference Room for the program. 'There a group of singers sang Christmas carols. This was followed by a program presided over by Santa Claus (Jose Alonso) and Mrs. Santa Claus (Trish Baisden). They presented a number of "annual awards." I received a high in the sky award - a $33 \mathrm{rpm}$ record "The short People." The "sponsors" of the party (Richard Diamond, A1 Ghiorso, Hermann Grunder, Earl Hyde (who had left), Ed Lofgren and I) received each a basket of fruit containing a bottle of wine. The conference room was beautifulIy decorated--Cindy Lee was largely responsible for this. Otto, Morrissey, McFarland, Cindy Lee, Diana Lee, Matti Nurmia, Ron Lougheed, Jerry Iandrum and John wild were among those present. After the program, the SuperHILAC Band played music and a number of people did some dancing.

I walked back down to my office; John Dana, KQED (Channel 9), asked if I would participate in a TV program tonight (Dan Ellsberg is going to talk on nuclear safety issues) to present the pro-nuclear view. I regretted this invitation.

I talked with Joseph Potenza of Rutgers University about information I need to write a letter of recommendation for Lester R. Morss. I had no current information on his teaching responsibilities or his present writing and research efforts with which Potenza supplied me, ending our conversation with the comment that Lester Morss is "... one of the most dedicated teachers I know."

I replied to $\mathrm{S}$. Biswas (Department of Chemistry, Purdue University) and Rajendra Singh (Department of Chemistry, Banarus Hindu University, India) that I was unable to add an additional post doctoral position here at IBL; however, I would be glad to have Mr. Biswas as a member of our group should he find it possible to obtain a fellowship or support from an outside source. 
I went to room $293 / 70$ and tajked to otto and Morrissey to make plans for a possible ${ }^{4} \mathrm{Ca}$ plus $248 \mathrm{Cm}$ bombardment near the barrier energy (245-Mev) in the middle of January. We will check to see if Ken Hulet would like to collaborate in this effort to produce sHE. We will also do ${ }^{48} \mathrm{Ca}$ plus $\mathrm{Ag}$ to complete work on this reaction. Walter Loveland called during our session and we brought him up-to-date I also discussed with otto some changes for our iodine isotopes ( $40_{\mathrm{Ar}}$ plus U) paper which is nearly ready for submission to Physical Review Letters. (We have received notification that our recoil range paper, by otto, Fowler and Seaborg, has been accepted by them, but we still have recejyed no worg as to the fate of our lowered fusion cross section ( ${ }^{48} \mathrm{Ca}$ plus $\left.208 \mathrm{~Pb}\right)$ paper.

Bonner Nishida told me that her application for admission to the UCB Department of Chemical Engineering had been turned down.

Bill Dauben called to tell me that he has learned from Bob Sachs of ANL that John Rasmussen received only nine votes from the physics section for his joint election to NAS (Physics and Chemistry sections --he received 75 votes in chemistry), which means he will not be put on the ballot for the final vote in the spring. I will have to determine how to proceed next.

After returning to my office awhile, I drove home and had dinner in the playroom with Helen and Dave. Dave went to Lafayette square to hear the singing of Christmas carols. Helen and I watched on TV a debate between Daniel Ellsberg and Lowell wood on the role of UC in operating LLL. Then I went to the study, as usual, to read my papers, correspondence, etc.

Wednesday, December 21, 1977 - Berkeley

I dictated letters of recommendation for Lester Morss and David Hendrie (copy of latter attached).

I met with Iuciano Moretto, along with Otto and Morrissey, to discuss our $4{ }_{A r}$ plus $U$ recoil resulfs and their impact on the Dubna interpretation of their $4 \mathrm{Ar}_{\mathrm{Al}}$ plus $243 \mathrm{Am}$ as very asymmetric fission. He may do some kinematic experiments to check on this.

Gordon Bixler called at 12:15 p.m. I approved a statement on activities of the ACS Office of International Activities for use at the board and council meeting at the spring meeting in Anaheim. I also suggested he proceed with the drafting of the letters of inquiry regarding an ICS. He said he has a letter from Bentley Glass (of the AAAS Committee on Scientific Freedom \& Responsibility) again requesting ACS involvement; Bixler will write him to say we will discuss this at our Anaheim IAC meeting.

I had lunch in the cafeteria with McFarland. A choral group sang Christmas carols. She told me something about the circumstances surrounding her marriage. After lunch, we went by her office and I gave her some reprints and also some of my books to keep in room $203 / 70$. 
Professor Alex $\mathrm{J}$ : Dragt

Dapartment of Physics and Astronomy

University of Maryland

College Park, Maryland 20742

Dear Professor Iragt:

This is in reply to your request for my evaluation of Dr. David liendrie in connection with his possible appointment to the position of Professor of Physics and Director of the Cyclotron Laboratory at the University of Maryland.

I have lnown David flendrie for about ten years and more intimately for the last five years covering the period of my return to the Lawrence Eerkeley Laboratory. I rate hin caite high in both research and administrative ability and accomplisiments.

Iis research achievements can be evaluated guite well from a study of his research papers. I can say that he directed the design, construction and implementation of the spectrometer at the $88^{n}$ Cyclotron. Iis concept was the first of the new type spectrometers designed for active focal plane arrays instead of photographic emulsions for detectors. Innovative aspects were the use of active quabrupoles and sextupoles instead of detailed shaping of iron pole pieces, rotation of the focal plane for normal entry, crucial to high resolutions active detector work, and use of air pads for changing angles.

I an most Eamiliar with his work during the last five years involving heavy ion reactions at the $88^{\prime \prime}$ Cyclotron. He has been the leader of a group that discovered a marked iiscrepancy in the matching of theoretical cross sections in simple transfer reactions at high energies where no systematic deviations from the theory are seen at $10 \mathrm{keV} /$ nucleon and lower. Eis group has also discovered a strong break in the temperature measured in reactions such as deep inelastic of compound nucleus, the break with theory again occurring at about $15 \mathrm{MeV} /$ nucleon. Be has a special interest now 
in attempting to tie the explanation to much higher energy Bevalac work and to this end he is working with a post doctoral student on similar studies at the Bevalac.

Dr. Hendrie has not taught classes at Berkeley but he has supervised the Ph.D. thesis work of students such as J. hoss (now an Assistant Professor of Physics at Texas A \& M), J. Sherman (How workint with P. D. Barnes at Ios Alamos Scientific Laboratory), and the research of numerous post doctoral students.

Fendrie has served rather extensively in administrative assignments at the Lawrence Berkeley Laboratory. Fie has been. the Director of the 88" eyclotron since 1973; has served as Chairman of our Nuclear Science Division Staff Committee; Chairman of our Nuclear Science Division Advisory Comittee and is now serving as Chairman of our Nuclear Science Division Committee on Accelerator Planning. In the service category, he has been a member of the IBI Equal Employment Opportunity Council (1974-77); a consultant to the NSF Science Panel (1976-77); member of the APS Committee on Professional Concerns; organizing Co-chairman of the "Symposium on Nuclear Science at Cyclotron Energies" at Calcutta, September 1977, and a member of the organizing comittee of the "Cluster Conference" to be held in winnepeg, Manitoba in June 1978.

I would compare David Fendrie favorably with the other specialists in his general field here at the Iamence Berkeley Laboratory.

I can recommend David Hendrie for the position at the University of Maryland, especially from the standpoint of the research and administrative components. I would consider it a rather serious loss to the Nuclear Science Division here should he decide to leave us. Such an apprehension constitutes an ultimate recommendation.

Cordially yours,

Glenn T. Sezbors

GTS:Pq 
I went by room $203 / 70$ to talk to Morrissey about calculations of heavy ion cross sections according to the Bass model. otto told me he has accepted a position with Sidney Phillips in the Energy and Environment Division of LBL.

The letter to Mike McCormack was prepared for mailing today, signed by Earl Hyde and me (copy attached).

From 3:30-4:30 p.m., I went down.to room 1116 on the first floor of Building $70 \mathrm{~A}$ to attend the Christmas party of the actinide chemistry and Dave Shirley's groups. Pat also attended for a short while. I introduced Rose Marie McFarland to Andrew Streitwieser, Kenneth Raymond, John Conway, David Templeton and Jerry Bucher.

On my way home, I went by to see Otto and Morrissey. Otto told me Ken Hulet is not sure he wants to do another experiment to look for $\mathrm{SHE}$ from ${ }^{248} \mathrm{Cm}$ plus ${ }^{48} \mathrm{Ca}$ (at energy close to the barrier).

Thursday, December 22, 1977 - Berkeley

I distributed Christmas presents to Pat Quinn, Kathy Van der Haeghen, Sharon Date, Margie Hollander and Jane Kingston.

I dictated letters to Joseph Crook at Western Washington University in Bellingham in response to his inquiry about my possible interest in a position there as Dean of their Environmental studies program (I declined) and to Norman Jacobson at American Nuclear Society Publications in Ia Grange Park, Illinois, enclosing a revised foreword (copy attached) for John Cleveland's "The Chemistry of Plutonium." I also replied to James $\mathrm{C} .{ }^{\prime} \mathrm{W}$. Chien at the University of Massachusetts in Amherst that I would be pleased to write the dedication for the Festband in honor of John Willard's seventieth birthday.

Baisden dropped in to tell me she is applying for an assistant professorship in inorganic chemistry at the University of Miami and elsewhere. I agreed to write letters of recommendation for her. We also discussed her research and paper writing plans.

I called Kevin wolf to invite him to join us in a collaborative effort in our research program on determination of actinide and $\mathrm{Pb}$ to $U$ isotope yields in heavy ion bombardments of actinide targets. He accepted. He will arrive on January 5 for a year's stay at IBI, working primarily with Arthur Poskanzer.

I called Sam Markowitz and he agreed to give a lecture on "Techniques" to our Chemistry 123 class on Tuesday, March 14.

I attended a meeting in the conference room on the second floor of the annex to Building 71 (the HIIAC Building), to discuss the design and construction of a containment system for the bombardment of highly radioactive actinide targets (such as $248 \mathrm{~cm}$ and $249 \mathrm{Cf}$ ). Present were Bob Stevenson, Frank Selph, Jim Haley, Bob Force, Beat Ieeman, Rollie Otto, Dave Morrissey, Trish Baisden, Rose Marie McFarland, Richard Eggers and Bette Shipley. We agreed on a design. I asked that it be built in time for use in March if possible. We set Wednesday, January 21 , as the time for our next meeting. 


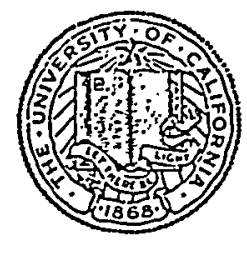

\section{Lawrence Berkeley Laboratory}

University of California Berkeley, California 94720

Telephone 415/843-2740

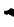

December 2I, 1977

The Honorable Mike McCormack, Chairman Subcommittee on Advanced Energy Technologies 1202 Longworth House Office Building Washington, D.C. 20515

Dear Miḳe:

-. The High Intensity Uranium Beams Construction. Project (78-12-b). at Lawrence Berkeley Laboratory is the only planned accelerator that will give U.S. scientists beams of ions from the lightest to the very heaviest elements. Approximately one-half of the construction cost will be used to upgrade the existing SuperHILAC so that it will be able to provide intense low-energy beams of all atomic nuclei up to uranium. The remainder of the funds will be used to modify the present Bevalac machine so that it can accelerate these same nuclei to very high velocities-up to $95 \%$ of the speed of light. The project was rated as a high priority item in a. 1977 National Acaderiy of Sciences study of the Future of Nuclear Science.

- In its present configuration, the SuperHILAC can accelerate much heavier ions than the Bevalac. Scientists from all over the United States and abroad at both machines increasingly need. the heaviest available beams, but they cannot now have them simultaneously. Thus an experiment with argon ions at the Bevalac forces the use of the same particles at SuperHILAC even though users of that machine almost invariably need much heavier pariicles. This rapidly increasing inefficiency and under utilization will be fully resolved by the proposed upgrading of superHILAC. Once that is completed it will be possible to deliver the desired beams simultaneously to users of the two machines.

The Iow-energy beams that the SuperHILAC will provide are already available from the new German Unilac machine and the competitive position of U.S. nuclear scientists is maintained only by their greater experience in research with heavy ions. This advantage is obviously temporary. Without an early availability of the Uranium Beams Project, we will lose our leadership in an important part of U.S. nuclear science.

The Project provides our best opportunity to synthesize new Super Heavy chemical elements by the bombardment of transuranium element targets with beams of uranium nuclei from the upgraded SuperHILAC machine; any further delay is likely to put us behind in this exciting and important field of research. Beams of lead nuclei, presently unavailable, are needed for studies of the behavior of atomic nuclei under conditions of very rapid rotation. The heaviest beams are essential for answering several fundamental questions in atomic physics. 
The Honorable Mike McCormack -2- December 21, 1977767

These same beams of very heavy nuclei further accelerated by the upgraded Bevalac will open up the possibility of studying totally new phenomena and new forms of matter. It already seems certain that the collision of two uranium nuclei at high velocity will produce a composite system whose denisity will be 5-6 times that of ordinary nuclei. Thus for the first time nuclear scientists will have an opportunity to study nuclear matter at high density and temperature. Its properties are now only a matter for speculation and they may well be totally different from those of ordinary nuclei.

The upgraded Bevalac will be able to accelerate the types of heavy ion beams that have been proposed as igniters for fusion power production. : While the beam intensities will be too low to trigger. a fusion reaction, they will be invaluable for studies of some fundamental problems of Heavy Ion Induced Fusion. Experiments with the beam of iron nuclei-the heaviest so far available--indicate that the magnitude of the pre-heating of the fusion pellet may be substantialiy greater than present estimates.' The earliest possible construction of the upgraded Bevalac is needed to answer this and other quiestions that are very important to the Heavy Ion Fusion program.

The minimum funding in FY'7-8 that would permit construction of the Uranium Beams Project to start in April/May 1978 is $\$ 800 \mathrm{~K}$. $E R D A / D O E$ and LBL plans were based on the assumption that the project would be funded in FY'78. The engineering effort required at $\mathrm{LBL}$ is therefore available and the preliminary R\&D work is more than 95\% complete.

Should \$800K be made available in FY'78, the balance of funds for completion of the project is estimated to be $\$ 5.650 \mathrm{M}$ (total construction cost of $\$ 6.450 \mathrm{M}$ ). This is greater than the construction cost of $\$ 6.0 \mathrm{M}$ initially requested for $F Y^{\prime} 78$ to compensate for inflation only. The scope of the project. has not been enlarged.

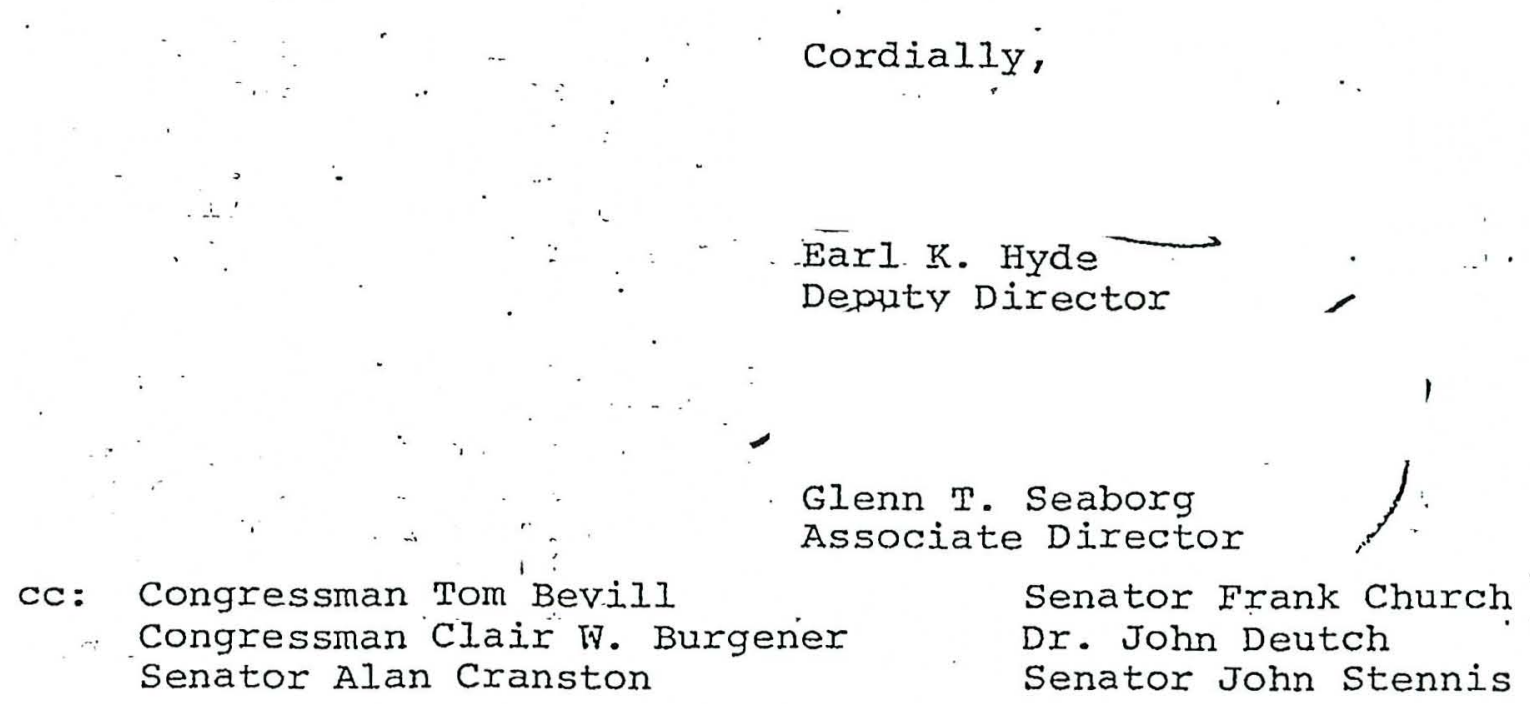


bcc: Dr. John Andelin

Mr. James Forcier

- Mr. Ezra Heitowit

Mr. Proctor Jones

Dr. Eric Leber

Mr. Robert Schule

Dr. Willis D. Smith

Mr. Hunter Spillan

\footnotetext{
.. Mr. Peter Goldschmiat

Dr. H. A. Grunder

Dr. B. G. Harvey

Dr. E. K. Hyde

Dr. A. M. Sessler
} 
Prepared for reprint of $O$. J. Wick's volumes on The Plutonium Handbook

FOREWARD

It was a little more than a quarter of a century ago on the night of February 23, 1941, that A. C. Wahl, J. W. Kennedy and $I$ succeeded in oxidizing a minute quantity of a new synthetic element, Element 94. This was the key step in the discovery of the new element, for which more than a year later we suggested the name plutonium. In the intervening years, there has been an enormous scale-up in the production of plutonium amounting to a factor of more than $10^{18}$.

Even as one who has been continuously associated with plutonium since its discovery, I never fail to be somewhat awed by how much knowledge about this synthetic element has been gained in the 35 years that have elapsed since we first performed the discovery experiments. Working with macroscopic quantities of plutonium is not an easy matter because of its radiological toxicity. On the other hand, its radioactivity makes it readily measureable in chemistry research. It is quite apparent that any disadvantage involved in studying the chemistry of plutonium is overridden by both the scientific interest in it as a new element and by the economic potential that it holds. Plutonium-239 is an article of commerce on an international scale because of its potential for use as fuel in fast breeder reactors to produce electricity for an energyhungry world. Transactions involving hundreds of kilograms have occurred: However there are some who so fear its toxicity and 
potential for the proliferation of nuclear weapons that they would forego its use. I believe that the need for energy will be so severe in many parts of the world that these negative aspects must and can be overcome. Tomorrow the world's inventory of plutonium might amount to hundreds of tons and more, as it is produced in convertor reactors and as it is consumed "and bred in fast breeder reactors. Chemical knowledge can contribute to safe handling and provide means of dealing with its toxicity.

The technical requirements that will be placed on plutonium as a nuclear fuel will become more stringent as the operating temperatures of power reactors are increased to obtain greater thermodynamic efficiency. There will thus be a general trend toward increased usage of ceramics and cermets in which plutonium or a mixture of uranium and plutonium will be the metallic constituents. This in turn will require the consideration of novel fuel reprocessing methods in which the fissile and fertile isotopes can be separated economically from fission products. Thus chemical technology and metallurgy will be as important as ever in making full use of nuclear power to satisfy the escalating demands for electricity.

Even more exacting chemistry is needed for the preparation of plutonium compounds employed to fuel radioisotope-powered electrical generators and other types of energy sources with plutonium-238. Some of these devices, used on the moon and for the exploration of planets, convert the decay heat of plutonium-238 
to electricity, and the heat sources operate at very high temperatures for. protracted lengths of time. The heat sources must survive unusual transient conditions as well. The preparation of ultra-pure plutonium-238 and compounds of the isotope with enriched oxygen-16 (to reduce neutron emission by alpha-n reactions) is being investigated for use as power sources in cardiac pacemakers and for artificial heart pumps. The chemist and metallurgist are at the forefront of this type of work.

As we stand on the threshold of what is likely to be a period of intensive development in the use of plutonium, it is especially valuable to have available this very comprehensive and authoritative treatise. It should provide much assistance to those who will be working to make plutonium fulfill its promise.

Glenn T. Seaborg University of California Berkeley, California 
Pat, Trish and I walked down to Building 88 to attend the traditional pre-Christmas Iuncheon. After Iunch, Lew Bish made some welcoming remarks and then called on Dave Hendrie. Hendrie gave some remarks expressing appreciation for the efforts of the people working in Building 88, then introduced some people who are retiring or leaving on sabbatical and gave them gifts. This included Dick Perkins who is retiring.

I walked back up the hill with Earl Hyde. At 2:30 p.m., I walked down to the campus to pick up my mail.

From 3:30-4:00 p.m., I met with otto in my office to discuss his termination with me and start in the Energy and Environment Division. He will start in E\&E on March 1, after he has finished writing a number of papers for publication (which we identified). He has started Pat McGaughey and Kenton Moody on the treatment of data from two of our experiments. He will come back to participate in SHE experiments. We will decide later whether he will attend the APS meeting in Washington, D.C. and the meeting in Puerto Rico to give papers. We then went to room 203/70 to explain to Morrissey our agreed upon schedule for otto.

Dianne called at 10:30 p.m. She is staying at Harrison St. She went to the Redskins-Rams football game last Saturday with Bob Puppa, Bill Puppa and Pete. She felt fine until early this week when she came down with the flu; she is nearly recovered now.

Friday, December 23,1977 - Iafayette

I spent a good part of the day reading and preparing my lecture notes for Chemistry 123. In the afternoon, I jogged and walked around the paved path (clockwise) at Lafayette Reservoir (30 minutes).

Saturday, December 24, 1977 - Lafayette

Steve and E. Coli arrived from Sacramento, where he left his cat with Al Jacobson, at 10:30 a.m. He drove up from San Diego on Wednesday, managing to drive through the Tehachapi during a break in the wind and snow.

We aII (Steve, Dave, Helen and I) watched the AFL playoff game, in Baltimore, between the Oakland Raiders and the Baltimore Colts. The Raiders won, in the 6th quarter, 37-31.

We all had Iunch in the playroom, then watched the other AFI. playoff game between the Denver Broncos and Pittsburgh steelers, played in Denver. During halftime and the 3rd quarter, Dave and I went to Iafayette Reservoir, where I jogged and walked around on the paved path (30 minutes). We returned to watch the Broncos win, 34-21.

Off and on during the day, I read proof on January 1944 of my Met Lab section C-I history.

At 6:00 p.m., we phoned Harrison St. in Washington. Helen, Steve, Dave and I talked to various people--Dianne, Iynne, Pete; Bill and Bob Puppa and Bill Cobb were also there. Dianne and Pete have 
been suffering from the flu. Lynne and Bill are staying at the Roth's house to watch over it; Helga went to England following Ted's suicide.

We all (Helen, Steve, Dave and I) had our Christmas Eve dinner-potato sausage, with rice pudding for dessert--in the kitchen.

Jeanette called at 8:30 p.m. and talked to Helen, Dave and me to wish us a Merry Christmas.

We opened our presents starting about 9:00 p.m. Helen gave me the books "The Pacific Crest Trail - Volume 1: California" and "A Measure of Standing by Queen Frederica," a pair of hiking socks and a box of mints. Dianne gave me a tape of Morton Downey songs, Dave the books "Rendezvous with RAMA" by Arthur C. Clark and "The Tao of Physics" by Fritjov Capa and Iynne and Bill a Photoflip (a rotating picture-holder). I gave Helen some books and a robe.

Sunday, December 25, 1977 - Lafayette

Christmas Day. I received a Texas Instrument computer in my stocking.

I worked on my lecture notes for Chem 123. At noon, Steve and I went to Lafayette Reservoir and jogged and walked (clockwise) around on the paved path (30 minutes).

We had our Christmas turkey dinner at 2:30 p.m. Helen, Steve, Dave and $I$, with guests Alice Thompson and Paul Segall and his friend Judy Marrell. Alice brought us a large book of paintings from the Peking Museum, a large box of See's chocolates and a fruit salad. We spent the afternoon in conversation at the dining room table and in the living room.

I read Chemistry 123 material in the evening. Monday, December 26, 1977 - Lafayette

I worked on April 1944 of my Met Lab Section C-I history off and on during the day.

In the late morning, Helen, Dave, Steve and I watched the NFI playoff game between the Dallas Cowboys and the Chicago Bears; the Cowboys won, 37-7. We had lunch in the playroom, then I went to Lafayette Reservoir to jog and walk around on the paved path ( 30 minutes). I then joined the others to watch the other NFL playoff game between the Minnesota Vikings and the Los Angeles Rams; the Vikings won, 14-7.

Helen, Steve and I had dinner in the playroom. Dave had dinner at the home of Harold and Mary Paige.

Tuesday, December 27, 1977 - Lafayette - Berkeley

I worked on my Chem 123 notes off and on during the day. Helen, Dave and I had Iunch in the kitchen. Steve was out shopping. 
In the afternoon, I drove in to the university, picked up my mail at Latimer and IBL and went to room $203 / 70$ to talk to otto who was working on our $40 \mathrm{Ar}$ plus $\mathrm{U}$ recoil range paper.

In the late afternoon, Dave and I went to Lafayette Reservoir. I jogged and walked (clockwise) around on the paved path (29 minutes). The distance is 2.7 miles with much up and down. Dave jogged the opposite direction.

Helen, Steve, Dave and I had dinner in the playroom. Wednesday, December 28, 1977 - Lafayette

I worked on Chemistry 123 notes off and on during the day. In the afternoon, Steve and I went to Pacific Stereo. I bought a Harman/Kardin audio amplifier (turned in my TransAudio 5502) and a TransAudio 4500 cassette deck.

Helen, Steve, Dave and I had dinner in the playroom. Steve left in the late evening to spend two days with his friends, Carol and Dave White in Atherton.

Thursday, December 29, 1977 - Lafayette

I worked on my Chemistry 123 notes. In the early afternoon, I went to the university to pick up my mail.

At 3:00 p.m., Percy Jennings, Kay Petersen and Lloyd Townley (chairman of the Lafayette Planning Commission) came by. We discussed the status of the Jennings property and the need for hiker's access through it to Lafayette Ridge. Jennings wants to sell to build four homes; he doesn't want access through it on the fire road but would agree to access along west or east edges (the city of Lafayette owns a strip along the west edge). We rode up Monticello Road and walked on to the Jennings property. Townley said approval of the development might be contingent on a trail easement. Jennings promised to tell me the price of the 18-acre "meadow" before going to developers so I can check with EBRPD. When we returned to our house, Jennings told me he doesn't have a right-of-way over the water tank road granted by the Ewells and Eisenbergs to the Hastings (Nordstrom) portion of his land, and he may sue to get it.

Helen, Dave and I had dinner in the playroom. Peggy Willig, Lynne's friend from Washington school days, came to stay with us for a few days. She arrived with Nathan Laks at 8:00 p.m.; he stayed awhile and we had tea in the living room.

\section{Friday, December 30, 1977 - Lafayette}

I worked on my Chemistry 123 notes. At noon, I went to Lafayette Reservoir and jogged and walked around the paved path ( 32 minutes). kitchen.

Ben Orlove joined Peggy, Helen, Dave and me for lunch in the 
I drove in to LBL to pick up my mail. In a letter, Reinhard Brandt, told me Hans-Joachim Becker has found a tenure position so he will not have a postdoc position with me this summer.

Steve returned from Atherton while I was in Berkeley. Harry and Molly Reeves and their children (Wesley, 6, and Ulla-Britt, 2,) came by for tea and cookies.

Helen, Dave, Steve, Peggy and I had dinner in the playroom while watching evening news on TV. Harvey Chinn arrived during dinner to attend Dave's Hammarsköjld House party to be held at our house this evening. A little earlier Marco and Joan Dondero and their little daughter, Rachel, came by and visited with us a while. Marco is a former Hammersköjlder.

The following attended Dave's party: Dave and Chris Crawford, Nancy Knowlton and her husband Steve Nedelson, Julie Nadich, Scott Smith and his friend Lynn, the James Hongs, Dennis Briggs, Paul Grant, Harvey Chinn, John Holdahl, Bob Joost and Mary Commans; Dave, James, Paul, Harvey, Marco and Mary are former Hammersköjlders.

Saturday, December 31, 1977 - Lafayette

Steve left this morning to visit his friends, the Brent Hubers, in Quincy.

Helen, Peggy and I took a hike up Mt. Diablo on Mitchell Canyon Fire Trail. We had our backpack lunch at Deer Flat. We continued on Deer Flat Trail. I went on ahead to Juniper and part way up to the top, then hiked back, catching up with Helen and Peggy as they were nearing our starting point.

Helen, Peggy, Dave and I had dinner in the playroom. I worked on my Chemistry 123 notes in the evening.

At midnight, Helen, Peggy and I watched, on TV from the Waldorf Astoria Hotel and Times Square in New York, the start of 1978 with GuY Lombardo's orchestra (conducted by Victor Lombardo). We drank toasts of juice. Dave was away at a friend's home. 
INDEX 1977

Aalbersberg, Bill 354

BOID = picture

Abell, Bess 334

Abou-EI-Azm, A. 523

Abraham, Bernard 557, 620

Abrams, Allan 389

Acuna, Bonnie 496

Adams 5

Adams, Bill 23

Adams, John 674

Adams, Maxine 496

Adams, Mrs. John 674

Addison, John 312

Adler, Kurt 747

Adlif, Paul 486

Adolfsson, Bengt 596-600, 597, 599

Adolfsson, Gösta $600,603,609$

Adolfsson, Irene (Mrs. Bengt) 596-600, 597, 599

Adolfsson, Irene (Mrs. Gosta) 600, 603

Adolfsson, Jenny (Mrs. Karl) 596-600, 597. 599

Adolfsson, Karl 596-600, 597, 599

Adolfsson, Lena 600,603

Agnew, Bill 158

Agnew, Harold 223

Ahlström, Arne 600

Ahlström, Barbro 600

Ahrens, Helmut 572-576, 575

Ahrens, Mrs. Helmut 576

Ahrland, Sten 524, 533

AI-Zuhair, Harb 473

Albaugh, Edrey (Mrs. Fredric) 200

Albrecht, Alan 140

Albrecht, Pedro 140

Albridge, Roy 720

Alder, Henry 279

Aleklett, KjeII 531, 594

Alexander, Albert 561

Alexander, George 80

Alexander, John 746

Alexander, Marjorie (Mrs. Albert) 561

Alexander, Scott 416,458

Alhén, Karl-Eric 608

Allaway, Bill 330,331

Allen, Howard 473

Allen, Richard 145, 146, 186, 187, 409, 486, 709

Alonso, Carol (Mrs. Jose) 28, 40, 52

Alonso, Jose 515, 761

Alpen, Edward $328,441,644$

Alperin, Mike $75,89,98,137$

Alsmiller, R. J. 528

Alter, Chester 126, 206

Alvarez, James 632

Alvarez, Luis $6,84,265,345,379,441,632,634,636,644,691$, 751,760

Ammendolia, Cindy (Mrs. Paul) 268

Ammendolia, Paul 268 
Amon, Elliott 496, 497

Andelin, John 97,103,105, 111, 144, 149, 150, 213, 333, 335, 384, $416,417,471,619$

Anders, Edward 643, 674, 676-678

Anders, Mrs. Edward 675

Andersen, Richard 214, 218, 231, 257, 297, 305, 324, 350, 703

Anderson, Doug 409

Anderson, Gene 382

Anderson, Greg 719

Anderson, Ingel 747

Anderson, Kinsey 706

Anderson, Leonard 354

Andersson, Erik 600

Andersson, Ingrid 600

Andersson, Olof 600

Andes, Daniel 496, 529

Andreasen, Andy 711

Angel, Sherry 306, 307

Angelopoulos, Michael 585, 592, 593

Apple, Richard 256

Arkebauer, John 375

Armbruster, Peter 574, 576

Armeniades, Constantine 674

Armeniades, Mrs. Constantine 674

Armistead, Davis 673

Armistead, Mrs. Davis 673

Armstrong, Calvert 569

Arnold, Harriet 181

Arnold, Henry 284

Arnold, Luther 181, 541

Arpigny, Claude 674, 676, 677

Arpigny, Mrs. Claude 677

Arrhenius, K. 606

Asaro, Frank 84, 328, 341, 342, 343, 393, 441, 679

Ashley, Shirley 296

Asprey, Larned 208, 375, 392

Astin, Allen 147, 413, 728

Atkinson, Richard 674, 677

Atkinson, Rita Loyd (Mrs. Richard) 677

Atterling, Hugo 594, 595

Audouze, Jean 674, 676, 677

Audrén, Carl-Gustav 612

Auger, Mrs. Paul 357

Auger, Paul 357

Aumann, Dieter 369

Auslander, David 150, 669

Austin, Sam 19

Austria, Olivia 42, 96, 103, 115, 496, 503, 620

Avdeef, Alex 5, 26, 50, 86, 185, 233, 372, 430, 480, 486, 561, 649

Averch, Harvey 284

Avery, Donald 569

Avery, Roy 170

Awapara, Jorge 674

Axelrod, David 140, 147

Ayer, John 331

Ayre, Pamela 164 
Azzam, Haten 632

Bachman, Knut 455

Badger, Paul 110, 115, 558, 559, 666, 739

Bailey, Clark 458

Bailey, Pearl 337

Bailey, Richard A. 276, 496

Bailey, William 164, 168, 181, 278, 279, 288, 292, 293, 357, 361, $363,411,533,538,723,734$

Bailey, Mildred 336

Baiocco, Norma 403

Baisden, Patricia 5-7, 16, 17, 23, 24, 28, 32, 41, 42, 48-50, 67, 72, $75,80,89-91,96,98,107,112,149,154,157,159,170,182$, $184,185,203,208,212,214,217,229,230,231,232,256,262$, $263,277,296,300,304,310,321,326,328,329,332,340,343$, $350,356,368,369,372,375,376,379,382,383,391,395$, $401-404,414,416,421,430,436,443,444,446,461,463,471$, $474,475,483-485,489,490,494-496,503,516,517,528,530$, $531,546,549,550,558,559,620,621,624,634,636,638-642$, $645,649,666-669,683,689,692,698,699,713,717,718,742$, $745,747,750-752,755,757,759,761,765,772$

Baker, Dale 168, 178, 363, 731

Baker, Edgar $26,50,86,430,486$

Baker, Frances (Mrs. William) 410, 411, 673, 677

Baker, Howard 472, 502, 624, 631

Baker, Joseph 673

Baker, Lydia 155

Baker, Mrs. Dale 178

Baker, Ted 233, 372

Baker, William 13, 14, 410, 411, 671, 672, 673, 675, 677, 724

Ballard, Jed 472

Baluka, Marian 372

Bancroft, Chris (Mrs. Ray) 402

Bancroft, Ray 402

Bangs, Scholer 39

Banks, Rodney $5,26,50,86,89,98,107,160,161,197,198,213$, $233,372,401,478,480,486,516,561,633,649,668$

Barach, Arnold 146

Barach, John 720

Baranowski, Bogdan 478

Baranowski, Frank 18

Barghoorn, Elso 416

Barrett, Jack 523, 524, 617, 731, 734, 737

Bartholomew, Dave 268

Bartlett, Neil 5, 19, 90, 103, 302, 470, 561, 620, 633, 691

Bartlett, Paul 305, 676, 703, 746

Bartley, Anne 334

Baruch, Jordan 538

Basiuk, Victor 285

Bassett, Edward 306

Bassham, James 28, 441, 644

Batchelder, Augustus 105, 156

Batchelder, Frank 357

Batchelder, Mrs. Frank 357

Bates, Thomas 550

Batista, Nogueira 589, 592

Battista, Mrs. O. A. 169 
Battista, O. A. 169, 205, 537

Batzel, Edwina (Mrs. Roger) 208, 209, 210

Batzel, Roger 52, 97, 208, 210, 219

Bauer, John 561

Bauer, Kay (Mrs. John) 561

Baumbach, Harlan 92, 200

Baumbach, Nathalie (Mrs. Harlan) 200

Bauna, Salim 720

Beach, Frank 84

Beadle, George 410, 411, 671-677, 672

Beadle, Marion (Mrs. George) 677

Bear, Liz 397

Bearden, Alan 305, 703

Beasley, George 292

Beaton, Roy 557

Bechtel, Bear 229, 382, 757, 759

Bechtel, Steve 473

Becker, Hans 517, 577-579, 775

Becker, Mrs. Hans 578

Beeley, Philip 708

Beeson, Albert 397

Begin, Menachim 707

Behrens, Dieter 525, 621, 630, 748

Belew, John 670

Belew, Mrs. John 670

Beling, Earl 169

Bell, Alexis 73, 207

Bel1, Robert 709

Bellama, John 692

Belleau, Bernard 708

Belliveau, John 140, 142

Bellmon, Henry 631

Belyaev, Spartak 369

Benhart, Denise 30

Benhart, Millie 30

Bennett, Donna 354

Bennett, Edward 265, 379, 634

Bennett, Tom 414

Benson, Kathleen 299

Bent, Henry 535

Berg, Joseph 692

Bergen, Edgar 472

Bergin, Thomas 334

Bergman, Rolf 607,608

Bergstrom, Anna 603

Bergstrom, Ingmar 484

Berkowitz, William 144, 459

Berlekamp, Elwyn 150, 312

Berman, Elliot 683

Berman, Sam 751

Bernal, Ivan 673

Bernal, Mrs. Ivan 673

Bernard, J. 524, 588

Bernard, Peter 440

Bernhard, Carl 611

Berris, Jan 711 


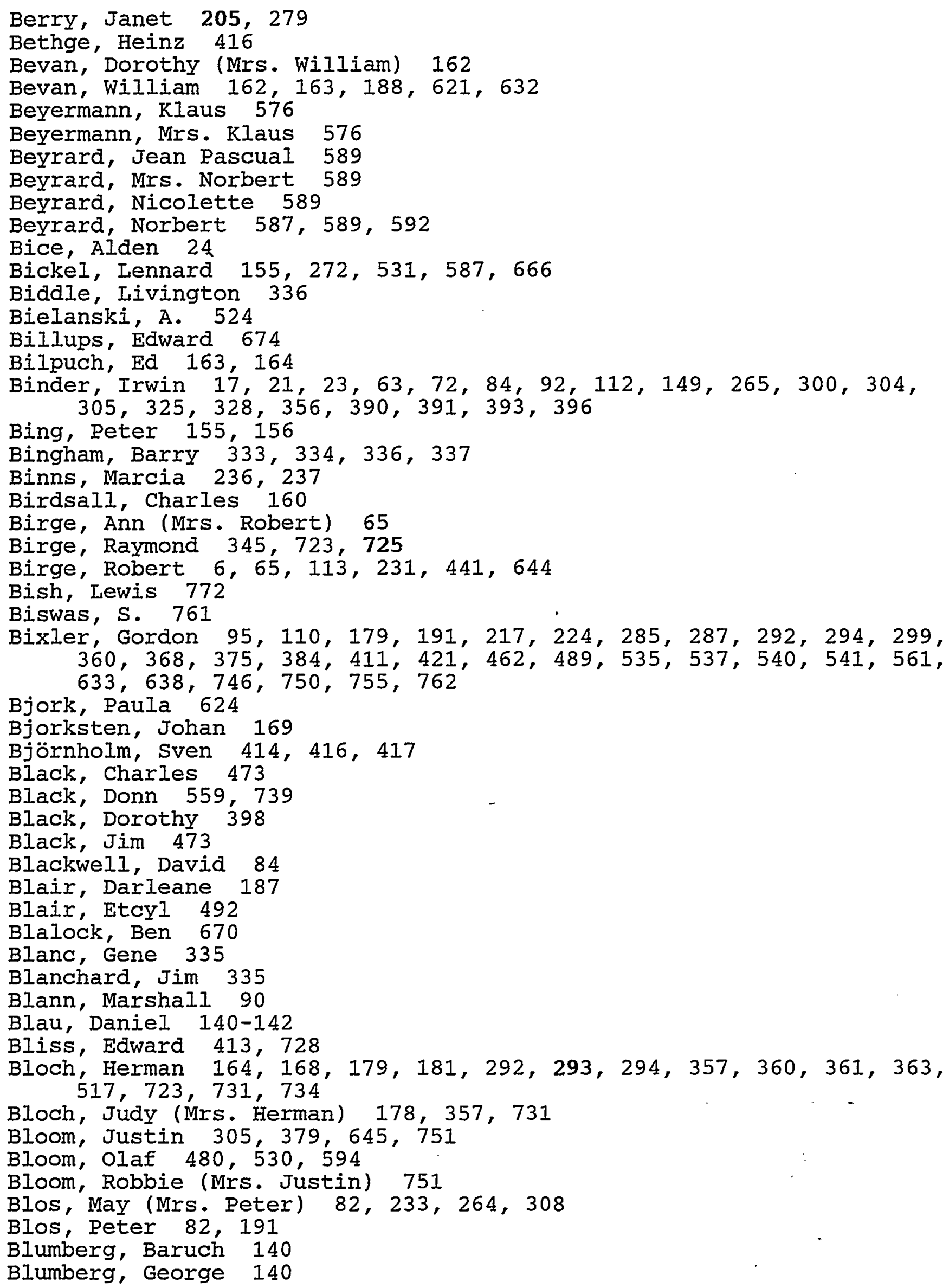


Blume, Martin 679

Boardman, Tom 310

Bodman, Richard 15

Bogel, Anne 677

Boggs, James 567

Boland, Edward 567

Boley, Bruno 472

Bolt, Bruce 312

Bolton, Earl 562

Bomar, Gary 719-721

Bond, Jack 670, 671

Bond, Walter 185

Boneysteele III, Parke 393

Bonner, Francis 295, 538, 679

Boorstin, Daniel 286

Boos, Alex 577

Borchers, Mary 458

Borchert, Bob 340

Boreskov, Georgiy 113

Borg, Göran 595

Borgström, Georg 615

Borgström, Greta (Mrs. Georg) 615

Borkowski, Casimer 356, 398, 479

Bornstein, Dan 650

Bossong, Ken 360

Botts, Truman 279

Boulware, John 158

Bowen, Michael 168, 363

Bowerman, Mary 440

Bowers, Curtis 490

Bowie, James 140,142

Bowker, Albert $84,219,313,473,486,663,664,710-712$

Bowker, Rosedith (Mrs. Albert) 86, 219, 710-712

Bowles, Norma 3, 22, 485

Bowman, Margaret (Mrs. Thomas) 191, 233, 493, 666

Bowman, Robert 169, 205

Bowman, Thomas 191, 198, 233, 305, 493, 550, 666

Boyd, George 200,337

Boyer, Vincent 279

Bradburn, John 299

Brademas, John 336, 337

Bradfield, Rich 670

Bradsher, Charles 162

Brandt 219

Brandt, Reinhard 182, 184, 232, 478, 502, 517, 574, 577-580, 775

Branigan, Frank 5

Branscomb, Harvey 720 .

Bransford, Noel 636

Brasted, Robert 113, 411, 412, 538, 691, 716, 755

Brauman, John 156

Brauman, Sharon (Mrs. John) 156

Braun, Manuel 594

Bray, Donald 198

Bregante, Tom 516

Breslow, David 179

Breslow, Ronald 521, 524, 526, 538 
Bṛewer, Leo 19, 82, 87, 91, 92, 103, 191, 200, 212, 231-233, 297, $305,324,350,369,620,621,679$

Brick, Thomas 310

Briggs, Dennis 775

Briggs, Paul 310

Briney, Ken 440

Brinkerhoff, Elmer 158

Brinkley, Clark 163

Brinton, Laurel 331

Britt, Chip 746

Britt, Harold 90

Brobeck, William 724

Brocart, J. L. 524

Brodzinsky, Richard 29

Bromley, Allan 113, 115, 439, 462, 464, 618, 666

Bronson, Bertrand 84

Brooks, Bernard 27

Brooks, Brian 728

Brooks, Mrs. Philip 674

Brooks, Peter 27, 28

Brooks, Philip 674

Brown, Colleen (Mrs. Harold) 334

Brown, David 516

Brown, Eddie 752

Brown, Edmund 219, 236, 237

Brown, Gerald 113

Brown, Glenn 179, 311, 411, 538

Brown, Greg 307

Brown, Harrison 208, 317, 557

Brown, Howard 19, 29, 42, 321, 488, 645

Brown, Ken 81, 558, 560

Brown, Theodore 692

Browne, Charles 748

Brubaker, Inata 279,538

Bruice, Thomas 471, 474, 47.9

Bruner, Kathryne 624, 625, 630

Bruson, Herman 169

Brylanka, Maria 525

Bucher, Jerome 5, 26, 50, 86, 185, 197, 198, 233, 372, 405, 430, 480, $561,633,649,765$

Büchl, Elisabeth 297

Buckley, James 15

Budinger, Thomas $6,89,379,515$

Budnitz, Robert $6,23,28,48,63,161,213,303,314,340,343,344$, $421,492,496,650,664$

Bul1, Elizabeth 179, 292, 411, 535

Bullock, Mary 288, 292

Bulotti, Charles 42

Bunnett, Joseph 692

Bupp, Lamar 379

Burchfield, David 15

Burgener, Clair 631

Burke, Helen 82, 491, 550, 666

Burke, Yvonne 567

Burnett, John 86, 185

Burns, Cary 707 
Burns, Garth 86

Burr, Horace 666

Burr, Joyce (Mrs. Horace) 82, 191, 211, 491, 550, 666

Burton, Milton 200

Busch, Kenneth 233, 389, 669-671

Busch, Maryanna (Mrs. Kenneth) 670, 671

Bush, Susan 335

Butcher, E. D. 674

Butler, William 168, 363, 534

Butowsky, David 727

Button, Ronald 397

Button II, Ronald 397

Bych, Kenneth 159, 160

Byrne, Dennis 331, 526, 546

Bystroff, Roman 445

Cable, Michael 631, 639

Cachere, Marvin 312

Cahill, Paul 140-142

Cairns, Kay (Mrs. Robert) 178, 357, 536, 537, 731

Cairns, Robert 164, 168, 179, 200, 287, 288, 292, 293, 294, 357, 360, $361,363,401,411,412,524,533,534,536-539,541,728,731$, 734

Cairns, Theodore 536

Caland, Francine 581, 588

Calhoun, John 673

Califano, Joseph 87

Calkin, John 336

Callis, Clayton $361,363,532,535$

Calvin, Genevieve (Mrs. Melvin) 378

Calvin, Melvin 6, 19, 52, 84, 103, 157, 212, 230, 303, 321, 325, 355, $364,378,439,470,502$

Cameron, Alastair 674, 676-678

Cameron, Clayton 676

Camp, Dave 445

Campbell, Arthur 40, 533

Campbell, Charles 719

Campbell, Robert 145, 709

Campbell, William 279

Canavan, Greg 722

Cane, Paul 236

Cannon, Howard 728

Cardin, Debbie 397

Cardinet, George 413, 689

Carey, William 278

Carlberg, Anita 142

Carlone, Ralph 155, 158

Carlsson, Allan 595

Carnall, William 4,179, 185, 236, 258, 485, 539, 750, 760

Carpenter, Ernest 363, 532, 723

Carrano, Carl 26

Carroll, Donald 334, 335

Carroll, James 236

Carroll, Lynn 279

Carroll, Paula 491

Carter, Edward 473

Casazza, Marty 496 
Case, Charlie 161

Cason, James 486

Cason, Rebecca (Mrs. James) 157

Cass, Don 354

Castleberry, Stephen 306

Castner, David 27

Catalano, Ed 445

Cavanaugh, Chuck 440

Cave, Jere 15

Ceausescu, Elena 92, 198, 420, 460, 475

Cefola, Michael 203

Cerny, Joseph 19, 23, 28, 103, 113, 156, 160, 203, 207, 213, 214, $231,240,256,276,329,340,341,342,354,395,418,492,496$, $539,638,642,679,706,7.14,746,755,760$

Chalaby, Barsoum 313

Chamberlain, Owen 231, 343, 344, 345, 470, 495, 747

Chan, Bill 707

Chance, Britton 692

Chang, Marjorie 480

Chang Lo-feng 288, 293, 340, 341, 342, 343, 344

Chang Wei 711

Chao, Buwei 711

Chao, Yuen 84,711

Chapital, Dorselyn 169

Chasman, Richard 184

Cheadle, Vernon 219

Chern, Shih-Ning (Mrs. Shiing-shen) 711

Chern, Shiing-Shen 348, 711

Chernin, Milton 272

Chew, Geoffrey 113, 706

Chiang Ping-nan 288, 293, 340, 341, 342, 343, 344

Chien, James 765

Chilcote, Ann (Mrs. William) 760

Chilcote, William 760

Childers, Lisa 384

Chin, Simon 632, 636, 642, 690, 698, 700, 706, 757, 758

Chin Han-fang 711

Chinn, Harvey 331, 775

Choppin, Gregory 176, 185, 645

Chou En-10 288, 293, 340, 341, 342, 343, 344, 348

Christensen, Dick 445

Christophersen, Arland 455

Christophilopoulos, Dimitros 586

Chung, Chien 708

Church, Frank 355

Cima, Michael 631

Cincotta, Dave 354

Cinquemani, John 236

Citrin, Jack 312

Claesson, Stig 107, 524, 604, 606, 607, 614

Clanton, Dean 721

Clapp, Leallyn 692

Clark, Burch 156

Clark, Chet 162

Clark, David 496

Clauss, David 546 
Clayton, Annette (Mrs. Donald)

Clayton, Donald 677

Cleaveland, Frederic

Clemenson, Mark 237

162

Cleveland, Bill 414

Cleveland, John 765

Cline, Douglas 516

Cobb, Lynne (Mrs. William) 126, 137, 140,141, 145, 147, 169, 186, $276,286,334,335,336,409,413,625,631,632,634,635,637$, $640,645,715,737,743,772,773$

Cobb, William 126, 137, 140,141, 145, 147, 186, 286, 335, 336, 635, $637,640,645,715,737,772,773$

Coblentz, William 219; 223, 663

Cockereli, Leone 670,671

Coffer, Henry 411

Cogswell, Howard 106, 187, 455, 558, 739

Coker, Dolores 670

Colby, John 700

Cole, A. R. H. 524

Cole, Debbie 302

Coleman, James 679

Collat, Justin $52,90,295,361,363,412,416,537,723,731$

Collie, Marvin $375,410,411,673-675$

Collie, Nancy (Mrs. Marvin) 410, 411, 673-675

Collins, Ann (Mrs. Ray) 86

Collins, Larry 269, 296

Collins, Ray 86

Collins, Sis 635

Combs, Leon 32

Commans, Mary 775

Commerford, Raymond 667

Condos 586

Cone, Pearl 219, 364

Connery, Sam 455

Connick, Robert 19, 103, 107, 160, 231, 257, 277, 297, 305, 324, 369, $620,621,703$

Conophagos, Constantine 586

Considine, Sheilah 236

Constance, Lincoln 86, 679

Constance, Sally (Mrs. Lincoln). 86

Content, Robert 150, 313, 345

Contogouris, Andy 708

Conway, Jack 150

Conway, John 15, 26, 50, 86, 198, 372, 430, 483, 649, 750, 765

Conzett, Homer 42, 103, 231, 240, 329, 395, 446, 496, 642, 706, 714, 755

Cook, John 41

Cooksey, Donald 526

Cooper, Ben 398

Cooper, Fred 126

Cooper, Leon $89,147,148,198$

Cooper, Mel 445

Cooper, Peggy 334-337

Cooper, Vance 203, 305, 324

Cooter, Bob 111

Cope, Carl 480 
Cordova, Mary Lou 405

Corey, Claire (Mrs. E. J.) 410, 411, 677

Corey, E. J. 410, 411, 671, 672, 673, 674, 677

Cornelius, Paul 237

Cornish, Edward 3, 146

Costa, Walter $70,81,84,107,115,558,559,643$

Cotton, Albert 410., 692

Covey, Elwin 208, 305

Covington, Martin 150, 691

Cowan, George 325

Cox, Jack 236

Cox, Morris 635, 636

Craddock, Dr. 158

Craig, Lavaughn 643,747

Craig, Paul 444

Cram, Donald 692

CrandalI, John 2

Crane, Dorothea 516

Cranston, Alan 619, 625, 626, 630, 631

Crawford, Bryce 73, 164, 168, 182, 357, 361, 363, 532, 533, 538, 723, 731

Crawford, Chris (Mrs. Dave) 775

Crawford, Dave 775

Crawford, Frank 258

Crawford, Hank 391, 494

Crawford, John 200, 708

Crawford, Lorraine 200

Crisp, Michael 489, 502, 503, 560, 624, 625, 631

Cristwell, David 559

Crome, Bill 311

Crook, Joseph 765

Crook, Norman 279

Crosby, Bing 636

Crosswhite, Henry 4

Crum, John 168, 178, 363, 533

Crum, Maggie 480

Crutchfield, Marvin 363

Csapo, Laszlo 111

Cudaback, David 150, 312, 669, 714

Culbertson, Thomas 310

Culkin, John 337

Cullen, John 39

Cullen, Jr., John 39

Curl, Mrs. Robert 674

Curl, Robert 674

Curtis, Emory 236

Cushing, Richard 700

Cushnir, Randi 455

Daddario, Emilio 264, 308, 326, 496

Dainton, Frederick 607

Dana, John 761

Danforth, Douglas 147, 148

Danielson, Mrs. Walter 747

Danielson, Walter 747

Danilov, Victor 350

Daskam, Bob 187, 515 
Date, Sharon 417, 441, 496, 498, 503, 624, 698, 699, 757, 758, 759, 765

Datz, Susan 163

Dauben, Carol (Mrs. William) 397

Dauben, William 19, 230, 303, 340, 341, 342, 364, 384, 397, 484, 620, $638,645,762$

Davenport, Derek 536

Davenport, Lee 698

David, Francois 176, 667, 703, 713

David, Shavin 163

Davidson, Jo Ann 480

Davidson, Norman 203

Davies, Mansel 618, 669

Davis, Harmer 84

Davis, Harold 302, 379

Davis, Jeff 558

Davis, John 334, 335

Davis, Richard 621, 642

Davis, Walter 334,335

Davis, William 630, 634, 640, 669, 692

Day, Dennis 472,473

Day, Melvin 737

Day, Mrs. Melvin 737

Day, Samuel 302

de Fremery, Donald 105, 187, 211, 455, 458

De Hoffmann, Frederic 473

De Leeuw, David 307

de Oliviera Campos, Roberto 403, 748

de Saint-Simon, Michel 161, 164, 223, 329, 332, 340, 356, 357, 368, $369,372,379,382,389-391,396,405,414,416,418,419,421$, $430,441,443,444,461,463,464,471,478,479,488,489,495$, $499,516,517,528-530,559,561,562,567,621,624,636,639$, $640,642,667,668,678,689,698,699,700,706,751$

De Vore, Frank 236

Dean, Ruth 461, 463, 464

Deeny, Bob 42, 397

Dees, Bowen 413

Deleplanque, Marie 639

Delphin, Walter 185

Delsemme, Armand 674, 677

Delyannis, Anthony 581, 583, 584, 586, 587

Delyannis, Eurydike (Mrs. Anthony) 583

Deming, Mrs. Stanley 673

Deming, Stanley 673

den Os, Dick 524, 526

Dennison, Charles 698

DeSilva, Alan 140

DesMarteau, Darryl 521

Deuser, W. H. 403

Deuslack, Peter 191

Deutch, John 722, 752

DeVolpi, A. 624

Devons, Samuel 619, 645

DeVries, Ralph 745

Diamond, Marian (Mrs. Richard) 669

Diamond, Richard 5, 549, 639, 642, 666, 701, 714, 746, 755, 761 
Dibble, Bill 719

Didsbury, Howard 73

Dietrich, Joseph 683

Dietrich, Manfred 576

Diksic, M. 707

Dilaris, Irene 587

Diliberto, Stephen 113

Dimiceli, Manny 324

Disler, Don 330, 331

Djerassi, Carl 156, 191, 217, 348, 612, 617, 747

Dodge, John 218

Doe, Mrs. Thomas 608

Doe, Thomas 607, 608

Doherty, Ada (Mrs. Robert) 410, 411, 673-676

Doherty, Robert 375, 410, 411, 673-676

Dolan, Tom 268

Dole, Francis 670

Dole, Malcolm 670, 671

Donald, Roger 436

Donald, William 474

Dondero, Joan (Mrs. Marco) 268, 775

Dondero, Marco 268, 775

Dondero, Rachel 775

Donnelly, H. C. 494, 560

Donough, Gus 679

Doolittle, Steve 330, 331

Dosch, R. G. 185

Dougal, Alan 198

Douglas, Mardy 479

Douglas, Robert 15

Dowden, Milo 317, 369, 395, 488-490, 557, 560, 618, 667, 669

Downing, Tom 335

Dreher, Leonard 208, 237, 442, 639

Dreiss, Gerard 731

Drew, Russell 284

Dreyfus, Dan 619

Dreyfus, Leonard 745

Drickamer, Harry 639, 645, 701

Driscoll, James 142

Drosnin, Michael 481

Druin, Victor 460,461, 463, 471, 493, 549

Du Bos, Fran 331

Du Russel, Mike 496

DuBridge, Lee 473

Duckworth, Edwin 439

Duffy, G. T. 558

Duffy, Jane (Mrs. Martin) 561

Duffy, Martin 561

Duk, Richard 105

Duke, Paul 286

Dum, Thomas 3

Dumke, Glenn 473

Duncan, Francis 620

Dunlap, Katherine 236

Dunne, Tom 402

Duran, Enrique 333, 334 
Durbin-Heavey, Patricia 633

Durkin, Steve 491

Duscha, Julius 728

Duschner, Heinz 578

Duyckaerts, Georges 525

Dyckes, Douglas 673

Dyckes, Mrs. Douglas 673

Eames, Ray 333, 334, 336

Easterling, Ben 330

Eberhardt, William 692

Ebright, Richard 142, 311

Eckroth, David 170, 224, 549

Edelstein, Norman $5,26,50,86,103,161,185,197,198,213,219$, $233,372,404,405,418,421,430,472,480,486,494,496,516$, $561,626,633,649,691,746,750$

Edward, Jack 707,708

Edwards, Jeanette (Mrs. Ray) 427, 546, 714, 715, 773

Edwards, Lucretia 82, 491

Edwards, Ray 427, 714, 715

Edwards, Tom 491

Egan, Harold 523, 525

Egan, Kenneth 140, 142

Eggers, Phil 746, 750

Eggers, Richard 714, 718, 765

Eichberg, Joseph 673

Eichberg, Mrs. Joseph 673

Eigenbrot, Charles 233, 372, 633, 649

Eiland, Eileen 496, 503, 624

Eirich, Frederick 297

Eisenberg, Adi 707-709

Eisenberg, Meyer 728

Eisenberg, Richard 258

Eisenbrand, Lynn 703

Eisenser, Allen 738

Ekstrand, Jim 50, 198

Ekstrom, Debra 491

Ekstrom, James 491

Ekstrom, Lorrie 491

Ekstrom, Mrs. Robert 491

Ekstrom, Mrs. James 491

Ekstrom, Richard 491

Ekstrom, Robert 491, 492

Elberg, Sanford 86

Eliel, Ernest 164, 532, 723

Elioff, Tommy 214

Ellick, Thomas 236

Ellis, Howard 111

Ellis, Walter 279

Elvee, Richard 26, 378

Ely, Ralph 162-164

Emanuel, Nikolai 521, 606, 609

Embree, Paul 142, 311

Emeneau, Murray 84

Emmes, Arthur 455

Eneberg, Ingmar 593, 613, 615, 617

Engbeck, Joseph 663, 689 
Engdahl, K-A. 606

Engel, Paul 674

English, Spofford 208

Epherre, Marcelle 39

Epstein, Edwin 723

Epstein, Mrs. Edwin 723

Epstein, Sandra 256

Ergun, Sabei 751

Erickson, Glen 331

Erickson, Laura 212, 213

Erickson, Richard 110, 636, 701

Eriksson, Albert 604

Eriksson, Daniel 604

Eriksson, Göran 600, 601, 603, 604

Eriksson, Gustav 600, 601

Eriksson, Karl-Eric 600, 601, 604

Eriksson, Margareta 600, 603

Eriksson, Maria (Mrs. Albert) 604

Eriksson, Stig 600, 604

Ernst, Eldon 313

Ernst, Klaus 444

Esser, George 496

Esterlund, Marie-Lou (Mrs. Robert) 577, 578

Esterlund, Robert 577, 578, 580, 650

Etemad, Akbar 581, 589, 592

Etzler, Peggy 710

Evans, Bruce 356

Evans, Dorothy 334

Evans, Margaret 14, 144, 738

Eyring, Henry $410,411,671,672,673,677$

Eyring, Winifred (Mrs. Henry) 410, 411, 673, 677

Faessler, Amand 417

Fairbank, Henry 162

Faircloth, Karen 689

Falconer, Warren 73, 90, 179

Falkehag, Ingmar 179

Fälldin, Torbjörn 612

Falvey, Henry 311

Farmakes, John 200, 264, 350, 377, 390, 413

Farrell, Corinne 458

Fawcett, R. J. 521, 524

Fearey, Peter 236

Federle, Martine 212, 213

Fein, Rabbi 743

Feldmeir, Daryle 306

Fellows, Robert 178,185

Ferguson, Donald 483, 750

Ferris, Les 185

Feshbach, Herman 149

Fialka, John 531, 626

Field, Rush 670

Fields, Ellis $179,182,411,538$

Fields, Emmet 719, 720

Fields, Mrs. Emmet 720

Fields, Paul 183, 404, 470, 472, 528, 533, 748

Figueras, Patricia 164, 168, 357, 360, 361, 363, 532-535, 723 
Finch, Agnes (Mrs. Claude) 440, 455, 458

Finch, Claude 440,455, 458

Finger, Milt 445

Fink, Amy 306,326

Fischer, Robert 430

Fisher, Adrian 87

Fisher, Barbara 405, 486, 516

Fisher, Michael 521

Fisher, Robert 22

Fitting, John 459

Fitzgerald, Anne 258, 266, 276

Flajser, Steve 279

Flambard, John 30

Flanigan, John 473

Flanigan, Peter 473

Fleming, Anne 496

Flemström, Mrs. B. 606

Flerov, G. N. 200, 383, 626

Flory, Paul 156, 744

Flower, Cliff 683

Flowers, walter 333

Flynn, Timothy 16, 161, 325, 330, 331

Foller, Peter 75, 328

Fong, F. K. 360

Force, Bob 765

Forcey, Robert 232

Forcier, James $619,624,630,631$

Ford, G. P. 183

Ford, Gerald 473

Ford, Jack 619, 631

Ford, O'Neil 333, 334

Forsling, wilhelm 594

Forsner, Lars 600

Forsner, Sven 600

Forssling, Bo 598, 599

Forssling, Mona (Mrs. Bo) 598, 599

Forster, Craig 608

Forsyth, Bill 158

Foss, Rainer 574

Foster, William 87

Fowler, Ardiane (Mrs. William) 677

Fowler, Charles 336

Fowler, Malcolm 67, 302, 368

Fowler, William 674, 675, 677

Fox, Dennis 527

Fox, Richard 491, 492

Fox, Robert 168, 179, 491, 533, 534, 539, 541, 561, 723, 735

Fox, Sidney 369, 474

Fraenkel-Conrat, Heinz 84,191

Frank, Arthur 350, 355

Frankel, Marvin 4, 15, 158

Frankel, Richard 7, 107, 156, 233, 269, 395, 474, 483, 489, 641, 700

Franken, Peter 278, 279

Franklin, Carl 155, 156

Franklin, J. I. 674

Franklin, Mrs. J. L. 674 


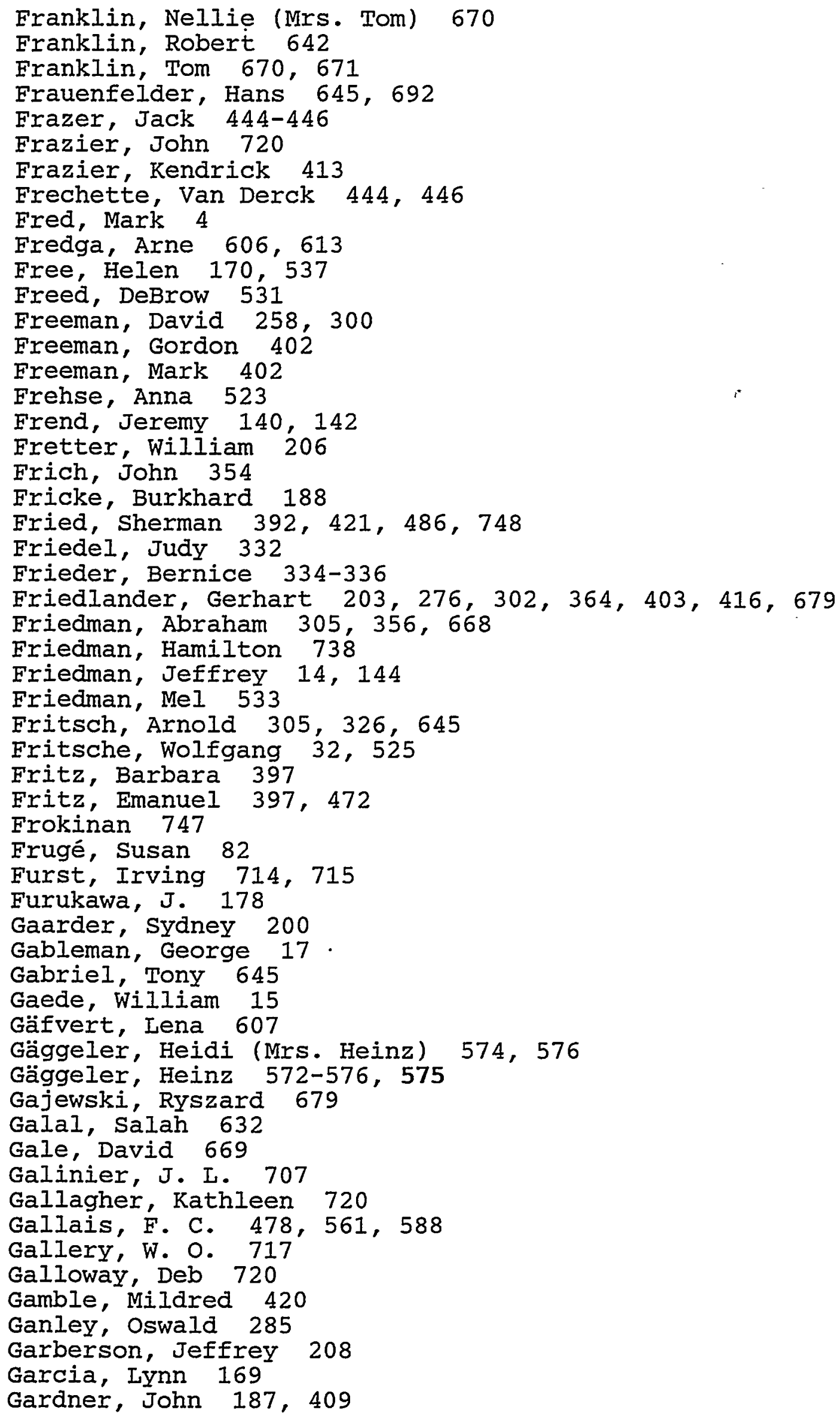


Garrison, Barbara 621, 632

Garvey, Gerald 549, 717

Gaskell, Bob 708

Gassman, Paul 73

Gatov, Albert 236

Gaustad, John 714

Gauvin, Mrs. William 357

Gauvin, William 357

Gavin, Robert 521

Geanange1, Mrs. Russel1 673

Geanangel, Russell 673

Geijer, Doris (Mrs. Erik) 603-605

Geijer, Erik 603-605

Geisel, Ernesto 589, 592

Geissler, $\operatorname{Val} 44,51,110,257$

Gendlin, Francis 491

Gentry, Robert 232

Georg, Erich 574

Gerhart, Howard 411, 538

Gershar, Dr. 492

Gevantman, Lewis 294

Gfaller, Hubert 297

Ghiorso, Albert $2,3,5-7,16-18,23,29,31,32,40,42,64,72,86$, $87,96,103,107,110,164,182-184,200,203,213,214,217$,

$218,229,231,240,266,269,272,300,318,325,328,329,332$,

$350,356,357,372,375,402,404,405,441,446,461,463,472$,

$485,488,493,495-497,516,531,559,567,618,621,624,630$, $636,640,649,650,665,698,699,706,714,739,748,752,760$, 761

Giauque, Muriel (Mrs. William) 747

Giauque, William 747

Gibbons, Mary 340,350

Gibson, Melba 190, 674, 676

Gigliati, Joan 444

Gilbert, Joseph 279

Gilbert, Richard 111

Gilbert, william 265

Gilcrest, John 561

Gilcrest, Maryann (Mrs. John) 561

Gilcrest, Steve 416

Gilford, Dorothy 279

Gilman, Henry 178

Gilmont, Ernest 169, 278, 279, 285, 537

Giscard d'Estaing, olivier 580, 587, 589, 592

Giunta, Frank 464

Glad, Brian 19, 27

Glaser, Donald 636

Glass, Graham 674

Glass,. Larraine 332

Glass, Michael 14, 144, 459, 481, 738

Glass, Mrs. Graham 674

Glass, Richard 156

Glendenning, Norman 42, 45, 103, 231, 240, 329, 446, 496, 563, 642, $706,748,755$

Glenn, John 186

Glennan, Keith 285, 300, 321, 645 
Glickman, Don 335

Goble, James 98

Godino, Carol (Mrs. Roger) 589

Godino, Roger 459, 589, 592

Goff, Harry 396

Gofman, John 203

Goggin, Walter 233

Goheen, Robert 14, 144

Goldanskii, Vitalii 164, 200, 258, 384, 405, 464, 472, 563, 645, 675, $676,677,692,701,717,750$

Goldberg, Joel 727

Goldfinger, Ed 402,481

Goldhaber, Alfred 113, 517, 678, 679, 691

Goldhaber, Gerson 266, 722

Goldhaber, Judith (Mrs. Gerson) 722

Goldschmidt, Bertrand 203, 701

Goldschmidt, Peter 494, 619, 678, 744

Goldsmith, Roxanne 580

Goldstein, Ernest 592

Goldwater, Barry 563

Golston, Jacalyn 306, 307

Good, Bill 168

Good, Don $440,455,643$

Good, Irene 191, 211, 233

Good, Mary 164, 168, 170, 285, 357, 360, 361, 363, 532, 534, 723, 734,735

Good, Ruth Ann (Mrs. Don) 455

Goodin, David 420, 621, 645, 650

Gordon, Glen 178, 229

Gordon, Monte 144, 459

Gortz, Erik 111

Goth, George 527

Gotlid, Louis 142

Gottschalk, Peter 578, 579

Gottstein, Carolyne 7, 17, 23, 32, 50, 96, 149, 198, 214, 224, 256, $263,296,393,398,403,414,416,443,461,474,495,530,559$, 560

Gould, Charles 306,326

Goulding, Frederick 265, 379, 395, 634, 641

Gove, Harry 546

Grainger, Mrs. Robert 673

Grainger, Robert 673

Gramse, Erna 205

Grant, Charles 304

Grant, David 142

Grant, Paul 775

Gravier, Maurice

611

Gray, Harry 533

Gray, John 187

Gray, Peter 539

Grayson, Martin 2, 170

Green, Donald 105

Green, Fitzhugh 286

Green, Jeff 397

Green, Tom 300

Greene, Lawrence 14, 459, 738 
Gregori, Simone 580

Greiner, Doug 87, 679, 723, 745, 746

Gries, Bill 187, 440, 455, 458, 558

Gries, George 279

Griggs, Lori 739

Grosch, Herbert 279

Groseclose, Clark 52

Gross, Paul 162

Grosse, Eckhart 90

Grosselli, Jeanette 311

Grossenback 666

Grosser, Arthur 707

Grover, Robb 517, 667, 691

Gruen, Dieter 162

Grunder, Hermann 29, 75, 149, 203, 214, 231, 265, 299, 379, 446, 464, $632,634,642,678,701,706,714,746,755,761$

Grünwald, Herbert 403, 748

Gryszkowiec, Mike 683

Grzywa, Edward 523

Guglielmino, Russell 144, 459

Guillamont, Robert 588

Guinan, Mike 445

Gullatt, Sally 332

Gundel, Lara $231,257,277,297,324,350,369$

Gunsalus, I. C. 279

Gussev, Alexandr 691

Gutbrod, Hans 90, 258, 701

Gutbrod, Ursula (Mrs. Hans) 90

Gvishiani, Dzhermin 620

Gwinn, Margo 82, 440

Habensak, Otto 43

Haberstadt, Anna Marie 577

Hackerman, Gene (Mrs. Norman) 674

Hackerman, Norman $18,19,418,429,632,674$

Hader, Lottie (Mrs. Rodney) 731

Hader, Rodney $7,39,40,72,146,164,168,176,179,285,308,323$, $324,360,363,389,390,398,412,517,532-534,537,562,650$, $716,723,731,734,736$

Hadley, Sheri 354, 714

Haefner, Walter 478

Haensel, Judy 689.

Haensel, Vladimir 534, 538

Hafstad, Lawrence 403

Hagar, Billie 496

Hagar, Ella (Mrs. Gerald) 219

Hägg, Gunnar 606

Hahn, Richard 5, 6, 16, 178, 182, 185, 314, 372, 405, 417, 460, 493, 539,717

Hahn, Roger 305

Haire, Richard 185, 392

Halaby, Najeeb 473

Hale, Arthur 541

Halén, Per Axel 607, 608

Haley, James 748,765

Hall, Drew 379

Hall, Steve 311 
Halstead, Gordon 5, 50, 86, 198, 233, 256, 258, 372, 430, 486, 619, 633

Halvorson, Harlyn 279

Hambraeus, Gunnar 595

Hamilton, Edward 336,337

Hamilton, Elizabeth 14, 144, 459

Hamilton, Joseph 416, 668, 701, 719-721

Hammer, Guy 279

Hammili, Betsey 1

Hammond, Barbara 18

Hammond, Owsley 472, 641, 755

Hanappe, Francis 155

Hand, Cadet 150

Handler, Philip 288, 530

Hanks, Nancy 334

Hanle, Hellmut 191

Hannay, Norman 444

Hanniwell, Lee 22

Hansen, Olivia 624

Hansen, Tim 534

Hanson, Arthur 363, 734

Hanson, Donald 751

Hardy, Jerome 738

Hargrove, James 410

Harless, Donald 413, 728

Harman, Chuck 331

Harms, Don 440

Harnett, John 207, 256, 300, 493

Harrar, George 14, 144, 458, 459, 738

Harris, Charles 19, 103, 305

Harris, E. G. 168,363

Harris, Michael 170

Harris, Milton 147, 537, 538, 728

Harris, Robert 103

Harris, William 521

Harrison, Anna 164, 168, 181, 292, 293, 294, 357, 360, 363, 364, 532, $534,538,723,731,734,735$

Harrison, Julian 163

Harrod, John 707, 709

Hart, James 663

Hart, Richard 288

Hart, Ruth (Mrs. James) 743

Harte, John 632

Hartley, Muriel 87

Hartsough, Walter $6,28,265,441$

Harvey, Bernard 1, 6, 32, 42, 45, 65, 75, 87, 96, 103, 113, 149, 197, $213,214,231,240,258,268,269,278,329,333,343,344,356$, $372,395,398,403,481,485,493,496,503,515,528,589,618$, $624,639,642-644,666,678,698,699,701,706,714,742,743$, $745,746,752,755,760$

Harvey, Margaret (Mrs. Bernard) 65, 268, 643

Harvey, Robert 168,363

Hatfield, Mark 395, 421, 480

Haubach, Walter 98, 302

Hauber, James 444

Hauser, Stuart 140 
Hauske, Hans 297

Haustein, Peter 276, 384

Havens, William 278, 279

Hayakawa, Sam 126, 563, 625, 630

Hayden, Carl 19

Hayden, Melissa 333, 334

Haydon, Dorothy (Mrs. Parker) 561

Haydon, Parker 561

Hayes, Janan 439, 527

Hayes, Peter 41

Hazdra, James 360, 361, 363, 536

Hazlehoffer, Barbara 398

Headley, Bob 440, 455, 458

Heard, Alexander 719,721

Hearst, John 19, 212, 214, 229, 231, 232, 242, 257, 262, 268, 277, $295,297,303,306,313,318,324,325,332,350,355,364,369$, $372,391,470$

Hearst, Randolph 230, 233, 326

Heathcock, Clayton 19

Hebert, Alvin 49

Heckman, Harry 90, 103, 231, 240, 258, 446

Heckrotte, Warren 294

Heese, Wolfgang 302

Heftel, cecil 336

Heidcamp, William 26

Heilbron, Louis 635

Heitowit, Ezra 727

Heller, Doug 430,442

Heller, Elinor (Mrs. Edward) 219

Hellmuth, Karl 578

Helmbold, Reinhard 578

Helvie, Carl 442

Henderson, Algo 748

Henderson, Bob 137

Henderson, Jean (Mrs. Algo) 748

Hendrie, David 28, 42, 103, 203, 213, 214, 231, 240, 257, 308, 329, $395,409,441,446,463,496,642,701,706,713,714,755,762$, 772

Hendrie, Dixie (Mrs. David) 463

Heneghan, Helen (Mrs. James) 405

Heneghan, James $405,421$.

Heneghan, Jim 405, 650

Heneghan, Michael 405

Henze, Robert 164, 168, 361, 363, 533, 723, 731

Herman, Kunrad 105

Hermansson, K. 606

Hernandez, Paul 391, 470

Herrlander, Carl 417, 546, 593-596

Herrmann, Ellen (Mrs. Günter) 576

Herrmann, Günter $63,83,86,87,89,90,176,182,441,478,530$,

$572,573,574,575,576$

Hesburgh, Theodore $383,567,650,746$

Hewlett, Richard 302, 326, 650

Hewlett, William 73, 106

Heylin, Michael 164, 168, 360, 363, 532, 557, 723, 735

Heyman, Ira 663,743 
Heymann, Dieter 677

Heyns, Esther (Mrs. Roger) 377

Heyns, Roger $377,378,698$

Hickman, Bob 444

Higgins, Gary 529, 748

Higgs, Dewitt 641

Hightower, Joe 674

Hilberry, Norman 45

Hildebrand, Joel 83, 161, 350, 502, 620, 644

Hill, Garrett 670,671

Hil1, Henry 168, 178, 179, 181, 258, 278, 279, 285, 287, 292, 293, $294,357,361,363,533,534,536-539,541,638,723,731$

Hill, Herbert 356

Hill, John 570-572

Hill, Michael 39

Hill, Mrs. Garrett 670

Hinckley, Robert 644

Hinderaker, Ivan 219

Hirsch, Robert 7, 43, 126

Hirsch, Werner 236, 237

Hitch, Charles 50

Hitchcock, C. R. 149, 191

Hitchcock, David 292

Hitt, Homer 168

Hjalmers, Folke 595

Hobbs, Marcus 162, 163

Hobbs, Nona 411

Hochmuth, Harold 236

Hodges, Janet $484,488,489$

Hoer, Judy $404,405,413,416,446,455,458,474,475,482,484$

Hoff, Richard 184, 185, 296, 483, 750

Hoffman, Allan 279

Hoffman, Darleane $83,182,183,185,203,266,405,441,442,488$, $635,691,703,750$

Hoffman, John 288

Hoffman, Philip 673

Hoffmann, Gunther 297

Hogan, James $707,709,751,755$

Högberg, Lars 595

Holdahl, John 775

Holden, Constance 393

Holding, T. B. 356

Holland, Don 268

Holland, Elsie (Mrs. John) 162

Holland, John 162

Holland, Robert 15, 21

Hollander, Jack $48,50,664,665,751$

Hollander, Lorin 334-337

Hollander, Margie (Mrs. Jack) 2, 262, 268, 325, 430, 443, 495, 496, $517,679,698,757,765$

Hollingsworth, Robert 110, 650

Holmdahl, Pro-rector 611

Holmqvist, Breata 609

Holzapple, Thomas 393

Hone, Sue 663

Hong, James 775 
Hong, Mrs. James 775

Hong, Stanley 237, 266, 304, 329, 343; 377, 421

Honkala, Fred 279

Hoopes, Townsend 87

Hopkins, Frank 146

Hopper, W. D. 179

Horeau, P. 588

Hori, Glenn 517

Horn, o. 524

Horn, Walter 84

Hornbeck, Hulet $51,64,65,81,82,106,113,187,440,559,689,739$ Horne, Catherine 348

Hornig, Donald 126

Horton, Jack 473

Hostetler, James 336

Hotzapple, Robert 689

Hough, Doris 663

Houghton, Norris 334-337

Hoveyda, Amir 589, 592

Howard, Alice 200

Howard, James 158

Howard, Jerry 515

Howard, John 336

Howard, Margaret (Mrs. John) 334, 336, 389

Howe, Jack 474

Howe, John 474

Howe, Marilyn (Mrs. John) 474

Hoyle, Fred 674, 676, 677

Hoyt, L. E. 236

Hrubesh, Lawrence 444

Hsia Tsung-hsiang 288, 293, 340,341, 342, 343, 344

Hsieh, Dennis 307

Hsieh Chi-Mei 292

Hsu Mao 288, 293, 340, 341, 342, 343, 344

$\mathrm{Hu} 711$

Huang, Huey 674

Huang Wei-yuan 288, 293, 294, 340,341,342, 343, 344, 345, 348

Hubbard, Barbara 146

Hubbell, Wayne 103

Hubbert, King 92, 170, 403, 748

Huddle, Franklin 285, 297

Hudes, Albert 15

Hudson 219

Huheey, James 692

Huizenga, John $86,113,115,178,184,489,750$

Hulet, Kenneth 16, 23, 27, 38, 52, 98, 176, 185, 213, 224, 265, 404, $405,445,463,470,484,493,560,567,624,636,642,665,689$, $690,703,717,718,745,750,751$

Hummel, James 140

Huppunen, Veikko 747

Hurley, Chuck 742

Hurschler, Flora 333, 334

Hutton, Robert 15

Hwa, Jesse 13, 14, 91, 92, 112, 178, 179, 183, 203, 206, 242, 262, $265,287,288,292,293,316,324,344,345,402,411,412,420$, $436,492,521-523,537,538,744$ 
Hyde, Carol 463

Hyde, Earl 6, 67, 87, 91, 103, 113, 161, 162, 203, 207, 214, 240, $241,265,268,269,324,343,344,345,356,360,372,379,392$, $396,405,441,443,463,464,471,485,493,496,539,634,642$, $644,679,706,714,743,746,751,760,761,765,772$

Hyde, Jean (Mrs. Earl) 268, 463

Hynds, Frances 22

Igo, George 678

Ijaz, Mujaddid 739

Inddenham, Reid 666

Ino, Don 621, 632

Inoue, Yoriteru 489

Ioannou-Yannou, John 706

Ionita, George 198

Iscoff, Ron 39

Iselin, John 334,335

Isen, Britta 615

Isham, Christopher 237

Ivars, Marie 598, 600

Jacak, Barbara 405, 530, 562, 619, 639, 698, 750, 757, 759

Jackson, Henry 398, 619

Jacobs, Eugene 236

Jacobs, Mark 738

Jacobs, Steve 340

Jacobson, Lars 608

Jacobson, Mrs. Ulf 608

Jacobson, Norman 765

Jacobson, Ulf 608

Jaffee, Robert 39

Jaffey, Arthur 213

Jancke, Gunnar 595

Janinek, Marie 31, 650

Jansen, James 241

Jansen, Peggy (Mrs. James) 241

Jansen, Robert 1, 208, 211, 241

Jardin, William 84, 115, 558, 739

Jared, Richard 2

Jarrett, Blair 49, 755

Jarvis, Tu 111

Javits, Jacob 336,337

Jefferds, Mary 82, 92, 115, 491, 558, 666, 739

Jeffery, Francis 491

Jenkins, Andy $475,482,483$

Jenkins, Tyrie 89, 429,430,436, 439, 440,442-444,446, 455, 458, $475,483,503,515,546$

Jenkins, William 87, 503

Jennings, Percival 774

Jenny, Hans 666

Jenny, Jean (Mrs. Hans) 666

Jensen, K. A. 524

Jensen, William 150

Jezowska-Trzebiatowska, Boguslawa 524, 526

Joesten, Melvin 721

Johansen, Gunnar 472

Johanson, Dorothy 460

Johansson, Borge 594 
Johnson, Ann 334

Johnson, Carroll 279, 444

Johnson, Celeste 643, 757, 759

Johnson, Debbie 738, 757, 759

Johnson, Harold 707

Johnson, Huey 41

Johnson, Jesse 409

Johnson, Josh 83

Johnson, Kristen Jean 632

Johnson, Madge 111

Johnson, Noah 745

Johnson, Quintin 444, 445

Johnson, Robert 444

Johnson, Russell 140

Johnson, Stanley 419

Johnson, Wilfred 111

Johnston, Harold 106

Johnston, John 157

Johry, K. N. 436

Jolly, William 19, 103

Jonas, Arnold 384

Jones, Alice 429,458, 738

Jones, Brian 306

Jones, Gail 137, 140, 147

Jones, Jack 236

Jones, Proctor 379, 409, 416

Jones, R. N. 525

Jones, Robert 150

Jones, Steve 720

Joost, Bob 268, 775

Jorgenson, Lee 233

Josey, Elva (Mrs. Jack) 410, 411, 673-675, 677

Josey, Jack 410, 411, 461, 479, 673, 675, 677

Judd, David 84,90

Judkins, Charles 145, 187, 409, 709

Jung, Ingvar 595

Jungclas, Hartmut 574, 578, 579

Jura, George 19

Kaback, Deborah 144

Kabbaj, M. 412

Kadish, Karl 673

Kadota, Yoshie 170, 181

Kagawa, George 496

Kahler, Carol 27

Kahn, Myer 665

Kahn, Sally (Mrs. Myer) 665

Kallbach, Connie 162, 163

Kallgren, Edward 711, 712

Kallgren, Joyce (Mrs. Edward) 711, 712

Kane, James $75,126,145,560,679,723$

Kantrowitz, Arthur 205

Kao Shang-yin 711

Kapiloff, Dorothy 141

Kaplan, Evelyn 236

Kaplan, Nathan 343

Kaplan, Riva 708 
Kapoor, R. C. 526

Karant, Yasha 328

Karlik, Berta 683, 742

Karol, Paul 502

Karplus, Robert 150, 312, 669

Karraker, David 539

Kasha, Michael 416

Katcoff, seymour 182

Katz, Joseph 3, 63, 96, 97, 154, 191, 200, 212, 295, 300, 390, 404, $429,516,533,535,636,742$

Katz, Sonia (Mrs. Joseph) 535

Katzin, Leonard 213,546

Kaufman, Joyce $72,75,160,170,375$

Kay, Dennis 169

Kaydel, John 15

Kearney, Joe 722

Keatley, Anne 13,66, 67, 285, 288

Keatley, George 559

Keefe, Denis 265, 751

Keenan, Paul 279

Kekelis, Gary 158

Kekkonnen, Urko 614

Keller, Andrew 142

Keller, Lewin 16, 22, 24, 26, 27, 29, 38, 45, 65, 73, 170, 178, 185, $232,276,328,350,405,436,441,458,460,529,701,743,760$

Keller, Robert 527

Kelly, Frances 268

Kelly, James 268

Kelly, William 19, 279

Kendall, Dick 23

Kennedy, John 323

Kent, Jerry $323,440,530,550,559,739$

Keppel, Francis 334, 335

Keppe1, Geoffrey 86

Kerkman, Don 286

Kerley, Robert 86,663

Kerman, Arthur 82, 84, 266, 441, 488, 678, 679

Kern, Don 168, 178

Kerr, Clark 69, 219, 264, 606, 611, 613

Kertesz, Francois 589, 593

Kerth, Leroy 266

Kesse1, Harlan 115, 558, 689

Keyes, Cornelius 306

Kienle, Paul 420

Kieper, David 142

Kihara, Sylvia 752

Kimbal1, Aubrey 673

Kimbal1, Charles 532, 534

Kimbal1, Karen 211

Kimball, Mrs. Aubrey 673

King, George 207

King, Judson $278,340,341,342,492$

King, Kenneth 403, 748

King Carl XVI Gustaf of Sweden 611, 612

Kingston, Jane $32,68,80,242,262,265,345,463,471,480,496$, $528,561,562,757,765$ 
Kinnear 664

Kinnear, Mrs. 664

Kinney, Eda 105

Kinney, Moira $150,6.69$

Kirby, Harold 97, 302, 636

Kirksey, Theodore 276, 277, 295, 316, 496, 497

Kirkwood, Robert 236

Kirschner, Stanley $179,287,324,411,412,537,538,703$

Kisling, Russell 411

Kissinger, Henry 473

Kjaer, A. 526

Klapisch, Robert 155

Klein, Dennis 419

Klein, Milt 751

Kliewer, Kenneth 679

Klingberg, Göte 755

Knowland, Joseph 473

Knowland, William 28

knowlton, Nancy 775

Knox, William 213

Kohman, Truman 203

Kohn, Harold 673

Kohn, Mrs. Harold

Kohnfelder, Loren

KoIb, Arthur 168

Kol1, Lynne 340,350

Kollar, John 169

Kollar, Mrs. John 169

Koshland, Daniel 27, 28, 208, 356, 474

Koski, Walter 72

Kossionides, Democritos 586

Koue, Don 306

Kouri, Donald 673

Kouri, Mrs. Donald 673

Kragen, Adrian 211, 308

Kragen, Billie (Mrs. Adrian) 211

Kragen, Kenneth 308

Kramer, Gary 700

Kratz, Jens 7, 26, 87, 492, 499, 503, 572-577, 575, 650

Kratz, Karin (Mrs. Jens) 576, 577

Kratzer, Myron 97, 147, 190, 198, 203, 218, 272, 302, 390, 490, 645

Kraus, Mrs. Robert, Sr. 491

Kraus, Robert 17, 27, 73, 96, 149, 214, 217, 262; 265, 300, 329, 350, $378,390,491,679,683,689,690$

Kraus, Robert, Sr. 491

Kraus, William 491

Krieger, Joan (Mrs. Murray) 378

Krieger, Murray 378

Krieger, Robert 75,307

Kriegsman, William 147

Krikorian, Oscar 444

Kroh, Anna 522

Krot, N. N. 403

Krupa, Jean-Claude 197, 198, 233, 405

Kruse, Hans 720

Ku Chao-hao 711 
Kuh, Ernest 486

KundeII, Fred 144, 150

Kunke1, Wulf 664

Kunz, R. M. 526

Kuppermann, Aron 418, 429, 460, 461

Kurfurst, Dana (Mrs. Pavel) 608

Kurfurst, David 608

Kurfurst, Pavel 598, 606-608

Kytle, Calvin 333,336

Laetsch, Watson 312, 478, 492, 630, 669, 692

Iaflin, Marjorie 168, 179, 360, 411

Laidig, William 641

Laitner, Reid 560, 562, 618, 629, 667

Laks, Nathan 714

Lam, Harry 708

Lamb, Tom 491

Lambertson, GIen 265

Lancaster, Robert 178

Landingham, Richard 444

Landis, Phillip 179

Landrum, Jerry 23, 642, 761

Lane, John 21

Lang, Mrs. Neal 674

Lang, Neal 674

Lange, Howard 536

Lange, Rector 611

Langer, Ludy 636

Langlois, Barbara (Mrs. Gordon) 643, 666

Langstaff, Glen 23

Larimer, Ruth-Mary 496, 497

Larkin, David 313

Larkin, John 493

Larsh, Almon 496

Larson 105

Larson, John 324

Larson, Susan 163

Laske, Douglas 141, 142

Laster, David 142

Lathrop, Fred 636

Laubmann, A. 669

Iaurenti, Giuseppe 580

LaVanda, Carol 5, 86, 233

Lavie, D. 526

Lawrence, Molly (Mrs. Ernest) 208, 209, 210, 345

Leatherman, John 39

Leavitt, John 98, 126, 558, 739

Leavitt, Neal 39

Leavitt, Norman 440

Leber, Eric 16, 17, 19, 26, 27, 32, 43, 49, 72, 84, 96, 107, 149, $160,187,191,203,207,213,217,262,266,272,300,302,304$, $317,321,343,356,375,391,416,418,436,479,489,495,515$, $530,531,645,700,727,752,761$

Lecam, Lucien 207, 231

Lederer, Michael 218, 446, 455, 496

Lee, Bruce 440 
Lee, Cynthia $31,42,64,218,224,237,343,393,414,416,418,439$, $443,463,471,478,479,495-497,499,503,530,531,550,559$, $668,718,750,751,757,758,759,761$

Lee, Diana 17, 49, 63, 72, 75, 80, 96, 197, 217, 262, 300, 302, 325, $356,389,391,443,463,478,479,495,496,530,559,621,624$, $638,640,642,668,669,678,698,699,718,746,751,761$

Lee, E. 669

Lee, Edward 241

Lee, I-Yang 65

Lee, Yuan 19, 103, 340,341, 342, 343, 344, 348, 492

Ieeman, Beat 765

Lefort, Marc 164

Lehmann, Thomas 297

Lehninger, Albert 692

Leiby, James 272

Leight, walter 620

Leiman, Leonard 14, 738

Leipper, Kenneth 105

Ieman, Gunnar 595

Lemmertz, Peter 574

Lemmon, Richard 496, 502, 538, 674, 676, 677, 700

Lemne, Mats 612

Lemon, Robert 313

Lenhert, Galen 720

Lenze, Rex 185

Leonoudakis, Steve 464

Lepkowski, will 383

Lesher, Dean 480

Iesko, Barbara (Mrs. Leonard) 233

Leslie, Seymour 409

Lessler, Dick 395

Letiche, John 111

Levanas, Leo 96, 105, 262

Levandoski, Carrie 137, 147, 310

Leventhal, Brigid 137, 140

Leventhal, Leon 105, 169, 755

Levy, Alan 6, 751

Lewis, Bob 332

Lewis, Brad 65

Lewis, Darleane 670

Lewis, Edward 674

Lewis, Grace (Mrs. Brad) 72

Lewis, Jack 200

Lewis, Mrs. Edward 674

Lewis, Oscar 397

Lewis, Patricia (Mrs. Bob) 332

Lewis, Roger 473

Li, Annie (Mrs. Chok Hao) 606, 613

Ii, Chok Hao 604, 606, 613

Li San-Ii 711

Liebig, Zbigniew 525

Lieser, K. H. 308

Liljeby, Leif 594

Lim, Drahoslav 563

Lin, Michael 113

Lind, Gunilla 606 
Lindås, Britt Marie (Mrs. Timo) 600

Iindås, Gunhild 600

Iindås, Gunvor 600, 601, 603

Lindås, Johan 600

Lindås, Karin (Mrs. Sven) 600

Lindås, Kerstin 600, 601, 603

Lindås, Lars 600,603

Lindås, Maja 600, 601

Lindås, Mats 600

Lindås, Nils 600,601

Lindås, Sara 600

Lindås, Sven 600

Lindås, Timo 600

Lindel1, Bo 595

Lindkvist, Siv 530, 593, 596, 598, 609

Iindner, Manfred 187

Iindqvist, Robert 16

Iindstrom, AI 440,458

Iindstrom, Peter 31, 391

Iingafelter, Edward 350

Link, George 219

Linkletter, Art 473

Iinn, Stuart 669, 691

Linowitz, Sol 272, 395, 502

Lippincott, W. T. 692

Lipson, Leslie 663

Iiss, BeverIy 52, 83

Iivermore, Arthur 638

Iivieratos, Anthony 585

Llewellyn, Crystal 496, 497

Lo, Andrew 142

Lochak, Boris 581, 589

Lochak, Paul 186, 187, 262, 376, 403, 439, 459, 494, 561, 569, 570, $571,572,580,581,583,585-587,589,592,593,624,639,737$

Lochak, Rose (Mrs. Boris) 581, 589.

Lodhi, Arfin 700

Loeb, Benjamin 31, 73, 147, 458, 478, 489, 492, 562, 620

Lofgren, Edward 6, 28, 214, 265, 345, 441, 470, 632, 644, 723, 724, 761

Lohman, Dave 630

Lohmann, Kenneth 141, 142

Lohr, Harold 707

Lohse, Christopher 140, 142

Long, David 558

Long, Deborah 163

Loomis, Henry 278

Lothrop, Fred 395, 443, 744

Loucks, Nathan 631, 632

Lougheed, Ronald 23, 265, 356, 357, 404, 405, 470, 636, 641, 642, 755,761

Loughrey, Kay 84

Lous, Per 525

Love, Bob 310 
Ioveland, Walter $2,3,6,16-19,23,26-29,31,32,38,42,44,48$, $68,72,84,90-92,96,105,107,112,115,126,149,155,156$, $162,188,197,198,200,217,218,224,229,230,232,237,240$, $256-258,262,263,265,266,269,272,277,296,300,302$, $304-306,325,328,329,332,345,350,356,369,375,376,379$, $382-384,392,395,404,414,474,480,483,485,567,626,638$, $641,642,650,665,666,679,683,689,690,718,719,751,762$ Iöwbeer, Hans 612

Lowder, Ron 496

Lowe, Gloria 21,72

Lowe, Warren 537

Loweth, Hugh 264, 284

Lowry, Larry 480

Iu Valie, James 156,348

Iuberoff, Ben 237, 537

Iucas, Joe 191, 329, 389

Iucchesi, Claude 538

Luce, Henry 49, 265, 709

Luck, Murray 156

Lui, Kinkuen 142

Luke, Wayne 198, 486

Lund, Torgeir 578, 579

Lundborg, Louis 470,473

Lunden, Lennart 594

Lundgren, Harold 606

Lundqvist, Delano 642

Lundqvist, Dick 595

Lunsford, Mrs. Willie 670

Lunsford, Willie 670,671

Luria, Scott 484, 488, 489

Lustig, Lawrence 237, 739

Luther, Homer 410

Luther, Monroe 410

Luther, Mrs. Monroe 410

Luther, Pat (Mrs. Homer) 410

Lux, Frànz 305

Lykos; Peter 541

Iyman, Richard 155

Iynn, Cornelia 328, 329, 384

M'Bow, Amadou Mahtar 611, 613, 615, 626

M'Bow, Raymonde (Mrs. Amadou Mahtar) 615

MacDougall, G. H. 357

Mackillop, Malcolm 236

Mackinlay, Ian 473

MacWaters, John 186

MacWhirter, Isabel 32, 41

Madden, Carl 146

Madden, Dave 397

Maddon, Paul 142, 147, 311

Maglich, Bogdan 722, 750

Magram, Jonas 402

Magrath, Peter 73

Maguire, Charles 721

Mahan, Bruce 103, 638

Mahoney, Jeannette 91, 158, 257, 471, 496, 502

Main, Robert 356 
Malatesta, Lamberto 525

Malik, Fazley 701

Malm, Lloyd 40

Malone, Frank 31

Mancarti, Gail 331

Manlove, Robert 158

Mann, Frances 496, 624

Manning, Robert 279

Manning, Winston 470, 533

Manske, Ed 706

Manue1, Guy 635

Manuel, Oliver 155, 490, 676, 678, 744

Manvilie, Harrington 263, 286, 494, 499

Marcos, Antonious 313

Marcy, Willard 168

Margolies, Daniel 285

Margolis, Bernie 708

Margrave, John 444, 674

Margrave, Mary Lou (Mrs. John) 674

Mariella, Raymond 164, 168, 357, 363, 483, 532, 534, 537, 538, 541, $674,723,728,734$

Marin-Price, Francisco 168, 363, 533

Mark, Hans 170,677

Mark, Herman 297

Mark, Tommy 708, 709

Markowitz, Samuel 19, 95, 103, 268, 321, 475, 496, 498, 619, 714, $757,759,765$

Markowitz, Sondra (Mrs. Samuel) 268, 757

Marrell, Judy 773

Marriner, Ernest 455

Marsh, Wayne 154, 160, 206, 207, 217, 262, 300, 356, 377, 461, 472, $495,503,530,559,620,633,692,698,699,739,746,760$

Martens, Tom 479, 528-530, 552

Martin, Bill 708

Martin, Freddie 43

Martin, Ronald 90

Martin, Trudy 663

Martinez, Vilma 641

Martino, Joseph 459

Marvel, Alberta (Mrs. Carl) 677

Marvel, Carl 410, 671-677, 672

Marx, William 187

Maslach, George 84, 663

Mason, Ben 146

Mason, Delores 16, 21, 182, 187, 212, 262, 285, 343, 377, 382, 398, 402,403

Mason, George 397

Mason, James 169

Mason, Stanley 708

Matcha, Mrs. Robert

673

Matcha, Robert 673

Matteson, Gary 75

Matthews, Kathleen 674

Matthews, Randall 674

Maxwell, Arthur 278, 279

Maybury, Robert 533, 549, 650 
Mays, Bibiana 147

Mazia, Daniel 84

Mazumdar, Amal 578

McAdie, CIC Board Chairman 357

McAfee, Janet 402

McAtee, Jim 670

McBride, John 198

McCal1, Abner 670

McCal1, David 179

McCiula, Gus 187

McCloskey, Ken 233, 550

McCloskey, Michael 491

McCloy, John 14, 144, 458, 459, 738

McColium, Don 105

McCone, John 389, 398

McCool, W. B. 111

McCormack, Elizabeth 333, 334, 336, 337

McCormack, Margaret (Mrs. Michael) 333, 727

McCormack, Michael 242, 264, 308, 321, 332-335, 372, 418, 470, 483, $515,645,700,727,752,761,765$

McCredie 219

McCune, ElIis 711

McCune, Hilda May 711

McDaniel, David 219

McDonald, Kim 479

McFadden, Betsy 302, 332, 649

McFadden, Stephen 142

McFall, John 567

McFarland, Rose Marie 630, 639, 692, 698, 713, 716, 744, 745, 747, $750,751,757,761,762,765$

McFarlane, Malcolm 113

McGaughey, Patrick 620, 625, 633, 640, 645, 668, 683, 689, 692, 698, $699,714,716,718$

MCGee, William 158

McGrath, Henry 169

McGuire, Hugh 636

McHarness, Don 105

McHarris, William 63

McKay, Kathy 161

Mckinney, John 162, 163

Mckinney, Sheila 162

MicLaren, Jim 455,458

Mclaughlin, Donald 219, 636, 663

Mclaughlin, Sylvia (Mrs. Donald) 491, 663

McLellan, Mrs. Rex 674

McLellan, Rex 674

McMillan, Edwin 84, 208, 345, 470,496, 636, 666, 723, 724, 725

McMillan, Elsie (Mrs. Edwin) 84, 208, 666, 723, 725

McMinn, John 578, 713

McNeese, Gene 185

McPherson, Betsy 332

McSweeney, E. E. 168, 176, 533, 716

McWaters, Prudy 491

McWilliams, Douglas 240, 262, 343

McWilliams, Jane 486

Mead, Dale 156 
Mead, Edward 334

Mead, Margaret 607, 609

Mechem, Charles 143

Melander, Lars 606

Meldner, Heiner 52, 277

Melese-d'Hospital, G. 663

Mel1o 5

Melion, Carlotta 75

Meloyneaux, Lana 440

Mendes, John 231

Menon, Victor 143

Mercer, Douglas 728

Merhaut, Jack 137

Merrill, Richard 150, 312, 631, 669

Mestemacher, John 491

Mestemacher, Trudy (Mrs. John) 491

Metag, Volker 502, 574, 576

Metzler, David 692

Meyer, James $16,29,331$

Meyer, Morton 158

Meyerhof, walter 631

Meyers, Henry 723

Michael, Glynn 179, 357, 525

Michael, Mrs. Glynn 357

Michaelis, Michael 146

Michalski, Jan 524, 525

Miche1, Maynard 621, 665, 678

Michener, James 334-337

Middlebrook, Diane 612, 617, 747

Migdal, Arkadiy 369

Mikheev, Nikolai 560, 567, 618, 621, 624, 630, 636, 642, 644, 649, $683,717,718,739,755,757,759$

Milanovich, Fred 445

Miles, Josephine 84,378

Milich, Melissa 331

Millard, Louise 496

Miliberg, Gösta 608

Miller, Daniel 213, 539, 679

Miller, David 669

Miller, Leslie $1,22,331$

Miller, Robert 103, 236, 305

Miller, Thomas 15

Miller, William 19, 717

Milligan, Mrs. W. O. 675

Milligan, W. O. 27, 28, 113, 190, 296, 308, 355, 364, 372, 375, 409, $410,441,624,670,671,673-677,691,718$

Milly, George 145, 186, 187, 409, 561, 667, 709

Milrod, Robert 140,143

Mineta, Norman 446

Mink, Patsy 284, 292, 294, 334-336

Minvielle, Al 464

Mirk, Kenneth 515, 751

Mislow, Jacqueline 615

Mitche11, Lawrence 392, 421

Mochisuki, Tom 458

Mock, Carol 219 
Moder, Tim 621

Moline, Robert 378

Möller, Goran 598, 600, 601

Möller, Karin (Mrs. Per) 594, 598, 599, 600, 603, 605

Möller, Per 480, 598, 599, 600, 603

Moltz, Dennis 45

Molzahn, Dieter $517,578,579$

Mondale, Joan (Mrs. Walter) 335

Mondale, Walter $1,7,24,28,87$

Montgomery, Robert 158

Moody, Kenton 624, 667, 689, 692, 698, 699

Moody, Ralph 397

Moore, Bradley 19

Moore, Dan Tyler 391, 403, 404, 496

Moore, Joseph 641,663

Morea, Gena 334

More1, Claud 581

Moreton, Lady (Mrs. John) 663, 664

Moreton, Sir John 664

Moretto, Iuciano 19, 471, 479, 484, 493, 642, 649, 706, 714, 746, 755,762

Morgan, Elmo 641

Morgan, Patricia 537

Morris, Donald 191, 297

Morris, Edward 219

Morris, Elizabeth 494

Morris, W. K. 236

Morrison, H. Frank 455

Morrison, Jack 334

Morrissey, David 3, 6, 16-18, 22, 23, 26-29, 32, 38, 40, 42, 48, 49, $63,72,90-92,96,98,107,112,115,126,149,162,185,191$, $197,198,200,207,208,213,214,217,218,224,229,230,232$, $240,256-258,262,265,266,269,277,297,300,302,304,305$, $316,324,325,328,329,340,343,345,350,356,368,369,372$, $375,379,382,391,393,395,396,398,401,402,404,405,414$, $416,419,420,421,430,436,441,443,444,455,461,463,464$, $471,474,478,479,481,483,485,488-490,494,495,496,499$, $502,503,516,517,528,530,531,549,550,558-562,567,581$, $620,621,624,626,632-634,635,636,640-642,644,645,649$, $650,665-669,678,683,689-692,698,699,701,716,718,719$, $738,745-747,750,751,755,757,759-762,765,772$

Morrissey, Deborah (Mrs. David) 90, 757, 759

Morse, Mrs. Roger 583

Morse, Roger 583

Morss, Lester $743,761,762$

Moss, John 299, 300

Moss, Simon 673

Mottelson, Ben 761

Mottur, Ellis $334,383,393,398$

Moulton, James 45

Moxley, David 15

Moynihan, George 150, 313, 630, 669, 692

Mrak, Emil 641

Muccio, Sam 464

Mudd, Betty (Mrs. Robert) 492

Mudd, Robert 492 
Mueller, Ron 208

Muetterties, Earl 23, 340, 341, 342

Muirs, Dan 44

Mulford, Donald 663, 747

Muller, Richard 632

Muller, Rolf 185

Muller, Werner 179, 185

Mullins, Hope 488

Murel1, Judy 268

Murphy, Franklin 473

Murphy, Ingeborg 461

Murray, Annie 140, 141, 143

Muscatine, Charles 743

Musikas, Claude 300

Musket, Ronald 308, 700

Myasoedov, Boris 176, 526, 748

Myers, Robert 330

Myers, Rollie 517, 619-621, 630, 633, 638, 640, 649, 666, 668, 678, 698

Myers, William D. 443, 496

Myers, William G. 83, 190, 305

Nader, Claire 285

Nadich, Julie 268, 714, 715, 775

Nagakura, S. 526

Nagamiya, Shoji 299

Nakai, Kozi 354

Narath, Albert 679

Nassikas, John 330

Natowitz, Joseph 86

Naugle, Thomas 187, 409

Nava, Julian 236

Navratil, James 297, 691

Neal, Homer 650

Neal, Steve 335

Neblett, Tom 397, 472

Nedelson, Steve 775

Needell, Allan 723

Negal, Fema 383

Nehls, James 185

Nelson, Cheri 540

Nelson, Christian 188

Nelson, Gordon 164, 168, 357, 360, 361, 363, 532, 535, 723

Nelson, John 540

Nemets, Oleg 203

Netherton, Lowell 179

Nettelbrandt, Cecilia 747

Nettles, Bill 720

Neuman, Robert 168, 363, 533

Nevitt, Michael 679

Newey, Richard 455

Newland, Tom 428

Newman, Pauline 164, 168, 169, 179, 217, 230, 303, 357, 361, 363, $411,533,534,537-539,541,669,717,723,734,735$

Newmark, Nathan 297, 403, 416

Newson, Henry 163, 164

Niederhauser, warren $164,168,357,361,363,723,735$ 
Nielsen, Julian 679

Nikoline 747

Nikoline, Mrs. 747

Nilsson, Sam 595

Nilsson, Sven Gösta 45, 377, 384, 391, 393

Nir 439

Nishi, Shunji 313

Nishida, Bonner 206, 213, 256, 263, 277, 296, 343, 398, 403, 416, $443,444,461,474,479,495,496,498,503,530,531,550,559$, $621,626,639,640,649,668,698,699,706,718,742,745,747$, $751,757,758,762$

Nitschke, Michael 2, 3, 5, 7, 72, 96, 98, 107, 113, 126, 149, 154, $160,197,213,217,232,272,300,302,304,317,328,343,383$, $390,391,396,402,416,419,436,441,443,444,461,463,470$, $471,478,485,495,496,499,516,550,559,624,640,641,690$, $698,699,701,714,746,750,752,757,759$

Nivens, Mrs. 499

Nix, Raymond 182, 184, 230

Nixon, Alan $105,277,279,295,538,540,634$

Nixon, Fred 720

Noble, Ray 42

Noddack, Ida 326

Norberg, Arthur 345, 620, 645

Norbert 576

Nordlander, Brita 611, 612

Nörenberg, Wolfgang 576

Norris, Edward 98, 264

Norris, John 145

Nosarzewski, Janusz 525

Noyce, Donald 19, 103, 401, 620

Nuccio, Sam 328

Nuckolis, Ruth (Mrs. John) 30

Nurmia, Matti 2, 17, 32, 72, 96, 106, 149, 198, 213, 262, 304, 559, $562,636,640,665,678,698,761$

Nygren, David 265

o'Brien, John 717

O'Donnell, Ashton 396

O'Donnell, Larry 236, 502, 691.

O'Donnel1, Thomas 5, 26, 28

O'Kelley, Davis 723

O'Konski, Chester 19, 340, 341, 342

O'Neill, Thomas 728

O'Rourke, Robert $28,42,63$

O'Sullivan, Dermot 521, 522

Oberman, Kenneth 14, 144, 459, 738

Odin, Lee 710

Offenbach, Jan 354

Oganessian, Yuri 626

OhIson, Ragnar 606, 609

Ohman, Mitzi 369

Okamura, Seizo 233, 414

Olander, Donald 84

Olausson, Leif 595

Oliphant, Mark 485

Oliver, Hugh 717

Oliver, William 279; 397 
Olovsson, J. 606

Olson, Jana 115, 187, 206, 417,440,455,458,559

Olson, John 674

Olson, Karl 644

Olson, Mrs. John 674

Olson, Ruth 2, 4, 5, 17, 526-528, 531

Olsson, Nils $146,313,742$

Oni, Camille 462

Oppenheimer, Frank 150, 334-336, 528, 562

orlemann, Edwin 213

Orlove, Ben 475, 531, 635, 637, 640, 774

Orly, Elira 723

Orr, Vernon 219

Ortgrem, Lars 560,562

Orvig, Sven 709

Osteryoung, Robert 692

Othmer, Donald 169, 170

Otto, Jane 22,485

Otto, Larry 286

Otto, Roland $2,3,6,7,16-19,22,23,26-28,31,32,38,40,41$, $48-50,63,70,72,75,80,84,90-92,96,105,107,112,126$, $149,154,155,160,162,188,198,207,208,213,214,217,224$, $233,240,256,258,262,265,266,269,277,296,300,302,304$, $316,324,325,329,350,356,369,372,375,382,392,393,395$, $398,401,402,404,405,414,416,419-421,430,436,439$, $441-443,444,455,460,461,463,464,471,474,478,479,483$, $485,488,489,493-496,499,502,503,516,527,528,530,531$, $546,549,550,558-561,567,581,619,620,621,624,526,633$, $635,636,640-642,644,645,650,666,668,669,683,690-692$, $698,699,701,713,714,716,718,723,731,739,742,745-748$, $760-762,765,772,774$

otto, Shari (Mrs. Roland) 90

Ourisson, Guy 524, 525

Ovadia, Jacques 279

Ovchinnikov, Yuriy Anatoliyevich 613

overberger, Charles 170,521, 524, 525, 538, 734

Overton, Joe 567

Owen, Josephine 348

Owen, Patty 191, 207

Pace, Nello 478

Page, Bea 527

Paige, Harold 561

Paige, Mary (Mrs. Harold) 561

Pake, George 92, 278, 279

Palmer, Graham 674

Palmer, Mrs. Graham 674

Palmer, Russell 15

Panofsky, Pief 278

Panvani, Bob 721

Papadatos, George 586

Pappas, George 6, 28, 441, 463, 496, 644

Park, Roderic 84, 256

Parker, Earl 84

Parmer 491

Parr, Robert 162

Parry, Marjorie (Mrs. Robert) 178 
Parry, Robert 18, 40, 150, 164, 168, 179, 180, 218, 287, 288, 292, $293,324,357,360,363,391,442,521-524,526,532,534,535$, $537,538,723,731,734$

Parry, Roger 649,714

Parsons, Thomas 65

Parvis, Byron 311

Passer, Moses 164, 168, 360, 361, 363, 490, 532, 535

Passman, Sidney 549, 593

Pasternak, Alan 350, 557

Patterson, Don 708

Patzelt, Paul 577, 717

Pauling, Linus 747

Paull, Elizabeth $14,144,738$

Paullsen, Valfrid 595

Pavlath, Attila 105

Pearlstein, Linda 720

Peck, Earl 397

Peck, James 236

Pederson, B. 606

Pederson, K. O. 606

Pederson, Mrs. I. 606

Peeples, Daryn 219

Peery, Annamary (Mrs. Victor) 561

Peery, Iuther 213

Peery, Victor 561

Peevey, Michael 236

Peiser, Steffan 288

Pel1; Claiborne 336, 337

Pellmyr, Olle 311

Pendergast, Gene 219

Penico, Sandy 106

Penneman, Robert 185, 258

Pennington, David 670, 671

Penrose, Joseph 630

Penzias, Arno 674, 676, 677

Percy, Charles 164, 224

Perkins, Bill 640

Perkins, Carl 336

Perkins, Dick 531, 772

Perlin, Arthur 707

Perlman, Isadore $213,272,441,474,503,561$

Perlman, Lee (Mrs. Isadore) 439, 474, 503, 561

Pernow, Bengt 612

Pernow, Mrs. Bengt 612

Perry, Dale 184

Persson, Steffan 311

Peschke, Jerome 673

Peschke, Mrs. Jerome 673

Pessier, Maria 675

Petersen, Kathryn (Mrs. Eugene) 559, 635, 643, 666, 747, 774

Petersen, Steve 492

Peterson, Conway 644

Peterson, Helen 557

Peterson, Joseph $176,185,191,484,750$

Peterson, Merlin 557

Peterson, Rudolph 473, 636 
Peterson, Russel1 95, 103, 144, 350, 392, 421, 632, 650

Pettitt, Newman 200, 350

Pewitt, Doug 722

Pfautch, Lee 559

Phares, Tom 137, 140, 147

Phillips, Norman 19, 103, 240, 278, 302, 321, 324, 325, 328, 340-342, 348,492

Philitips, Robert 236

Phillips, susan 382

Philpotts, Jacquelyn 494

Phleger, Herman 473

Pidgeon, Helen 52

Pierce, Elliot 27, 141, 541, 679

Pigford, Thomas 645

Pimentel, George 17, 19, 23, 26, 30, 39, 40, 44, 50, 64, 65, 72, 82, $84,86,92,103,106,113,269,340,341,342,414,470$

Pincus, Albert 670

Pines, Alexander $31,299,305,343,620$

Pinkston, Tom 720

Pinto Coelho, Aristides 625

Piret, Edgar 137, 140, 141, 147, 168, 179, 287, 288, 292, 293, 361, $363,389,411,443,532,533,535,537$

Pitzer, Kenneth 19, 40, 103, 305, 340, 341, 342, 470, 691

Place, John 15

Plainfield, Ruth 325,743

Plant, Albert $147,164,168,360,363,532,723$

Plasil, Franz $87,90,183,746,748,750$

Plumb, John 83

Poenisch, Paul 491

Poliakoff, Erwin 21

Polikanov, Sergei 549

Pollack, Herman $285,305,326,645$

Ponnamperuma, Cyril 141, 292, 293,416, 538, 589, 668, 674, 676, 677

Poole, Glenn 141, 143

Pope Shenouda III 313

Popp, George 105

Porath, Jerker 604, 606, 613

Porath, Mrs. Jerker 613

Porile, Norbert 87, 89, 90

Porter, Dwight 335

Poskanzer, Arthur 39, 42, 103, 113, 115, 178, 214, 231, 240, 258, $329,395,446,463,496,503,642,678,679,706,714,745,755$

Poskanzer, Lucille (Mrs. Arthur) 463

Postma, Herman 356

Potenza, Joseph 761

Potter, Elinor 496

Poulos, Arthur 183, 537

Povh, Bogdan 266, 678, 679

Powers, Philip 549

Pracht, Peggy 496

Present, Gerald 403

Press, Frank 32, 278, 297

Price, Buford 256, 706

Price, Charles 727

Prigogine, Ilya 606, 615

Prince Charles 663, 664, 665 
Prince Mohammed Al Faisal 632

Propp, James 141, 143

Proskauer, Eric 170

Pruitt, Malcolm 492

Prussin, Stanley 714

Puckett, Allen 474

Pugh, Debbie (Mrs. Howel) 486

Puppa, Robert 637, 665, 772

Puppa, William 4, 772

Purica, Ionel 692

Pyle, Robert 6

Queen Silvia of Sweden 612

Quigley, Stephen 168, 363, 409, 533,637,650, 734

Quincy, Tom 333

Quinn, Louis 147,162

Quinn, Patricia 442, 444, 460, 471, 483, 489, 490, 494, 496, 503, $516,527,531,546,562,607,618,619,624,643,668,678,692$, $698,699,713,738,748,757,759,761,765,772$

Quiocho, Florante 674

Quiocho, Mrs. Florante 674

Rabalais, Mrs. Wayne 673

Rabalais, Wayne 673

Rabi, Isidor 619, 645, 650

Rabideau, Sherman 205

Radloff, Patricia 107

Radunskya, Irena 636

Ragsdale, Becky 163

Raimbault, Sylviane 526

Ramayya, Akunuri 720

Rame1, Stig 375, 421, 614, 728

Ramell, Gunilla 106, 141, 155

Ramette, R. W. 535

Ramsay, Beatrice 496, 503, 641

Ramsay, Bertrand 667

Randolph, Paul 461

Randrup, Jorgen 368

Rao, C. N. R. 523

Rapaport, Mrs. Randy 674

Rapaport, Randy 674

Rapoport, Henry 65, 103

Rasmussen; EImer 747

Rasmussen, John 19, 42; 103, 126, 160, 182; 240, 268, 340, 341, 342, $356,391,403,416,418,443,495,496,498,517,626,639,642$, $644,649,706,714,755,760,762$

Rasmussen, Louise (Mrs. John) 268, 391

Rauch, Leonard 673

Rauch, Mrs. Ieonard 673

Rauscher, Elizabeth 159, 160, 418, 488, 641, 755

Ravneberg, Noel 279

Raymond, D. 523

Raymond, Kenneth 5, 26, 50, 84, 86, 103, 161, 185, 198, 200, 233, $369,372,486,626,633,649,663,765$

Reedy, Gale 440

Reedy, Mrs. Gale 440

Reeve, Marian (Mrs. Roger) 82, 549, 666

Reeve, Roger 17, 82, 305, 549, 550, 630, 666 


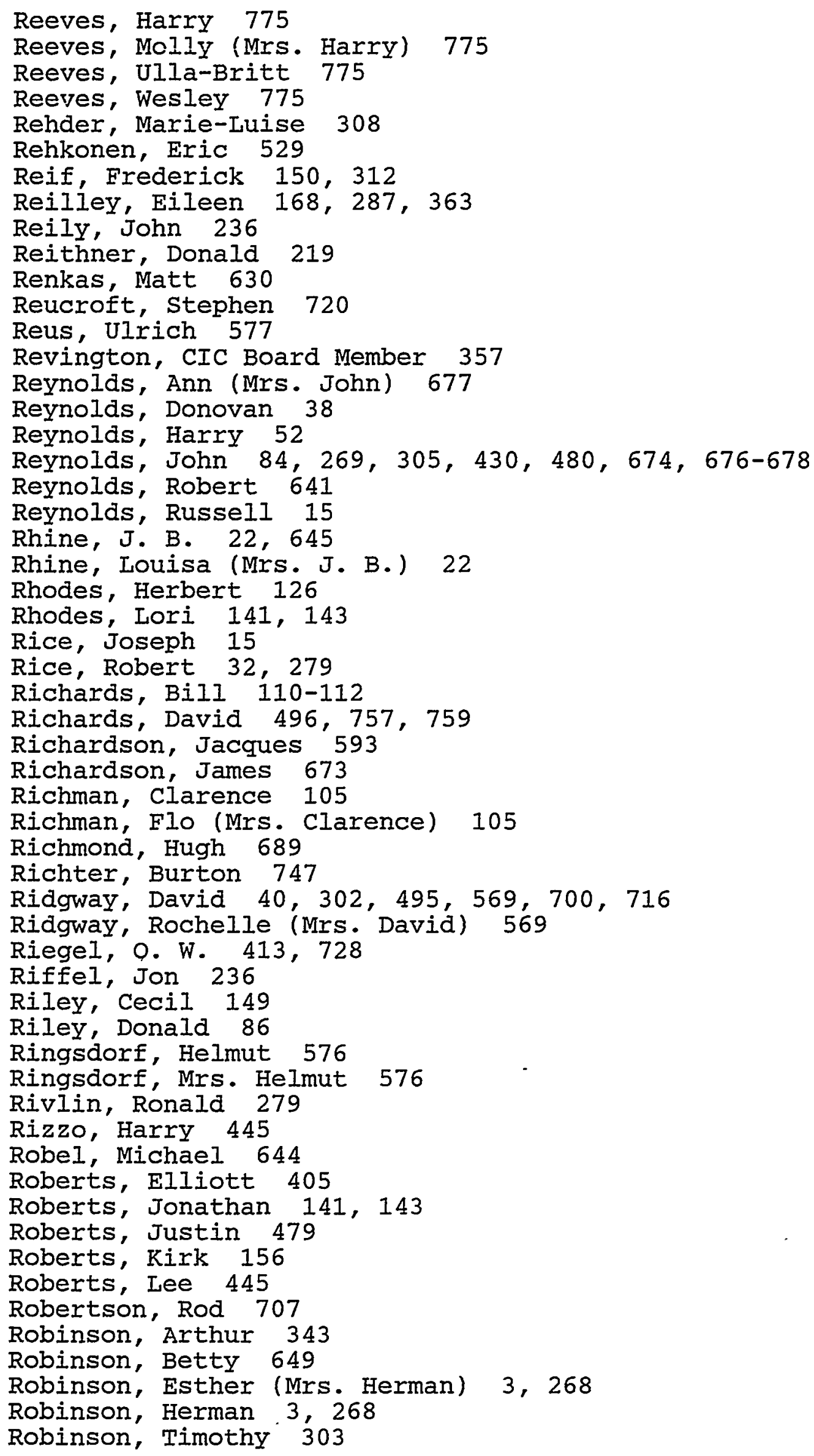


Robison, Janelle 334

Robson, John 708

Rockefeller, David 14, 149, 266, 333-337

Rockwell, Merry 268

Roe, James 620

RoeckI, Ernst 574, 576

Roeckl, Mrs. Ernst 576

Roethe1, David 169, 205, 279, 537

Roethe1, Mrs. David 169

Rogers, Carol 230

Rogers, Iinda 22

Rogers, Lockhart 692

Rogosa, George 45, 147, 258, 264, 420,463,464, 503, 679

Rojas, William 140, 143

Roller, Bob 158

Rolph, Earl 111

Rominger, Rick 331

Ronan, William 15

Rood, Rodney 236

Roos, Charles 720

Rooth, Anna Briget 609

Roper, Gerald 212

Rosati, Janet 528

Rose, David 419

Rose, J. 528

Rosenbacker, Carl 414

Rosenberg, Lawson 478

Rosenfeld, Arthur 632

Rosenfeld, Sherman 150, 312, 313

RosenthaI, Aaron 413, 728

Rosenthal, Sidney 416

Rossini, Anne 674

Rossini, Frederick 674

Rossiter, Bryant 92, 179, 287, 460, 521-524, 621, 632

Rothchild, Elizabeth 105

Rothman, Al 715

Rowlett, Russell 168

Roybal, Edward 567

Ruark, Arthur 147

Ruben, Helena (Mrs. Samuel) 50, 86, 198, 233, 372

Rubin, David 486

Rubin, Julius $305,350,650$

Rucci, Charlotte 332,333

Ruder, Charles 671

Ruder, William 15

Rudolph, Frederick 674

Rudolph, Mrs. Frederick 674

Rudstam, Gösta 531, 604, 606, 607, 612

Rudstam, Sven 612

Ruete, Ray 678

Runcorn, S. K. 633,679

Rush, Stockton 397

Russell, McKinney 286

Ryan, Jack 4

Rynecki, Alex 126

Sachs, Robert 494,742 
Sadat, Anwar 707

Salame Martin, Rene 701, 718

Salerno, Michael 641

Sandorfy, C. 526

Sandoval, Andres 679

Sanford, Terry 746

Sankary, Richard 42, 63, 624

Sarabia, oscar 675

Sarett, Lewis 168

Sargent, Tony 689

Sarup, Ram 198

Sasser, Jim 631

Saunders, Donald 334

Savage, Donald 150, 669

Sawyer, Brian 404, 405, 413, 416, 446,455,458,474,475,482, 484

Saxby, Sheila 13, 30, 31, 52, 70,83, 84, 106, 149, 150, 161, 164, $187,188,208,212,218,256,268,276,295,299,305,306,307$, $308,321,325,330,337,340,341,342,343,344,345,350,360$, $364,377,393,403,405,409,412,413,417,421,429,430,439$, $442,446,464,484,489,496,497,502,503,563,619,645$

Saxon, David 65, 67, 219, 223, 262, 378, 529, 641

Saxon, Shirley (Mrs. David) 65, 219, 378, 641

Scalapino, Dee (Mrs. Robert) 711, 712

Scalapino, Robert 711, 712

Schaefer, Henry 231, 257, 277, 297, 324, 350, 369

Schäfer, K. 302

Scherman, Barry 236

Schirato, Richard 140, 141, 143, 311

Schlegel, David 669

Schmelzer, Christoph 305, 574, 576

Schmidt, Nadine (Mrs. Victor) 211

Schmidt, Victor $211,484,527$

Schneider, Renee (Mrs. Stanley) 147

Schneider, Stanley 106, 147, 198, 277, 314, 317, 442, 488, 618, 645

Schneider, William 179

Schoffner, Jim 537

Schoofs, Gary 105

Schriver, Dorothy (Mrs. Oliver) 1, 28, 67, 83, 89, 137, 138, 140, $147,214,217,263,299,310,311,332,413,638,665,716,728$ Schriver, Oliver 665

Schroeder, Lee $231,266,678,701,714,744$

Schroepfer, George 674

Schufman, Jay 224

Schurr, Bert 643, 757

Schuster, Werner 297

Schwartz, David 286

Schweitzer, Glenn 284

Scott, Benjamin 213

Scott, David 42, 103, 214, 231, 240, 265, 329, 446, 634, 642, 701, $706,714,751,755,759$

Scribner, Richard 279

Scripps, Edward 317 
Seaborg, David 1, 13, 18, 21-23, 26, 30, 39-41, 43, 45, 50-52, 63, $64,71,73,75,81,83,86,105,107,115,126,154,157,197$, $200,213,214,229,232,241,256,258,268,278,295,296,299$, $302,305,306,310,313,314,317,318,324-326,329-331,343$, $348,357,382,491,503,515,516,526,527,617,631,637,641$, $665-667,689,706,714-716,745,748,757,759,762,772-775$

Seaborg, Dianne $1,2,5,6,13,17,18,21-23,26,30,31,39,40$, $43,44,45,50,51,63,64,71,73,75,81-83,86,89,90,91$, $96,105,107,115,154,157,187,188,197,198,200,208,211$, $213,214,223,229,230,232,241,256,258,263,266,268,278$, $294-296,299,302,305,306,310,313,314,317,318,324-326$, $329-331,343,348,349,357,364,368,375,382,383,389$, $392-394,396-398,405,416,417,419,421,428-430,436,439$, $440,441-444,446,455,458,464,474,475,478,480,481$, $482-484,488,492,494,516,546,550,557,559,560,561,563$, $567,: 569,617,637,640,665,666,690,706,714-716,743,745$, $757,772,773$

Seaborg, Eric 1, 2, 4, 5, 17, 18, 21, 22, 26, 29, 30, 52, 63, 73, 81, $91,115,154,156,157,187,188,241,258,268,278,295,302$, $306,318,330,331,364,396,397,404,405,413,416,417,429$, $439,440,442,444,446,455,458,474,475,482,484,488,489$, $503,515,526-528,531,546,549,550,557-561,563,567$, $569-578,570,575,580,581,582,583,584,585,587,589$, $593-601,597,599,601,603-615,605,610,616,617,639,689$, 714

Seaborg, Glenn 138, 148, 180, 205, 209, 210, 293, 320, 342, 337, $344,496,498,570,582,584,599,605,610,616,664,672$, 699,759

Seaborg, Helen 1, 2, 5, 13, 16-18, 21-23, 26, 27, 30, 39, 40, 43-45, $50-52,63-65,71,73,75,81-84,86,89-91,96,105,107,115$, $126,137,149,154-158,162,169,170,176,181,182,184,187$, $188,197,208,209,211-213,214,218,219,223,229,230,232$, $237,241,256,258,266,268,278,294-296,299,302,304-306$, $310,311,313,314,317,318,324-326,329-331,333,337,343$, $348,349,357,364,368,375,377,382,383,389,391,392,393$, $396-398,402,405,409,413,416,417,419,421,427-430,436$, $439-443,446,455,458,460,462,464,474,475,478-482,484$, $488,489,491,492,494,496,497,498,502,503,515,517,527$, $528,530,531,546,550,552,557,559-561,563,567,581,617$, $618,621,629,631,632,636,637,640,641,643,645,649,663$, $665,666,669,678,689,690,706,707,710,712,714,715,716$, $719,738,743,745,747,748,751,752,757,762,772-775$

Seaborg, Peter 1, 6, 13, 17, 18, 21-23, 26, 27, 157, 258, 288, 292, $336,715,772$

Seaborg, Stephen 115, 211, 229, 256, 326, 337, 368, 397, 442, 443, $474,475,492,494,515,560,631,716,772-775$

Searchinger, Gene 86

Searcy, Alan 265, 379, 634

Searle, Milton 337

Sebesta, Edward 113, 157, 160, 190, 303, 402, 404, 439, 461, 478, $479,485,495,516,530,531,550,624,633,640,698,751$

Seelye, Mary-Averett 334

Segall, Paul 268, 773

Segerstedt, Torgny 314, 557, 606, 611-613

Segrè, Emilio $3,84,86,211,375,376,470,560,747$

Segrè, Rosa (Mrs. Emilio) 84, 211 
Seitz, Frederick 49, 558

Selig, Walter 445

Sellden, Håkan 608

Sellschop, J. P. F. 701

Selph, Frank 701, 765

Seltzer, Richard 292, 304

Semenov, Nikolai 416, 692

Serning, Boris 598

Service, Carolyn (Mrs. John) 711

Service, John 711

Sessler, Andrew 6, 28, 31, 52, 65, 67, 214, 219, 242, 265, 345, 357, $379,404,409,412,441,470,485,493,494,496,515,560,619$, $632,634,644,663,664,665,739,751$

Sessler, Gladys 65,219

Severinghaus, Jean 649

Sewell, Duane 52

Sexton, Keith 669

Shalimoff, George 5, 26, 50, 86, 198, 372, 430, 486, 649

Shapiro, Andrew 632

Shapiro, Irving 92, 183, 198, 257, 403, 748

Shapiro, Zalman 683

Sharma, Hari 462

Sharnoff, Sylvia 42

Sharp, Bob 708

Shea, W. 709

Sheehan, John 179, 538

Shelby, Diane 19, 161

Sheldon, Clayton 212, 213, 258

Sheldon, Jill 212, 213

Sheldon, Rita (Mrs. Clayton) 212, 213

Sheline, Raymond 416

Shelley, Mrs. Walter 611

Shelley, walter 611

Shelton, Robert 236

Shen, Mitchel 161, 340, 341, 342, 343, 344, 348, 421, 492

Shen Ke-Chi 711

Shepard, Rose Mary 665

Sheppard, William 179, 539

Sherburne, Edward 41, 137, 140, 147, 200, 217, 310, 311, 393, 413, 728

Sherby, Oleg 444

Sherman, Catherine (Mrs. Yehuda) 241, 483, 561, 706, 714

Sherman, Tamar 440,561, 714

Sherman, Yehuda 561, 714

Sherman, Yehudit $440,561,714$

Shieh Lung-chuang 292, 294

Shih Ming-cheng 711

Shipley, Bette 765

Shirley, David $6,19,28,44,63,103,230,303,343,344,364,368$, $441,484,494,496,638,679$

Shoaf, Dave 335

Shockley, William 747

Shorter, Dan 306

Shotter, A. C. 485

Shugrue, Sylvia 279

Shultz, George 473 
Sibley, Beatrice 486

Sibley, Liza $26,50,198,233$

Sidrakian, Armen 154

Silber, Robert 279

Silberman, Lewis 721

Sill 666

Silva, Robert $5,176,185,302,318,325,328,356,376,429,441$, $546,561,621,668,698,717,718,760$

Simeon, D. N. 585

Simeons, Adeline 747

Simionescu, C. 526

Simkin, Terry 515, 561

Simmons, Charlotte 41

Simmons, Melvin 265, 379

Simon, H. 302

Simon, John 170

Simon, Lee 149

Simonson, Thomas 397

Sims, Norman 187,559

Singh, Rajendra 761

Siri, Jean (Mrs. William) 82, 491

Siri, William 330, 441, 491

Sisco, Bernard 641

Sister Agnes 527

Skolnikoff, Eugene 284,285

Skoog, Douglas 692

Skriabin, G. K. 638

Slimp, Brian 671

Slowinski, Emil 692

Smalley, Mrs. Richard 674

Smalley, Richard 674

Smart, James 231, 277, 297, 324, 369

Smelser, Neil 378

Smelser, Sharin (Mrs. Neil) 378

Smets, Georgès 524

Smith, Alan 285, 742

Smith, Ashley 311

Smith, Benedicte (Mrs. Howard) 264, 286

Smith, Clifford 208, 493

Smith, David 306, 307

Smith, Dorothy 472, 537

Smith, Douglas 496

Smith, Dow 279

Smith, Eleanora (Mrs. Waverly) 550

Smith, Emil 692

Smith, Gerard 87

Smith, Howard 286

Smith, Kate 286

Smith, Mabel 28

Smith, Paul 168, 723, 735

Smith, Philip 316

Smith, Quentin 471

Smith, Scott 775

Smith, Sidney $312,376,378,383,420$

Smith, Wanda $395,446,496,624,642,706,755$

Smith, Waverly 256, 550 
Smith, will 355, 412, 722

Smith, William 223, 305, 649

Smith, William I. 703

Smyth, Harry 650

Snell, Ed 105

Sobolev, Igor 105, 748

Sobotka, Lee 631, 639

Sofen, Stephen 21, 372

Soff, Gerhard 405

Sohns, Ernest 595

Soldaton, Sophie 583

Solem, Don 236

Solerno 219

Solomon, Linda 670

Somerton, Wilbur 150,312

Somervilie, Pat 16, 17, 28, 32, 49, 64, 72, 91, 96, 149, 158, 197, $200,213,217,218,232,262,300,304,325,350,356,368,395$, $404,416,419,478,479,485,495,516,530,567,618,621,640$, $649,650,668,669,698,699,703,718,750,751,752$

Somorjai, Gabor 19, 65, 96, 213, 242, 321, 340, 341, 342, 343, 344, 421,492

Sooy, Francis 219

Sorenson, Lionel 158

Sorg, Leonard 361,363

Sorsdahl, Nancy 332

Sotelo, Carol 82

Souers, Clark 444

Spellman, A. B. 334,335

Spence, Roderick 404, 472, 494, 748

Spencer, Donald 334

Spencer, Earl 236

Spilhaus, Athelstan 279

Spilhaus, Fred 278

Spillan, Hunter $369,420,464$

Spindel, William 184, 229, 521, 523, 524

spinks, John 150

sprotte, William 458

Sproul, Richard 331, 458

Squires, Lombard 208

Staats, Elmer 264

Stack, Helen (Mrs. James) 147

Stack, James 106, 147, 279

Stacy, Gardner 164, 168, 182, 357, 360, 361, 363, 480, 532, 533, 535, $537,538,716,723,731$

Stahlhammar, Johan 745

Stairs, Doug 708

Stanerson, Bradford 147, 168, 357, 360,-361, 363, 533, 723, 731

Stanerson, Louise (Mrs. Bradford) 147

Stark, Fortney 126

Starke, Kurt 578

Starr, Chauncey 40

Stauffer, Deborah 393

Stebbings, Mrs. R. F. 674

Stebbings, R. F. 674

Stein, Howard 14, 429, 458, 459

steiner, Herbert 326,714 
Steinsapir, Kenneth 414

Stennis, John 379, 626

Stephan, Deiter 297

Stephens, Frank 42, 103, 214, 231, 240, 329, 395, 440, 446, 463, 642, $701,706,714,745,746,755$

Stephens, Mary 332

Stephens, Mrs. W. R. 670

Stephens, W. R. 670

Stephenson, Edward 83, 713

Stephenson, Iinda 484,496

Stephenson, Thomas 92

Stern, Marilyn 460

Stevens, Robert 393

Stevens, Roger 334

Stevenson, H. L. 306

Stevenson, Robert $515,713,748,761,765$

Stever, Guyford 147

Stewart, Donald 417, 462, 516, 533, 557, 750

Stewart, John 279

Stileman, Richard 300

Stock, Reinhard $240,258,266,624,678,679,701$

Stoddard, Dick 311

Stokely, Edwin 299, 379

Stokes, Grant 141, 143

Stokstad, Robert 326, 405

Stoll, W. G. 523

Stoney, Bill 147

Stoney, Nancy (Mrs. Bill) 147

Storrs, Greg 738, 757

Stoughton, Raymond 21, 185, 188, 214, 403, 479, 490

Stowe, Richard 409

Straight, Michael 334

Strängnäs, Sanda 600,601

Strassmann, Fritz 302

Strauss, Herbert 19, 65, 103

Street, Jane (Mrs. Kenneth) 268

Street, Kenneth 52, 218, 268

Streitwieser, Andrew 5, 26, 50, 86, 198, 233, 340, 341, 342, 471, $486,620,633,765$

Stroeher, Shelley 491

Stromberg, Joel 111

Strong, Edward 211, 473

Strong, Gertrude (Mrs. Edward) 211

Strong, Maurice 403, 748

Strouse, Norman 397, 472

Struble, Gordon 445

Stuart, Charles 396

Su Feng-lin 288, 292, 293, 340, 341, 342, 343, 344, 345

Sugihara, Thomas 113

Sugimoto, Kenzo 645

Sundelöf, Iars-olof 308, 369, 490, 606, 612, 613, 615

Sundelöf, Mrs. Lars-olof 615

Surface, James 721

Sutch, Richard 111

Sutherland, Gunborg 612

Sutherland, Randall 718 
Suttle, Andrew 576

Suzuki, David 326

Svensson, Ulla 609

Sventek, Joseph 18, 107

Sweitzer, Glenn 698

Swiatecki, Uta (Mrs. Wladyslaw) 391

Swiatecki, Wladyslaw 158, 391

Szmant, Harry 411, 538

Täckholm, Frederik 614, 615

Tadros, Azmy 313

Taft, Dale 728

Taft, Henry 488, 494

Takaki, Katherine 137, 138, 143

Takei, Barbara 140

Talbott, David 311

Tamayo, Jorge 713

Tang Ao-ching 288, 293, 294, 340, 341, 342, 343, 344, 345, 348, 430

Tape, Gerald 141, 147, 190, 198, 203, 217, 272, 297, 329, 413, 645, 728

Tape, Jo (Mrs. Gerald) 141, 147

Tarbell, Stanley 721

Tarpley, Garry 671

Tarski, Alfred 84

Tart, Charles 22, 208

Tart, Judy (Mrs. Charles) 22

Taschek, Richard 679

Tate, Fred 168, 361, 363, 534

Tate, Patilee 332

Taube, Henry 156

Taube, Marianne (Mrs. Henry) 156

Taylor, Angus 219, 641

Taylor, Louise 442

Teague, Olin $333,372,384$

Teague, Sam 713

Teal, Gordon 670

Teem, John 737

Tegenfeldt, J. 606

Teller, Edward 208

Tellinghuiser, Jod 720

Temmer, George 723

Templeton, David 5, 19, 26, 50, 86, 198, 233, 268, 372, 430, 549, $604,606,612,616,633,649,765$

Templeton, Lieselotte (Mrs. David) 5, 26, 50, 86, 198, 268, 372, 430, $604,606,612$

Ter-Akopyan, G. M. 460, 461, 463, 471, 493

Terkel, Amelia 636

Terroux, Richard 708

Tersmeden, Carl 530, 600, 601

Tersmeden, Monica (Mrs. Carl) 600, 601

Tezak, Bozo 524, 525

Tezuka, Kazue 332

Thibault, Catherine 528, 529

Thiele, Ernest 537

Thier, Herbert 150, 313, 669

Thomas, Darrah 350

Thomas, Emery 207, 231 
Thomas, Frances 163

Thomas, Greg 473

Thomas, Kenneth $2,4,6,7,16,17,23,26,27,32,40,41,48,49$, $63,72,75,83,89,92,95,96,98,107,110,112,150,185$, $212-214,217,262,266,277,296,300,302,310,316,318,325$, $328,329,332,350,356,369,391,398,402,403,405,414,416$, $430,436,443,444,461,463,464,474,475,479,483,485$, $488-490,495,496,516,530,550,559,560,562,618,621,624$, $634-636,638,640,642,644,645,649 ; 650,666,668,678,679$, $683,692,698,699,701,713,714,716,742,745,747$

Thompson, Alice (Mrs. Stanley) 7, 64, 91, 110, 168-170, 176, 178,

$182,184,268,296,390,391,441,481,488,490,503,621,773$

Thompson, Carol 187, 206, 440,455, 458

Thompson, K. M. 179

Thompson, Stanley 170, 172, 458, 484, 667, 701

Thompson, Wayne 472

Thomsen, Dietrick 446

Thornberg, Bob 369

Thornton, Jack 670

Thorpe, Richard 607, 608

Thummel, Randolph 673

Thun, John-Eric 615

Tick, Evan 141, 143

Tiemann, Kenneth 178

Tinker, Irene 284

Tinoco, Harold 19, 103

Tishler, Elizabeth (Mrs. Max) 169

Tishler, $\operatorname{Max} 2,13,14,92,169,179,205,744$

Tittel, Frank 674

Tittel, Mrs. Frank 674

Tobias, Cornelius 724

Tobias, Stuart 692

Tobin, Herb 236

Toland, William 670, 671

Tolba, M. K. 403, 748

Tomaker, Warren 278

Topper, Len 147

Torell, John 15

Torre, Elizabeth 31 .

Torrens, John 236

Toth, Kenneth 5, 6

Touster, Oscar 721

Townes, Charles 378, 677, 678, 701

Townes, Frances (Mrs. Charles) 378, 677

Townley, Lloyd 774

Toy, Arthur 179, 411, 439

Tracy, Margaret 82

Trapane, Tina 168, 169

Trautman, Ute (Mrs. Norbert) 576

Trefethen, Eugene 663

Treon, Steve 620, 639

Tress, Gerhard 578, 579

Trevisani, Robert 145, 187, 409, 709

Triebel, Carol 676

Troan, John 413

Trojanowski, Michael 525 
Trotter, Robert 446, 728

Troutin, Ann 526

Trowbridge, Alexander 15

Trudeau, Pierre 218, 219, 223

Trudeau, Richard $126 ; 223,739$

Tsai Chi-jui 711

Tsang, Dorothy 143

Tsuchitani, Patricia 95, 276, 288, 323, 325, 340, 341, 342, 344, 345, $348,421,492$

Tsutsui, Minoru 287, 411, 412, 537, 667, 668

Tuley, Dorothy 496, 497

Tunney, John 297

Turk, Elton 214

Turkevich, Anthony 375

Turner, Nancy 440

Tuthili, John 348, 478, 700

Tuttle, Doreen 442

Tweedle, Virgil 670

Underhil1, Robert 641

Underwood 286

Urbanski, Tadeusz 526

Urian, George 369

Ursu, Ioan 746

Vallera, Robert 236,237

Van der Haeghen, Kathleen (Mrs. Steven) 262, 402, 485, 496, 498, 503, $624,757,765$

Van der Haeghen, Steven 757, 759

Van Dorn, Ann 443, 446

Van Duzer, Theodore 160

Van Fleet, Hugo 44

Van Tamelen, Eugene 155, 156

Vance, Charles 393

Vandenbosch, Robert 190

Vandiver, Frank 674

Vandiver, Mrs. Frank 674

Vasconcelios, John 188

Vasilenas 583

Vater, Peter 578, 579

Vendley, E. M. 752

Verhoogen, John 84

Vermeulen, Theodore 157, 640, 752

Vesic, Aleksandar 162

Vestal, Marvin 673

Vial, Donald 236

Vieira, David 490

Vihlen, Kim 332

Vincent, Barbara 82

Vink, A. K. 170, 206

Viola, Victor 90, 483

Voelker, Candace 436, 562

Vogel, Emanuel 526

Vogel, Richard 369

Volman, David 28, 29

von Gunten, Hans 183, 185

von Holle, Bill 445

von Kantzow, Hans 614 
Vonderleith, Robert 81

Voter, Art 213

Vourvopoulos, George 586

Waddarns, John 569

Waddington, C. J. 678, 679

Wagner, Hermann 578

Wahl, Arthur 203

Wahl, Werner. 169

Wahlig, Michael 644

Wakefield, Rowan 146

Wakeham, Helmut 169

Wakeman, Carolyn (Mrs. Fredric) 711, 712

Wakeman, Frederic 711, 712

Wakerling, Raymond 6, 83, 441, 497, 549, 644

Walcher, Wilhelm 578

Waldenström, Erland 595

Waldrop, Mitchell 517

Walds, Matt 141

Walker, James 674

Walker, Mike 631

Walker, Mrs. James 674

Walker, William 162, 163

Wall, Florence 169,537

Wall, Frederick 460, 674

Wall, Mrs. Frederick 674

Walsh, Judy 440

Walsh, Patricia 563, 636

Walsh, Winifred 111

Walters, James 728

Walton, Gary 111

Walton, Tina May 645

Wang, C. H. 421

Wang, Normita 21

Wang Erh-kang 288, 293, 294, 340, 341, 342, 343, 344, 348

Ward, Thomas 306

Warder, Michael 276

Warnke, Paul 87

Warnow, Joan 634,723

Warren, Don 439

Warrick, Sherry 665

Washburn, Henrietta (Mrs. Sherwood) 378

Washburn, Sherwood 84, 378, 669, 691

Wasserburg, G. J. 674, 675, 677, 717

Watanabe, colin 217

Waters, William 312

Watson, Barry 184

Watson, Robert 455, 458

Watson, Susan (Mrs. Robert) $82,191,224,233,455,458,550$

Weart, Spencer 689, 723

Weast, Robert 620

Weatherford, Iawrence 143

Weatherly, Abbott 442

Webb, Catherine 2, 303, 635

Webber, Alfred 169

Weber, Roland 269

Weber, Wes 28 
Webster, Medford 721

Weekes, Fred 689

Wehner, E. I. 410, 411, 673, 674

Wehner, Jo Alice (Mrs. E. I.) 410, 411, 673, 674

Weidl, Fred $50,86,233,372,430,486,516,561$

Weigel, Fritz 63, 191, 297, 302, 439, 742, 751

Weinberg, Alvin 44

Weinberg, John 15

Weinstein, Sidney 279

Weinstock, Bernard 21, 73

Weiss, Carroll 496, 497

Weiss, Leonard 186

Weiss, Schmuel 714

Welch, Andrew 306

Welch, Mrs. Steven 673

Welch, Steven 673

Wells, Allison 156

Wells, Mrs. Willie 673

Wells, Willie 673

Wendlandt, Wesley 673

Weneser, Joseph 155, 190, 484, 739

Wenkert, Ernest 418, 674

Wenkert, Mrs. Ernest 674

Wentworth, Mrs. Wayne 674

Wentworth, Wayne 674

Werner, Jim 428

Werner, Louis 214

Werner, Wilhelm 578

Werthamer, Richard 15

Wessel1, Nils 295, 430, 470, 668, 703

West, T. S. 525

Westermark, Torbjörn 595

Westfal1, Gary 87, 89, 115, 258, 269, 717

Westlund, Roy 179

Westmeier, Wolfram 577

Westphal, Chris 480

Wetstone, David 168, 169, 361, 363, 532, 534, 538, 541

Wheeler, John 416

Wheeler, Paul 52

Whelan, Juliann 41

Whinnery, John 207, 231, 463

White, Harvey 692

White, Lynn 378

White, Maud (Mrs. Lynn) 378

White, Michael 75

White, Wayne 489

Whitman, F. B. 197

Wight, Virginia 140, 143

Wight, William 203

Wijkman, Birgit (Mrs. Gunnar) 612

Wijkman, Gunnar 606, 611

Wikström, Jan-Erik 611, 612

Wikswo, John 720

Wild, John 23, 265, 356, 357, 405, 755, 761

Wilde, James 263

Wilde, Stephen 463, 470, 636 
Wilhelmy, Jerry 183, 184, 404, 405

Wilke, Charles 343,344

Wilkes, Daniel 52, 208, 209, 210, 692

Wilkes, Evelyn (Mrs. Daniel) 208

Wilkes, Fred 538

Wilkins, Ernest 279

Wilkins, Henry 472

Willard, John 214, 539, 546, 549

Willcott, Mark 674

Willcott, Mrs. Mark 674

Willens, Earl 219

Williams, Cole 236

Williams, Howard 396

Williams, Janet 332

Williams, $\operatorname{Kim} 2,4,6,7,16,17,23,28,29,32,41,48,63,72,90$, $92,96,98,105,112,149,188,197,200,207,213,214,229$, $256,262,268,276,277,297,316,324,325,329,332,343,350$, $354,356,357,391,393,395,396,403,404,405,414,416,481$, $483,488-490,493,495,496,497,499,516,531,559,618,620$, $621,634,636,638,640-642,644,650,666,668,683,690,691$, $698,699,700,703,706,714,716,718,739,742,745,750,751$, $752,757,759,760$

Williams, Maurice 524, 526

Williams, Mennen 137

Williams, Michael 19, 23, 27, 75

Williams, Paul 105

Williams, Reba 332

Williamson, Doug 670

Willig, Peggy 743, 774, 775

Willis, Lemar 230

Wilson, Bob 163

Wilson, Ed 3.96

Wilson, Garff 430, 486, 663, 664

Wilson, Hugh 445

Wilson, Kent 311

Wilson, Leigh 527

Wilson, Lionel 663, 747

Wilson, Ion 674

Wilson, Mabel 7

Wilson, Mrs. Lionel 663, 747

Wilson, Robert 198

Wilson, Ted 203

Winchester, John 178

Winget, Craig 393

Wining, Jack 479

Winkle, Steve' 354

Winkler, G. 742

Winn, John 103

Winsberg, Lester 420,439

Winslow, H. 521

Winstead, AI 363

Winters, Jan 52

Wise, Mrs. Robert $674,675,677$

Wise, Robert 410, 673, 674, 677, 691

Wishnevsky, Victor 297

Witherspoon, Elizabeth (Mrs. Paul) 65 
Witherspoon, Paul 65, 446, 634, 664

Withington, Charles 279

Witser, Robert 82, 550

Witser, Sharon (Mrs. Robert) 82

Witter, Jean 219

Wittman, Franz-Dieter 297

Wivstad, Ingvar 595

Woestendiek, William 306

Wold, Aaron 538

Woldseth, Rolf 700

Wolf, Gerhard 176

Wolf, Joseph 207, 231

Wolf, Kevin 90, 765

Wolfe, Deborah 728

Wolfe, Mrs. Roger 676

Wolfe, Roger 410, 411, 673-676

Wolfle, Dael 297

Wollnik, Herman 574

Wonters, Jan 19

Woo, Edward. 700

Wood, Harold 302

Wood, John 674,677

Wood, Mrs. John 677

Wooden, Diane 141, 191

Wooden, Neal 191

Woods, Lawrence 15

Woolman, Marjorie 417

Woolridge, Clyde 110

Worthington, Hood 87

Worthington, Martha (Mrs. Hood)

Wotiz, John 179, 258, 297, 538

Wozniak, Gordon 666

Wozniak, M. 523

Wray, Ann 625

Wright, Frank 212

Wright, Leo 335

Wu, Chien-Shiung 278

Wu Yueh $288,293,340,341,342,343,344$

Wuest, Craig 391, 409

Wulf, Erika 389

Wyeth, Phyllis 336,337

Yaffe, Leo 294, 302, 541, 549, 707-709, 718

Yamada, Margaret 496

Yamagada, Ben 355, 409

Yang Ting-pao 711

Yankwich, Peter $360,361,363$

Yashita, Saburo 29, 49, 96, 126, 191, 197, 200, 207, 214, 218, 224, $232,266,276,305,314,321,328,343,356,368,379,414,478$, $479,485,496,516,530,559,621,650,698,718,748,752,757$

Yasinsky, John 335

Yau, Shing-Tung 231, 256

Yeh, Sam 314

Yin Yuan-ken 288, 293, 340, 341, 342, 343, 344

Yodh, Arjun 143

York, Carl 48

Young, David 179, 185 


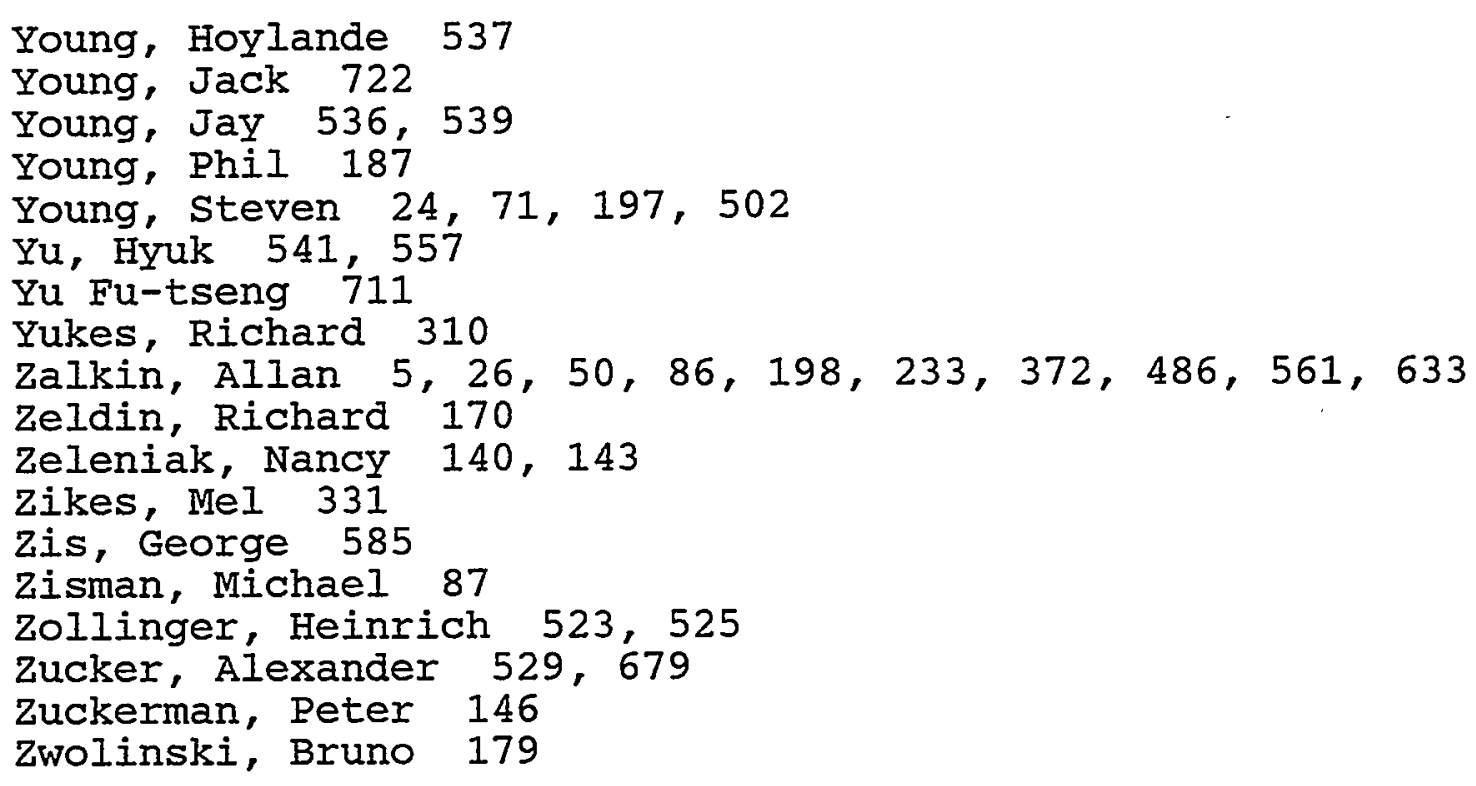

